\title{
9. Fotoalbum
}

\section{Themen und Motive \\ der Partisanenfotografie}

Fotografien führen unweigerlich zur Anlegung von Archiven. Der Teil des Fotoarchivs, der bei der Recherche zu diesem Kapitel entstand, wird im Folgenden in Form eines Fotoalbums oder Kataloges präsentiert. Während der Untersuchung des Fotoarchivs drängten sich thematische und motivische Schwerpunkte auf, die in insgesamt 21 Einheiten gruppiert im vorliegenden Kapitel vorgestellt werden. Auf diese Weise kann kritisch betrachtet werden, wie die Mitglieder der Partisanenbewegung sich selbst, ihre Ideologie, ihre Zielsetzungen, Ansichten und Werte gesehen haben. Der französische Philosoph Louis Althusser behauptete zu Recht, dass Ideologien unter anderem mit Hilfe der Fotografie kommuniziert werden. Eine solche Repräsentation erfolgt vor allem unbewusst, wir denken nicht detailliert genug darüber nach; die Ideologie wird durch die Vorstellung der Gesellschaft sich selbst gegenüber repräsentiert. Wenn man das Medium der Fotografie semiotisch interpretiert, lässt sich die Fotografie genauso wie die Sprache als Epizentrum ideologischer Auseinandersetzungen begreifen. Sind wir denn nicht gerade in unserer Gegenwart an einem Punkt angelangt, an dem ein heftiger politischer Kampf mit dem Versuch ausgefochten wird, Akteuren - in diesem Falle den Partisanen - eine andere Bedeutung zu verleihen, um eine revisionistische Oberhand über die Repräsentation der Vergangenheit zu gewinnen?

Über die in diesem Buch bereits gezeigten Beispiele hinausgehend, eröffnet das Kapitel mit Auszügen aus der Zeitschrift Liberation, die von projugoslawischen Emigranten in den USA während des Zweiten Weltkriegs ins Leben gerufen wurde. Ihr Redakteur Louis Adamic, amerikanischer Schriftsteller mit slawischen Wurzeln, beteiligte sich ab 1942 aktiv an dem in der US-amerikanischen Presse ausgetragenen Propagandakrieg. Mit aller Macht schaltete er sich ein in den Kampf um Repräsentation zwischen jenen, die die jugoslawische Exilregierung bzw. die Tschetniks unterstützten, und jenen, die die antifaschistische Partisanenbewegung befürworteten. ${ }^{1}$ 


\section{LBERATION}

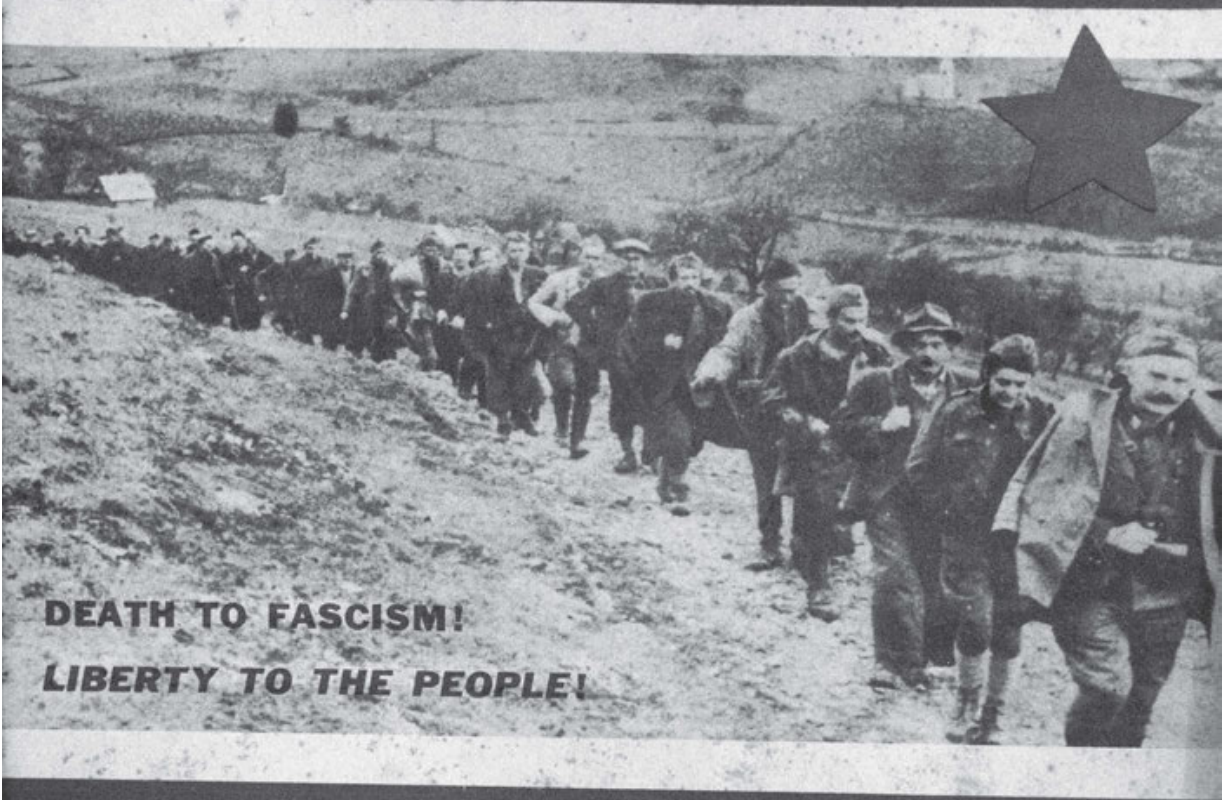

PICTURE STORY OF THE YUGOSLAV PEOPLE'S EPIC STRUGGLE AGAINST THE ENEMY-TO WIN UNITY AND A DECENT FUTURE 1941-1945

Titelseite der Zeitschrift Liberation, undatiert. Ljubljana, Institut für neuere Geschichte.

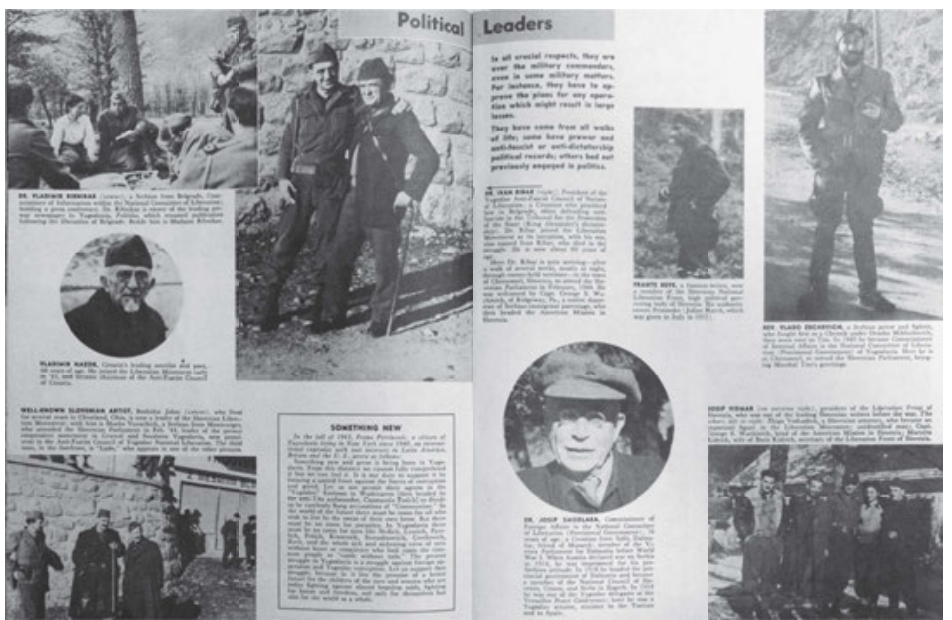

Doppelseite aus der Zeitschrift Liberation, undatiert. Ljubljana, Institut für neuere Geschichte. 

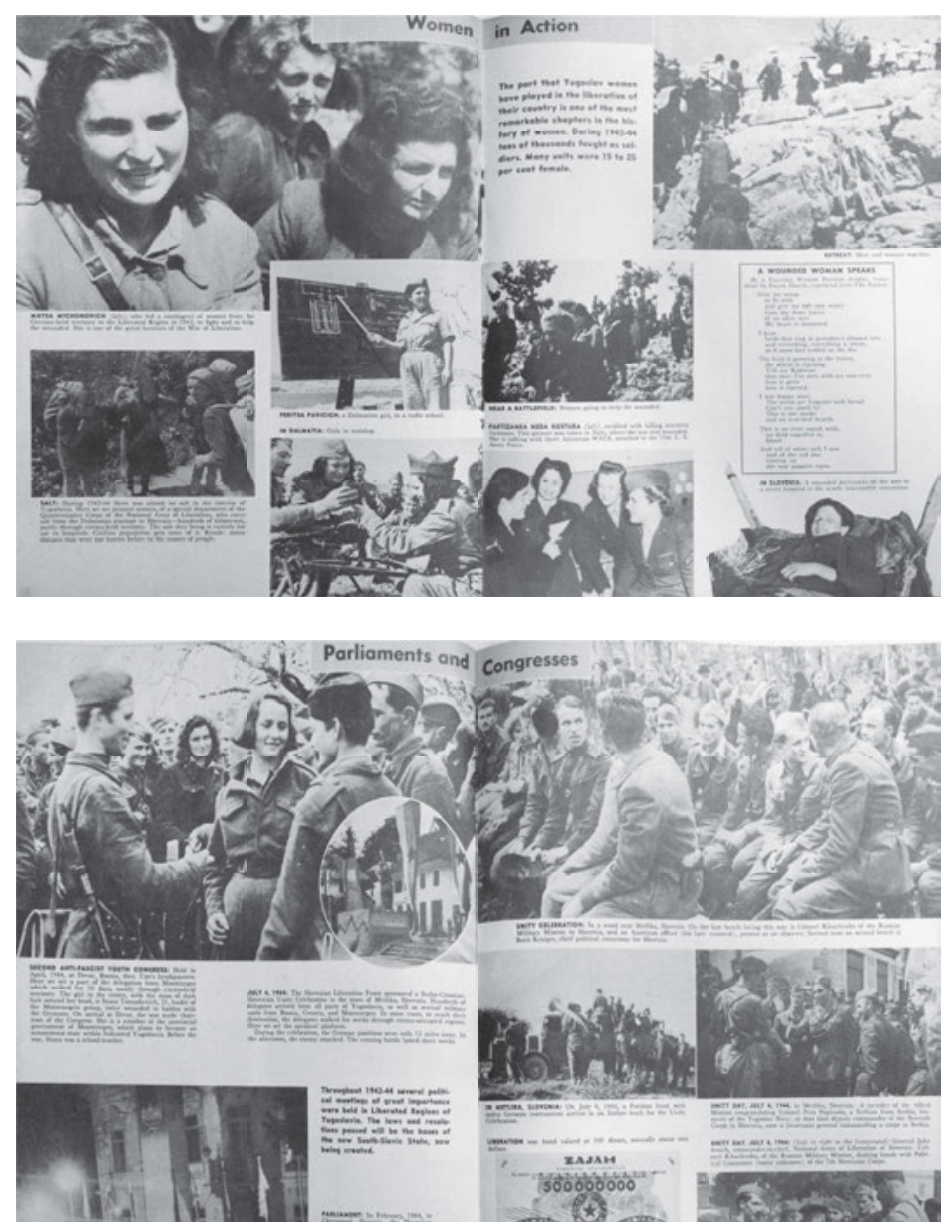

Doppelseite aus der Zeitschrift Liberation, undatiert. Ljubljana, Institut für neuere Geschichte.
Doppelseite aus der Zeitschrift Liberation, undatiert. Ljubljana, Institut für neuere Geschichte.

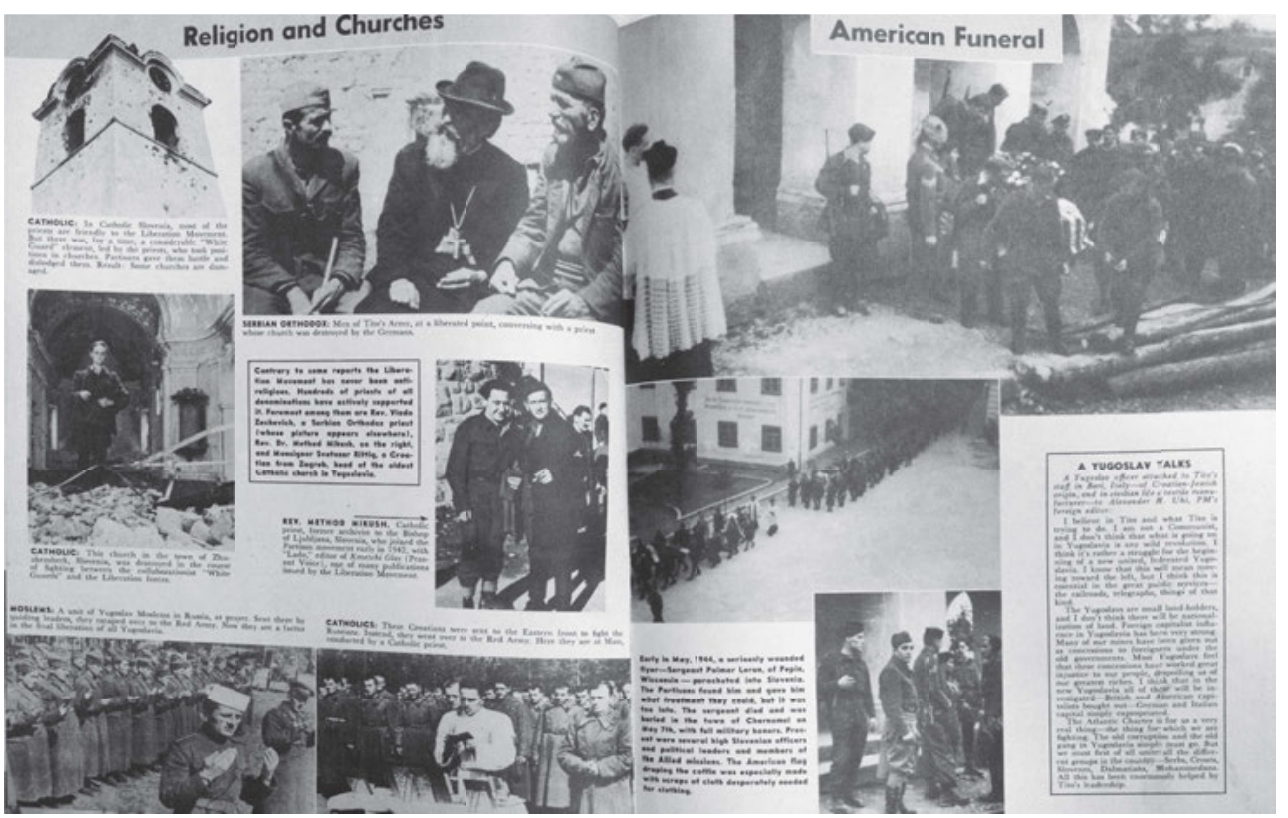

Doppelseite aus der Zeitschrift Liberation, undatiert. Ljubljana, Institut für neuere Geschichte. 



\section{Aus dem Leben der Partisanen}

Zu Beginn seines Essays Das Ornament der Masse behauptet Siegfried Kracauer, dass der Stellenwert, der einer bestimmten Epoche im Geschichtsprozess zukommt, anhand »ihrer unscheinbaren Oberflächenäußerungen schlagender zu bestimmen [ist] als aus den Urteilen der Epoche über sich selbst. « Diese, so Kracauer, »sind als der Ausdruck von Zeittendenzen kein bündiges Zeugnis für die Gesamtverfassung der Zeit. Jene gewähren ihrer Unbewußtheit wegen einen unmittelbaren Zugang zu dem Grundgehalt des Bestehenden. An seine Erkenntnis ist umgekehrt ihre Deutung geknüpft. Der Grundgehalt einer Epoche und ihre unbeachteten Regungen erhellen sich wechselseitig. "« Eine Vielzahl solcher Äußerungen findet man auch auf der fotografischen Oberfläche der Bilder aus dem Leben der Partisanen und ihren Stunden der Muße - in Materialien, die bis heute Historikern und anderen Wissenschaftlern nicht interessant zu sein schienen. Ihre Oberfläche spiegelt ein anderes Bild wider als die Fotografien der Nationalsozialisten, der Ustascha und der Tschetniks, auf deren Körpern, insbesondere im Falle der deutschen Soldaten, die Ideologie tiefe Spuren hinterlassen hat - im Hugo-Boss-Design ihrer Uniformen, in ihren Gesten und Posen. Deutlich sichtbar war dies vor allem bei politischen Ritualen und Feierlichkeiten, bei denen ein kollektiver Körper gebildet wurde. Ist denn nicht im Deutschland der beginnenden 1930erJahre das fotografische Werk August Sanders vernichtet worden, der sich diesem kollektiven nationalsozialistischen Körper widersetzte, indem er Individualität zuließ und gegen Gesetze und den physiognomischen Mythos des deutschen »Übermenschen" verstieß? Für die Typologie der deutschen Gesellschaft, die Sander jahrelang aufbaute, konnte es im Nationalsozialismus keinen Platz geben.

Die Partisanenfotografie bildet auf der anderen Seite oftmals einen unerwarteten Kontrast zum Kriegsumfeld, in dem sie entstanden ist, sowie zur drohenden physischen Vernichtung der gesamten Partisanenbewegung. Einige dieser Fotografien strahlen eine Normalität aus, die den herrschenden Kriegszuständen nicht entspricht, so als wollten sie die Schrecken des Krieges und die Geschichte des Verbrechens negieren. Beim Betrachten der Oberflächenäußerungen auf den Fotografien aus dem Leben der Partisanen nimmt man oft völlig gelassene und lächelnde Gesichter von Personen wahr, die angesichts des erstmaligen Fotografierens oder der Möglichkeit eines Bades glücklich zu sein scheinen. Ihre Körperhaltung wirkt locker und trotz der militärischen Uniform häufig individualisiert. 
Die Fotografien aus dem Partisanenleben sind auch deshalb bedeutsam, weil sie einen unmittelbaren Einblick in das Leben der vorübergehend auf dem befreiten Territorium entstandenen Gemeinschaften erlauben - in die Gewohnheiten der Menschen, die Atmosphäre, das Verhältnis zwischen Militär und Zivilbevölkerung, die ersten Arbeitsaktionen, religiösen Freiheiten und Gewissenskonflikte. Wenn man unter die Oberfläche der Fotografie vordringt, kann mit Hilfe sorgfältiger Analysen und insbesondere von Vergrößerungen die Ernährung der Partisanen erfasst werden, doch es kann auch der Blick erstarren angesichts der faltigen Kindergesichter sowie jener Gesichtsausdrücke, die Menschen nach schweren Schicksalsschlägen eigen sind. In gewisser Weise lassen sich die an dieser Stelle vorgestellten Fotografien auch als erweiterte Familienalben auffassen, blickt man auf einige der behandelten Themen wie Hochzeiten, Geburten, wichtige Ereignisse, Jahrestage oder Beerdigungen. Die Fotografien können zudem zu Filmsequenzen, zu Vorlagen für Drehbücher von Dokumentar- und Experimentalfilmen werden.

Milan Štok, Autor des ersten Handbuchs für Fotografie, meinte, dass die Partisanenfotografen Szenen aus dem Leben festhalten sollten: Partisanen beim Frühstück, bei morgendlichen Turnübungen, beim Sport, Musizieren und Tanz, Fußballspielen, in verschiedenen Werkstätten, Seifenfabriken. Zudem war er der Ansicht, dass sie sich auch den Offizieren zuwenden sollten, die auf den Fotografien zu selten vertreten seien, was wiederum für die These spricht, dass selbst die Auswahl der Themen und Motive der Partisanenfotografie wahrlich demokratisch erfolgte. Oftmals spiegeln die Fotografien auch den Humor ihrer Urheber oder deren unmittelbaren Kommentar der Situation wider.

Von großer thematischer Bandbreite und Anziehungskraft sind die Fotografien von Schlafenden, von Menschen mit Tieren, von Schneeballschlachten und vom Baden, also jener Aktivitäten, die Augenblicke des Glücks und besonderer Freude schufen. Mit folgenden Worten beschrieb ein slowenischer Partisan, der sich lediglich als Franci aus dem Ersten Bataillon vorstellte, seine Erfahrungen:

"Das, was ich heute erlebt habe, schien wie ein Traum zu sein. Das Vierte Bataillon ging nach Toplice zum Baden. Ich war natürlich nicht zu faul, um mich innen anzuschließen. Der Weg führte durch Felder und hohes Gras, das nun in seiner schönsten Blüte stand. Wegen der herrschenden Zustände, des fehlenden Viehs und der Arbeitskräfte lagen alle Felder brach. [...]. Wir kamen nach Toplice, wo wir zahlreiche Kameraden aus unserer Brigade antrafen. Im Schwimmbecken tummelten sich wahnsinnig viele Badende, die sich alle zufrieden dem Genuss des Badens hingaben. Einer der Kameraden, der sich dort schon längere Zeit aufhielt, führte mich in ein separates Zimmer mit Bad. Als ich die Tür öffnete, blieb ich verblüfft stehen. Das gesamte Badezimmer erstrahlte in weißem Marmor. Ich begann wie ein kleines Kind zu lachen, als in mir der Gedanke aufstieg, dass hier früher die Reichen gebadet haben, während nunmehr arme Partisanen hierhin kommen. Ein wahres Wunder! «²

Über seine Badeerlebnisse berichtete auch Žorž Skrigin in seinem Tagebuch: 
„Wir wollten auch ein Bad nehmen, weil wir uns seit über einem Monat nicht einmal die Füße gewaschen hatten. Wir suchten uns ein Plätzchen aus, wo wir nackt baden konnten. Der wunderschöne sonnige Tag ließ unsere ohnehin gute Laune noch besser werden. Wir legten unsere Kleider ab und badeten im ziemlich flachen Wasser. Der Genuss schien kein Ende nehmen zu wollen... Doch dann tauchte hinter dem Berg plötzlich ein Flieger auf, den wir gar nicht gehört hatten. Er bemerkte uns sofort, ging in einen Sturzflug über und beschoss uns aus seinen Maschinengewehren. Uns blieb nicht einmal Zeit, unsere Kleidung zusammenzuraffen, sodass wir nackt, wie Gott uns schuf, in Richtung der nahestehenden Bäume rannten. Da der Wald alles andere als dicht war, stellten wir eine gute Zielscheibe dar. Jeder von uns suchte sich einen dicken Baumstamm aus, um sich vor dem Angreifer zu schützen. Und wie der Flieger uns umkreiste, so liefen wir auch wie auf Kommando um die Bäume herum. Dem Piloten schien es Spaß zu machen, uns nackt in der Falle sitzen zu sehen, weshalb er mit seinem Spielchen fortfuhr. Und um unsere >Tragödie noch größer werden zu lassen, vernahmen wir schallendes Gelächter aus dem Wald, und zwar Frauengelächter! Einige unserer Kameradinnen, die vorsichtiger als wir gewesen waren, fanden ein sicheres Plätzchen und beobachteten uns die ganze Zeit. Ich weiß überhaupt nicht, wie lange wir noch unser `Karusselk weiter betrieben hätten, wenn der Pilot nicht all seine Munition verschossen hätte. Am Ende streckte er seinen Arm aus dem Flugzeug zum Hitlergruß aus, drehte noch eine Runde und flog davon. ${ }^{3}$
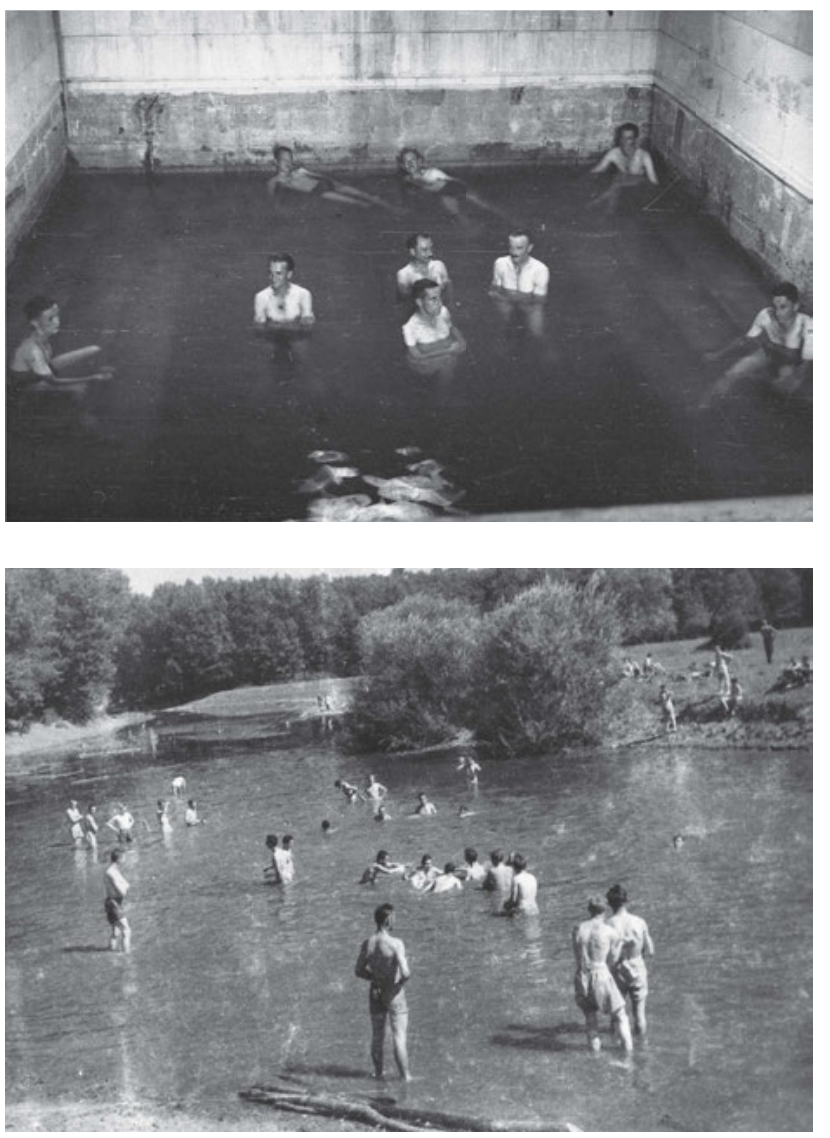

Gruppe Schwerverwundeter aus den Einheiten des Neunten Korps. Innerkrain, September 1944. Fotograf unbekannt. Ljubljana, Museum für Neuere Geschichte Sloweniens | TN319/8.

Badefreuden. Fotograf unbekannt. Museum der Stadt Zagreb. Ohne Inv.-Nr. 


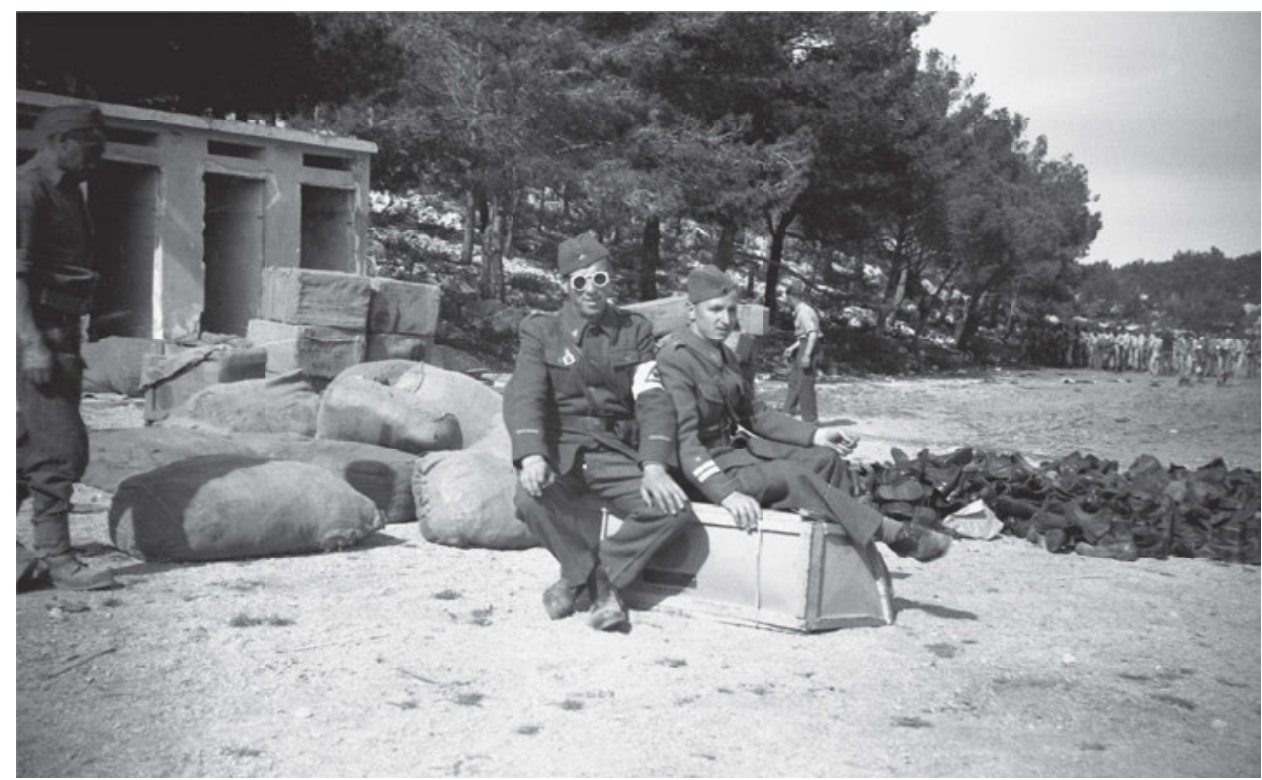

Kämpfer der mazedonischen Brigade beim Baden vor der Fortführung der Kämpfe, Biograd, April 1945. Foto: Peter Jelič. Ljubljana, Museum für Neuere Geschichte Sloweniens | TN710/1.

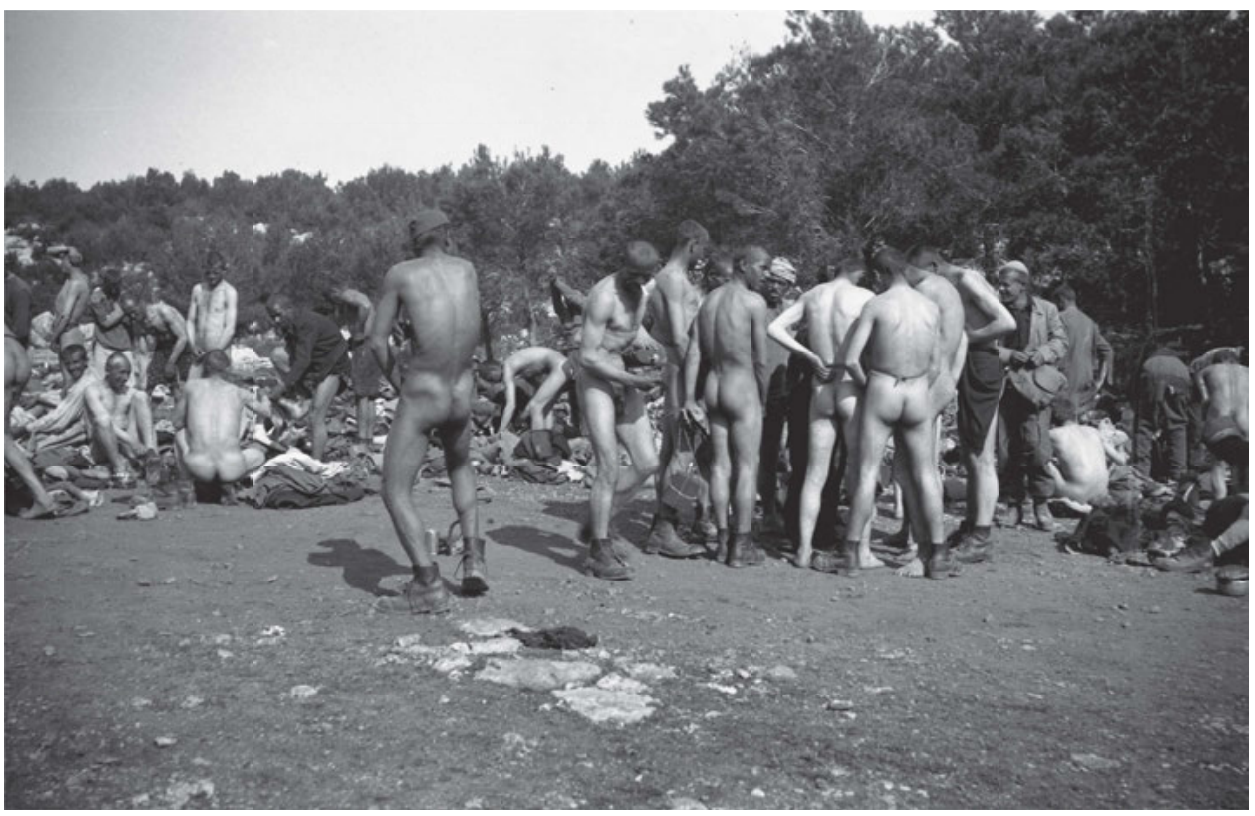

Kämpfer der mazedonischen Brigade beim Baden in Zadar, 1945. Fotograf unbekannt. Ljubljana, Museum für Neuere Geschichte Sloweniens | TN618/2. 


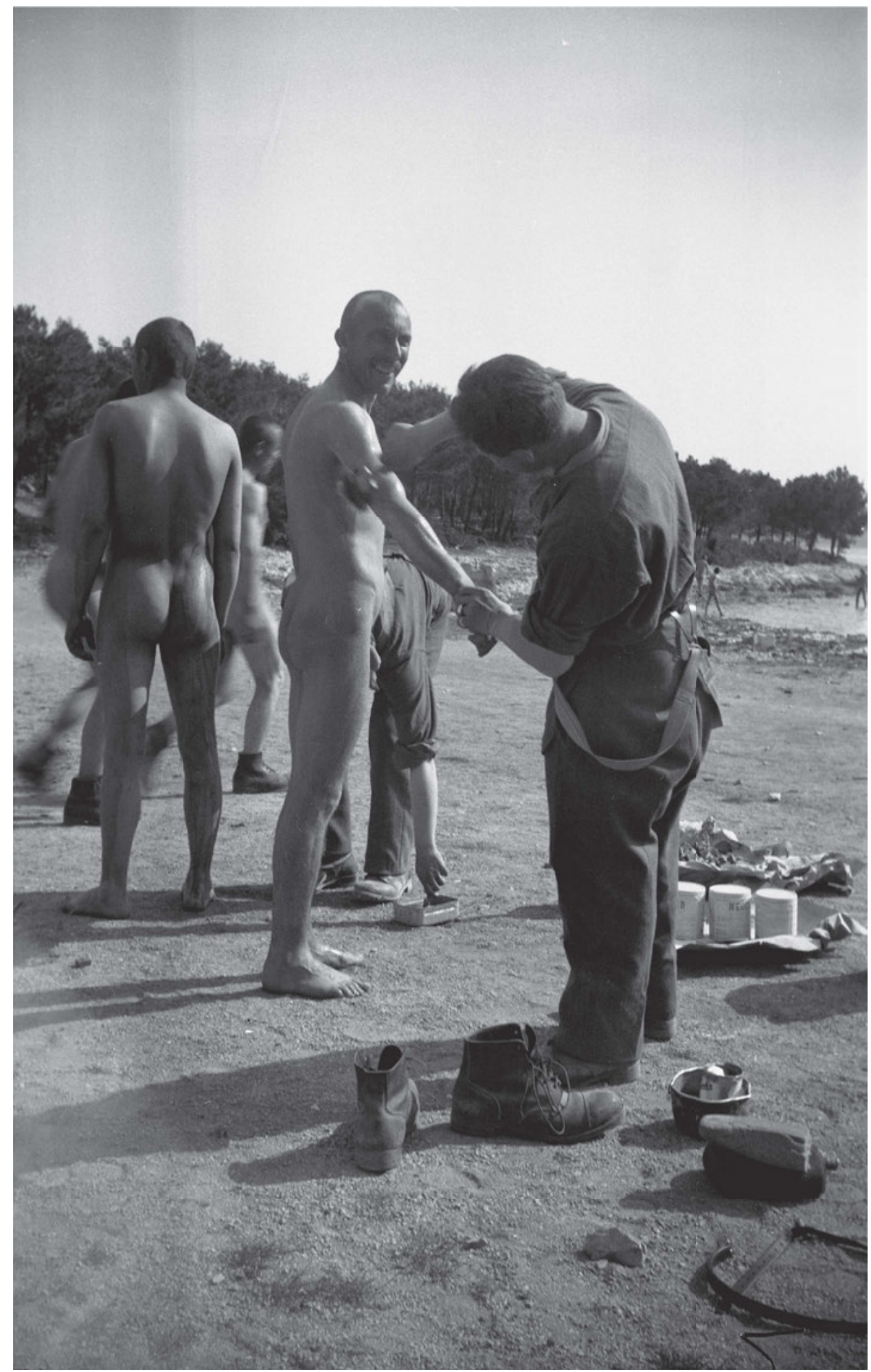

Kämpfer der mazedonischen Brigade beim Baden vor der Fortführung der Kämpfe, Biograd, April 1945. Foto: Peter Jelič. Ljubljana, Museum für Neuere Geschichte Sloweniens | TN710/2. 


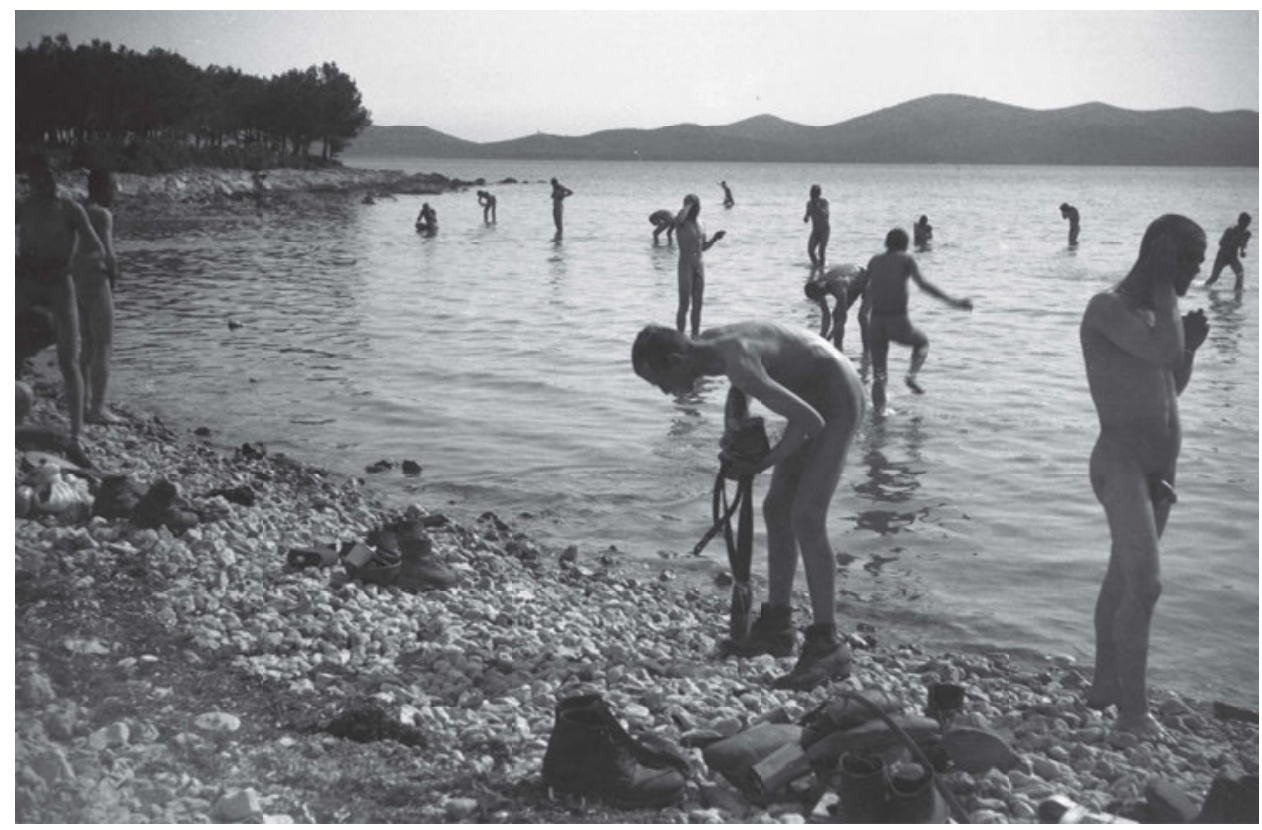

Kämpfer der mazedonischen Brigade beim Baden vor der Fortführung der Kämpfe, Biograd, April 1945. Foto: Peter Jelič. Ljubljana, Museum für Neuere Geschichte Sloweniens | TN710/5.

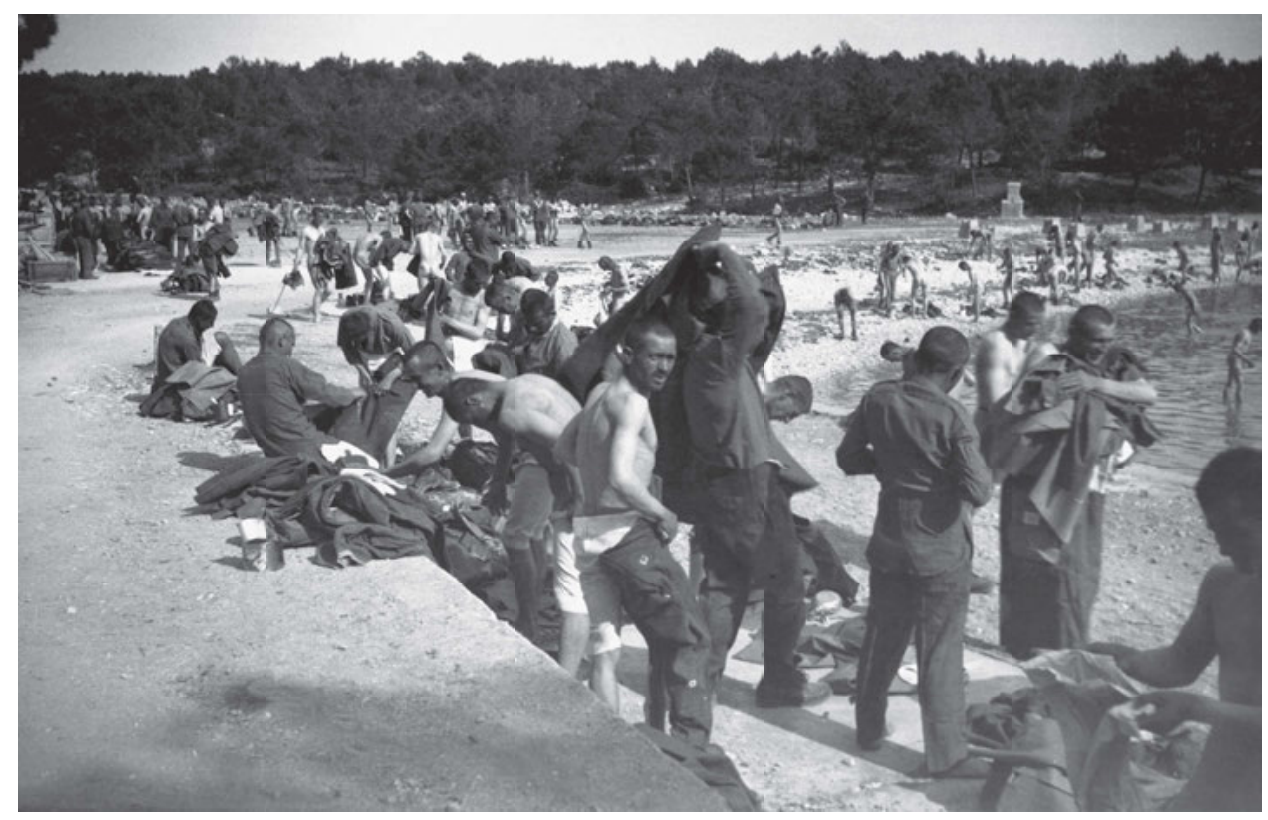

Kämpfer der mazedonischen Brigade beim Baden vor der Fortführung der Kämpfe, Biograd, April 1945. Foto: Peter Jelič. Ljubljana, Museum für Neuere Geschichte Sloweniens | TN710/6. 


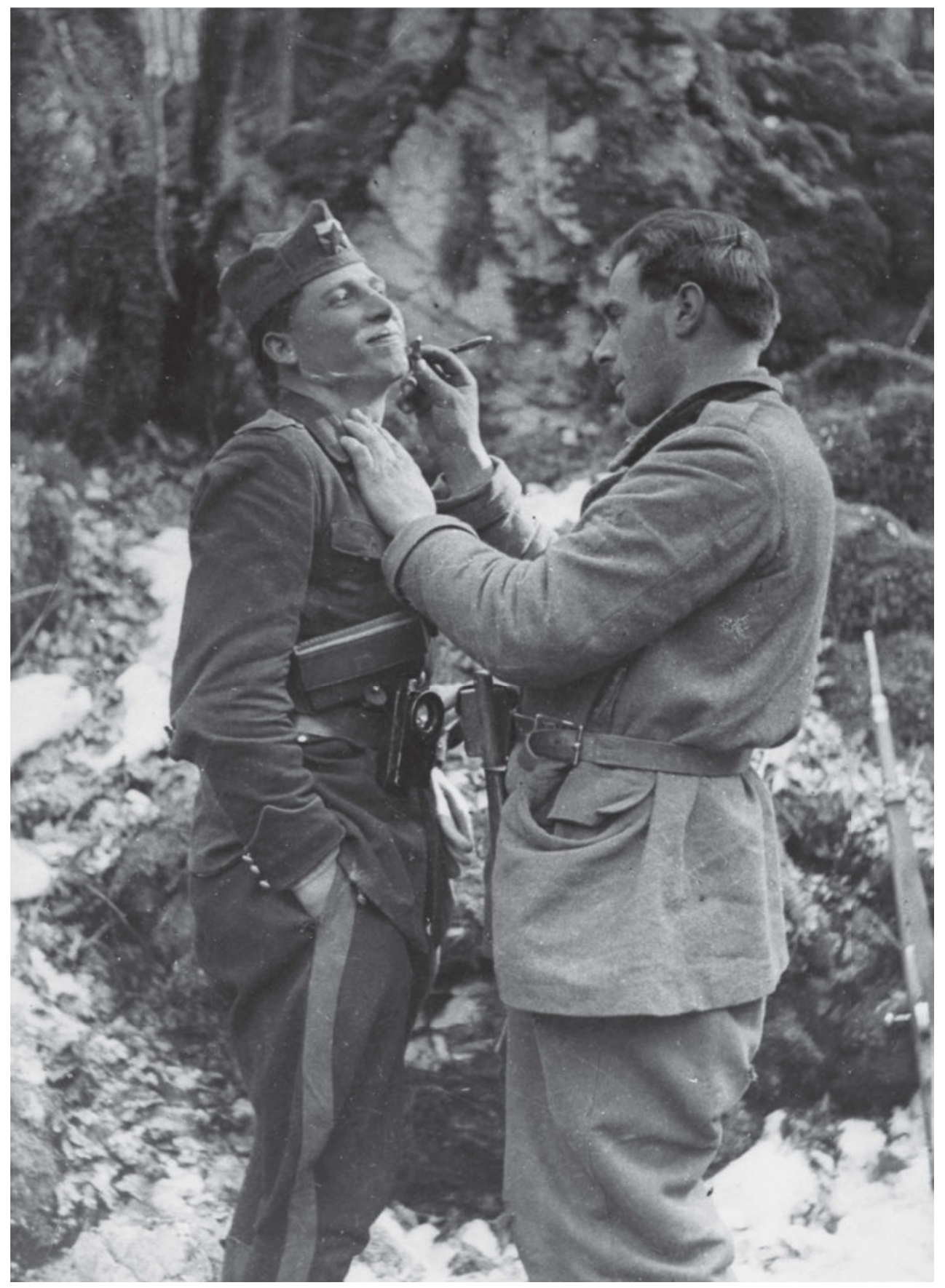

Im Lager der Ersten Kompanie des Ersten Bataillons der Nordadriatischen Einheit bei Dobro (Šentviška-Hochebene), 3. April 1943. Fotograf unbekannt. Ljubljana, Museum für Neuere Geschichte Sloweniens | 5410/b. 


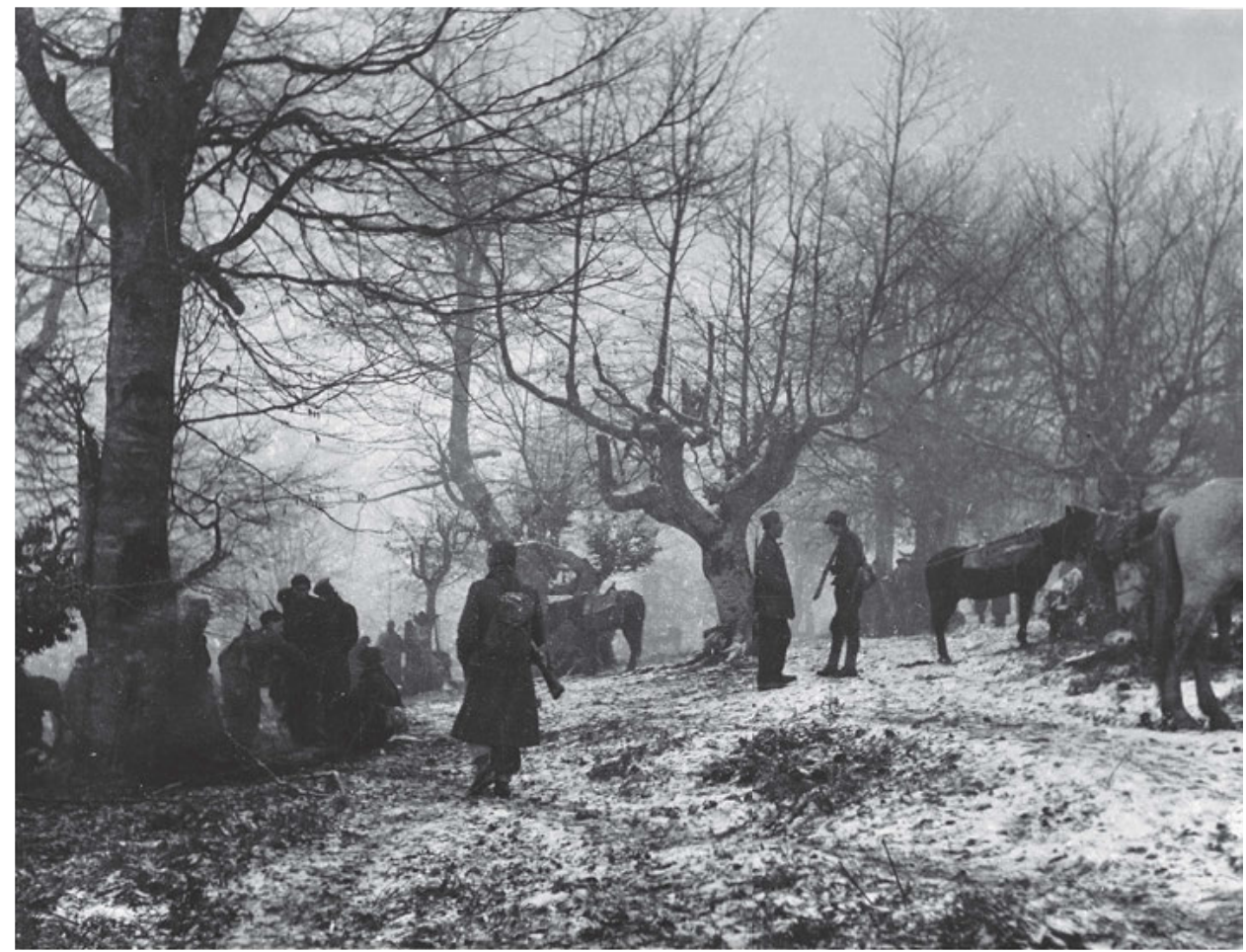

Kurze Rast der Krajina-Partisanen an der Bergspitze Maslin Bajir, Kozara-Gebirge, Ende 1943.

Fotograf unbekannt. Belgrad, Museum Jugoslawiens | III-1273.

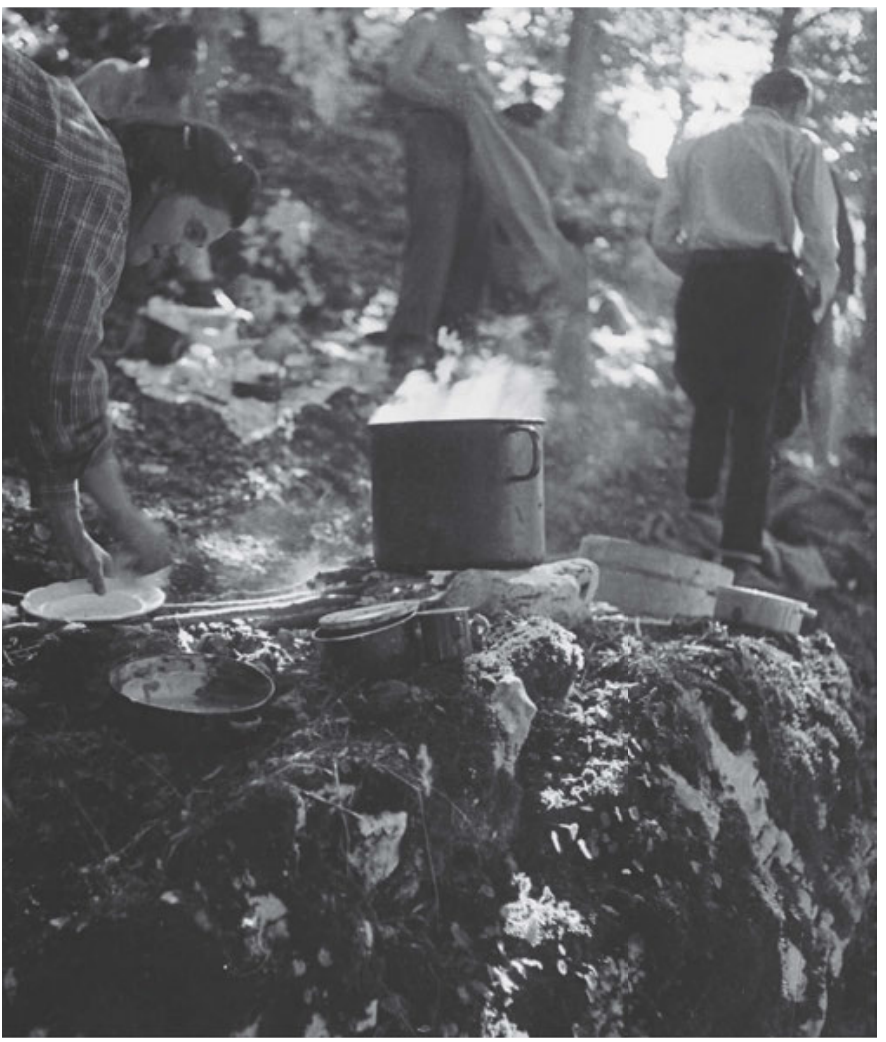

Zubereitung des Mittagessens für die Kämpfer im Volksbefreiungskampf in der Herzegowina, Mai 1943. Fotograf unbekannt. Belgrad, Museum Jugoslawiens | III-3469. 


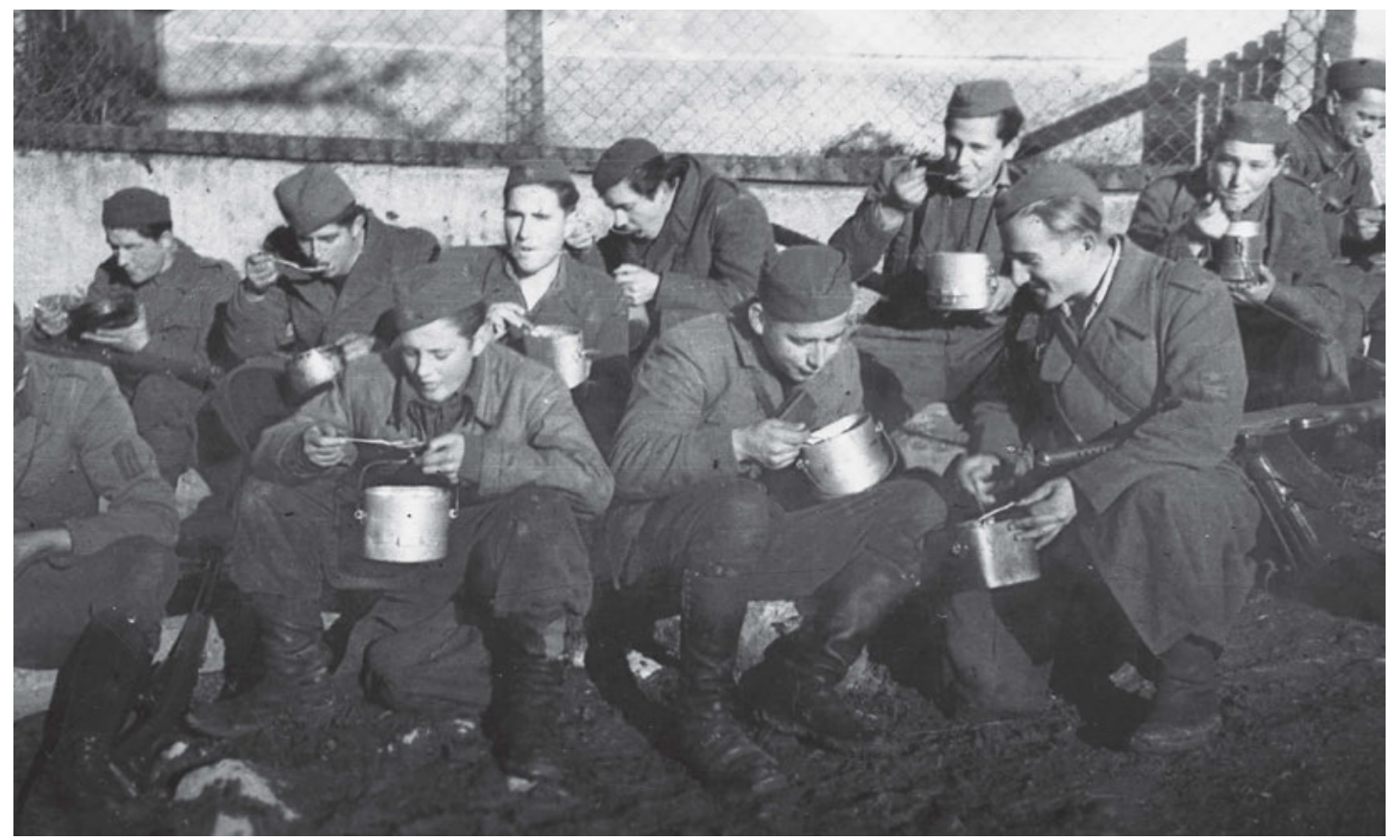

Kochen und Essensausgabe in der Tomšič-Brigade in Hinjah, 19. Dezember 1943. Foto: Miloš Brelih. Ljubljana, Museum für Neuere Geschichte Sloweniens | TN53/40a.

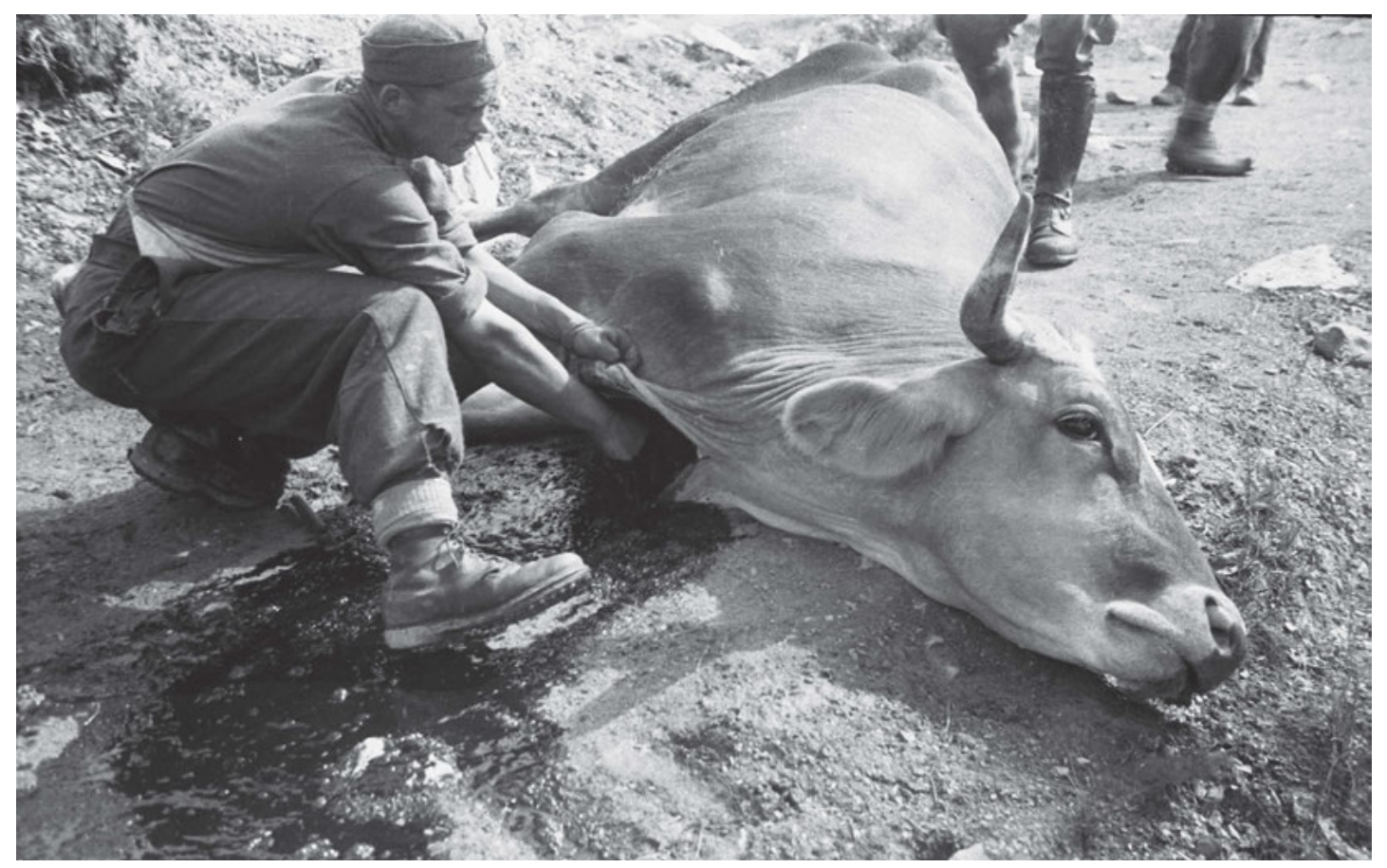

Metzger beim Schlachten eines Ochsen, Lokve, Juli 1944. Foto: Čoro Škodlar. Ljubljana, Museum für Neuere Geschichte Sloweniens | TN218/7. 


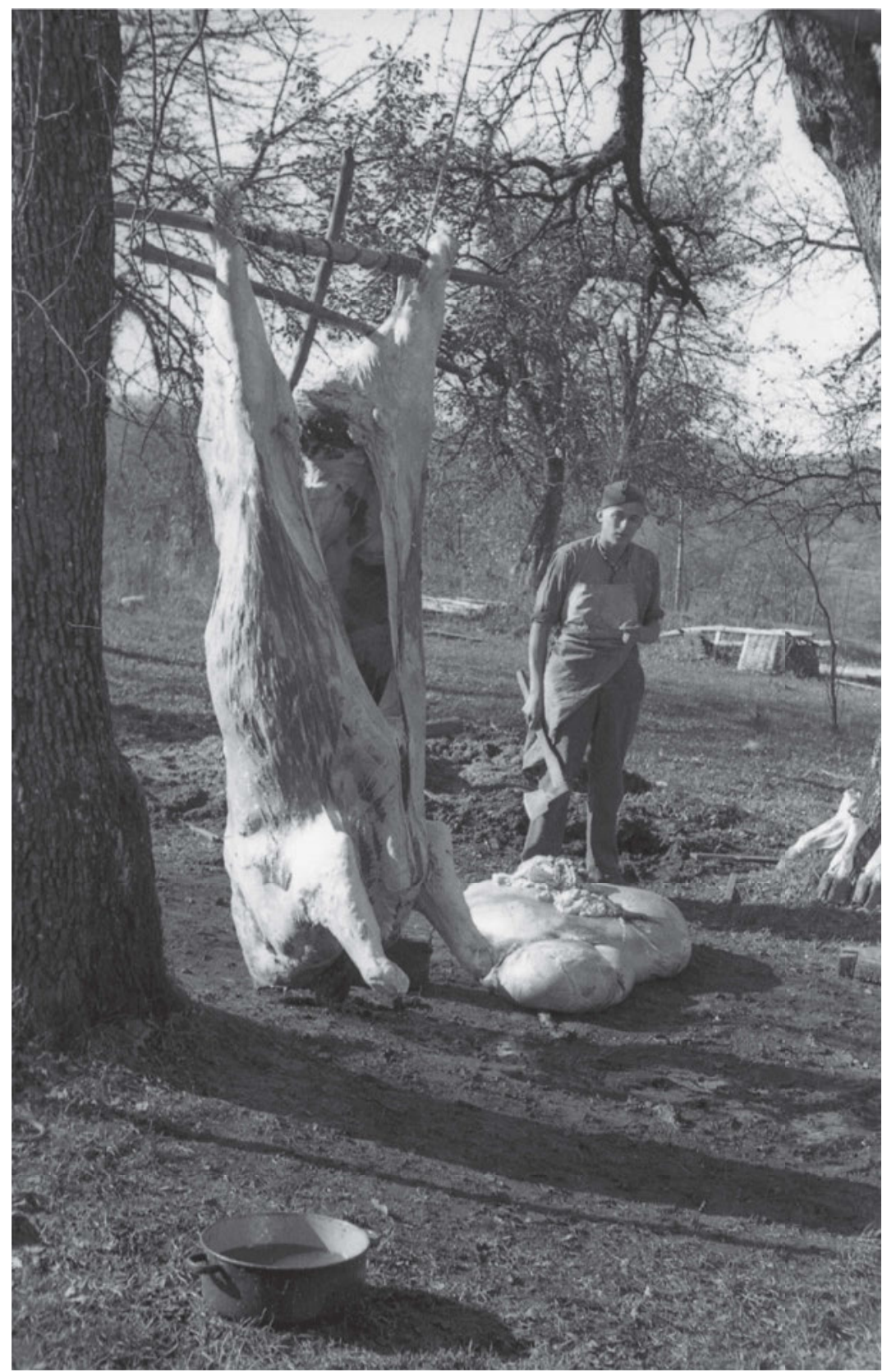

Rinderschlachtung, Kumarna Vas, Winter 1943/44. Foto: Dr. Janez Milčinski. Ljubljana, Museum für Neuere Geschichte Sloweniens | 1227/5. 


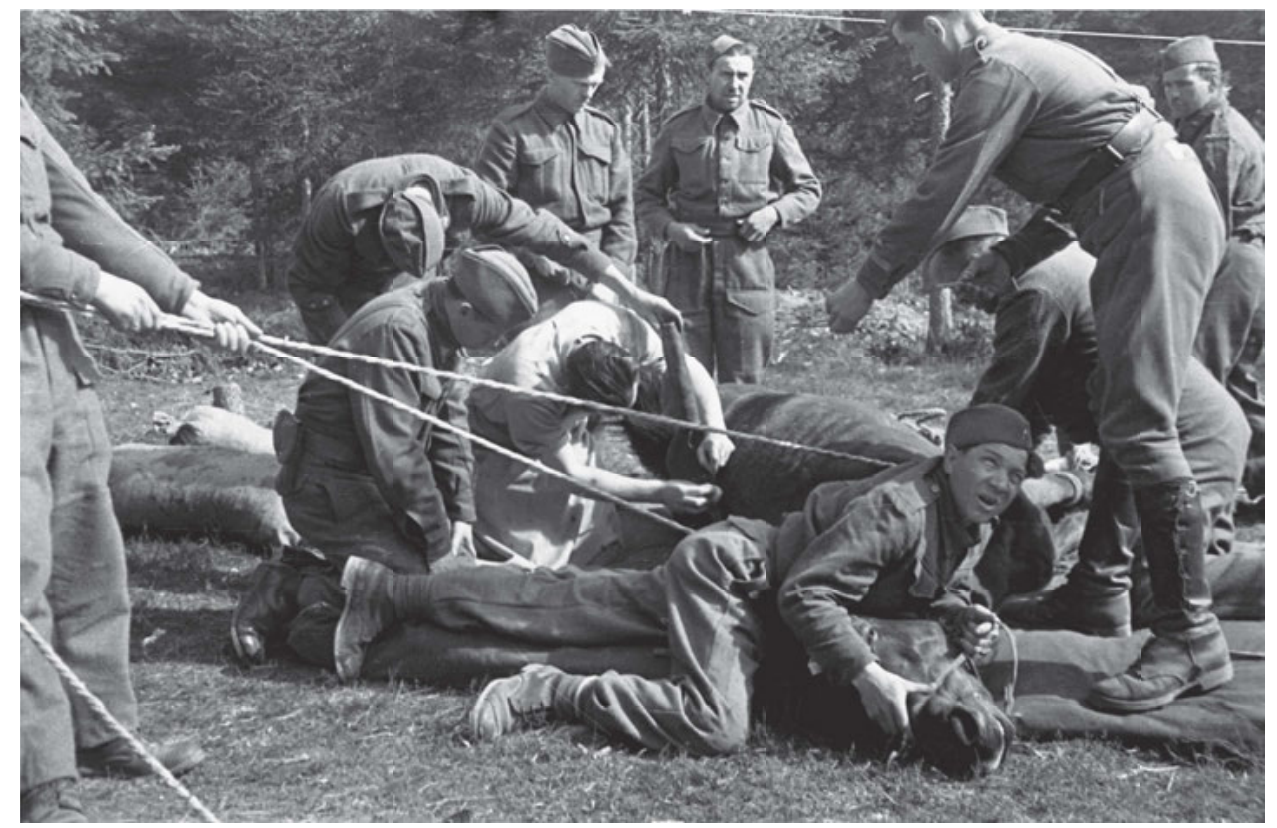

Operation eines Pferdes, Kanižarica, April 1944. Foto: Franjo Veselko. Ljubljana, Museum für Neuere Geschichte Sloweniens | TN792/12.

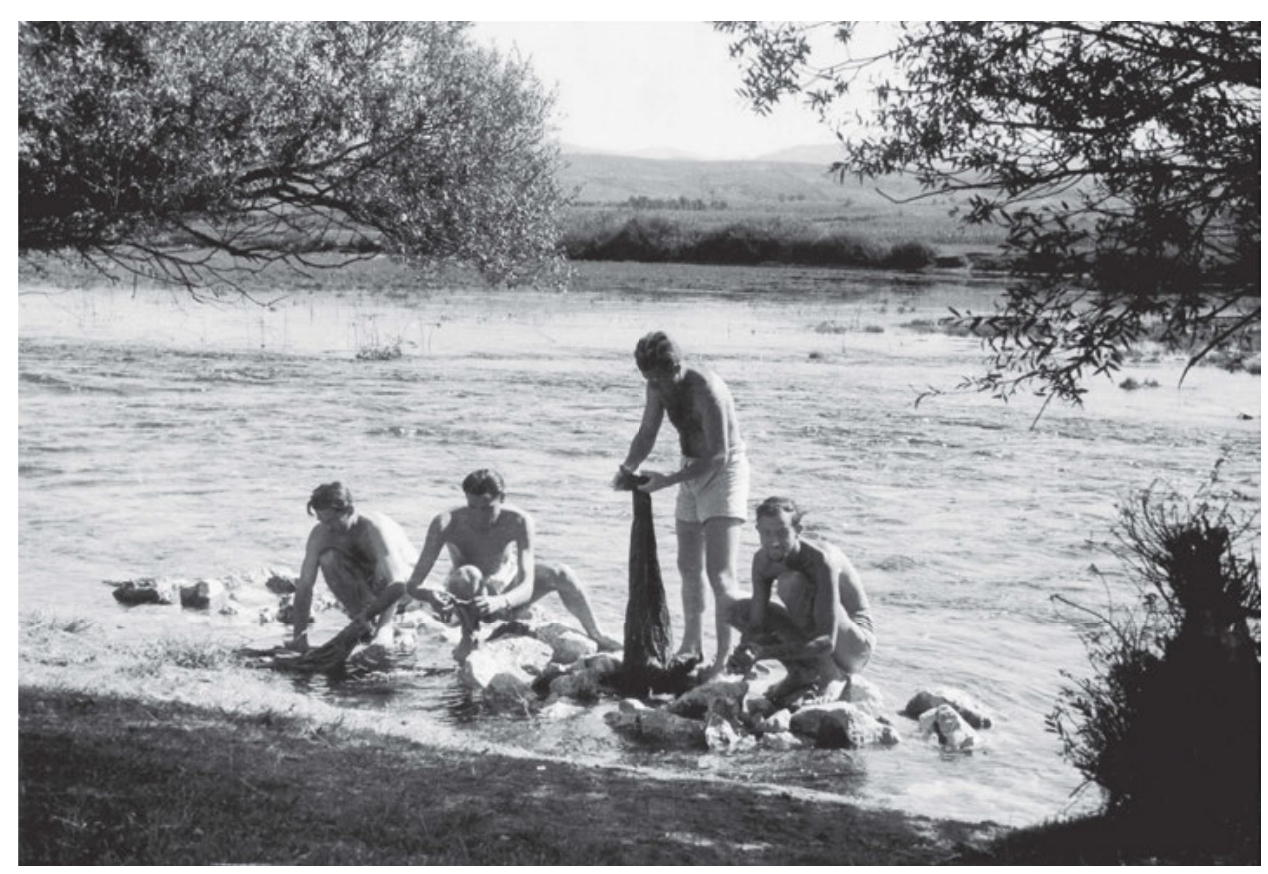

Piloten der Ersten Fliegerstaffel der Volksbefreiungsarmee und der Widerstandsbewegung beim Wäschewaschen, Sanski Most, 1944. Fotograf unbekannt. Belgrad, Museum Jugoslawiens | III-3292. 


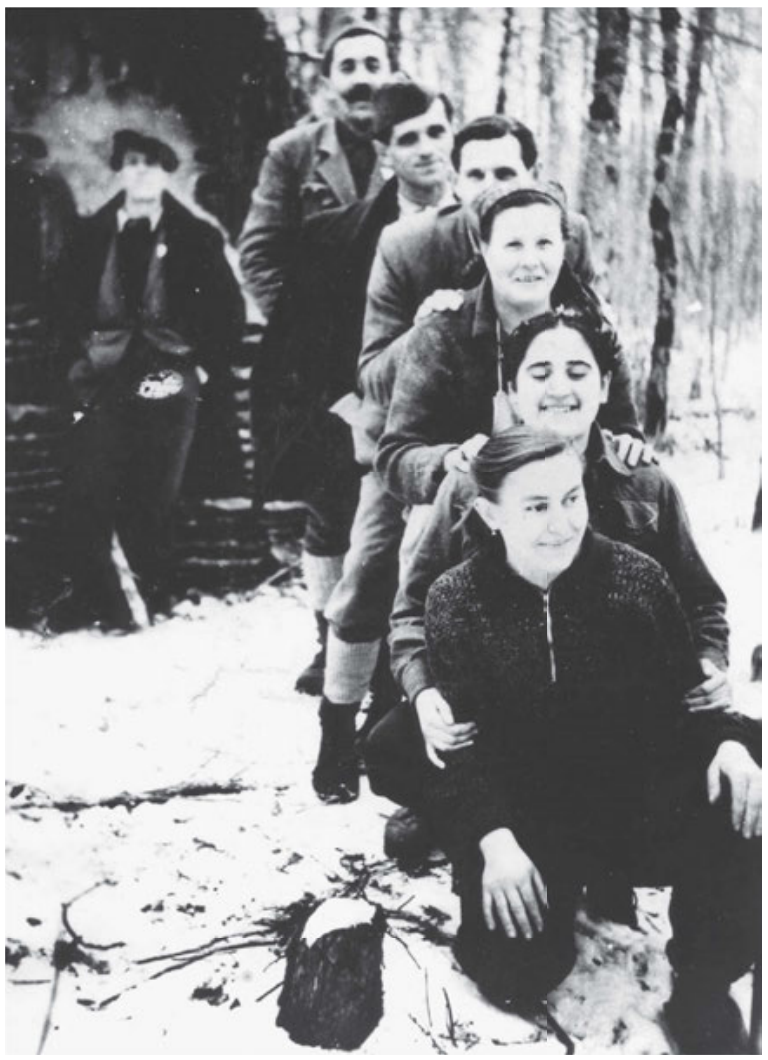

Zehntes Zagreber Korps, Februar 1945. Fotograf unbekannt. Museum der Stadt Zagreb. Ohne Inv.-Nr.

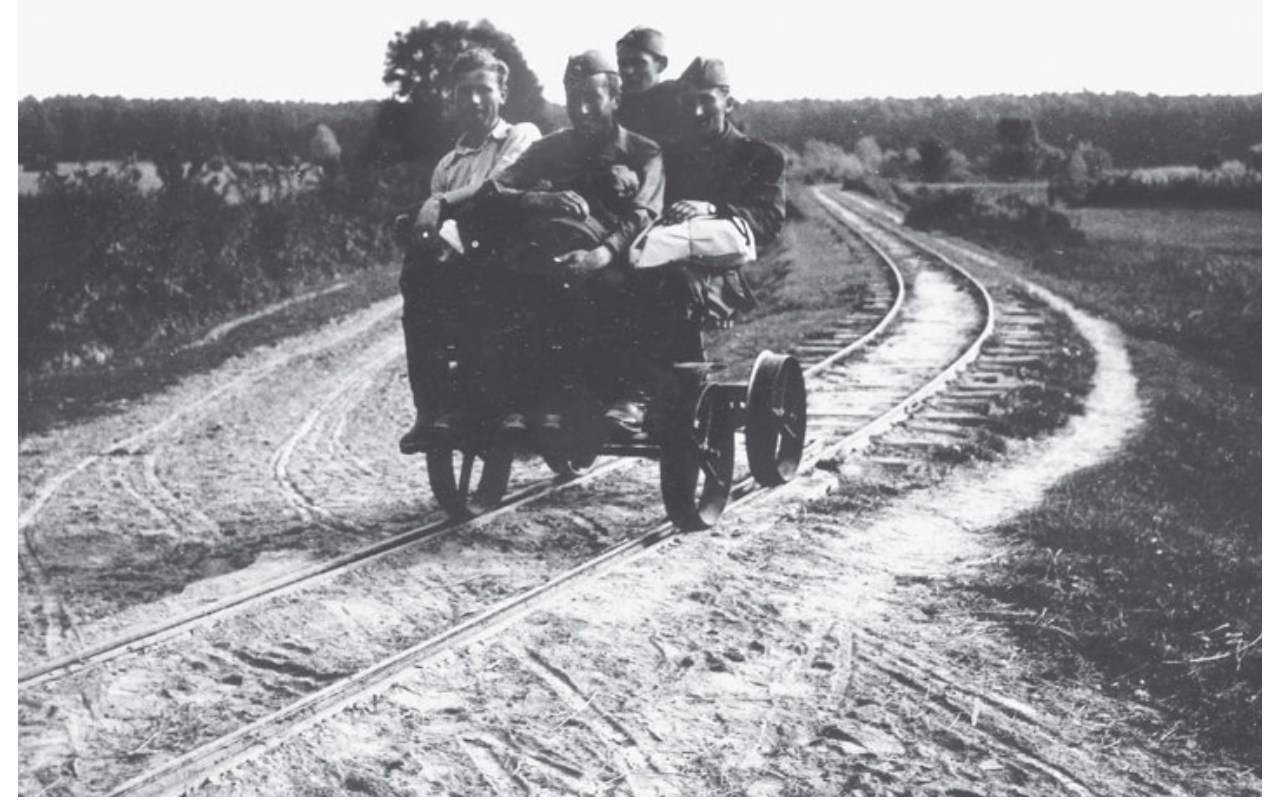

Zehntes Zagreber Korps. Fotograf unbekannt. Museum der Stadt Zagreb. Ohne Inv.-Nr. 


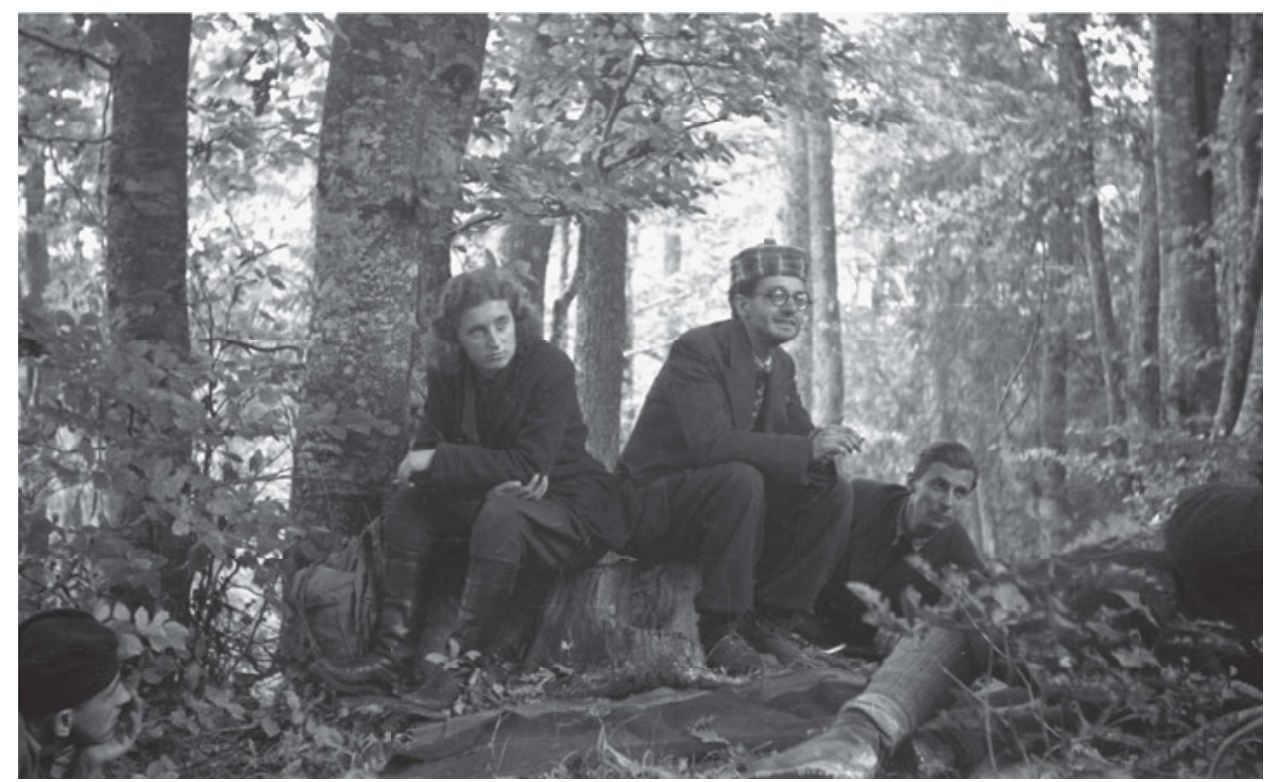

Aus dem Alltag der Cankar-Brigade. Janja und Doktor Zwitter, Oktober 1943. Foto: Franjo Veselko. Ljubljana, Museum für Neuere Geschichte Sloweniens | TN45/11.

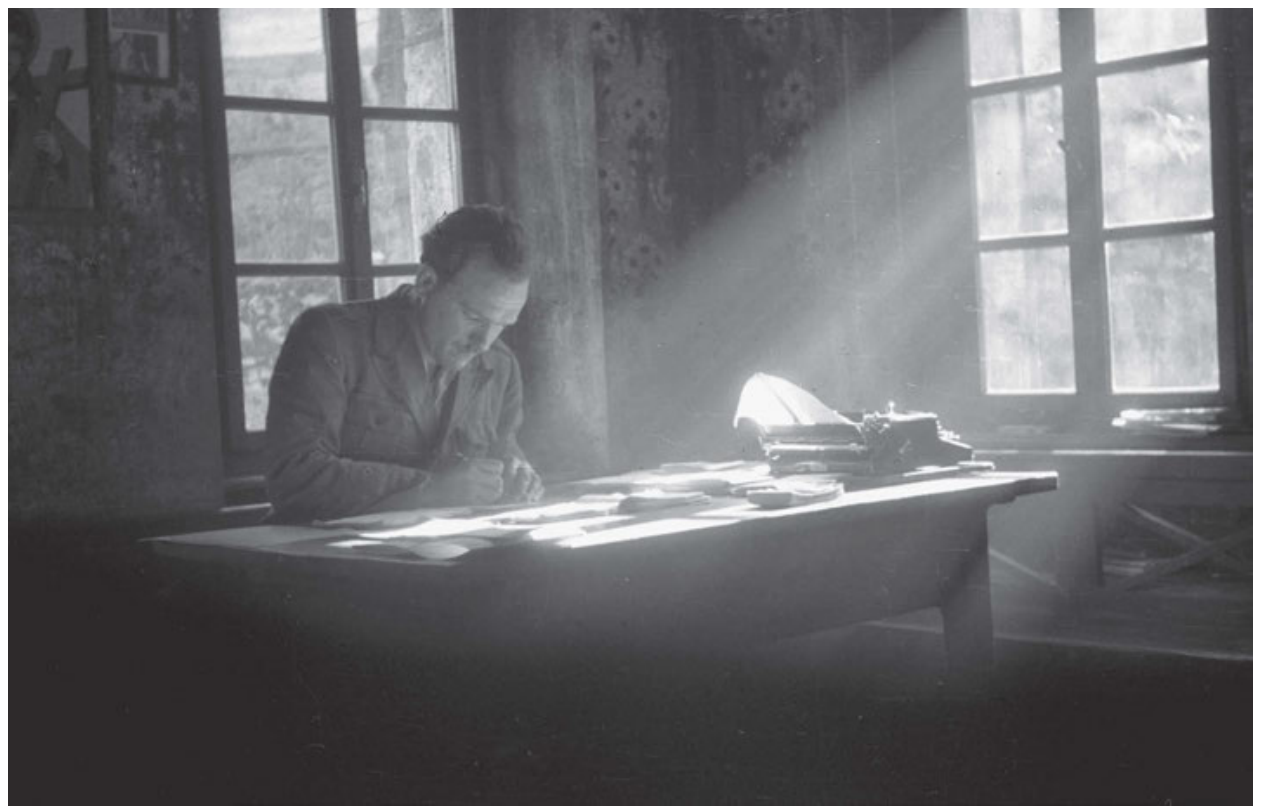

Aus dem Alltag der Cankar-Brigade, Dolž, Februar 1944. Foto: Franjo Veselko. Ljubljana, Museum für Neuere Geschichte Sloweniens | TN48/27. 


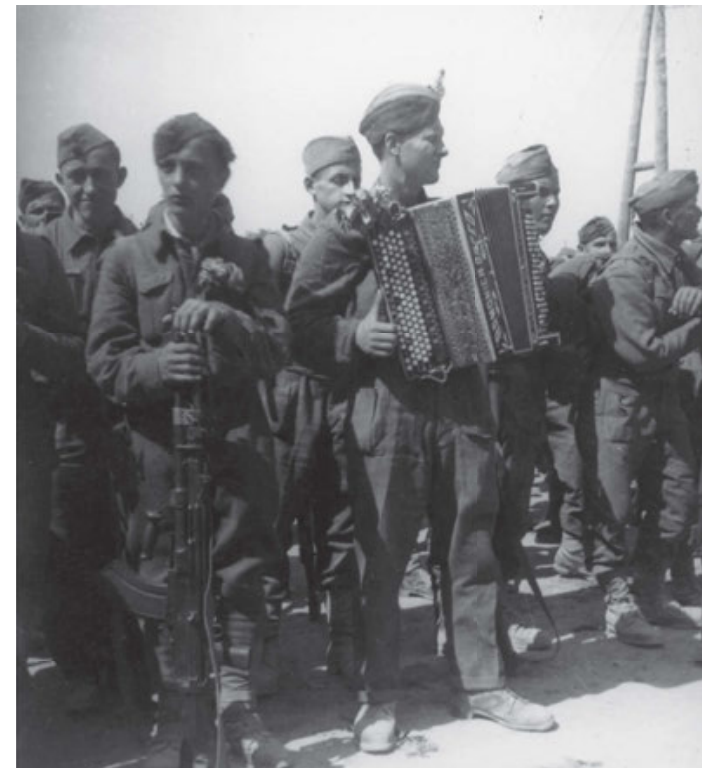

Kämpfer der Fünften Überseebrigade in Črnomelj, 1945.

Fotograf unbekannt. Museum für Neuere Geschichte der Stadt Celje | FZ2B.

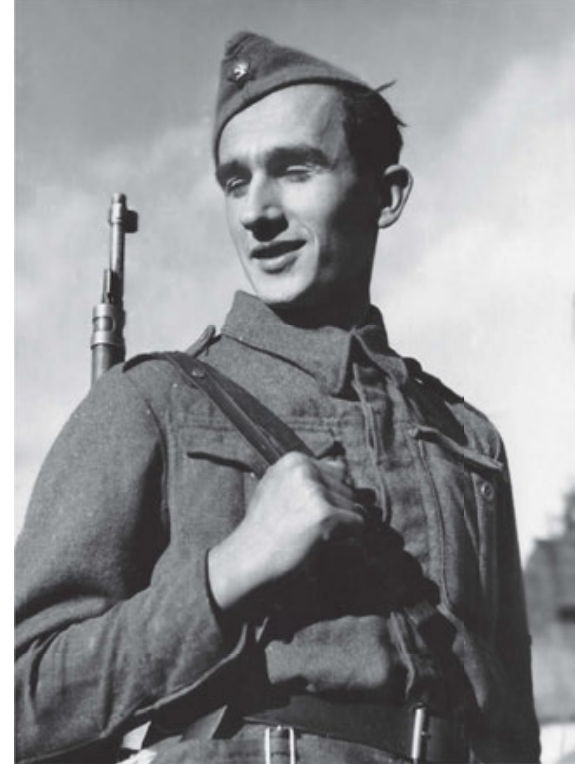

Gvozden Djukanić, Kämpfer der OberkommandoBegleitkompanie. Fotograf unbekannt. Belgrad, Museum Jugoslawiens | III-433.
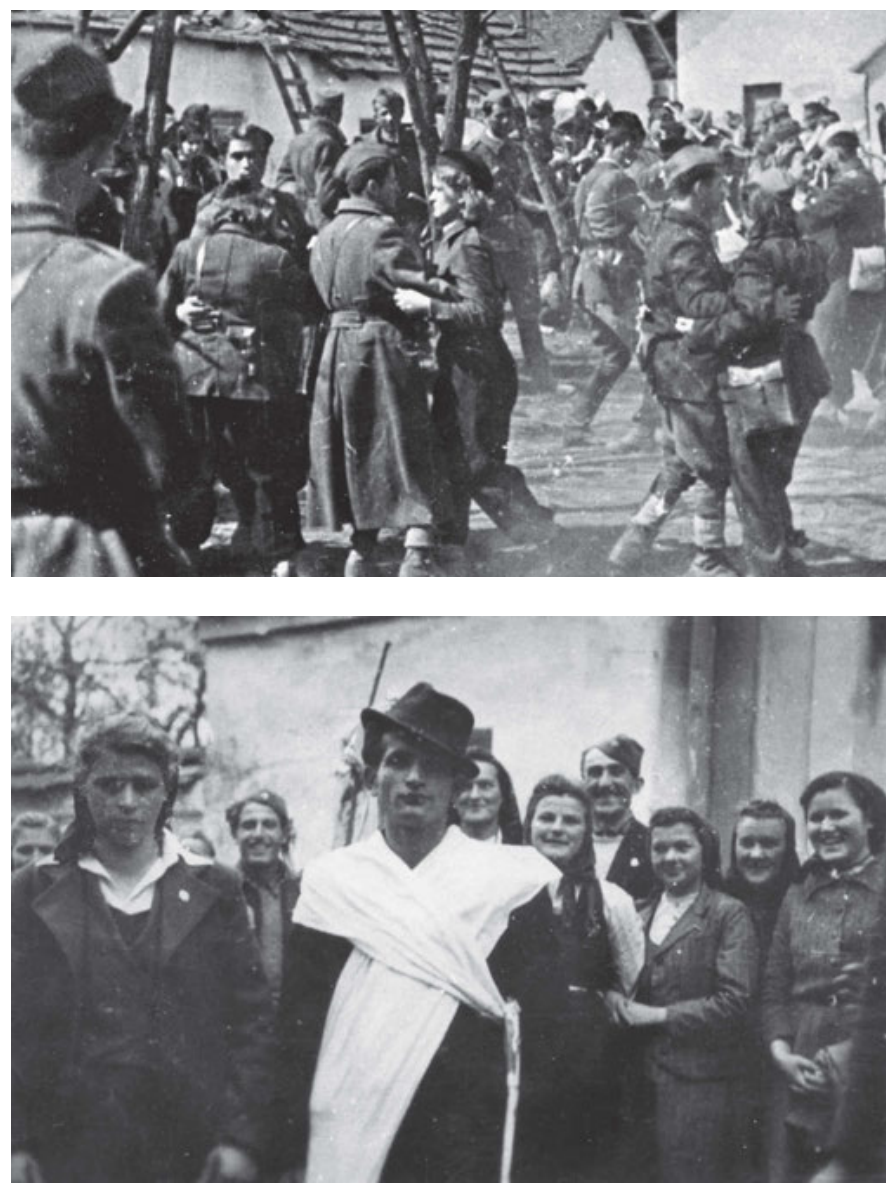

Tanz der Ersten Krajina-Brigade vor dem Kampf um Bijeljina. Šabac, 1945. Fotograf unbekannt. Sarajevo, Historisches Museum von Bosnien und Herzegowina | FNOB 17419.

Partisanen-Hochzeitgesellschaft im Dorf Krasnić unweit von Glina. Fotograf unbekannt. Zagreb, Kroatisches Historisches Museum I HPM-MRNH-R-366. 


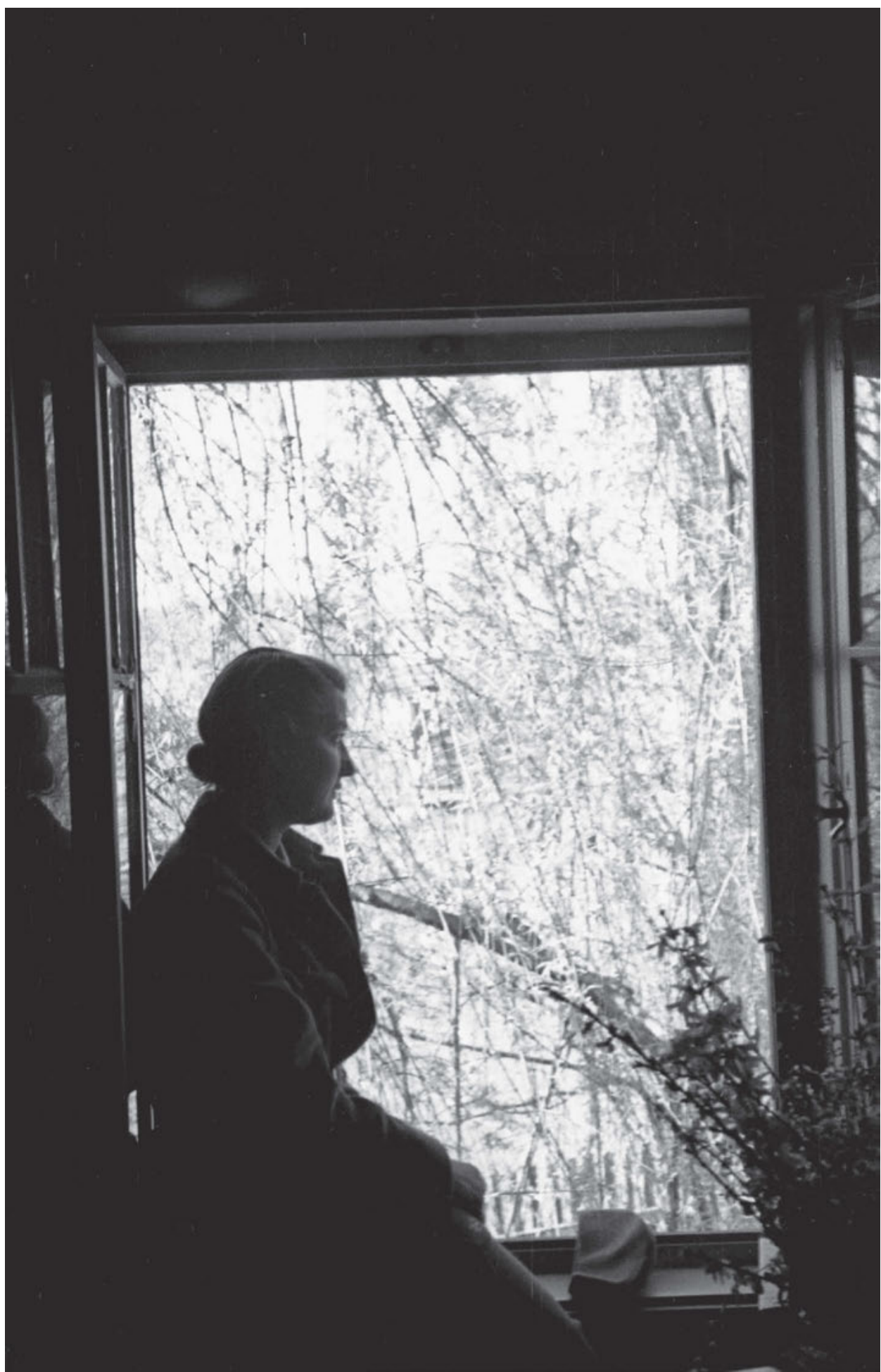

Eheschließung von Vera Hreščak und Aleš Bebler, Vojna Vas, 3. April 1945. Foto: Stane Lenardič. Ljubljana, Museum für Neuere Geschichte Sloweniens | TN728/8. 


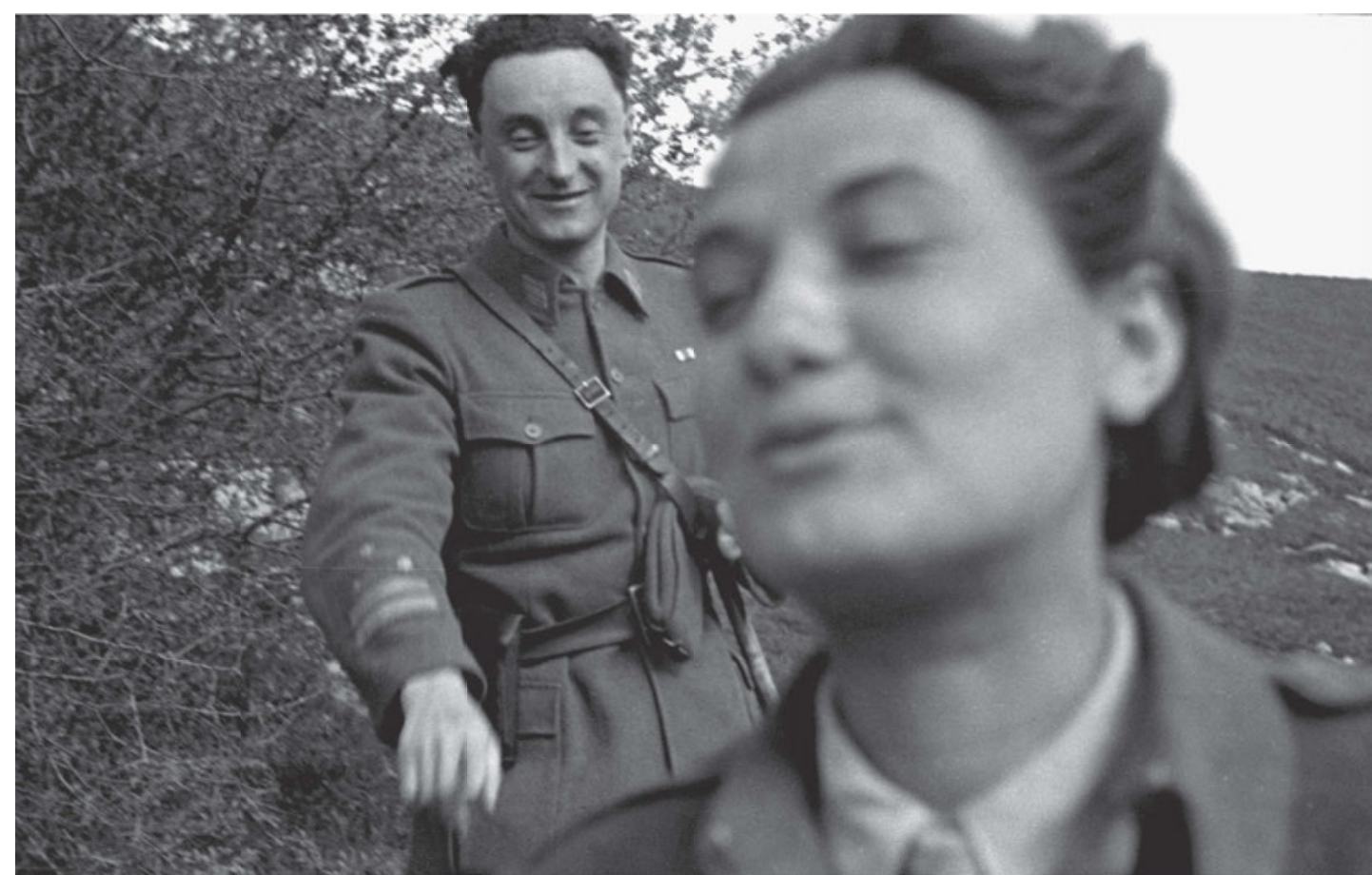

Eheschließung von Vera Hreščak und Aleš Bebler, Vojna Vas, 3. April 1945. Foto: Stane Lenardič. Ljubljana, Museum für Neuere Geschichte Sloweniens | TN728/28.

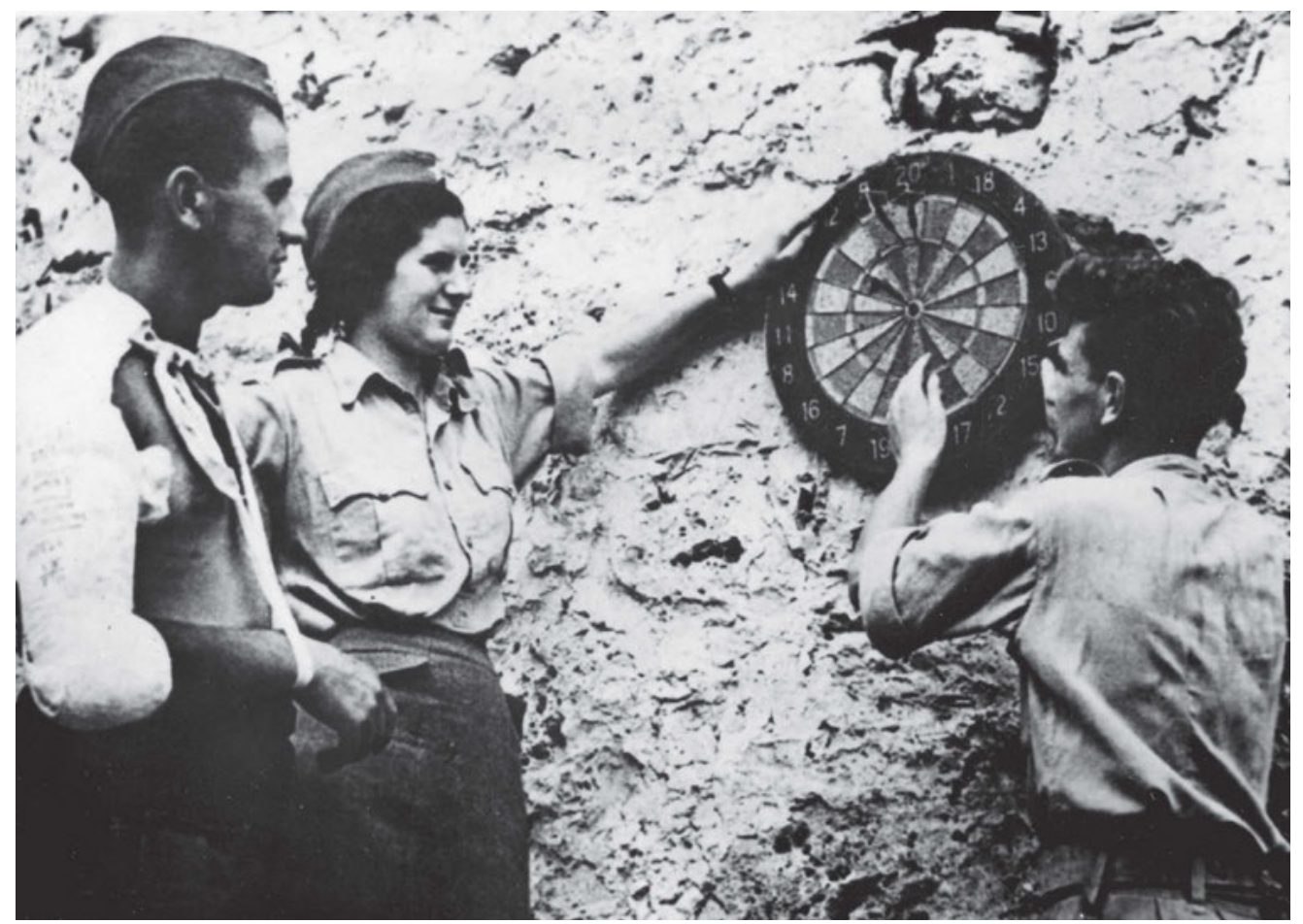

Behandlung eines Verwundeten. Szene zwischen Krankenschwestern und einem Patienten, die sich die Zeit mit Dart vertreiben, 1944. Fotograf unbekannt. Sarajevo, Historisches Museum von Bosnien und Herzegowina | FNOB 1349. 


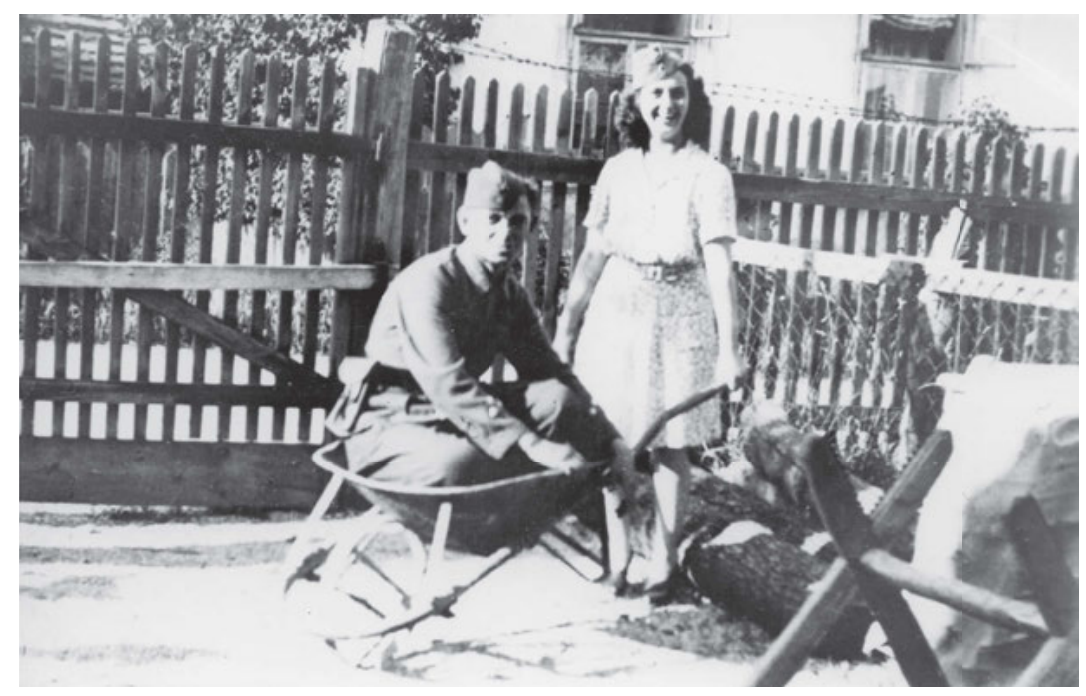

"Zugführer auf dem Weg nach Zagreb« - spaßige Fotografie. Zugführer der Dritten Kompanie und unbekanntes Mädchen, 1945. Fotograf unbekannt. Museum der Stadt Zagreb. Ohne Inv.-Nr.
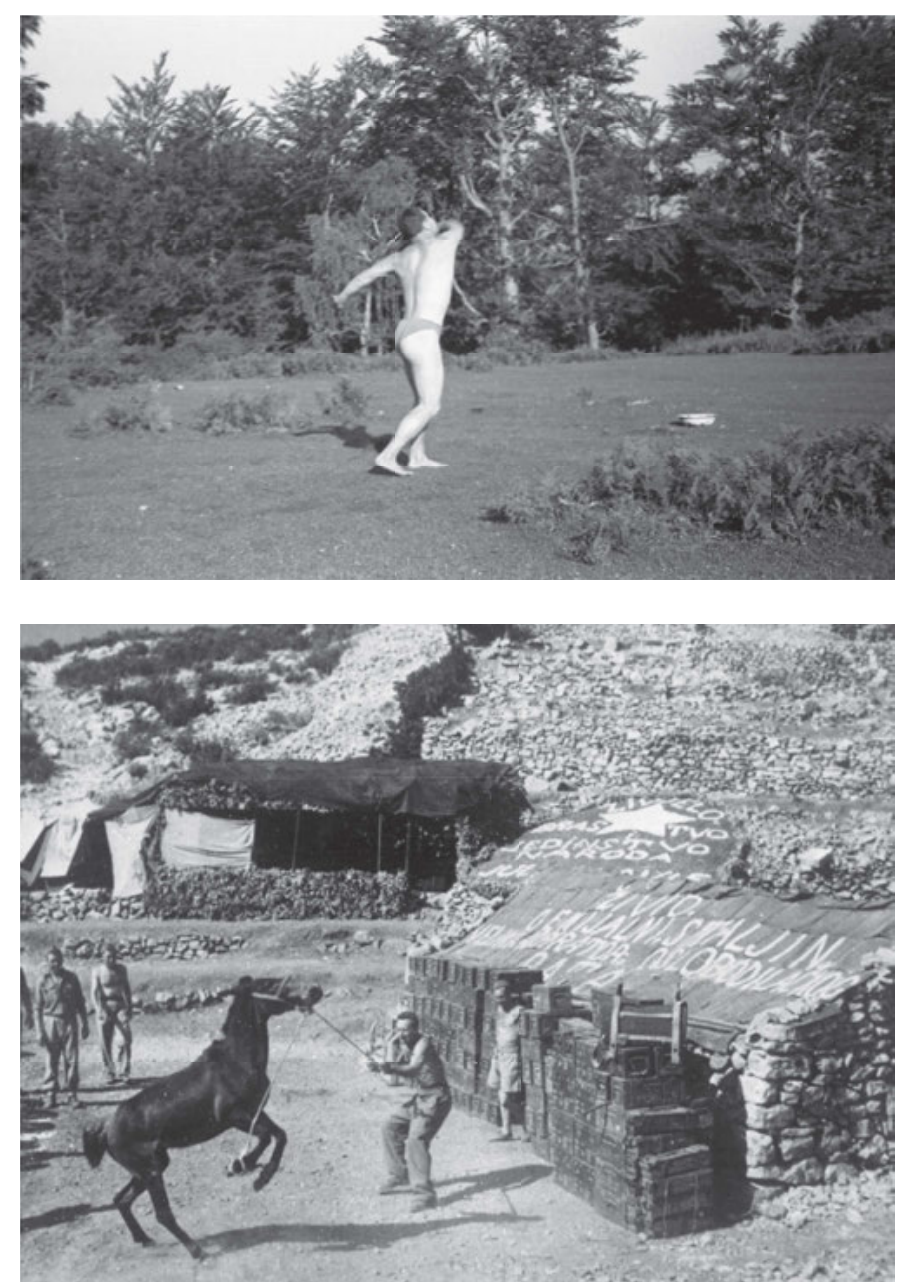

Der Leichtathlet Šoić, Beauftragter für Körperkultur der 13. Küstenlanddivision, 1944. Fotograf unbekannt. Zagreb, Kroatisches Historisches Museum I HPM-MRNH-A2603-f14_030.

Bändigung eines Maultiers in einer Partisaneneinheit auf der Insel Vis, 1944 Fotograf unbekannt. znaci.net. 


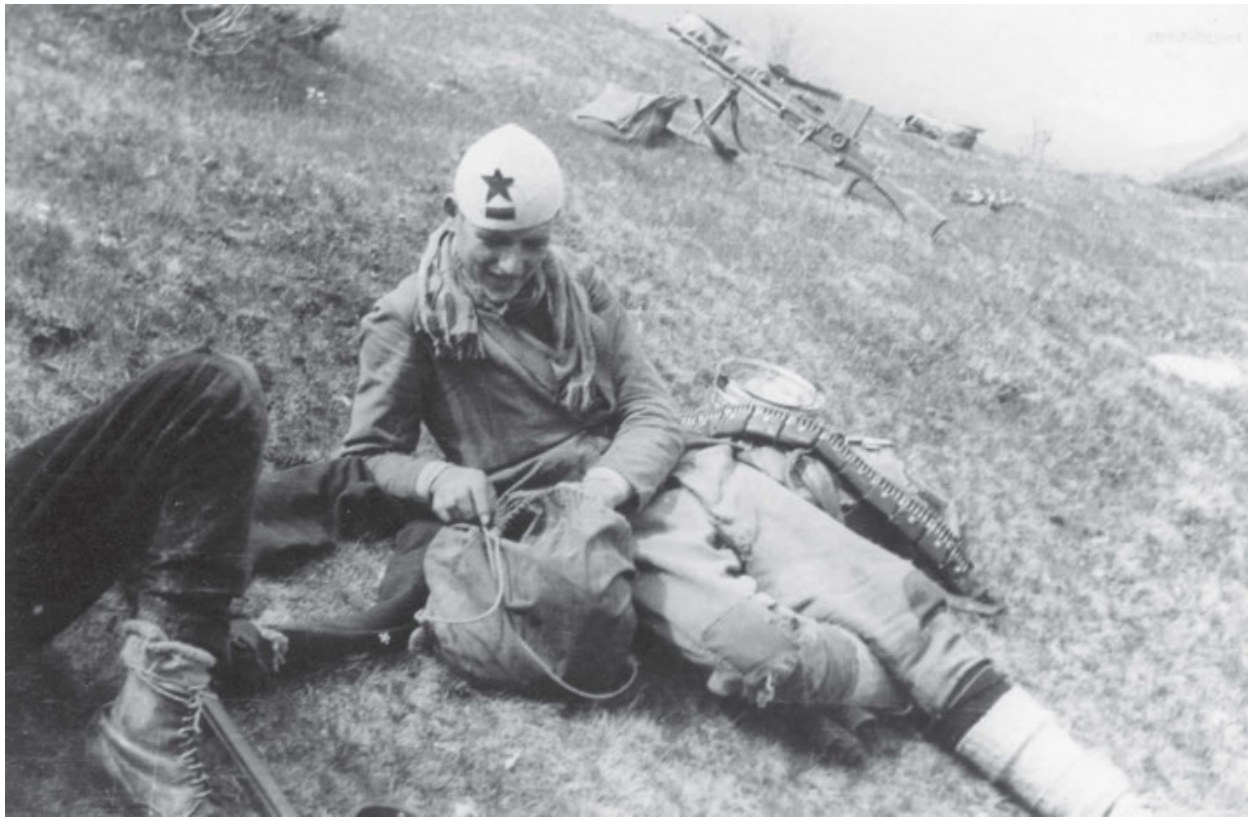

Partisanen der Šar-Planina-Einheit im Gebirge Šar Planina, Serbien, 1943. Fotograf unbekannt. Belgrad, Militärmuseum | 1295.

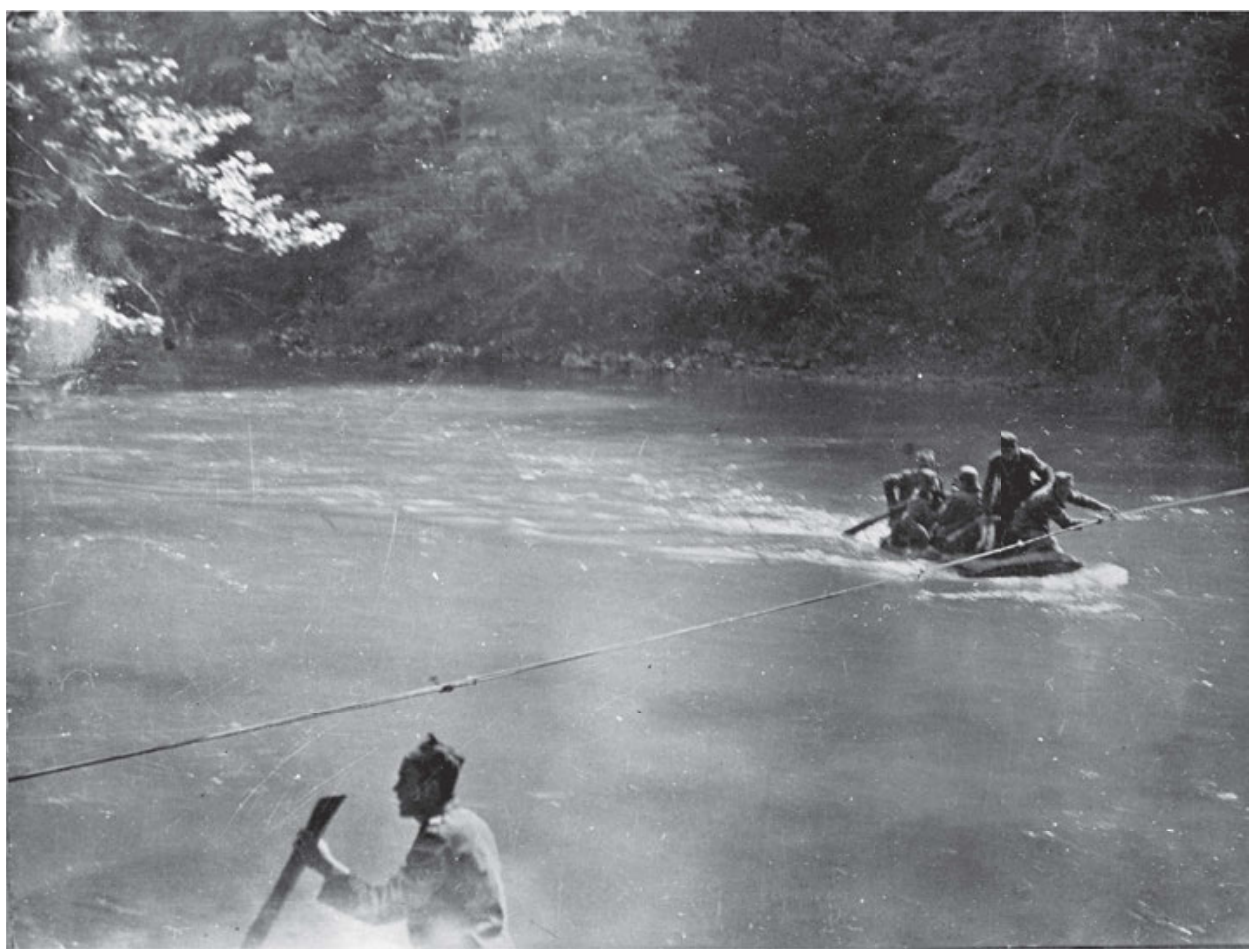

Zweite Proletarische Division beim Überqueren des Flusses Piva 1943. Fotograf unbekannt. Sarajevo, Historisches Museum von Bosnien und Herzegowina | FNOB 17737. 


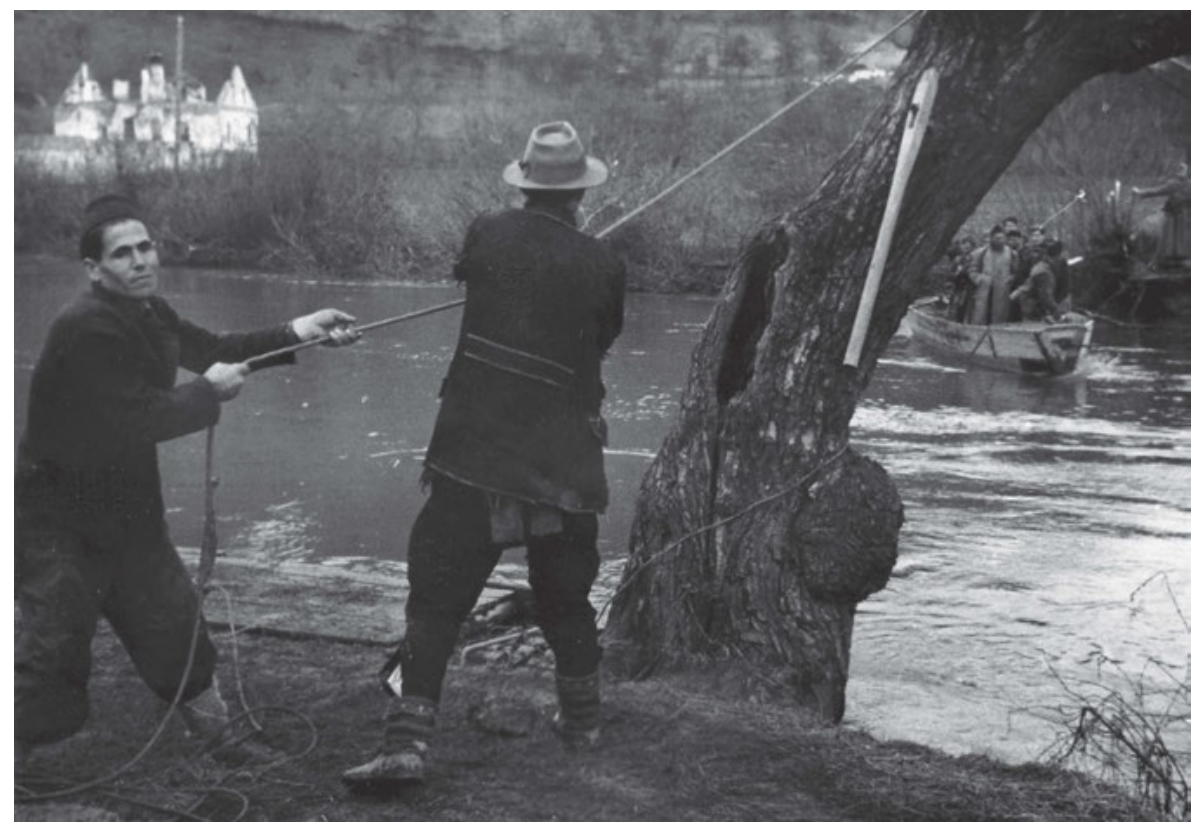

Delegierte der Zweiten Sitzung des Antifaschistischen Rats der Volksbefreiung Jugoslawiens überqueren bei ihrer Rückreise den Fluss Sanica bei Ključ. Fotograf unbekannt. Fotolaboratorija Instituta za istoriju radnickog pokreta naroda Jugoslavije/znaci.net.

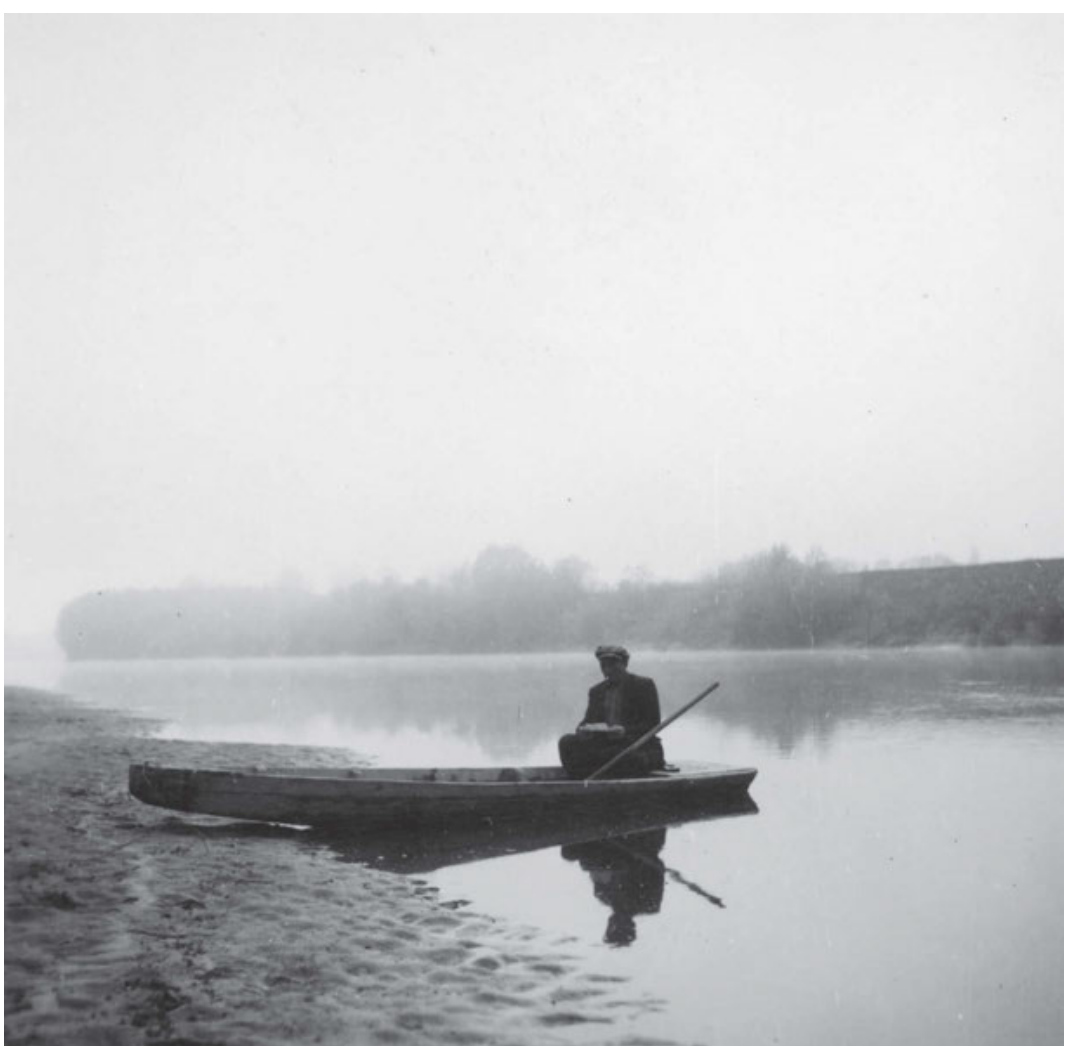

Djuro Jambrek in seinem Boot, mit dem er Partisanen über den Fluss Kupa beförderte. Foto: Emil Vičić. Zagreb, Kroatisches Historisches Museum | HPM/MRNH-F-4069. 


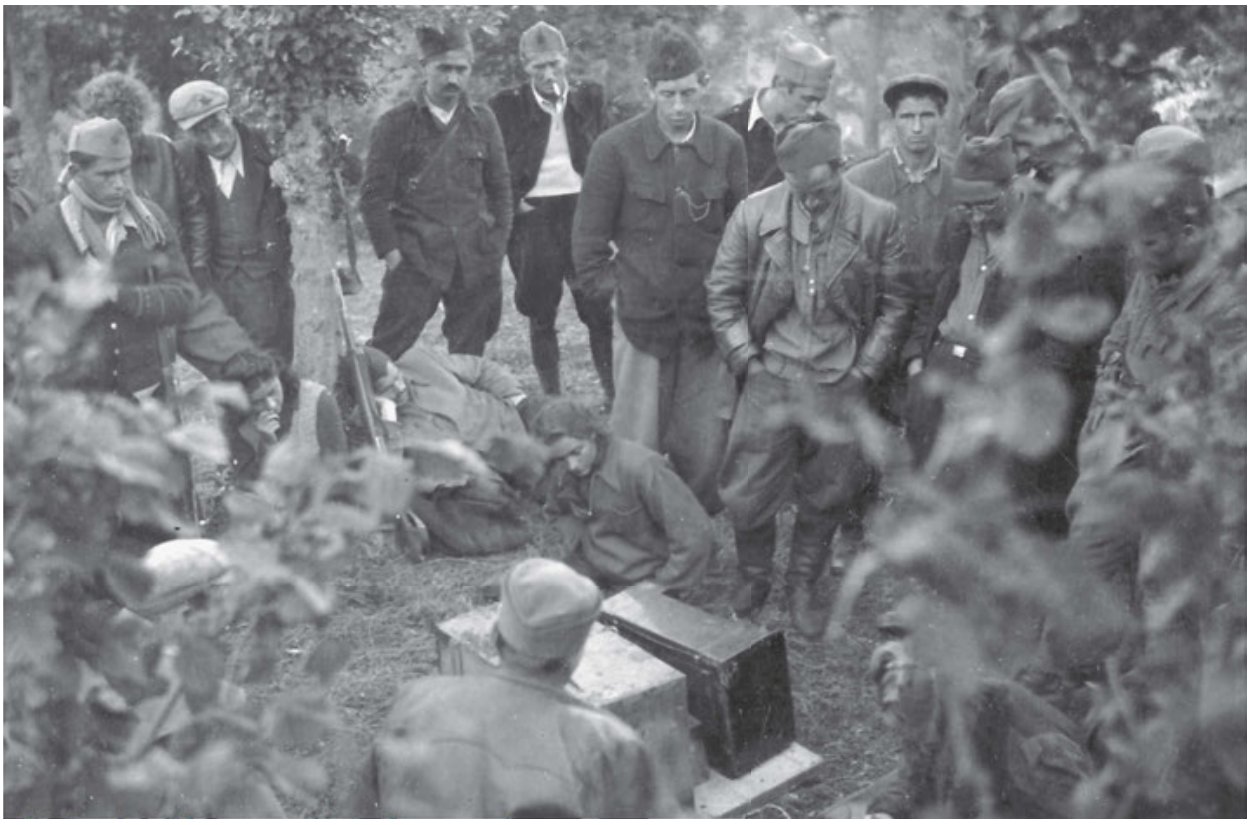

Kämpfer der Vierten Montenegrinischen Brigade hören während der Schlacht an der Sutjeska die Nachrichten im Radio, 1943. Fotograf unbekannt. Belgrad, Militärmuseum | 4394.

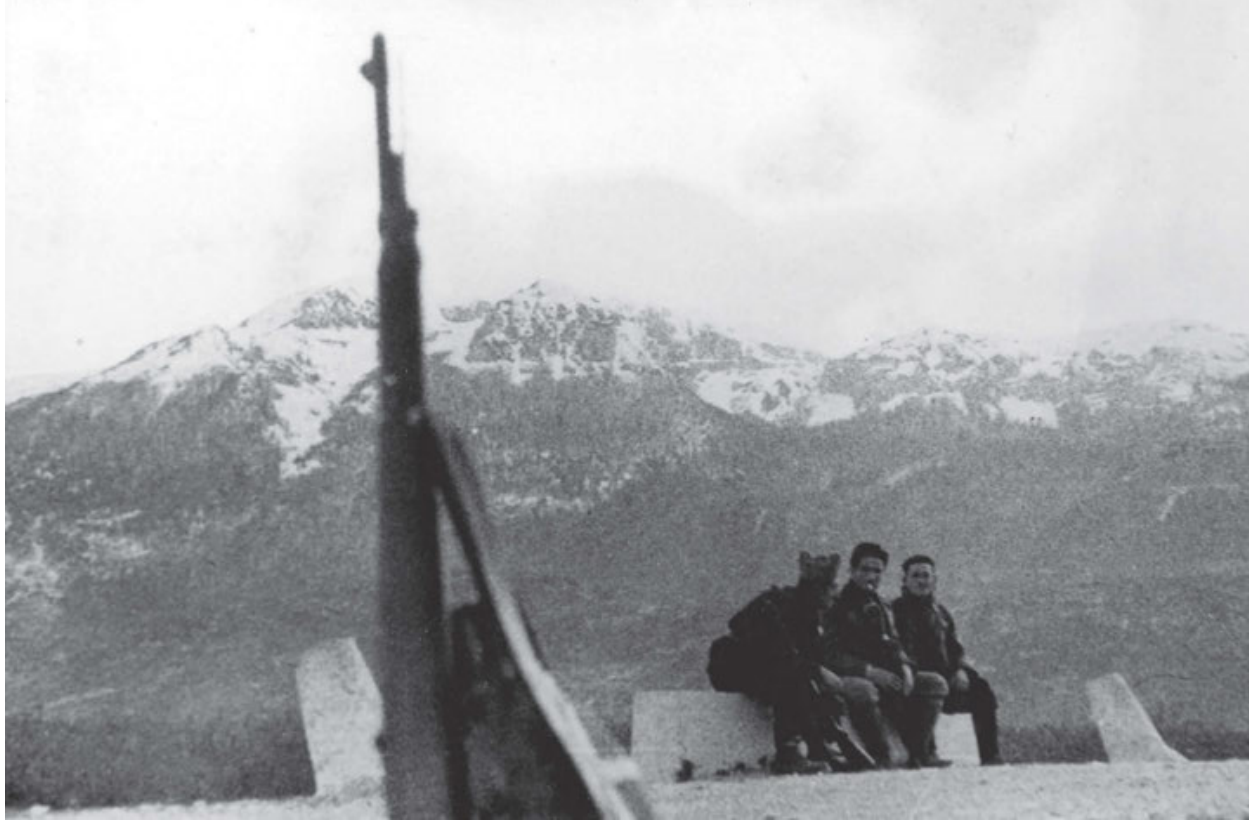

Die ersten Kuriere der Dalmatinischen Einheit und der Krajina-Einheit bei ihrer Rast auf dem Livno-Feld unterhalb des Berges Triglav, Mai 1942 (Redaktion Crvena zvezda [Roter Stern], 7. Juni 1956). Fotograf unbekannt. Sarajevo, Historisches Museum von Bosnien und Herzegowina | FNOB 10843. 

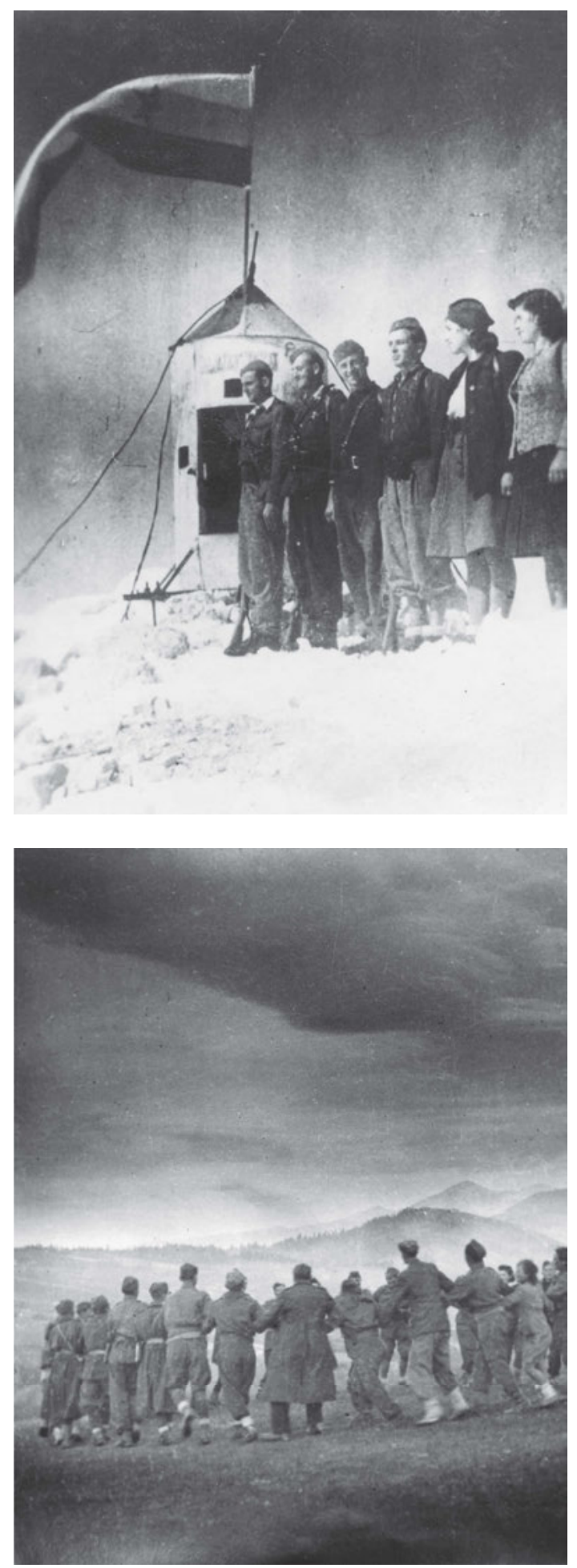

Beim Reigentanz Kolo. Fotograf unbekannt. Sarajevo, Historisches Museum von Bosnien und Herzegowina | FNOB 207.
Dritter provisorischer Weg zum Gipfel Triglav, Oktober 1944. Foto: Bogo Tavčar. Ljubljana, Museum für Neuere Geschichte Sloweniens | 2214/1.

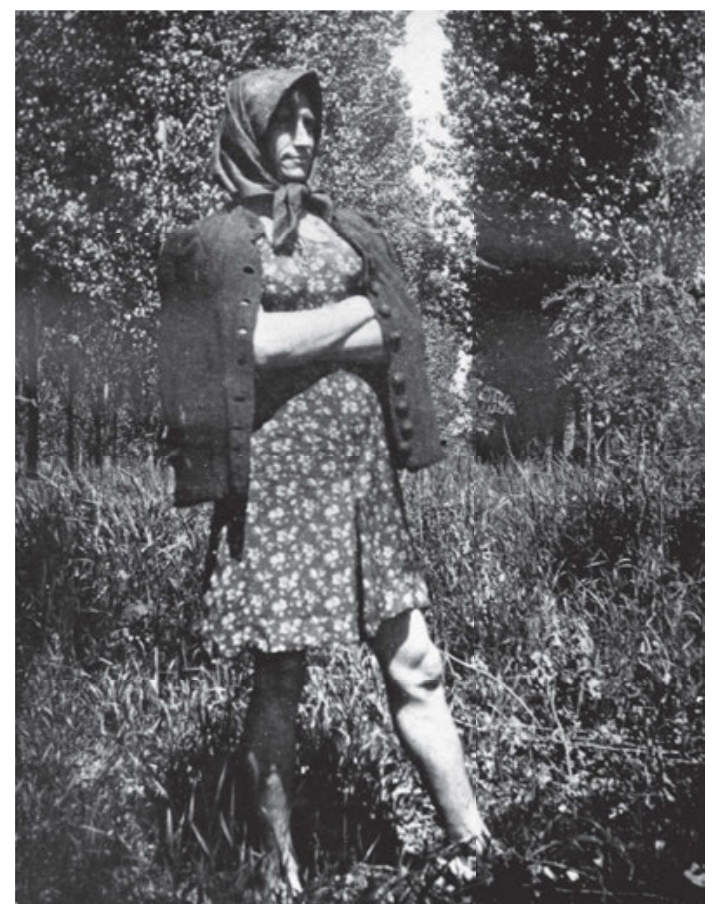

Lazar Tešić als illegaler Arbeiter in Tuzla.

Fotograf unbekannt. Sarajevo, Historisches Museum von Bosnien und Herzegowina | FNOB 14741. 


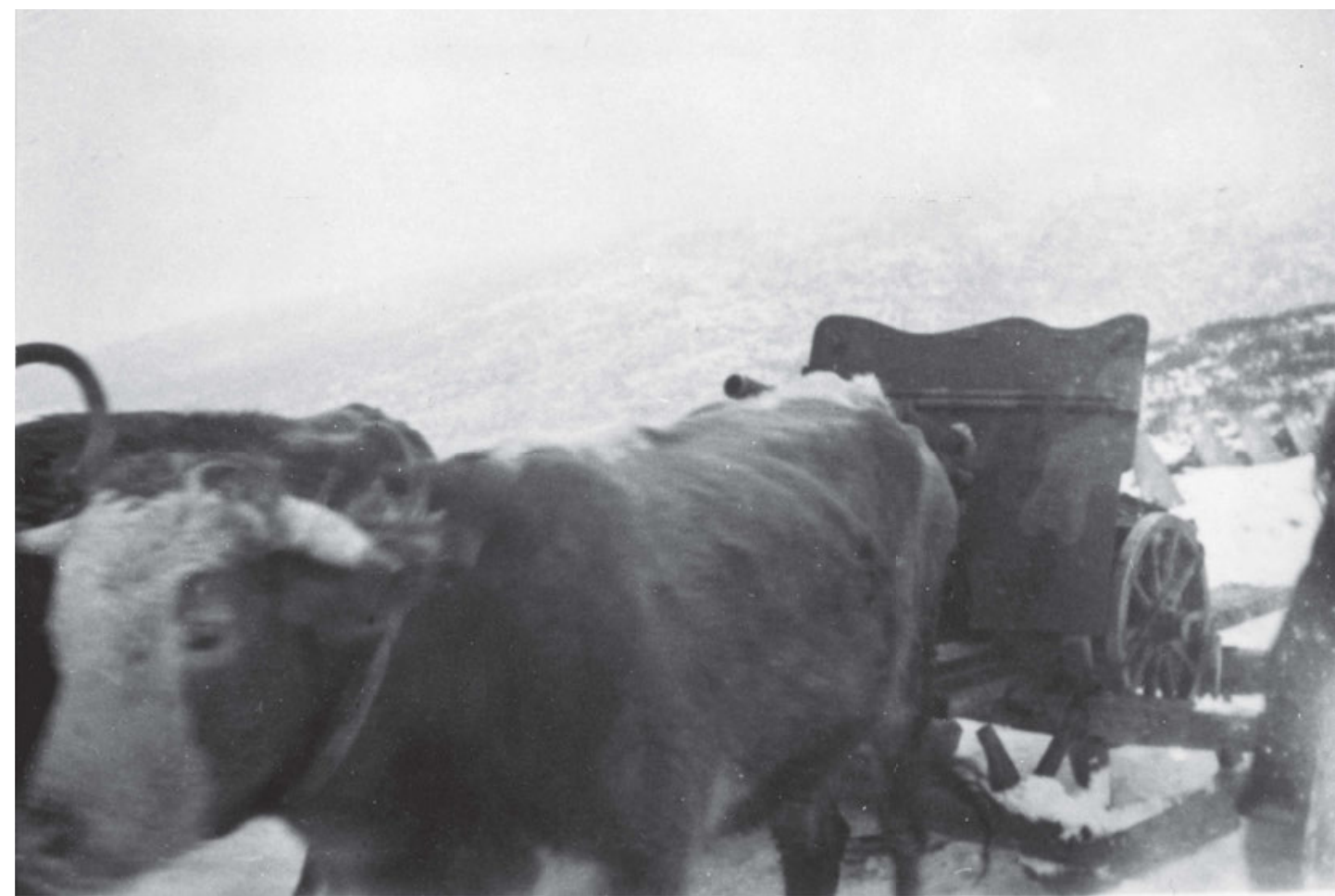

Die erste Panzerabwehrkanone, die das Oberkommando nach Podgora geschickt hat, um die Adriaküste zu verteidigen. Die Kanone wird von Ochsen gezogen. Korićani zwischen Glamoč und Livno, 17. Januar 1943. Fotograf unbekannt. Sarajevo, Historisches Museum von Bosnien und Herzegowina | FNOB 14533.

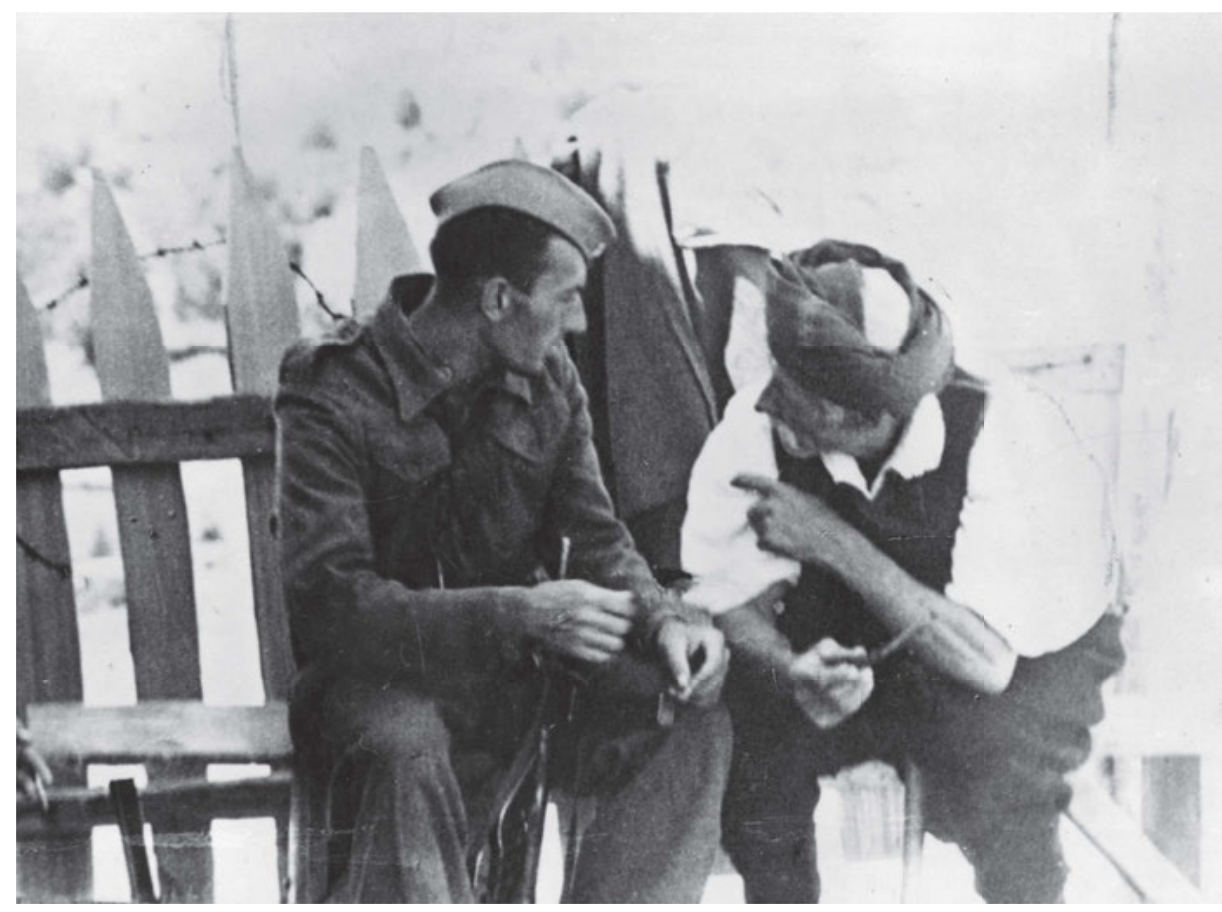

Begegnung von Vater und Sohn in der Nähe von Tuzla, 1943. Fotograf unbekannt. Sarajevo, Historisches Museum von Bosnien und Herzegowina | FNOB 16418. 


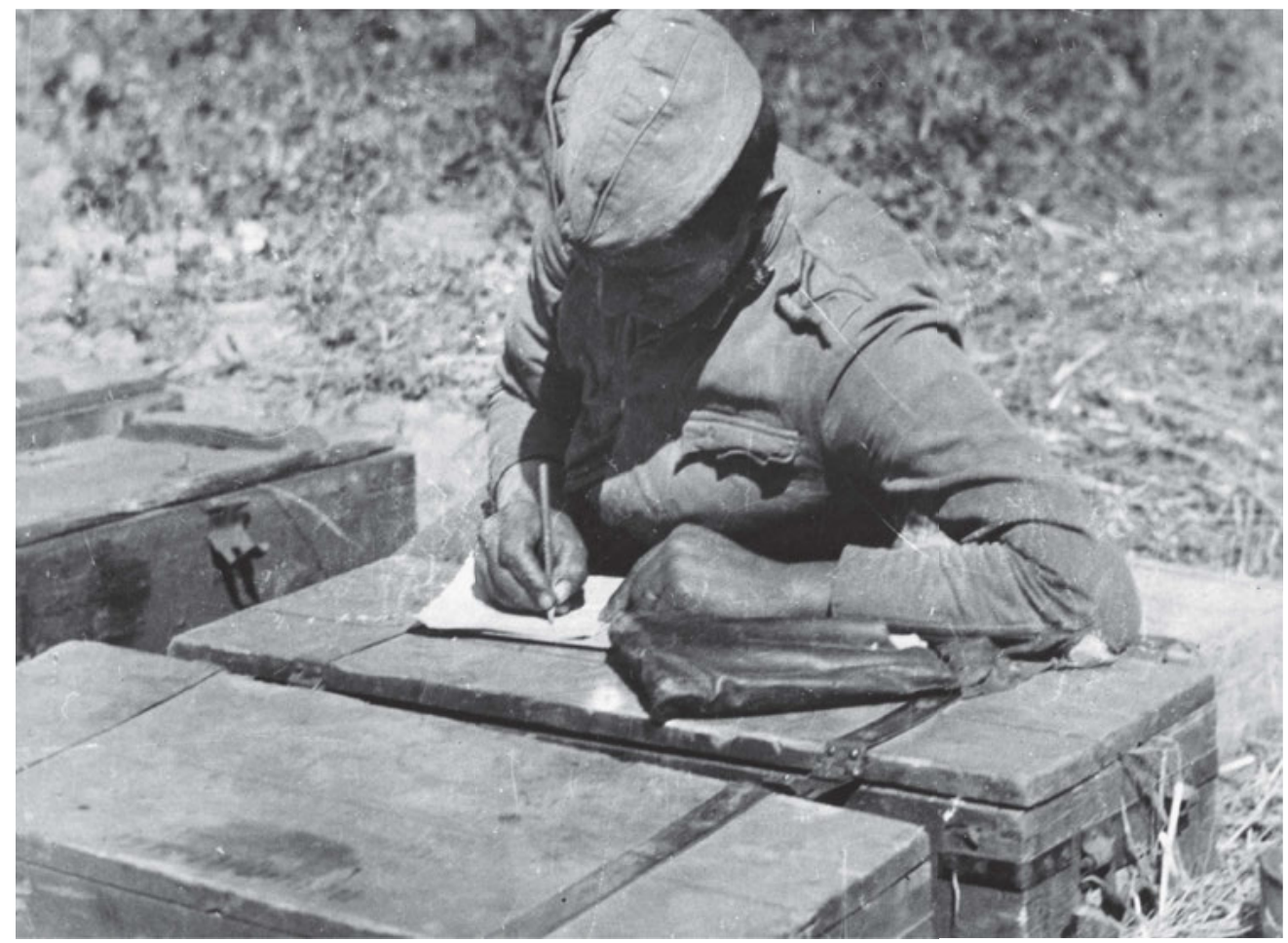

Ein Soldat der Ersten Krajina-Brigade schreibt einen Brief an seine Familie. Srem-Front, Frühling 1945. Fotograf unbekannt. Sarajevo, Historisches Museum von Bosnien und Herzegowina | FNOB 1885.

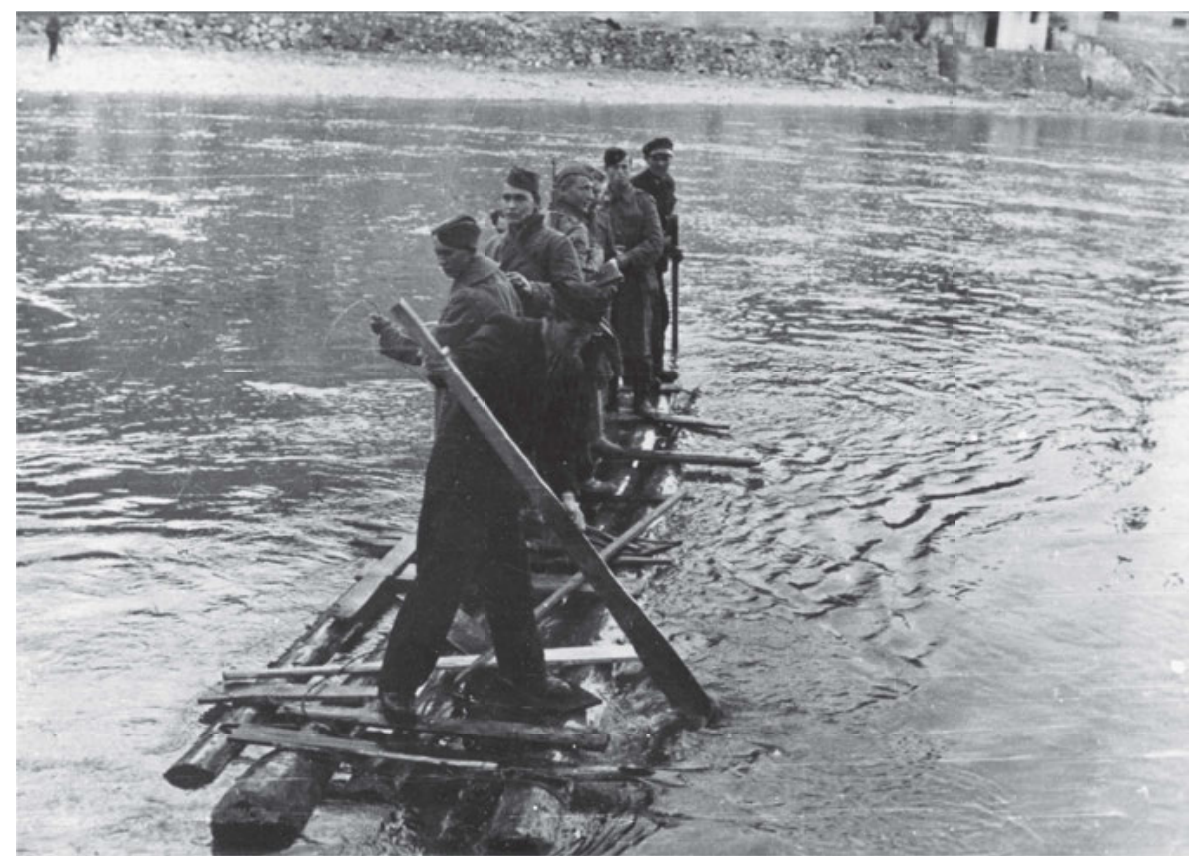

Vorstoß der Vorhut der Zweiten Herzegowinischen Brigade an das linke Neretva-Ufer in Konjić. Überquerung des Flusses mit einem provisorisch gefertigten Floß am 18. Februar 1945. Fotograf unbekannt. Sarajevo, Historisches Museum von Bosnien und Herzegowina | FNOB 16695. 


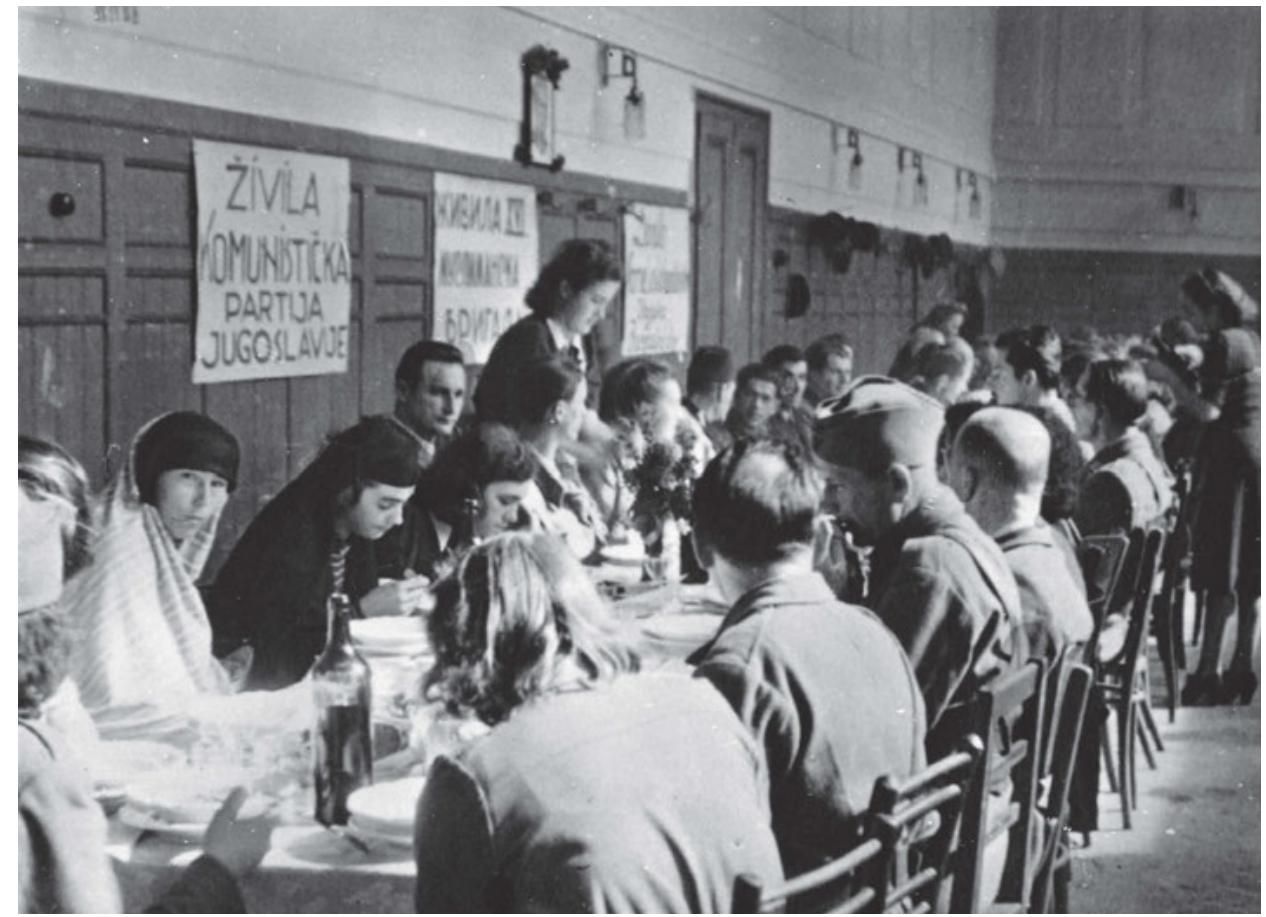

Jahrestag der Gründung der 16. Muslimischen Brigade, 21. September 1944. Fotograf unbekannt. Sarajevo, Historisches Museum von Bosnien und Herzegowina | FNOB 17201.

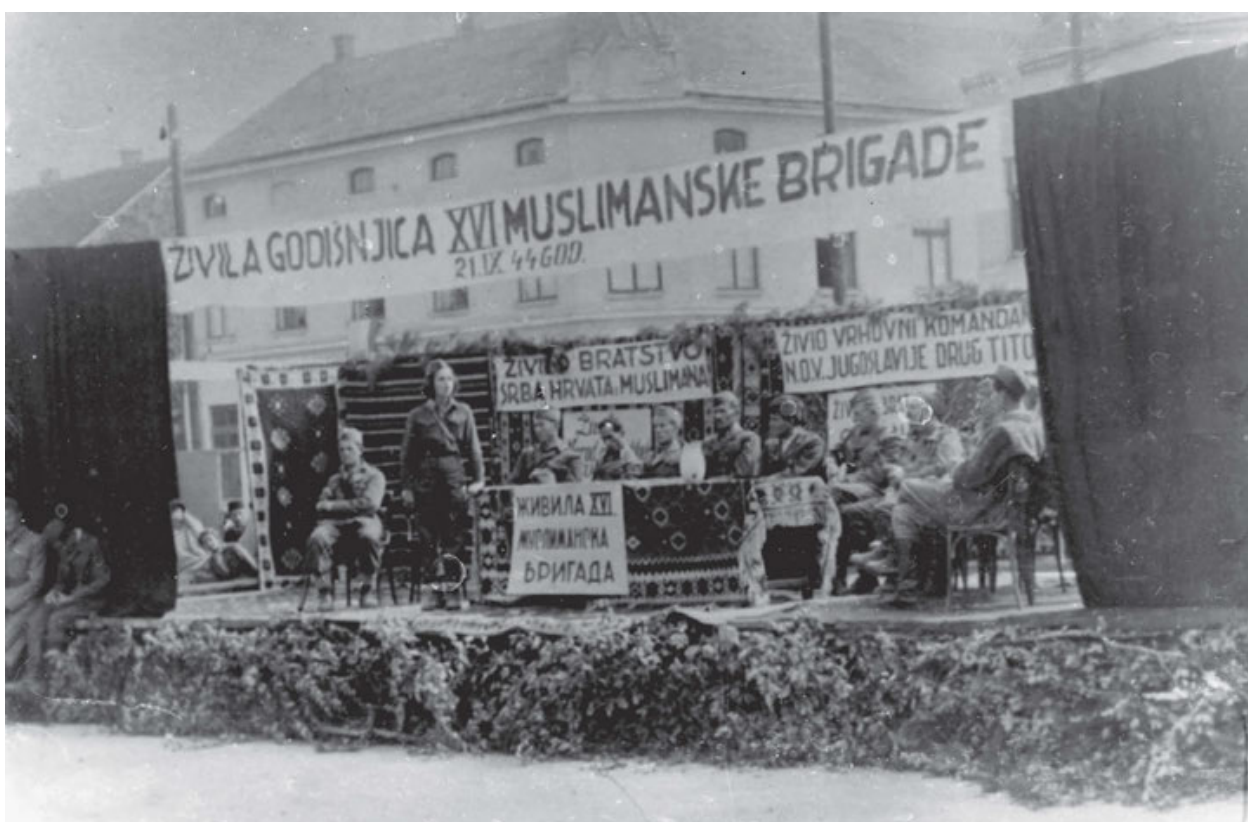

Jahrestag der Gründung der 16. Muslimischen Brigade, 21. September 1944. Fotograf unbekannt. Sarajevo, Historisches Museum von Bosnien und Herzegowina | FNOB 17202. 


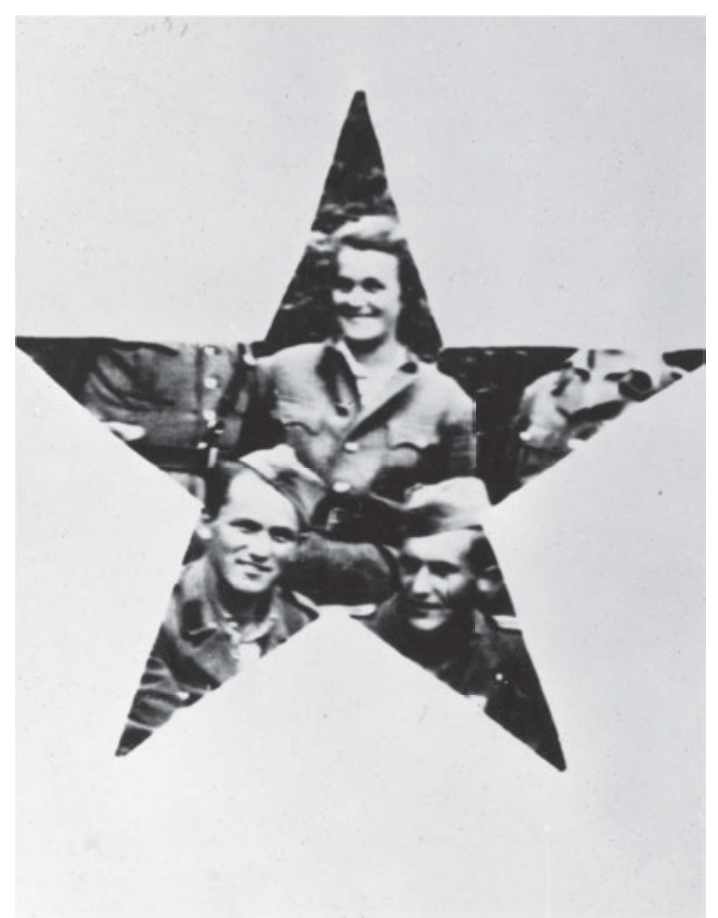

Partisanen der Zwölften Krajina-Brigade.

Fotograf unbekannt. Sarajevo, Historisches Museum von Bosnien und Herzegowina | FNOB 18689.

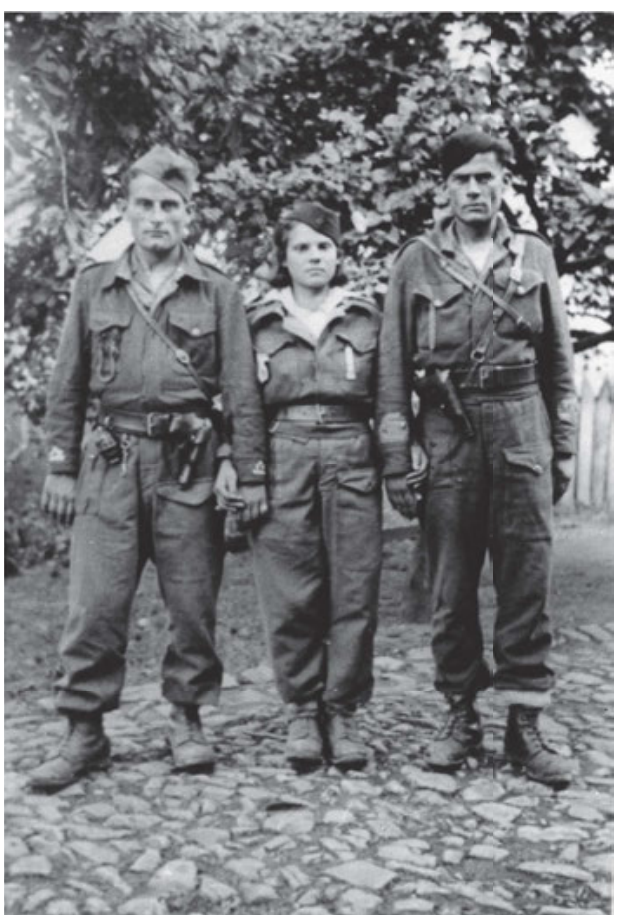

Partisanenkämpfer der Dritten Krajina-Brigade des Dritten Bataillons. Von links nach rechts: Nikola Kalanj, die Krankenschwester Fatima Hanzić und Nikola Lučić, Kommandant des Bataillons, gefallen im März 1945 in Veliki Dragaljevac bei Bijeljina. Fotograf unbekannt. Sarajevo, Historisches Museum von Bosnien und Herzegowina | FNOB 18080.

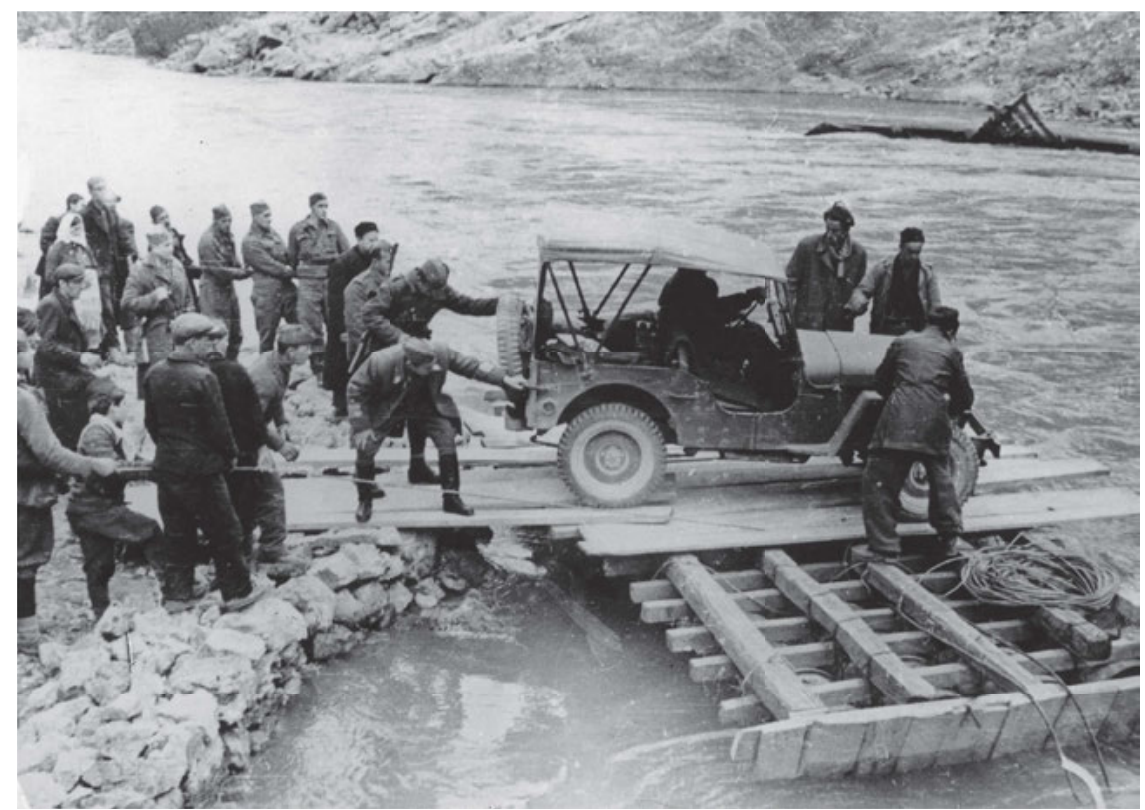

Übersetzen eines Geländewagens über den Fluss Neretva mit Hilfe einer neu gebauten Fähre.

Fotograf unbekannt. Sarajevo, Historisches Museum von Bosnien und Herzegowina | FNOB 18198. 


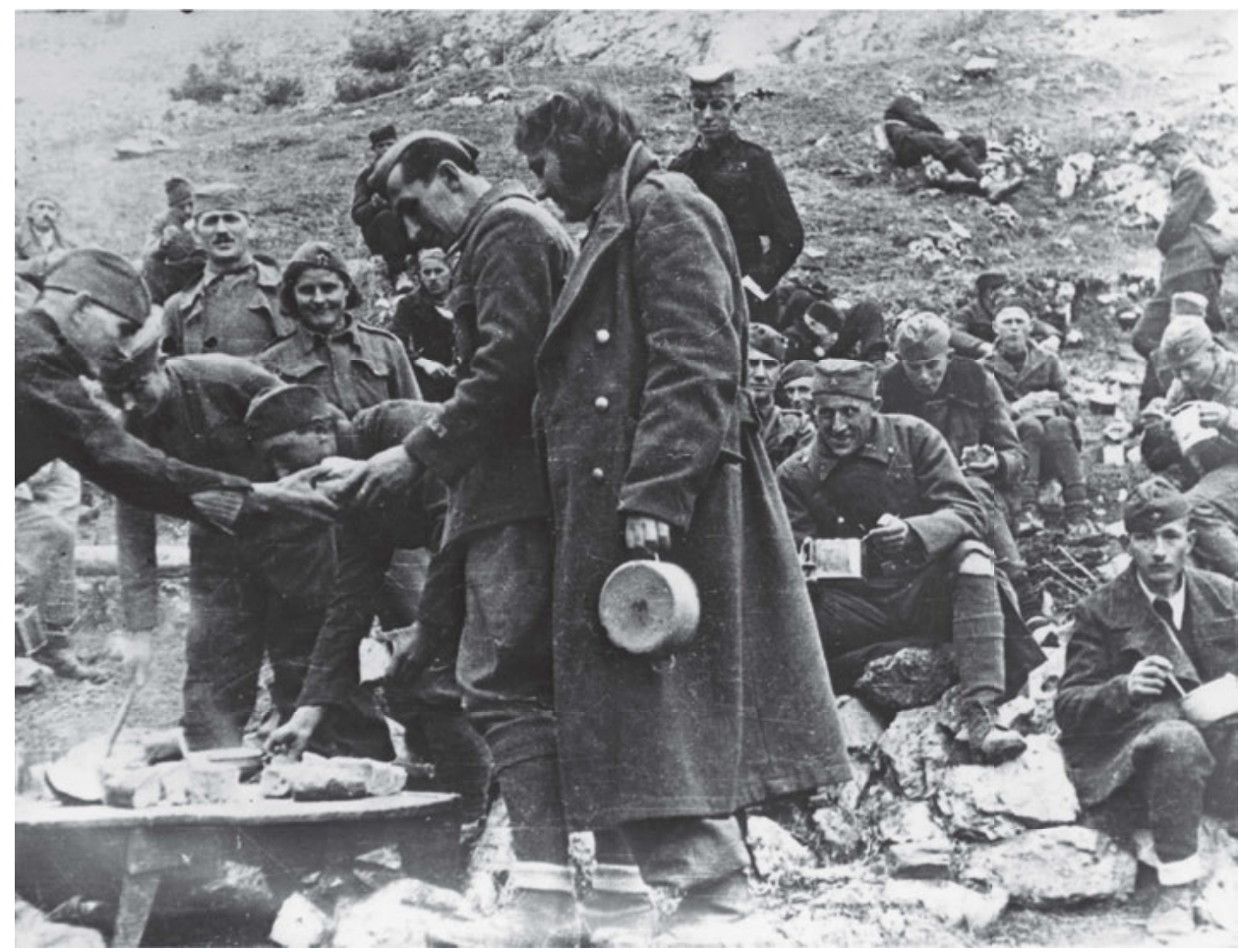

Kämpfer für die Befreiung von Sarajevo bei einer kurzen Ruhepause während der Essensausgabe in der Nähe der Feuerstellungen. Rote Felsen bei Trnovo, Ende März 1945. Fotograf unbekannt. Sarajevo, Historisches Museum von Bosnien und Herzegowina | FNOB 18748.

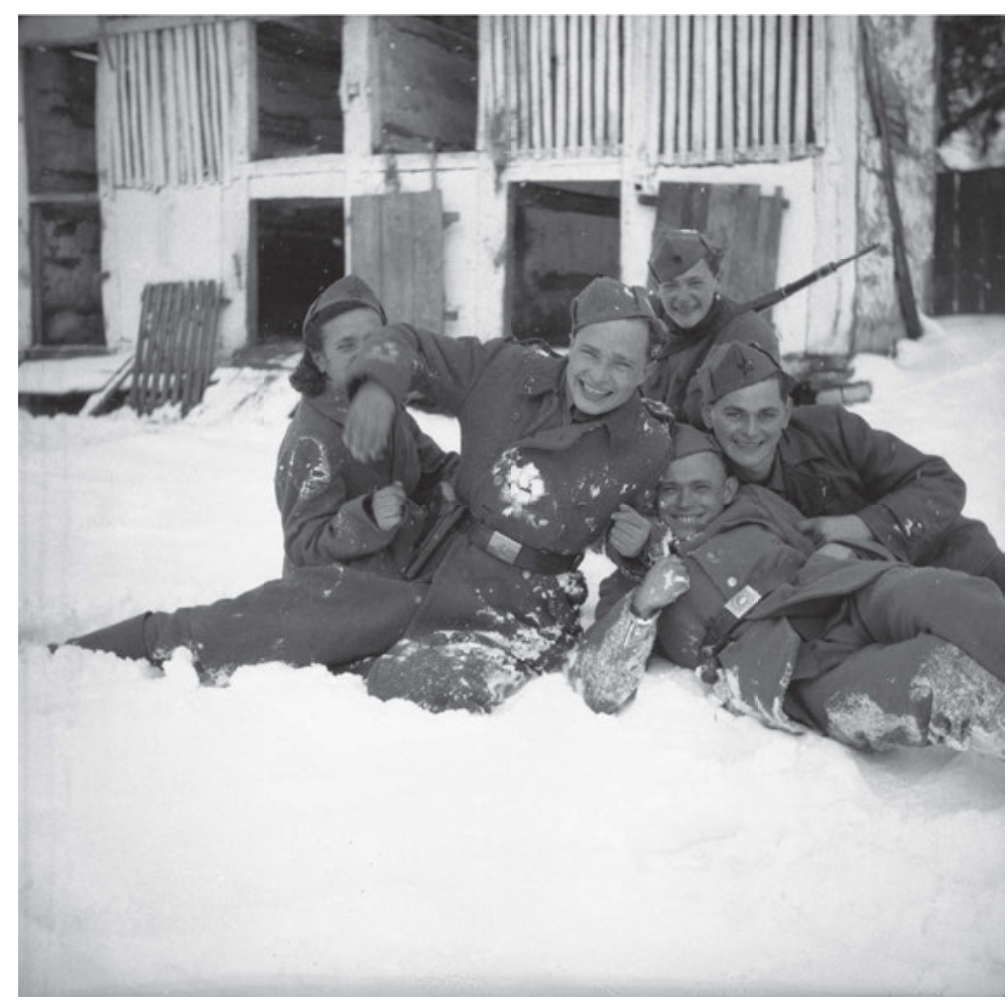

Unbekannte Partisanen im Schnee. Foto: Fotodienst des Landesrats der Volksbefreiung für Slawonien. Zagreb, Kroatisches Historisches Museum | HPM-MRNHA-2203_1695. 


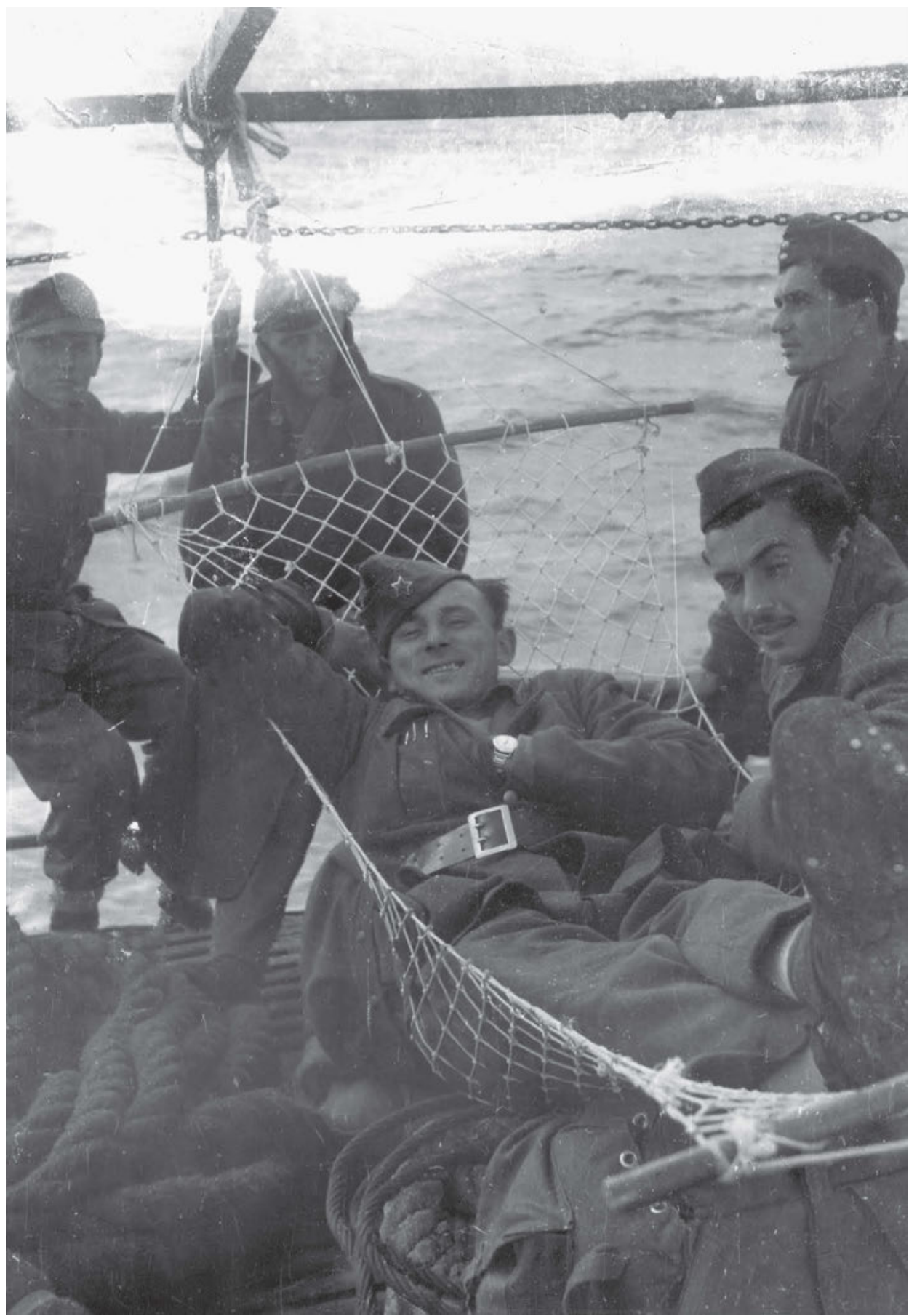

Piloten der Volksbefreiungsarmee in einem Partisanenboot auf der Insel Korčula, 1944 Fotograf unbekannt. znaci.net. 


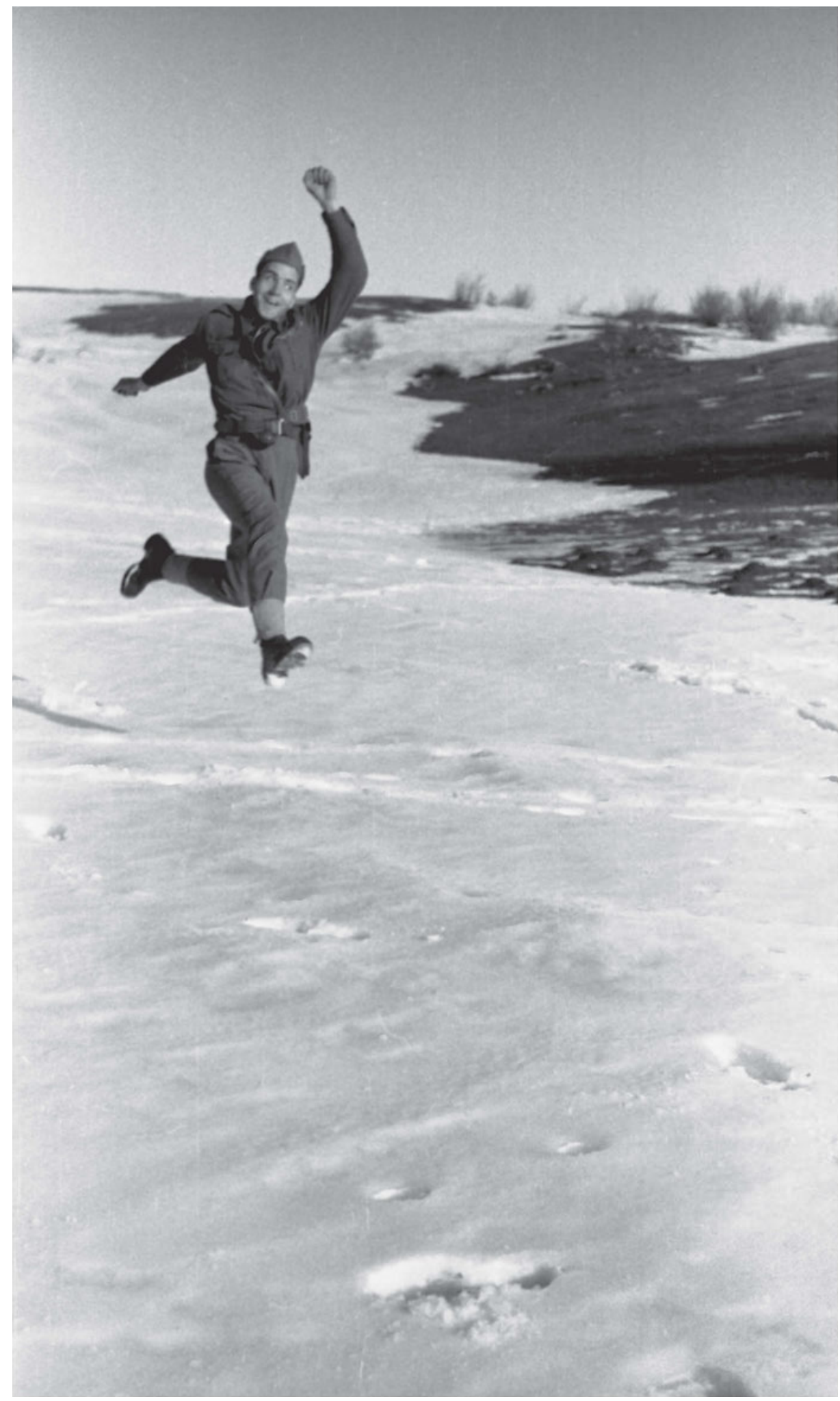

Radiotelegrafist der Schule für das Nachrichtenwesen des Hauptstabs für Kroatien. Lika, Winter 1943. Fotograf unbekannt. Zagreb, Kroatisches Historisches Museum | HPM-MRNH-A-2603-f123_23A. 


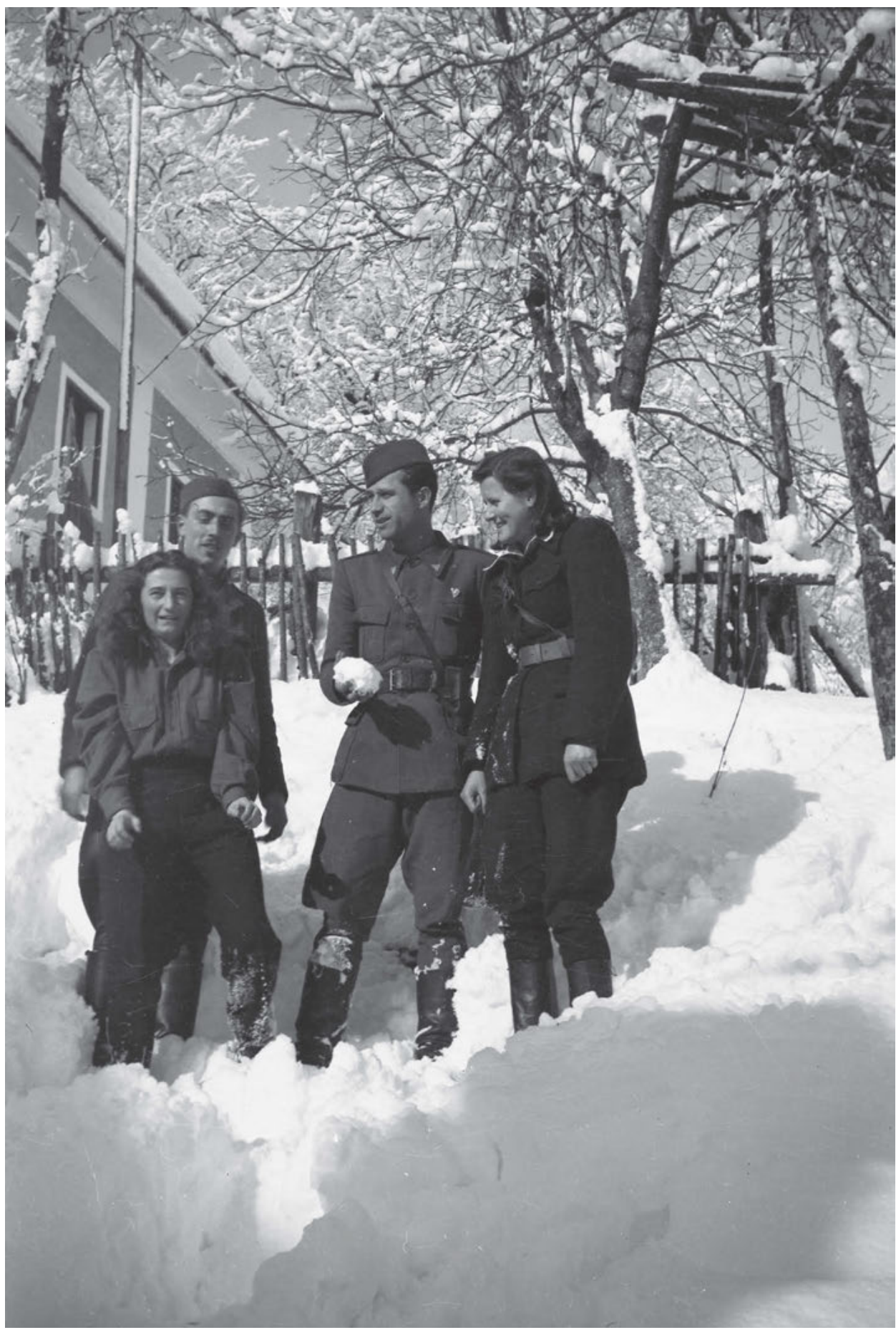

Im Schnee. Von links nach rechts: Iva Valenti, Verwaltungsangestellte der Operativen Abteilung des Neunten Korps, Stanko Gorjanc, Leiter der Geodäsiesektion, Leutnant Mitar Raičević und eine Partisanin, die eine Zeitlang für die Verwaltung der Operativen Abteilung des Neunten Korps verantwortlich war, später jedoch als Lehrerin in eine Volksschule wechselte. Im Hintergrund ist das Haus zu sehen, in dem während des Zweiten Weltkriegs der Stab des Neunten Korps untergebracht war. Poljane, nahe Cerkno, 21. Januar 1945. Foto: Aleksander Jesenovec. Ljubljana, Museum für Neuere Geschichte Sloweniens | SJ2/6. 

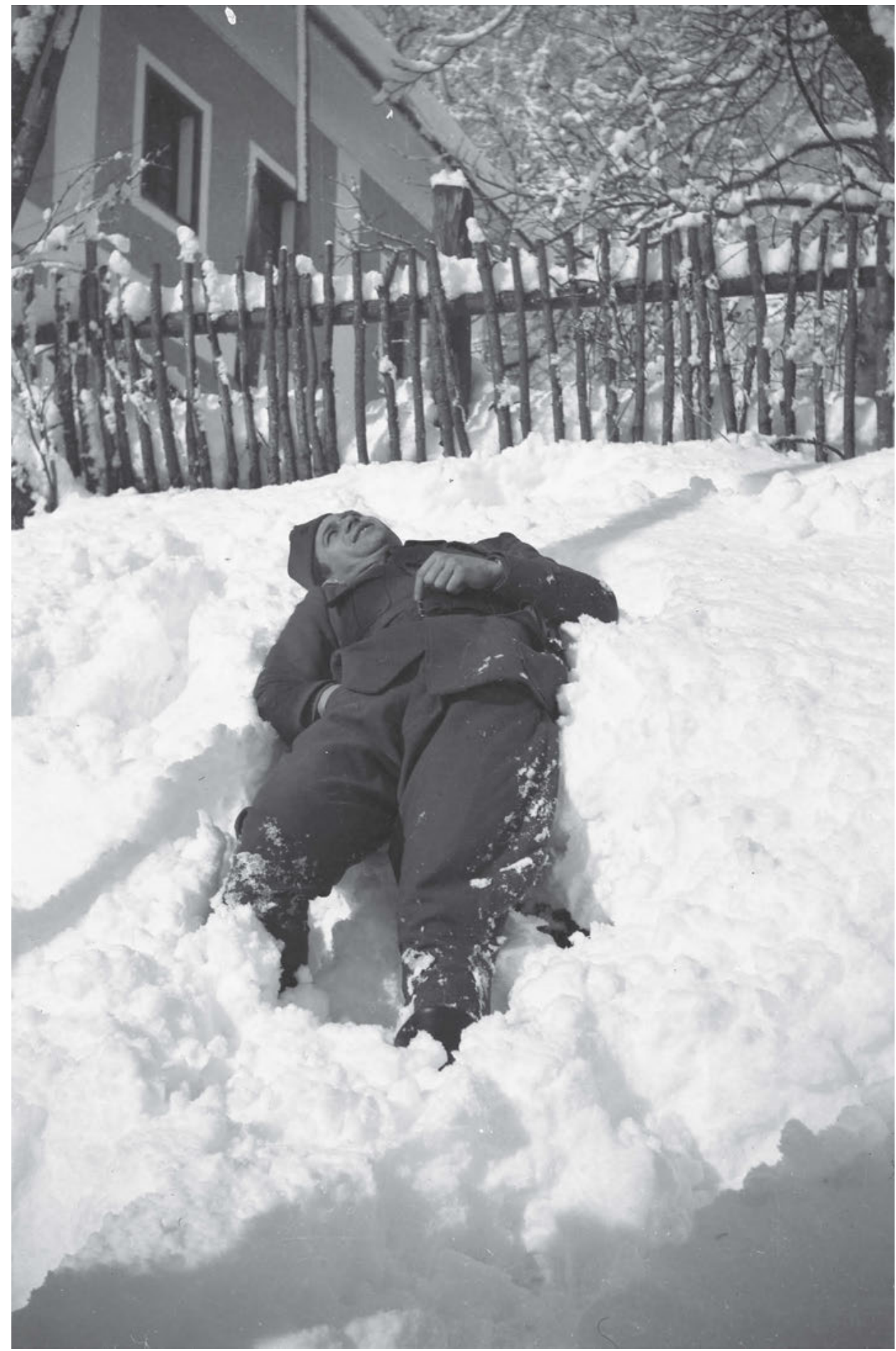

Leutnant Mitar Raičević posiert im Schnee. Im Hintergrund ist das Haus zu sehen, in dem während des Zweiten Weltkriegs der Stab des Neunten Korps untergebracht war. Poljane, nahe Cerkno, 21. Januar 1945. Foto: Aleksander Jesenovec. Ljubljana, Museum für Neuere Geschichte Sloweniens | SJ2/5. 


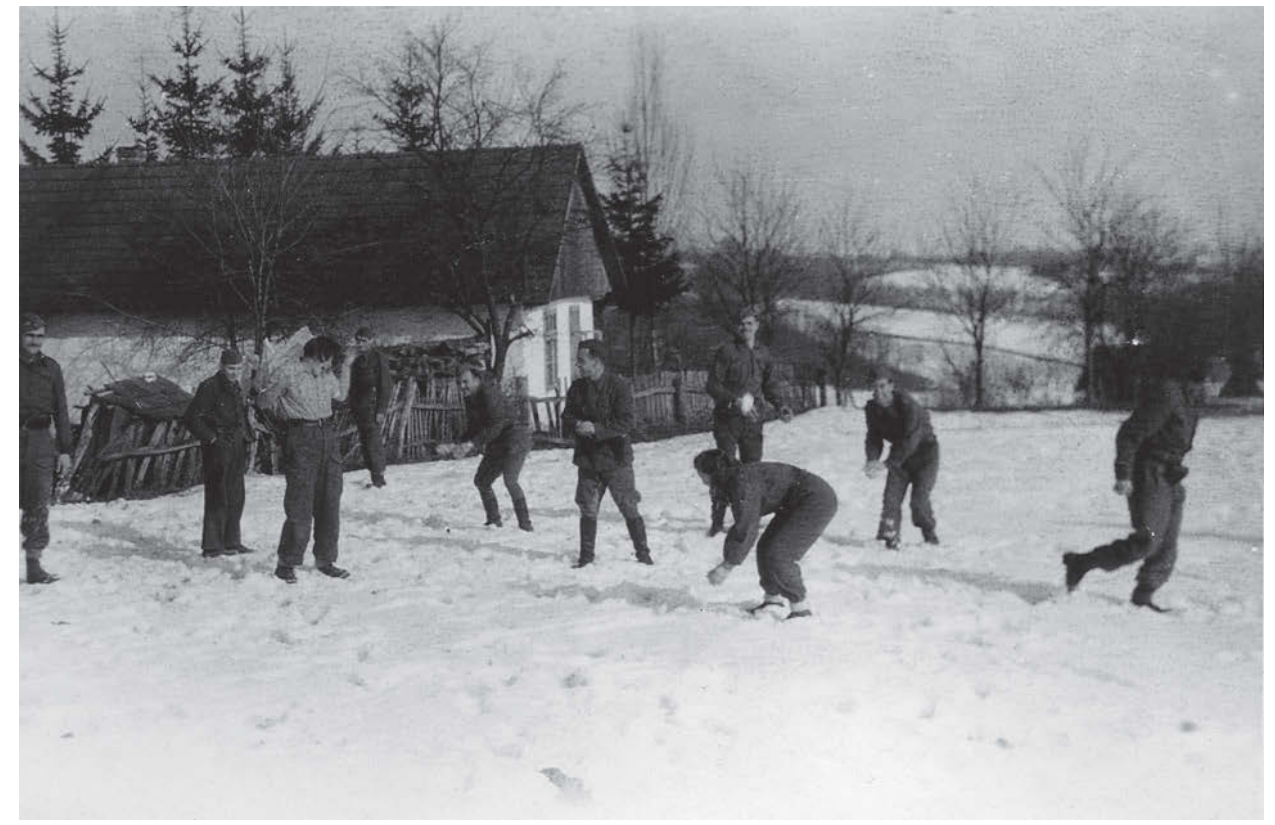

Zehntes Zagreber Korps. Chirurgenteam der 33. Division in Bilogora, Ende 1944. Museum der Stadt Zagreb. Ohne Inv.-Nr.

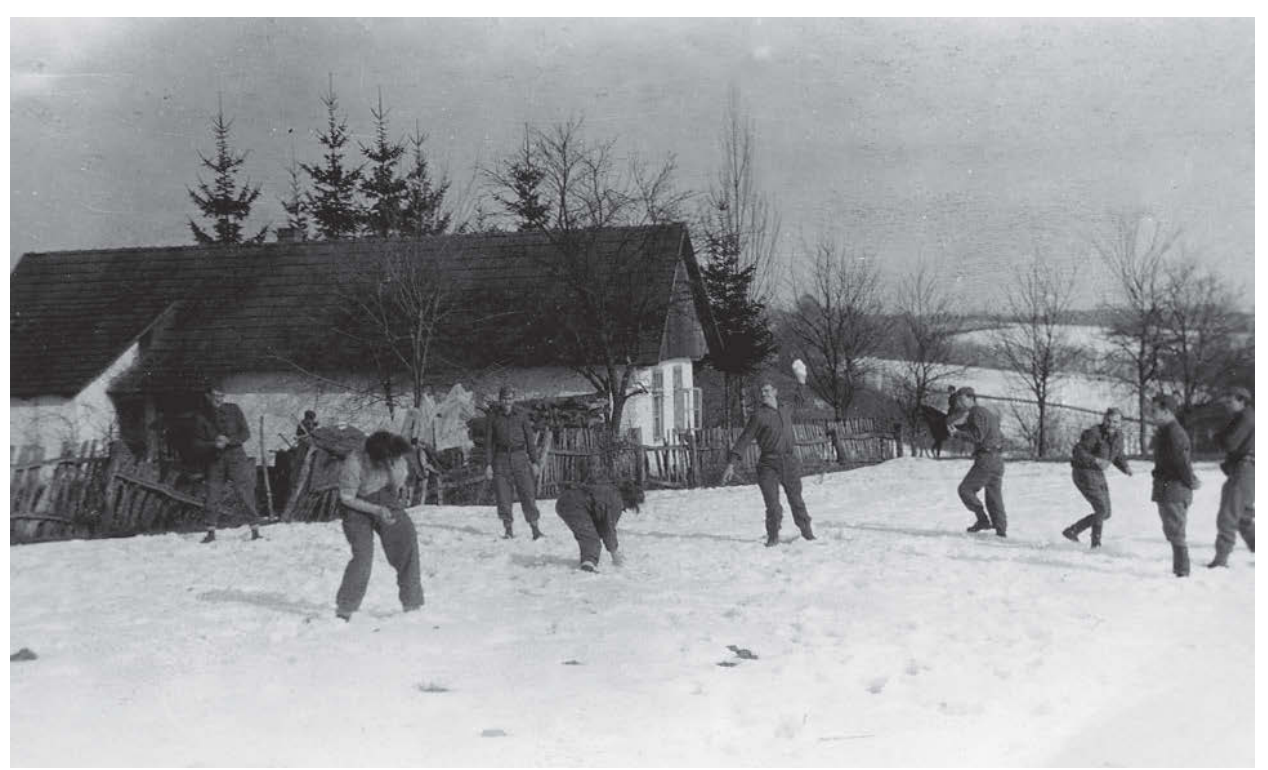

Zehntes Zagreber Korps. Chirurgenteam der 33. Division in Bilogora, Ende 1944. Fotograf unbekannt. Museum der Stadt Zagreb. Ohne Inv.-Nr. 

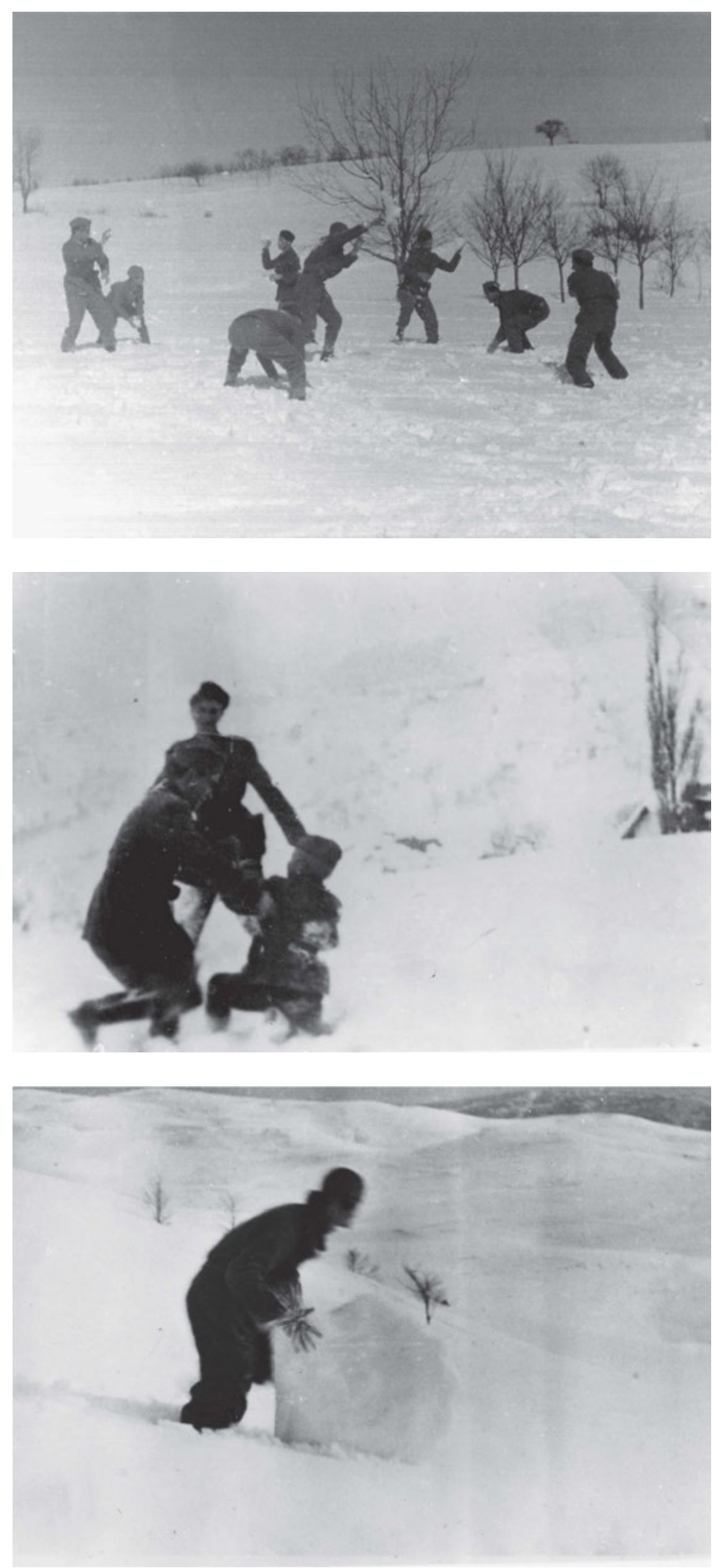

Undatierte Szene im Winter. Foto: Drago Mažar. Banja Luka, Archiv der Republik Srpska, Ohne Inv.-Nr.

Elfte Krajina-Brigade in Gučja Gora, Travnik, Winter 1944/45. Fotograf unbekannt. Sarajevo, Historisches Museum von Bosnien und Herzegowina | FNOB 17306.

Čedomir Perić baut während der Feuerpause einen Schneemann, Dinara-Gebirge, 10. März 1942. Fotograf unbekannt. Sarajevo, Historisches Museum von Bosnien und Herzegowina | FNOB 17674. 


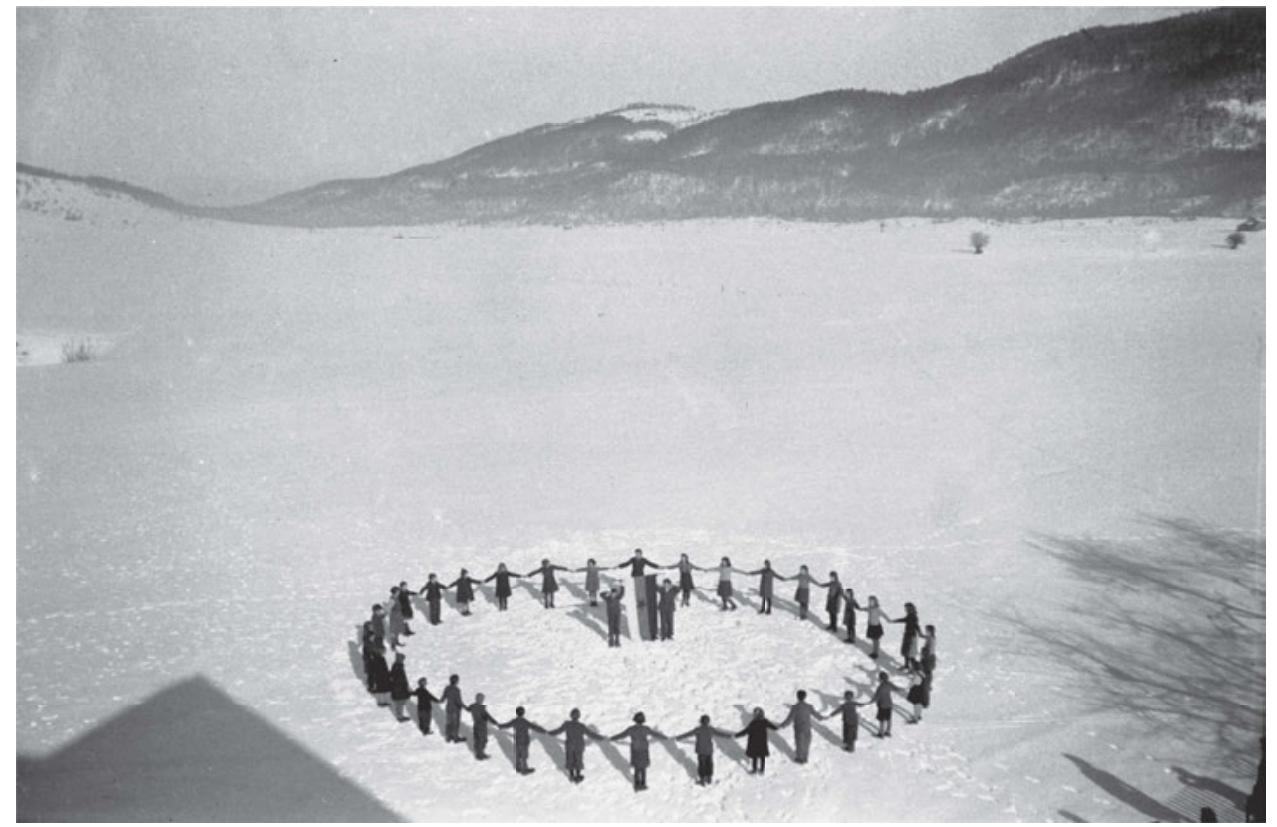

Schuljugend aus Babno Polje (oder Trnava?) tanzt den Tito-Reigen im Schnee, 1945. Foto: Edi Šelhaus. Ljubljana, Museum für Neuere Geschichte Sloweniens | TN957/6.

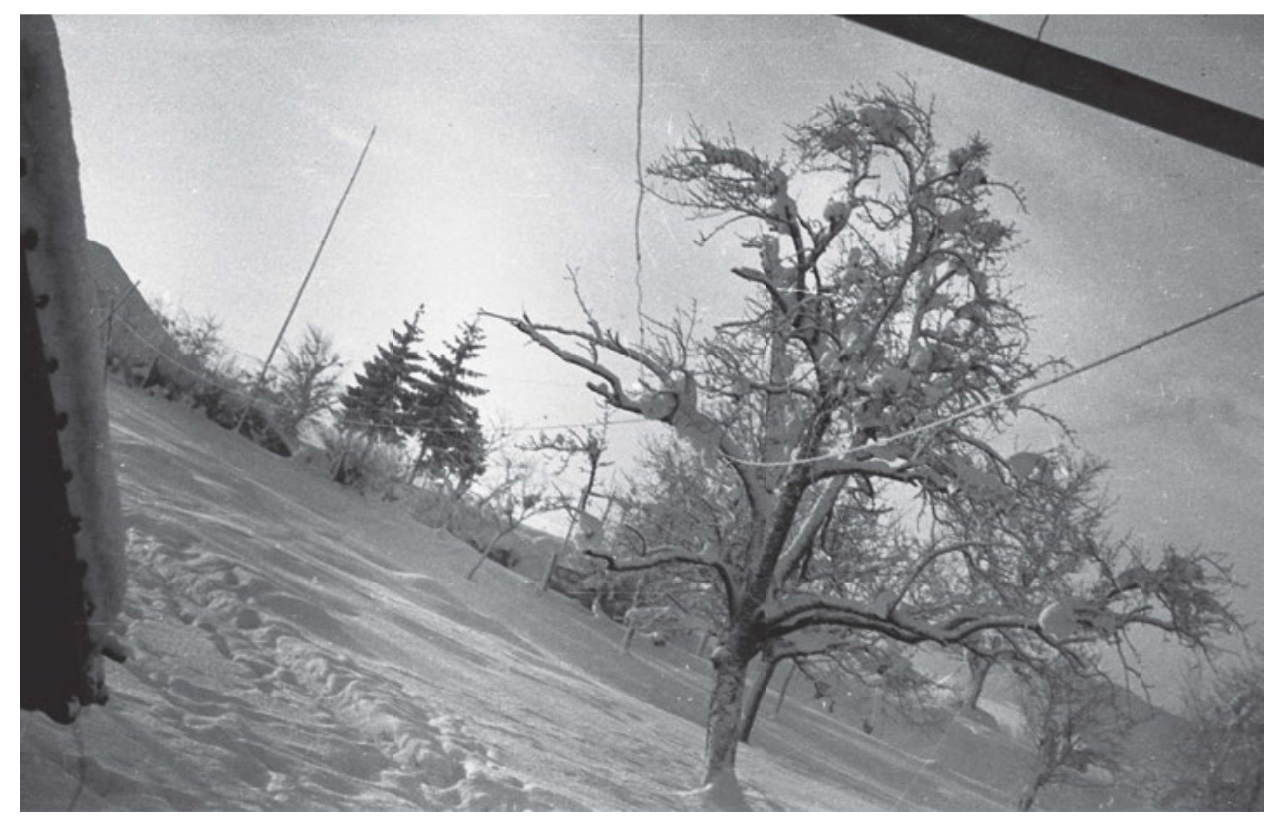

Winterlandschaft in der Nähe von Otovec in der Bela Krajina, Januar 1945. Foto: Klis. Ljubljana, Museum für Neuere Geschichte Sloweniens I TN912/18. 


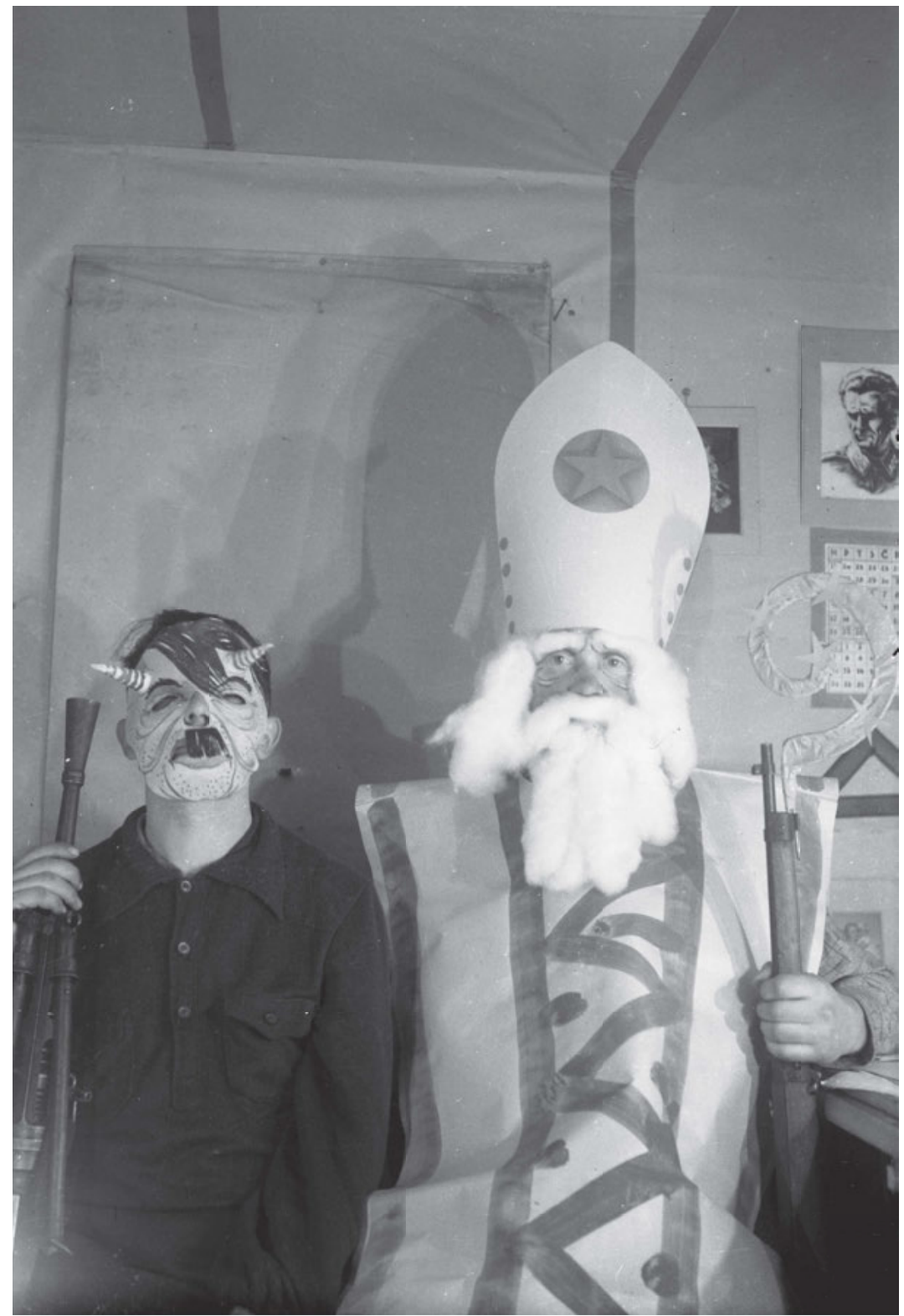

Ohne Angaben. Fotograf unbekannt. Ljubljana, Museum für Neuere Geschichte Sloweniens | TN1205/4. 


\section{Schlafende}
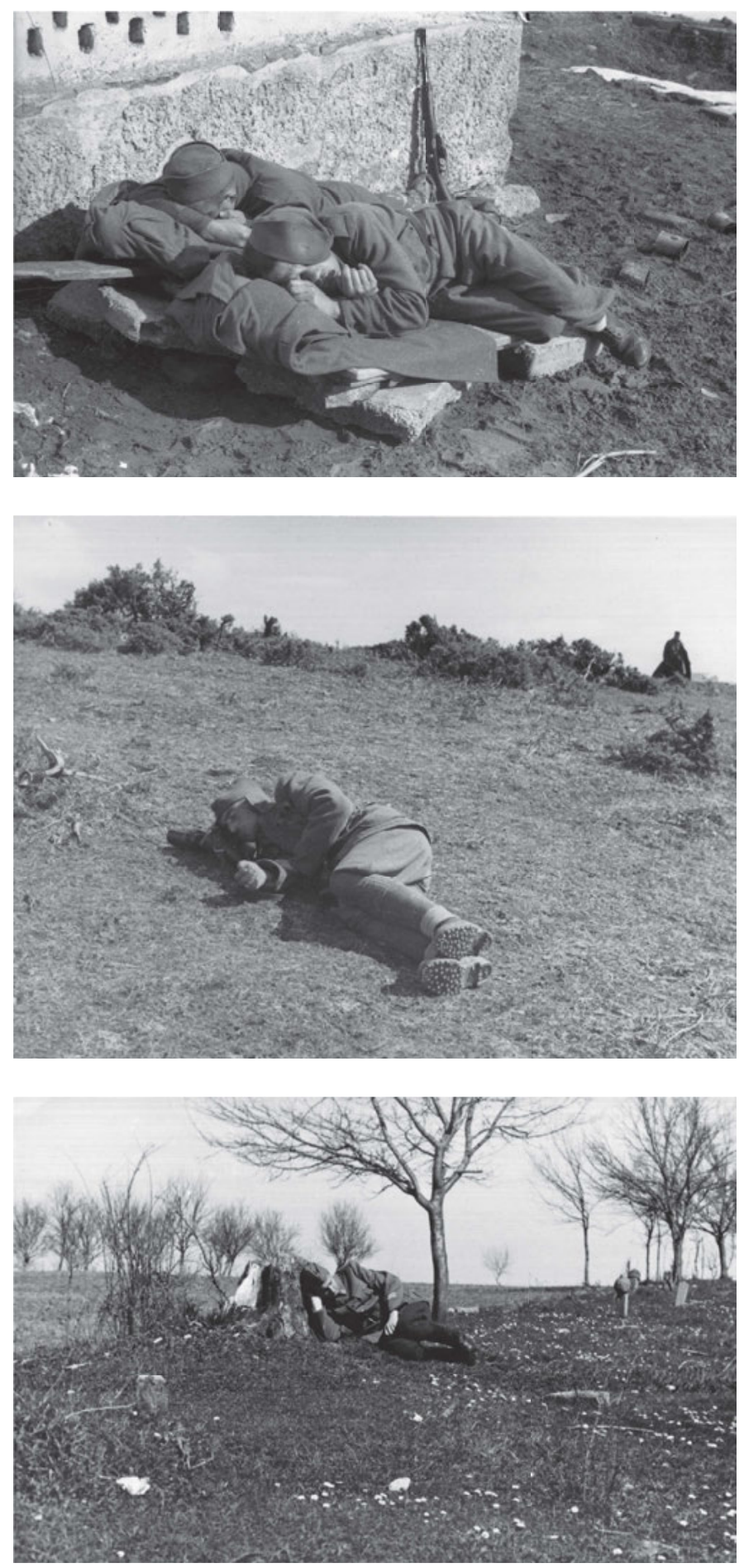

Evakuierung aus der Bela Krajina auf die Zadar-Halbinsel, 25. Februar 1945. Foto: Dr. Janez Milčinski. Ljubljana, Museum für Neuere Geschichte Sloweniens | 1236/20.

Ohne Angaben. Foto: Drago Mažar. Banja Luka, Archiv der Republik Srpska. Ohne Inv.-Nr.

Ohne Angaben. Foto: Drago Mažar. Banja Luka, Archiv der Republik Srpska. Ohne Inv.-Nr. 


\section{Farbfotografien von Partisanen und Wandzeitungen}

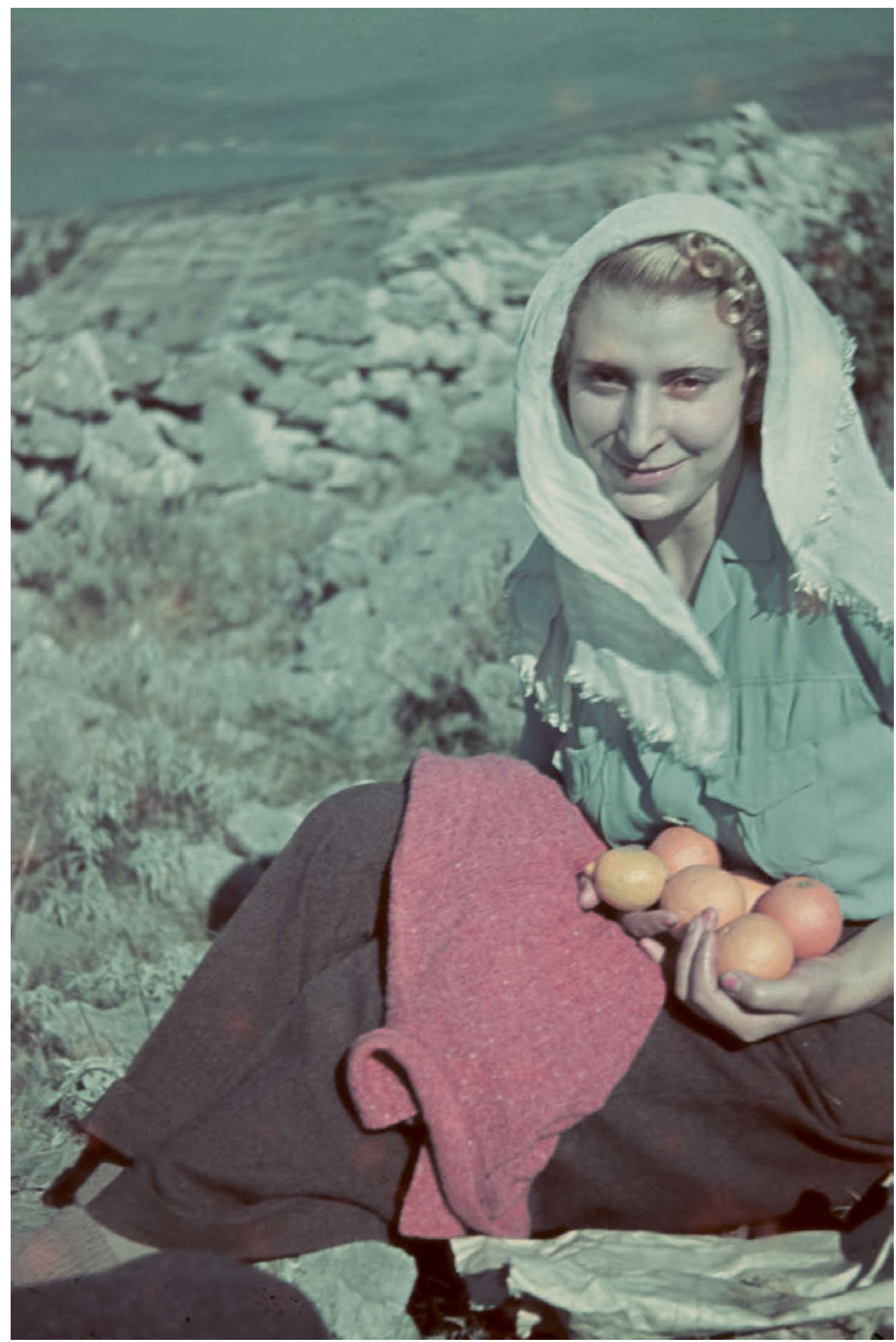

Frau mit Orangen, Čiovo, 1942. Foto: Živko Gattin. Privatarchiv von Ingrid Gattin Pogutz. 


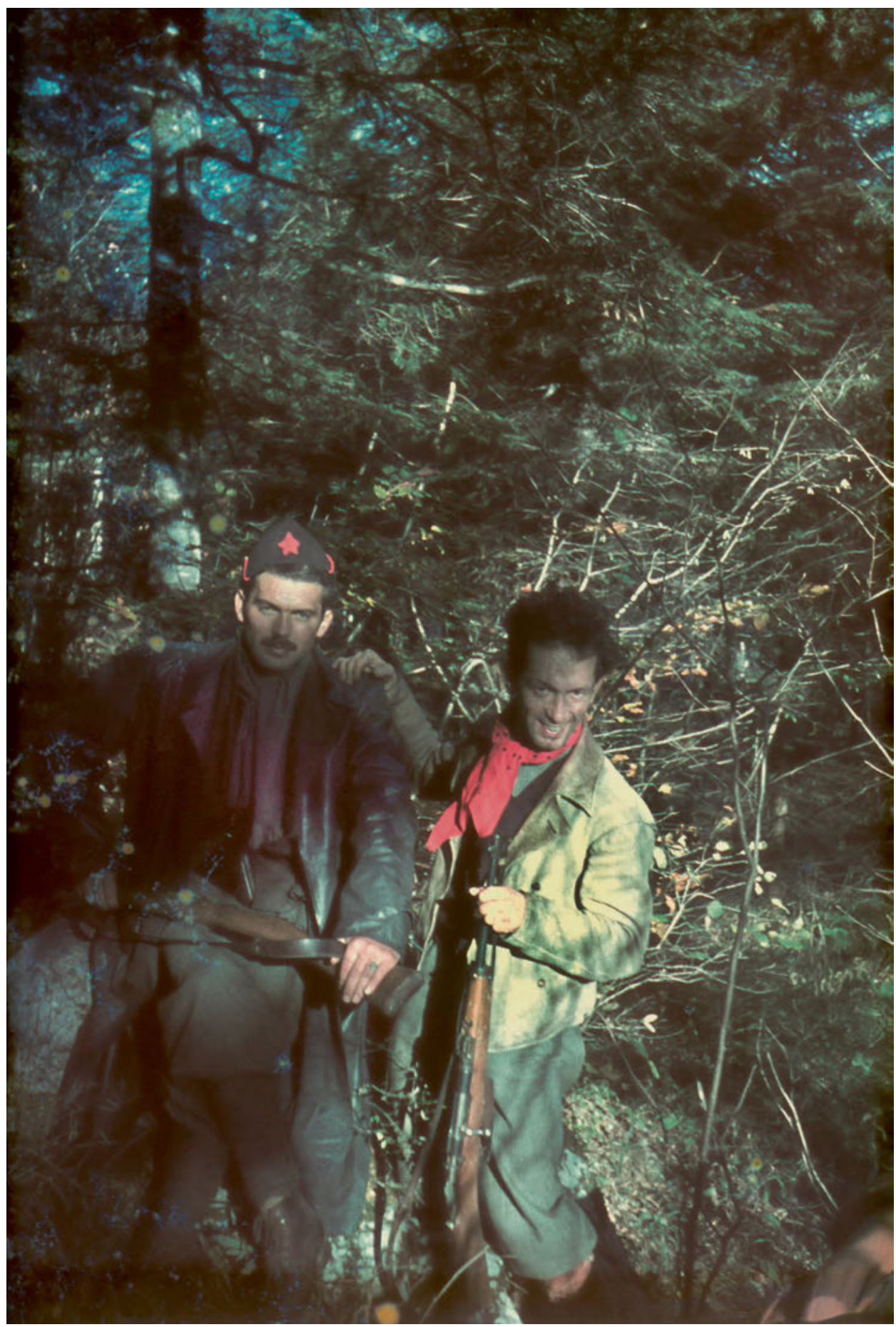

Ein unbekannter Partisan und Čoro Škodlar, Sommer 1944.

Fotograf unbekannt. Ljubljana, Museum für Neuere Geschichte Sloweniens | DP72DP64. 


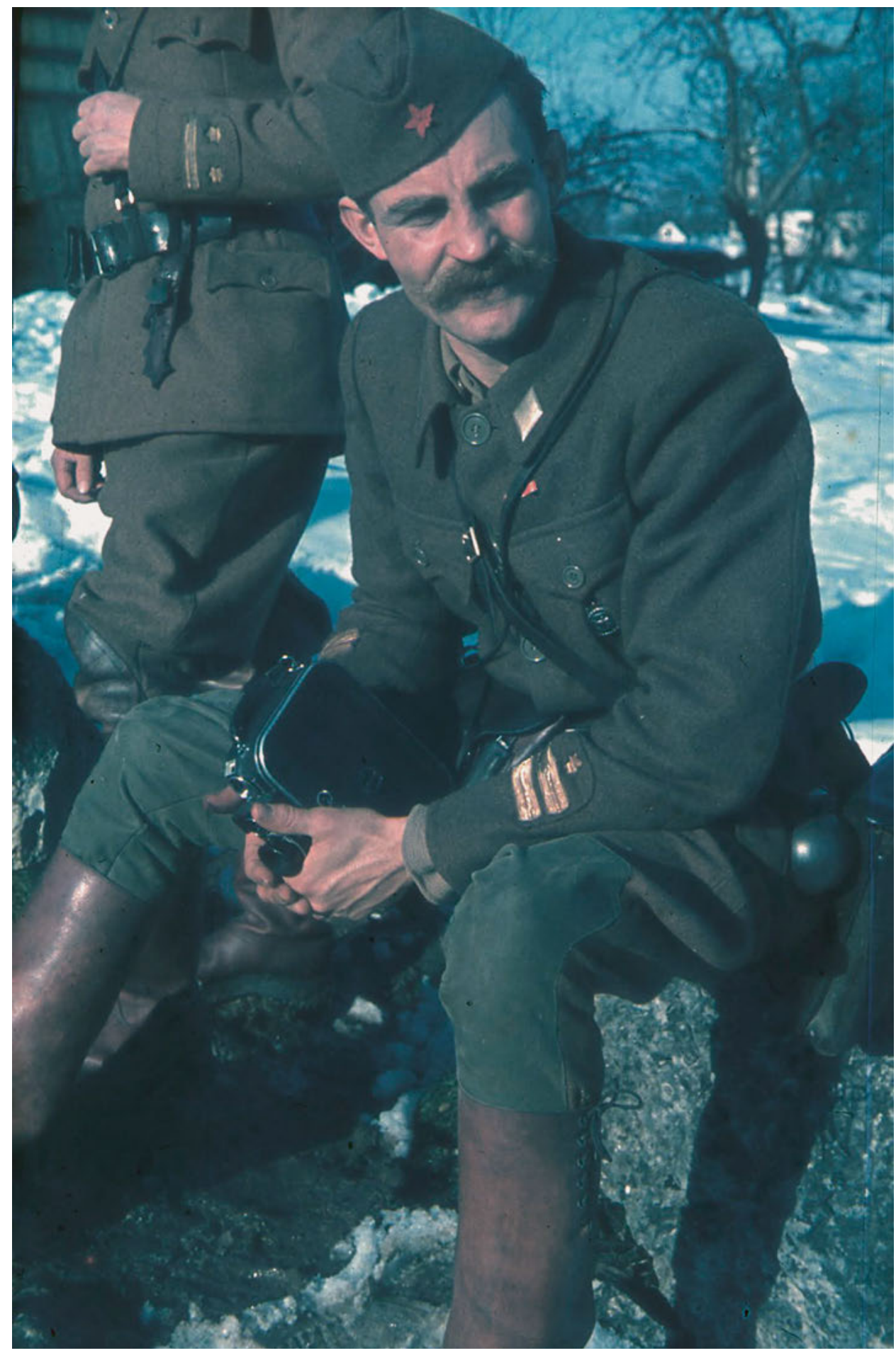

Ein Partisanenkommandant mit einer 16-mm-Kamera, Winter 1944/45.

Fotograf unbekannt. Ljubljana, Museum für Neuere Geschichte Sloweniens | DP3. 


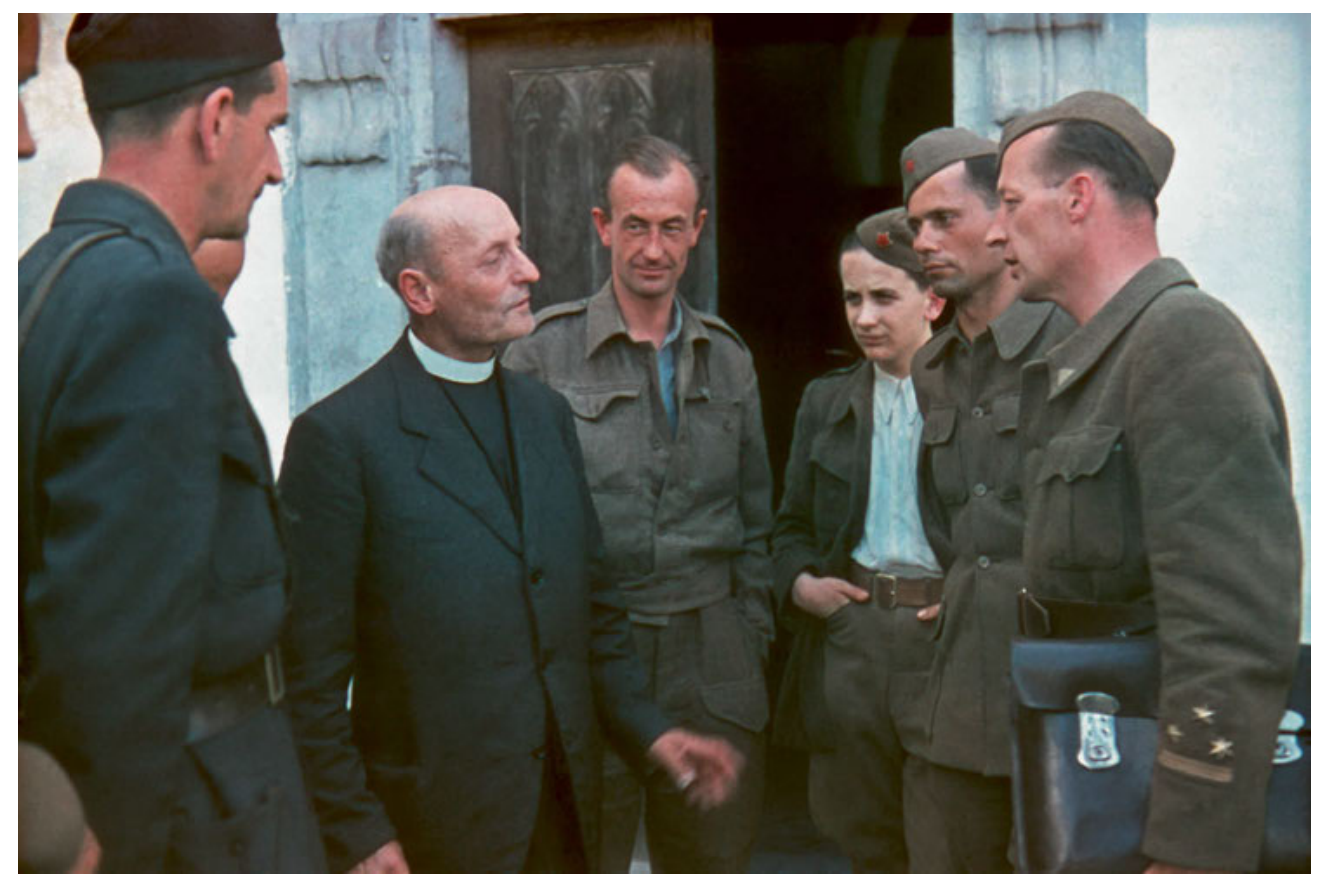

Rechts Mile Klopčič, zu seiner Rechten Miško Kranjec und Ciril Kosmač, in der Mitte der Geistliche Ksaver Meško. Kloster Stična, Sommer 1944. Fotograf unbekannt. Ljubljana, Museum für Neuere Geschichte Sloweniens | DP72.

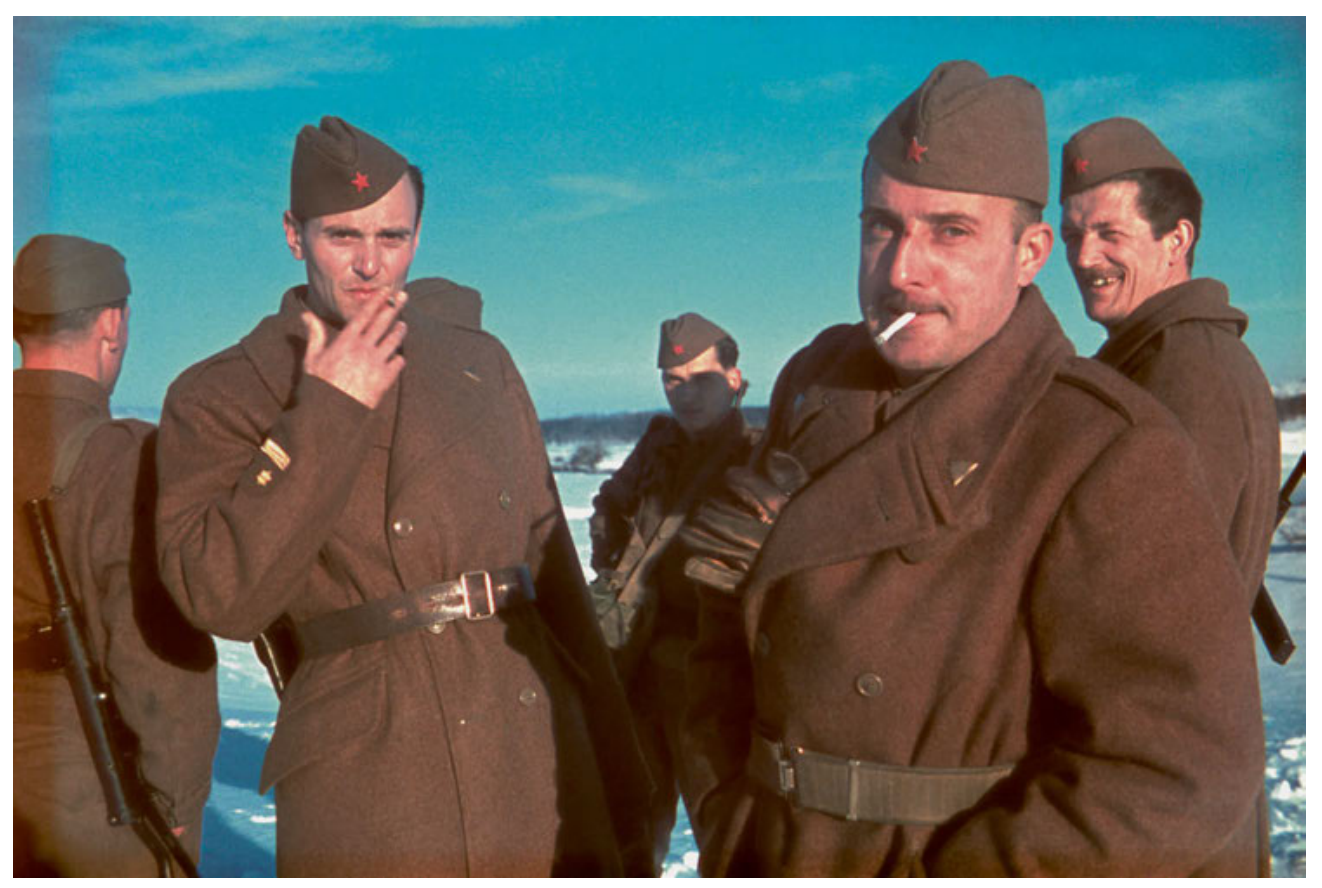

Partisanen im Winter 1944/45. Fotograf unbekannt. Ljubljana, Museum für Neuere Geschichte Sloweniens | DP72. 


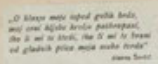

ZD SEBE
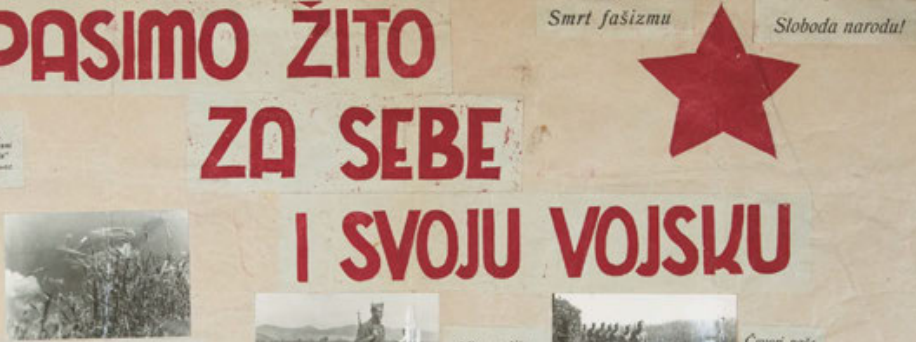

NASE KLASJE ZRIJE
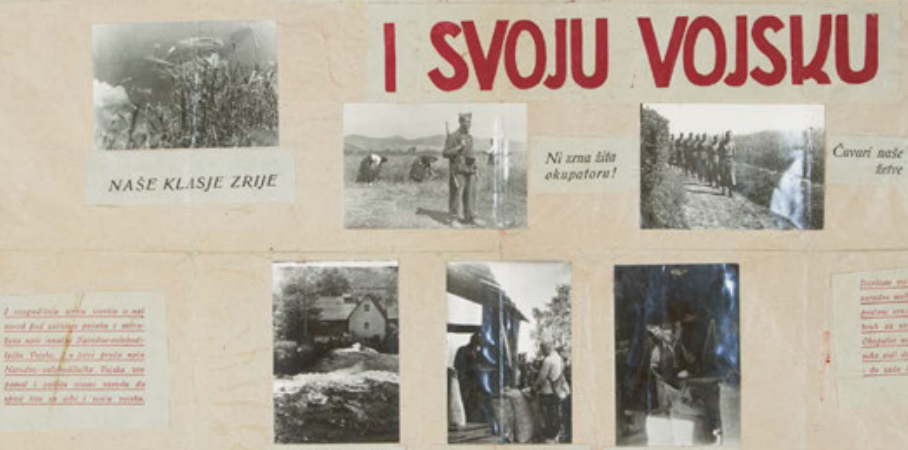

Minuri chation tito
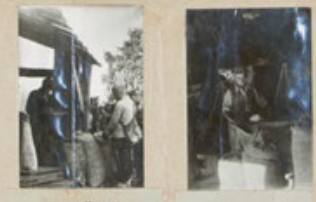

.i iz prih unde.

sipi movo bruino
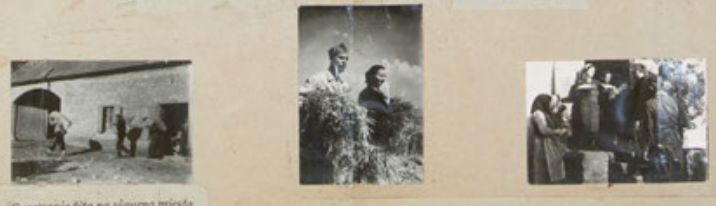

Vojska pomaze svome nandus

narod daje svojoj wojsa

Wandzeitung Spasimo žito za sebe i svoju vojsku (Retten wir das Getreide für uns und unsere Armee). Foto: Fotosektion des Gebietskomitees des Bezirksrates der Volksbefreiung Dalmatiens. Zagreb, Kroatisches Historisches Museum | HPM/MRNH-F-11961.

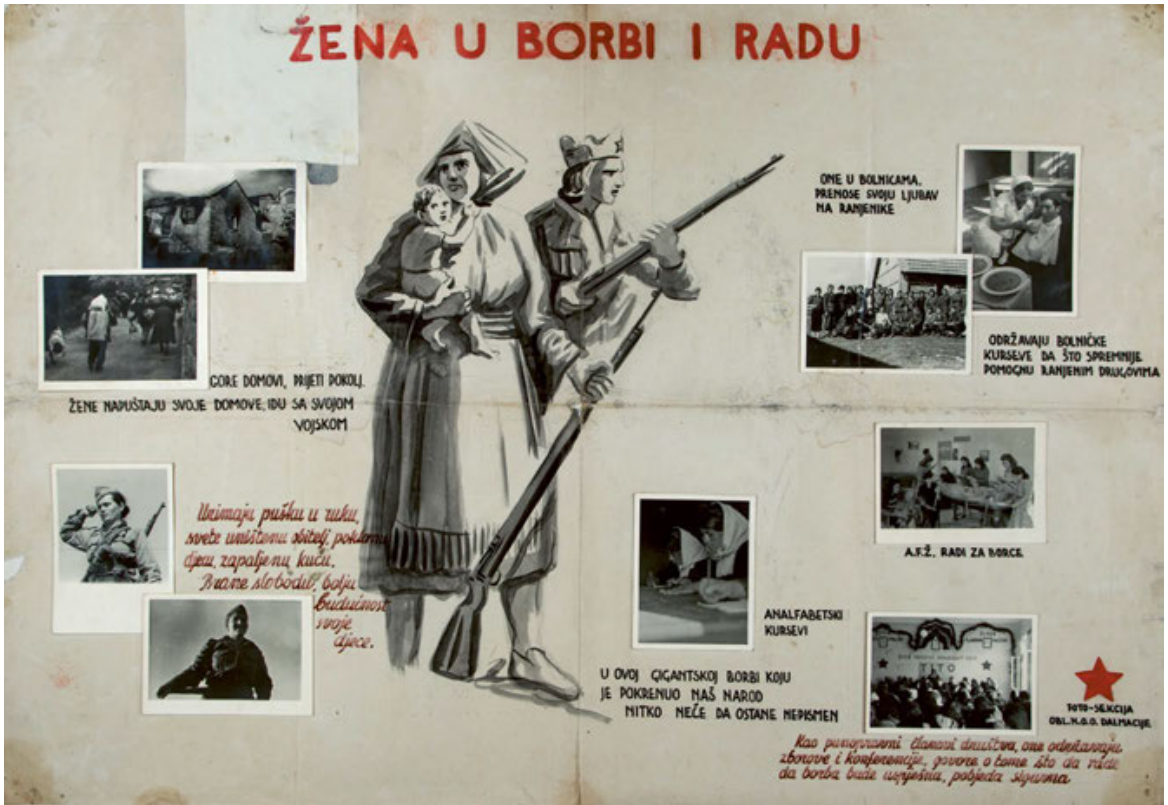

Wandzeitung Žena u borbi i radu (Frauen im Kampf und bei der Arbeit). Foto: Fotosektion des Gebietskomitees des Bezirksrates der Volksbefreiung Dalmatiens. Zagreb, Kroatisches Historisches Museum | HPM/MRNH-F-11963. 


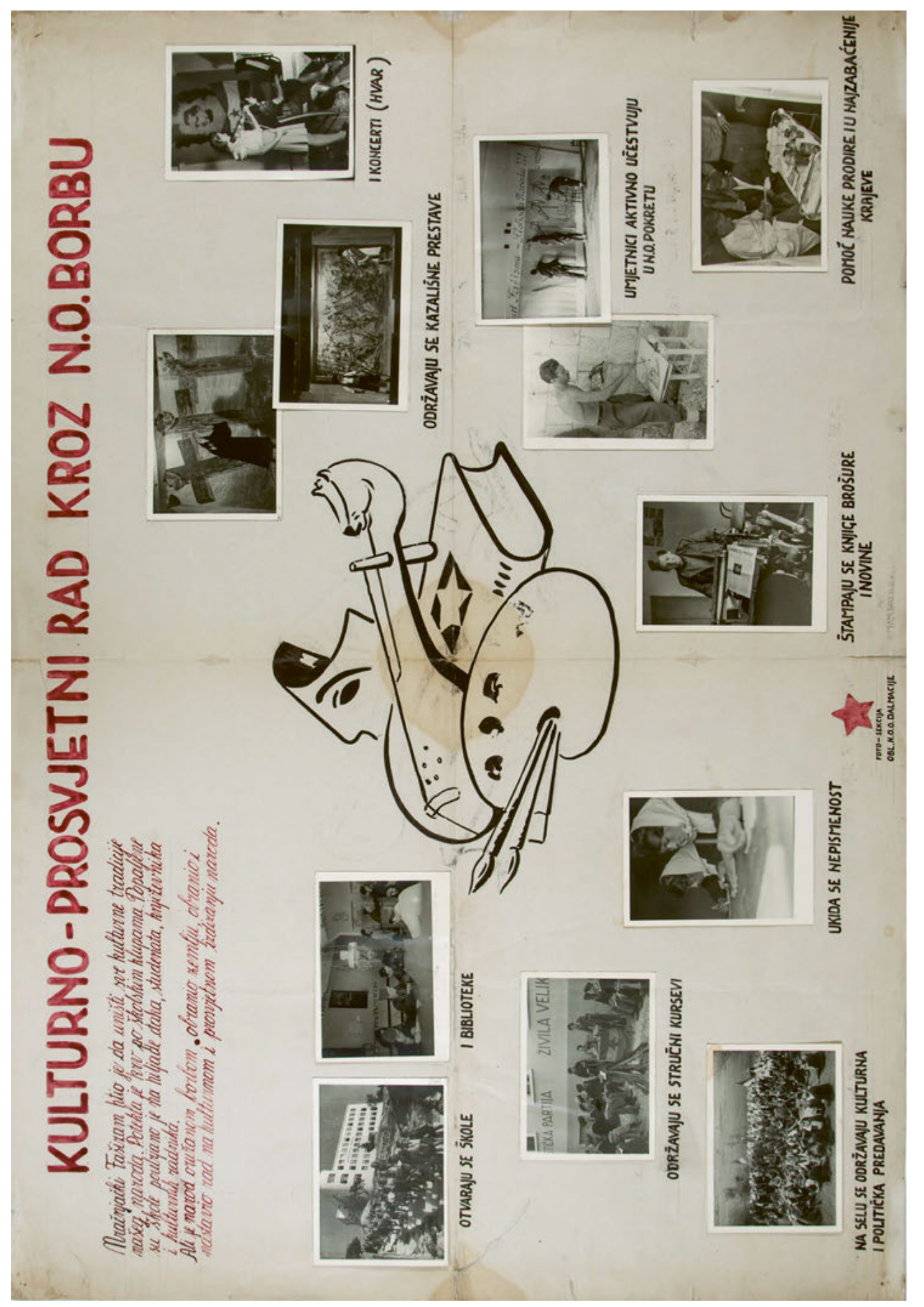

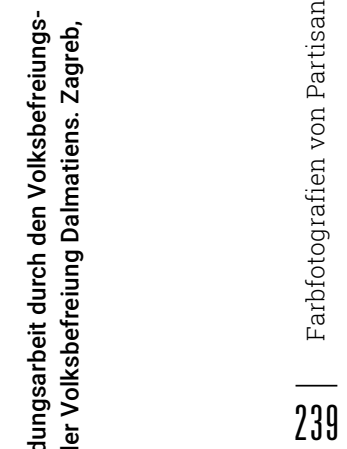


Unter dem Kreuz

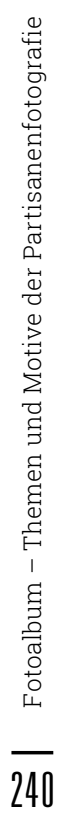

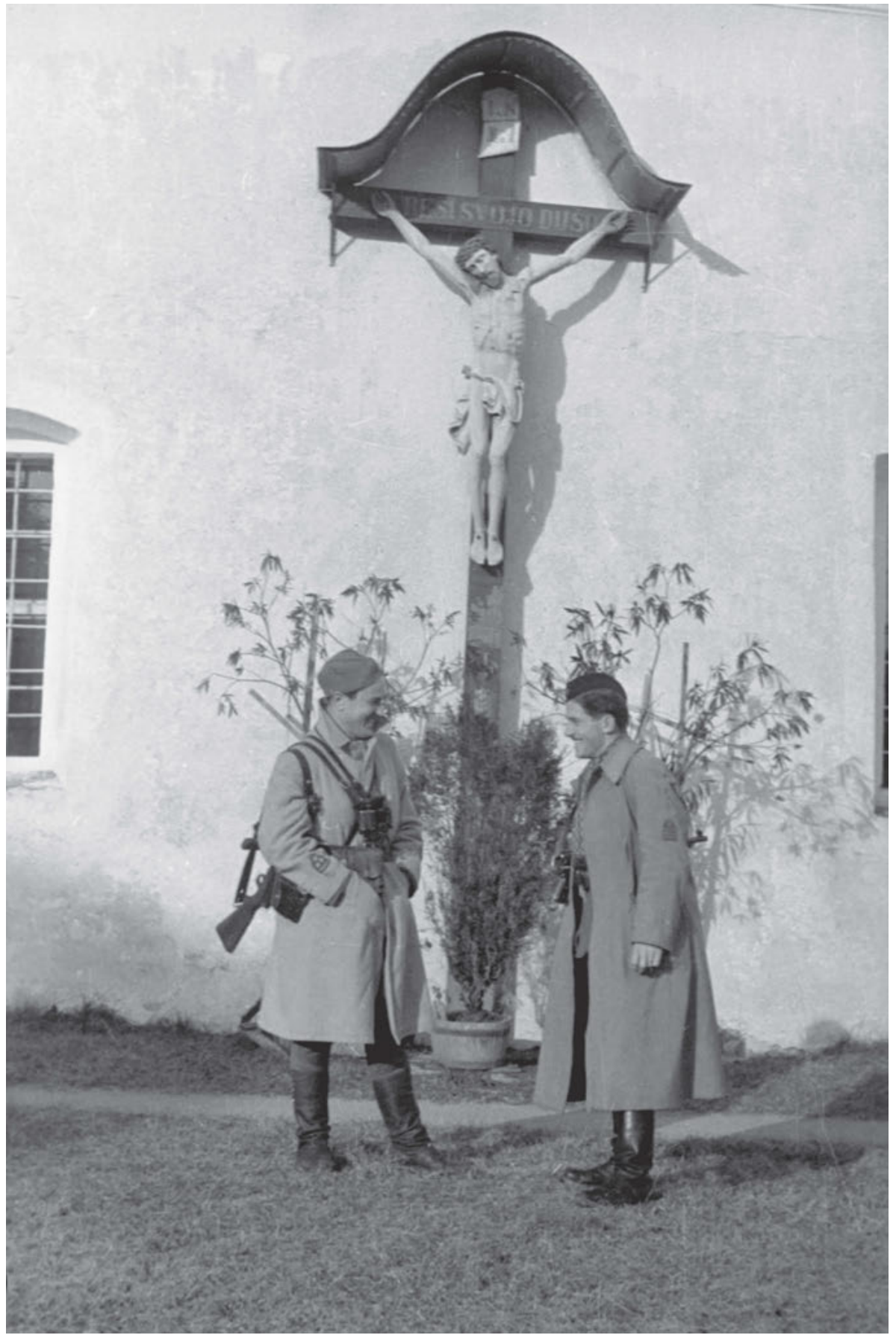

Begegnung von Partisanen unter einem Kreuz, Innerkrain, 1944. Foto: Vinko Bavec. Ljubljana, Museum für Neuere Geschichte Sloweniens | TN126/21. 

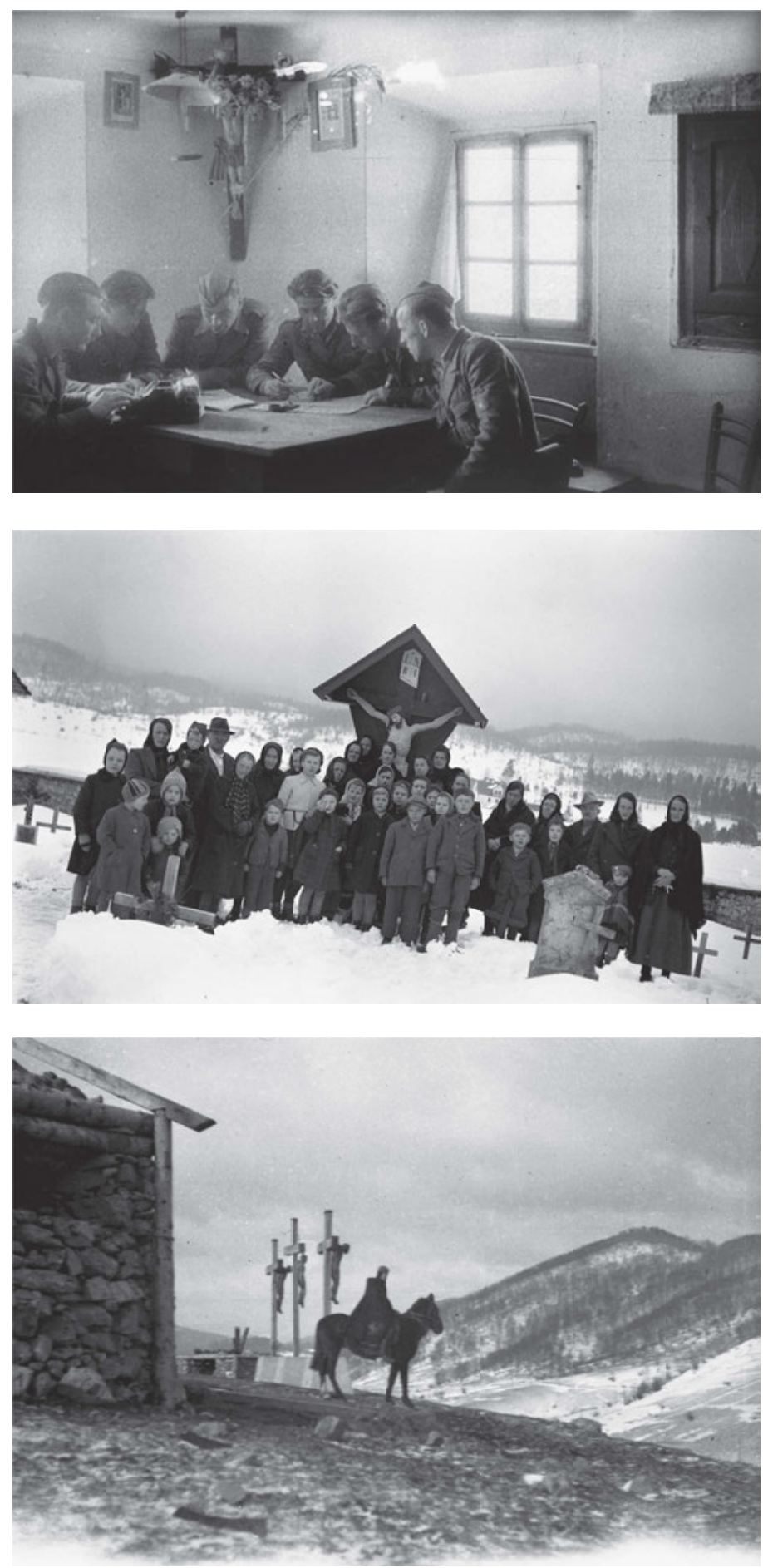

Stab der Zwölften Brigade bei einer Sitzung in Trebnje, 1944. Von links nach rechts: Stojan Petrovič, Stane Sever, Ivan Groznik, Bogomil Gaberc, Niko Šilih und Tomaž Slapar. Foto: Maksimiljan Zupančič. Ljubljana, Museum für Neuere Geschichte Sloweniens | TN 106/21.

In Babno polje, 1944. Foto: Edi Šelhaus. Ljubljana, Museum für Neuere Geschichte Sloweniens | TN941/4.

Partisan auf einem Pferd vor einer italienischen Festung, 1944/45. Foto: Edi Šelhaus. Ljubljana, Museum für Neuere Geschichte Sloweniens | TN1659/6. 


\section{Menschen und Tiere}

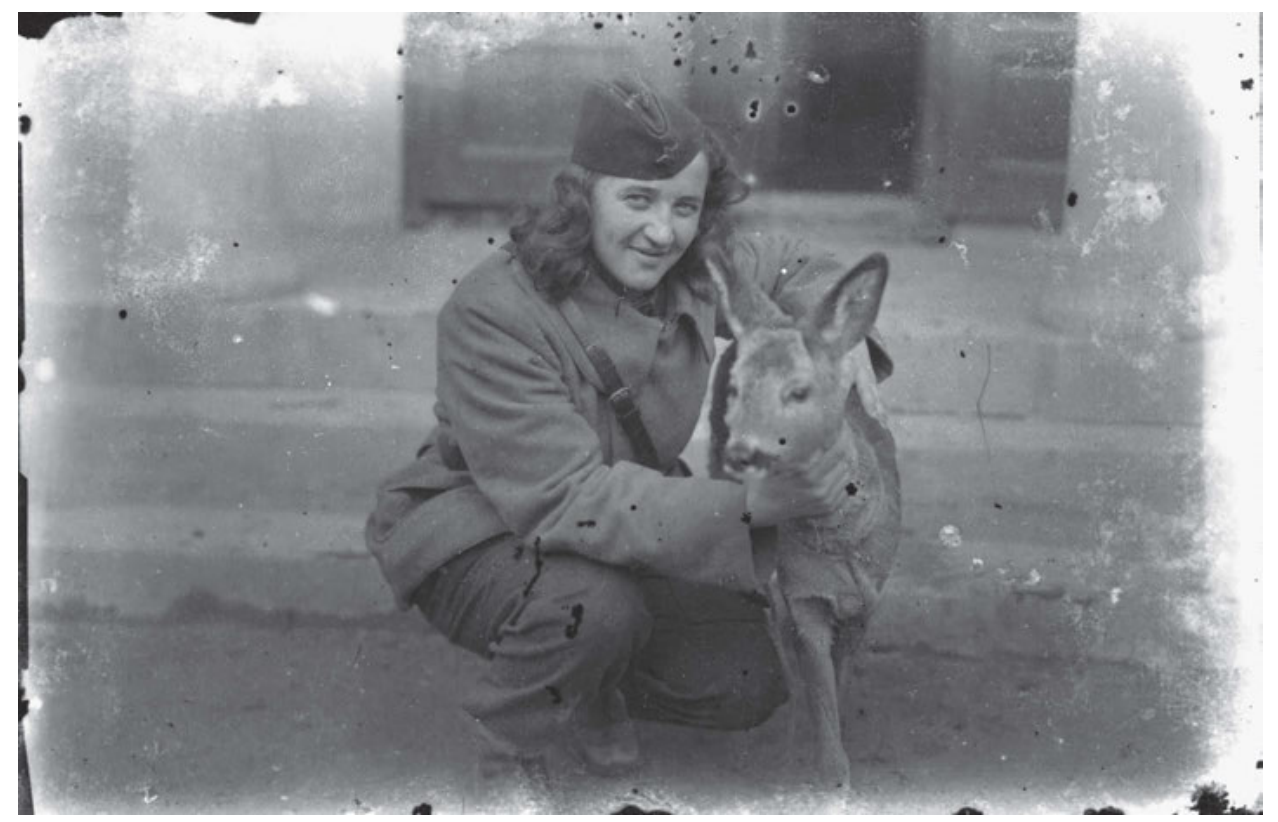

Partisanin aus der Save-Partisaneneinheit. Foto: Stjepan Šubek. Zagreb, Kroatisches Historisches Museum I HPM-MRNH-F-10814.

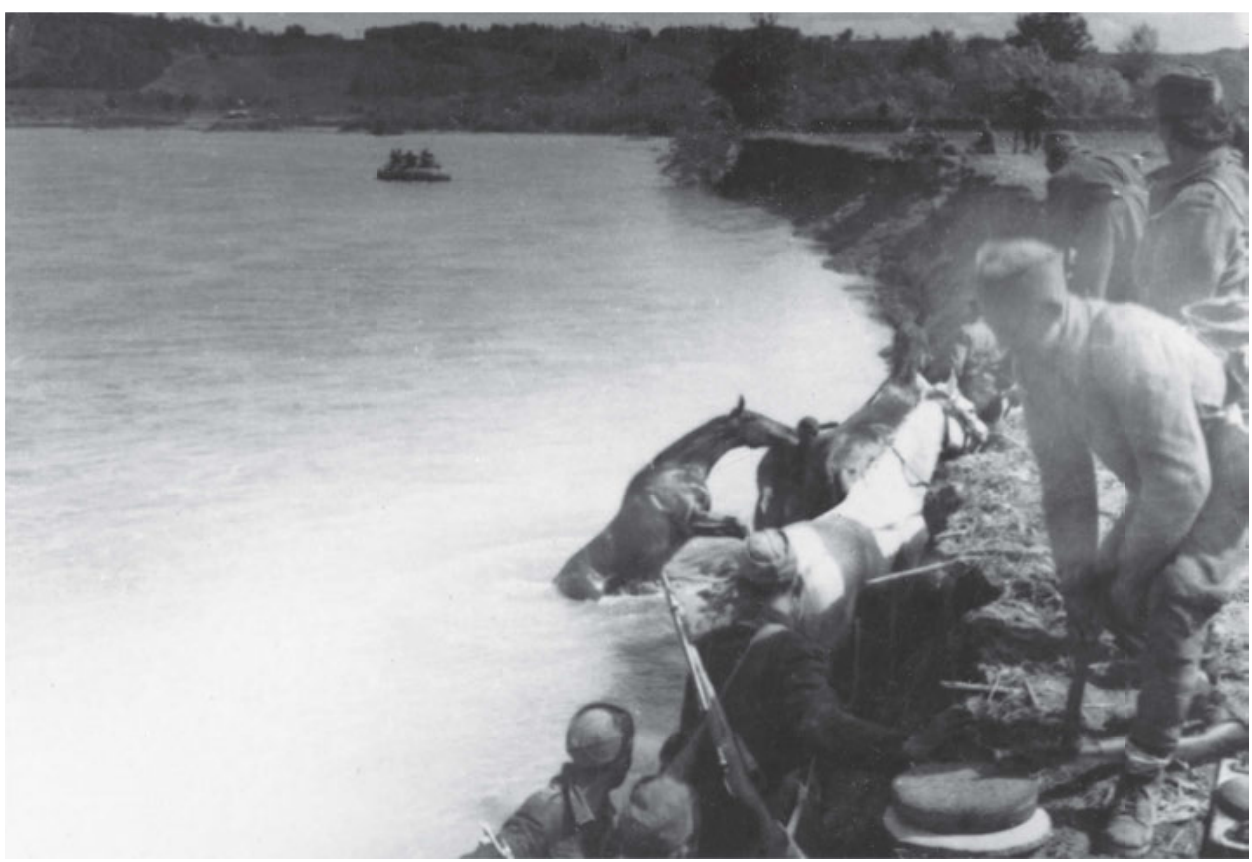

Einheiten der 28. Stoßdivision beim Überqueren des Flusses Vrbas in der Nähe des Dorfes Kukolja, 23. April 1945. Fotograf unbekannt. Belgrad, Militärmuseum | 6764. 

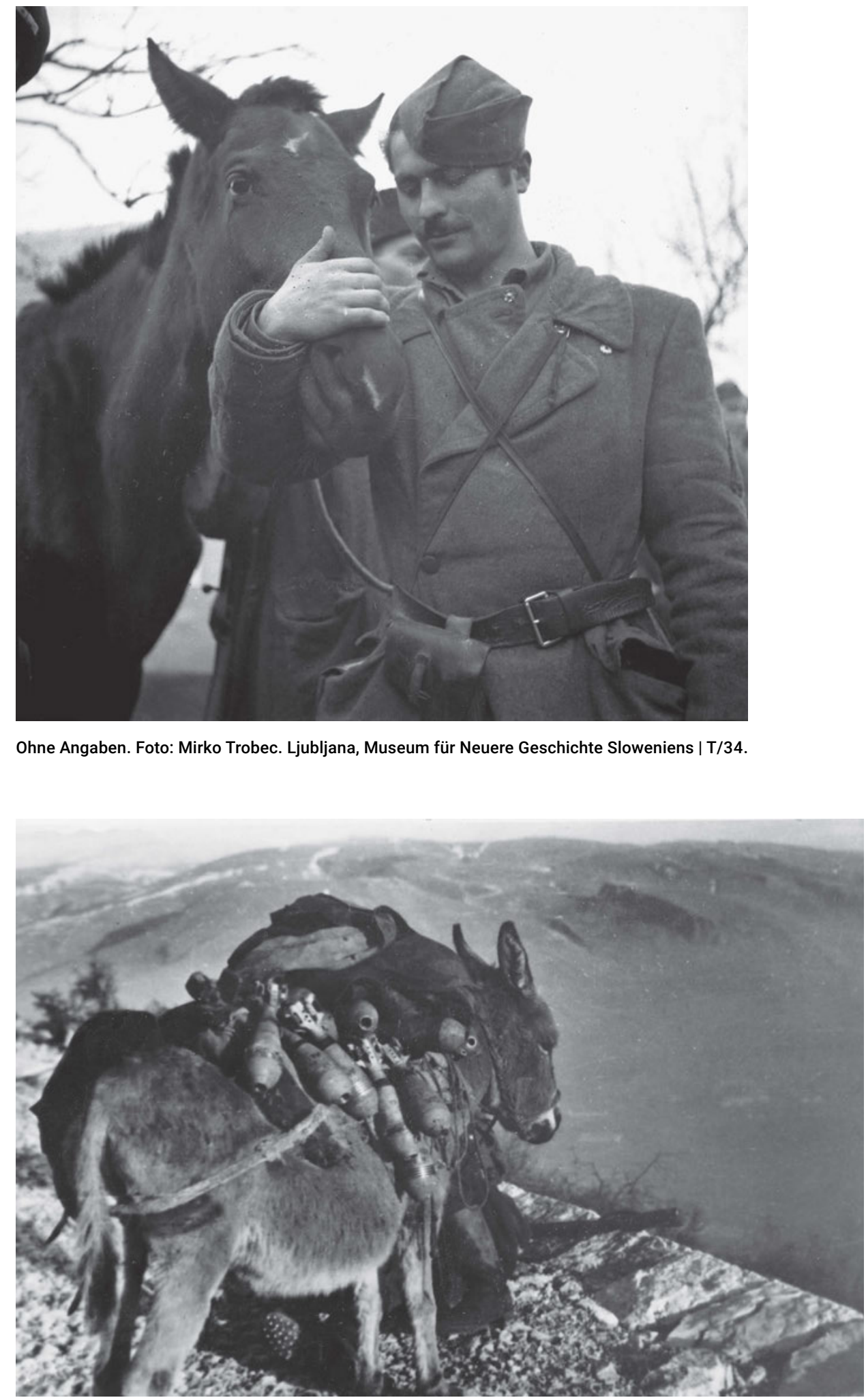

Kurze Rast in der Nähe von Mostar, Februar 1945. Fotograf unbekannt. Belgrad, Militärmuseum | 6218. 


\section{Kinder}

Zu Beginn des Zweiten Weltkriegs hatte der Bund der Kommunistischen Jugend Jugoslawiens circa 35.000 Mitglieder, während des Krieges stieg die Zahl auf 70.000 an. Im Krieg wirkten innerhalb des Kommunistischen Jugendbundes Jugoslawiens und des Vereinigten Verbandes der Antifaschistischen Jugend Jugoslawiens auch Pioniere, die zumeist Kurierdienste und Hilfsaufgaben übernahmen. Einige wurden aber ebenso als Bombenwerfer, Diversanten und gewöhnliche Soldaten eingesetzt. In Ostbosnien erfolgte in der Gegend von Birač sogar die Gründung einer Pionierdivision.

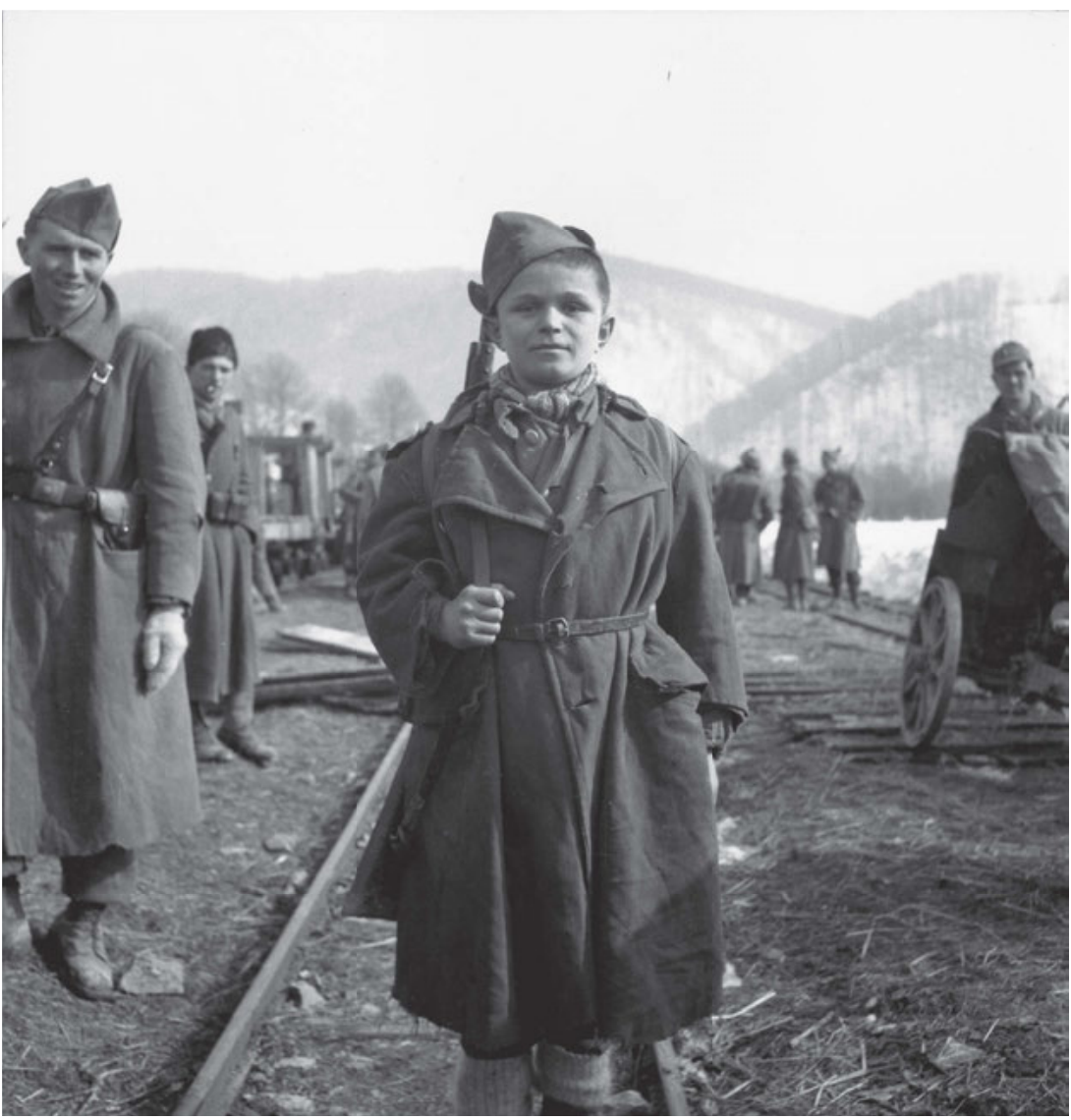

Milan Ostojić, Mitglied der Jugendbrigade Joža Vlahović, Januar 1944. Milan fiel 1945. Fotograf unbekannt. Zagreb, Kroatisches Historisches Museum | HPM-MRNH-A-2201_556. 


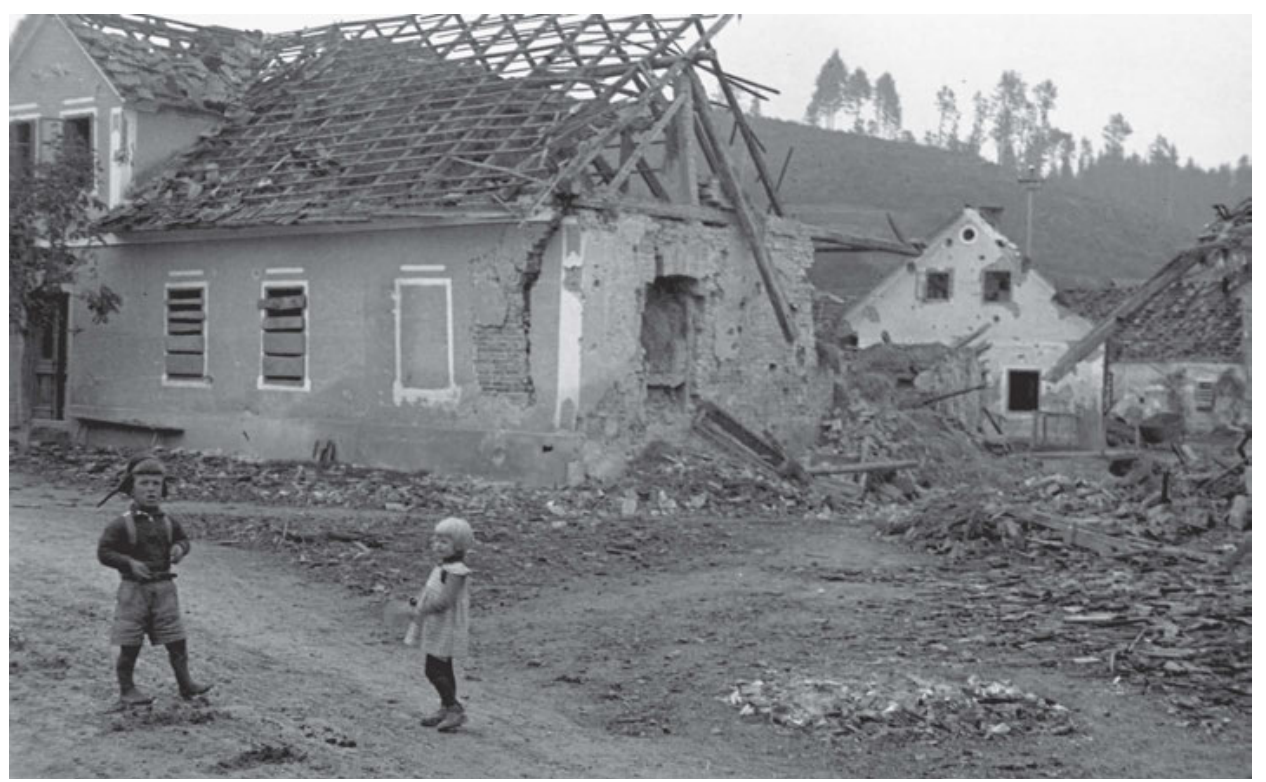

Kinder vor Ruinen nach dem Angriff auf Mokronog, September 1943. Foto: Maksimiljan Zupančič. Ljubljana, Museum für Neuere Geschichte Sloweniens | TN36/16.

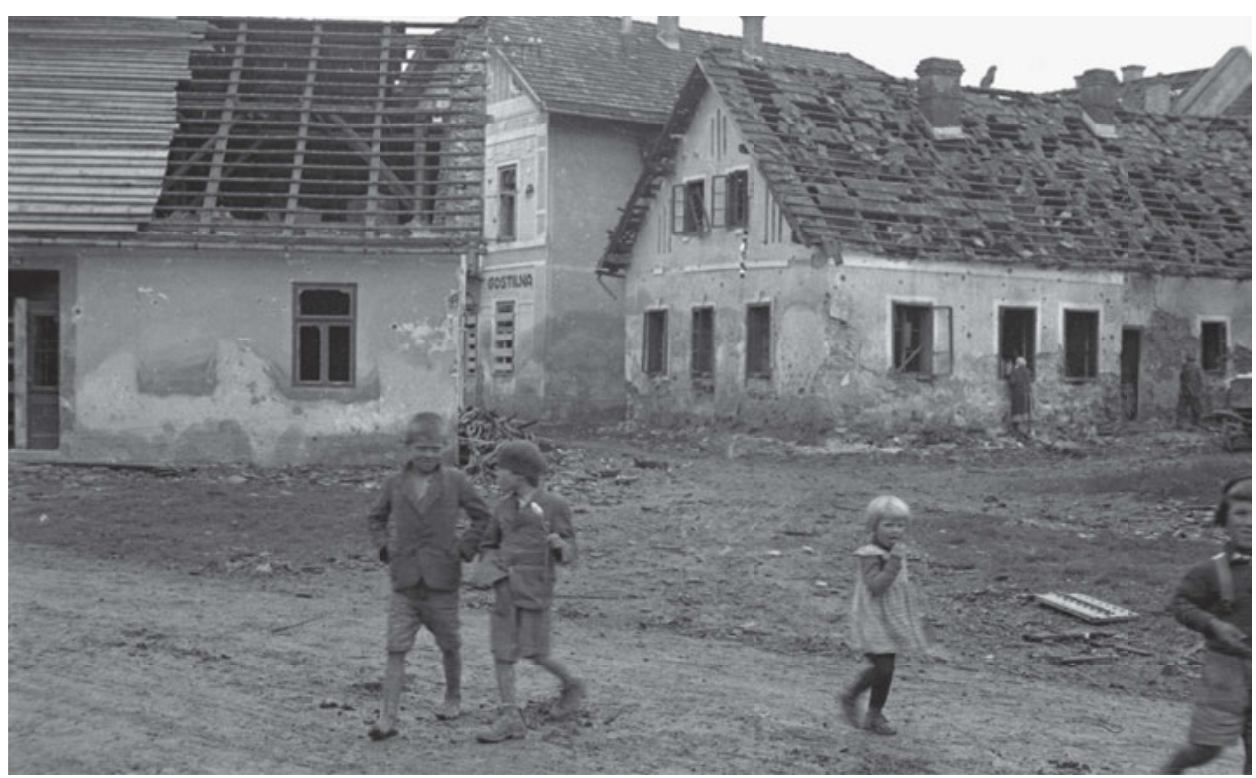

Kinder vor Ruinen nach dem Angriff auf Mokronog, September 1943. Foto: Maksimiljan Zupančič. Ljubljana, Museum für Neuere Geschichte Sloweniens | TN36/17. 


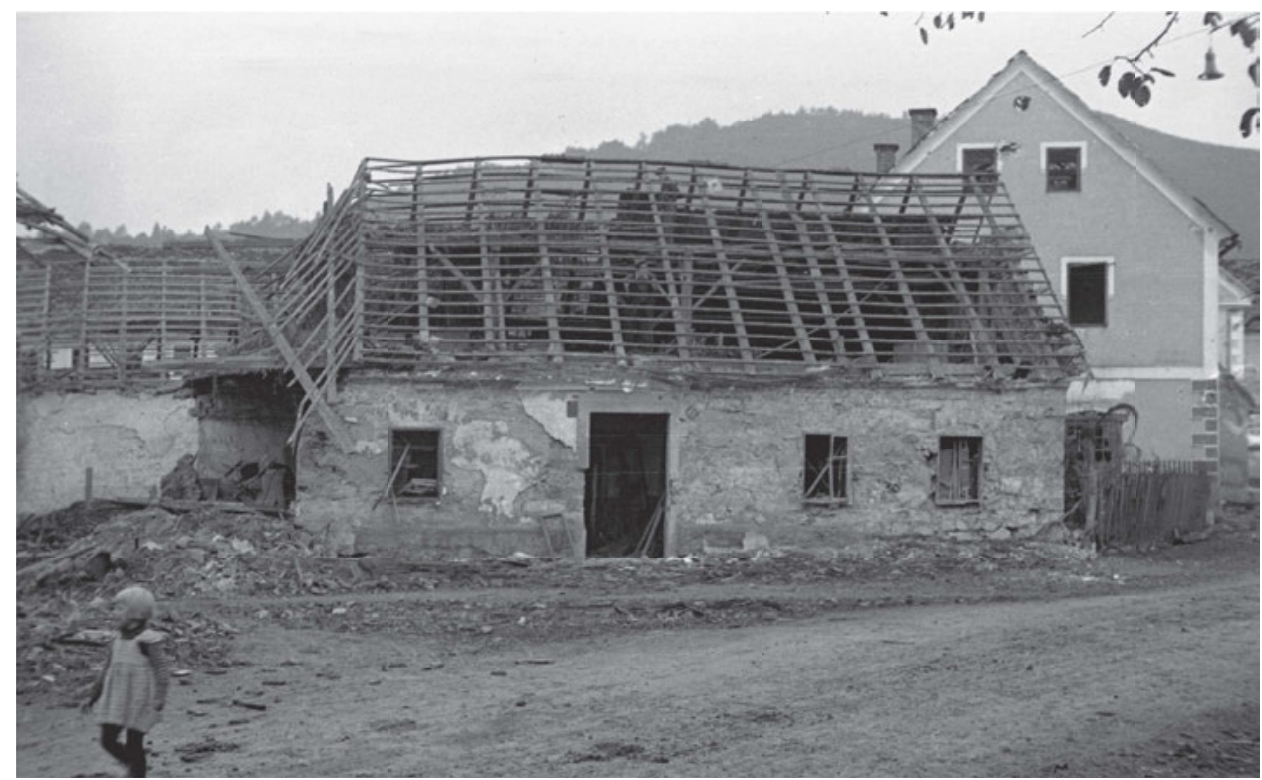

Kind vor Ruinen nach dem Angriff auf Mokronog, September 1943. Foto: Maksimiljan Zupančič. Ljubljana, Museum für Neuere Geschichte Sloweniens | TN36/20.

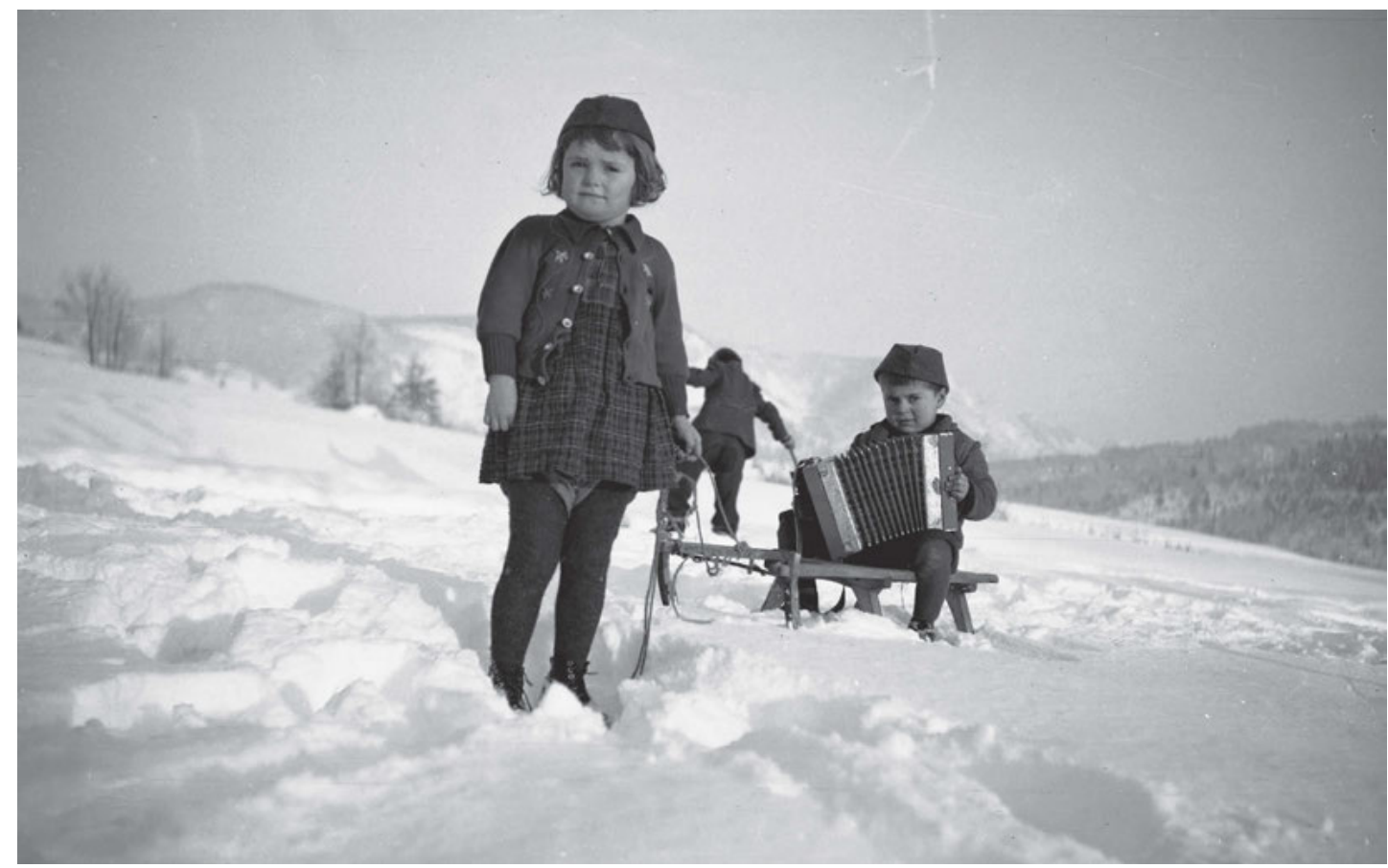

Zwei der jüngsten Pioniere aus dem Dorf Potok in der Gegend von Kočevje. Foto: Edi Šelhaus. Ljubljana, Museum für Neuere Geschichte Sloweniens | TN577/5. 


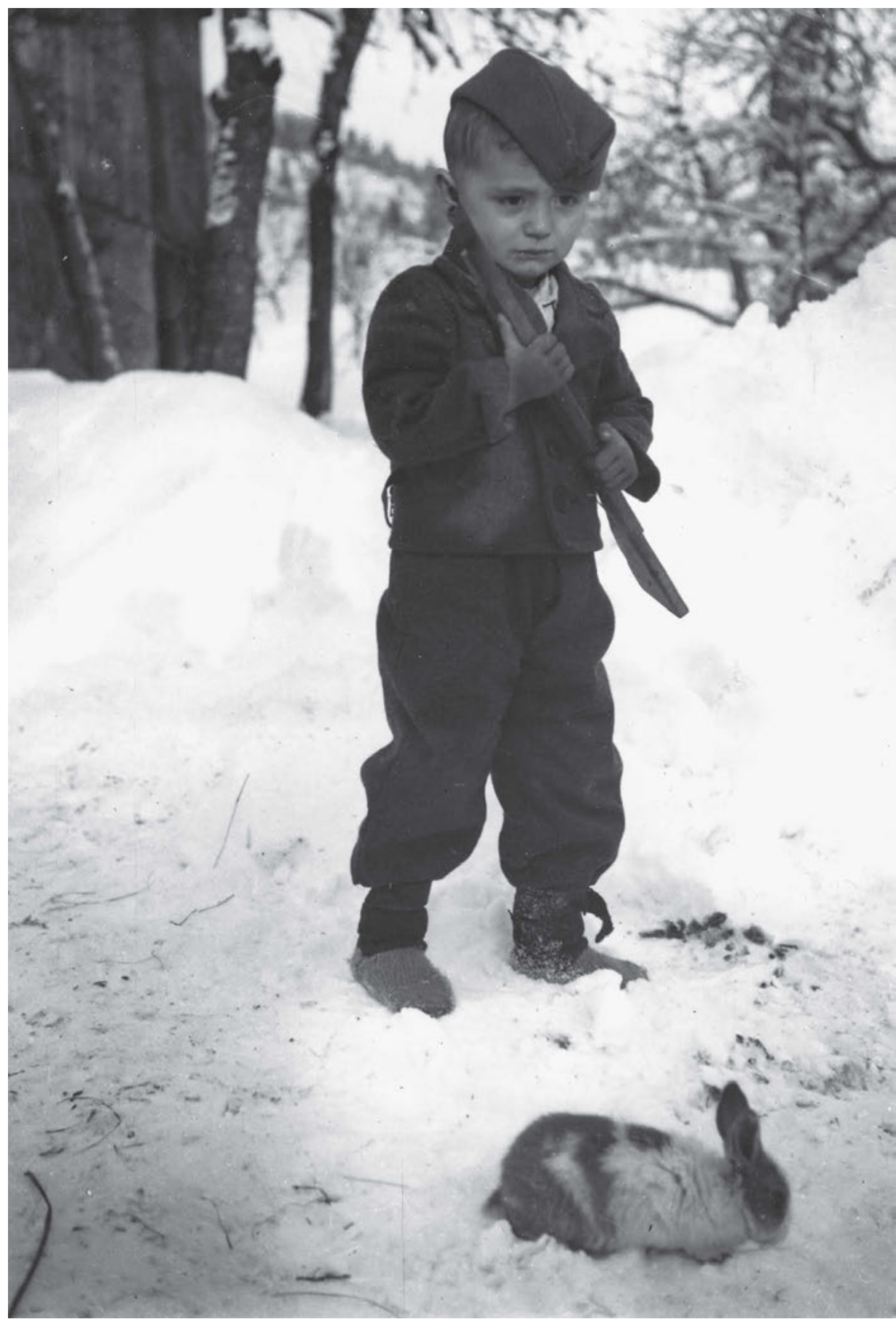

Pionier aus Kočevje mit einem Hasen, Slowenien. Fotograf unbekannt. Private Fotosammlung. 


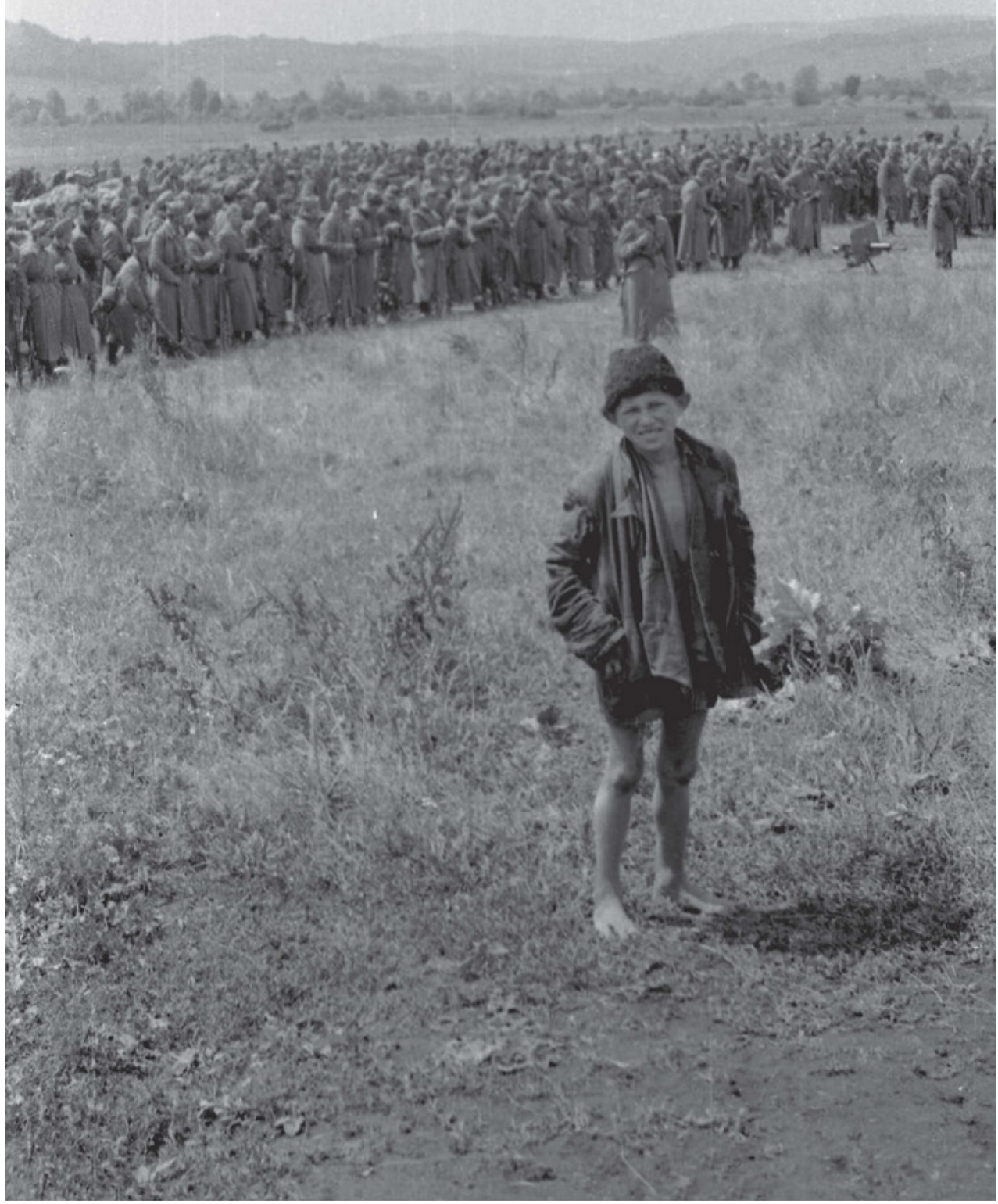

Feier anlässlich des zweiten Jahrestags der Gründung der Zwölften Proletarischen Stoßbrigade der Dritten Slawonischen operativen Zone in Levanjska Varoš, Herbst 1944. Fotograf unbekannt. Zagreb, Kroatisches Historisches Museum I HPM-100525_027. 


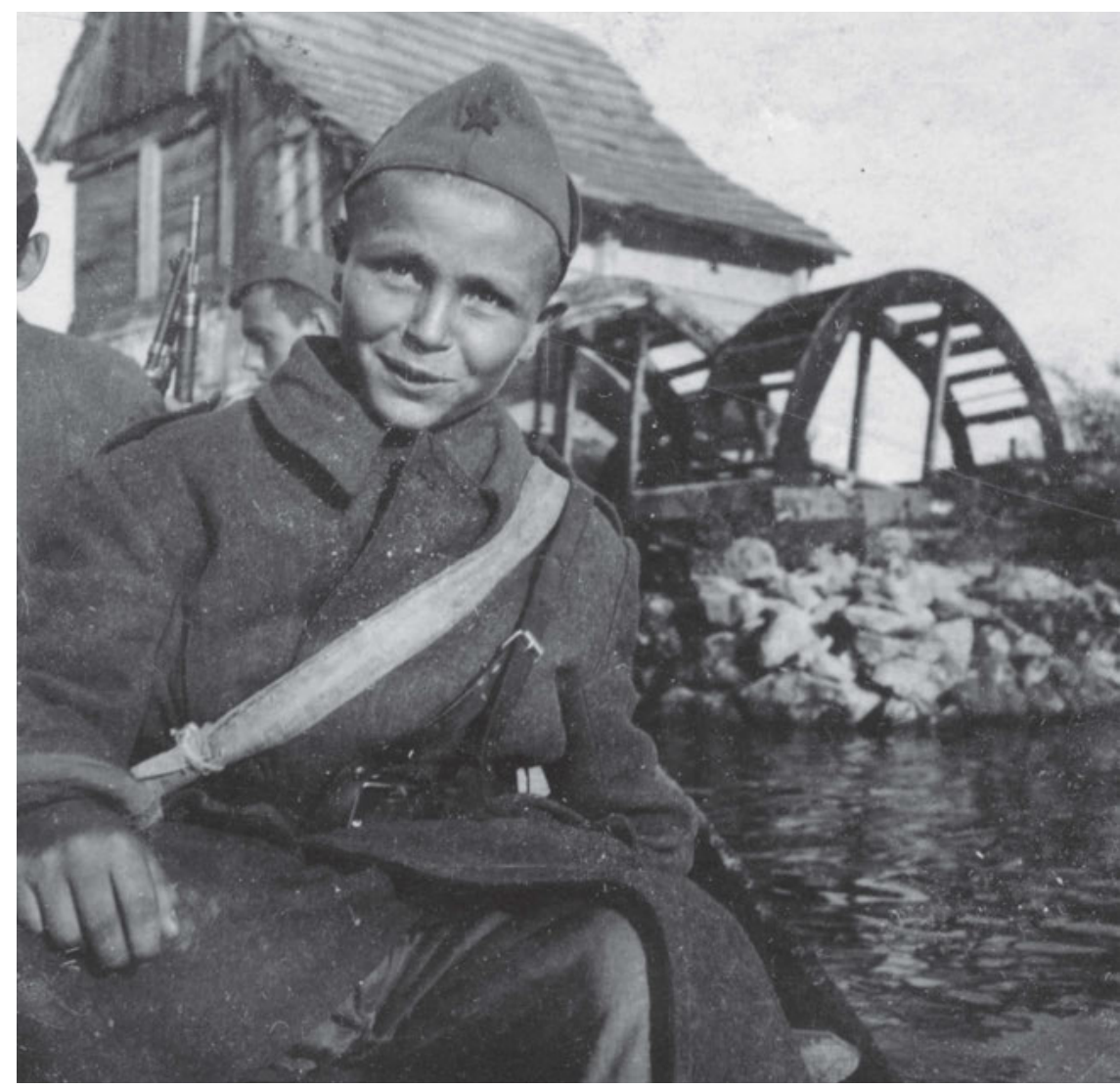

Miloš Brkić, der jüngste Soldat der Nachrichtenkompanie der Siebten Kordun-Division vor dem Angriff auf Duga Resa, Juni 1944. Foto: Mahmud Konjhodžić. Zagreb, Kroatisches Historisches Museum I HPM-MRNH-F-4723.

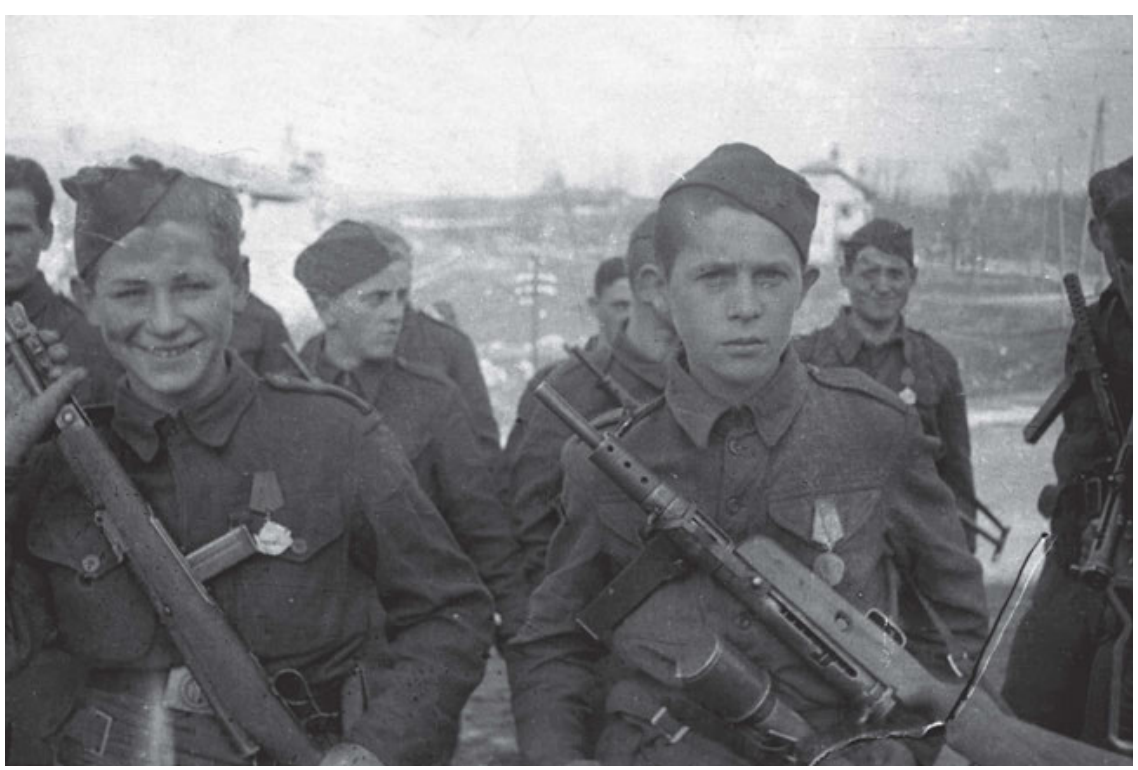

Marsch der Einheiten des Ersten Proletarierkorps über die Straße nach Šid. Syrmische Front, Dezember 1944. Foto: Pavle Bojčević. znaci.net. 

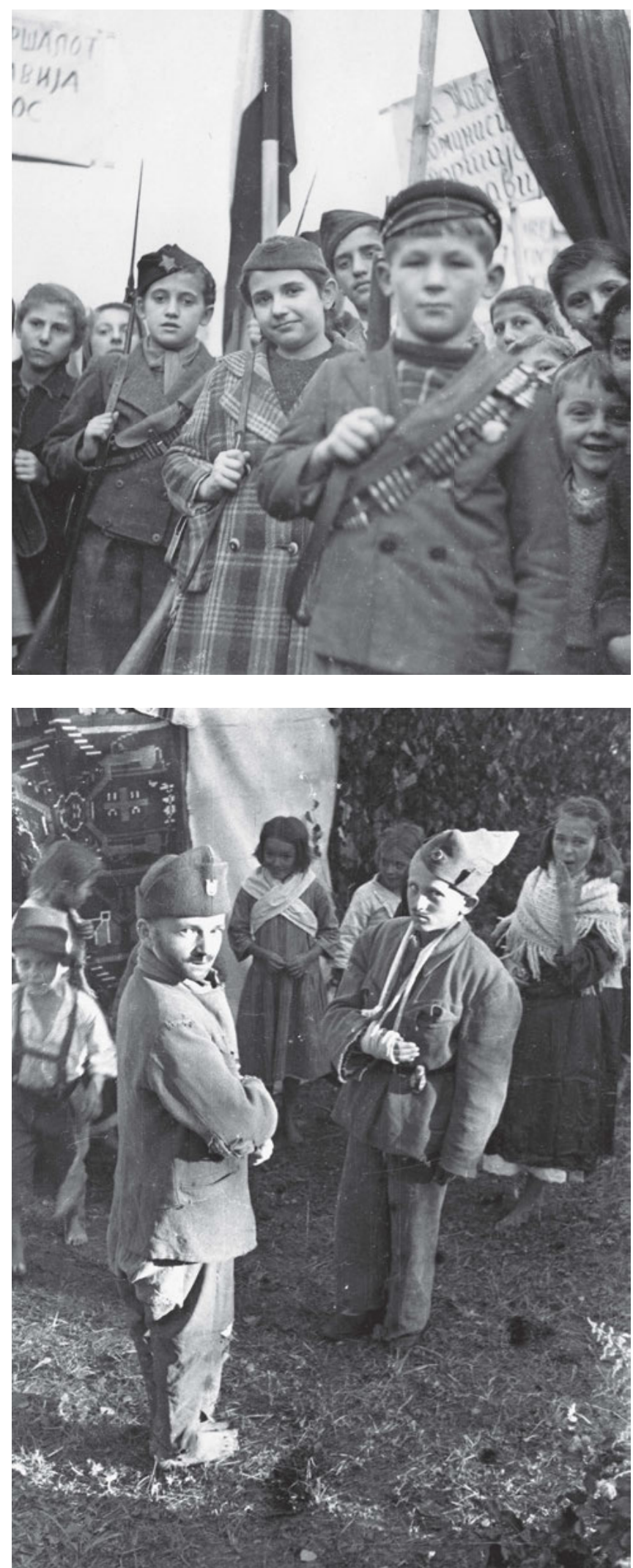

Jugendtreffen in Skopje, 1944.

Fotograf unbekannt. znaci.net.
Kindertheatergruppe in Psunj, 1944. Foto: Pero Dragila. Zagreb, Kroatisches Historisches Museum | HPM-100544-003. 


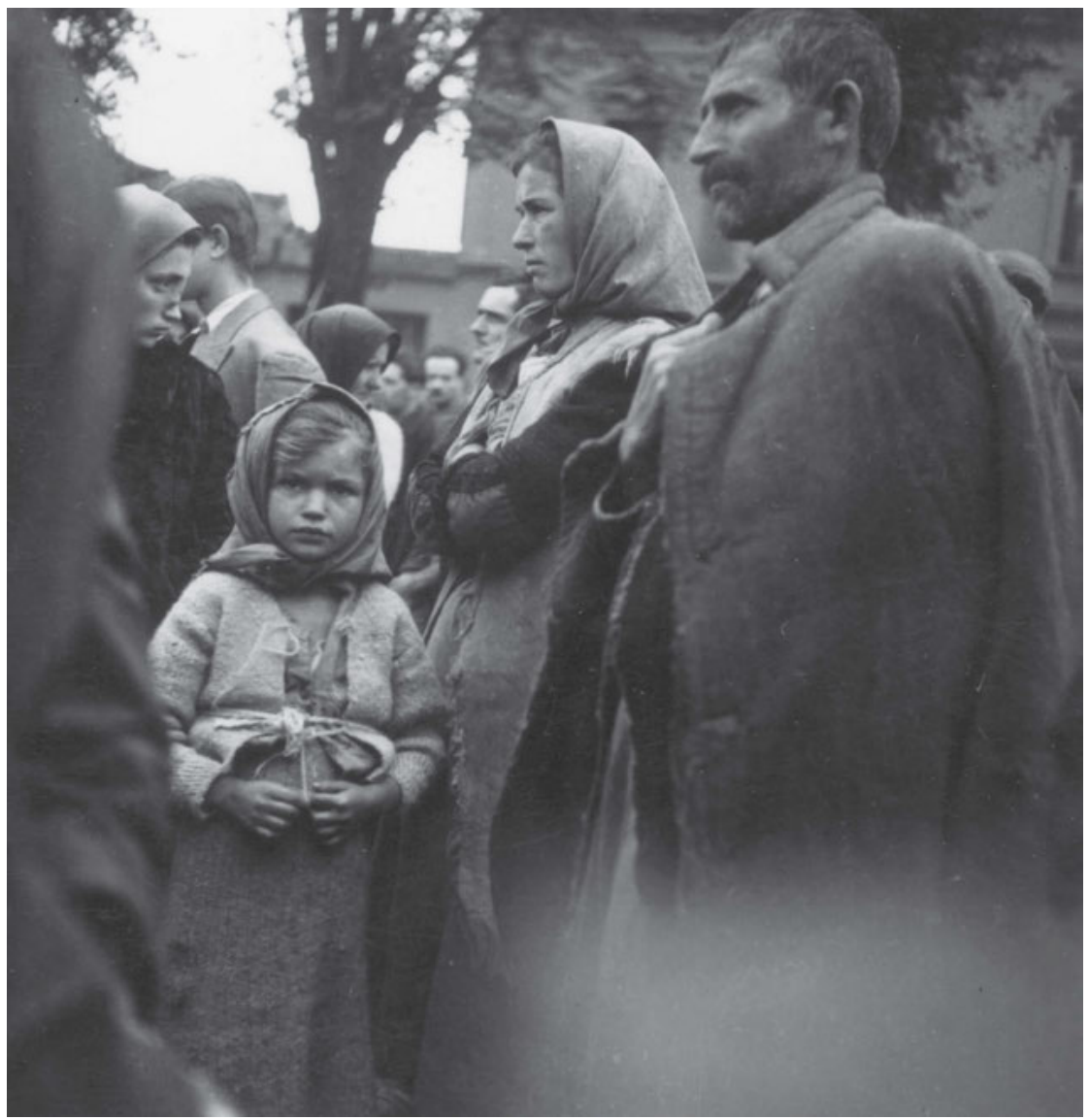

Fahnenweihe des neu gegründeten serbischen Gesangsvereins Obilić und Ehrung der Opfer des faschistischen Terrors in den Ruinen der Kirche in Glina, in der die Ustascha im August 1941 eine Vielzahl von Serben hingerichtet haben. Oktober 1944. Foto:

Mahmud Konjhodžić. Zagreb, Kroatisches Historisches Museum I HPM-MRNH-F-4777.

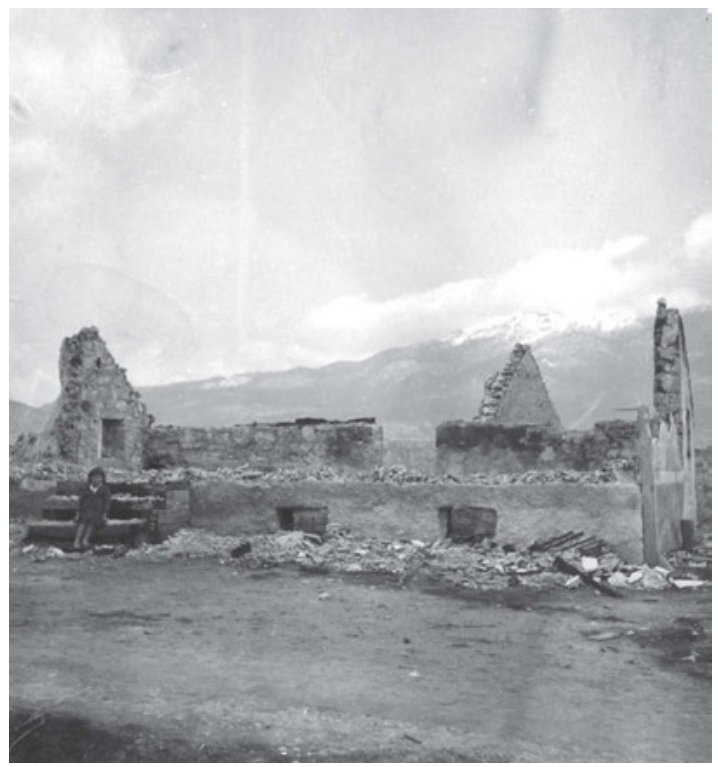

Kind an der Türschwelle seines zerstörten Elternhauses, Kamenica, Bosnien und Herzegowina. Foto: Žorž Skrigin. znaci.net. 


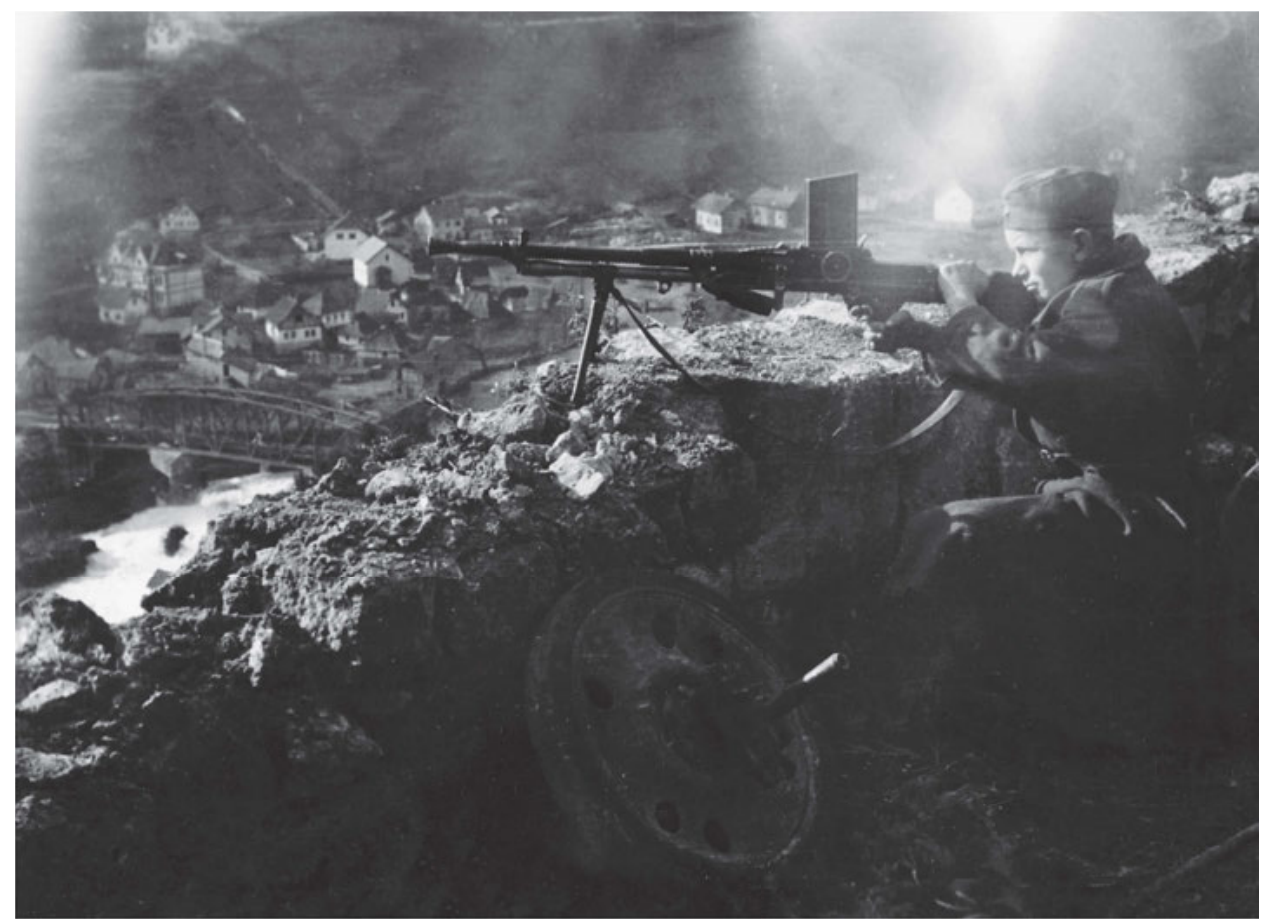

Maschinengewehrschütze auf dem Turm in Jajce während der Zweiten Sitzung des Antifaschistischen Rats der Volksbefreiung Jugoslawiens im November 1943. Fotograf unbekannt. Belgrad, Museum Jugoslawiens | III-204.

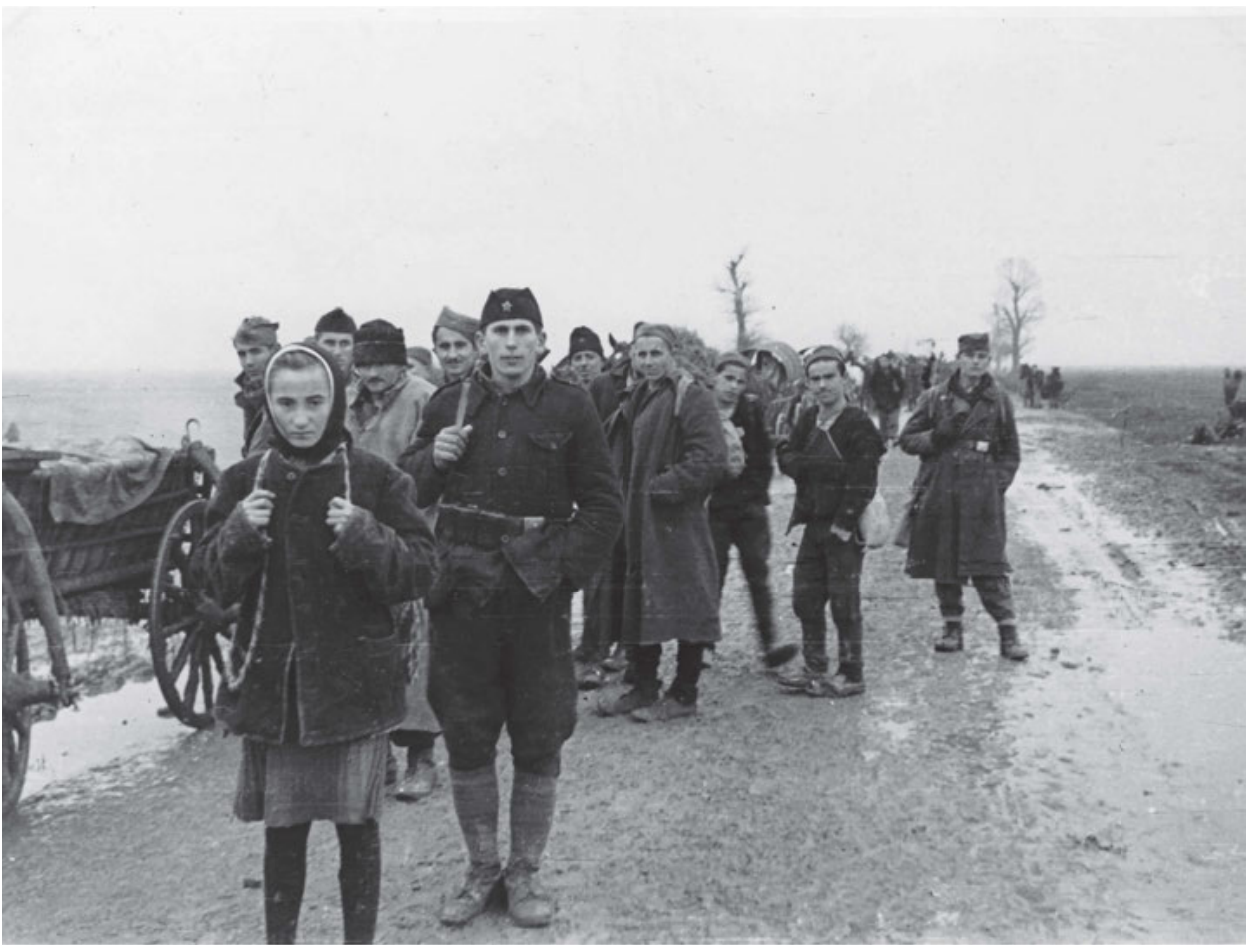

Marsch der Einheiten des Ersten Proletarierkorps über die Straße nach Šid.

Syrmische Front, Dezember 1944. Foto: Pavle Bojčević. znaci.net. 


\section{Aus dem Leben der Bevölkerung}

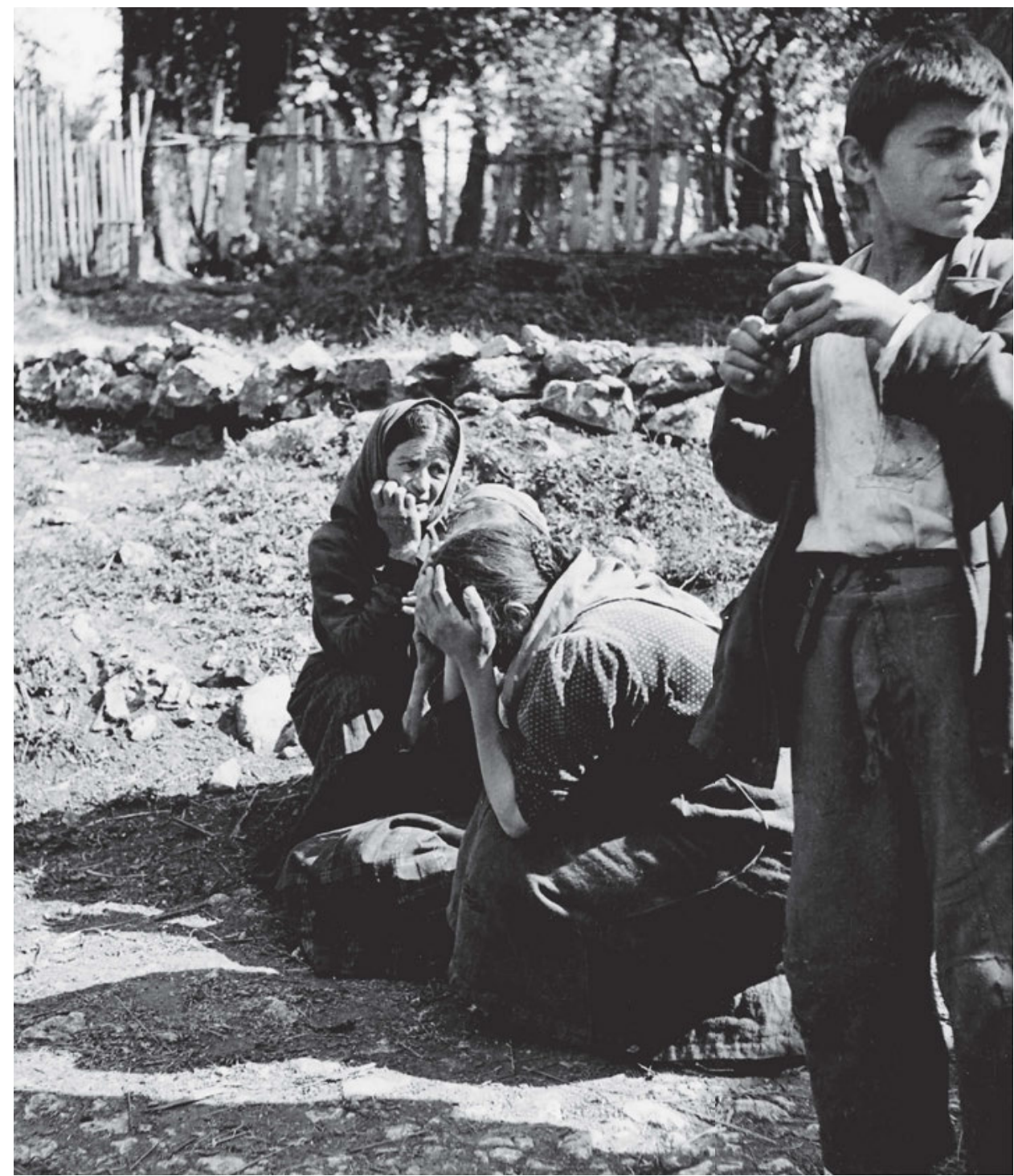

Obdachlose Familie nach der Bombardierung von Drežnica im Juli 1942.

Fotograf unbekannt. Belgrad, Museum Jugoslawiens | III-3705. 


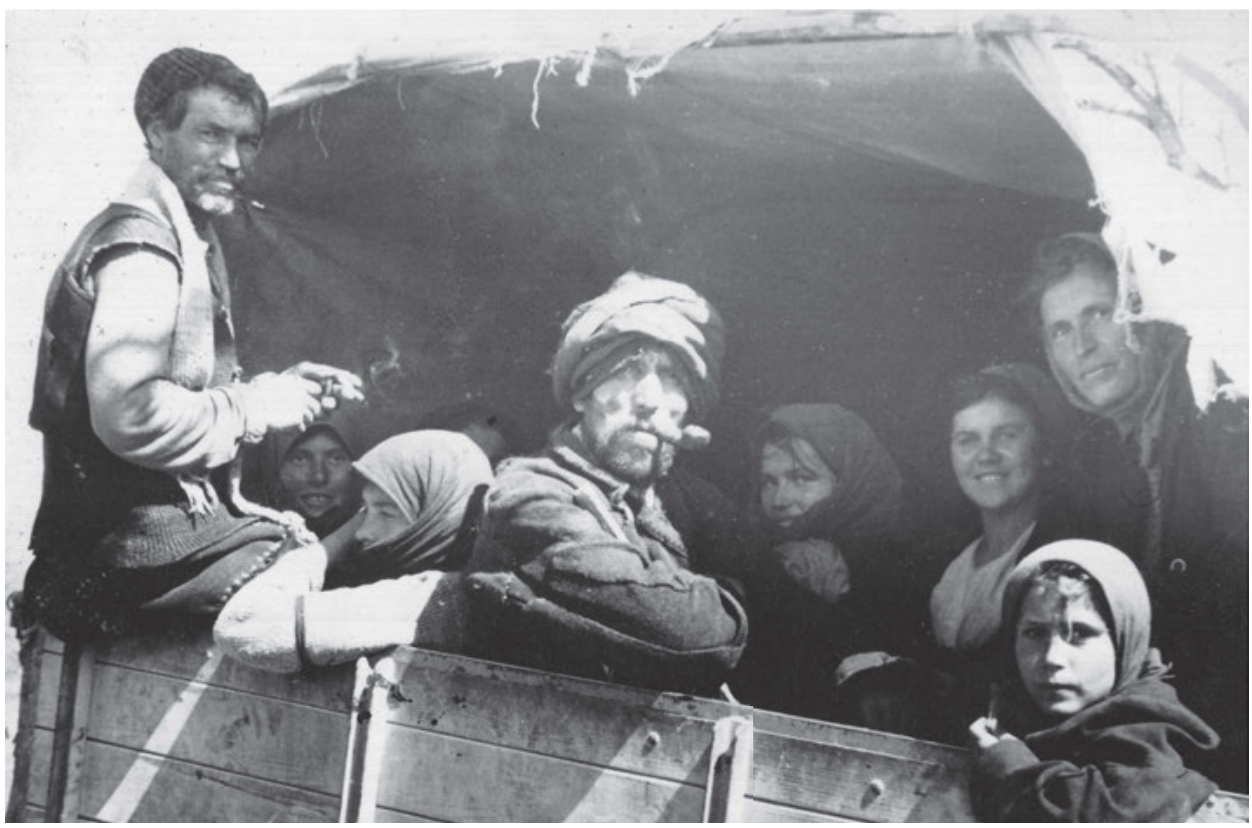

Ohne Angaben. Foto: Drago Mažar. Banja Luka, Archiv der Republika Srpska. Ohne Inv.-Nr.

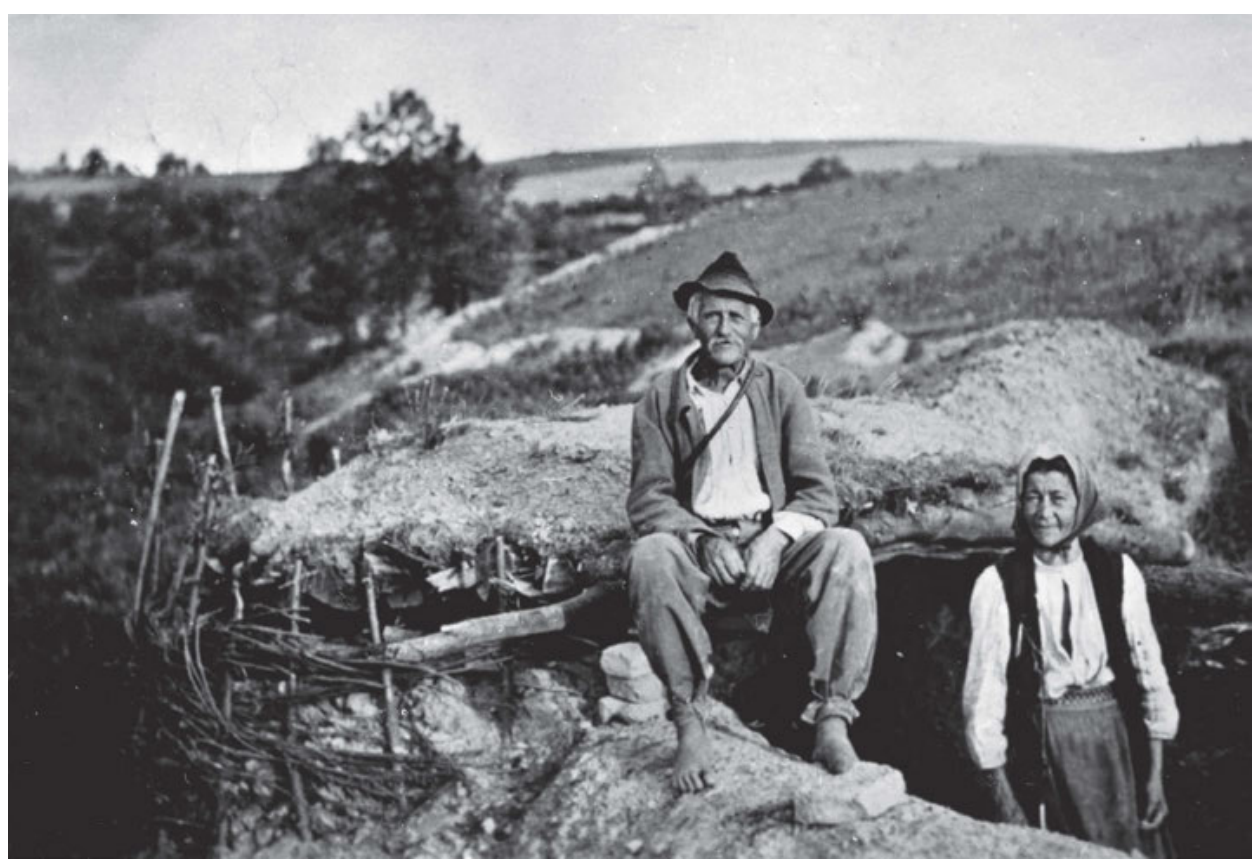

Geflüchtete aus den Dörfern am Fuße des Grmeč-Gebirges, April 1943. Fotograf unbekannt. Sarajevo, Historisches Museum von Bosnien und Herzegowina | FNOB 16223. 


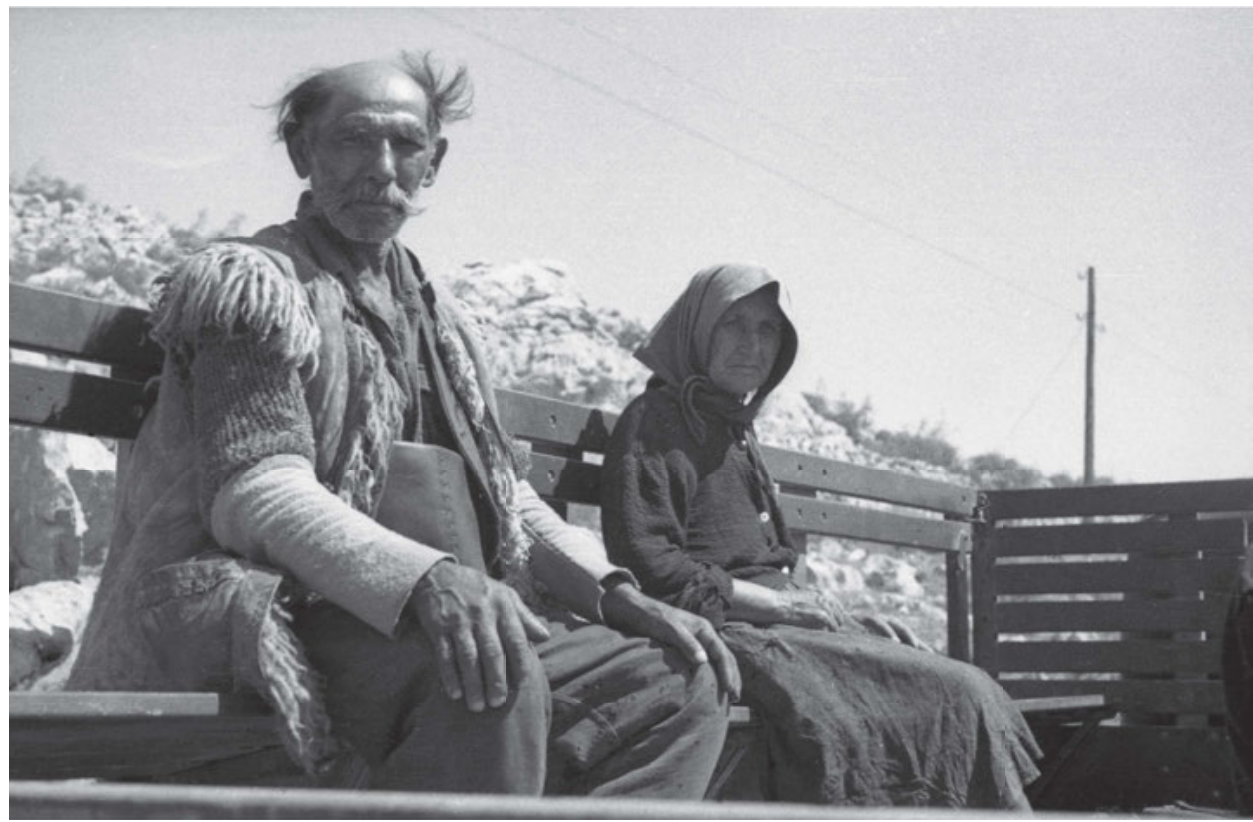

Auf der Adria-Straße, Mai 1945. Foto: Dr. Janez Milčinski. Ljubljana, Museum für Neuere Geschichte Sloweniens | 1239/5.

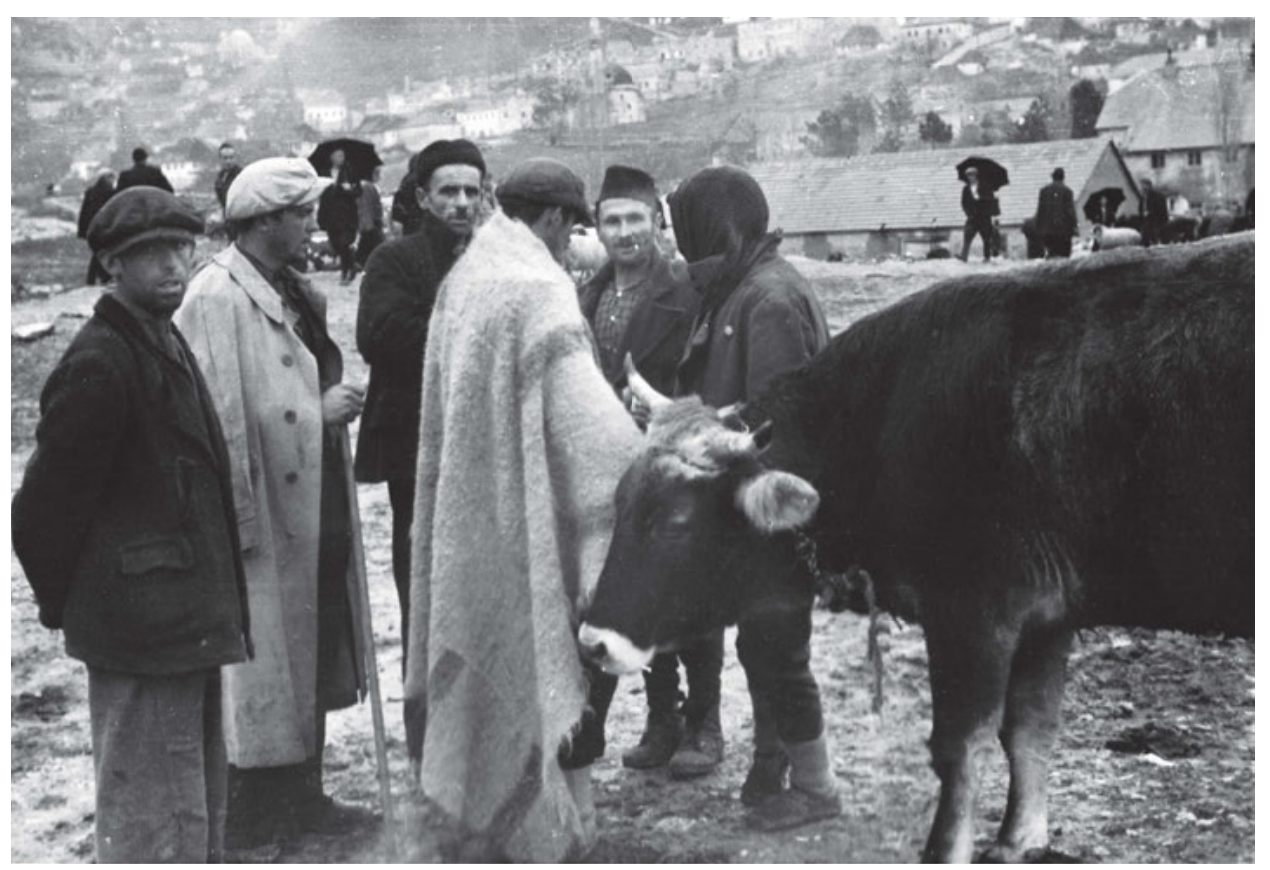

Markt in Livno, 1943. Fotograf unbekannt. Belgrad, Museum Jugoslawiens | III-1812. 


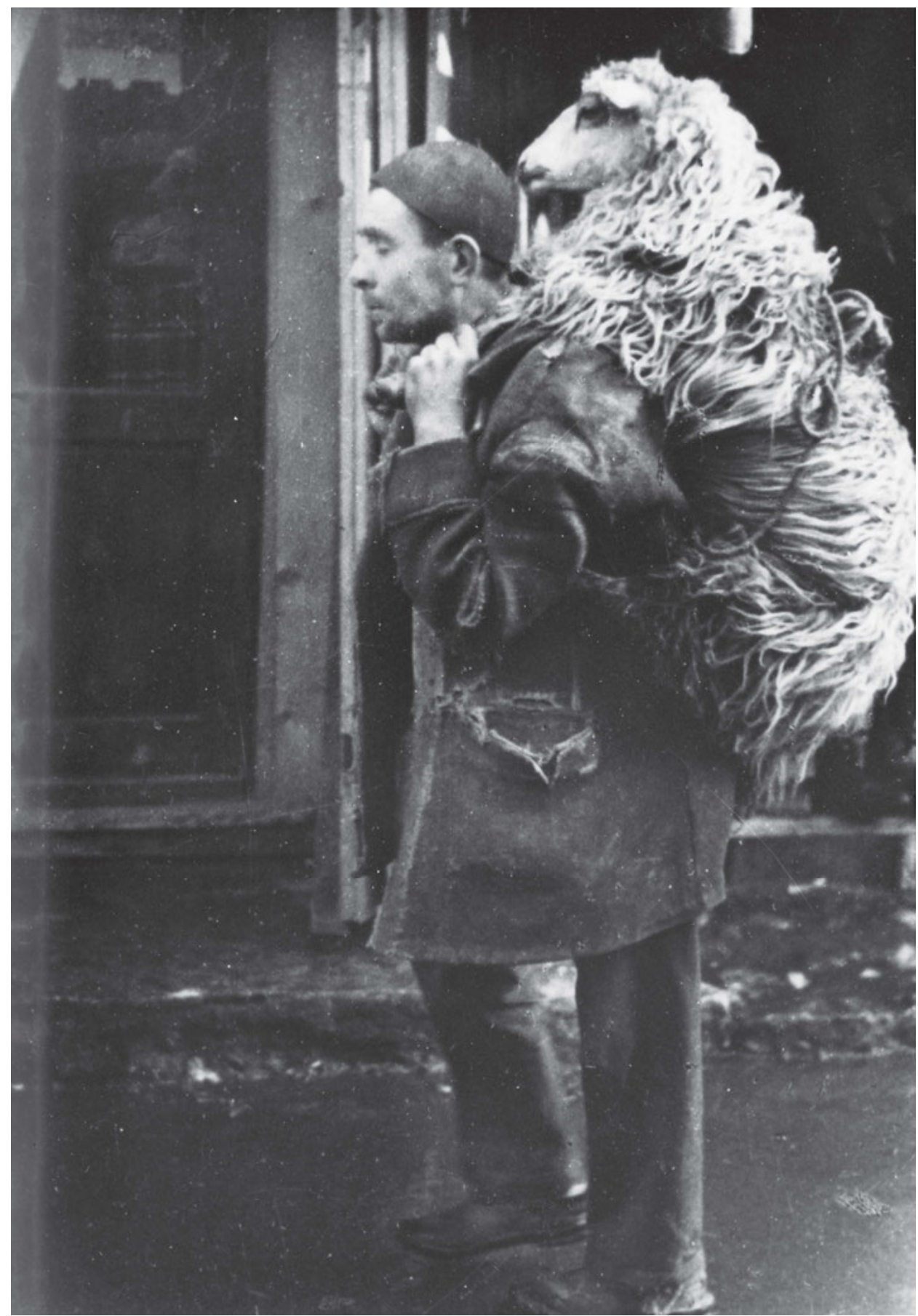

Geflüchteter aus Ostbosnien. Fotograf unbekannt. Sarajevo,

Historisches Museum von Bosnien und Herzegowina | FNOB 1994. 


\section{Partisanen und die Bevölkerung}
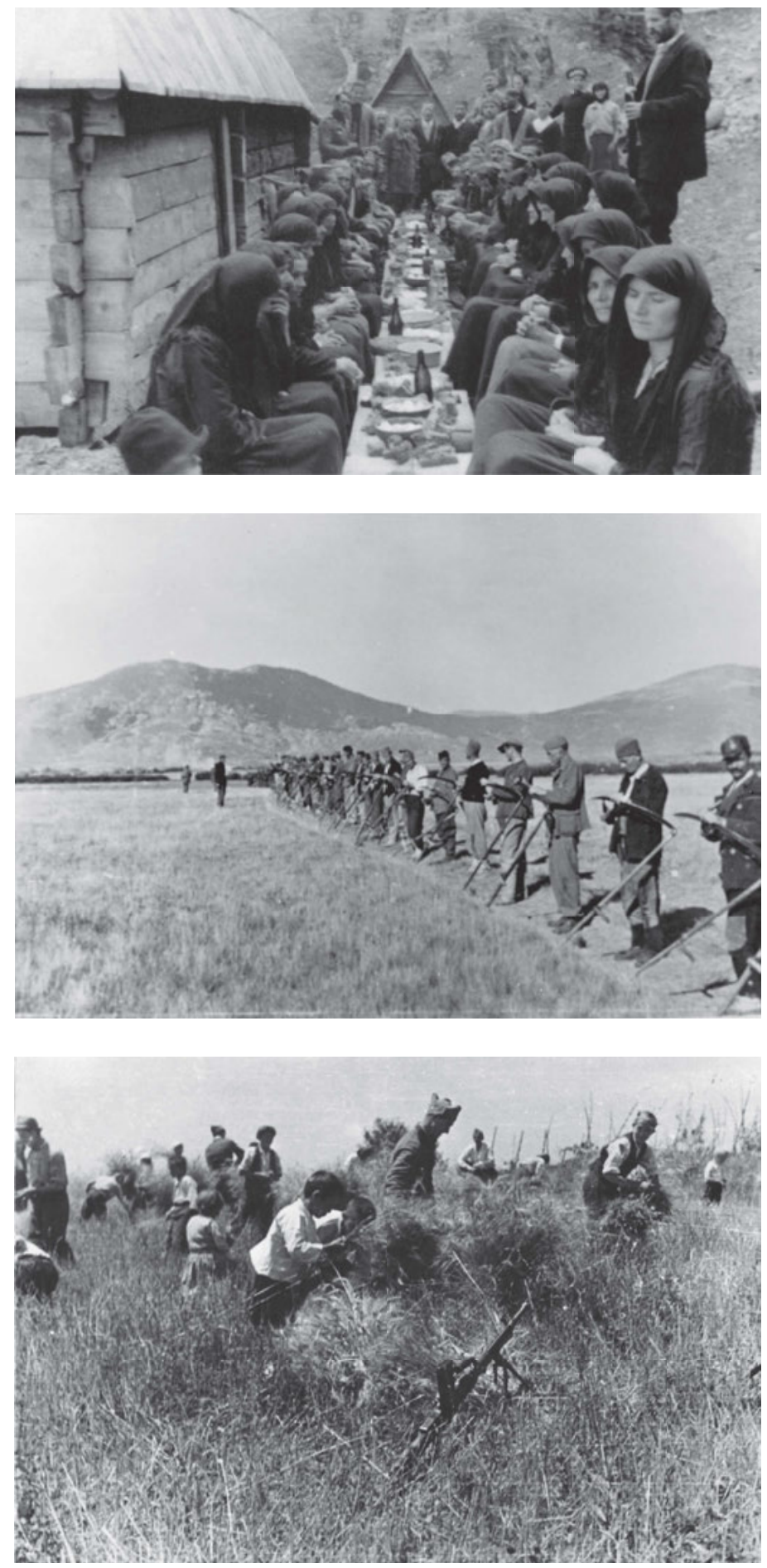

Leichenschmaus. Dr. Ivan Ribar und Dr. Simo Milošević stehen am Kopfende des Tisches. Dorf Zaglavak im Sandžak, 16. Mai 1943.

Foto: Dr. Mladen Iveković. Zagreb, Kroatisches Historisches Museum I HPM-MRNH-A-6337_149.

Das Stabsbataillon der 39. Division hilft der Bevölkerung beim Mähen der Kupres-Felder, April 1944. Fotograf unbekannt. Sarajevo, Historisches Museum von Bosnien und Herzegowina | FNOB 17704

Das Zehnte Zagreber Korps bei der Sicherung der Ernte, Sommer 1944. Fotograf unbekannt. Museum der Stadt Zagreb. Ohne Inv.-Nr. 


\section{Auf befreitem Territorium}

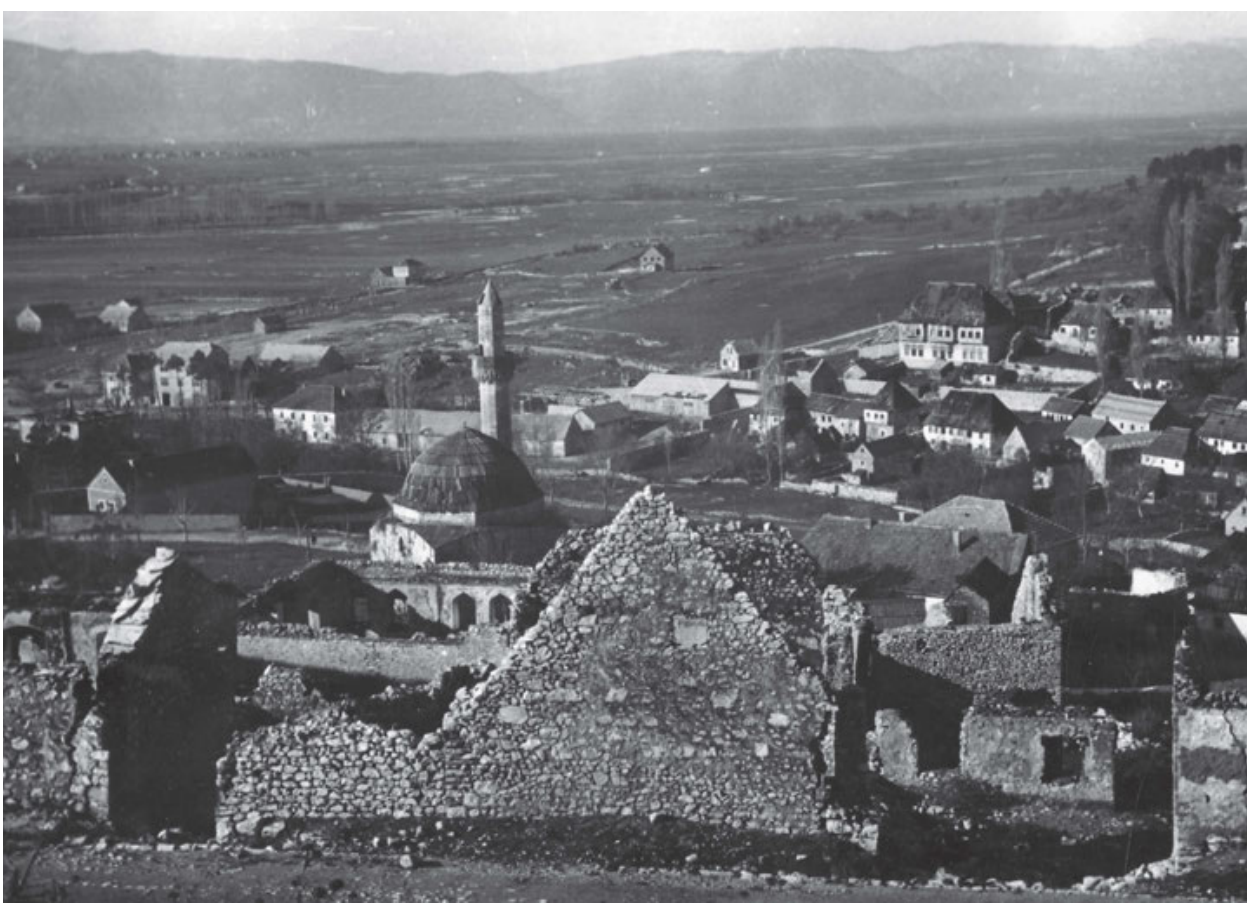

Panorama der Stadt Livno, 1943. Fotograf unbekannt. Bestand des Historischen Archivs beim ZK BdKJ | znaci.net.

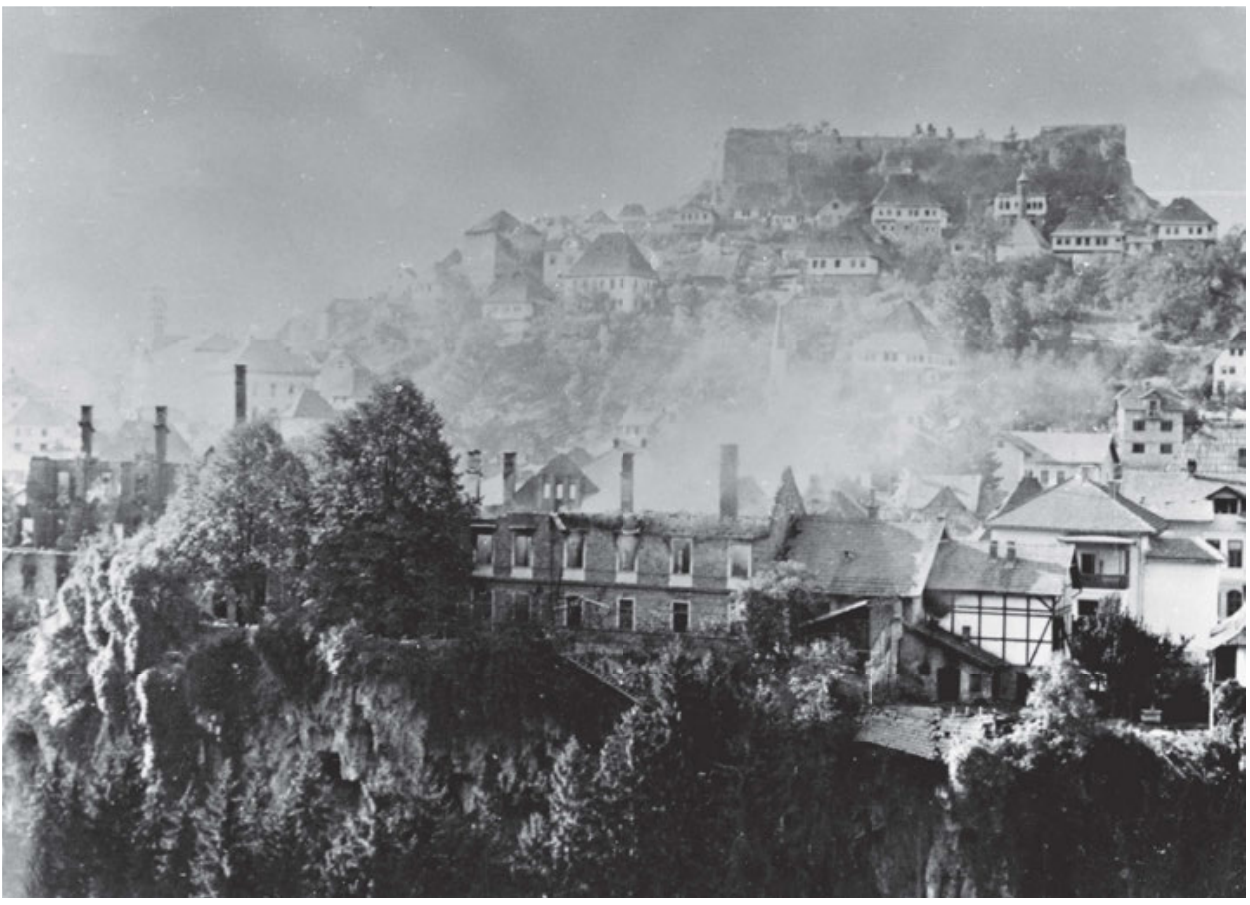

Jajce zur Zeit der Zweiten Sitzung des Antifaschistischen Rats der Volksbefreiung Jugoslawiens. Fotograf unbekannt. Sarajevo, Historisches Museum von Bosnien und Herzegowina | FNOB 17882. 


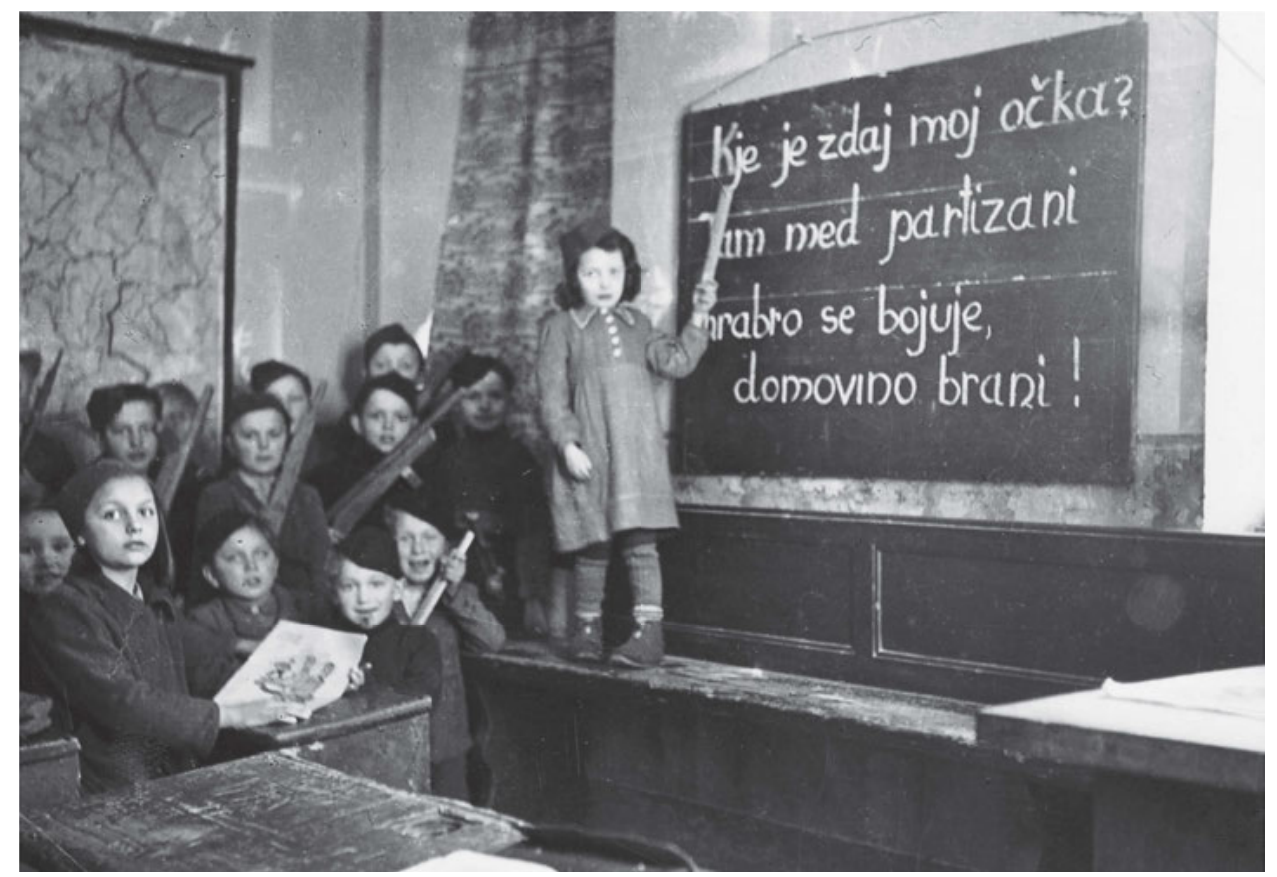

Schulkinder in Podprel, Kočevje, 1944. Fotograf unbekannt. Ljubljana,

Slowenisches Revolutionsmuseum | znaci.net.

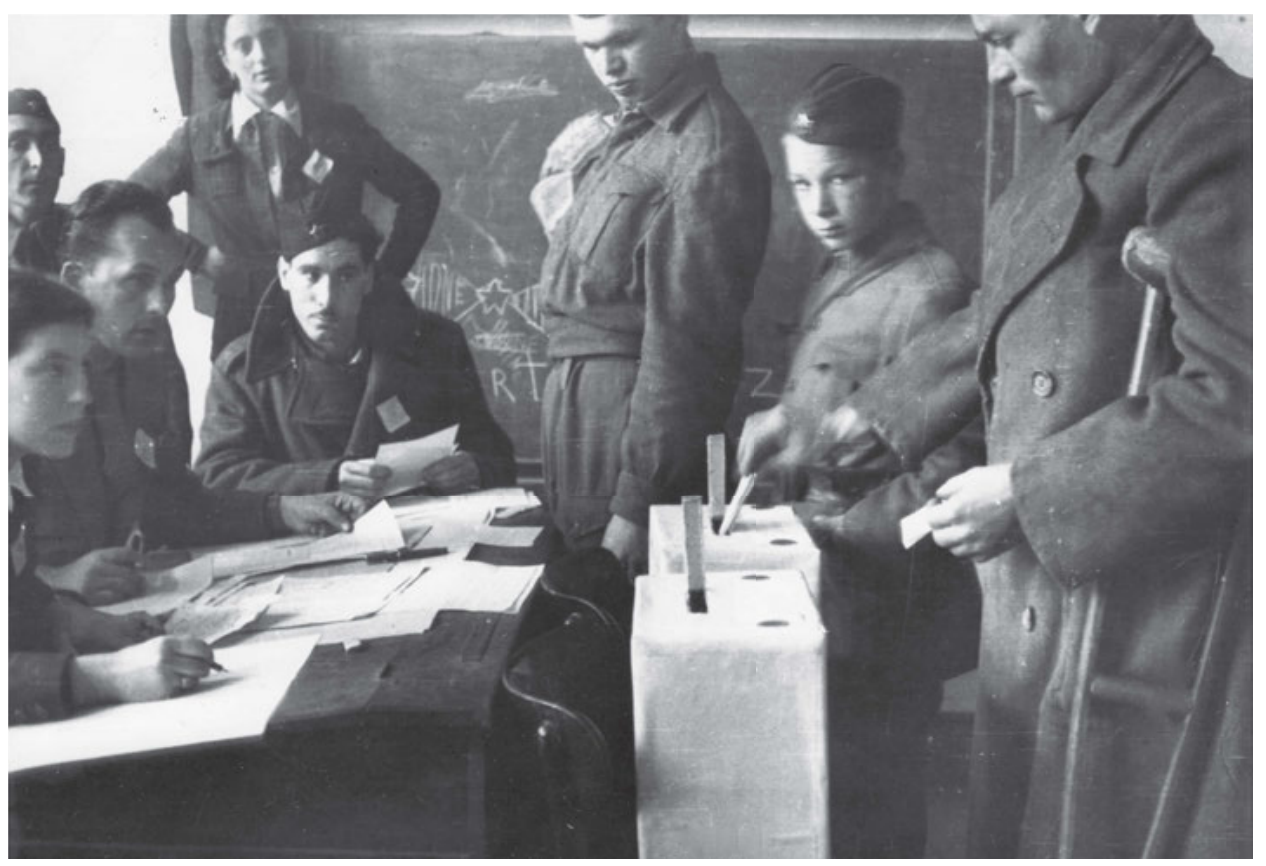

Wahl der Volksbefreiungsräte in Split, März 1945. Fotograf unbekannt. Split, Museum der Volksrevolution | 4963/znaci.net. 


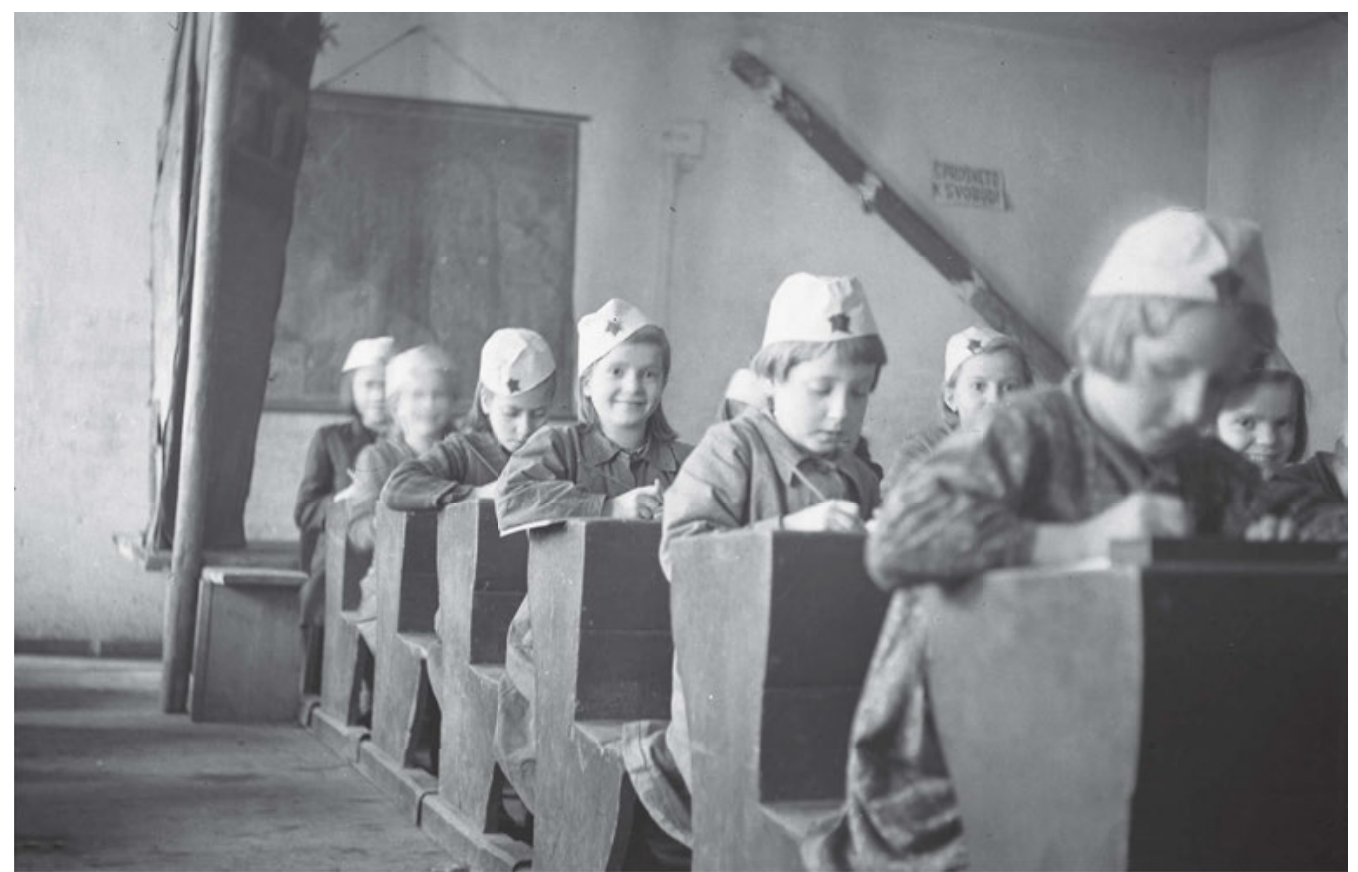

Schulbesuch in Osilnica, Slowenien, 23. März 1945. Foto: Edi Šalhaus. Ljubljana, Museum für Neuere Geschichte Sloweniens | TN829/5.

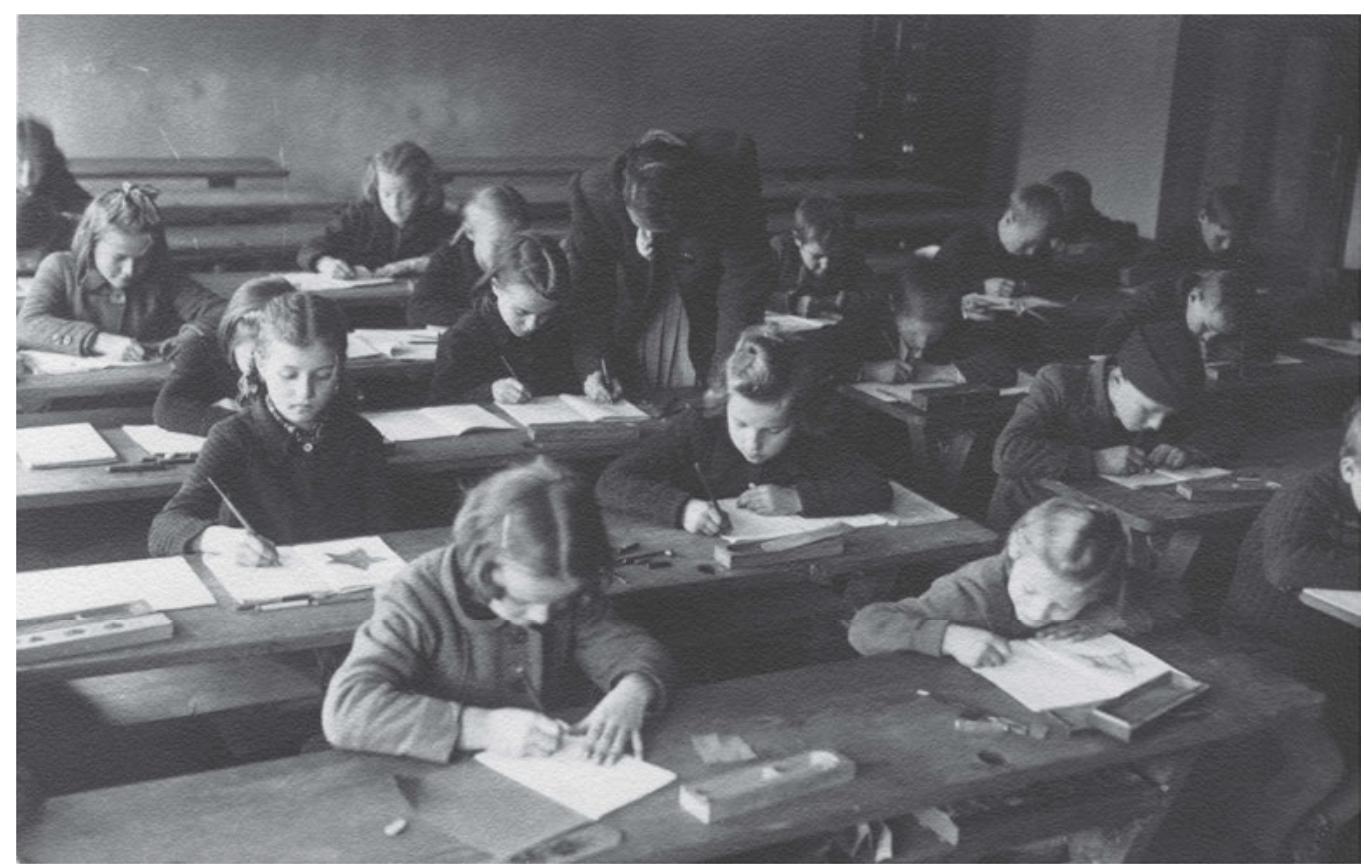

Partisanenschule in Ljubno, Save-Tal, Herbst 1944. Fotograf unbekannt. Museum für Neuere Geschichte der Stadt Celje | FZ2 1612. 


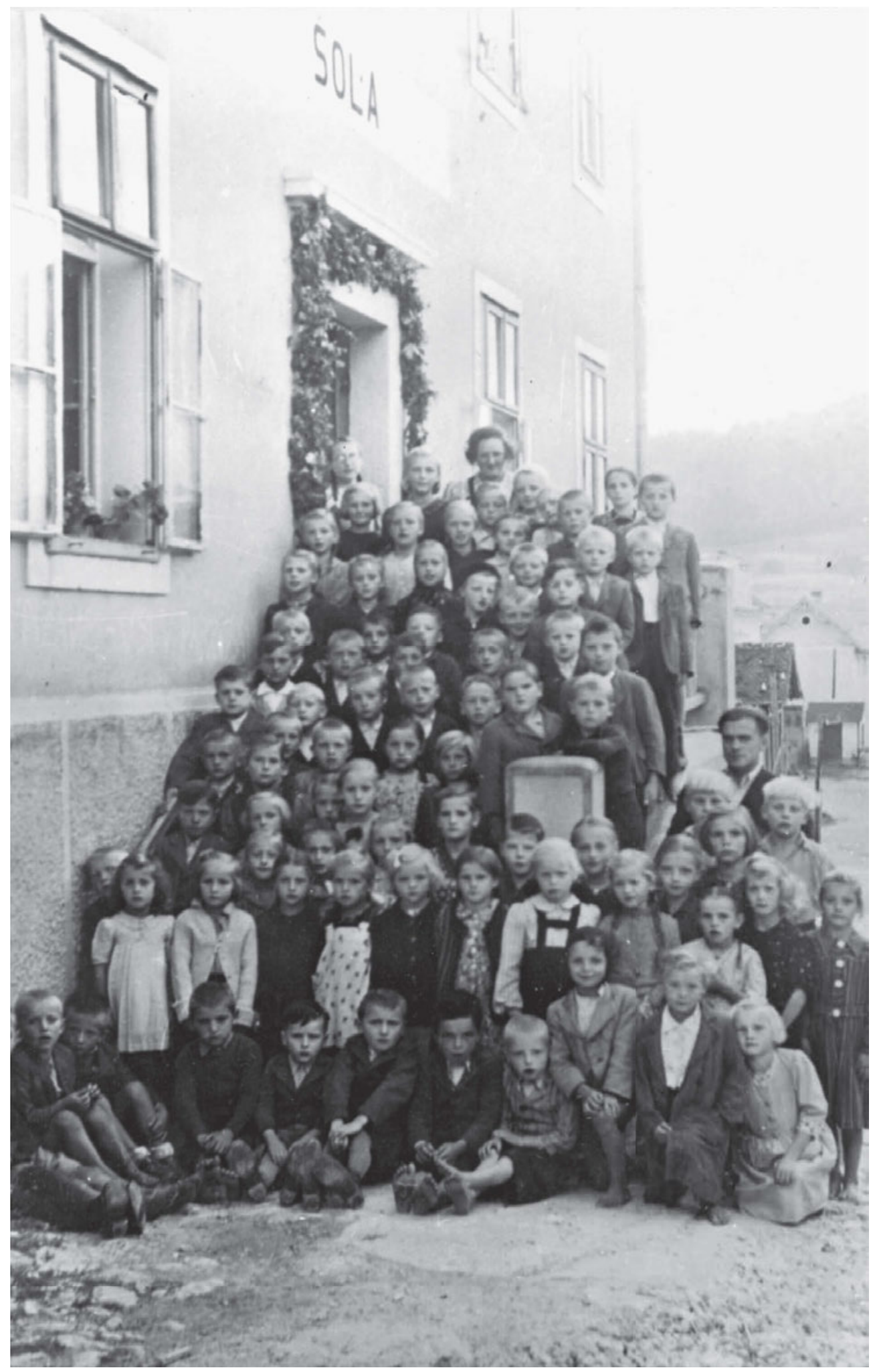

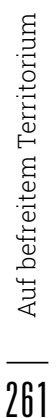

Partisanenschule im Gebirge, Kozje 1944. Fotograf unbekannt. Museum für Neuere Geschichte der Stadt Celje | FZ2 A. 


\section{Kundgebungen}

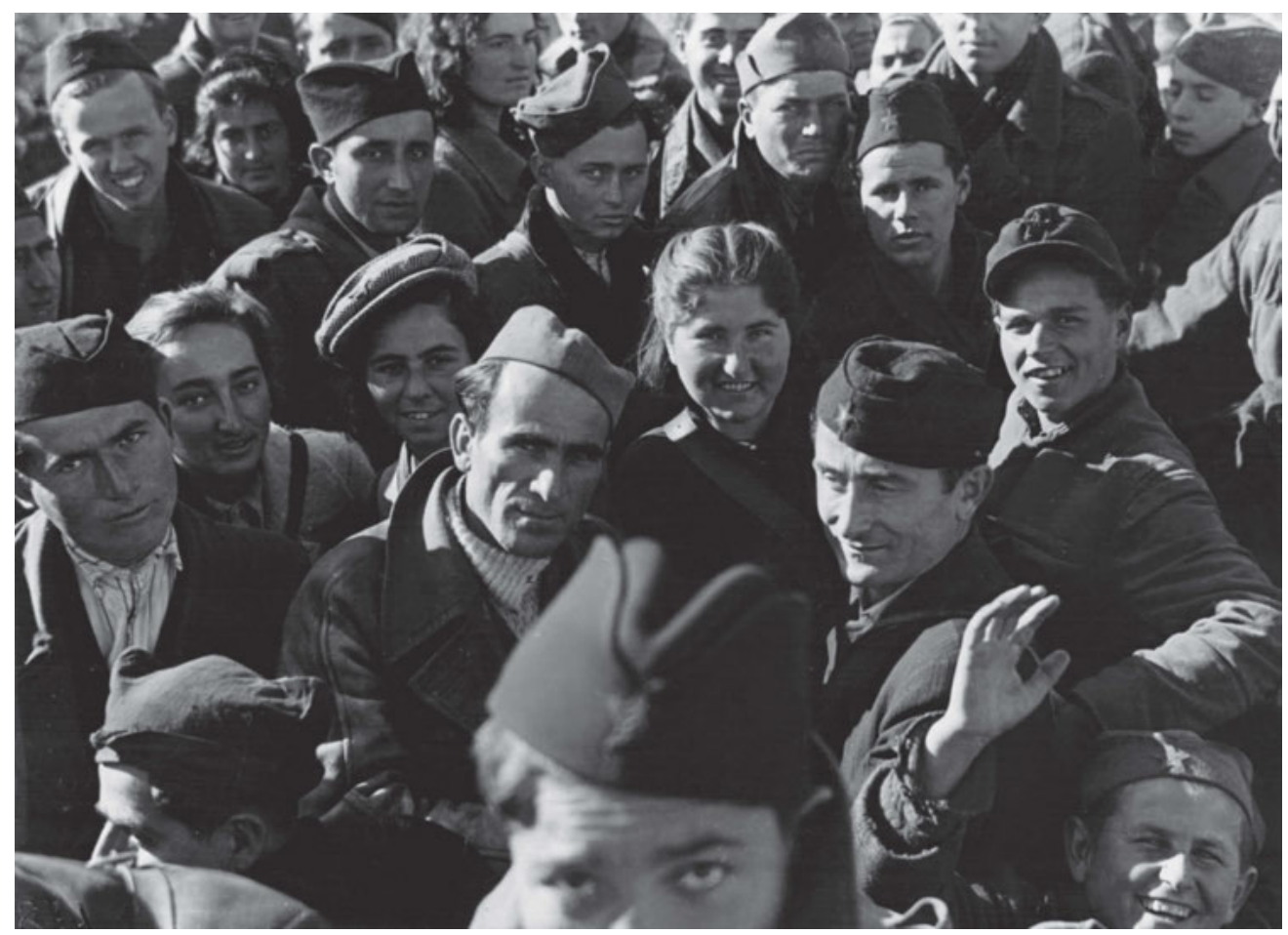

Jugenddelegation der Zweiten Proletarischen Division für den Ersten Kongress des Verbands der Antifaschistischen Jugend Jugoslawiens auf der Straße von Livno nach Glamoč, 22. Dezember 1942. Erste Reihe von rechts nach links: Boško Buha, zweite Reihe: Pavle Bojčević, dritte Reihe: Dragica Djurašević, Grozdana-Zina Belić Penezić, Zaga Stojilović, vierte Reihe: Jurica Ribar, Stana Tomašević. Fotograf unbekannt. Belgrad, Museum Jugoslawiens | III-11983.

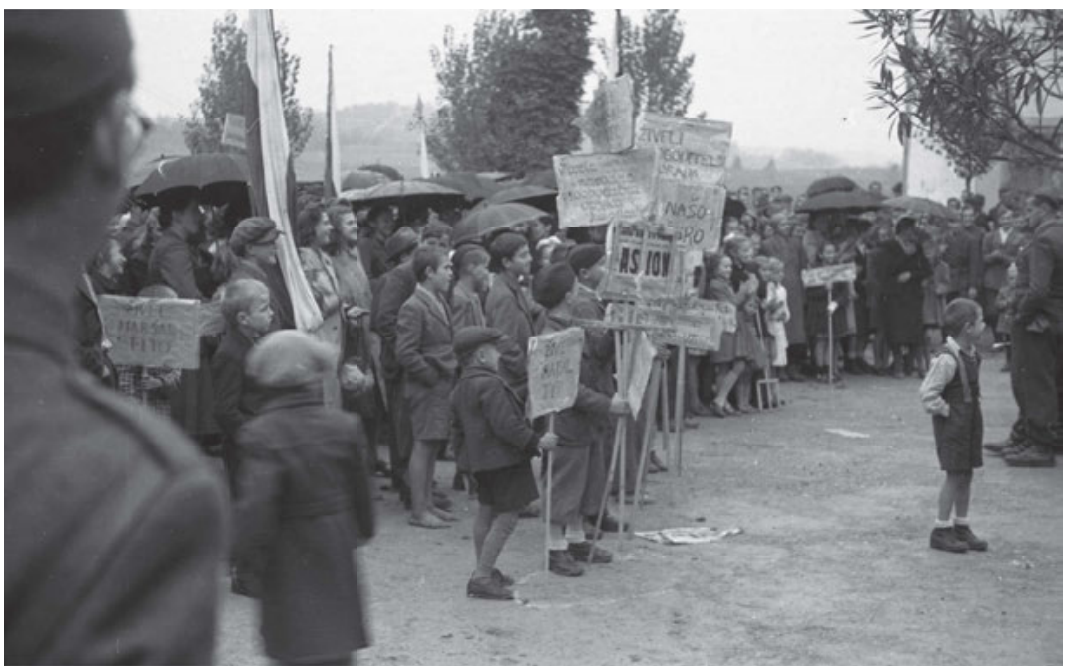

Jugendliche mit Transparenten bei einer Kundgebung, Črnomelj, 22. Oktober 1944.

Foto: Franjo Veselko. Ljubljana, Museum für Neuere Geschichte Sloweniens | TN376/901. 


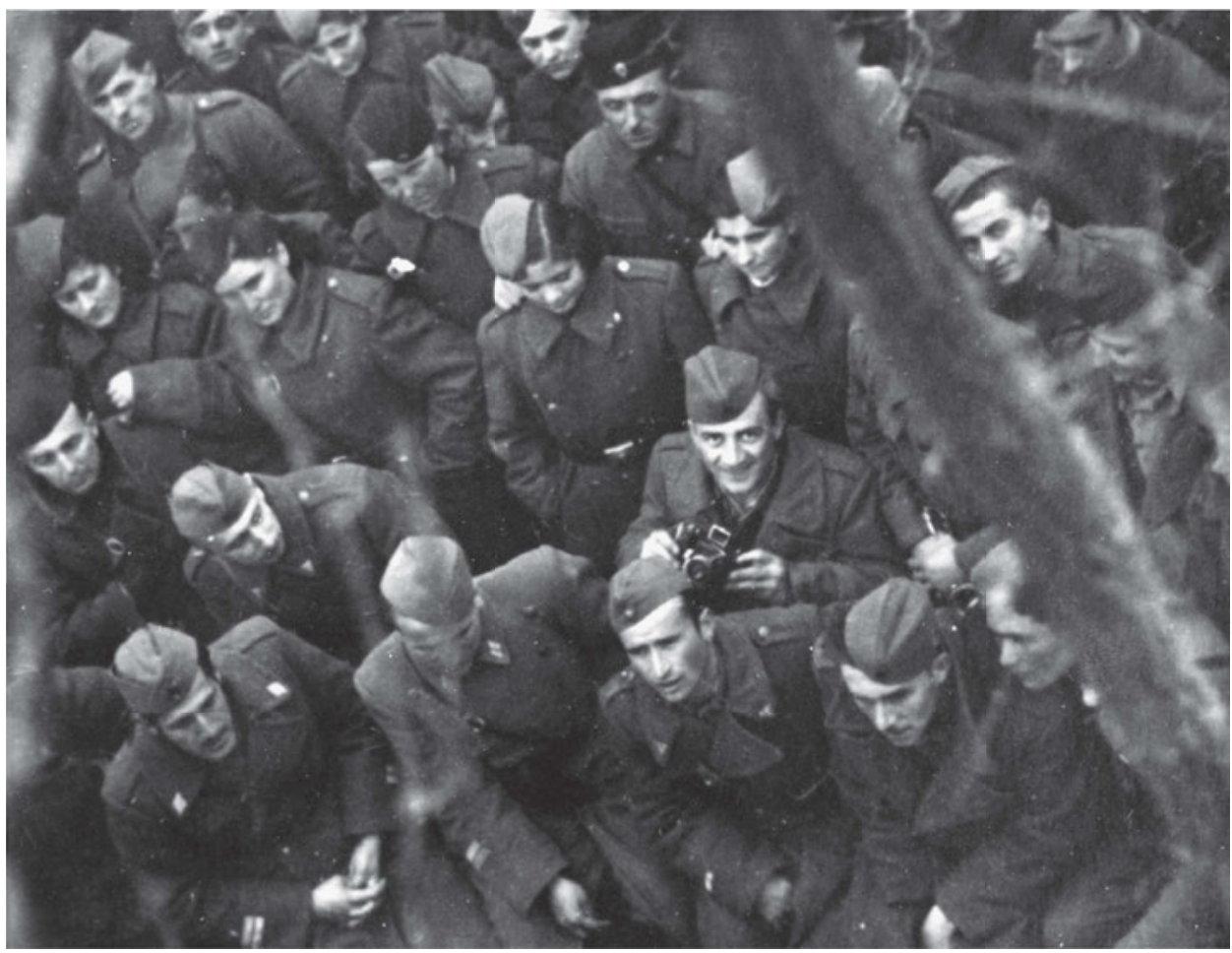

Kundgebung in Banja Luka. Foto: Drago Mažar. Banja Luka, Archiv der Republika Srpska. Ohne Inv.-Nr.

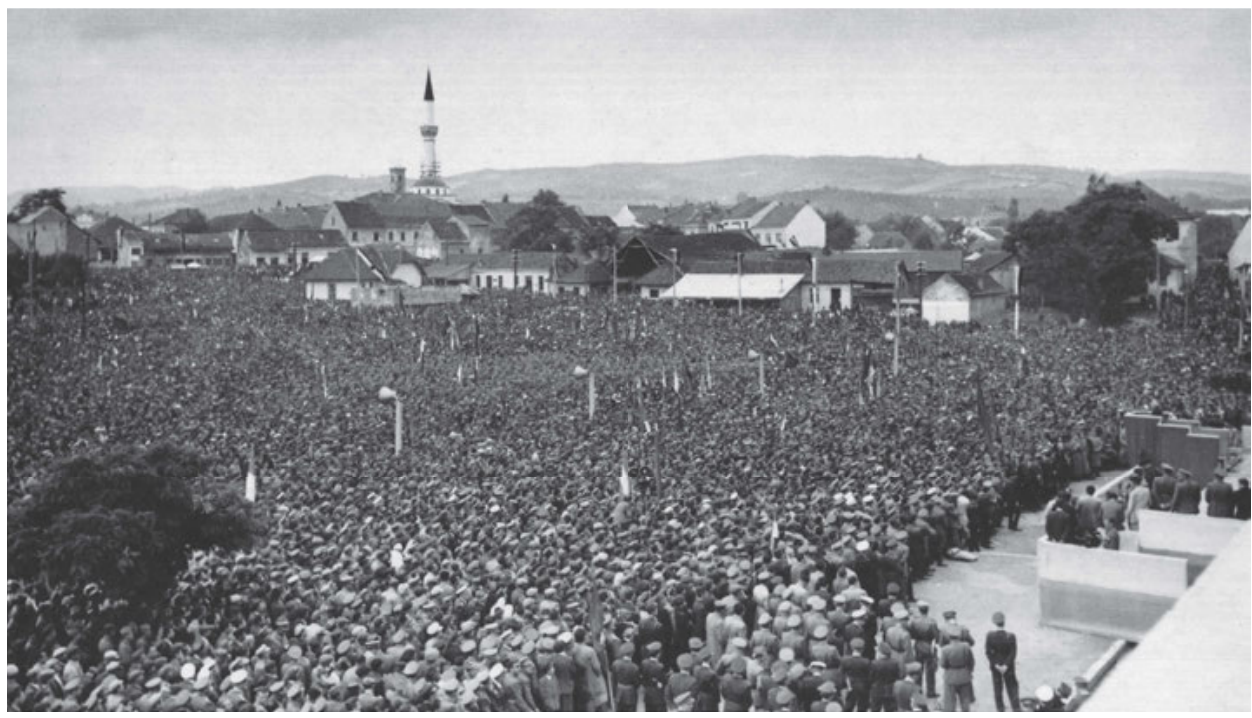

Kulturveranstaltung der Ersten Krajina-Brigade an der Syrmischen Front, Herbst 1944.

Fotograf unbekannt. Sarajevo, Historisches Museum von Bosnien und Herzegowina | FNOB 18826. 


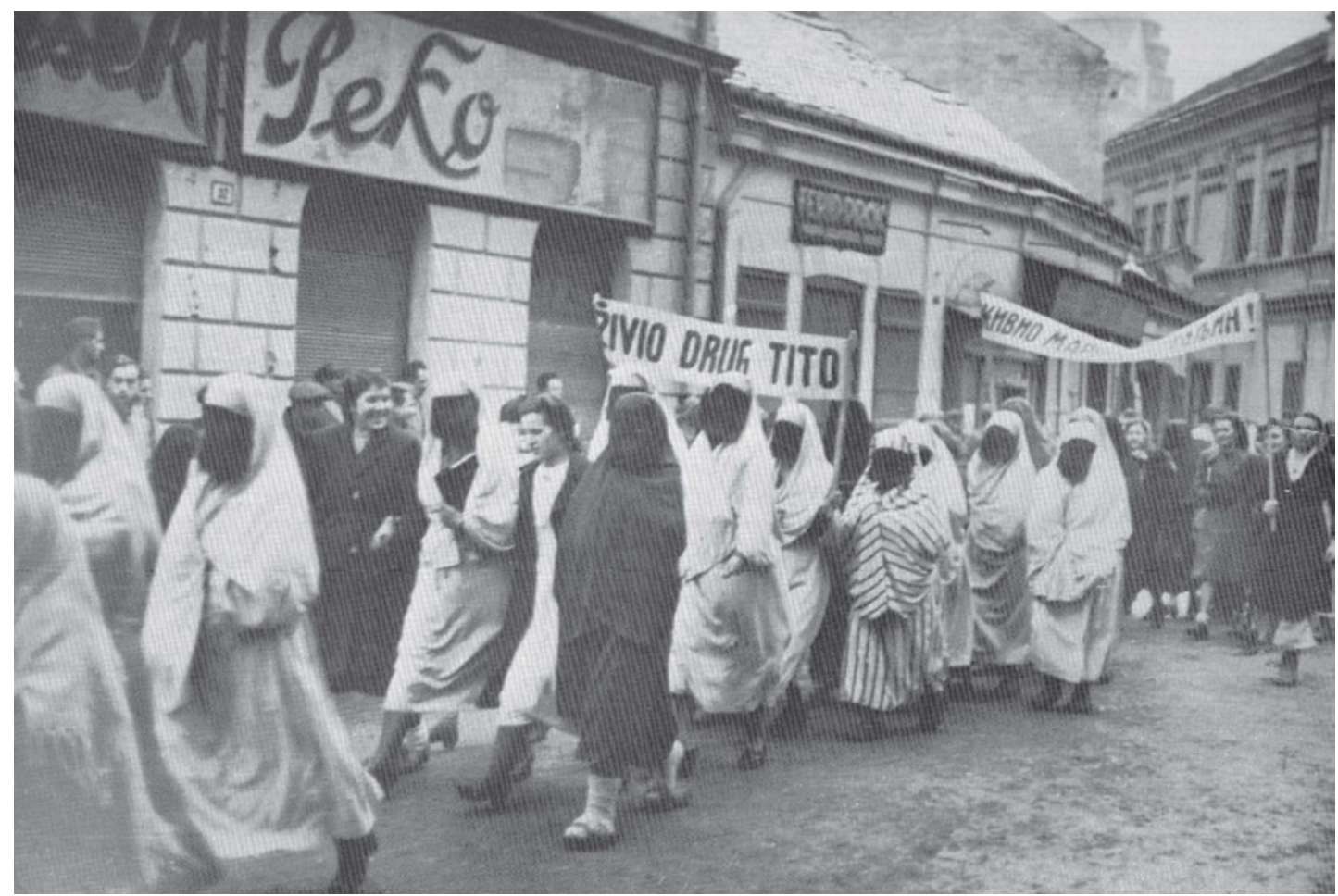

Antifaschistische Kundgebung der Frauen aus Ostbosnien in Tuzla. Foto: Drago Mažar. Banja Luka, Archiv der Republika Srpska. Ohne Inv.-Nr. 


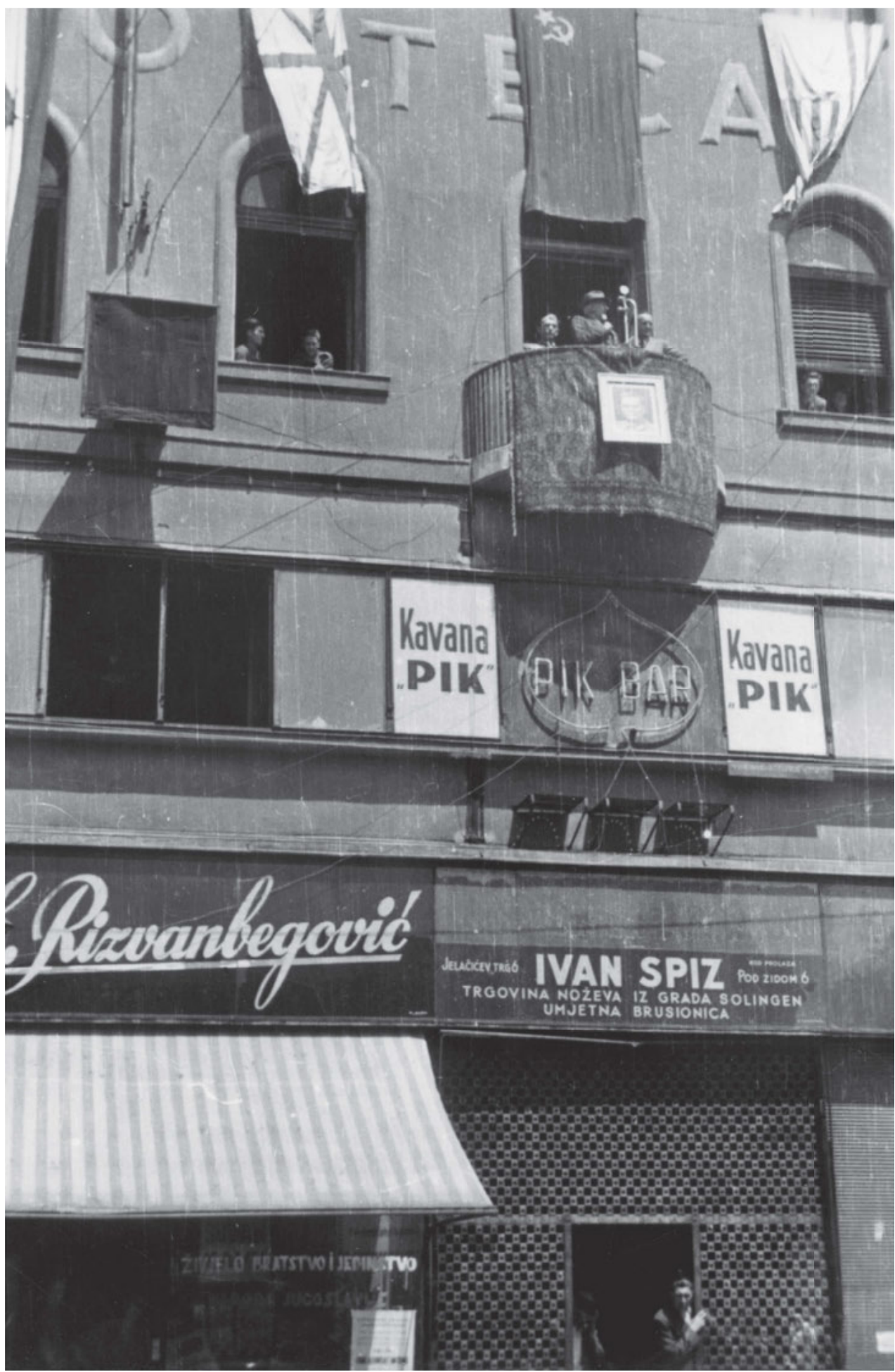

Der Schriftsteller und Partisan Vladimir Nazor wendet sich an die versammelte Bevölkerung vom Balkon eines Hauses am heutigen Ban-Jelačić-Platz in Zagreb. Am Balkon hängt eine Fotografie von Josip Broz Tito, darunter ist der Schriftzug Pik-Bar (Gasthaus Pik) zu lesen. Zagreb, 16. Mai 1945. Foto: Milan Blašković. Zagreb, Kroatisches Historisches Museum | HPM-MRNH-F-2407. 


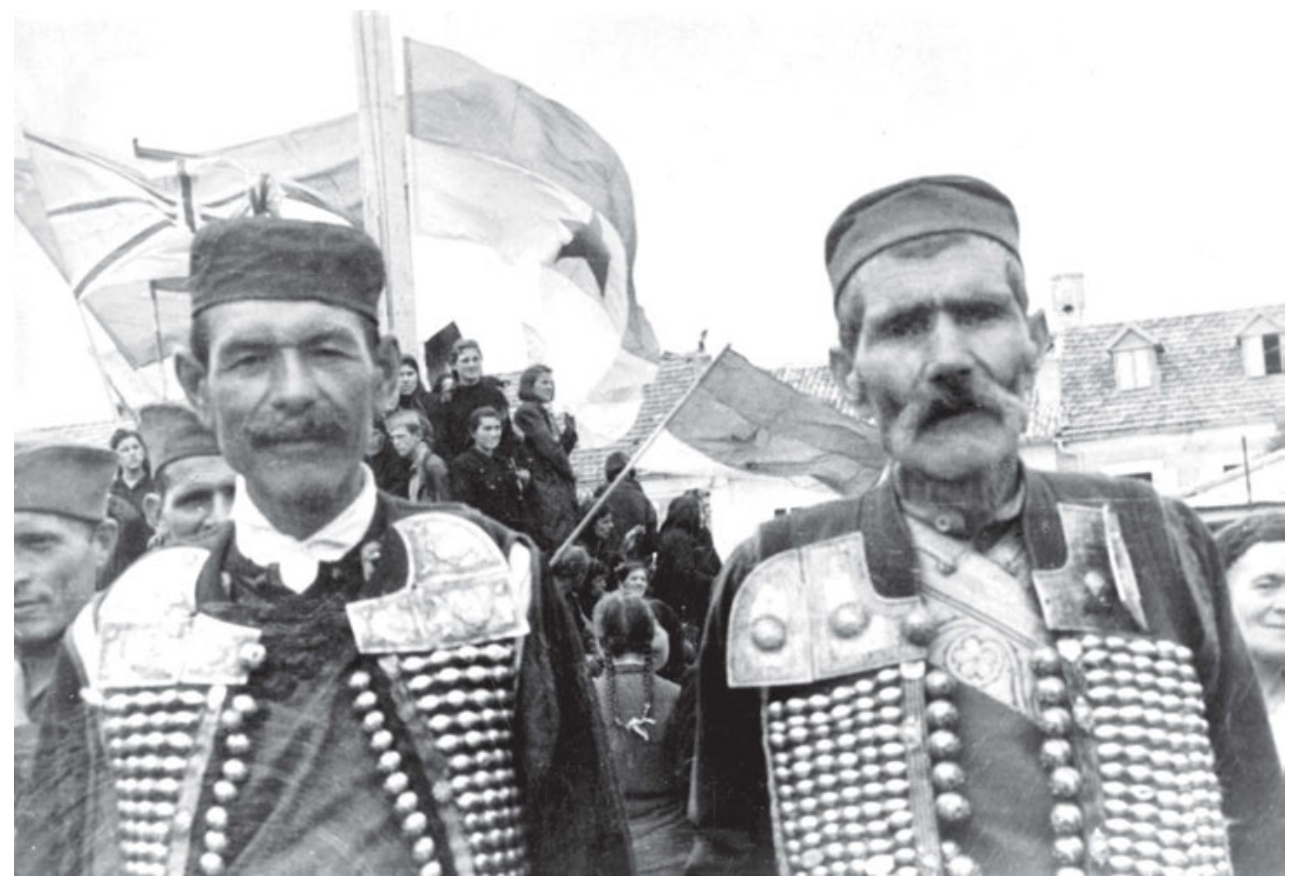

Kriegsveteranen bei den Feierlichkeiten anlässlich der Oktoberrevolution in Nikšić, 1944. Fotograf unbekannt. Belgrad, Militärmuseum | 12683.

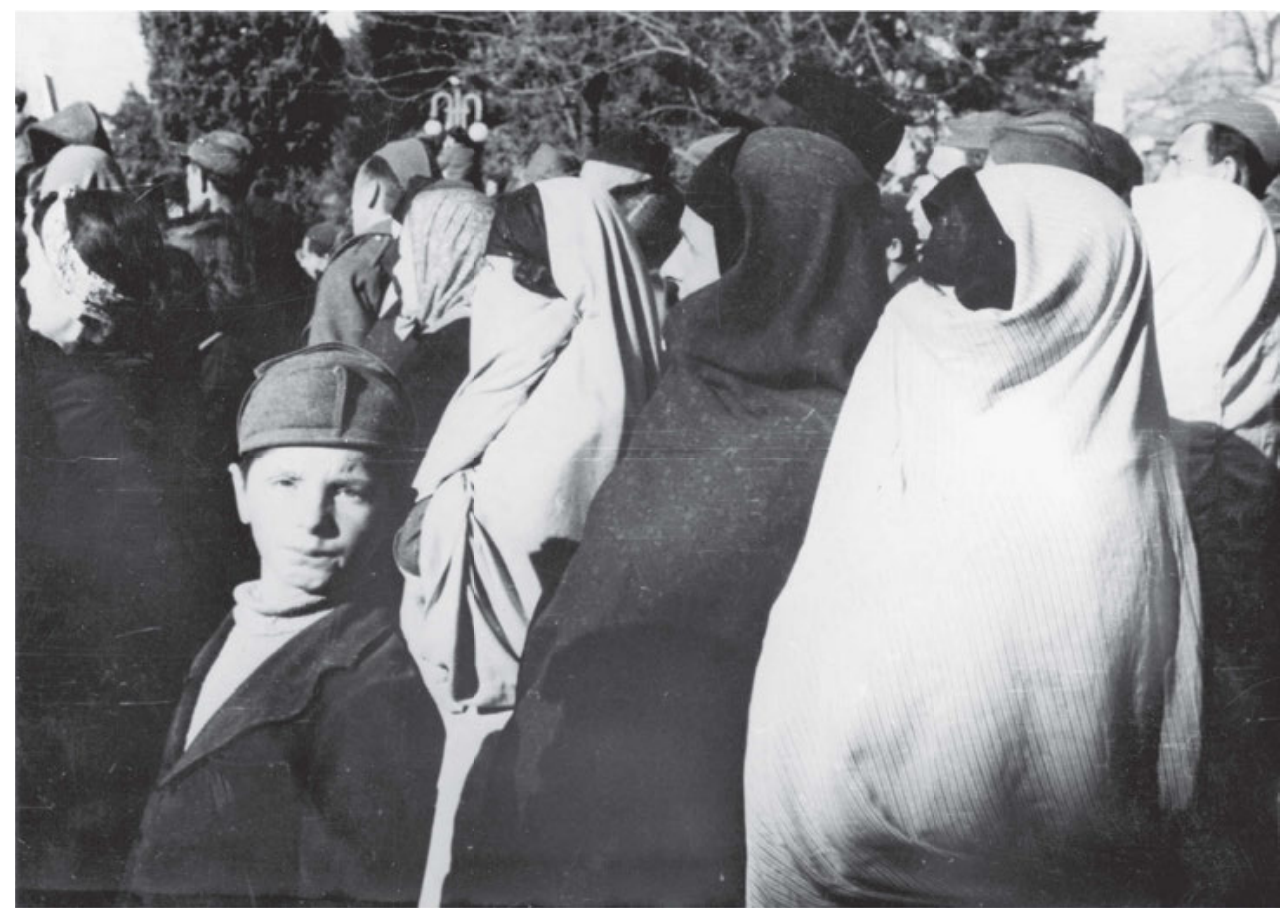

Kundgebung im befreiten Mostar, 16. November 1945. Fotograf unbekannt. Sarajevo, Historisches Museum von Bosnien und Herzegowina | FNOB 11209. 


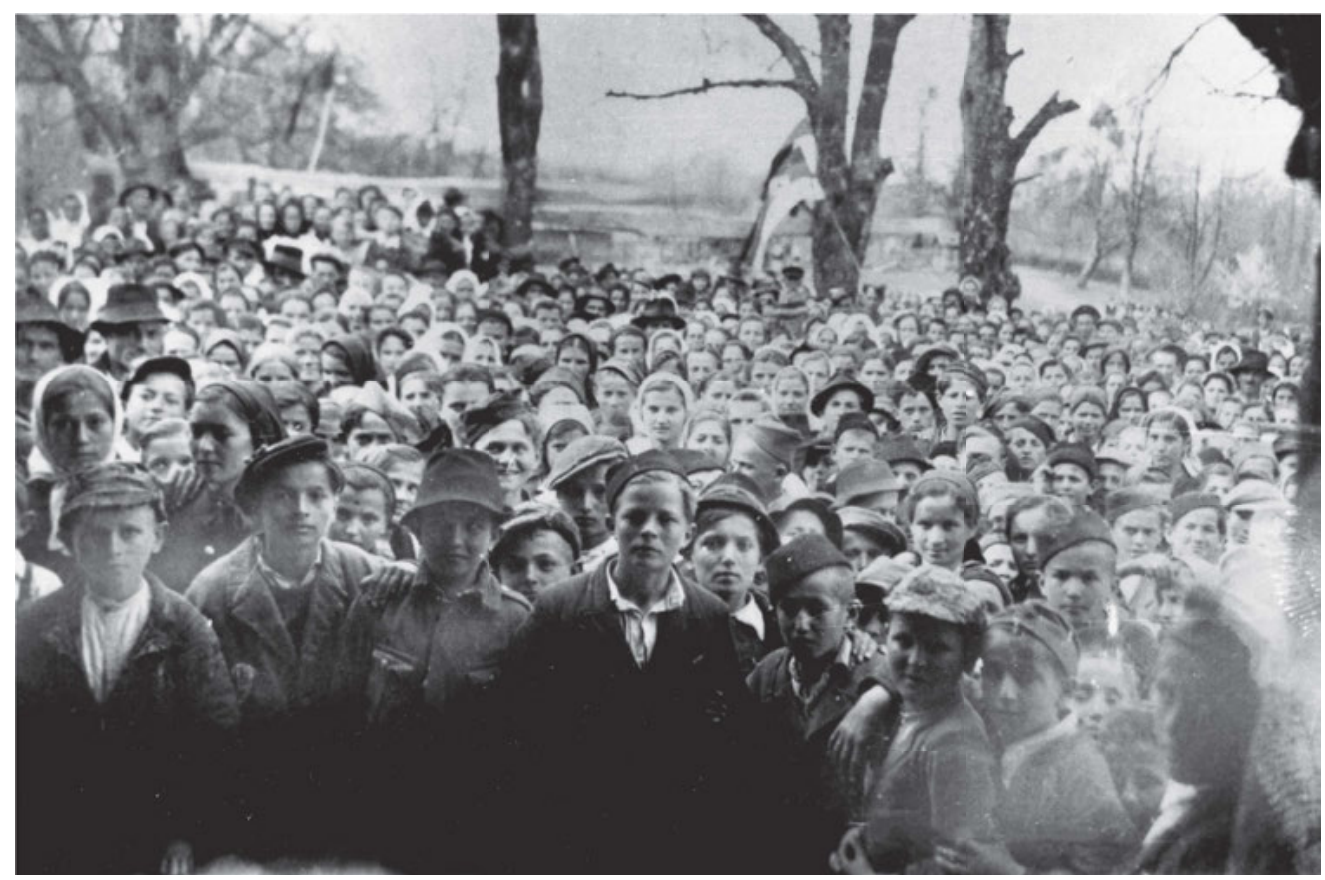

Volksversammlung im Dorf Brekinja in der Umgebung von Bosanska Dubica. Fotograf unbekannt. Sarajevo, Historisches Museum von Bosnien und Herzegowina | FNOB 2982.

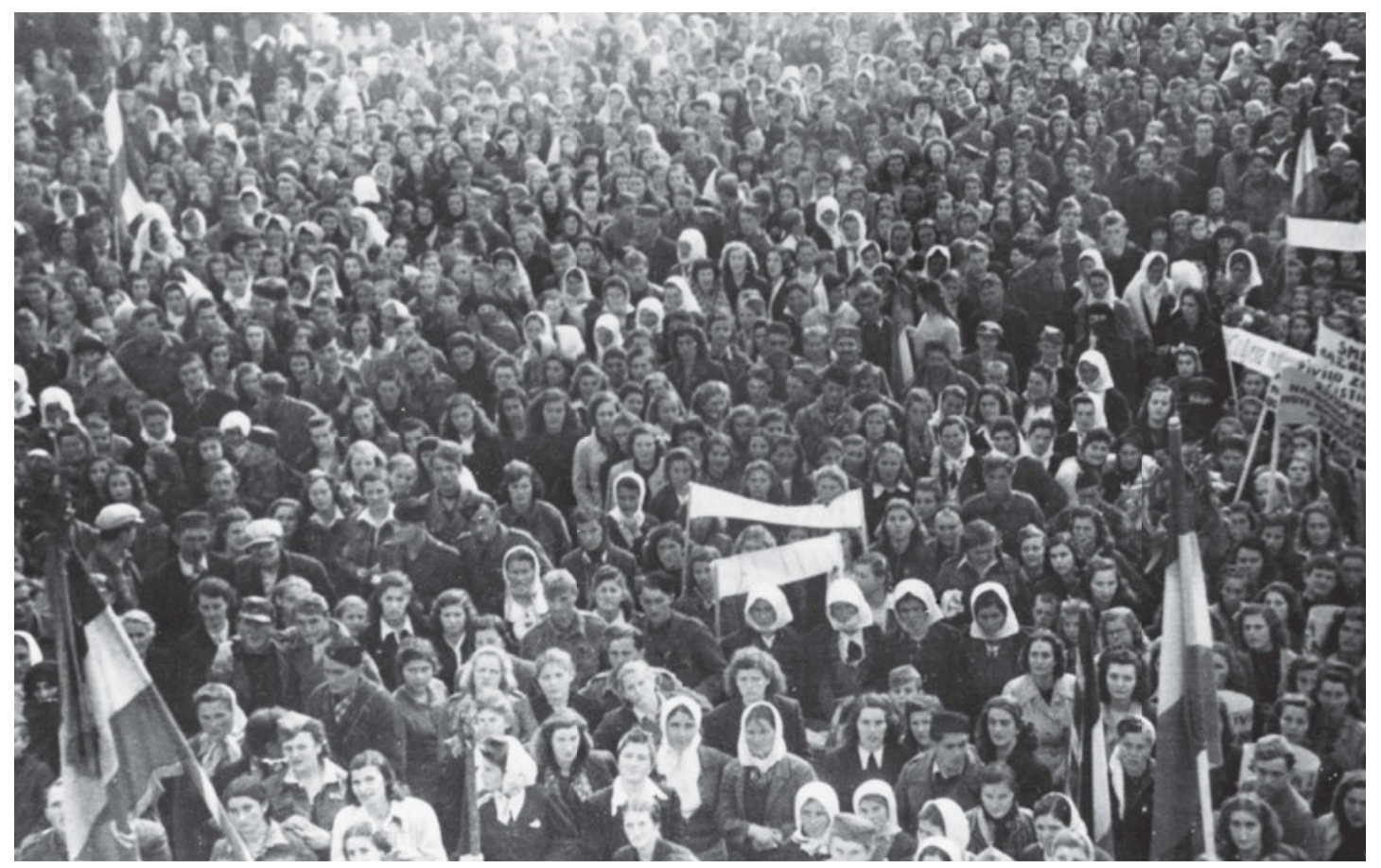

Kundgebung in Trebinje anlässlich des Verbots der Rückkehr von König Petar II. nach Jugoslawien, 1944.

Fotograf unbekannt. Sarajevo, Historisches Museum von Bosnien und Herzegowina | FNOB 19351. 


\section{Graffiti}

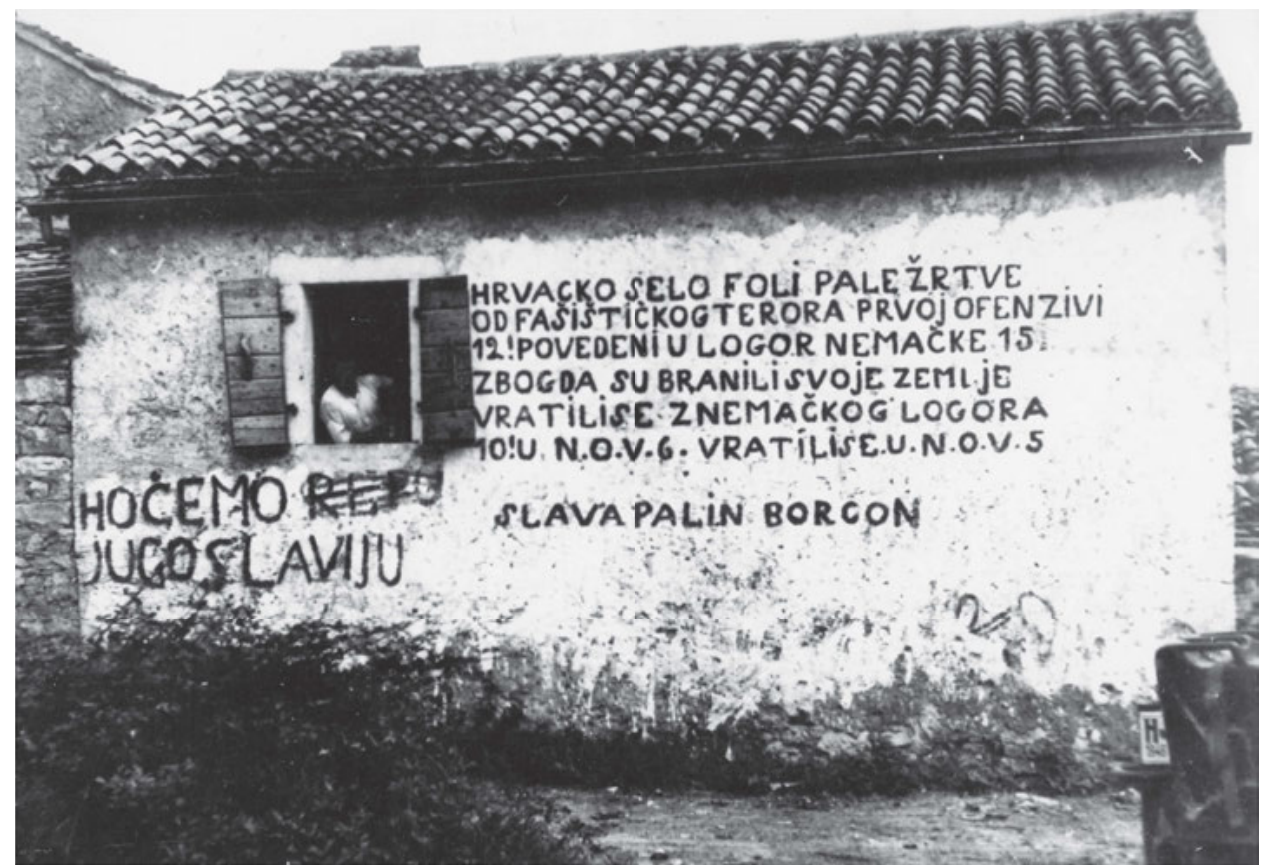

Parolen in einem Dorf in Istrien. Fotograf unbekannt. znaci.net.

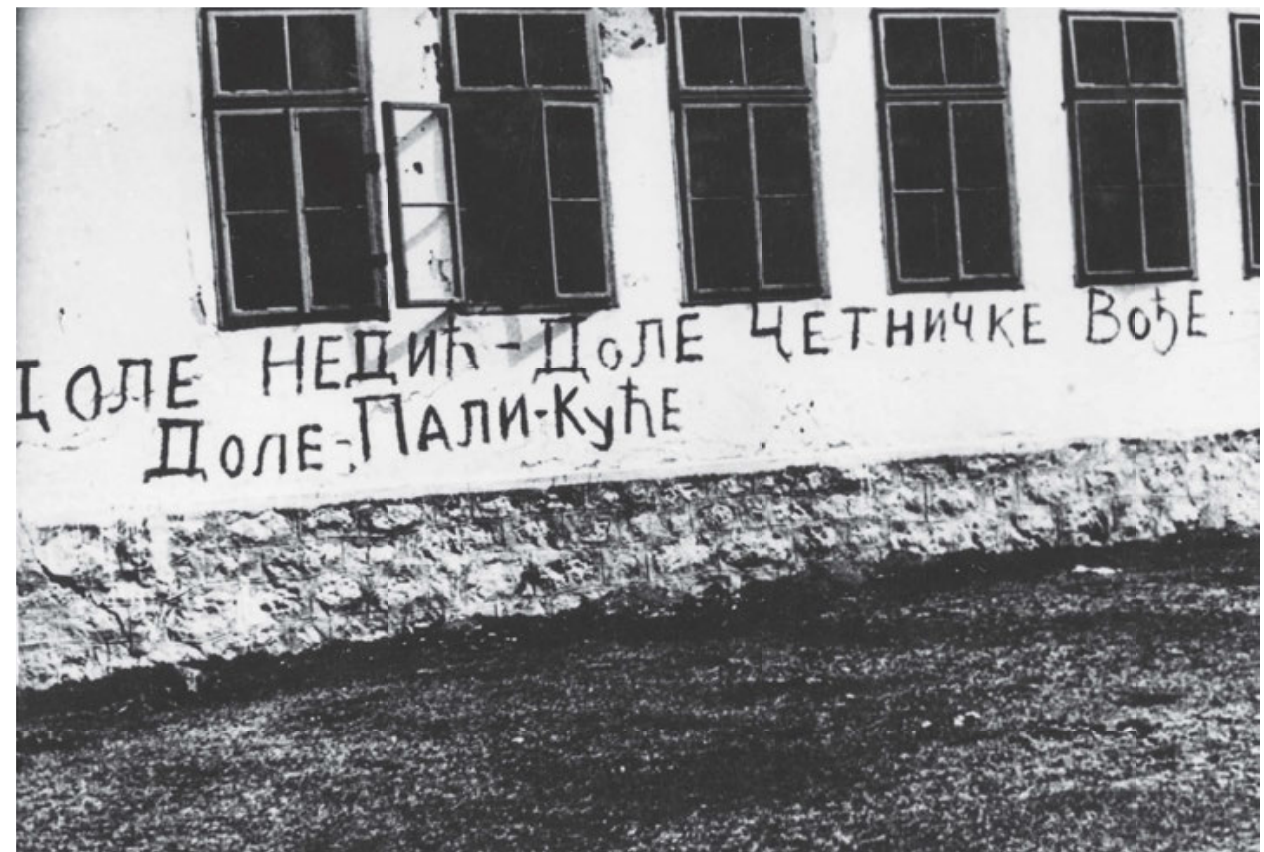

»Nieder mit Nedić - Nieder mit den Tschetnik-Führern - Nieder mit den Brandstiftern«.

Auf der Straße von Sarajevo nach Zvornik. Fotograf unbekannt. Sarajevo, Historisches Museum von Bosnien und Herzegowina | FNOB 38. 


\section{Religionsfreiheit}

Eine besondere Bedeutung kommt heute jenen Fotografien zu, die Einsichten in die Frage der Religionsfreiheit und des Rechts auf Glaubensfreiheit innerhalb der Partisanenbewegung bieten. Diese Aufnahmen belegen, dass sich auch viele Geistliche am Volksbefreiungskampf beteiligt haben. So zeigen die Fotografien Aktivitäten der Geistlichen, die der Partisanenbewegung beigetreten sind oder sie unterstützt haben: Kirchenfeiertage, Messen, Salbungen, Religionsunterricht, Segnung von Partisanenfahnen, Aufstellen von religiösen Symbolen sowie andere religiöse Handlungen. Bei zahlreichen Begräbnissen der Partisanen wurden zudem kirchliche Totenmessen zelebriert, etwa bei der Bestattung von 27 Partisanen, die am 12. und 13. September 1943 als Verwundete im Krankenhaus in Otočac von den Ustascha ermordet wurden. Bei ihrem Begräbnis hielt der Geistliche Grga Starčević die Totenmesse.

Als bereits offensichtlich war, dass es zum Großen Krieg kommen würde, veröffentlichte Josip Broz Tito 1936 in der Zeitung Proleter (Proletarier), dem Organ des Zentralkomitees der Kommunistischen Partei Jugoslawiens, den Artikel Komunisti i katolici (Kommunisten und Katholiken), in dem er sich auf den Beschluss der Kommunistischen Internationale über die Gründung einer gemeinsamen antifaschistischen Front stützte und zu folgendem Schluss gelangte:

»Ohne jene Dinge außer Acht zu lassen, die uns trennen, müssen wir nach Dingen suchen, die uns ihnen [den Katholiken - Anmerkung D. K.] näherbringen. Näherbringen kann uns vor allem der gemeinsame Kampf um das tägliche Brot. Der gemeinsame Kampf für Frieden und Freiheit, gegen den Krieg und den Faschismus. Der gemeinsame Kampf für die Gleichberechtigung und Freiheit des kroatischen und slowenischen Volkes. Der gemeinsame Kampf gegen die am 6. Januar eingesetzten faschistischen Gruppierungen, die nicht nur Kommunisten, sondern auch katholische Kirchenoberhäupter und Organisationen verfolgt und eingesperrt haben. Der Kampf um ein menschenwürdiges Leben. Angesichts der Gefahr der höllischen Gewalt des Krieges und des Faschismus lasst uns die Hände reichen, um gemeinsam den Frieden und das Wohlergehen der gesamten Menschheit zu verteidigen. « ${ }^{1}$

Das Schlüsseldokument für die Einführung der Gottesdienste in den Partisaneneinheiten war der Befehl des Oberkommandos, der am 23. Juni 1942 an die Stäbe der Proletarierbrigaden über die Einsetzung von Referenten für Religionsfragen erging. In der Zuständigkeit

1 Broz, Josip Tito. Komunisti i katolici. In: Proleter, 1936. 
der Referenten lag die Führung der Bücher mit den Namen der gefallenen und verstorbenen Kameraden, aber auch die Popularisierung des Volksbefreiungskampfes und das Abhalten von kirchlichen Ritualen, wenn dies vom Volk gewünscht war.

Eine der angesehensten Persönlichkeiten der Partisanenbewegung war der orthodoxe Priester Vlada Zečević. Er schloss sich den Partisanen an, nachdem die Tschetniks begonnen hatten, mit der deutschen Wehrmacht zusammenzuarbeiten. Der überwiegende Teil der orthodoxen Geistlichen in Montenegro hatte sich wiederum von Beginn an auf die Seite der Partisanen geschlagen. ${ }^{2}$ Eine herausragende Rolle in Kroatien kam dem katholischen Geistlichen Svetozar Rittig zu, der vor dem Krieg als Pfarrer der Kirche des Heiligen Markus in Zagreb tätig war und bereits seit 1929 Ante Pavelić scharf kritisierte. Nach der Ausrufung des Unabhängigen Staates Kroatien begab sich Rittig nach Novi Vinodolski und anschließend auf die Insel Krk, wo er den dortigen Bischof um die Beistellung von zwei jungen Geistlichen ersuchte, um mit ihnen auf dem befreiten Territorium Gottesdienste abhalten zu können. Der Bischof von Krk lehnte seine Bitte ab, doch Rittig folgte gleichwohl den Partisanen, in deren Reihen sich insgesamt 147 katholische Priester befanden.

Im Hinblick auf Glaubensfreiheiten stellte sich die Situation in Mazedonien besonders interessant dar. Der Republikstab hatte einen Referenten für Religionsfragen installiert und auf dem befreiten Territorium fand im Juli 1943 eine Versammlung der orthodoxen Priester sowie die Feier zu Ehren des Heiligen Sava statt, auf der die Autokephalie von der SerbischOrthodoxen Kirche gefordert wurde.

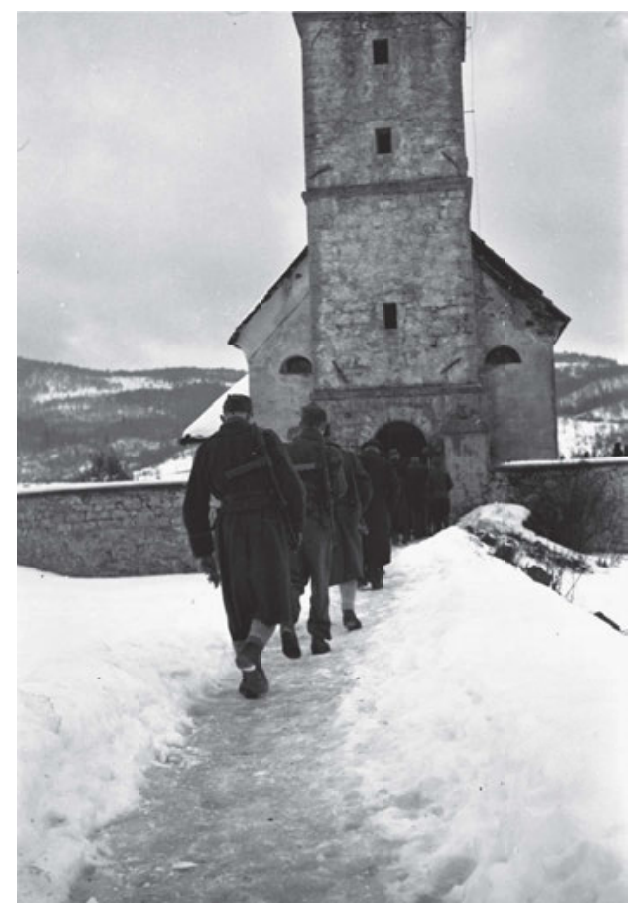

Partisanen auf dem Weg in die Kirche in Babno Polje, 1945. Foto: Edi Šelhaus. Ljubljana, Museum für Neuere Geschichte Sloweniens | TN964/1. 


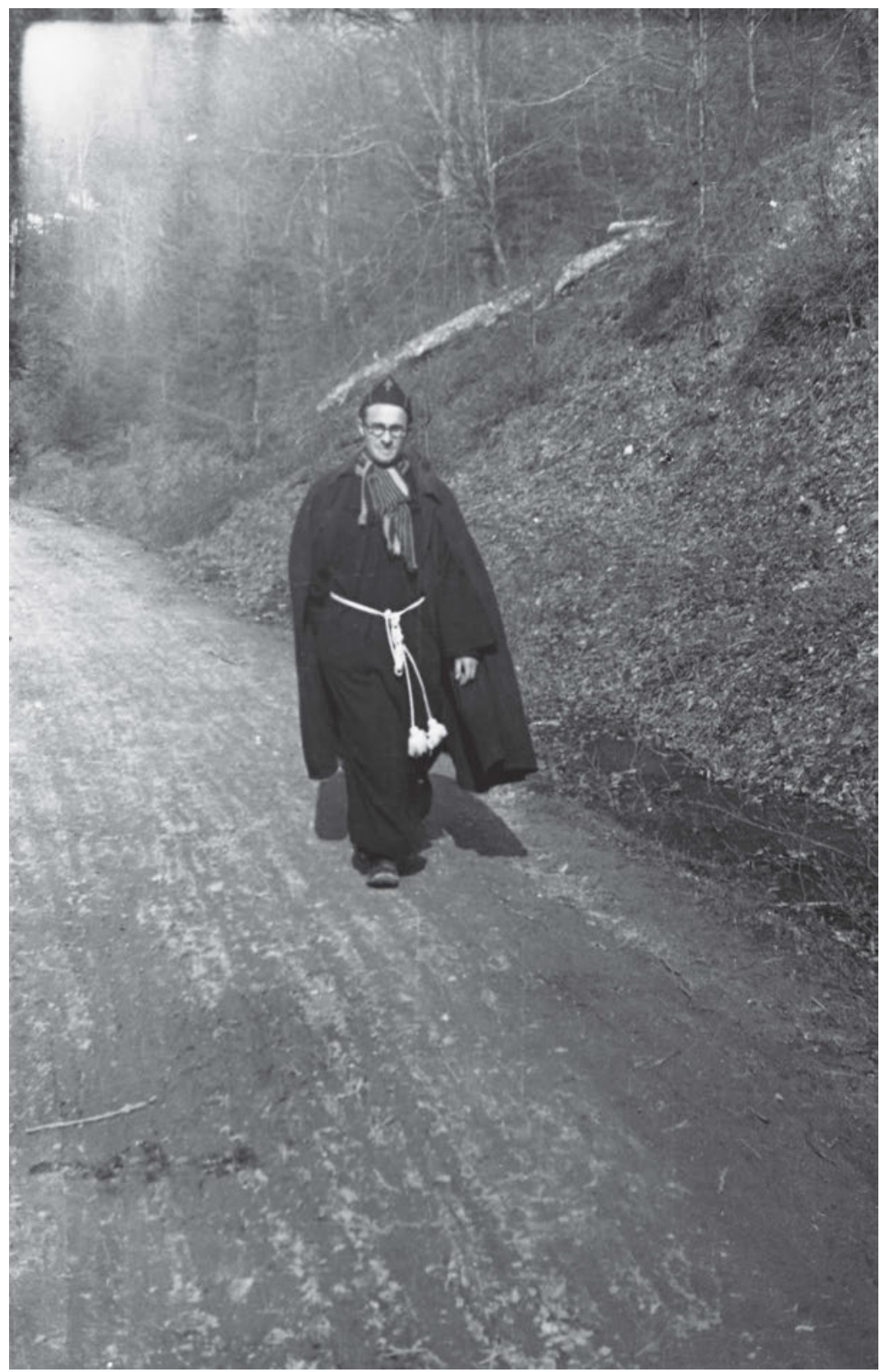

Partisanenfrater in Slawonien, 1943. Foto: Pero Dragila. Zagreb, Kroatisches Historisches Museum | HPM-100545/8. 


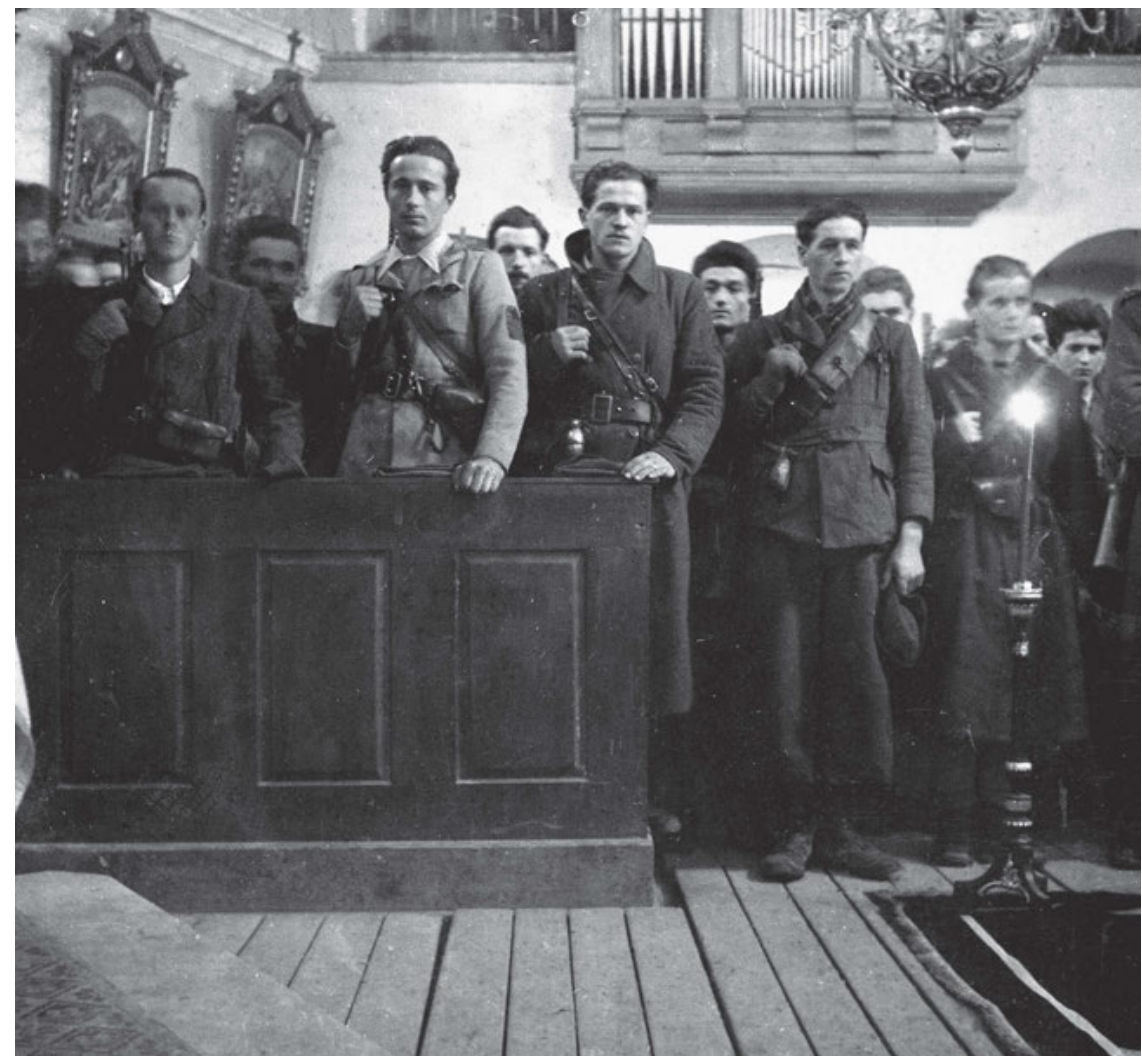

Partisanen in einer Kirche. Zweiter von rechts: Oberst Ivan Gošnak.

Foto: Mirko Trobec. Ljubljana, Museum für Neuere Geschichte Sloweniens | T/31.

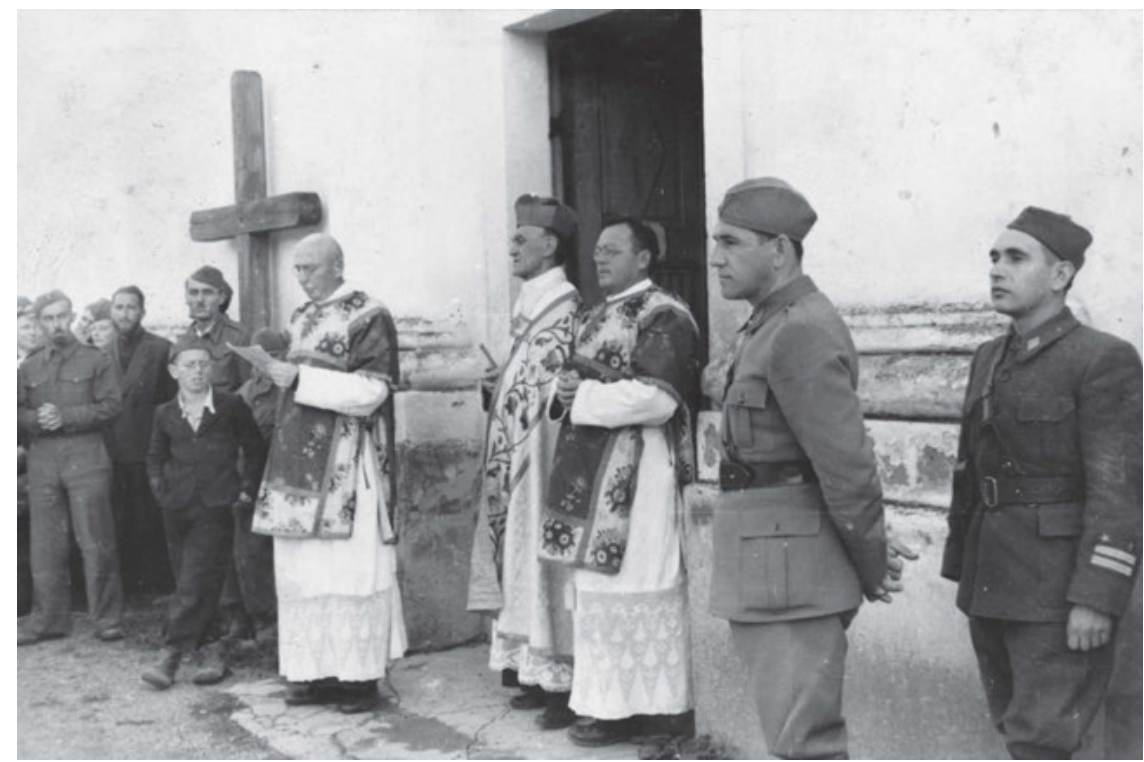

Monseigneur Svetozar Rittig zelebriert die Messe anlässlich der Befreiung Belgrads. Topusko, Oktober 1944. Foto: Fotodienst des Antifaschistischen Landesrats der Volksbefreiung Kroatiens. Zagreb, Kroatisches Historisches Museum | HPM-MRNH-A-2602_f8_21a_s. 


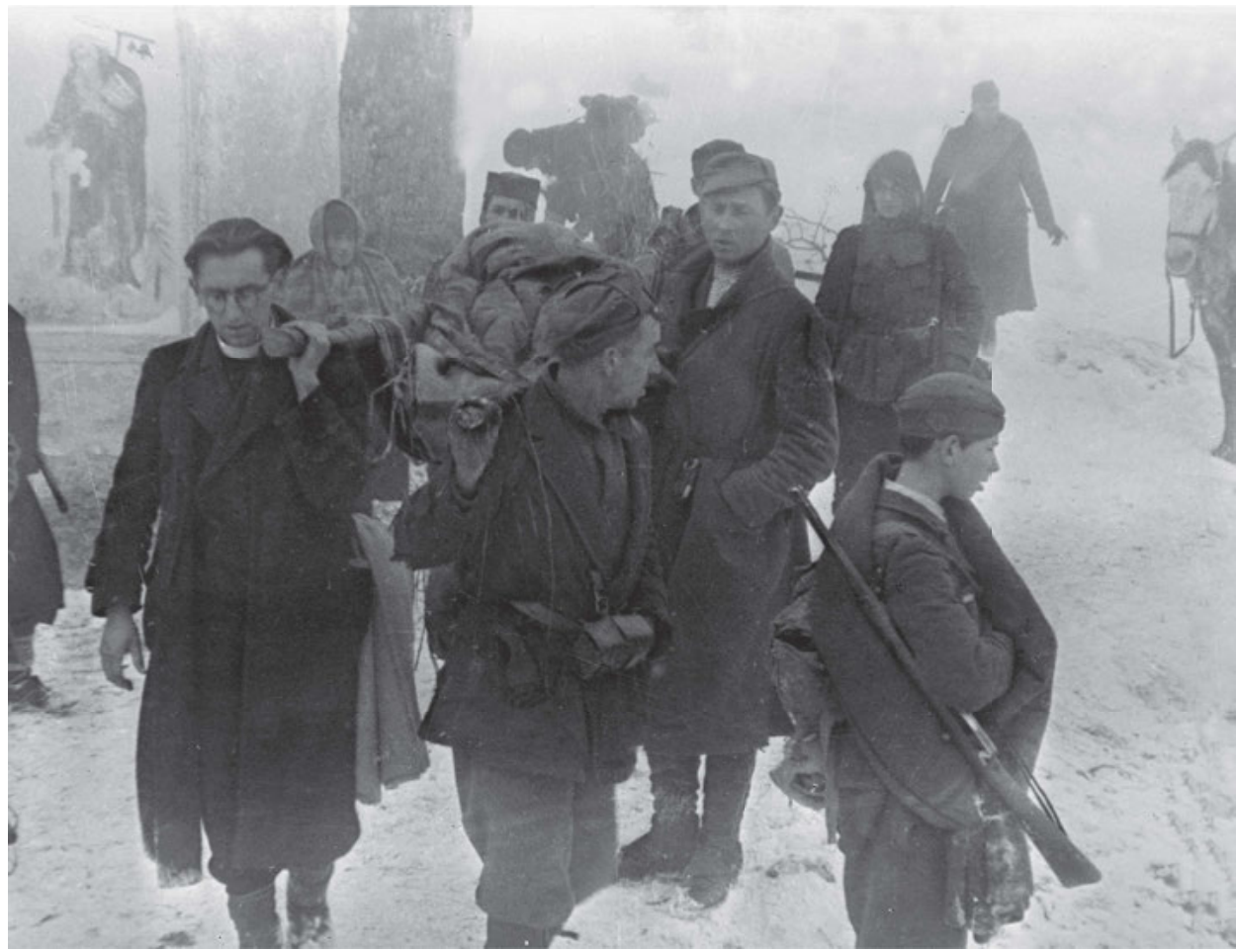

Tragen der Verwundeten der 14. Division. Der erste von links ist der Divisionsreferent für Religionsfragen Jože Lampret. Foto: Jože Petek. Ljubljana, Museum für Neuere Geschichte Sloweniens | 1734.

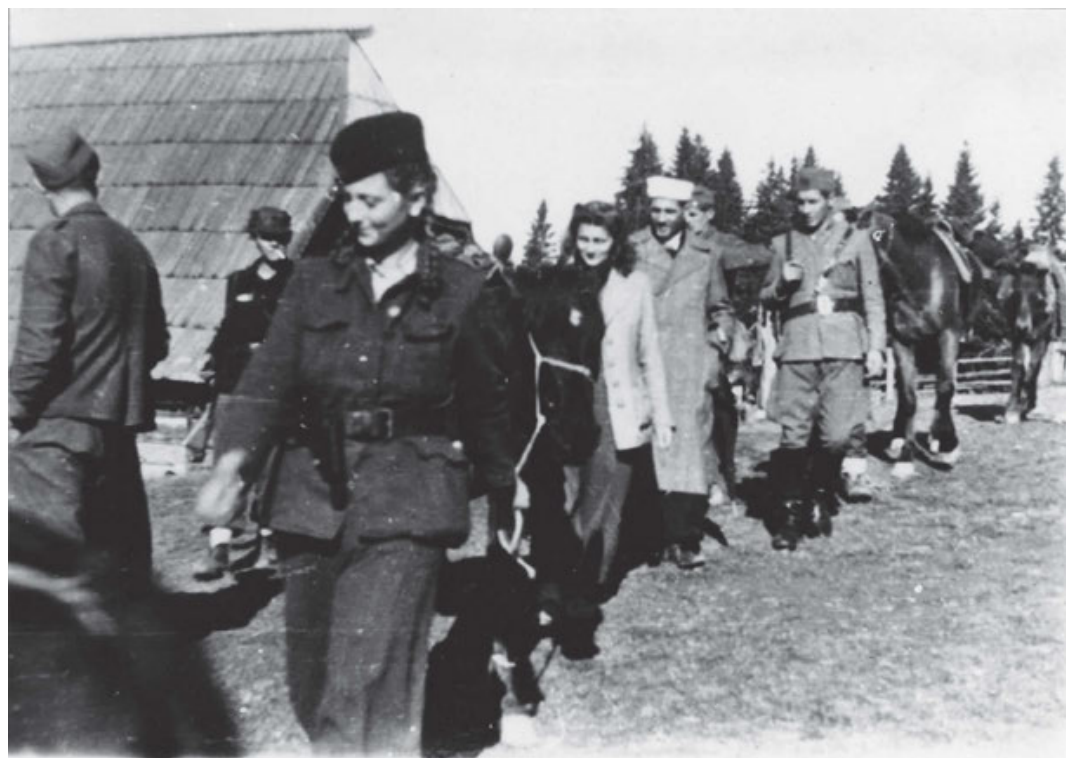

Der erste muslimische Hodscha aus Kotor-Varoš bei den Partisanen. Er verstarb 1943 beim Marsch der Partisaneneinheiten aus Jajce. Foto aus dem Album von Albert Trimki. Sarajevo, Historisches Museum von Bosnien und Herzegowina | FNOB 19545. 


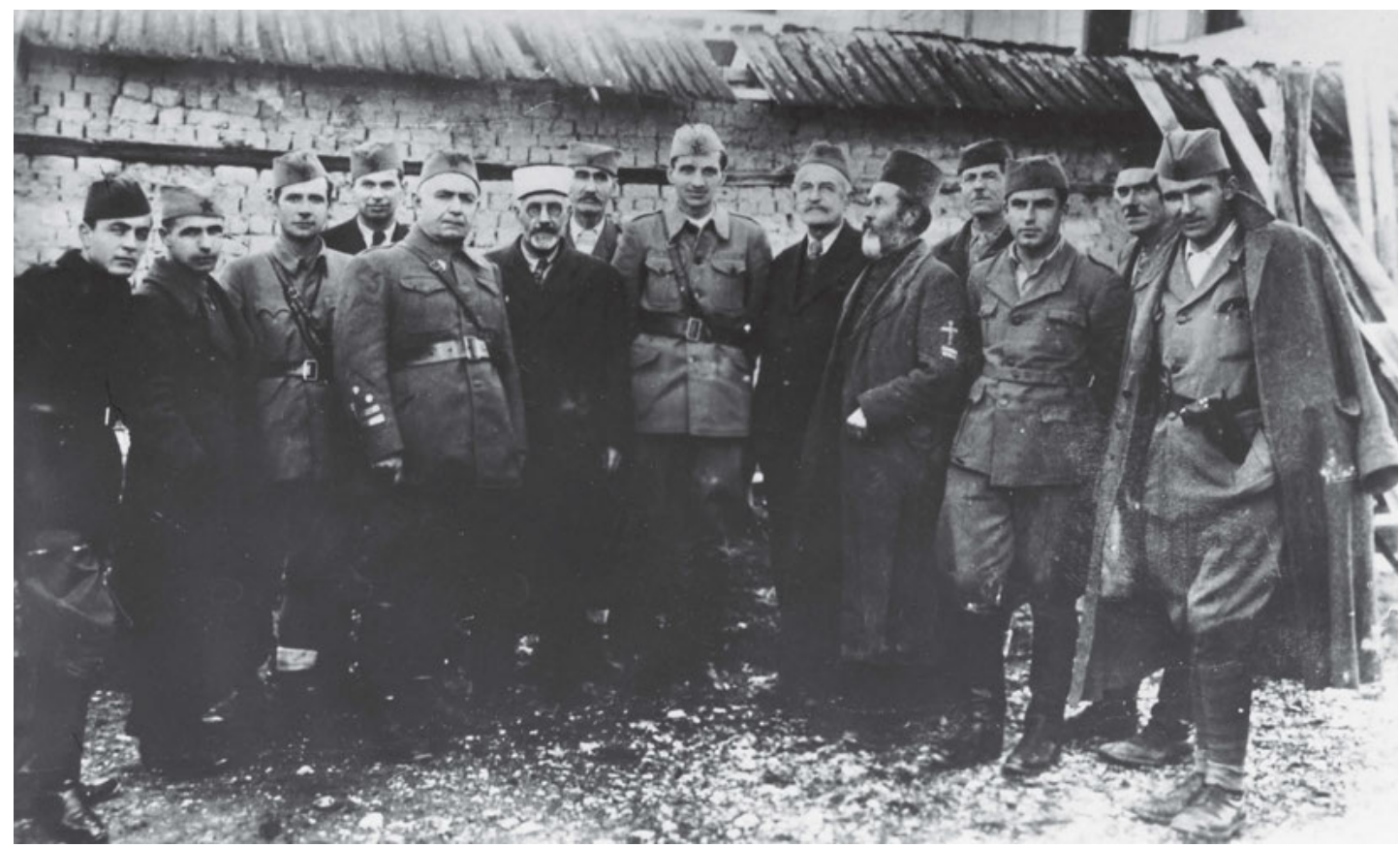

Hauptstab der Volksbefreiungsbewegung für den Sandžak und Exekutivrat des Antifaschistischen Rats der Volksbefreiung Sandžak, November 1943. Fotograf unbekannt. Institut der Arbeiterbewegung Serbiens | znaci.net.

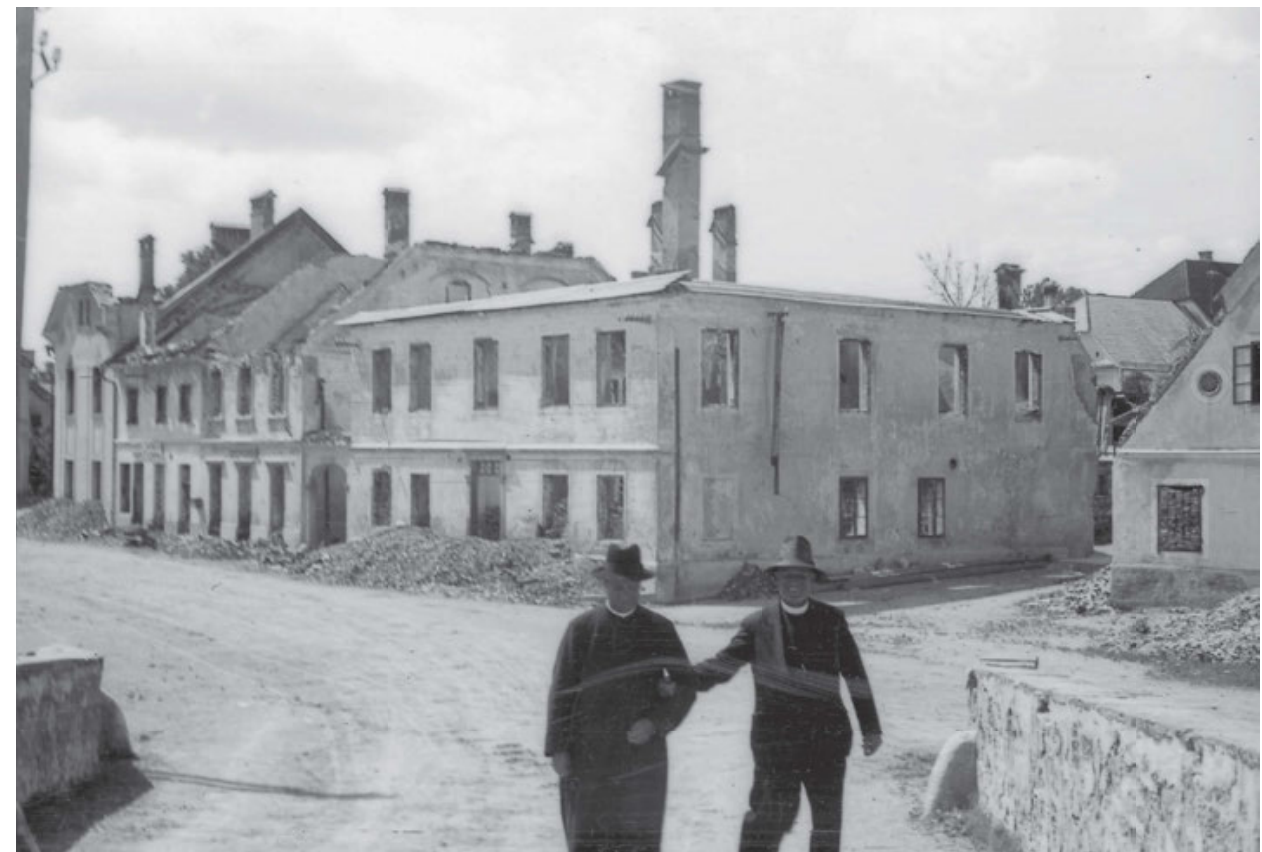

Gläubige vor dem zerstörten Hotel Žumer in Cerknica, 1944. Foto: Vinko Bavec. Ljubljana Museum für Neuere Geschichte Sloweniens | TN173/15. 


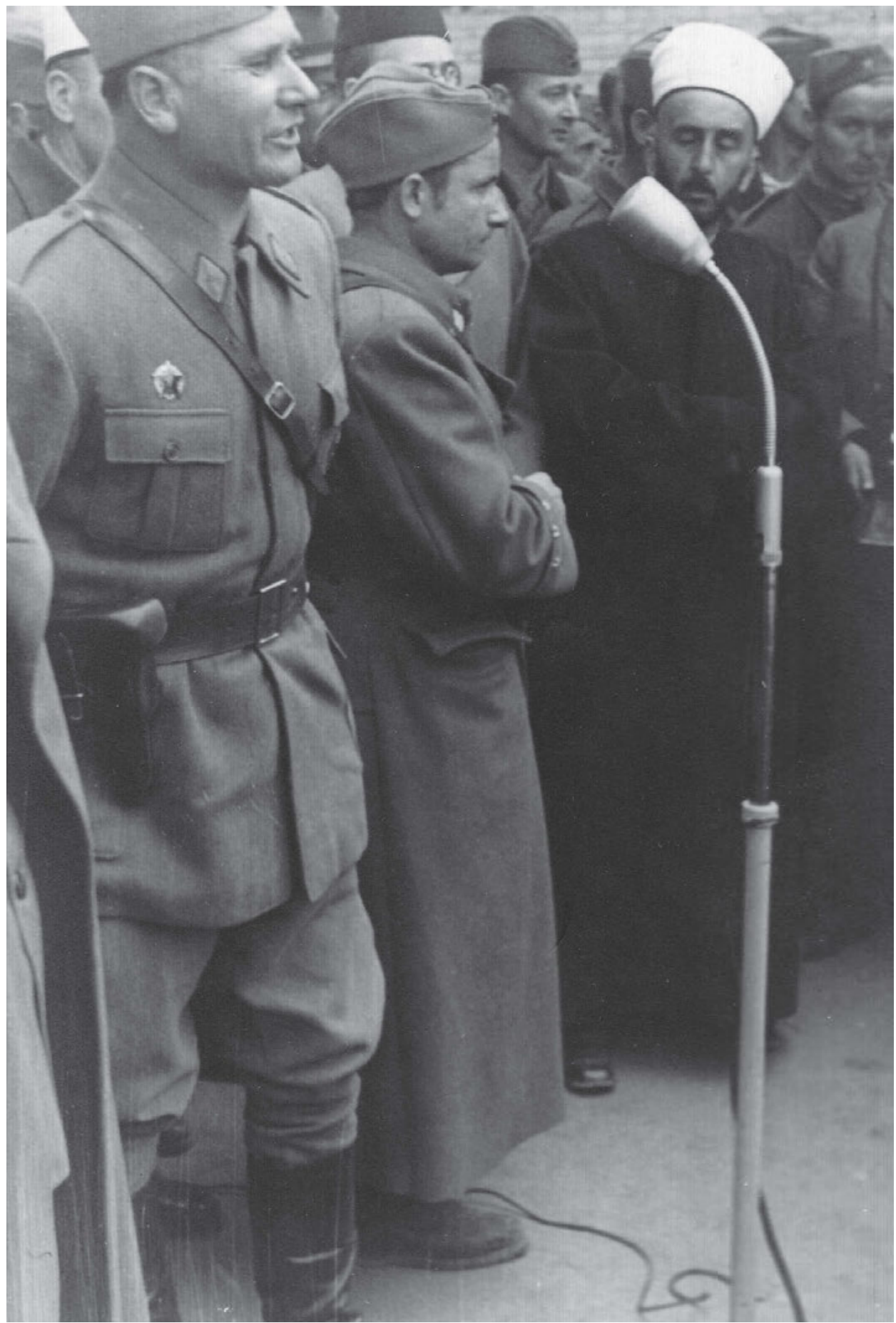

Ohne Angaben. Foto: Drago Mažar. Banja Luka, Archiv der Republika Srpska. Ohne Inv.-Nr. 


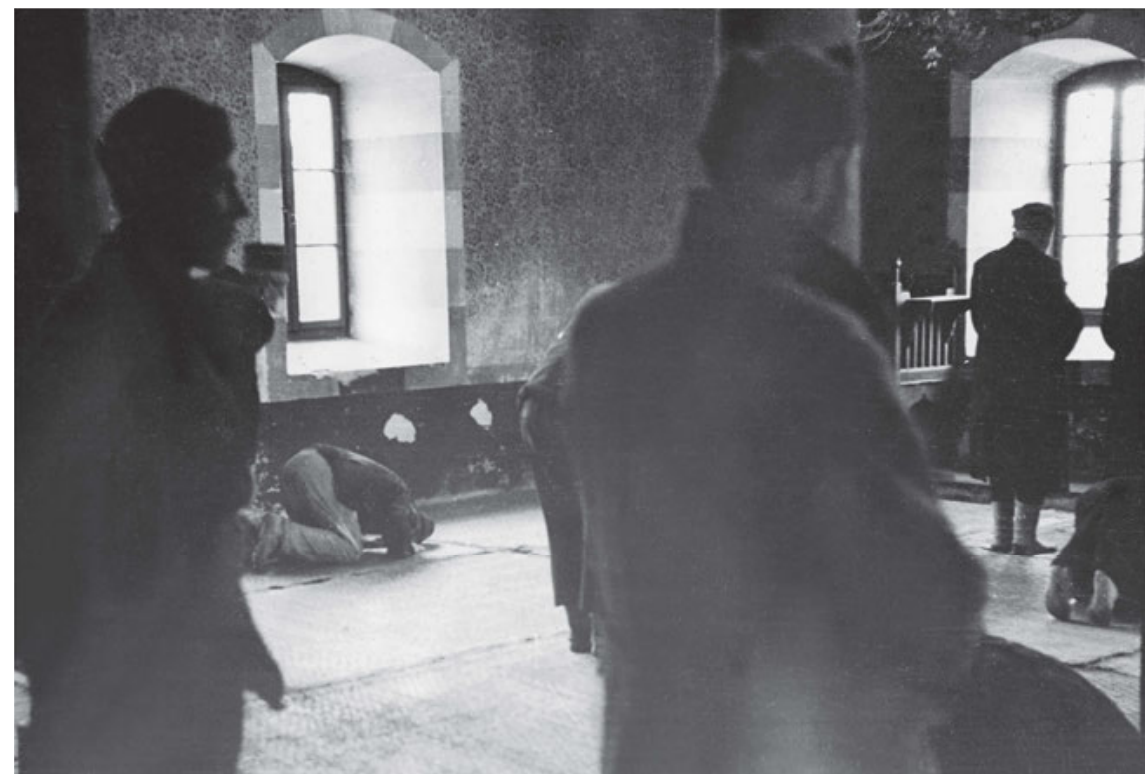

Gebet in einer Moschee, Mrkonjić Grad, 1943. Belgrad, Museum Jugoslawiens | III-1780.

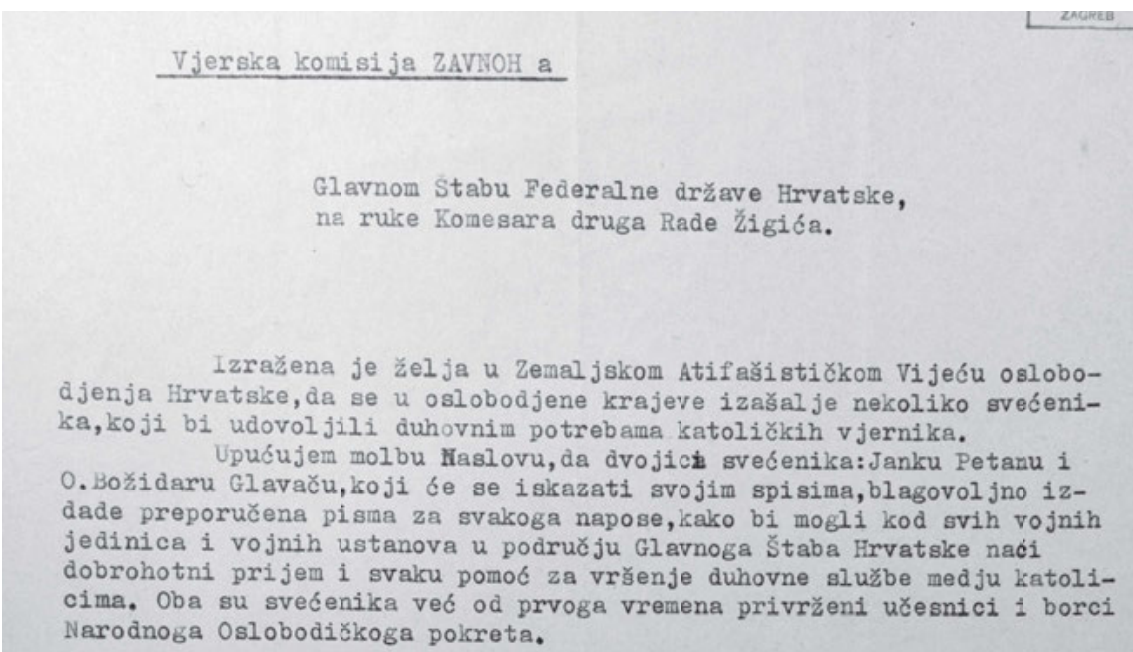

10.III.1945.

predsjednik:

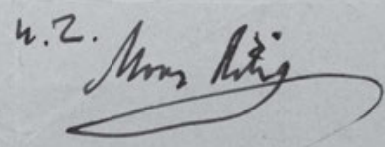

Bitte der Glaubenskommission des Antifaschistischen Rates zur Volksbefreiung Kroatiens an den Hauptstab der Föderativen Republik Kroatien, einige Geistliche auf das von Katholiken besiedelte Territorium zu schicken, 10. März 1945. Zagreb, Kroatisches Staatsarchiv, Bestand ZAVNOH. Ohne Inv.-Nr. 


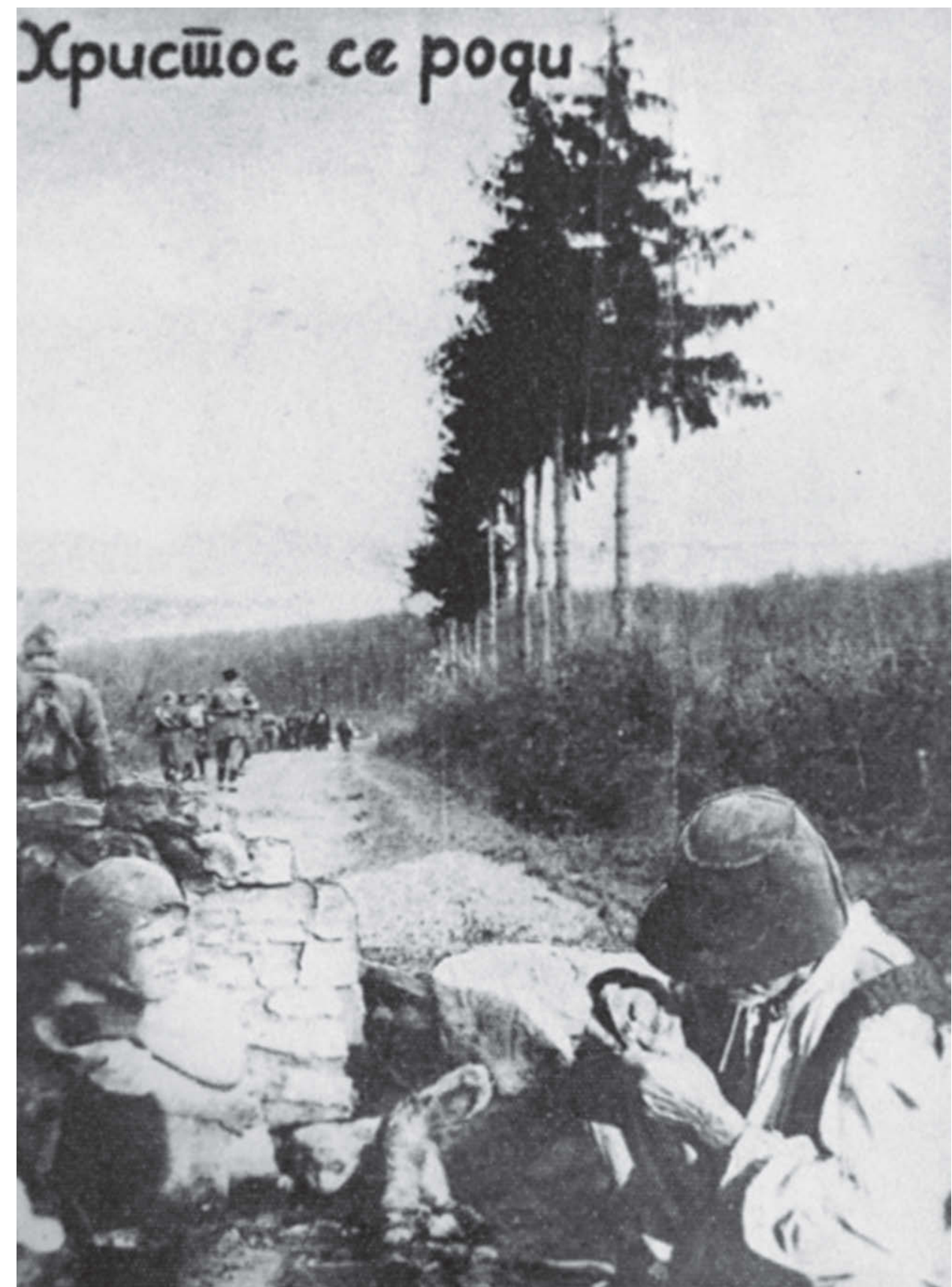

Fotomontage anlässlich des orthodoxen Weihnachtsfestes, gefertigt von der Fotosektion des Volksbefreiungsrats für Slawonien. Privatarchiv. 


\section{Bestattungen der Partisanen}

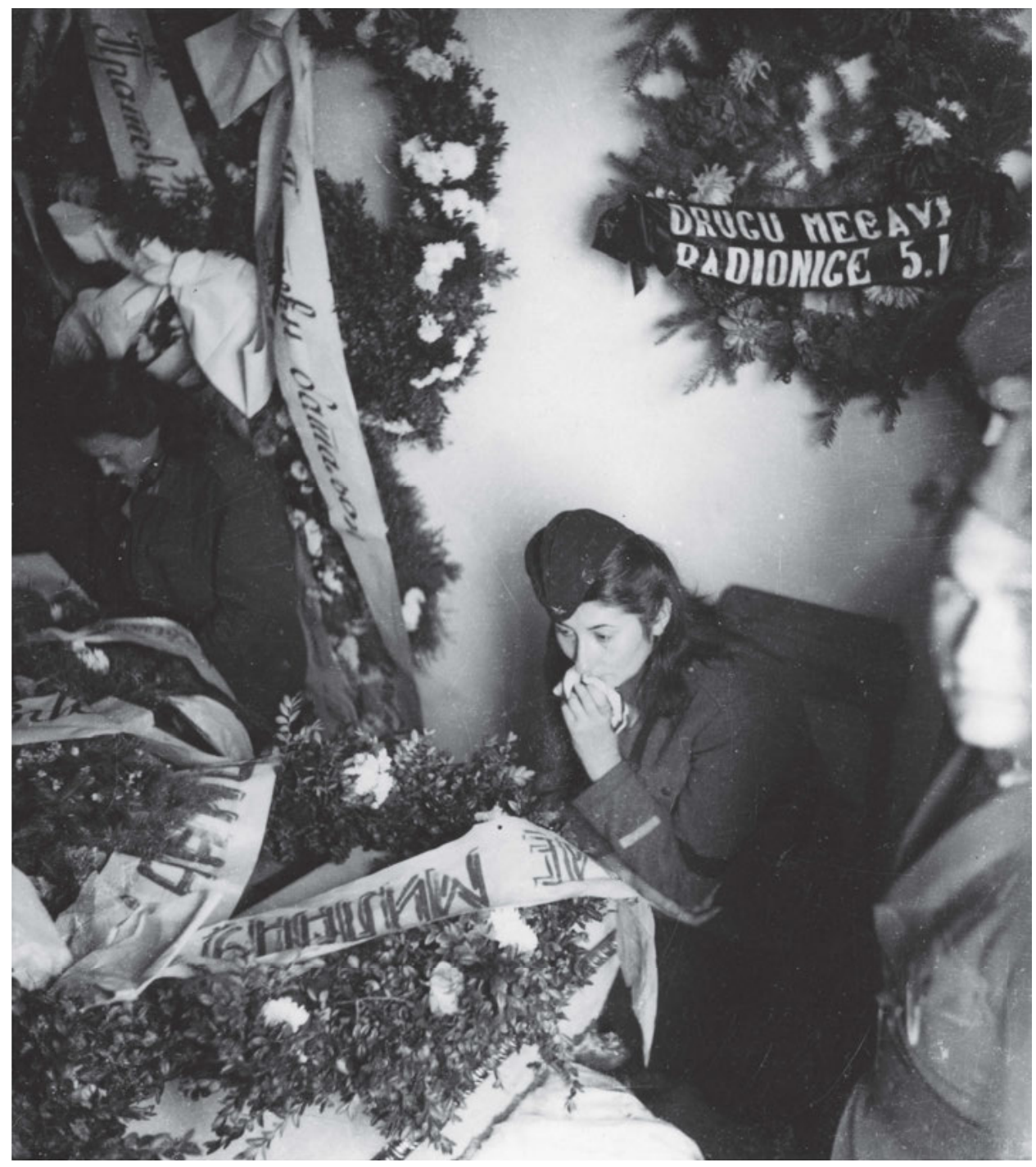

Bestattung des Volkshelden Petar Mećava in Travnik, November 1944. Fotograf unbekannt. Sarajevo, Historisches Museum von Bosnien und Herzegowina | FNOB 4920. 


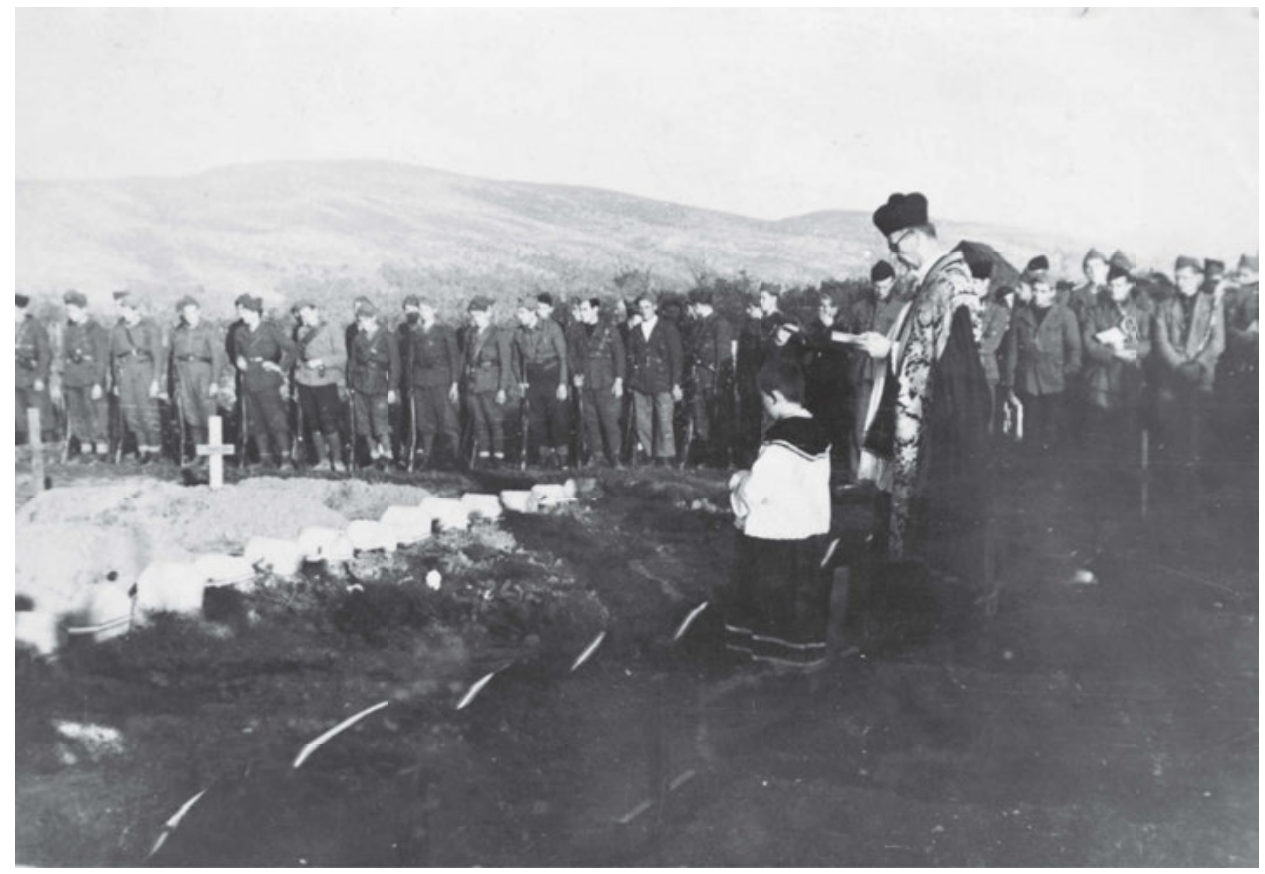

Bestattung der Partisanen, die als Verwundete im Krankenhaus in Otočac von den Ustascha ermordet wurden. September 1943. Fotograf unbekannt. Zagreb, Kroatisches Historisches Museum I HPM-MRNH-A-2601_f22_12_s.

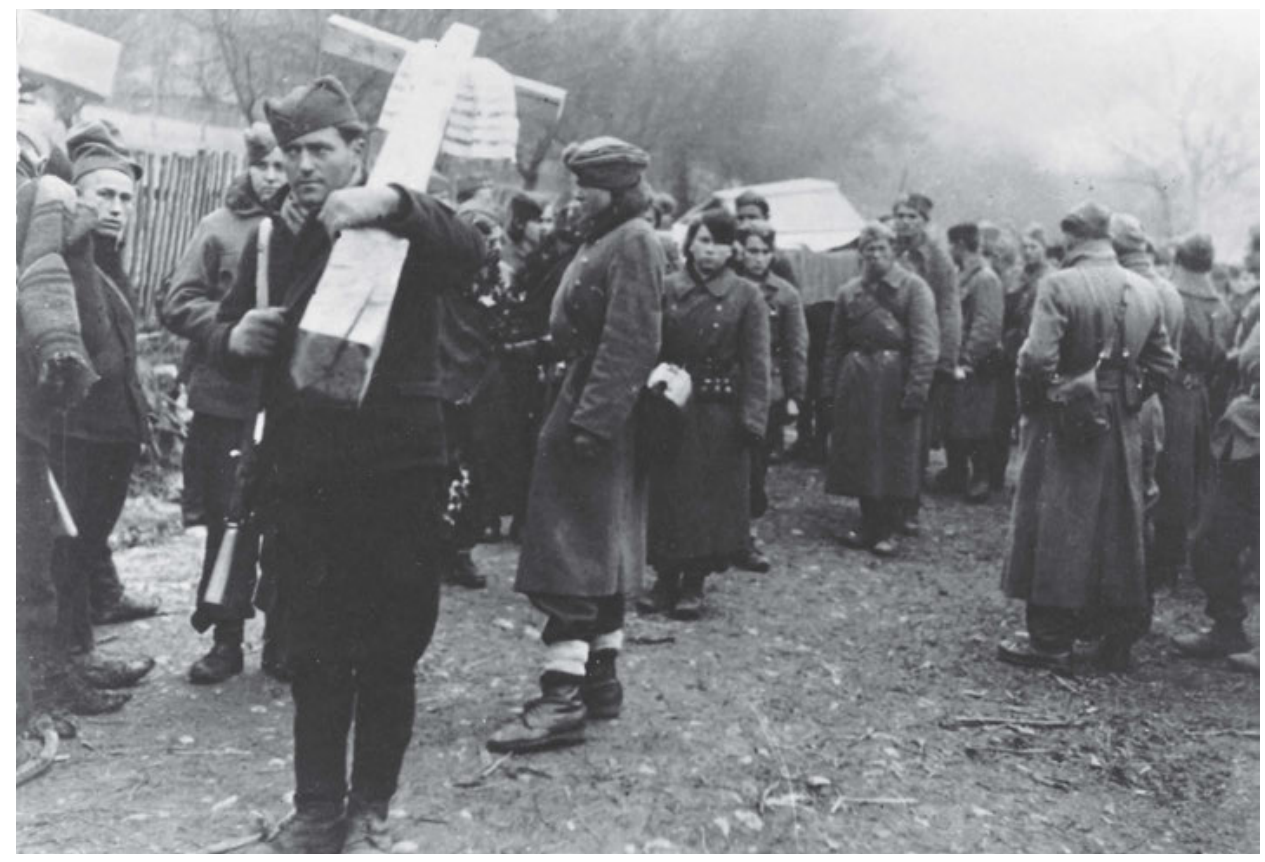

Begräbnis von Branko Kuprešanin, Politkommissar der 21. Stoßbrigade der 28. Stoßdivision. Pilice, Bosnien und Herzegowina, Januar 1945. Fotograf unbekannt. Belgrad, Militärmuseum | 6770. 


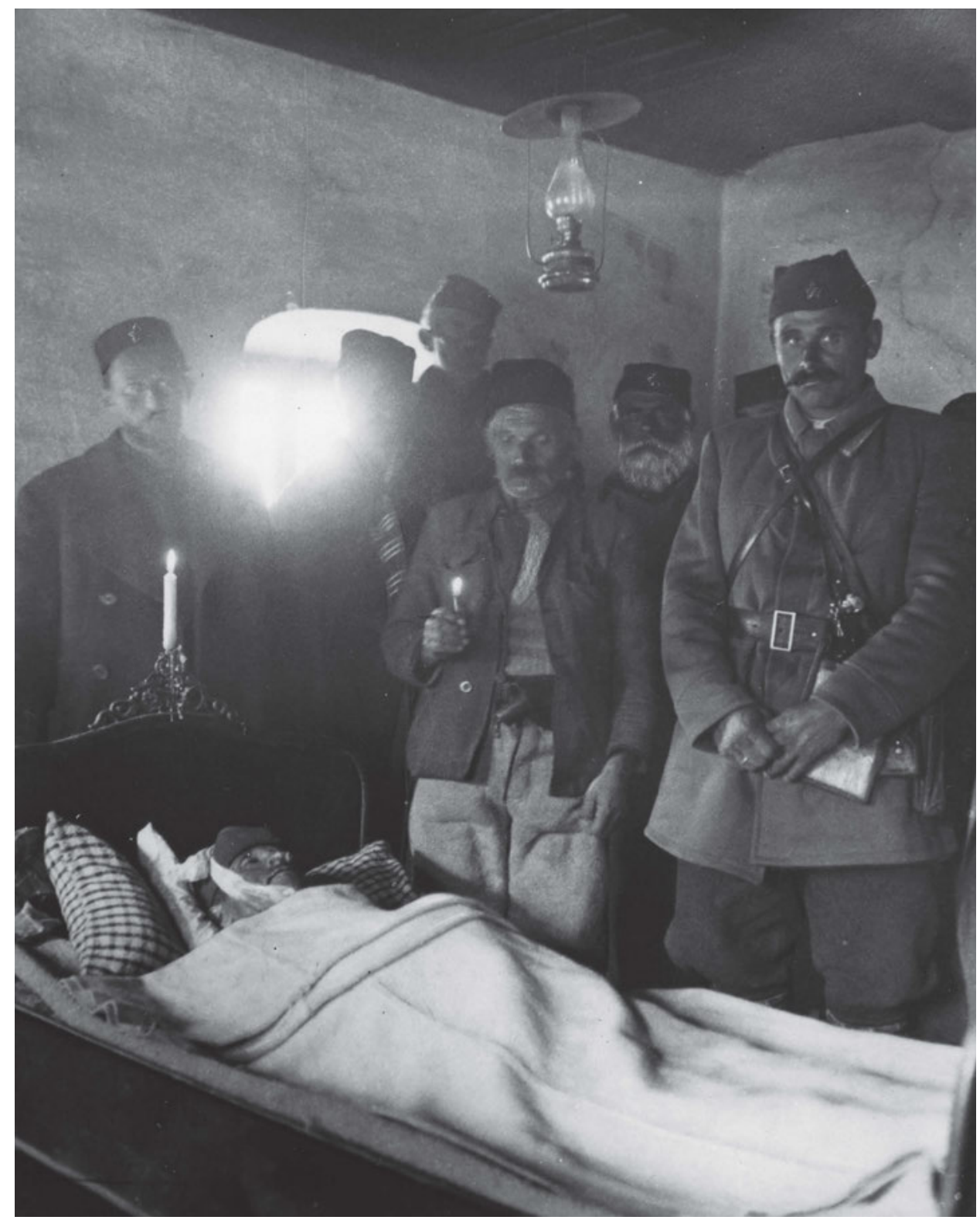

Tod des Kommandanten der Vierten Division, Četković, während der Vierten feindlichen Offensive, in der Nähe von Nevesinje. Erster von rechts: Volksheld Sava Kovačević. Foto: Žorž Skrigin. Sarajevo, Historisches Museum von Bosnien und Herzegowina | FNOB 214. 


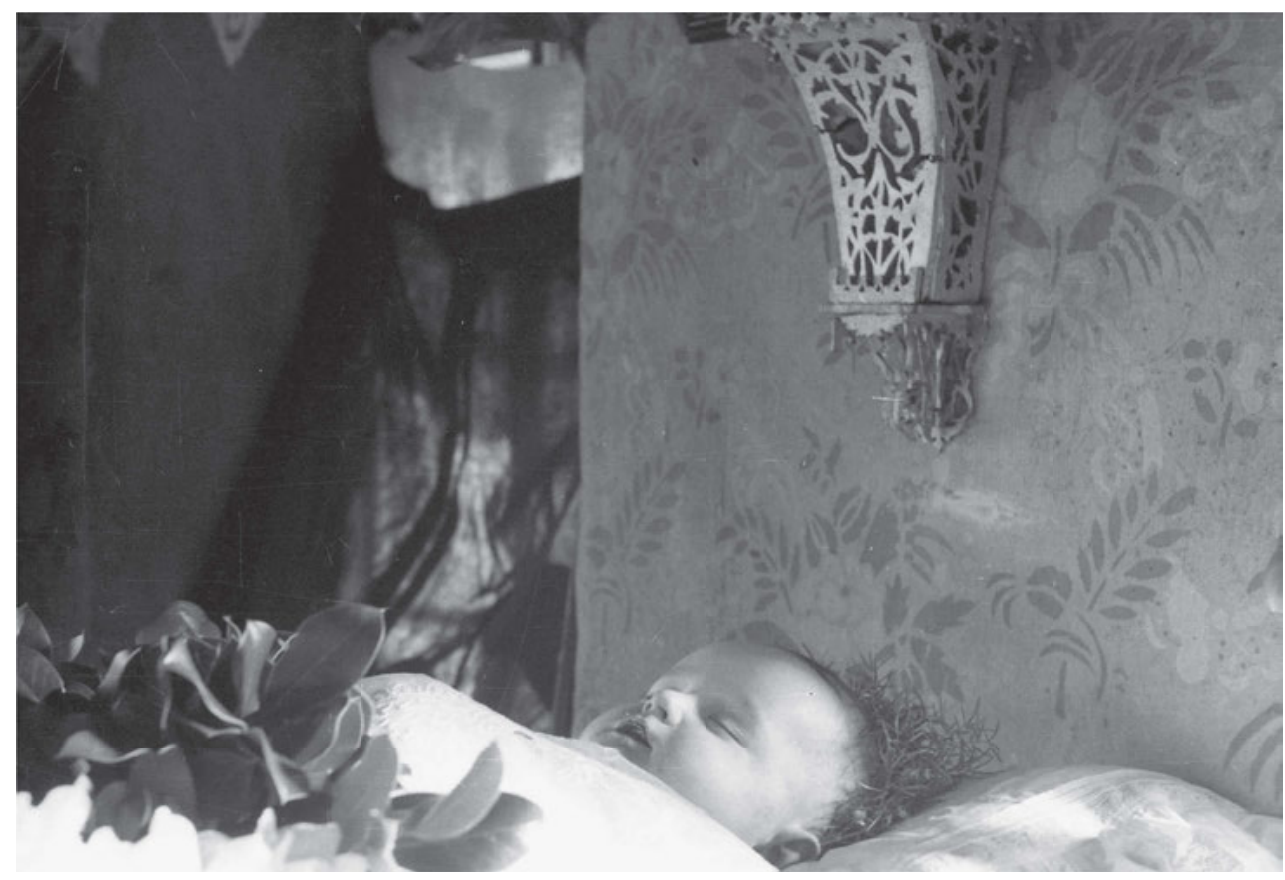

Kind auf dem Totenbett. Foto: Dr. Janez Milčinski. Ljubljana, Museum für Neuere Geschichte Sloweniens | 1226/29.

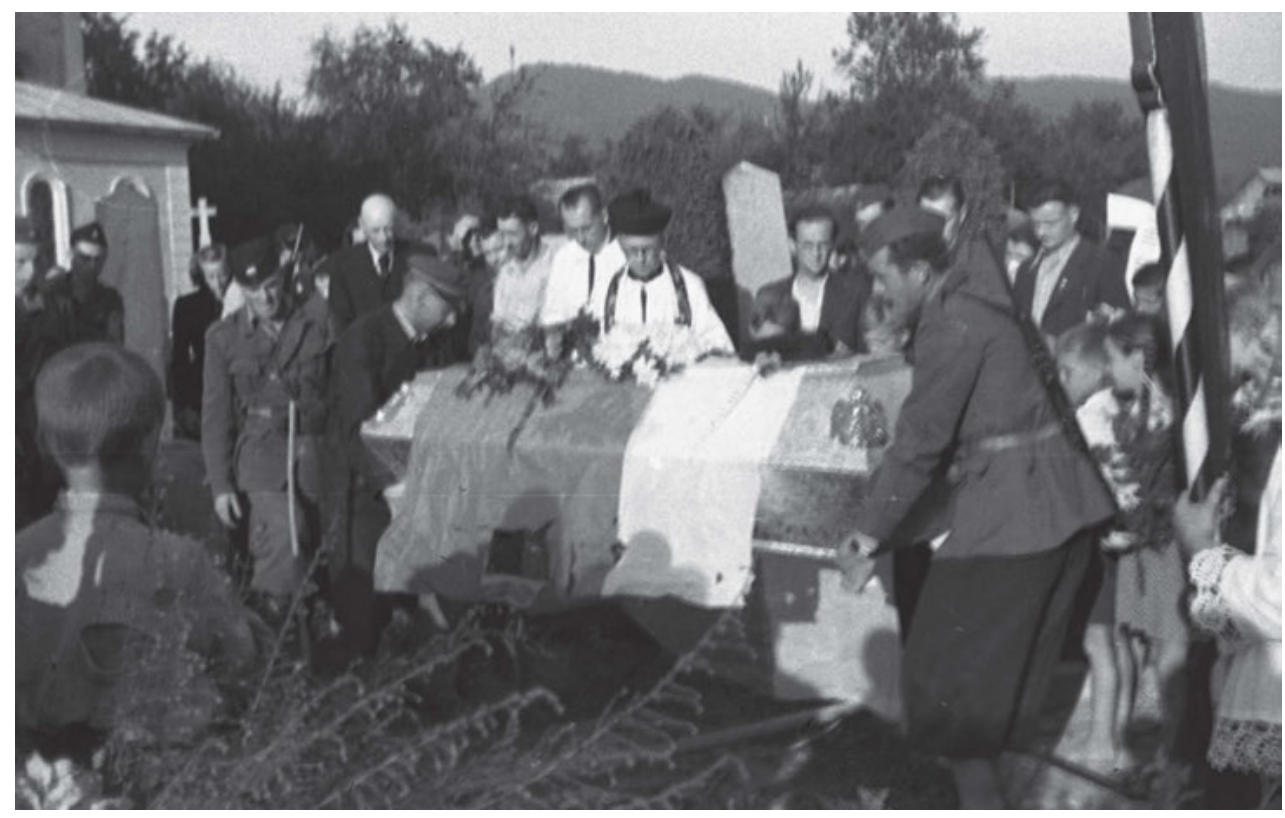

Bestattung eines gefallenen "Partisanenbürgermeisters" aus dem Dorf Gorenje in der Nähe von Ribnica, September 1943. Foto: Vinko Bavec. Ljubljana, Museum für Neuere Geschichte Sloweniens I TN39/19. 


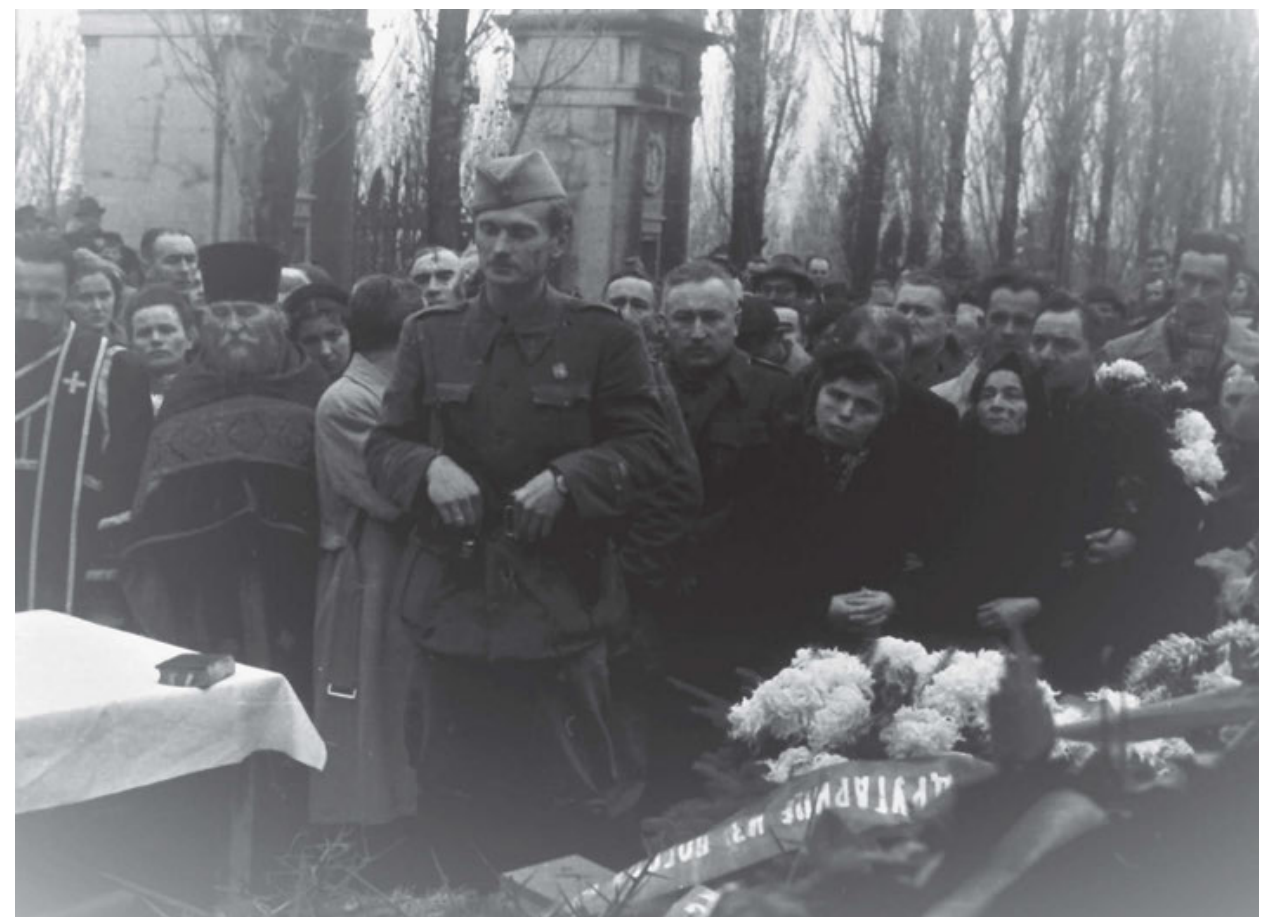

Beerdigung der Opfer des Faschismus, die im Konzentrationslager Banjica hingerichtet wurden, auf dem Neuen Friedhof in Belgrad, November 1944. Belgrad, Militärmuseum | 18431.

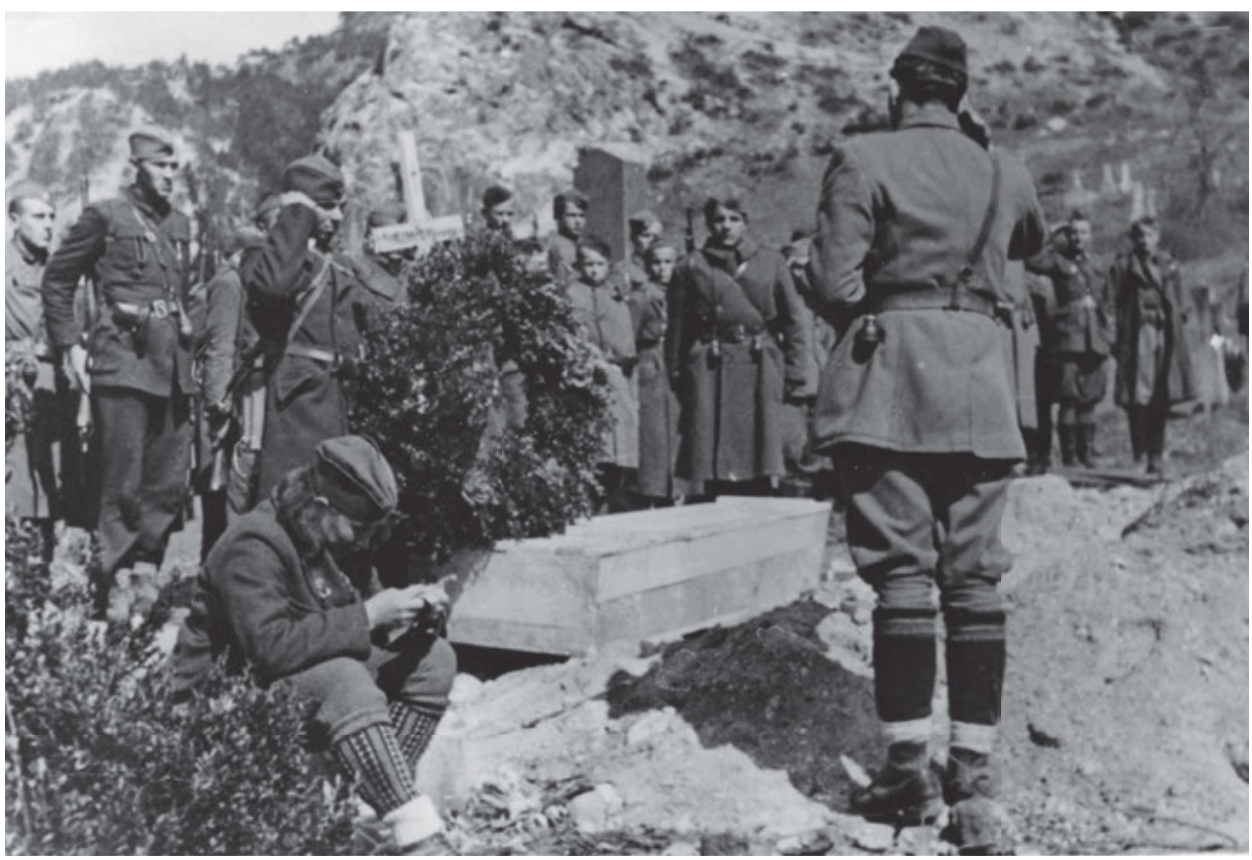

Bestattung von Rajko Milošević, Politkommissar des Dritten Bataillons der Zwölften Brigade.

Fotograf unbekannt. Sarajevo, Historisches Museum von Bosnien und Herzegowina | FNOB 16367. 
Werkstätten, Schulen, Druckereien, Institute

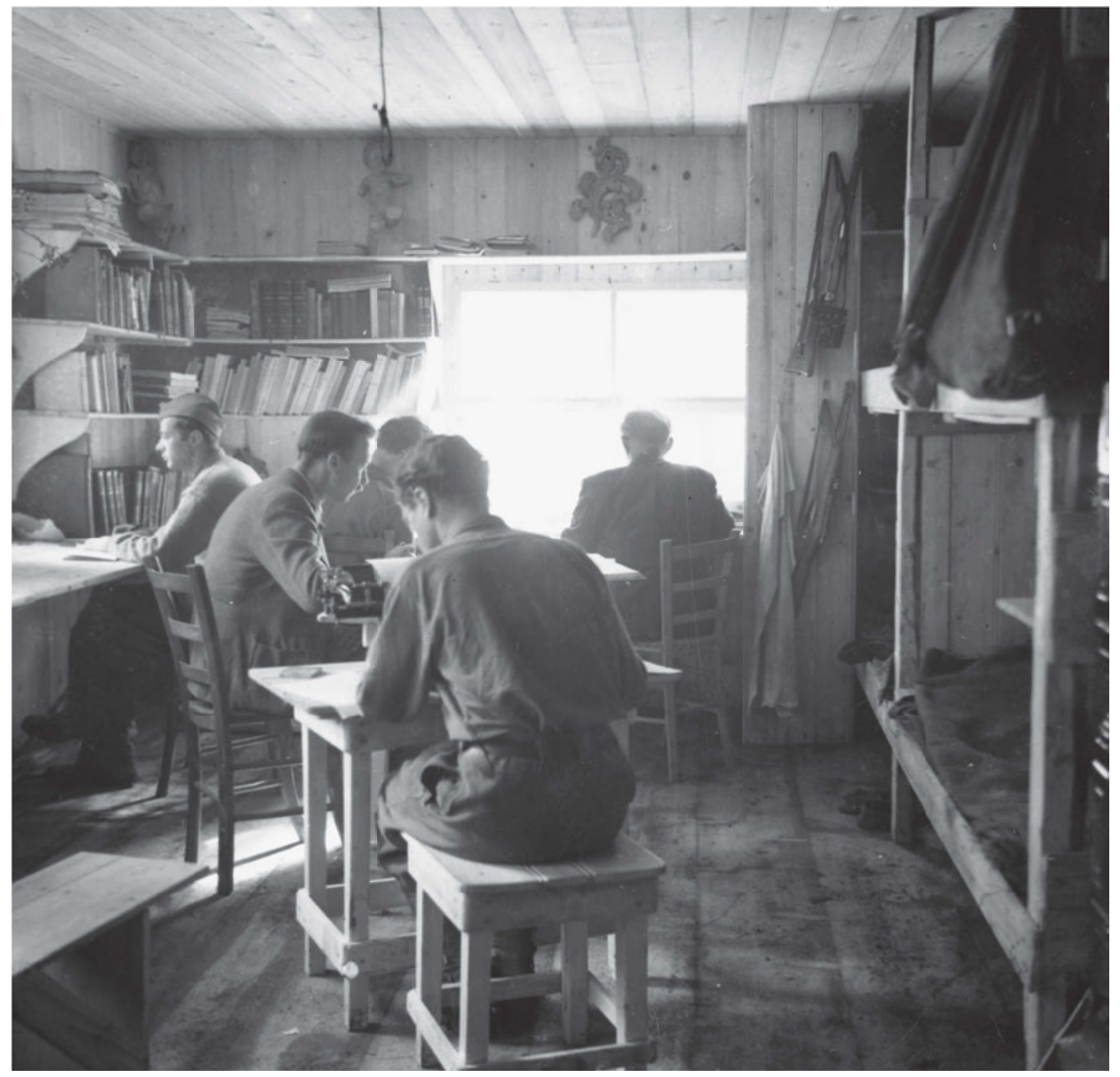

Mitglieder des Wissenschaftlichen Instituts bei ihrer Arbeit, Kočevski Rog, 1944. Fotograf unbekannt. Ljubljana, Museum für Neuere Geschichte Sloweniens | TN364/5. 


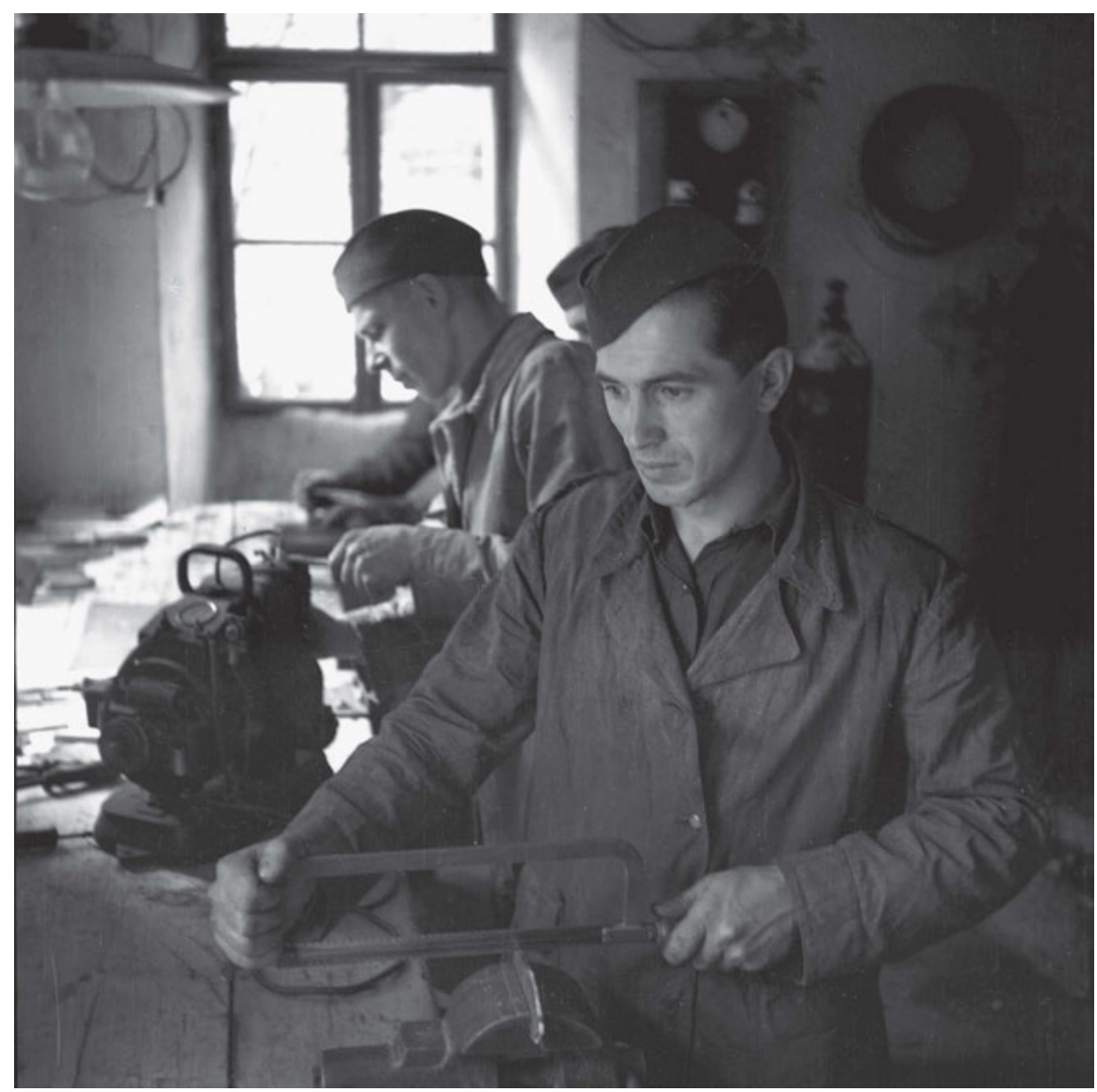

Mechanische Werkstätten des Oberkommandos der Volksbefreiungsarmee und der Widerstandsbewegung Sloweniens für Fahrrad-, Motorrad- und Autoreparaturen. Auf dem Foto ist die Werkstatt für Elektronik zu sehen. Stare Žage, 1944. Foto: Stane Viršek. Ljubljana, Museum für Neuere Geschichte Sloweniens | TN117/2.

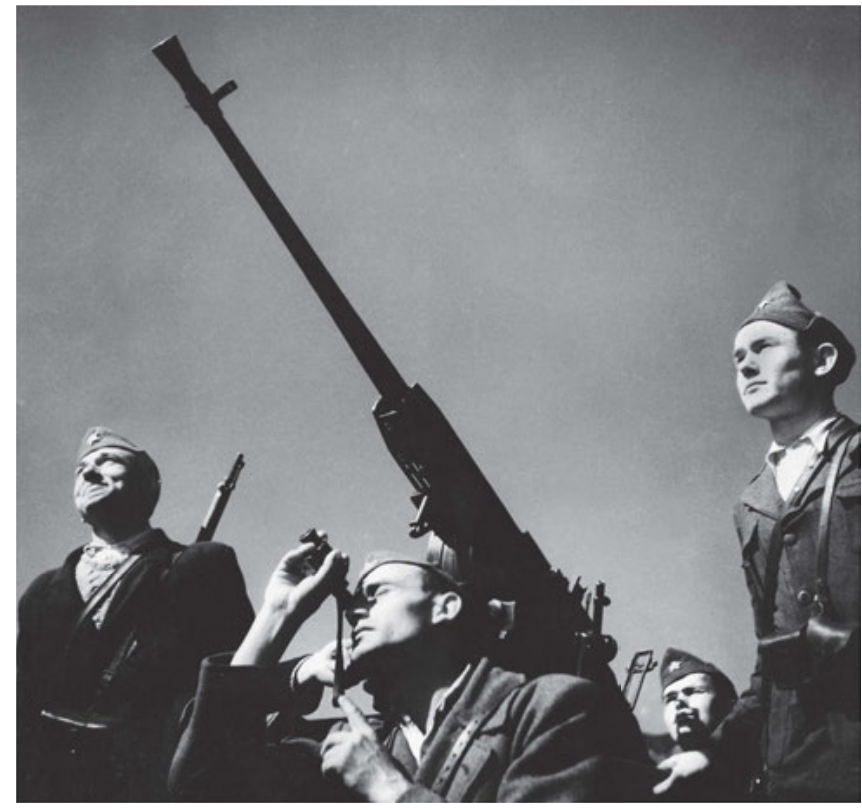

Manöver der Offiziersschule in Lapac, 1942. Auf dem Foto ist unter anderem Ivan Gošnjak zu sehen. Fotograf unbekannt. Belgrad, Museum Jugoslawiens | III-5541. 


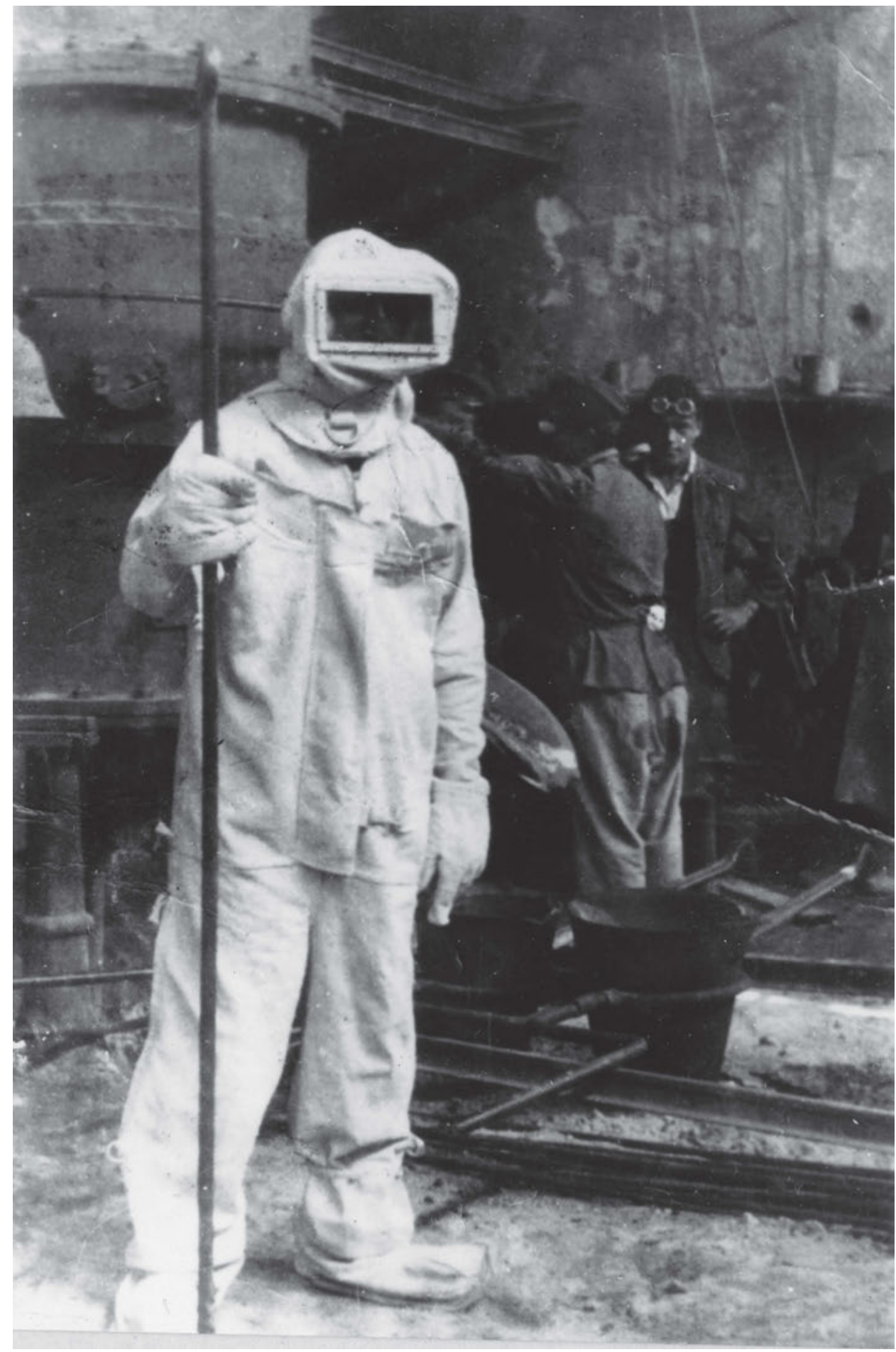

Partisanenwerkstatt für die Bombenherstellung und Waffenreparaturen in Drvar, 1941.

Fotograf unbekannt. Sarajevo, Historisches Museum von Bosnien und Herzegowina | FNOB 2681. 


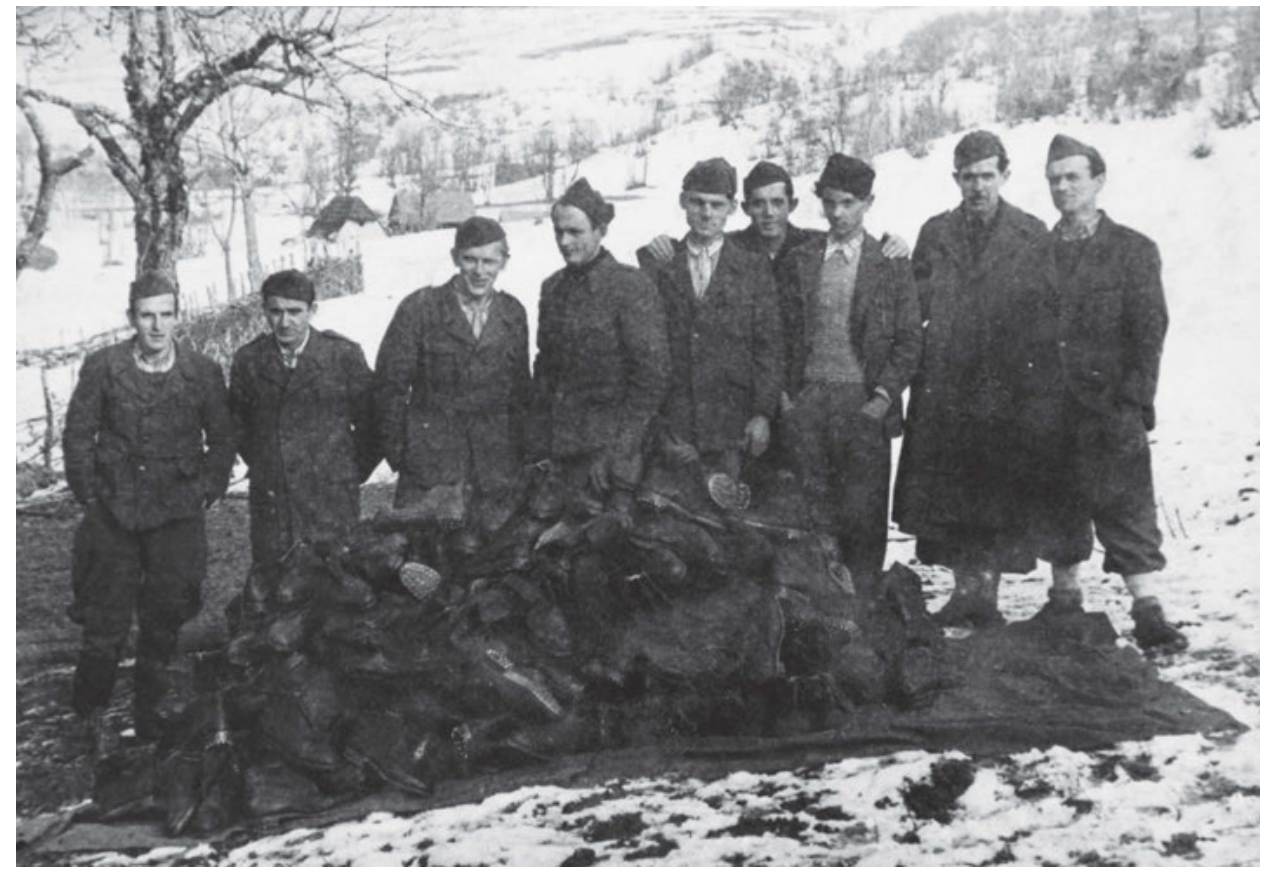

Partisanen-Arbeiter der Dritten zentralen Tischlerwerkstatt des Hauptstabs Kroatiens in Turjansko bei Vrhovina in Lika, Februar/März 1944. Fotograf unbekannt. Zagreb, Kroatisches Historisches Museum HPM-MRNH-A-2601_f82_25_s.

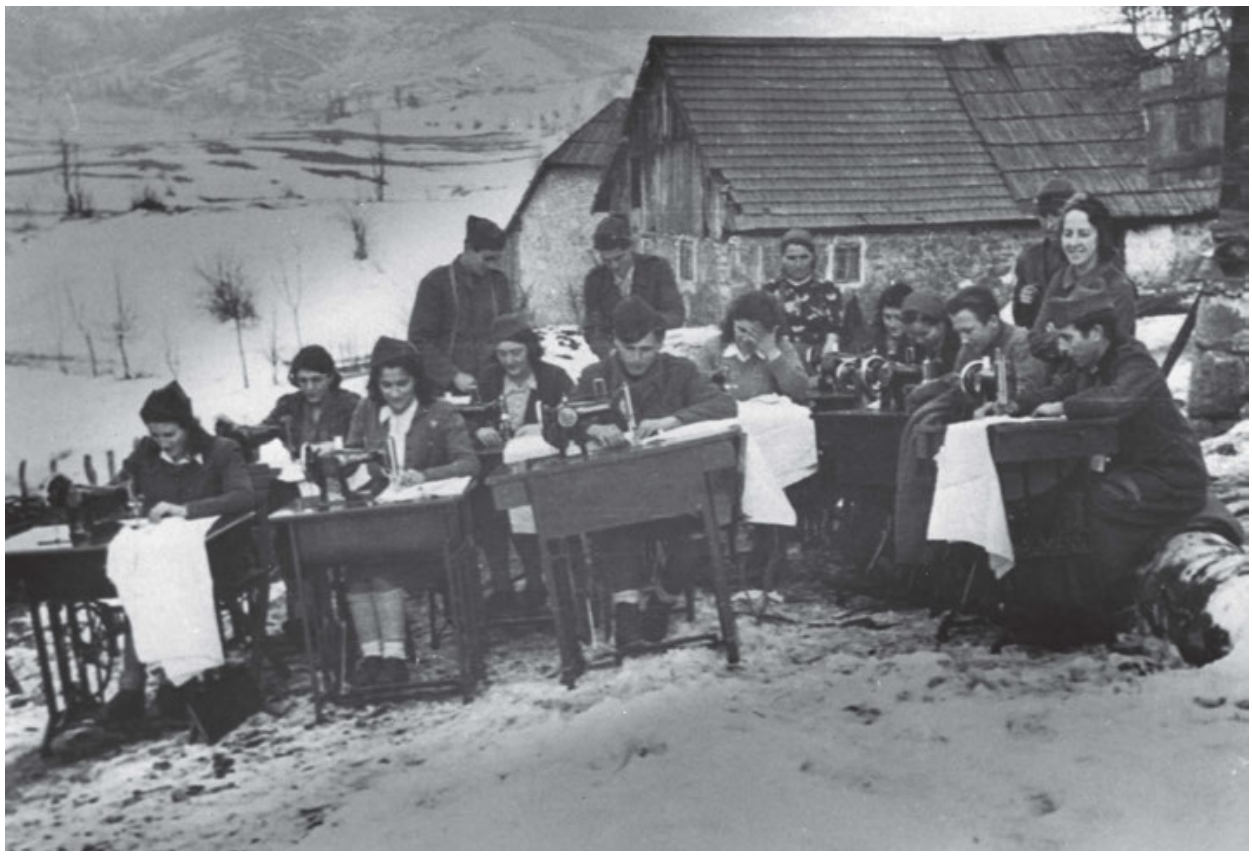

Aktion der Frauen aus Lika mit ihren Nähmaschinen. Aufgenommen im Winter 1944/1945.

Museum der Volksrevolution Kroatiens | znaci.net. 


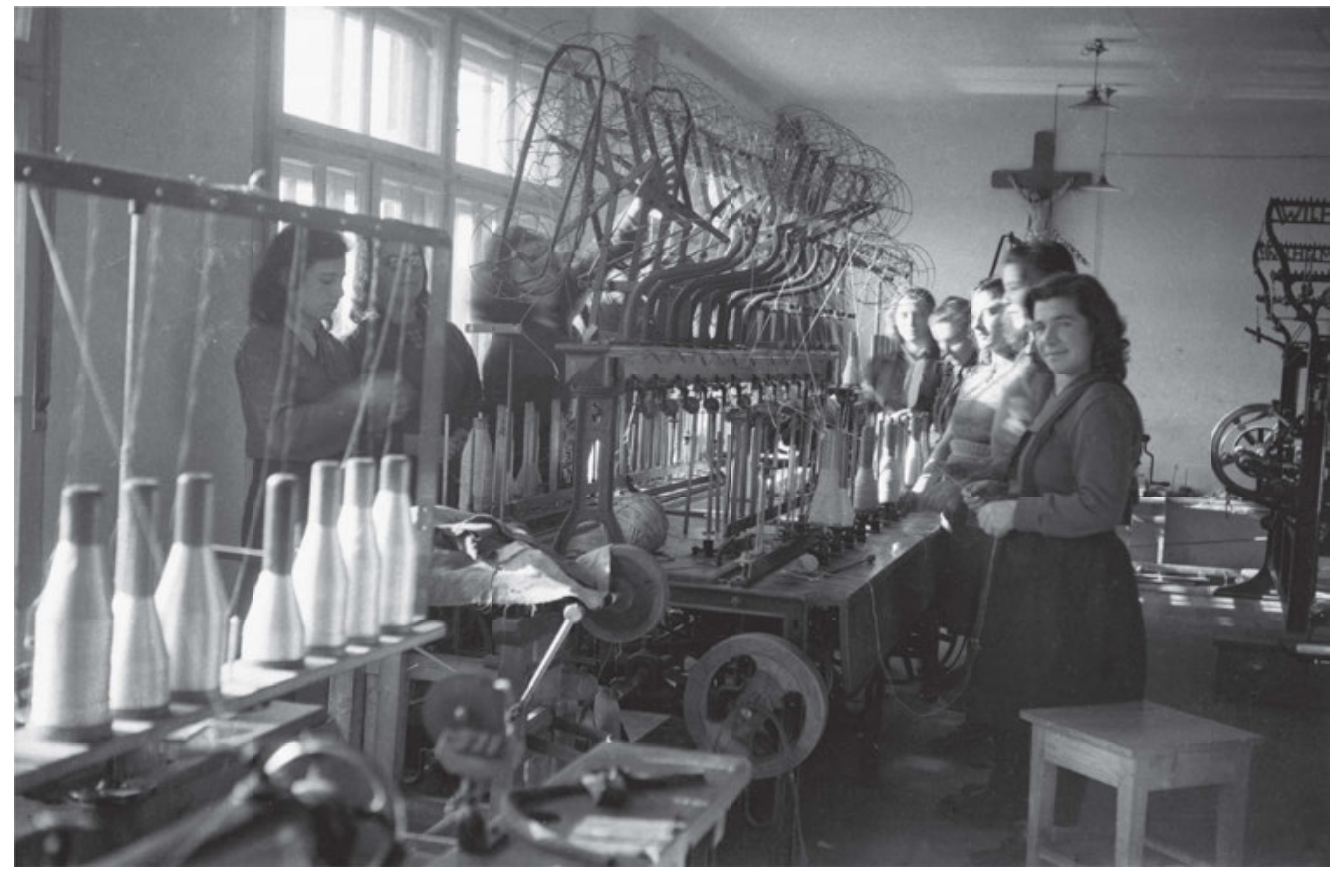

Nähwerkstatt der Partisanen in Črnomelj, November 1944. Foto: Edi Šelhaus. Ljubljana, Museum für Neuere Geschichte Sloweniens | TN387/2.

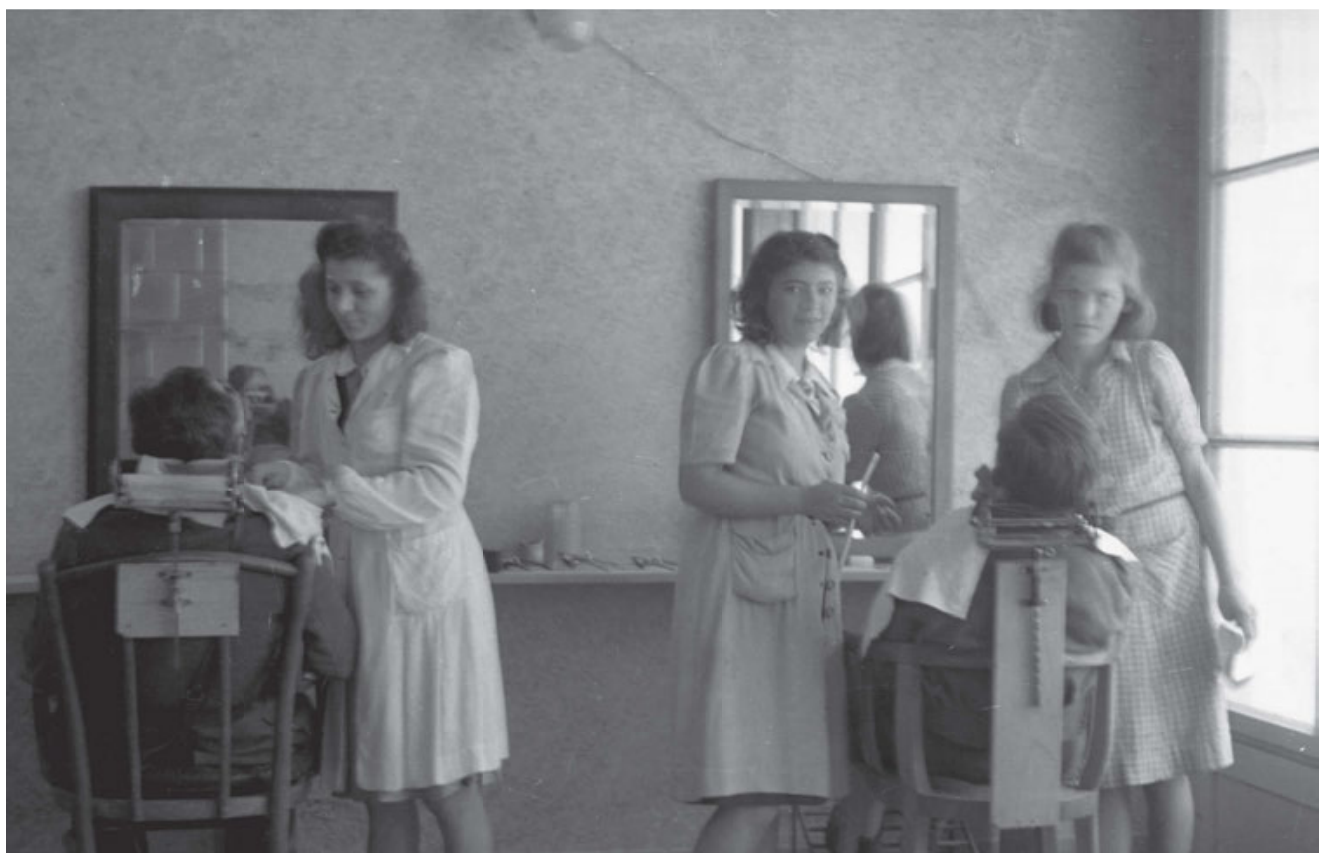

Barbier-Laden in Črnomelj, 1944. Foto: Maksimiljan Zupančič. Ljubljana, Museum für Neuere Geschichte Sloweniens | TN389/32. 


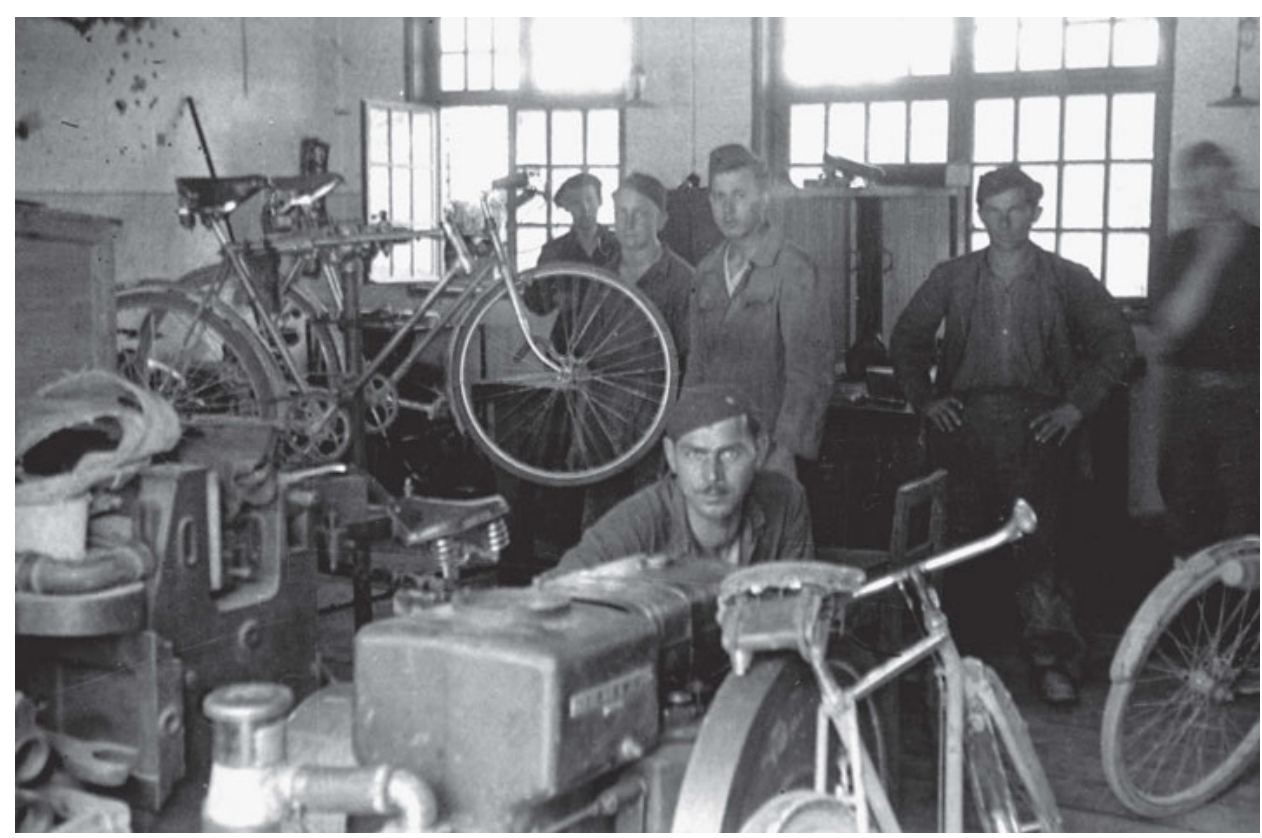

In Župančičs Mechanischer Werkstatt, August 1944. Foto: Alfred Kos. Ljubljana, Museum für Neuere Geschichte Sloweniens | TN213/14.

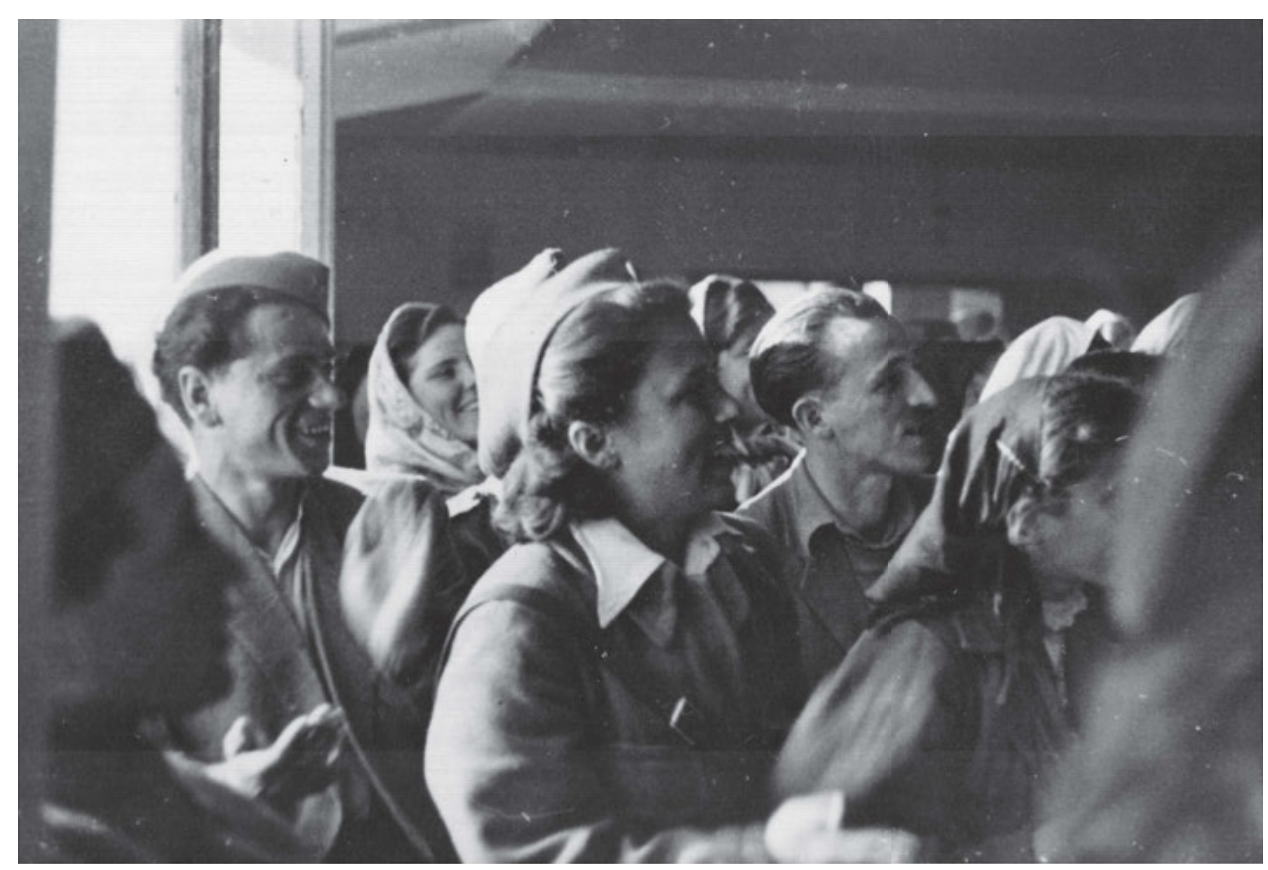

Unterrichtung von Partisanen. Foto: Drago Mažar. Banja Luka, Archiv der Republika Srpska. Ohne Inv.-Nr. 


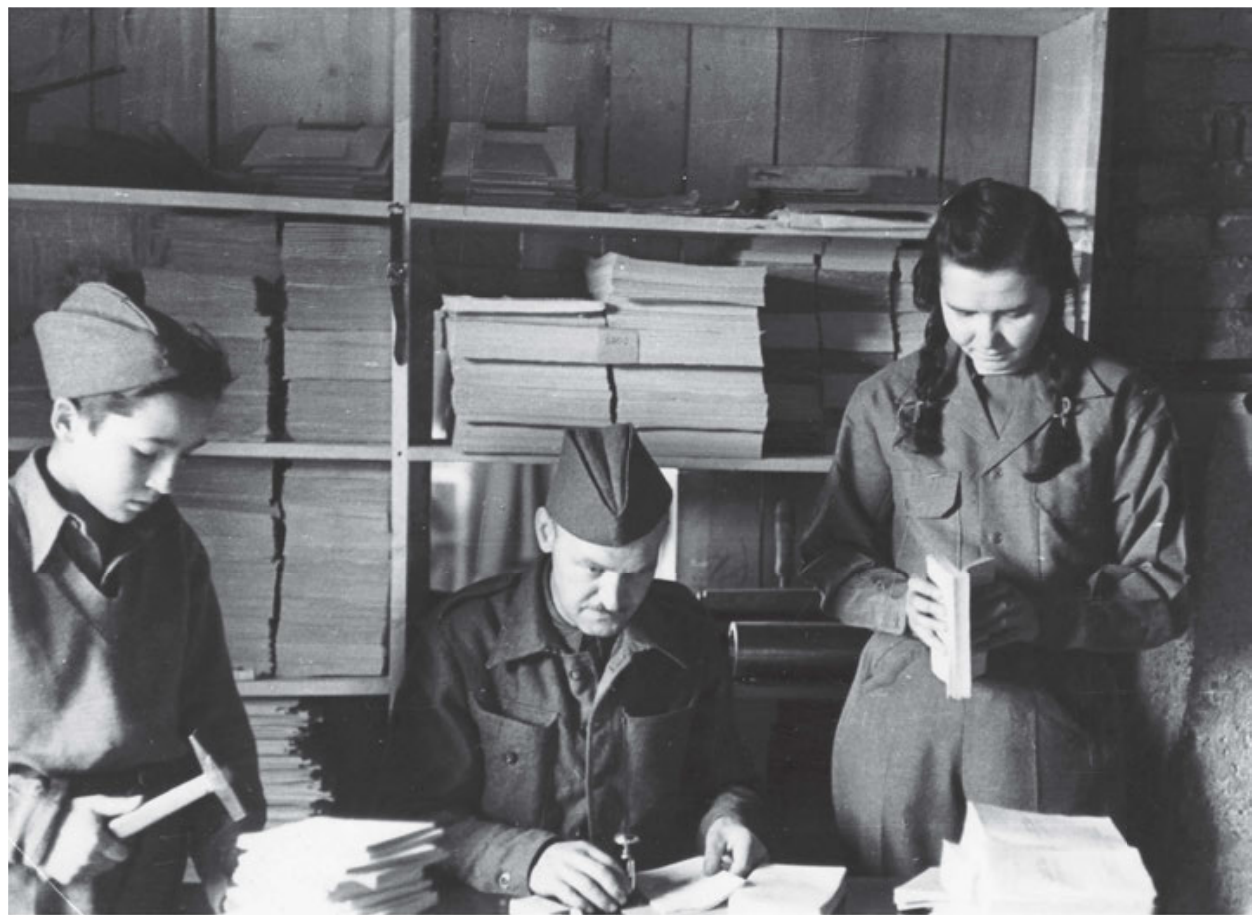

Druckerei der Partisanen in Slowenien. Buchbinderei des Hauptstabs, 1945.

Fotograf unbekannt. Ljubljana, Museum der Volksrevolution Sloweniens | znaci.net.

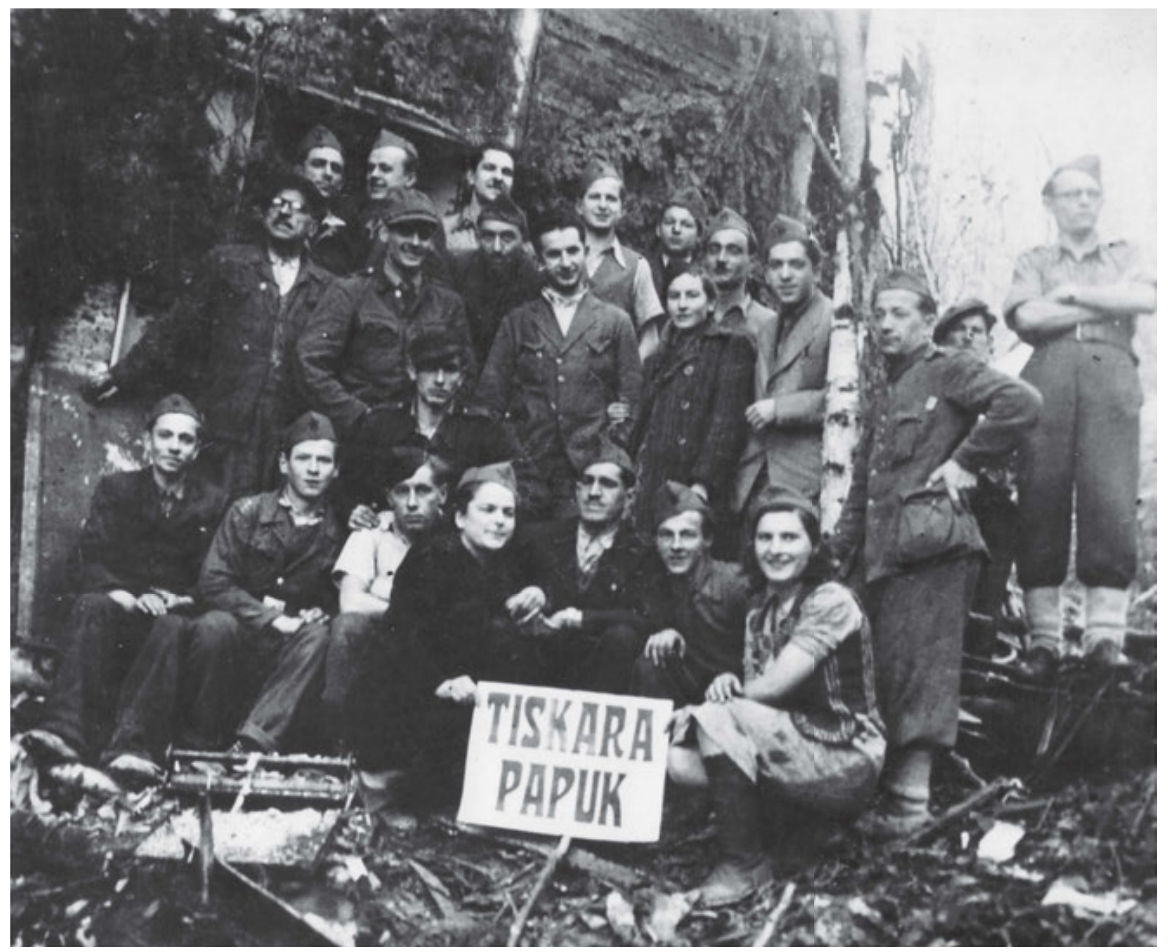

Der erste Druck auf einer großen Maschine in der Druckerei in Papuk.

Fotograf unbekannt. znaci.net. 


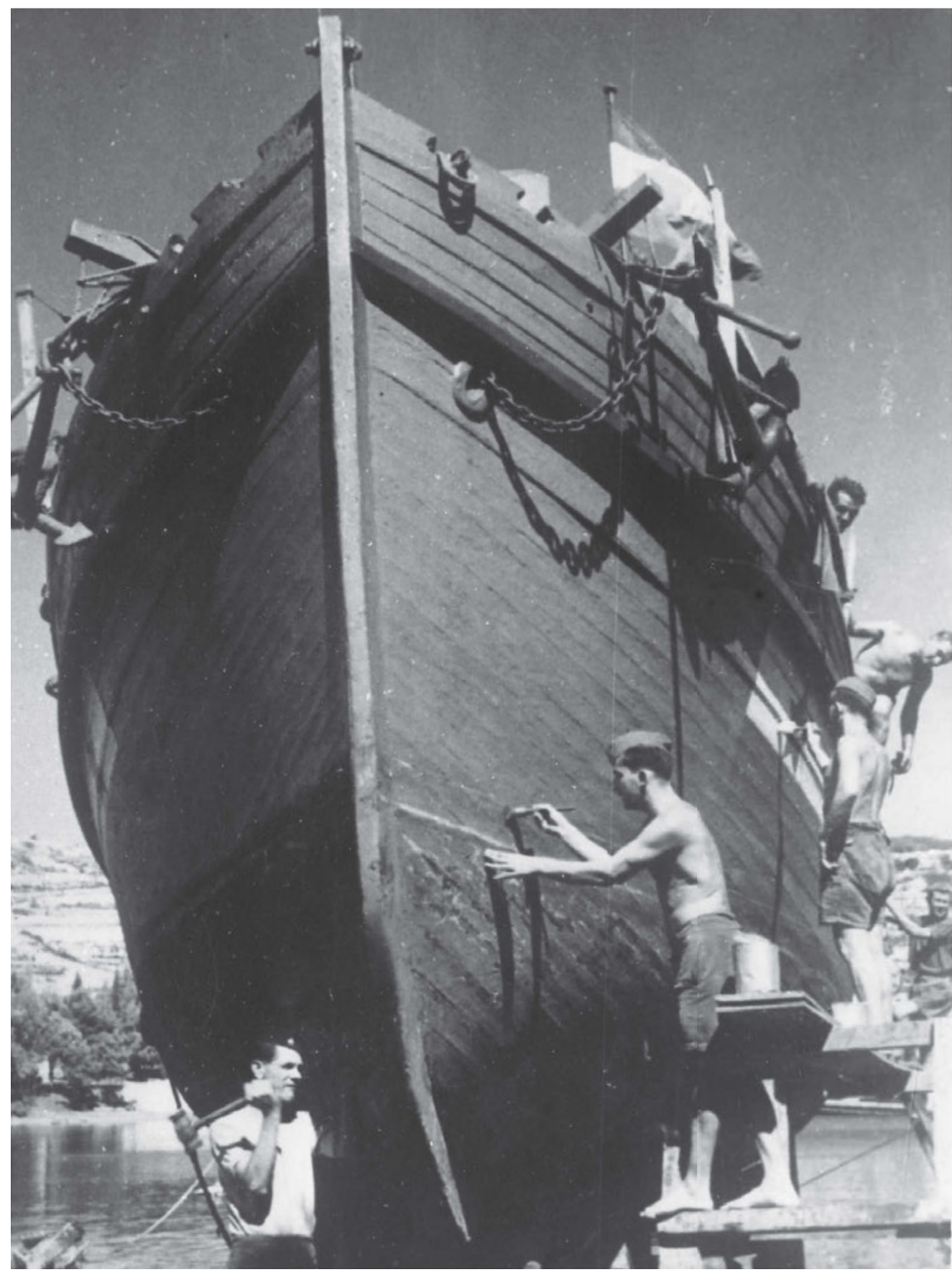

Gruppe von Partisanen bei den letzten Vorbereitungen am Kampfboot. Fotograf unbekannt. Fotolabor des Instituts der Arbeiterbewegung der Völker Jugoslawiens 


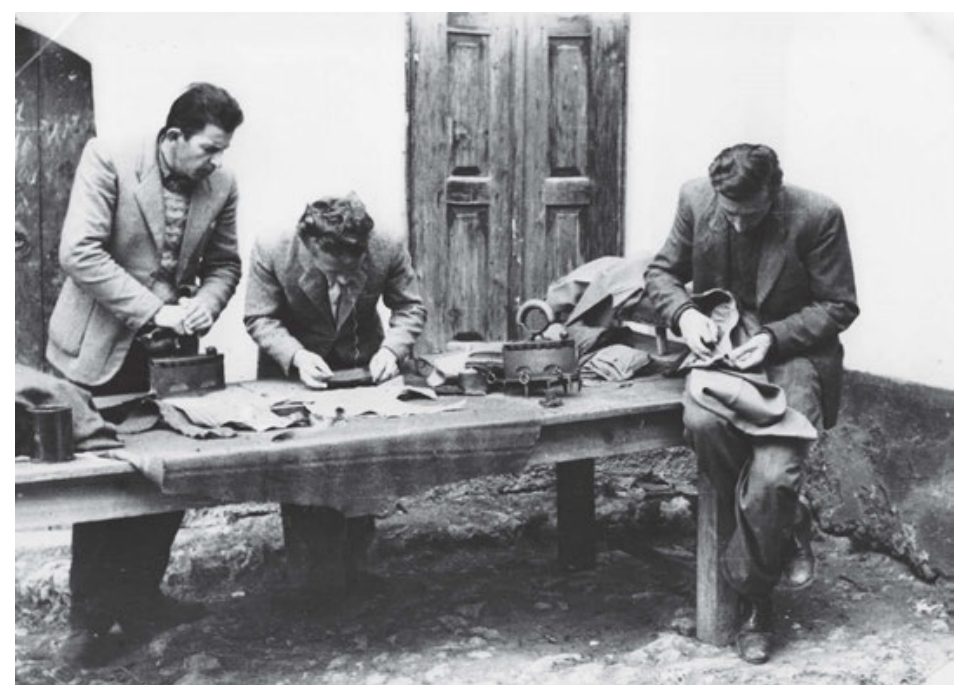

Schneiderwerkstatt in Pljevlja. Fotograf unbekannt. znaci.net.

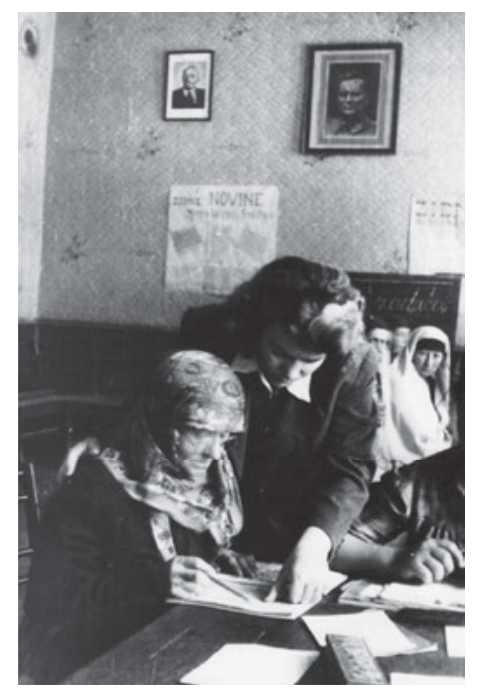

Analphabeten-Kurs, organisiert in der Region Zahum in Mostar. Fotograf unbekannt. znaci.net.

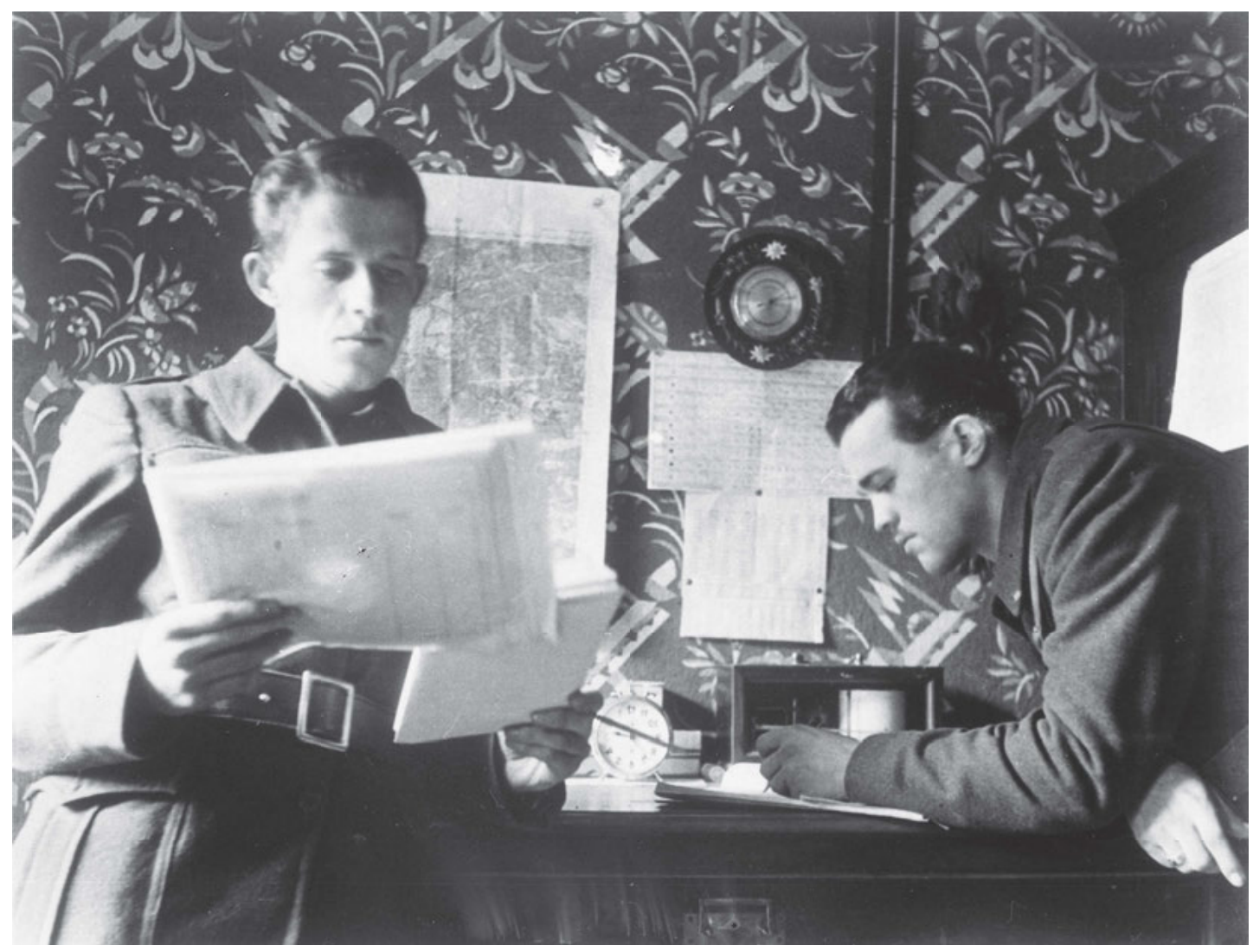

Radiotelegrafische Wetterstation des Neunten Korps in Cerkno. Auf dem Foto sind Dare Dodić und Mirko Župančič zu sehen. März/April 1944. Fotograf unbekannt. Ljubljana, Museum für Neuere Geschichte Sloweniens | TN1066/11. 


\section{Kulturschaffende und Kulturproduktion}

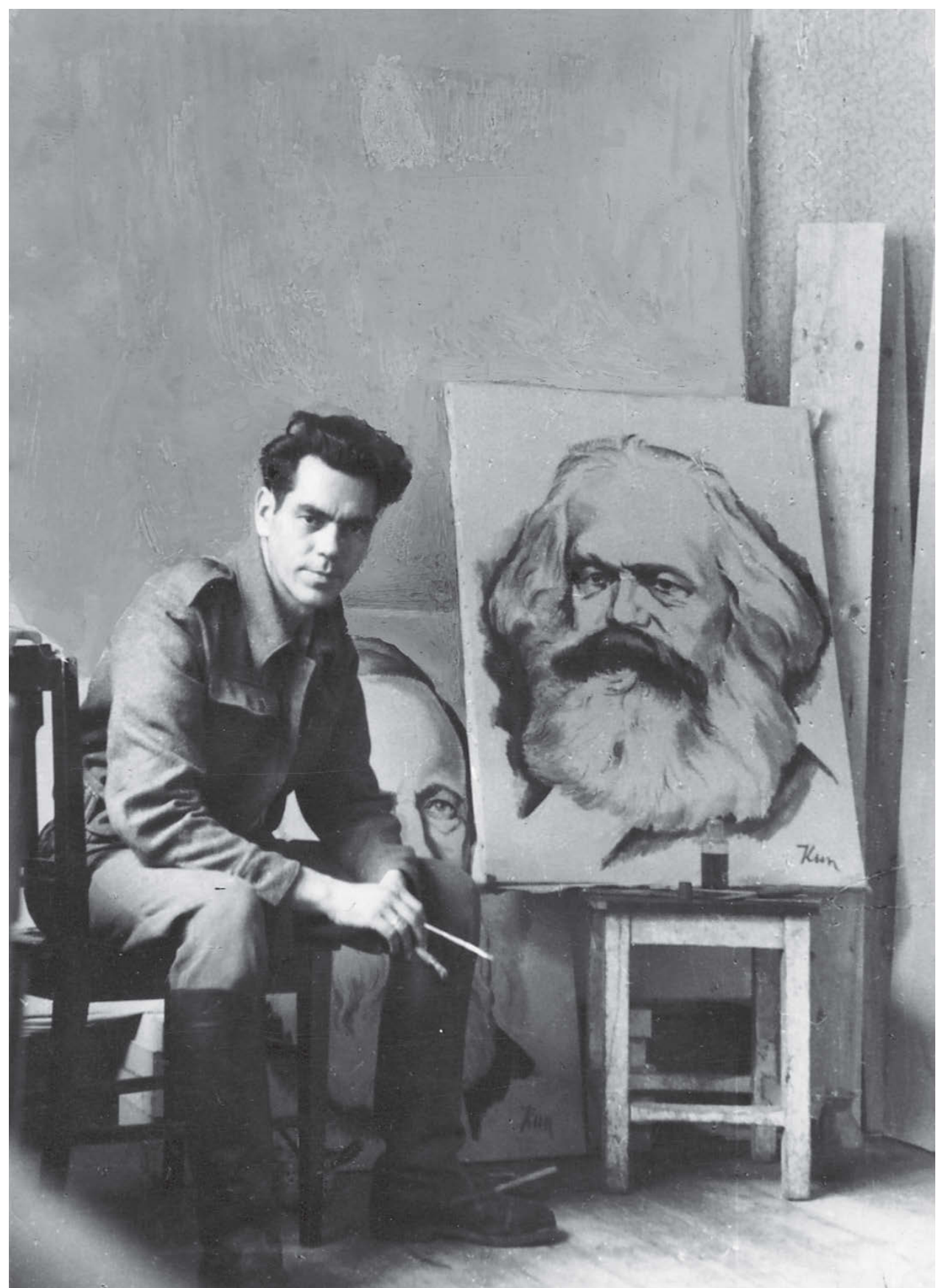

Der Maler Djordje Andrejević-Kun in seinem Atelier in einer Fabrikhalle, September 1943. Fotograf unbekannt. Bestand Historisches Archiv beim ZK BdKJ | znaci.net. 


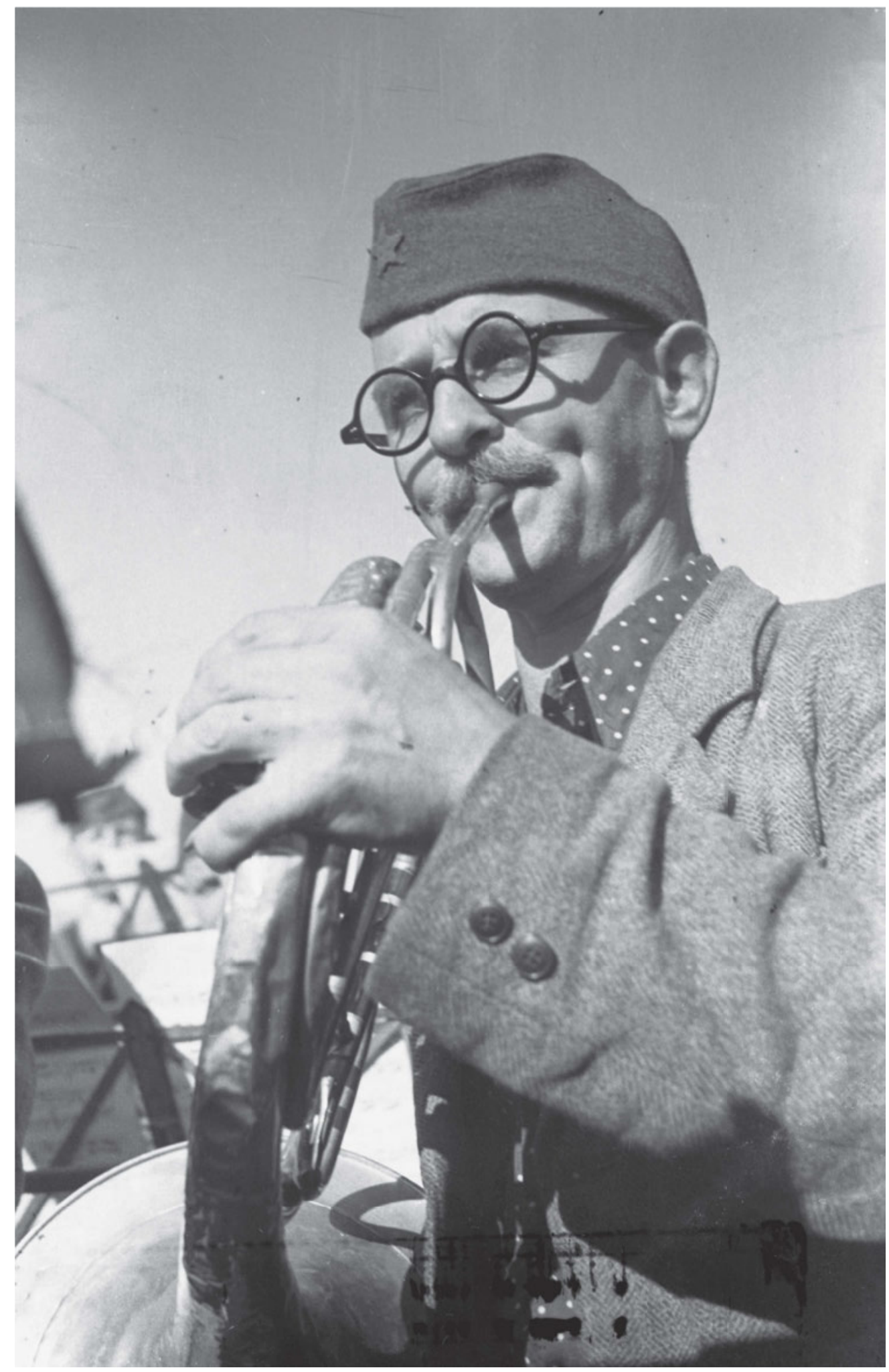

Flügelhornist in Srednja Vas, 1944. Foto: France Cerar. Ljubljana, Museum für Neuere Geschichte Sloweniens | TN321/39. 

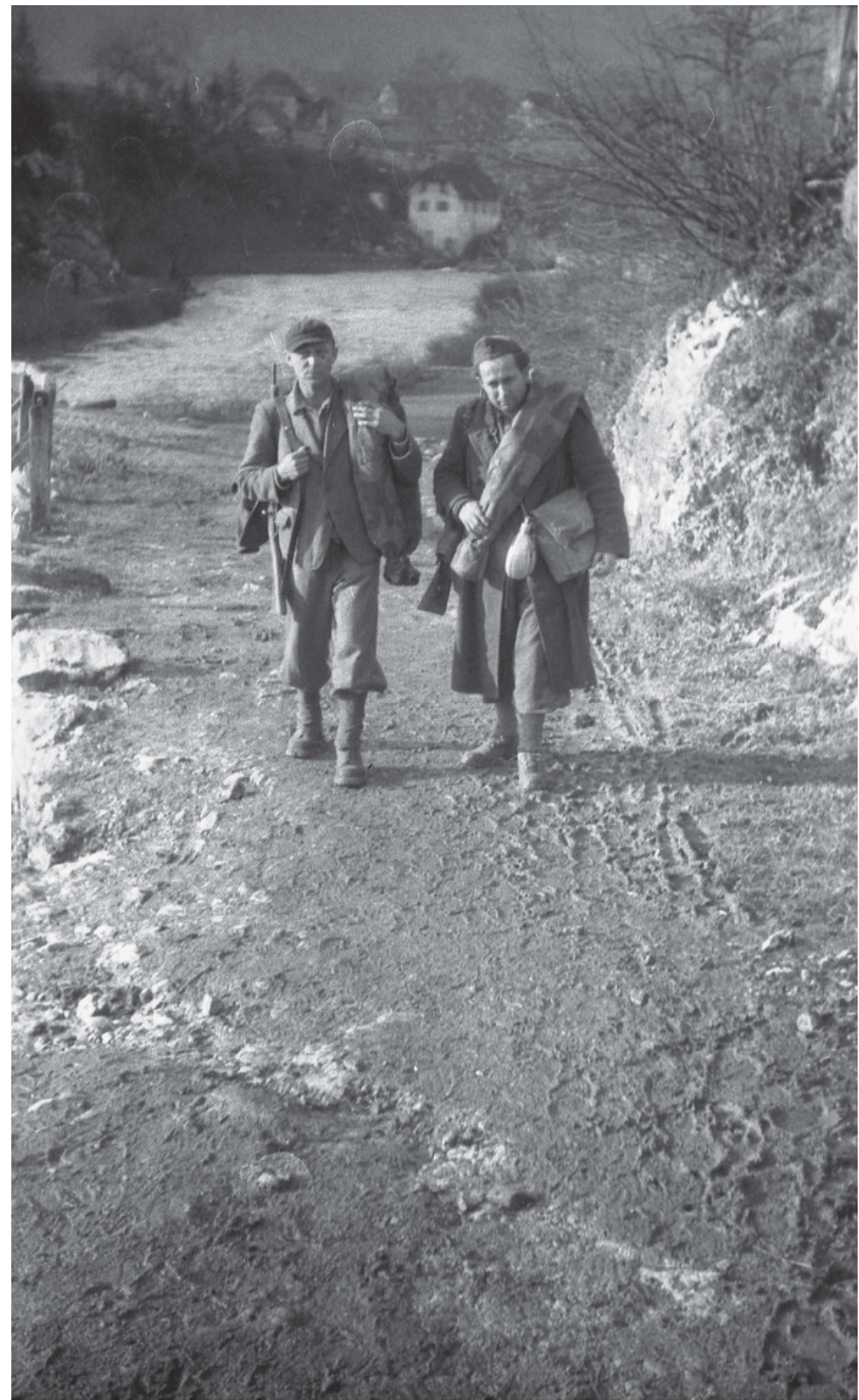

Prof. Franček Veselko und Ivan Kronovšek, Mitglieder der Kulturgruppe der Cankar-Brigade und der Wirtschaftsabteilung, in Zagradec im November 1943 nach der Offensive der deutschen Wehrmacht. Foto: Franjo Veselko. Ljubljana, Museum für Neuere Geschichte Sloweniens | TN56/21. 


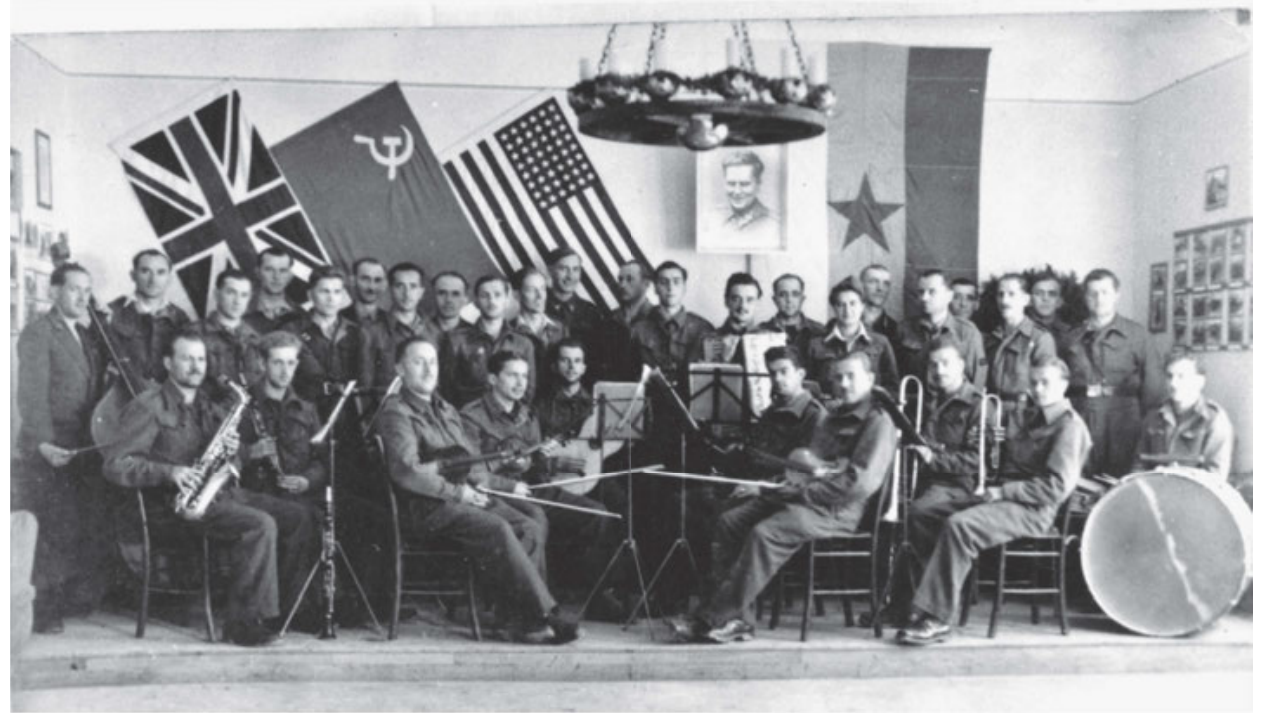

Orchesterauftritt in Ljubno im Save-Tal. Fotograf unbekannt. Museum für Neuere Geschichte der Stadt Celje | FZ25539.

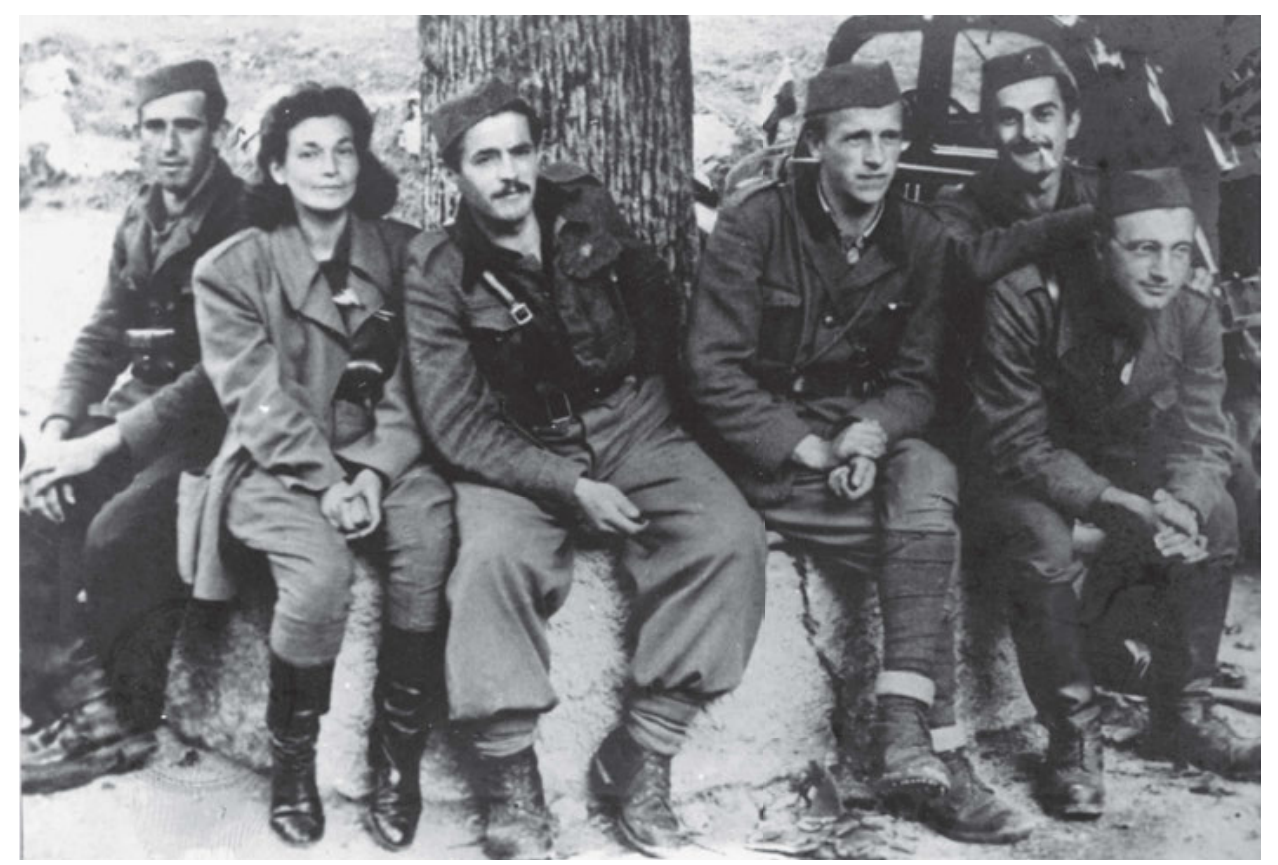

Kulturgruppe der 14. Division. Fotograf unbekannt. Museum für Neuere Geschichte der Stadt Celje | FZ2836. 


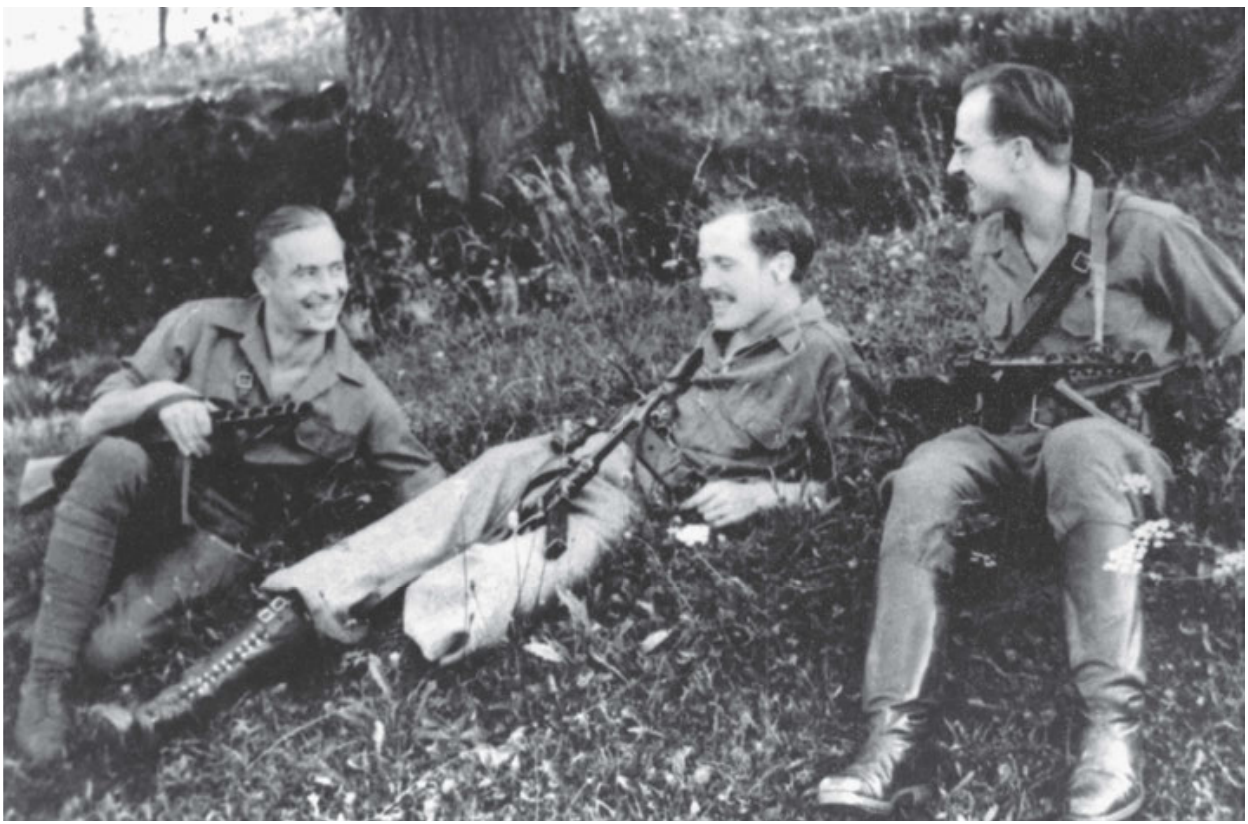

Von links nach rechts: Ivo Lipar Iztok aus der Agitprop der 14. operativen Zone, Milan Venišnik und Jože Petek, Fotoreporter der 14. Division. Fotograf unbekannt. Museum für Neuere Geschichte der Stadt Celje | FZ2876.

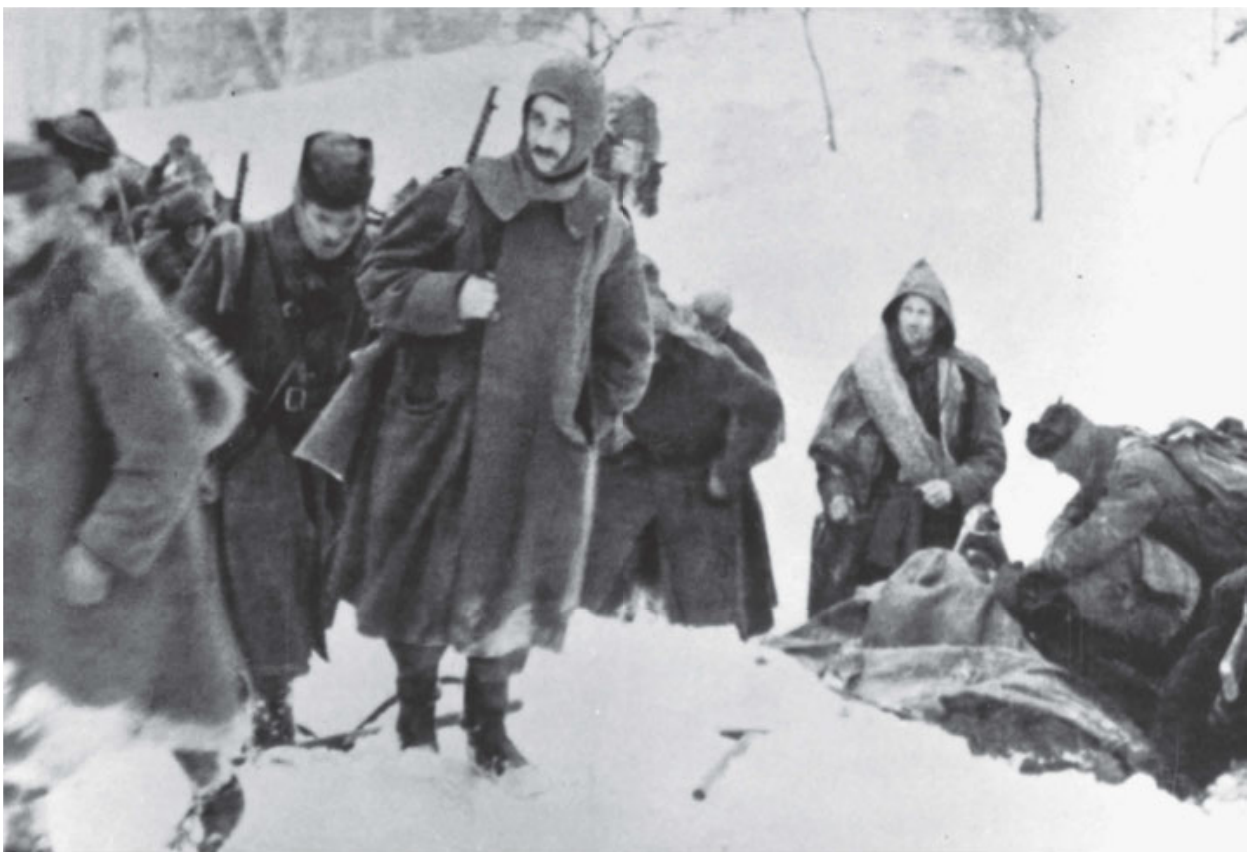

Eine der letzten Aufnahmen von Karl Destovnik-Kajuh, Paški Kozjak, 16. Februar 1944.

Foto: Jože Petek. Museum für Neuere Geschichte der Stadt Celje | FZ2910. 


\section{Politische Führer}

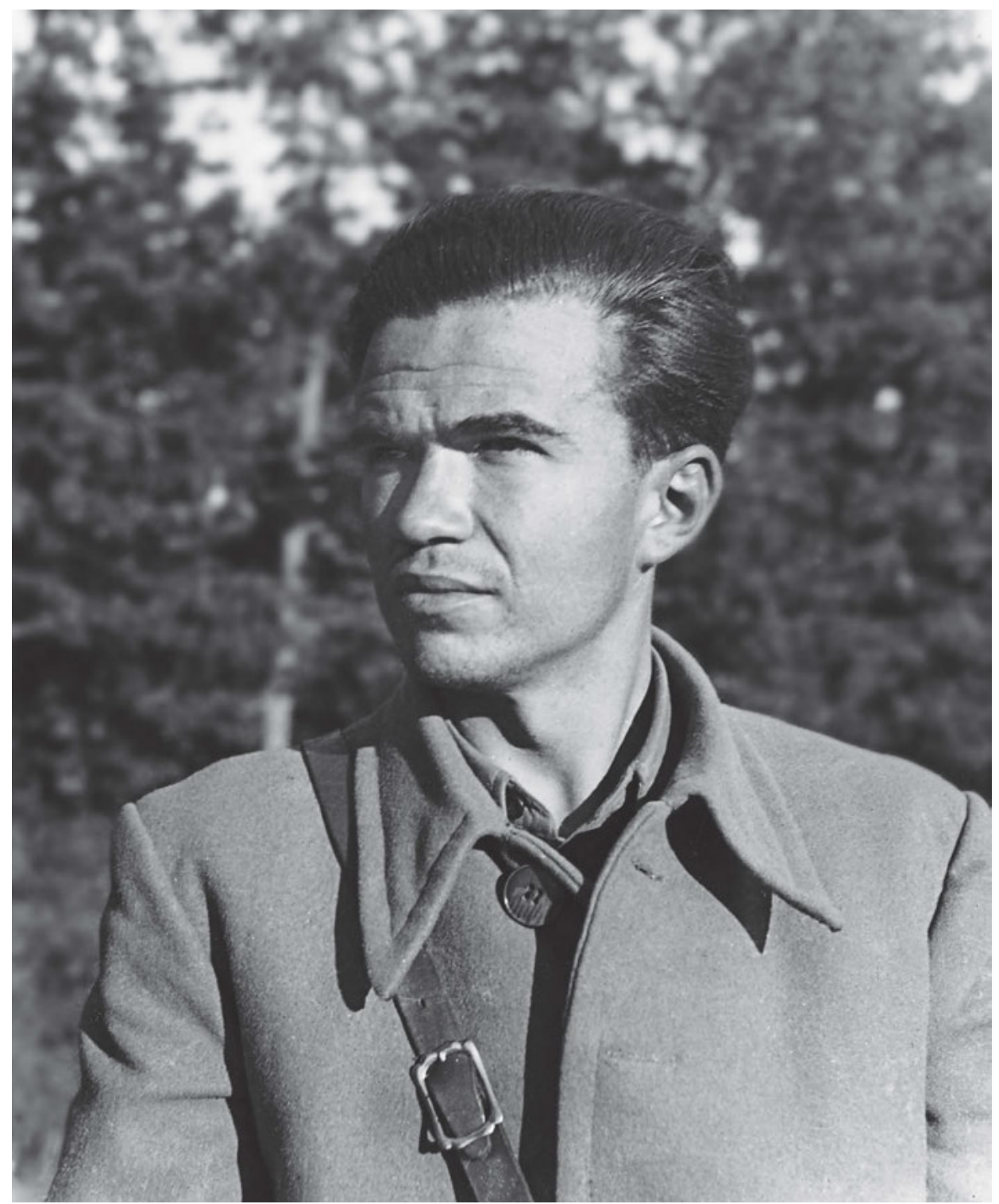

Ivo Lola Ribar. Foto: Žorž Skrigin. Belgrad, Museum Jugoslawiens | III-477. 


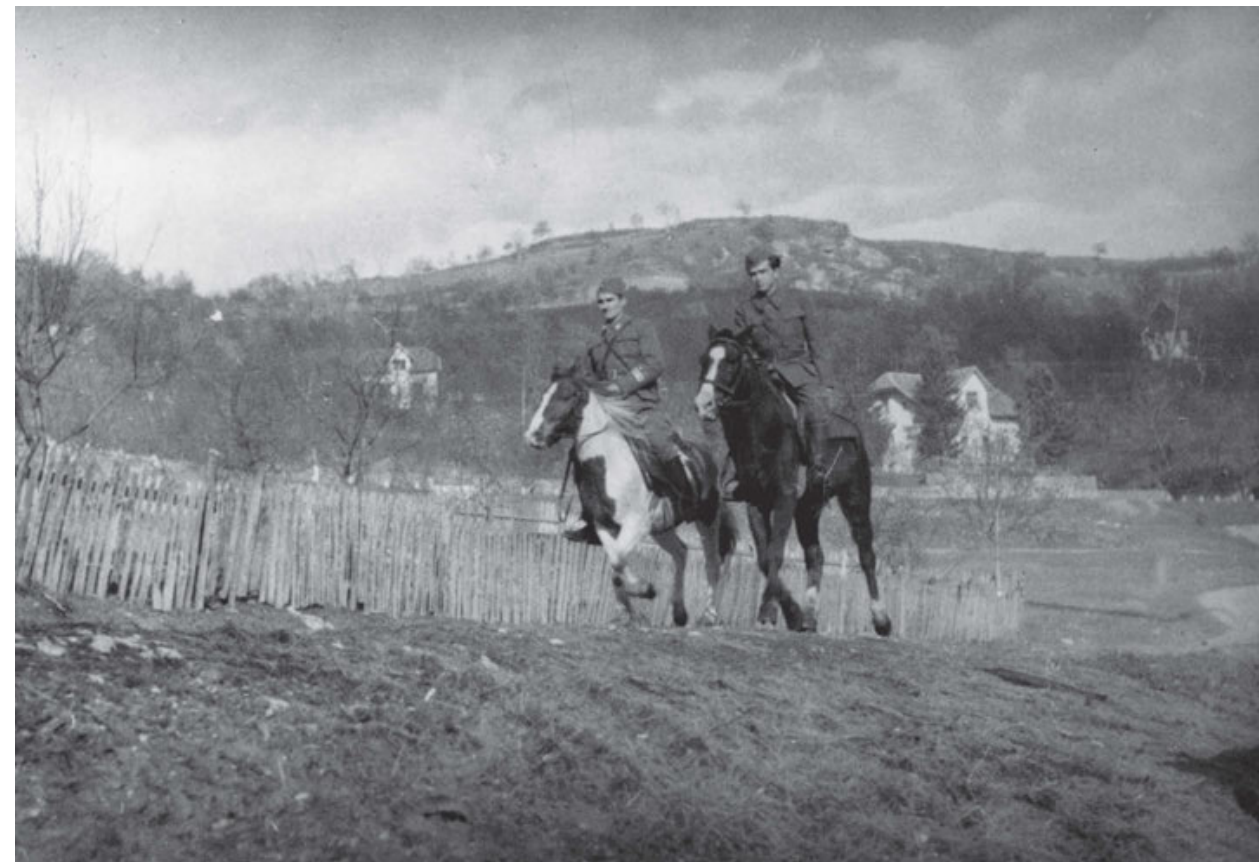

Ivo Lola Ribar und Miloje Milojević, Mitglieder der Militärmission des Oberkommandos der Volksbefreiungsarmee und der Widerstandsbewegung Jugoslawiens, beim Kommando der Alliierten für den Nahen Osten, vor dem Abflug nach Kairo und unmittelbar bevor Ivo Lola Ribar auf dem Glamoč-Feld gefallen ist. 27. November 1943. Fotograf unbekannt. Zagreb, Kroatisches Historisches Museum I HPM-MRNH-F-1073.

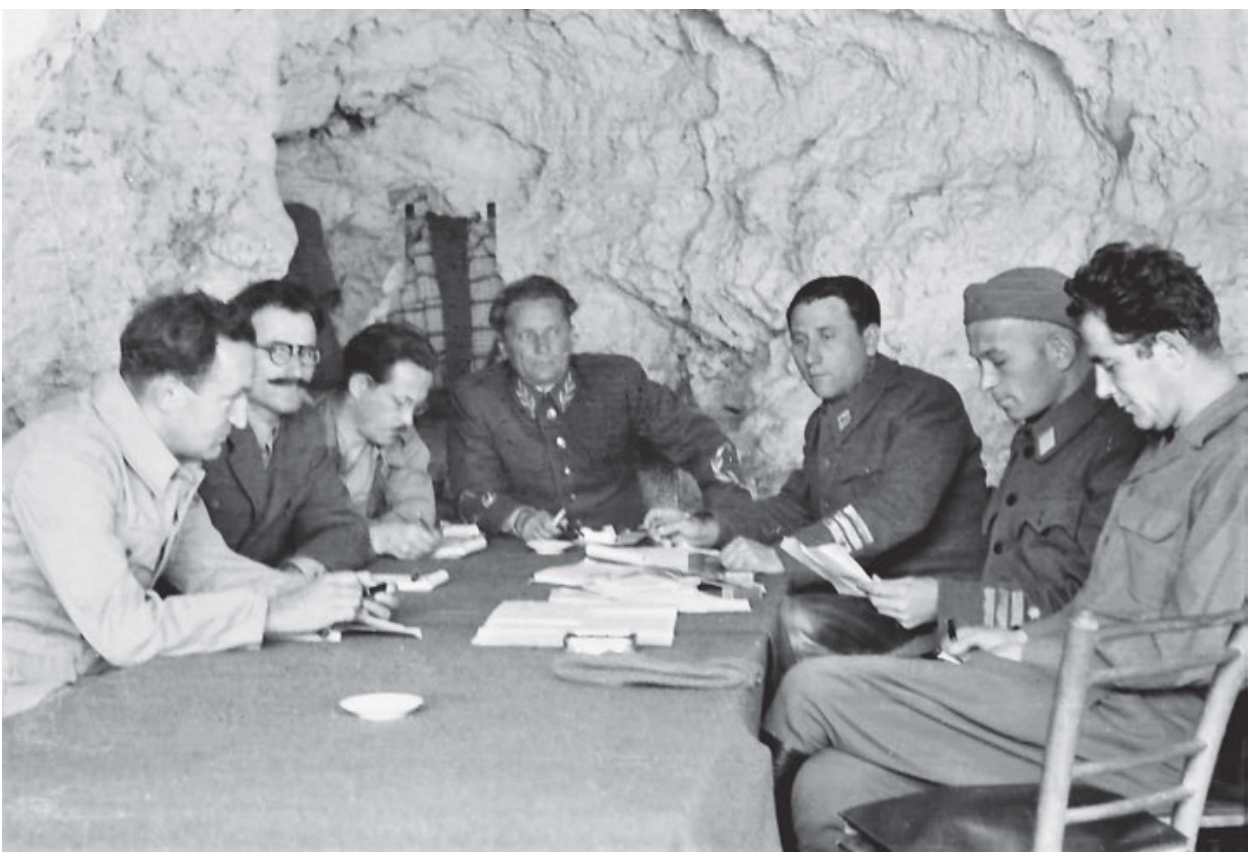

Von links nach rechts: Vladimir Bakarić, Ivan Milutinović, Edvard Kardelj, Josep Broz Tito, Aleksandar Ranković, Pavle Gregorić und Milovan Djilas, Vis, 1944. Fotograf unbekannt. Belgrad, Militärmuseum | 18679. 


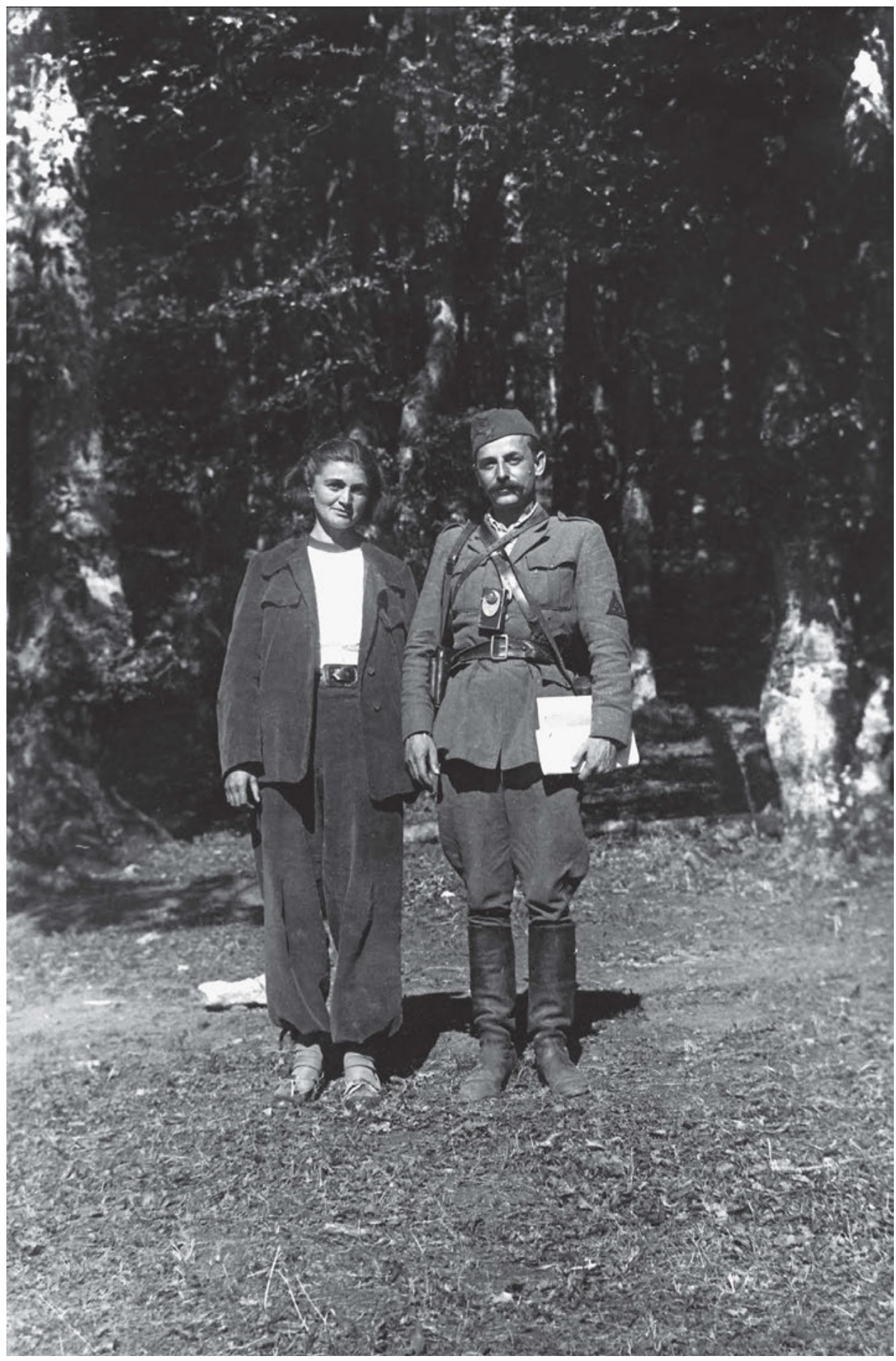

Koča Popović beim Eintreffen zu Beratungsgesprächen beim Oberkommando. Bosanska Krajina, Oštrelj, September 1942. Foto: Savo Orović. Belgrad, Museum Jugoslawiens | III-8852. 


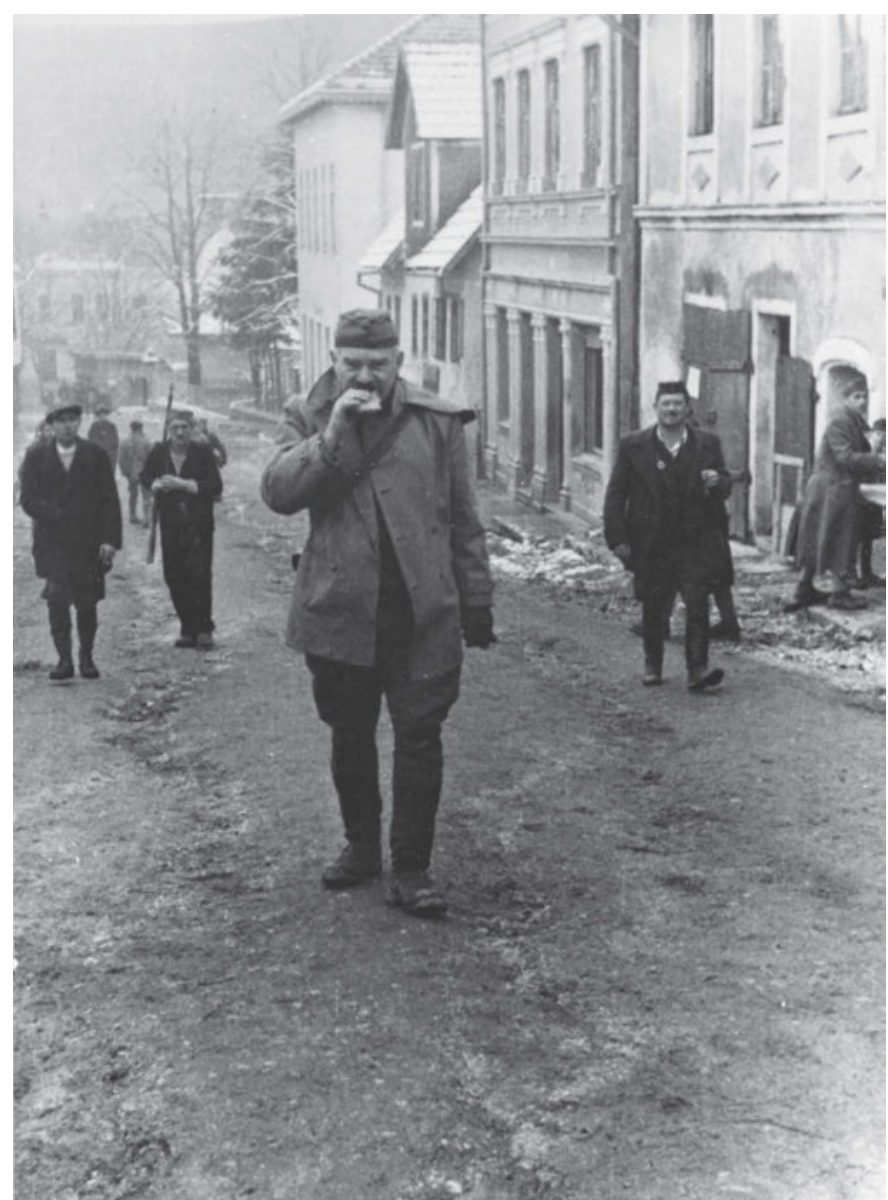

General Jakov Avšič, Abgeordneter im Antifaschistischen Rat der Volksbefreiung Jugoslawiens aus Slowenien, in Jajce. Fotograf unbekannt. Sarajevo, Historisches Museum von Bosnien und Herzegowina | FNOB 721.

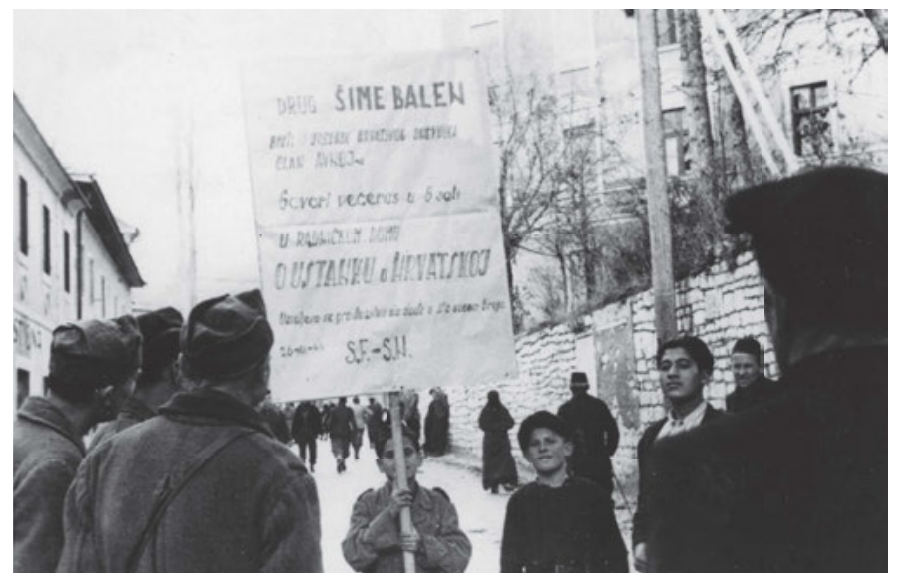

Kundgebung in Livno unmittelbar vor der Zweiten Sitzung des Antifaschistischen Rats der Volksbefreiung Jugoslawiens. Plakataufschrift: „Genosse Šime Balen spricht über den Volksaufstand in Kroatien«. 26. November 1943. Fotograf unbekannt. Sarajevo, Historisches Museum von Bosnien und Herzegowina | FNOB 726. 


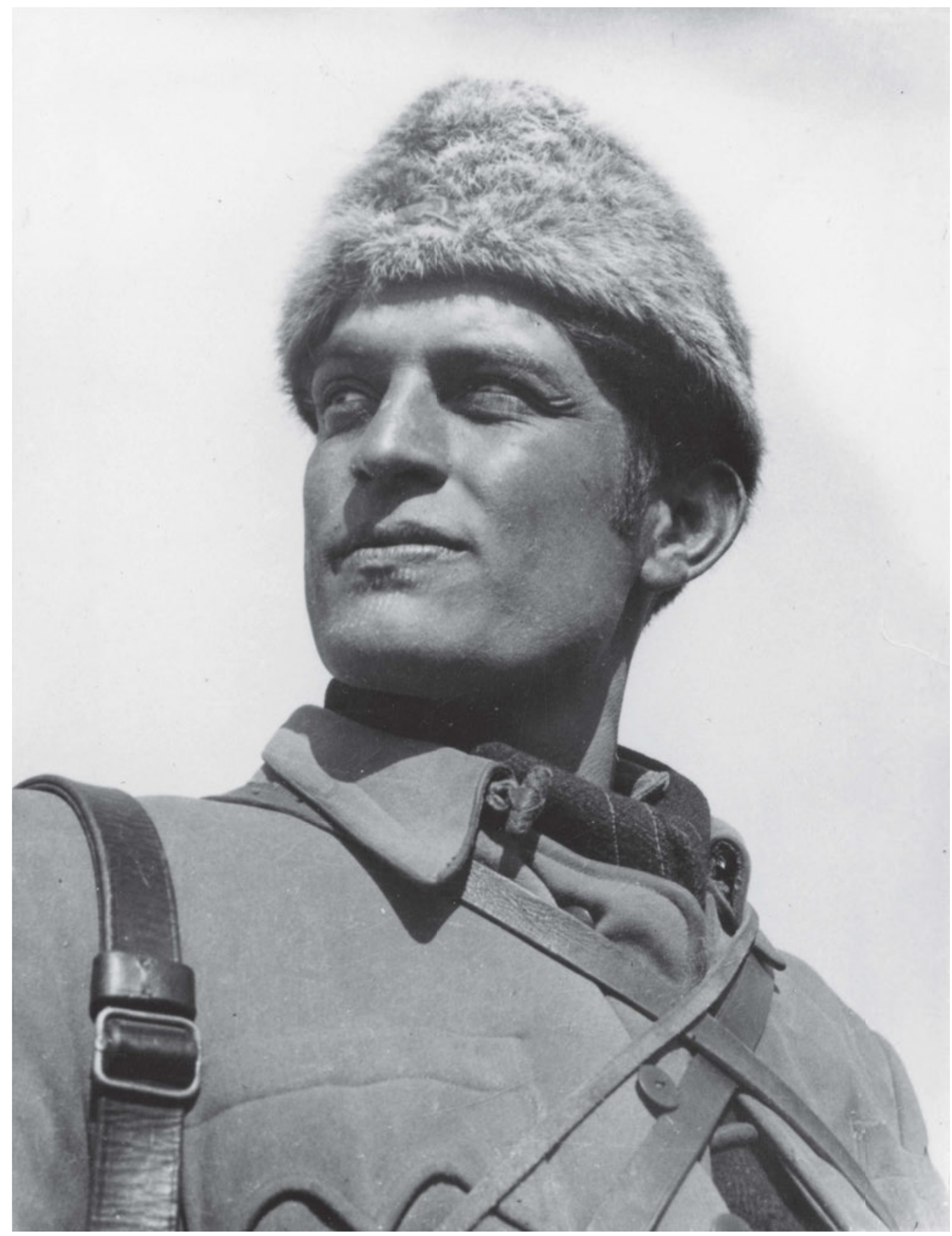

Dragiša Ivanović, Politkommissar der Fünften Montenegrinischen Brigade,

während der Vierten Offensive in Nevesinje (Operation Weiß II). Foto: Žorž Skrigin.

Sarajevo, Historisches Museum von Bosnien und Herzegowina | FNOB 6476. 


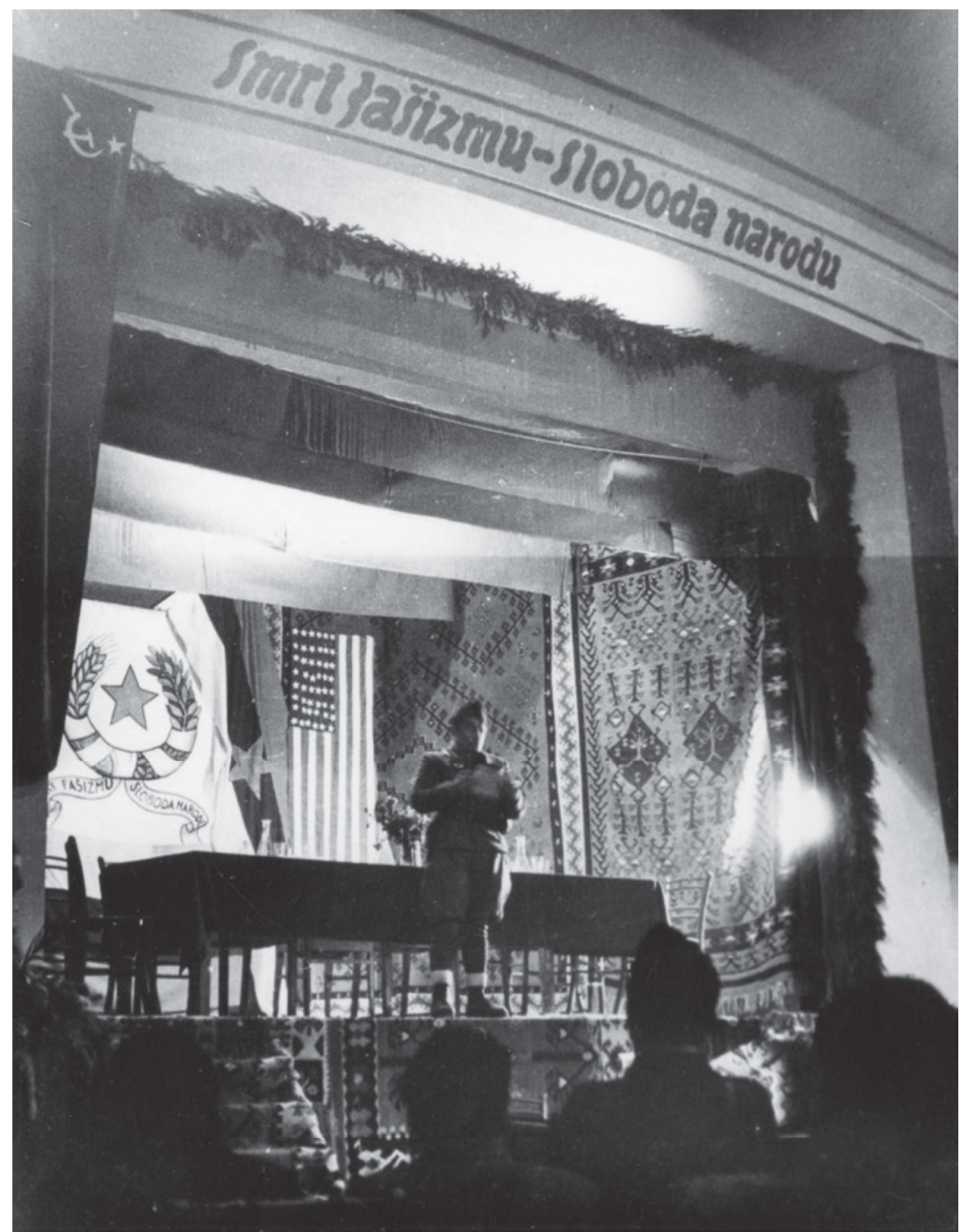

Erste Sitzung des Antifaschistischen Rats der Volksbefreiung Jugoslawiens. Foto: Žorž Skrigin. Sarajevo, Historisches Museum von Bosnien und Herzegowina | FNOB 6490. 


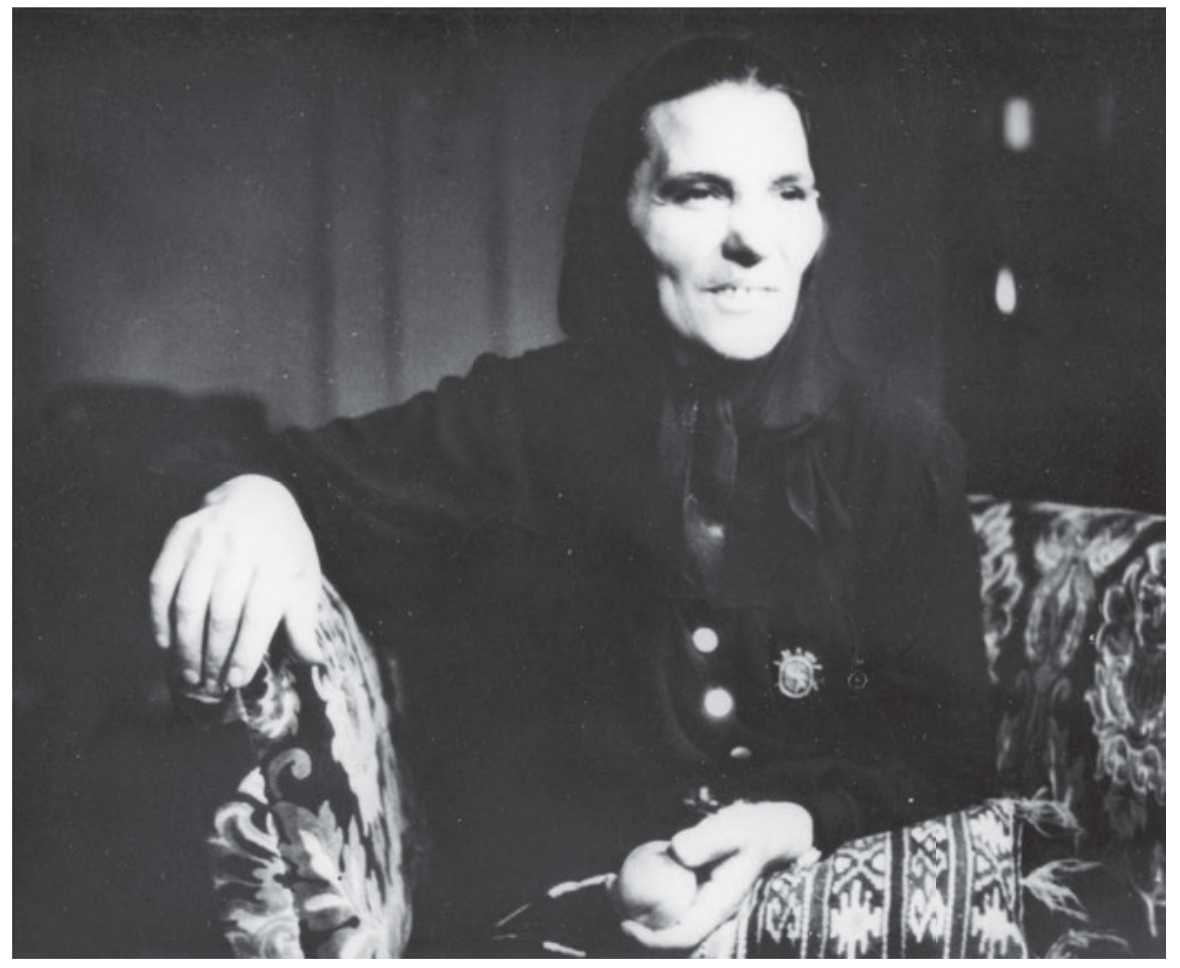

Kata Pejnović, Präsidentin der Antifaschistischen Frauenfront Kroatiens, 1945. Fotograf unbekannt. Sarajevo, Historisches Museum von Bosnien und Herzegowina | FNOB 10701.

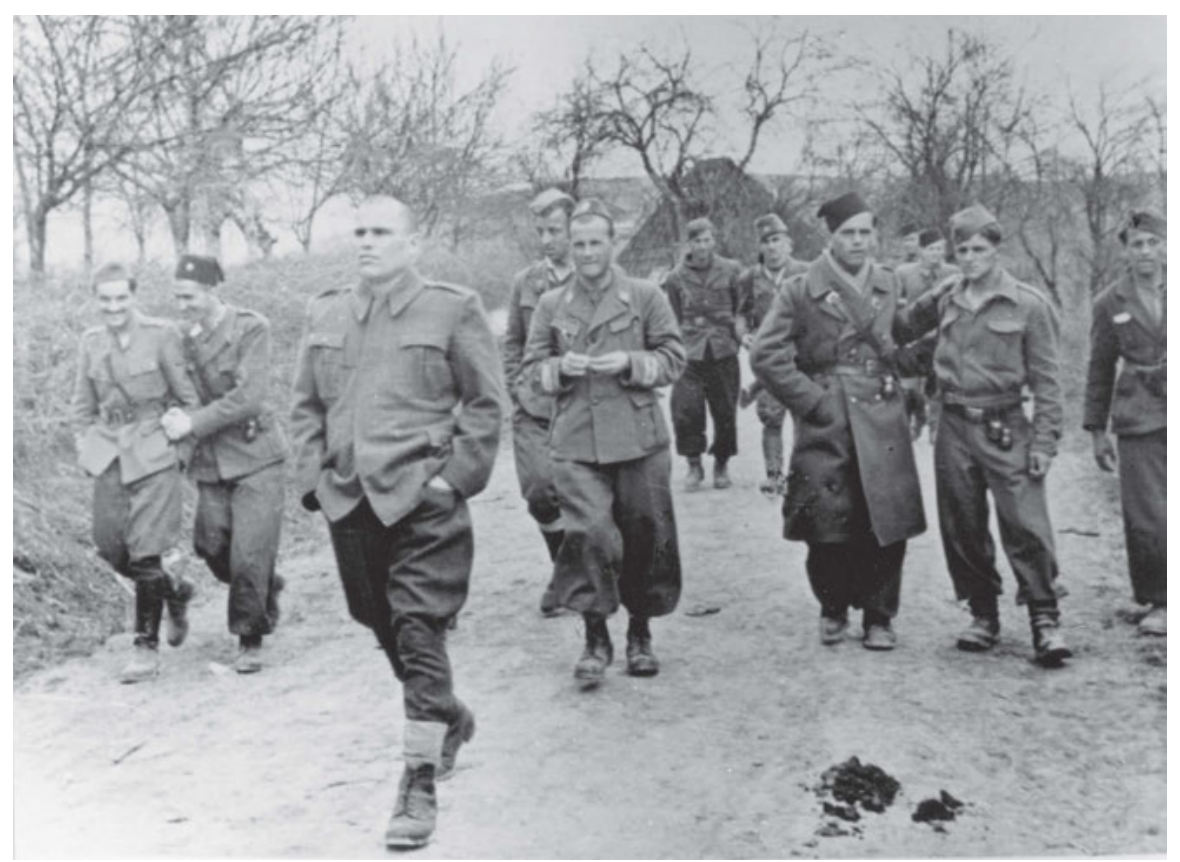

Einheiten der operativen Una-Gruppe, nachdem Husko Miljković der Widerstandsbewegung beigetreten ist. Auf dem Foto sind Offiziere, Mitglieder des Stabs mit Husko Miljković (ohne Mütze und Rangabzeichen) im Frühling 1944 zu sehen. Fotograf unbekannt. Sarajevo, Historisches Museum von Bosnien und Herzegowina | FNOB 16176. 


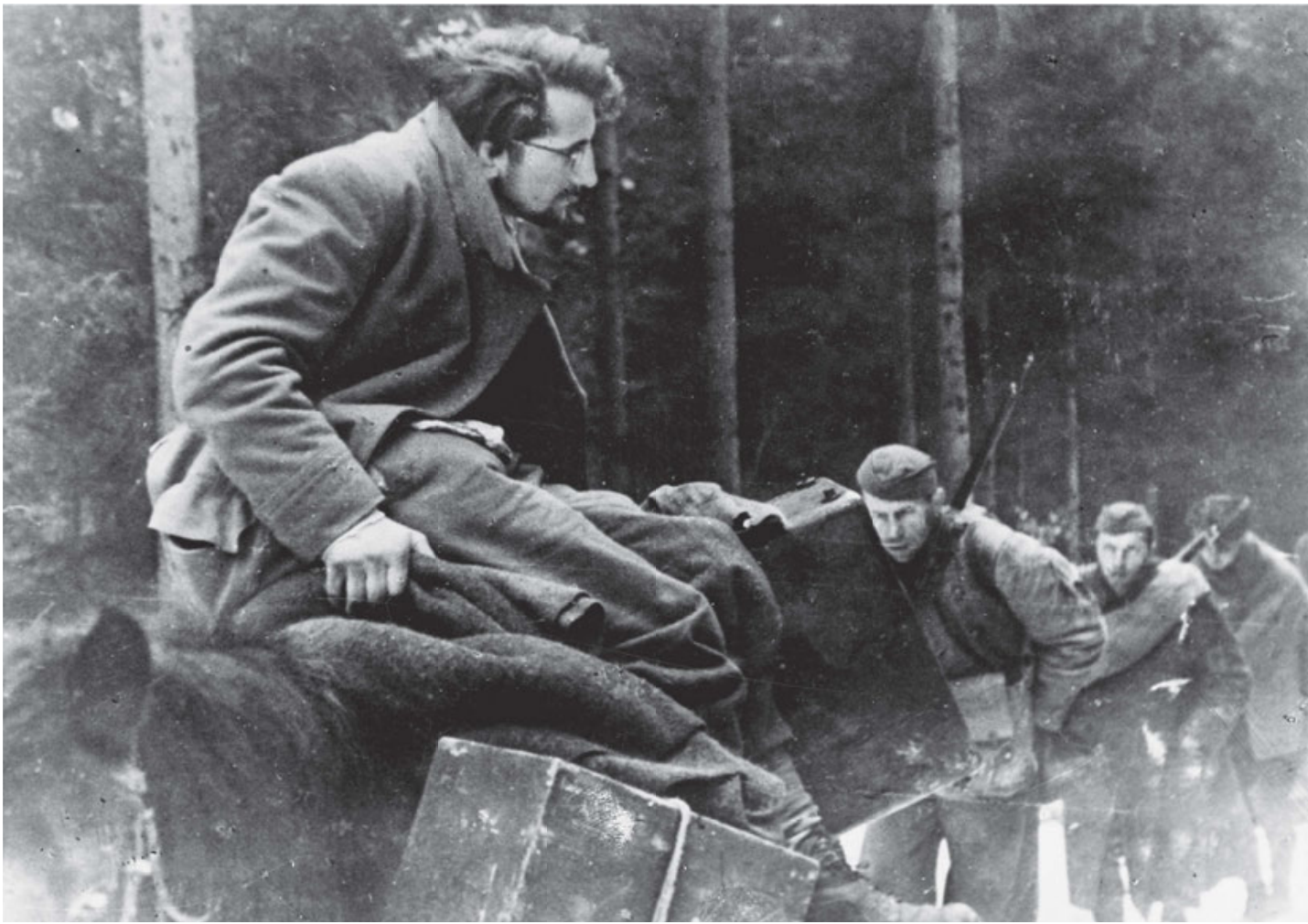

Der verwundete Franc Šlajph, Politkommissar der Bračič-Brigade, bei dem Durchbruch der deutschen Stellungen auf der Straße von Šoštanj nach Črna am 22. Februar 1944, der später gefangen genommen und ermordet wurde. Foto: Jože Petek. Ljubljana, Museum für Neuere Geschichte Sloweniens | pl7898a.

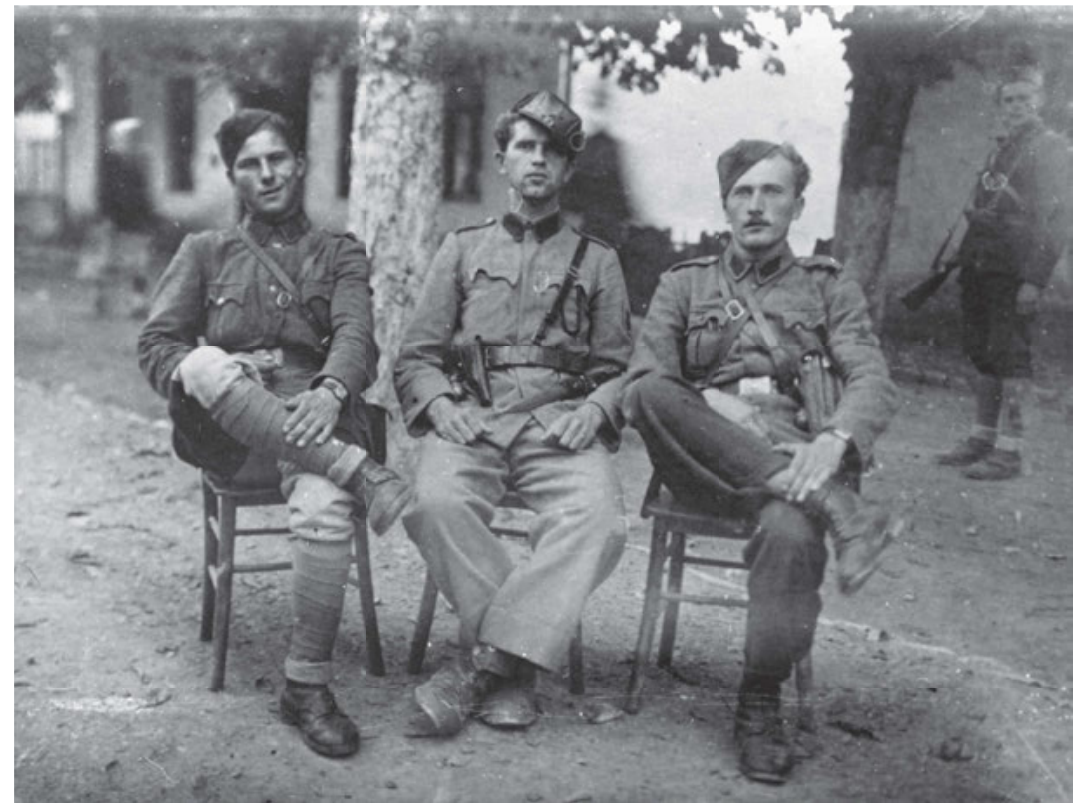

Von links nach rechts: Dragan Milašin, Kommandant des Bataillons der 14. Brigade, Brane Babić und ein Soldat namens Milan. Zentralbosnien, 1944. Fotograf unbekannt. Sarajevo, Historisches Museum von Bosnien und Herzegowina | FNOB 16969. 


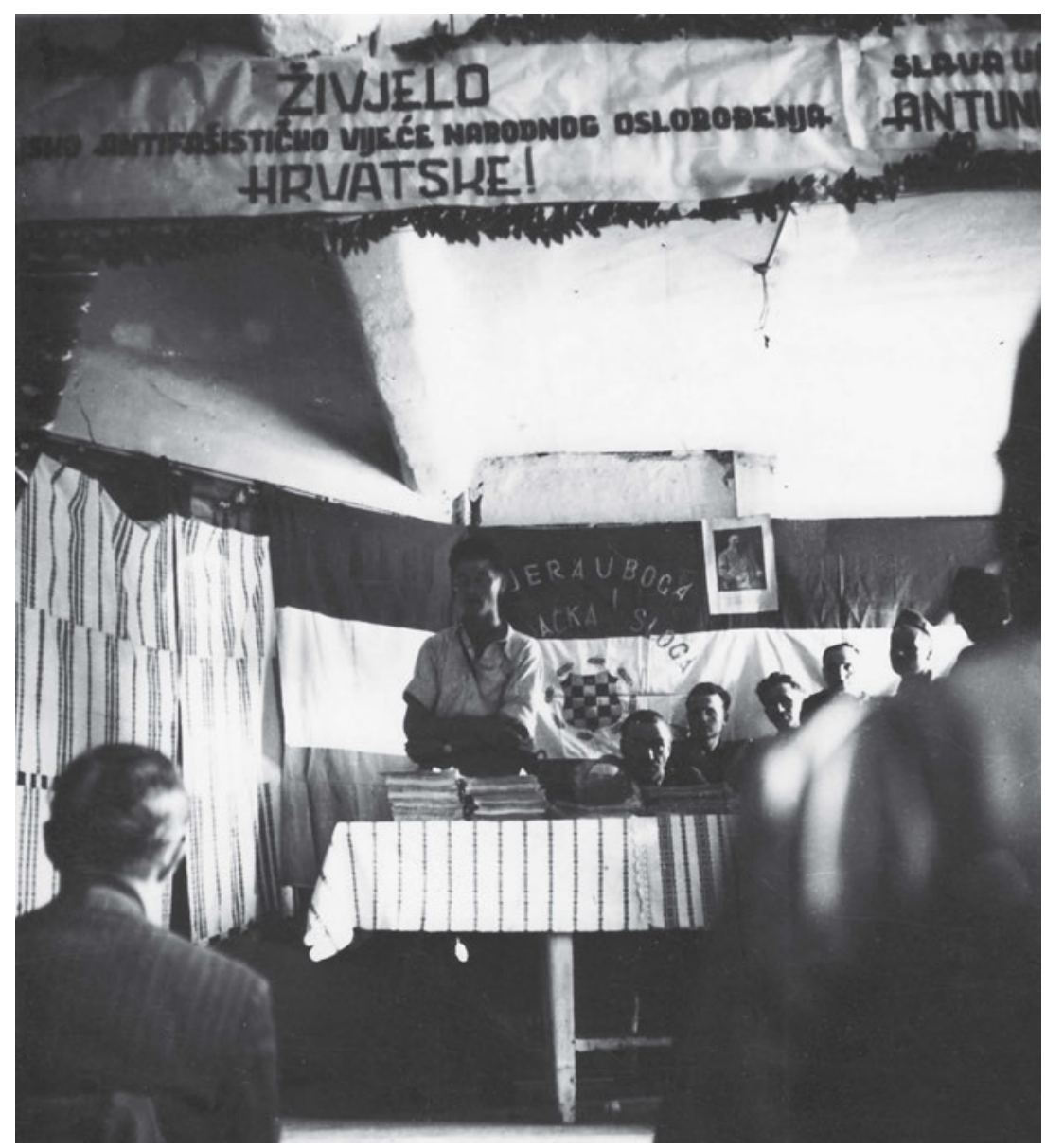

Konferenz mit Vertretern der Kroatischen Bauernpartei in Voćin, 1943. Fotograf unbekannt. znaci.net.

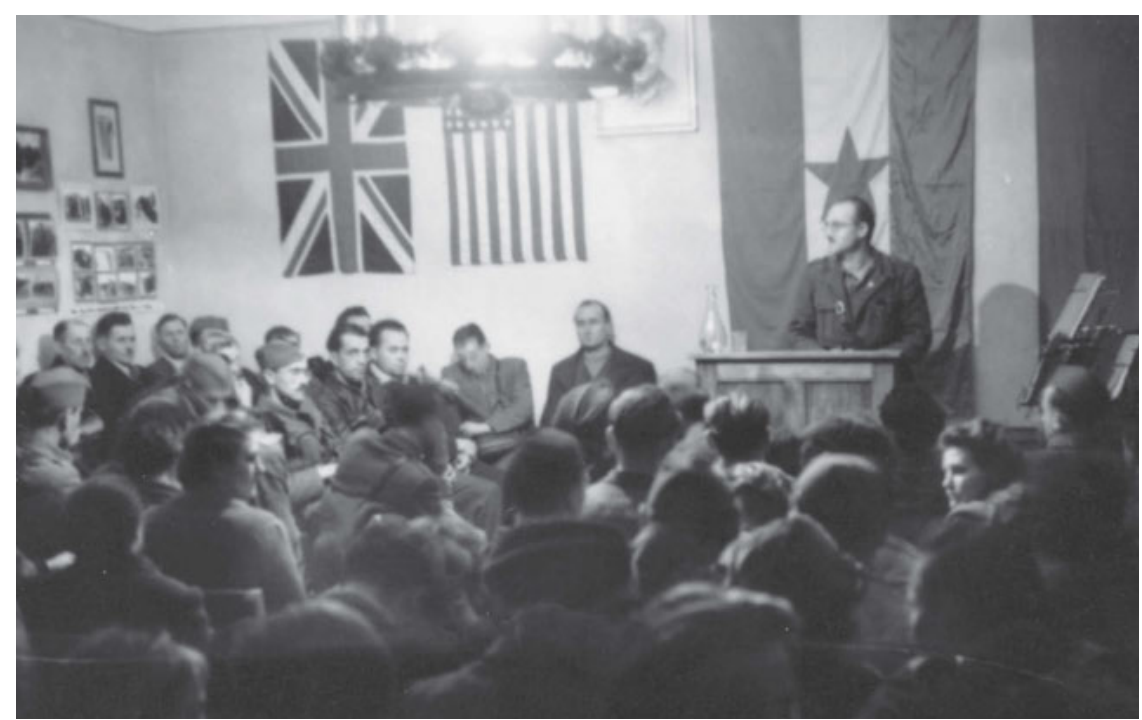

Versammlung der Propagandisten, Mitglieder der Volksbefreiungsarmee und der Widerstandsbewegung der Befreiungsfront für die Steiermark. Am Rednerpult Dušan Bole in Gornji Grad, Save-Tal. Fotograf unbekannt. Museum für Neuere Geschichte der Stadt Celje | FZ2 1587. 


\section{Darstellungen von Josip Broz Tito}

Die Darstellung des Oberkommandierenden der Partisanen Josip Broz Tito hat im Verlauf des Zweiten Weltkriegs eine bedeutende Transformation erfahren. Zu Beginn wussten viele Partisanen und auch der feindliche Geheimdienst nicht, wie Tito in Wirklichkeit aussah, was eine Folge seines langjährigen höchst illegalen Wirkens unter dem Decknamen Ingenieur Slavko Babić war. Die erste Fotografie Titos unter Partisanen wurde 1942 in Foča aufgenommen. Es gab auch Mutmaßungen, was hinter dem Spitznamen Tito steckte, wobei eine der märchenhaftesten Erklärungen lautete, dass es sich um ein Akronym aus »TriInternationale - terroristische Organisation« handelt.

Die Fotografie wurde erstmals in der Zeitung Borba vom 6. Dezember 1942 und in den Medien der Alliierten, der New York Times, am 5. Dezember 1943 publiziert. Einer der ersten Fotografen Josip Broz Titos war Žorž Skrigin, der ihn am 14. September 1942 im Ort Mlinište ablichtete. Aufnahmen von Tito gelangen auch Savo Orović, dessen Partisanenfotografien sich unter anderem laut Nikolina Kurtović wegen ihrer »Unzeitgemäßheit« und der schlechten Qualität nicht für eine Veröffentlichung in westlichen Medien geeignet hätten. Kurtović zufolge hätte die Partisanenfotografie für die Redakteure des Magazins Life eine seltsame Ausstrahlung gehabt, Skrigins Piktorialismus wäre vergleichsweise »altmodisch, während Orovićs amateurhafter Ansatz wiederum zu wenig persönlichen Stil und formale Politur « geboten hätte. ${ }^{1}$ Die Autorin führt an, dass die Partisanen sich auf die Tradition der Uskoken und Haiducken stützten, obwohl dies tatsächlich für die Tschetnik- und der Ustascha-Bewegung, am wenigsten jedoch für die Partisanenbewegung galt.

Solchen und ähnlichen Deutungen der Partisanenfotografie sind vor allem die Produktionsbedingungen entgegenzustellen. Zu betonen ist aber auch, dass gerade Skrigin vor dem Krieg internationale Erfolge aufzuweisen hatte - er erhielt zahlreiche Auszeichnungen, einschließlich des Preises für die Fotografie Proljeće (Frühling) 1939 in San Francisco. Wie die meisten anderen Fotografen entwickelte Skrigin seine Bildsprache während des Krieges weiter. Er wandte sich von piktorialistischen Themen ab, folgte - im Gegensatz zu vielen westlichen Fotografen - seiner künstlerischen Intuition und wusste die vor dem Krieg erworbenen Kenntnisse der Fotografie anzuwenden. Als Anhänger der Zagreber Schule stand er sicherlich unter dem Einfluss des Piktorialismus, doch zweifelsohne auch 
unter dem Einfluss der Neuen Sachlichkeit. Im Hinblick auf das Verhältnis zwischen westlicher Zeitungs- und jugoslawischer Partisanenfotografie ist der Vergleich von Skrigins Fotografie Majka Knežopoljka mit den Aufnahmen einer Mutter mit ihren Kindern von John Phillips, Fotograf der Nachrichtenagentur Reuters, lohnenswert. Beide Fotografen näherten sich dem Thema identisch - mit dem einzigen Unterschied, dass Phillips Fotografie wegen der besseren Produktionsbedingungen von technisch höherer Qualität ist. In den Medien der Alliierten wurde die Partisanenbewegung aus kolonialer Perspektive betrachtet, gleichzeitig bezeichnete man die Partisanen oftmals als unorganisierte Guerillagruppen.

Vor der Veröffentlichung der Fotografien von Tito nahmen die Geschichten über den bis dahin unsichtbaren Kommandanten nahezu mythische Formen an, die feindliche Propaganda zweifelte gar seine Existenz an. Die Propaganda der Ustascha behauptete, die Partisanenbewegung sei besiegt und liquidiert, während in der deutschen Zeitschrift Signal Fotografien des Oberkommandos erschienen. Die Kommunistische Partei, die in den Jahren vor dem Krieg gezwungen war, im Untergrund zu agieren, entschloss sich aus drei Gründen zur Veröffentlichung der Fotografien von Tito: um seine Existenz zu bestätigen und die Geschichten zu dementieren, es handele sich lediglich um eine fiktive Persönlichkeit, sowie um der Verbreitung von auf Unwahrheiten beruhenden Geschichten und Mythen über das Oberkommando ein Ende zu bereiten und die Moral der Widerstandskämpfer zu stärken. Auf der anderen Seite ebneten diese Fotografien den Weg für die Etablierung eines Personenkults. Viele Jahre später wurde beim Kampf der Zapatisten in Mexiko zu Zwecken eines Medienspektakels die Figur des Subcomandante Marcos erschaffen, ohne jedoch seine Identität zu offenzulegen. »Die Zapatisten verhüllten ab den ersten Tagen des Aufstands ihre Gesichter mit Sturmhauben und Bandanatüchern, um anonym zu bleiben und keine Führungsfiguren zuzulassen « - geleitet von dem Wunsch, auf diese Weise ein kollektives Wesen hervorzubringen und nicht einen charismatischen Anführer in den Vordergrund zu stellen. ${ }^{2}$

Skrigin fotografierte Tito ein zweites Mal 1943 während der Zweiten Sitzung des Antifaschistischen Rates der Volksbefreiung Jugoslawiens, wovon seine detaillierten Aufzeichnungen zeugen:

"Es war wolkig und es nieselte, sodass ich deswegen Onkel Janko [Moša Pijade - Anmerkung D. K.] zu erklären versuchte, dass ich für die Qualität der Fotografien nicht garantieren könnte. ,Du schon wieder! ... Du und Deine künstlerischen Geschichten! ... Du musst ihn heute fotografieren und nicht dann, wenn die Sonne scheint!« Ich versuchte Onkel Janko nicht weiter zu widersprechen. [...] Das Wetter und die Belichtung sagten mir nicht zu, da dunkle Regenwolken den Himmel bedeckten. Und dennoch begann ich zu fotografieren, bemüht, alles technisch zu bewältigen. $\aleph^{3}$

Bei diesem Anlass fotografierte Skrigin Tito aus leichter Untersicht als entschlossenen Führer, just an jenem Tag, als Tito zum Marschall erklärt wurde. Skrigin beabsichtigte, auf

2 Memou, Antigoni. Photography and Social Movements. Manchester und New York: Manchester University Press 2013, S. 35.

3 Skrigin, Žorž. Rat i pozornica. Belgrad: Turistička štampa 1968, S. 218. 
diese Weise seine Größe und durch den in die Ferne gerichteten Blick das Visionäre zu suggerieren. Er nutzte das harte Licht, um die scharfen Gesichtszüge hervorzuheben und damit seine Stärke zu betonen.

Titos repräsentative Verwandlung zum Staatsmann zeigen am eindrücklichsten jene Fotografien, die John Phillips am 12. Mai 1944 auf der Insel Vis schuf. Phillips war auf Einladung von Vladimir Dedijer gemeinsam mit Stojan Pribićević auf die Insel gereist. Es galt Fotografien aufzunehmen, mit denen man die bis dahin bestehende Medienblockade der Alliierten durchbrechen würde. ${ }^{4}$ Auf den Fotografien von Phillips wird Tito wie ein amerikanischer Hollywoodstar präsentiert, als starker und männlich wirkender Oberkommandierender, stilvoll, intelligent, mit vornehmen Manieren und festem Charakter. Die Aufnahmen zeigen ihn beim Schachspiel, wodurch gute strategische Fähigkeiten suggeriert wurden. Man zeigte ihn wie einen Star der amerikanischen Popkultur jener Zeit. Für die auf der Insel Vis entstandenen Fotos posierte er mit seinem Hund, dem deutschen Schäferhund Tiger, was damals bei vielen Staatsmännern Mode war - Roosevelt ließ sich mit seinem geliebten schottischen Terrier und Churchill mit seinen Pudeln ablichten.

Vor dem Objektiv war sich Tito vollends seiner eigenen Erscheinung, der Bedeutung der Repräsentation und des Publikums bewusst, an das er sich wandte. Auf diesen Fotografien sieht Tito ganz anders aus als auf den Bildern aus dem Jahr 1942 in Foča, wobei er Phillips bei den späteren Aufnahmen Folgendes sagte: „Sie können mich den ganzen Tag fotografieren, doch verlangen Sie nicht, dass ich Ihnen posiere. Es würde unnatürlich wirken. $\aleph^{5}$ Mit dieser, wenngleich ein wenig abgeänderten Feststellung sollte auch Phillips Artikel beginnen, der erst Monate nach dem Treffen im Magazin Life gedruckt wurde. ${ }^{6}$ Bei seiner ersten Zusammenkunft mit Winston Churchill trug Josip Broz Tito sein Marschallabzeichen nicht, im Unterschied zur zweiten Begegnung, bei der ihm Churchill eine eigenhändig unterschriebene Fotografie als Zeichen für die endgültige Anerkennung Titos wie auch der Partisanenbewegung schenkte. ${ }^{7}$

Wie bereits dargelegt wurde, führte die Partisanenbewegung während des gesamten Krieges neben dem bewaffneten Kampf auch einen Kampf auf der Ebene der Repräsentation. In den USA hingen zum Beispiel ab Mitte 1942 Fotografien des Tschetnik-Führers Dragoljub Draža Mihailović zusammen mit dem Bild von Präsident Franklin Roosevelt in öffentlichen Räumen. ${ }^{8}$ Tito galt als Anführer und Politiker, der selbstsicher vor der Kamera auftrat, und Walter Bernstein war der Ansicht, Titos Auftreten würde dem eines guten Schauspielers entsprechen. ${ }^{9}$ Nach vier Jahren, in denen die Partisanenbewegung auf der Ebene der Repräsentation gänzlich ignoriert wurde, stieg Tito in der amerikanischen Presse schließlich zur Ikone des antifaschistischen Kampfes in Jugoslawien auf. Phillips fotografierte und arbeitete auch nach Kriegsende in Jugoslawien.

4 Phillips, John. Jugoslovenska priča. Belgrad: Jugoslovenska revija 1983, S. 31.

5 Ebd., S. 34.

Phillips, John. Marshal Tito. In: Life, 16, Nr. 17, 1944, S. 35-38.

Maclean, Fitzroy. The Life and Times of Josip Broz-Tito, New York: Harper 6c Brothers 1957, S. 211.

Petranović, Branko. Istorija Jugoslavije 1918-1988. Bd. 3: Socijalistička Jugoslavija 1945-1988. Belgrad: Nolit 1988, S. 186.

Bernstein, Walter. Interview with Tito of Yugoslavia. In: Yank Magazine, 16.06.1944, S. 8-9. 


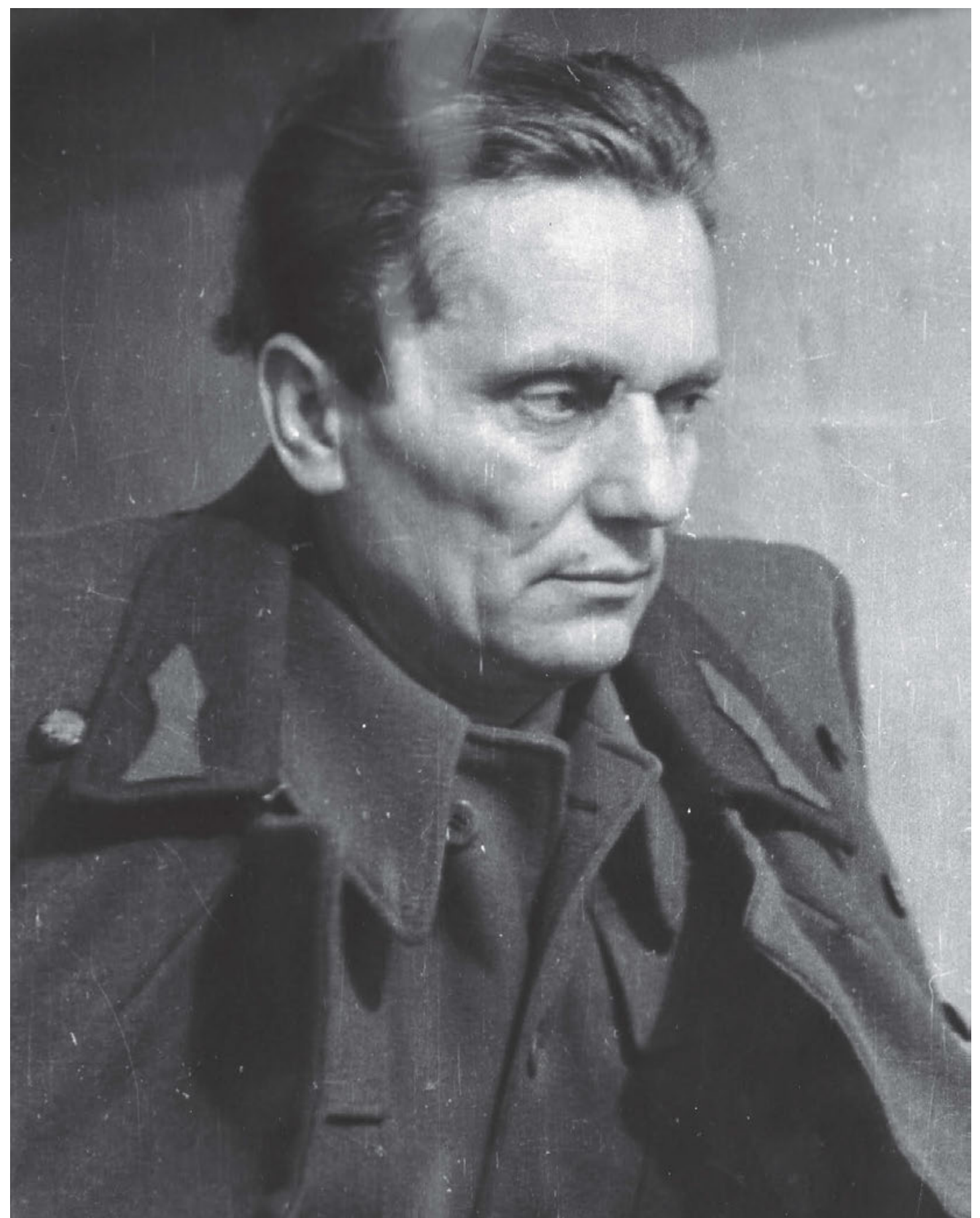

Josip Broz Tito zur Zeit der Zweiten Sitzung des Antifaschistischen Rats der Volksbefreiung Jugoslawiens am 29. und 30. November 1943 in Jajce. Foto: Žorž Skrigin. znaci.net. 


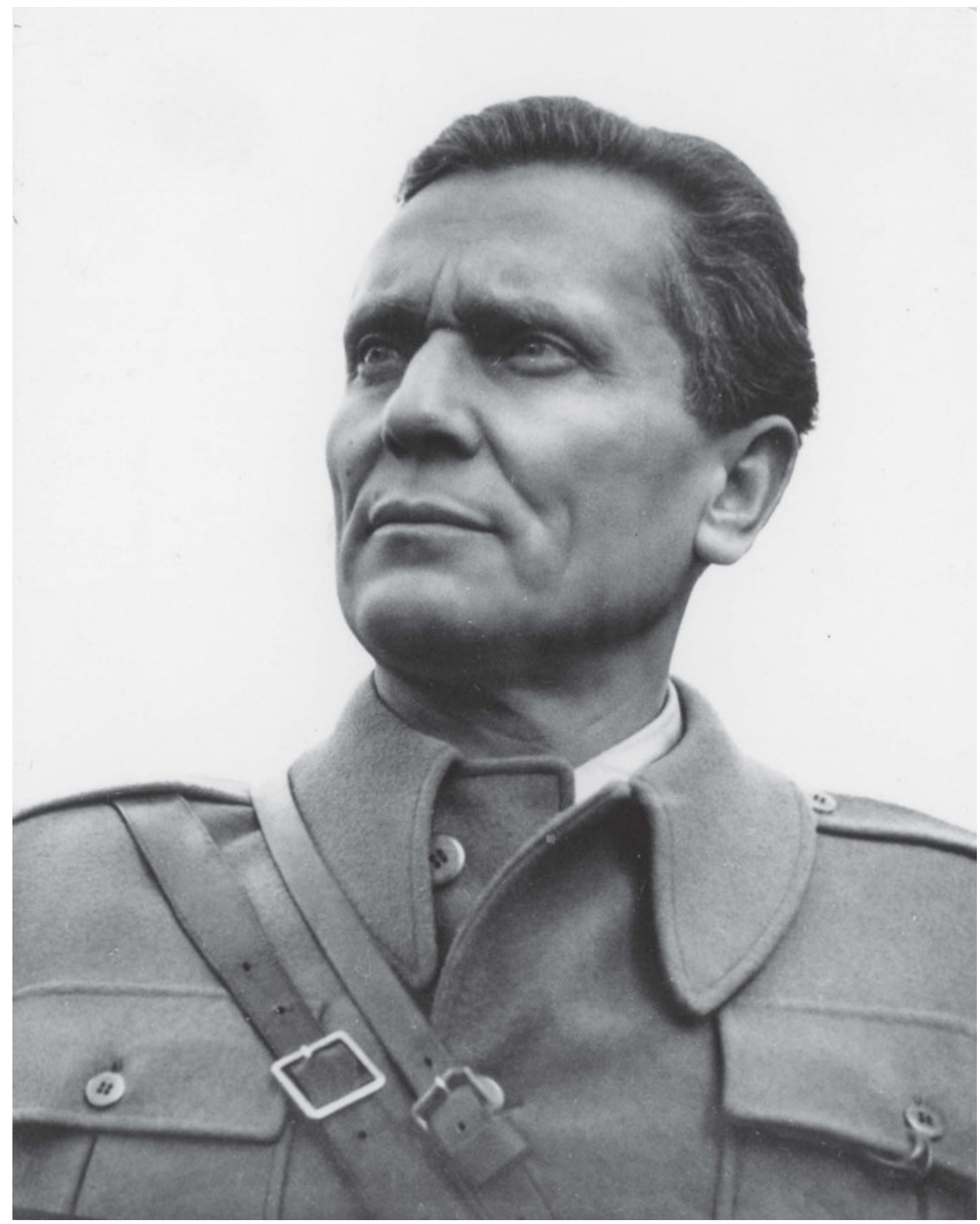

Josip Broz Tito am Tag seiner Ernennung zum Marschall Jugoslawiens in Jajce, 29. November 1943. Foto: Žorž Skrigin. Sarajevo, Historisches Museum von Bosnien und Herzegowina | FNOB 2954. 


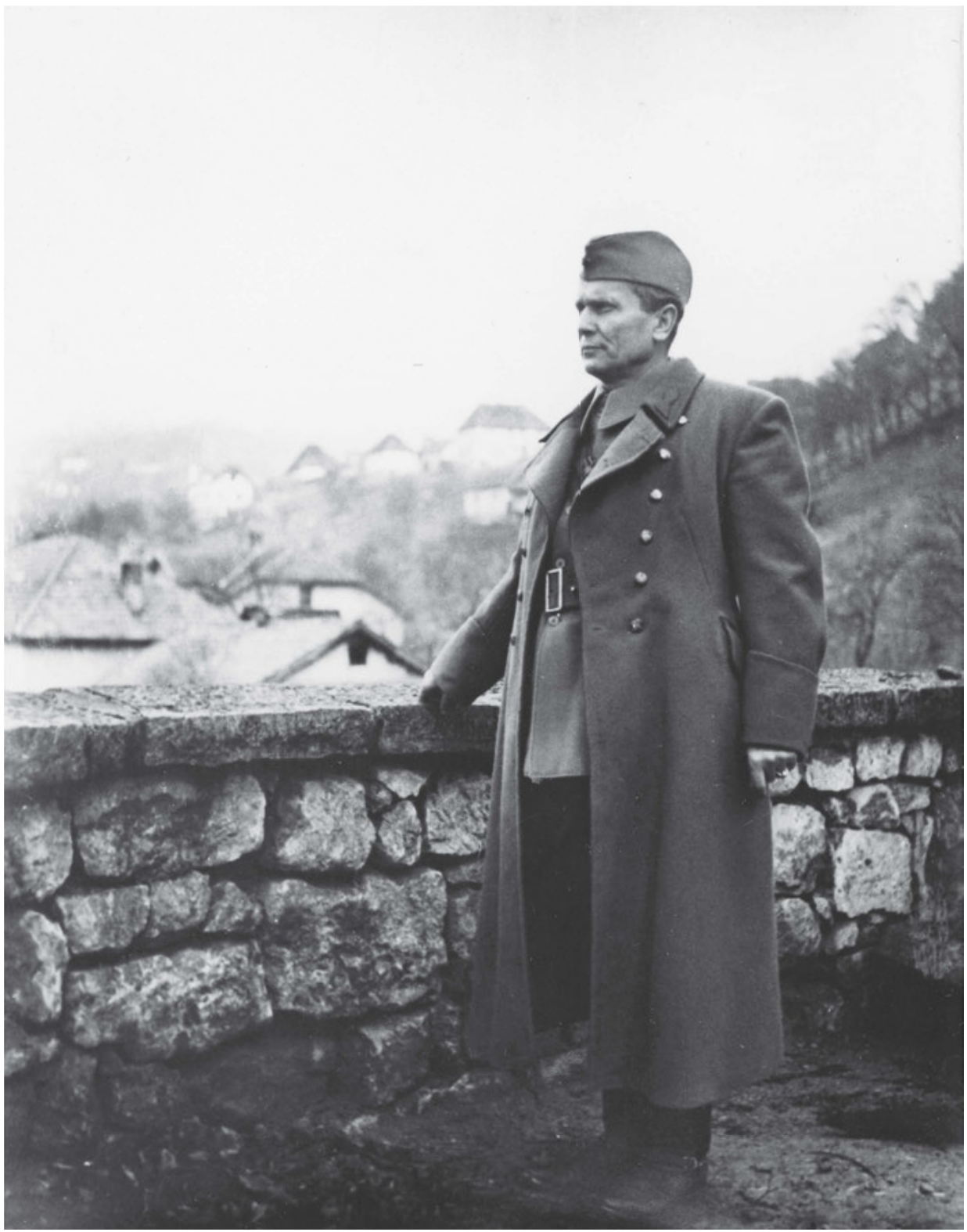

Josip Broz Tito am Tag seiner Ernennung zum Marschall Jugoslawiens in Jajce,

29. November 1943. Foto: Žorž Skrigin. Sarajevo, Historisches Museum von Bosnien und Herzegowina | FNOB 2955. 


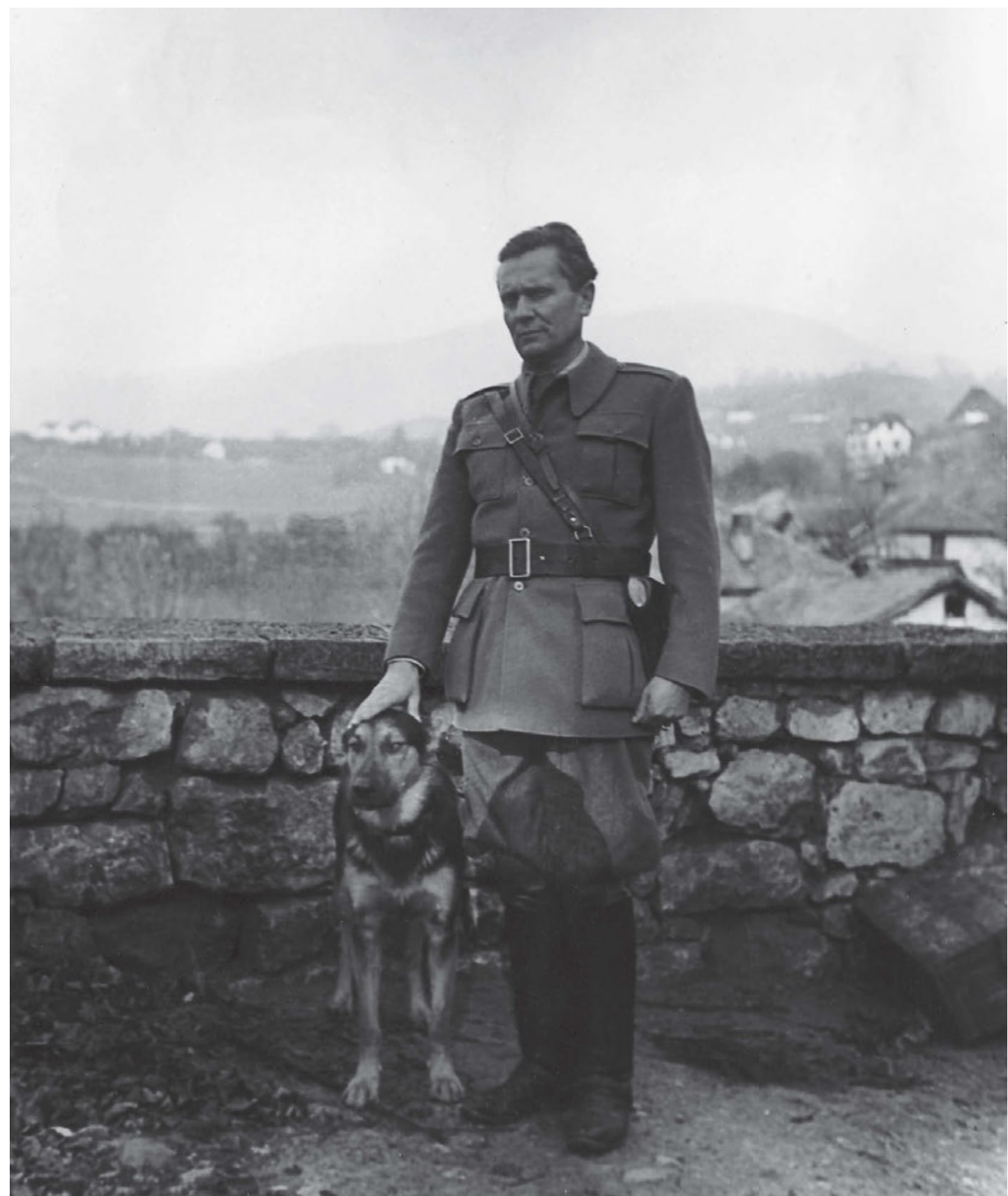

Josip Broz Tito in Jajce unmittelbar vor der Zweiten Sitzung des Antifaschistischen Rats der Volksbefreiung Jugoslawiens. Foto: Žorž Skrigin. Belgrad, Museum Jugoslawiens | III-444. 


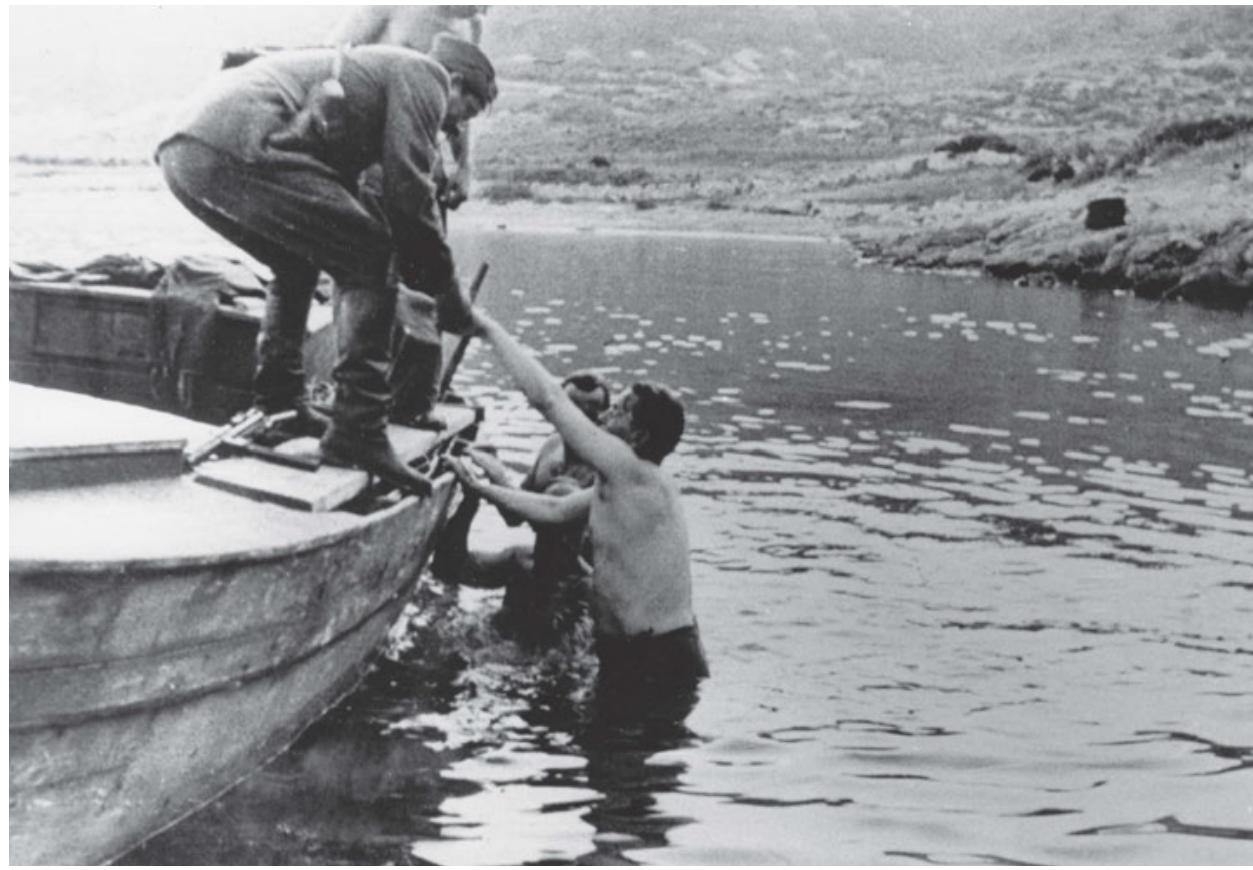

Josip Broz Tito auf der Insel Vis, Juli 1944. Split, Museum der Volksrevolution | Album III/2, Serie 126 (16). znaci.net.

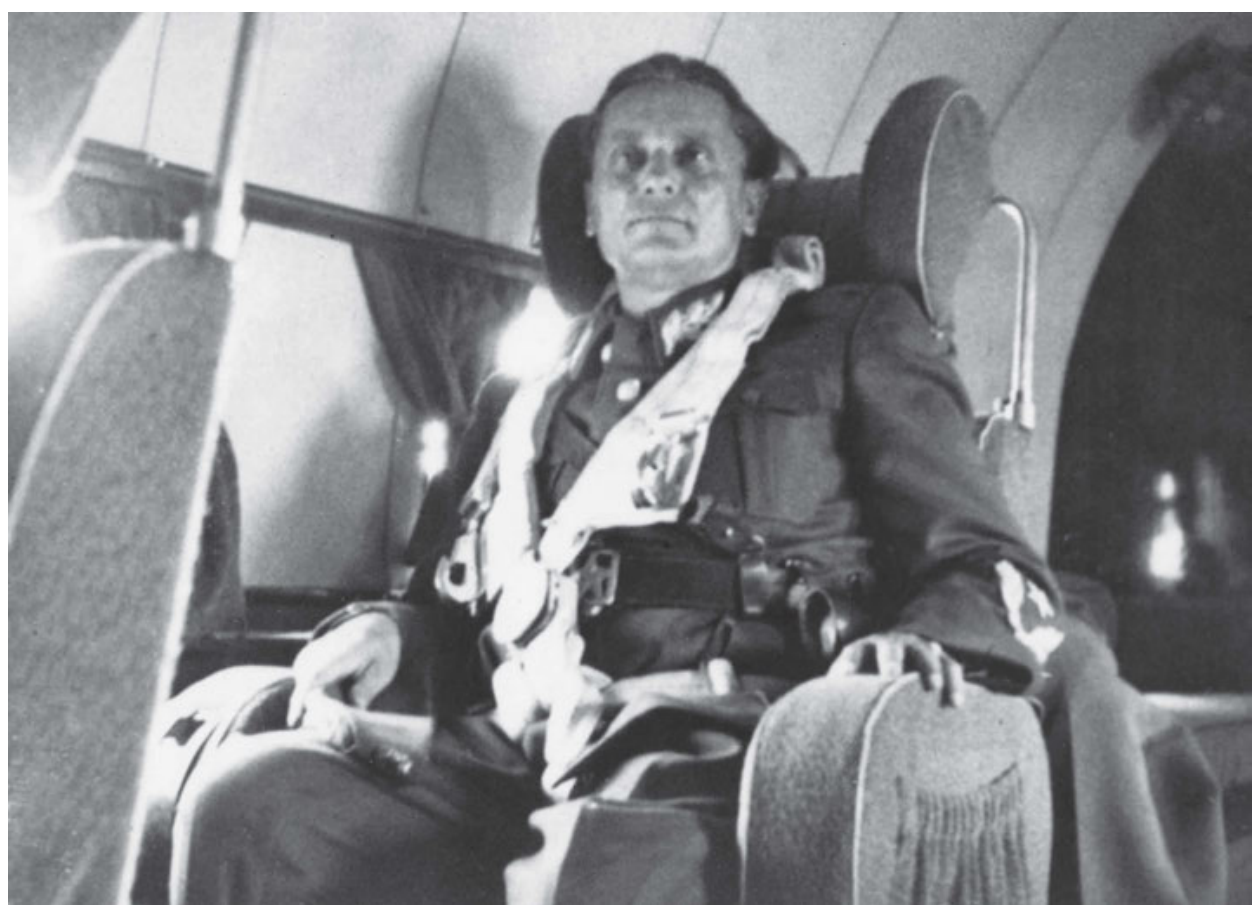

Josip Broz Tito im Flugzeug nach Rom am 8. August 1944.

Fotograf unbekannt. Belgrad, Militärmuseum | 19627. 


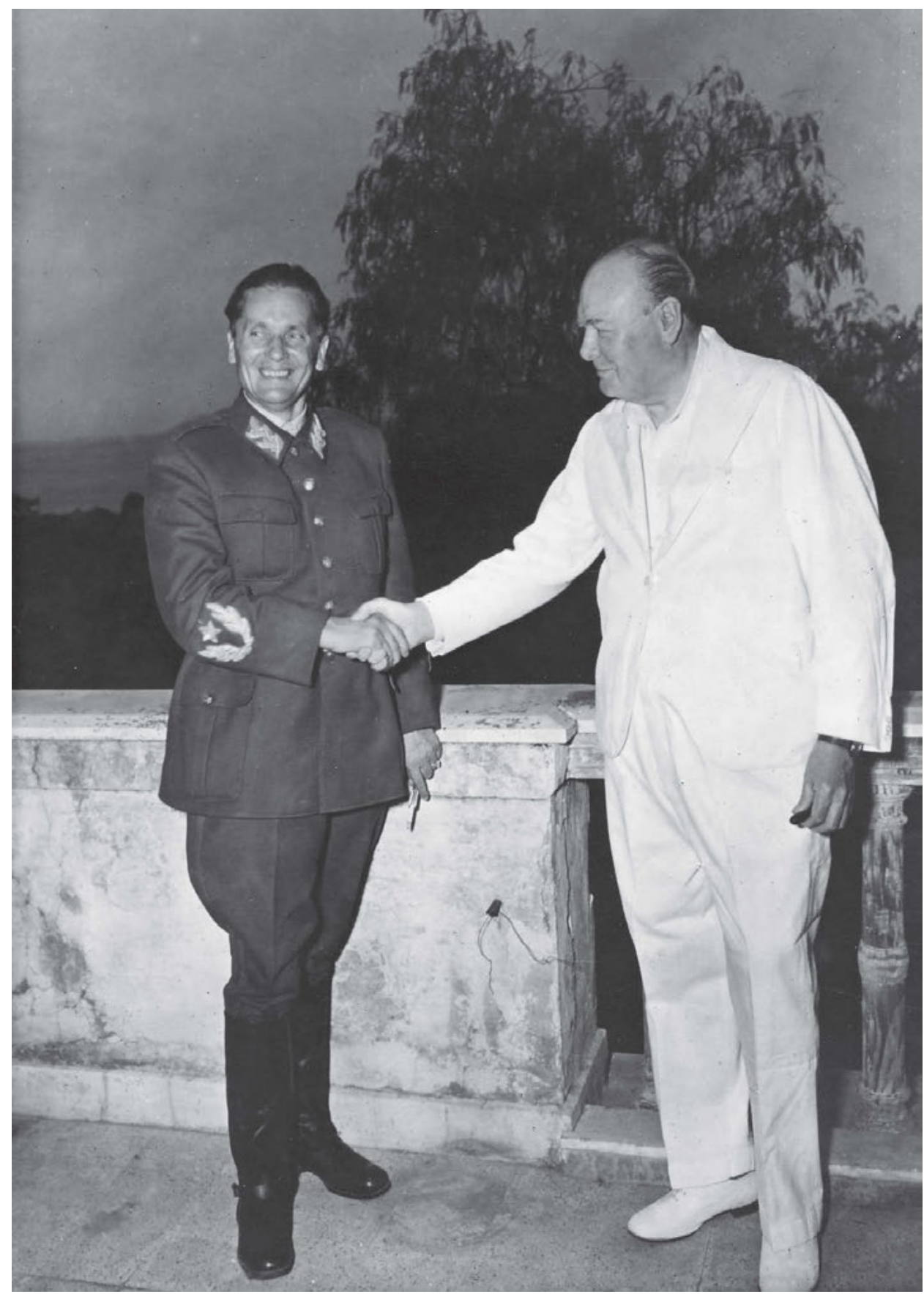

Josip Broz Tito und Winston Churchill. Fotograf unbekannt. znaci.net. 


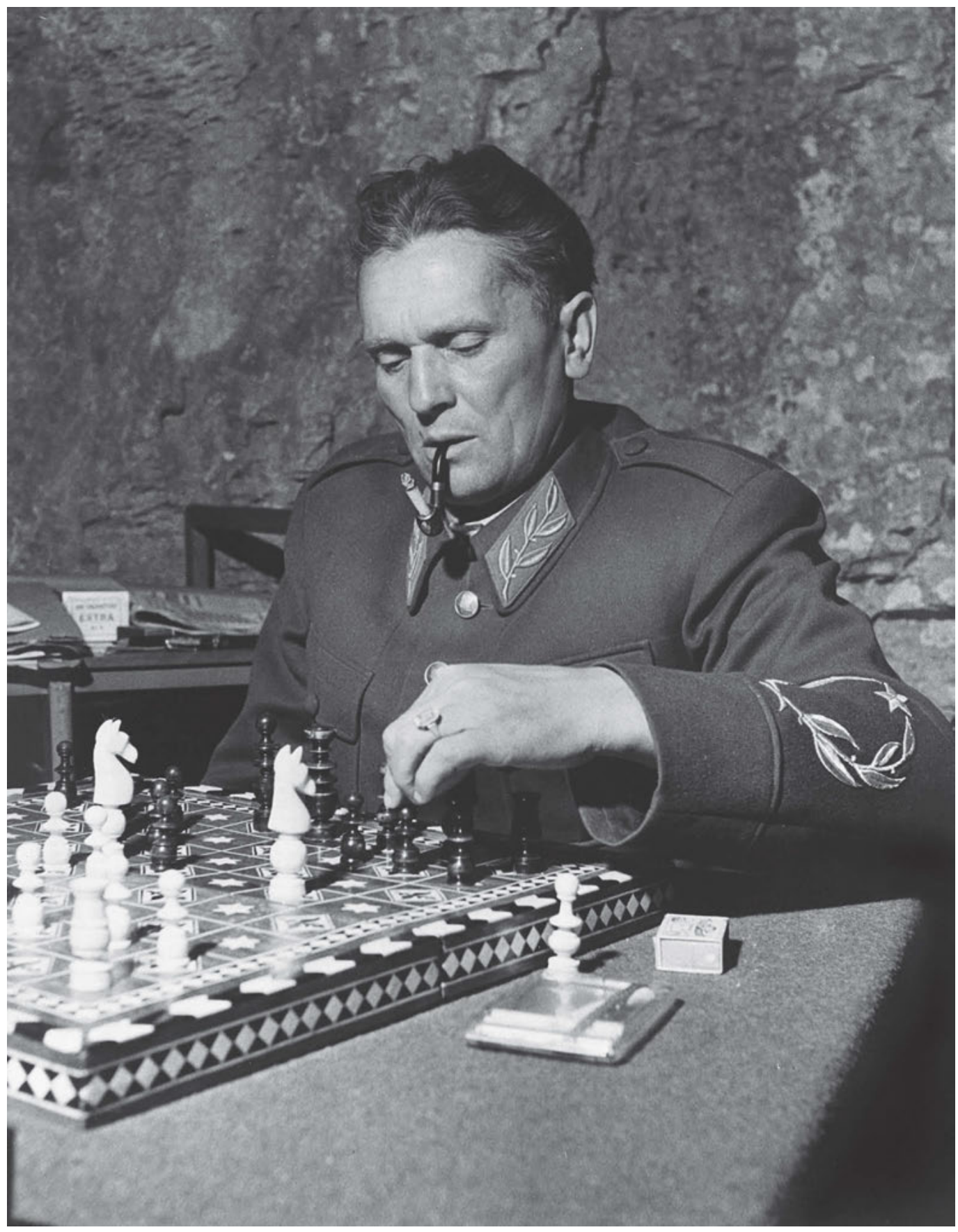

Marschall Tito auf der Insel Vis, 1944. Foto: John Phillips. Belgrad, Museum Jugoslawiens | MIJ-1993-005. 


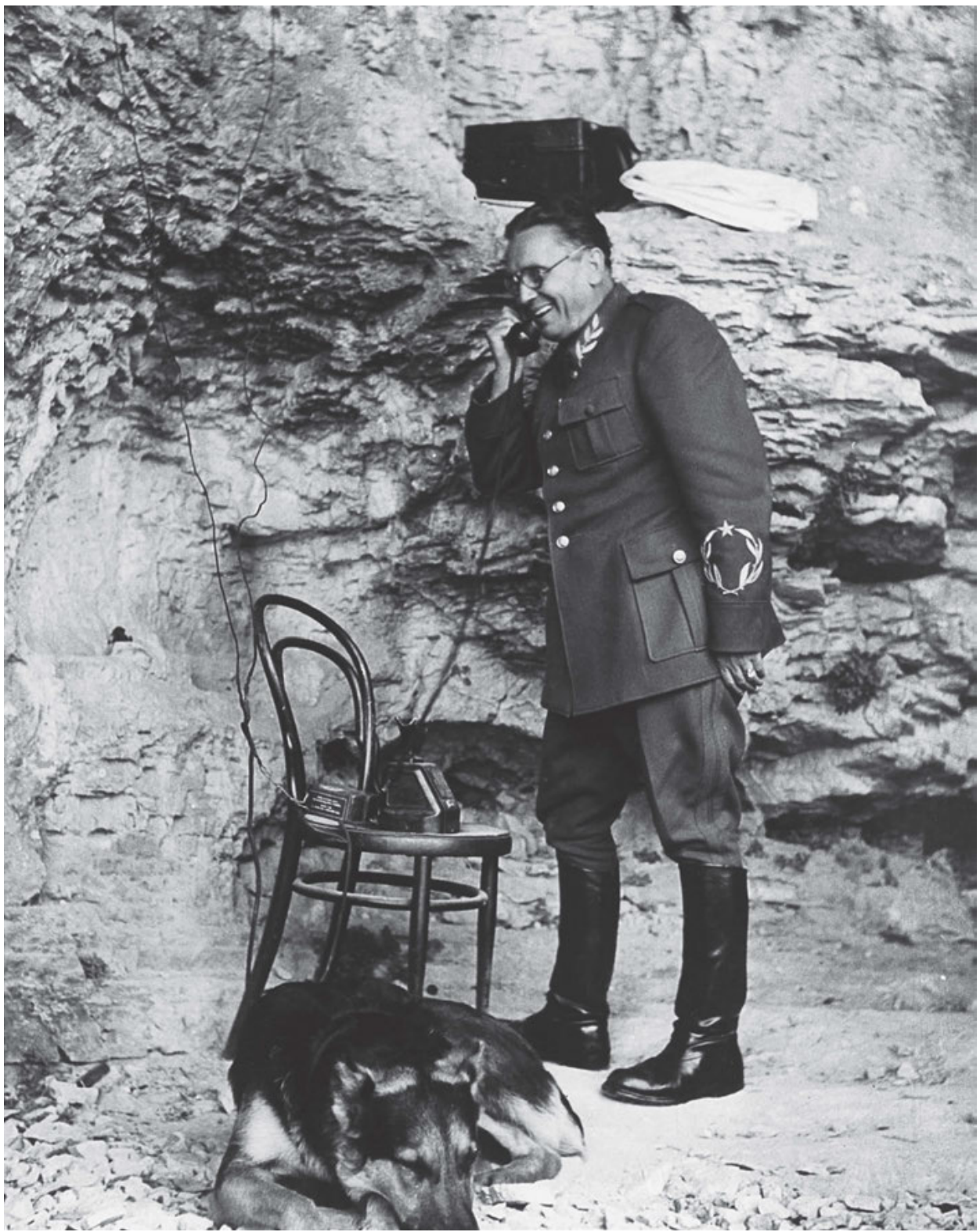

Marschall Tito auf der Insel Vis, 1944. Foto: John Phillips. Belgrad, Museum Jugoslawiens | MIJ-1993-001. 


\section{Fotografien von Partisaninnen}

Die Repräsentation der Frauen innerhalb der Partisanenbewegung, die Gleichberechtigung der Geschlechter und die Aktivitäten der Antifaschistischen Frauenfront stellen in der Partisanenfotografie einen besonderen thematischen Komplex dar. Kommunistinnen spielten in der feministischen Bewegung der Vorkriegszeit eine wichtige Rolle, die Mitte der 1930erJahre zwar verboten wurde, aber die Grundlage dafür bildete, dass sich zahlreiche Frauen der Partisanenbewegung anschlossen.

Von Beginn an war den Frauen in der Volksbefreiungsbewegung eine Kandidatur und eine Beteiligung an Wahlen möglich, was die Bestimmungen von Foča 1942 bestätigten, während das offizielle Frauenwahlrecht erst am 11. November 1945 eingeführt wurde. ${ }^{1}$ Verschiedenen Schätzungen zufolge waren etwa 100.000 Frauen in der Partisanenbewegung aktiv. Partisaninnen wurden oft fotografiert, wobei ihre Bedeutung im Partisanenkampf und ihr Heldenmut im Vordergrund standen. So betonte auch der Fotograf Milan Štok in seinen Weisungen an die Partisanenfotografen Folgendes:

"Eine besondere Charakteristik unserer Armee sind unsere Partisaninnen. Bisher kam es nie vor, dass sich slowenische Frauen und Mädchen Seite an Seite mit ihren Männern und Brüdern am bewaffneten Kampf beteiligt haben, und zwar zum einen, weil wir bis heute noch nie eine eigene slowenische Armee hatten und zum anderen, weil sich nunmehr jede Frau ihrer Rolle im heiligen Kampf bewusst ist. Dieses Bewusstsein gilt es, auf Filmen festzuhalten, ihren Heldenmut als Kämpferinnen an vorderster Front, als Krankenschwestern und ihre wertvolle Hilfe in den Versorgungseinheiten oder in den Truppen als Verwaltungskräfte, Köchinnen, Wäscherinnen oder Aktivistinnen zu zeigen. Uns fehlen solche Aufnahmen und wir müssen uns beeilen, damit wir nicht weit zurückbleiben, das heißt die Ereignisse selbst uns nicht überholen.«²

Hieraus wird ersichtlich, dass den Frauen durchaus eine typische weibliche Rolle mit entsprechenden Aufgaben zugewiesen wurde. Trotz der Tatsache, dass in der Partisanenbewegung viele Frauen kämpften, und trotz der Absicht der kommunistischen Führung, die Gleichberechtigung der Geschlechter durchzusetzen, existierte ein Unterschied zwischen den proklamierten Standpunkten und der Realität. Es fehlte auch an der Bereitschaft, die etablierten patriarchalischen Strukturen zu ändern, sodass die Frage der Gleichberechti-

\footnotetext{
1 Miletić, Miloš und Radovanović, Mirjana. Početak sistematizacije. In: Dies. (Hrsg.). Lekcije o odbrani, Prilozi za analizu kulturne delatnosti NOP-a. Belgrad: KURS und Rosa Luxemburg Stiftung Southeast Europe 2016, S. 105.

2 Štok, Milan. Fotografski priručnik. Propagandni odsjek Sedmog korpusa. O. O. 1944, o. S.
} 
gung der Geschlechter bestenfalls an zweiter Stelle stand. ${ }^{3}$ Auf der anderen Seite brachte laut den überlieferten Aussagen der Partisaninnen, die Jelena Batinić in ihrem Buch detailliert ausgewertet hat, ihre Partizipation an der Partisanenbewegung ein außerordentlich wichtiges emanzipatorisches Potenzial mit sich, wodurch sich die Partisaninnen zum ersten Mal als politische Subjekte beim Aufbau einer neuen Gesellschaft anzusehen begannen. ${ }^{4}$ Im Unterschied zu den Männern, die man mit männlichen Attributen des Kriegers präsentierte, lag bei den Darstellungen der Frauen ein Akzent auf ihrer Weiblichkeit. Es offenbarten sich neue Relationen, die wiederum bestimmte Widersprüchlichkeiten nach sich zogen:

»Die jungen Frauen in den Truppen der Ersten Brigade wurden wahrhaft geliebt. Man achtete darauf, ihnen die besten Stücke der eroberten Kleidung, die schönsten, zugleich aber auch die bequemsten Schuhe, Ledertäschchen, Halstücher oder seidene Taschentücher zu geben. [...] Und auch wenn sie in jeder Hinsicht gleichberechtigt waren, so waren die Partisaninnen dennoch Frauen: Auch auf den Fotografien ist zu sehen, dass sie sich hübsch gemacht haben, besser gekleidet und stets gepflegt sind. Ebenso die Parteiführung war der Meinung, dass in der Ersten Brigade sowie in der gesamten Sechsten Division sdas Verhältnis zwischen Kameraden und

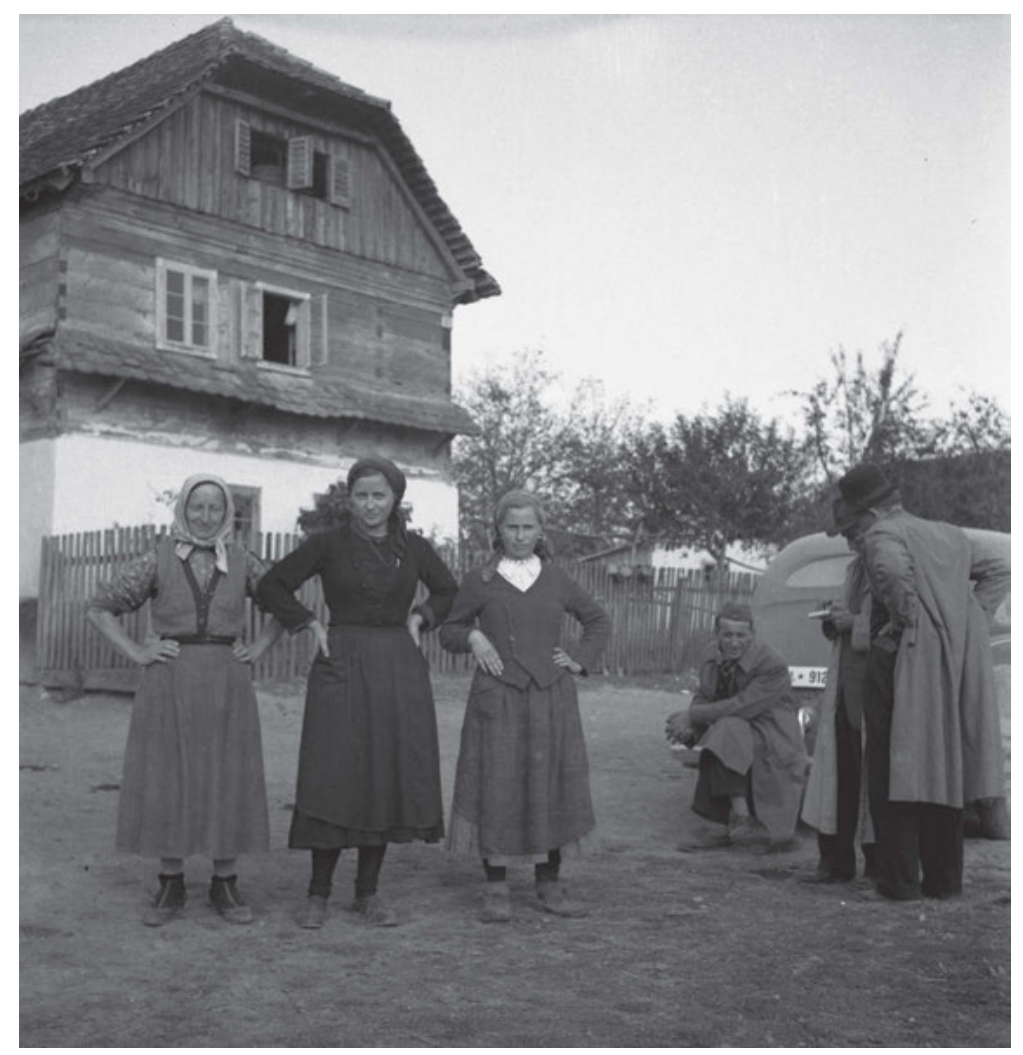

Illegales Verlassen der Stadt Zagreb und Abreise zu den Partisanen. Autor: Emil Vičić. Kroatisches Historisches Museum I HPM/ MRNH-N-4042

\footnotetext{
3 Batinić, Jelena. Women and Yugoslav Partisans: A History of World War II Resistance. New York: Cambridge University Press 2015, S. 166.

4 Ebd., S. 167
} 


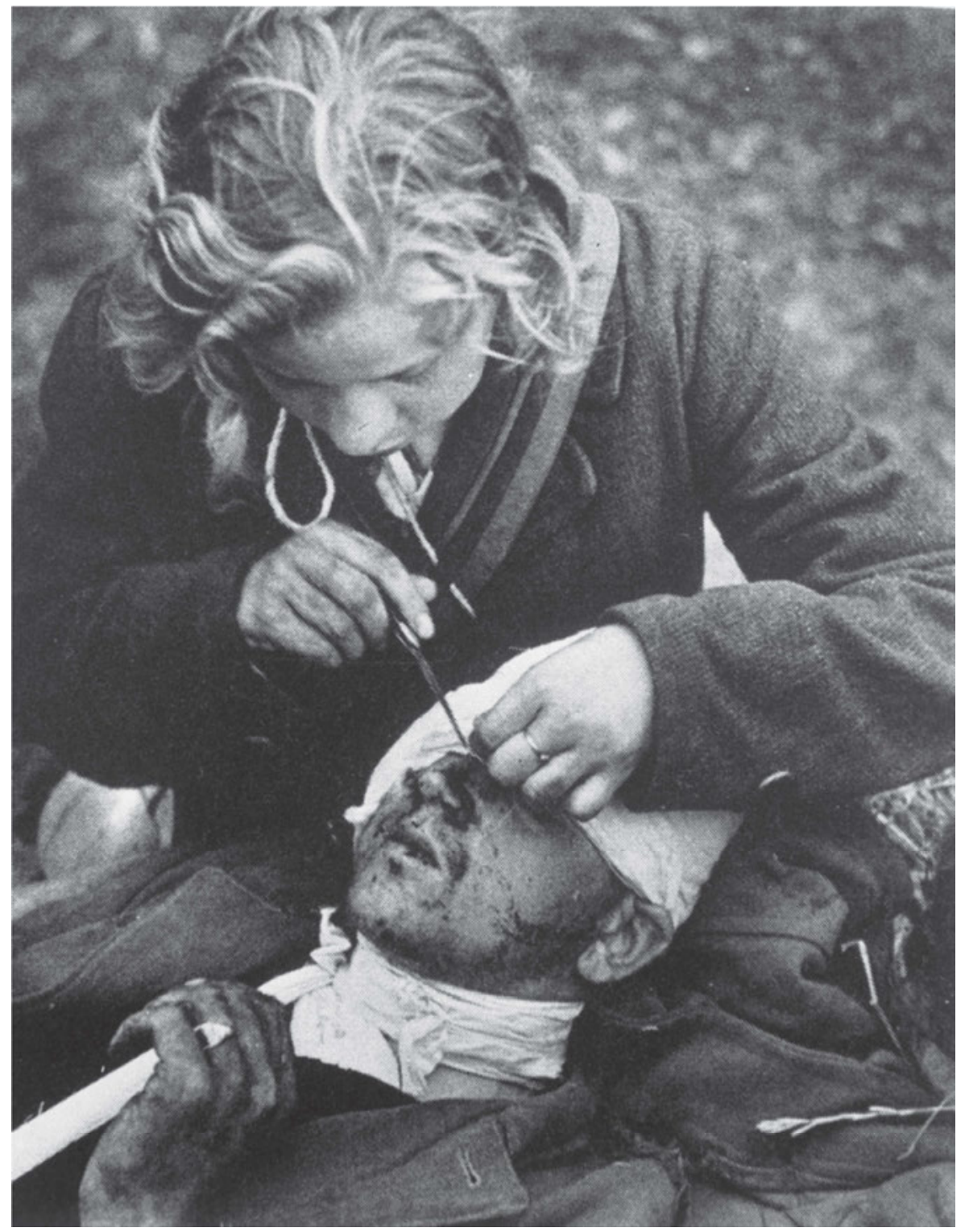

Eine Krankenschwester versorgt die Wunde eines Kämpfers der Gubac-Brigade nach dem Angriff auf die Pogornik-Brücke bei Litija im September 1944. Foto: John Philips. Ljubljana, Museum für Neuere Geschichte Sloweniens | TN5124/8.

Kameradinnen im Allgemeinen gut sei<, doch auch hier verlief es nicht ohne Kritik, denn man sagte - ohne dabei Namen zu nennen -, dass ses Ausnahmen gegeben hätte, als manch ein Kamerad meinte, die Kameradinnen seien weniger wert, das heißt sie seien nicht in der Lage, Aufgaben der Soldaten genauso wie die Männer auszuführenı, doch sdiese falsche Meinung ließ sich durch politische Erklärung aus der Welt schaffenı. ${ }^{5}$ 


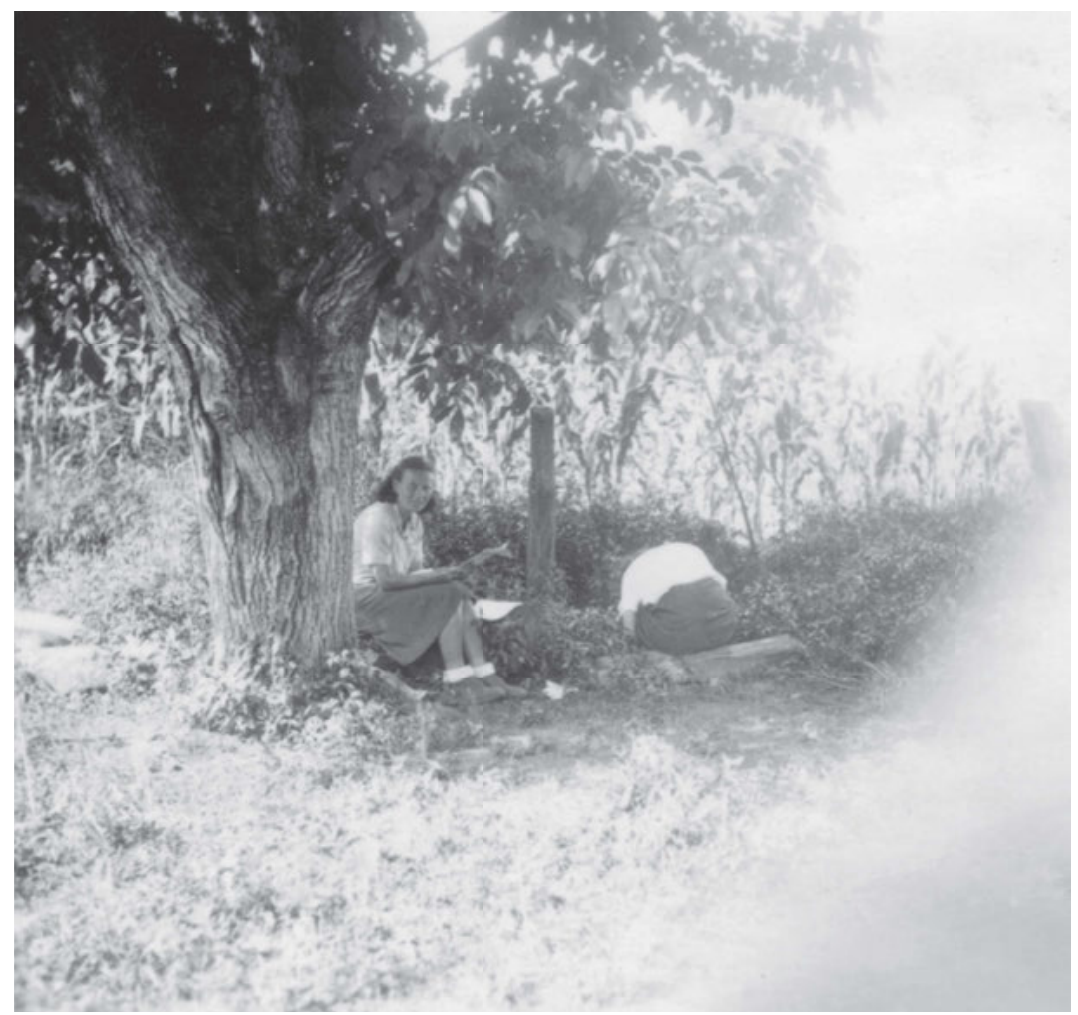

Olga Kreačić-Žoga und Bosiljka Krajačić-Beba, Redakteurinnen der Zeitschrift Žene $u$ borbi (Frauen im Kampf). Topusko, 1944. Zagreb, Kroatisches Historisches Museum | HPM-MRNH-F-4644.

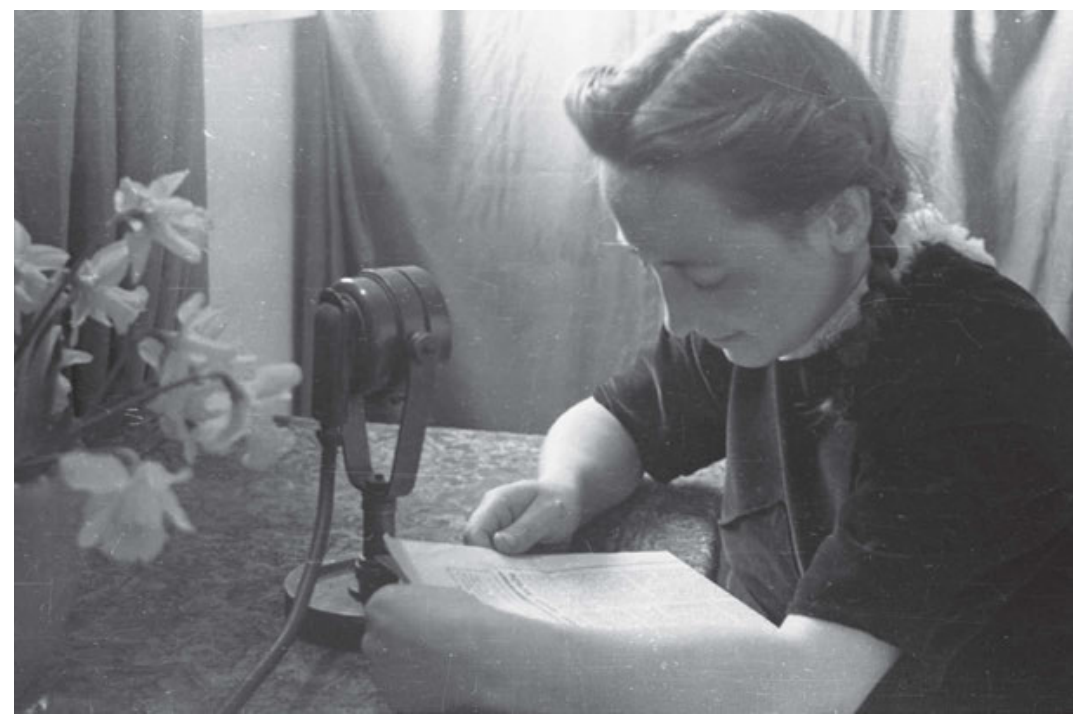

Cilka Maležič, Mitarbeiterin des Radios der Befreiungsfront, am Mikrofon. Črnomelj, April 1944. Foto: Jože Petek. Ljubljana, Museum für Neuere Geschichte Sloweniens | TN700/5. 


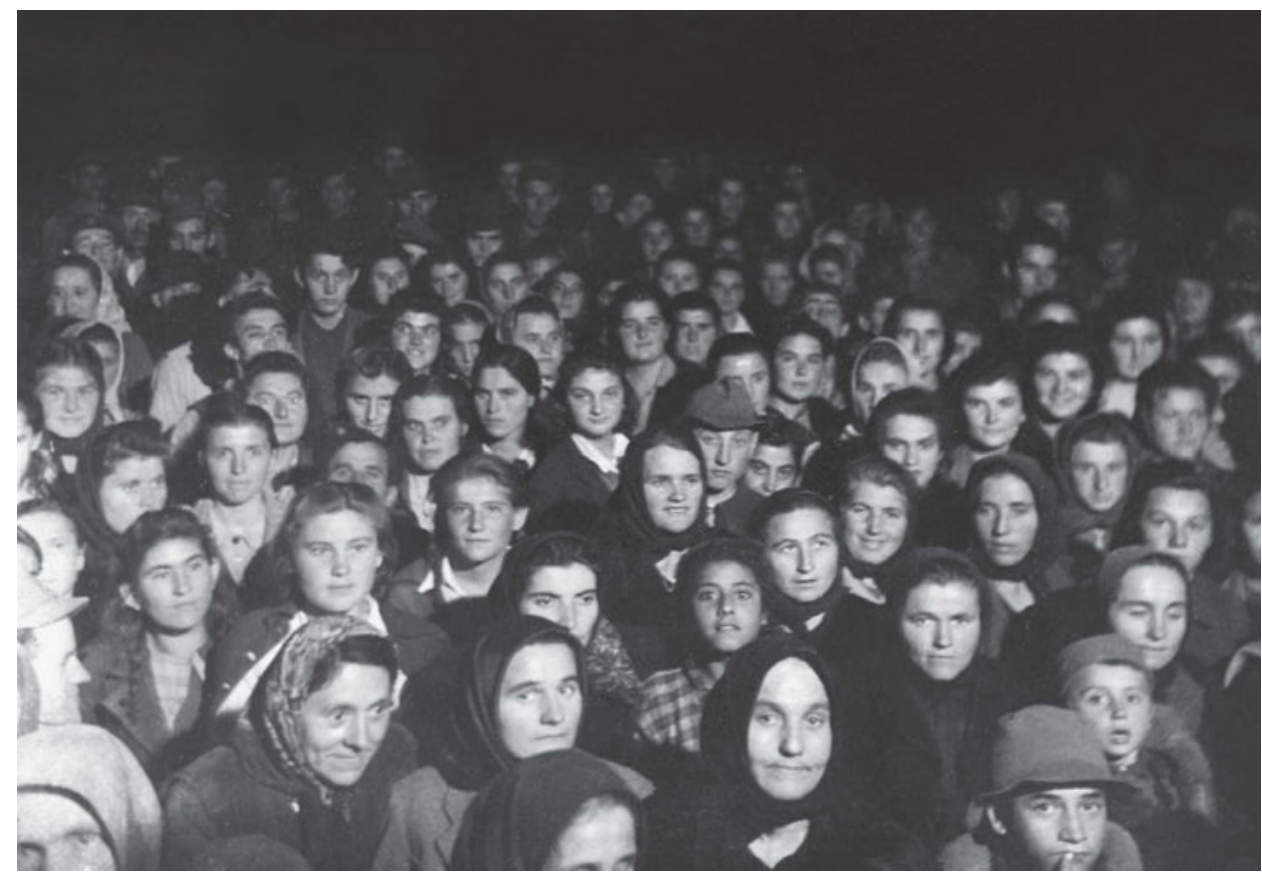

Am 1. Januar 1945 begann in Novi Sad in Anwesenheit von 650 Delegierten die Erste Provinzkonferenz der Antifaschistischen Frauenfront in der Vojvodina. Im Verlauf der viertägigen Sitzung wurde der Provinzrat der Antifaschistischen Frauenfront gewählt und die Aufgaben für die künftige Arbeit abgesteckt. Belgrad, Museum Jugoslawiens | III-8596.

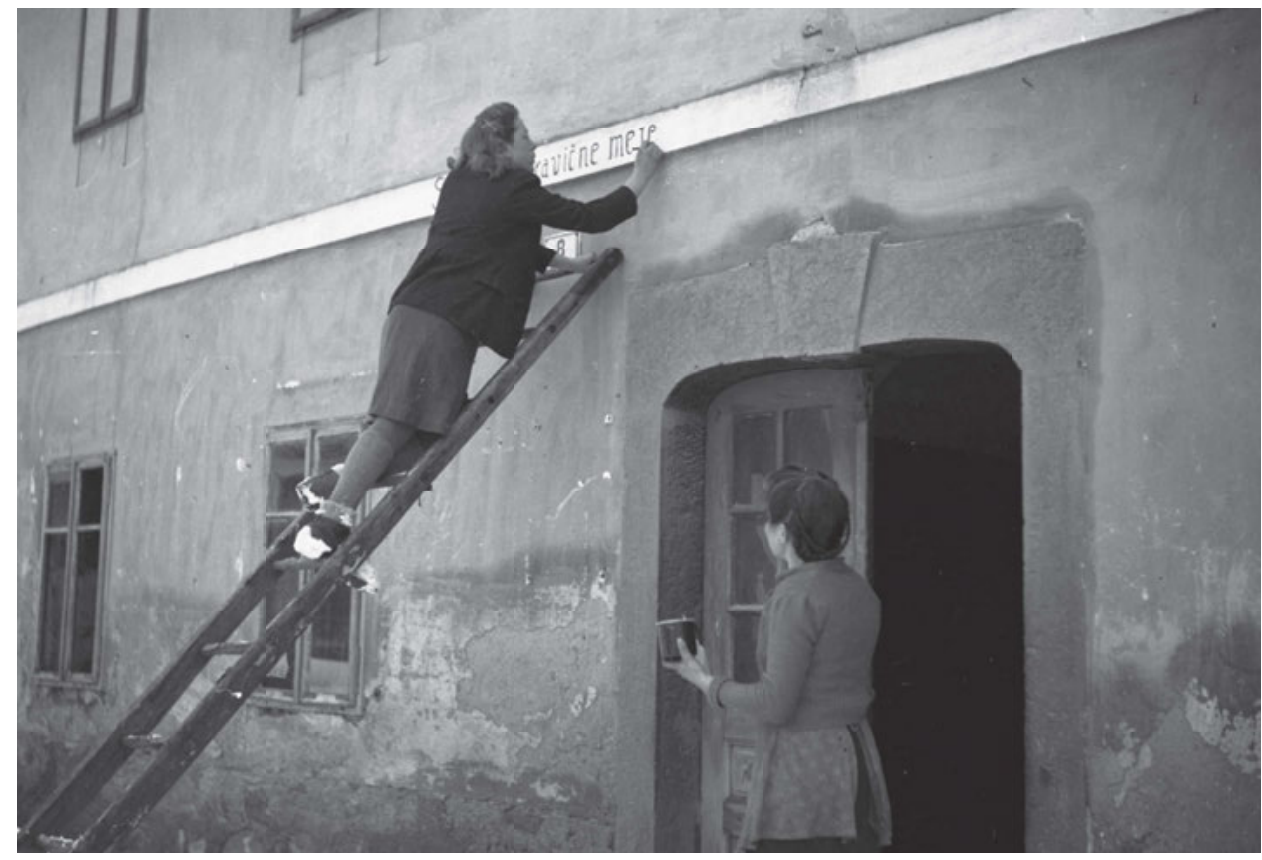

Die im Bund der Slowenischen Jugend organisierten Jugendlichen schreiben Parolen zum Zweiten Vorkongresswettbewerb an die Hauswände in den Dörfern im Landesinneren. Osilnica, 1945. Foto: Edi Šelhaus. Ljubljana, Museum für Neuere Geschichte Sloweniens | TN1663/4. 


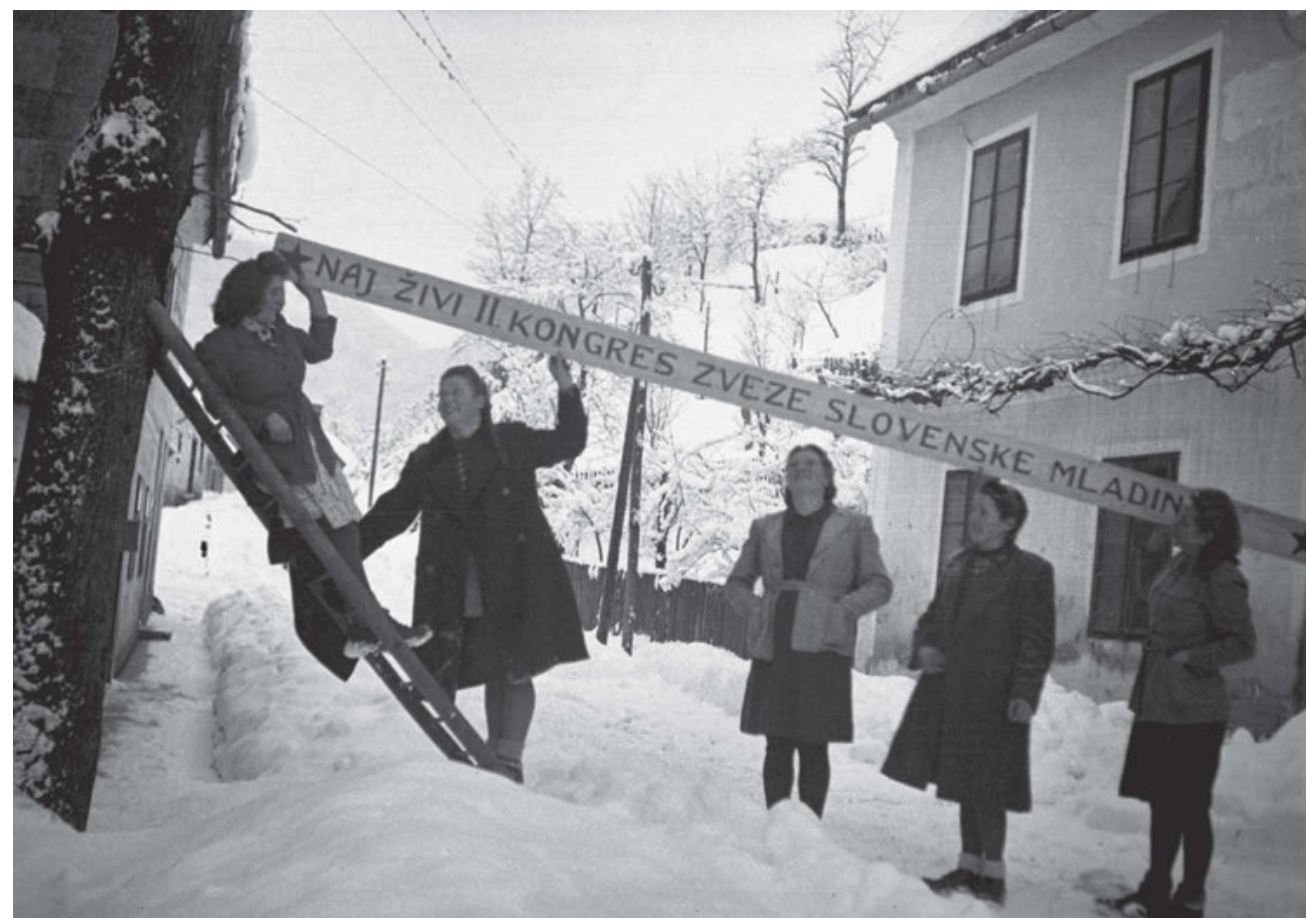

Die im Bund der Slowenischen Jugend organisierten Jugendlichen schreiben Parolen zum Zweiten Vorkongresswettbewerb in den Dörfern im Landesinneren. Osilnica, 1945. Foto: Edi Šelhaus. Ljubljana, Museum für Neuere Geschichte Sloweniens | TN1663/5.

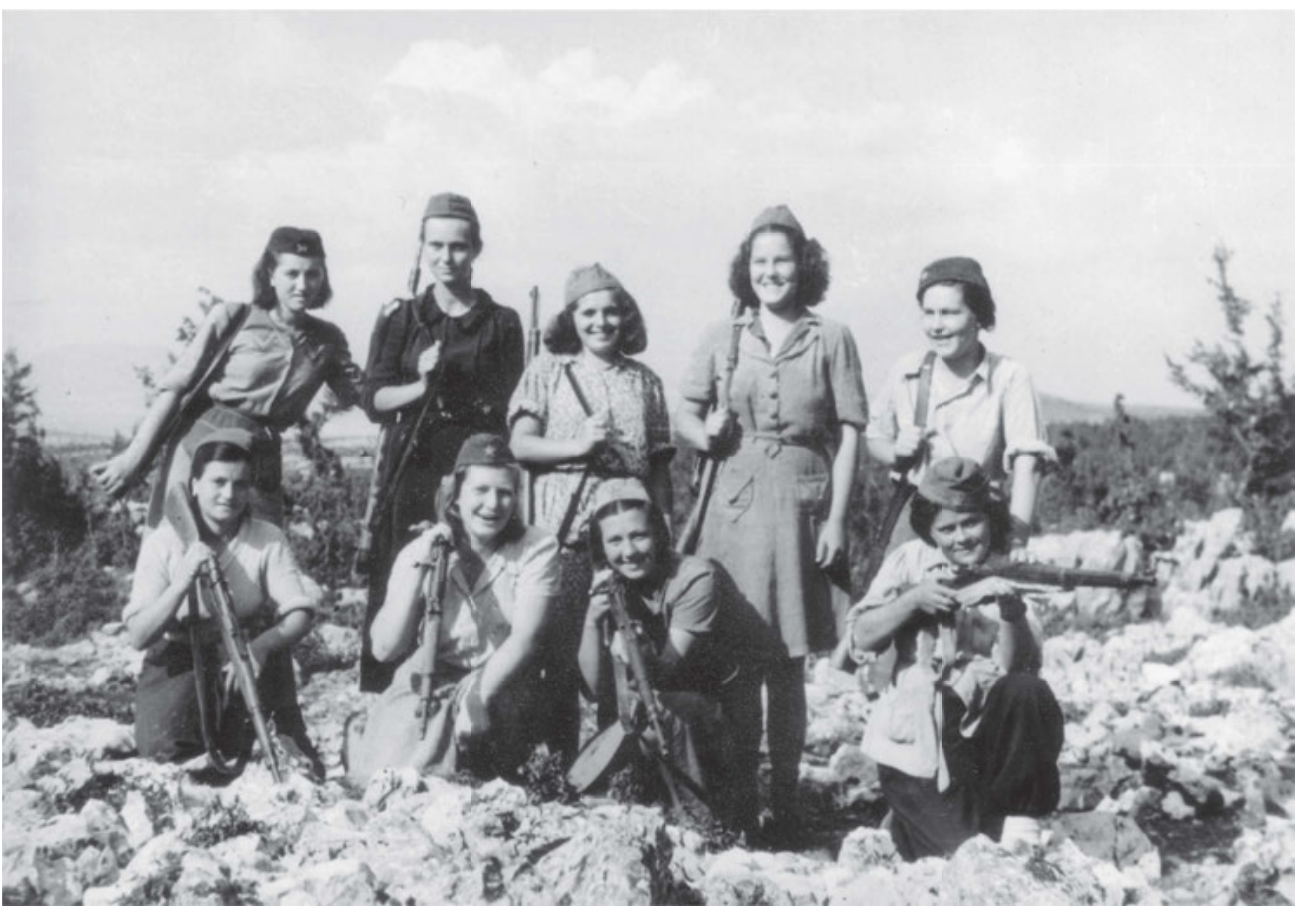

Jugendliche Kämpferinnen des Mosor-Bataillons bei einer kurzen Rast in Ugljane, August 1943.

Fotografie erhalten von Marko Strpić. 


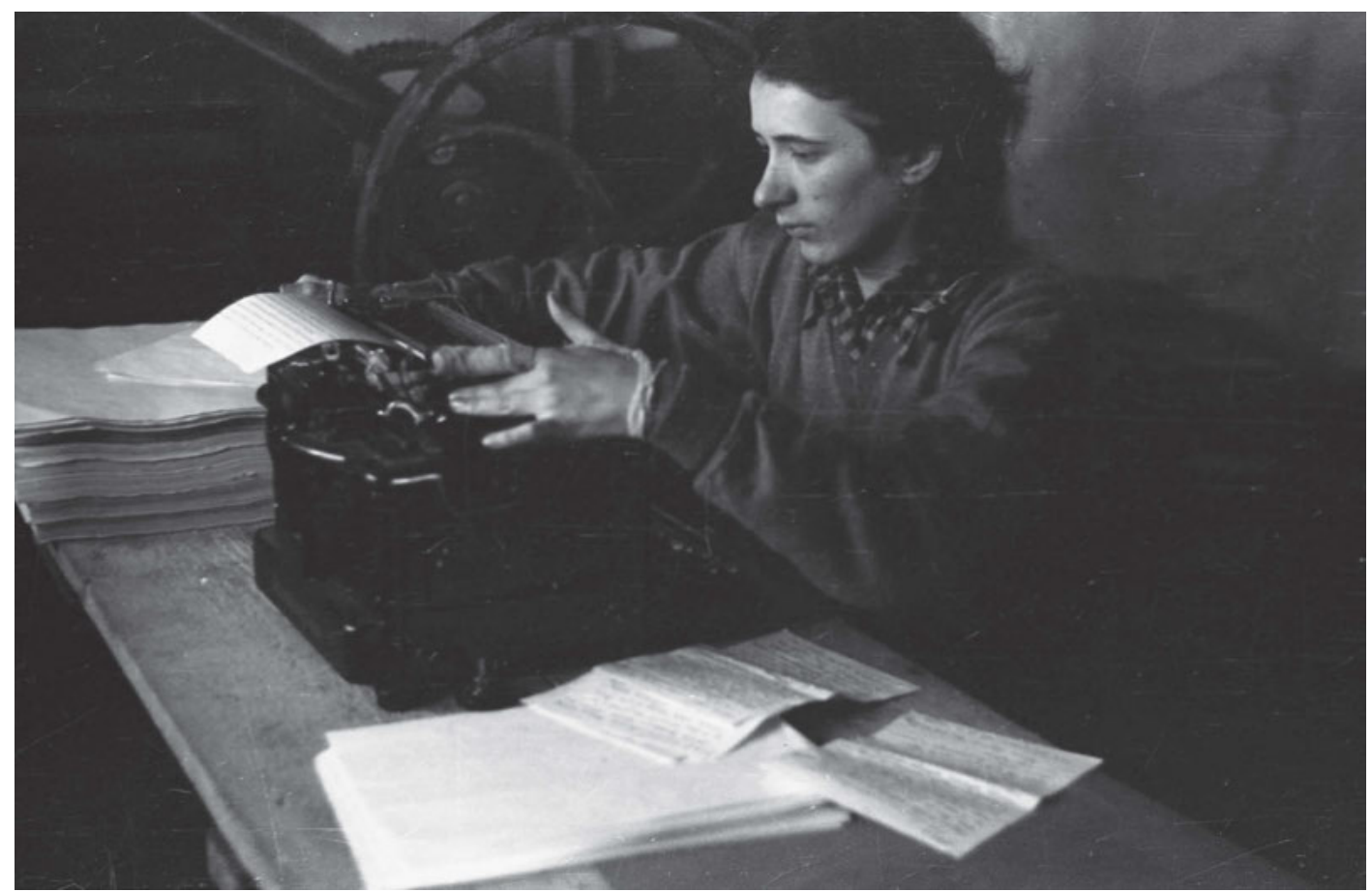

Partisanin vor einer Schreibmaschine in der Druckerei Vjesnik. Lika, nahe Turjanski, Winter 1943. Zagreb, Kroatisches Historisches Museum | HPM/MRNH-A-2601-f83-14.

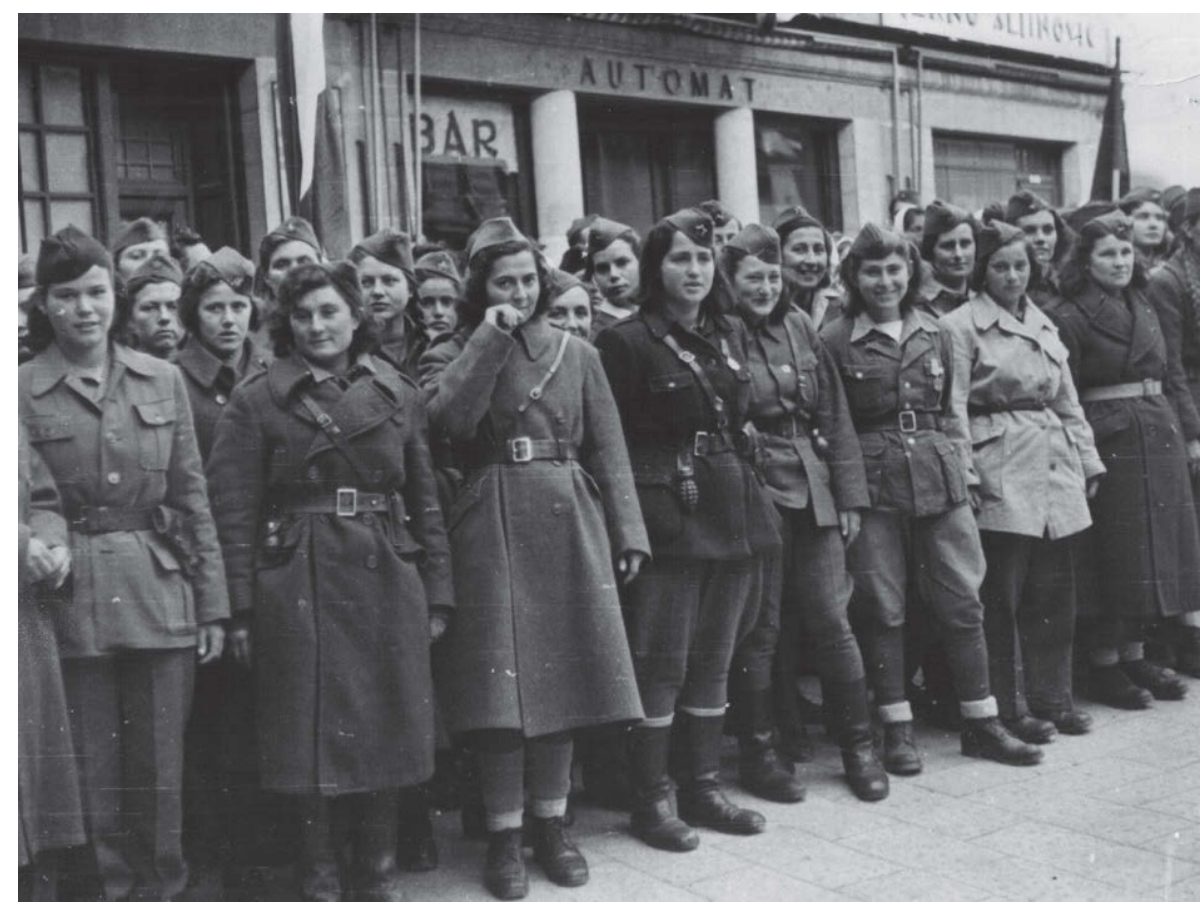

Dalmatinische Partisaninnen im befreiten Split, 1944. Bestand ZK BdKJ | 7174/znaci.net. 

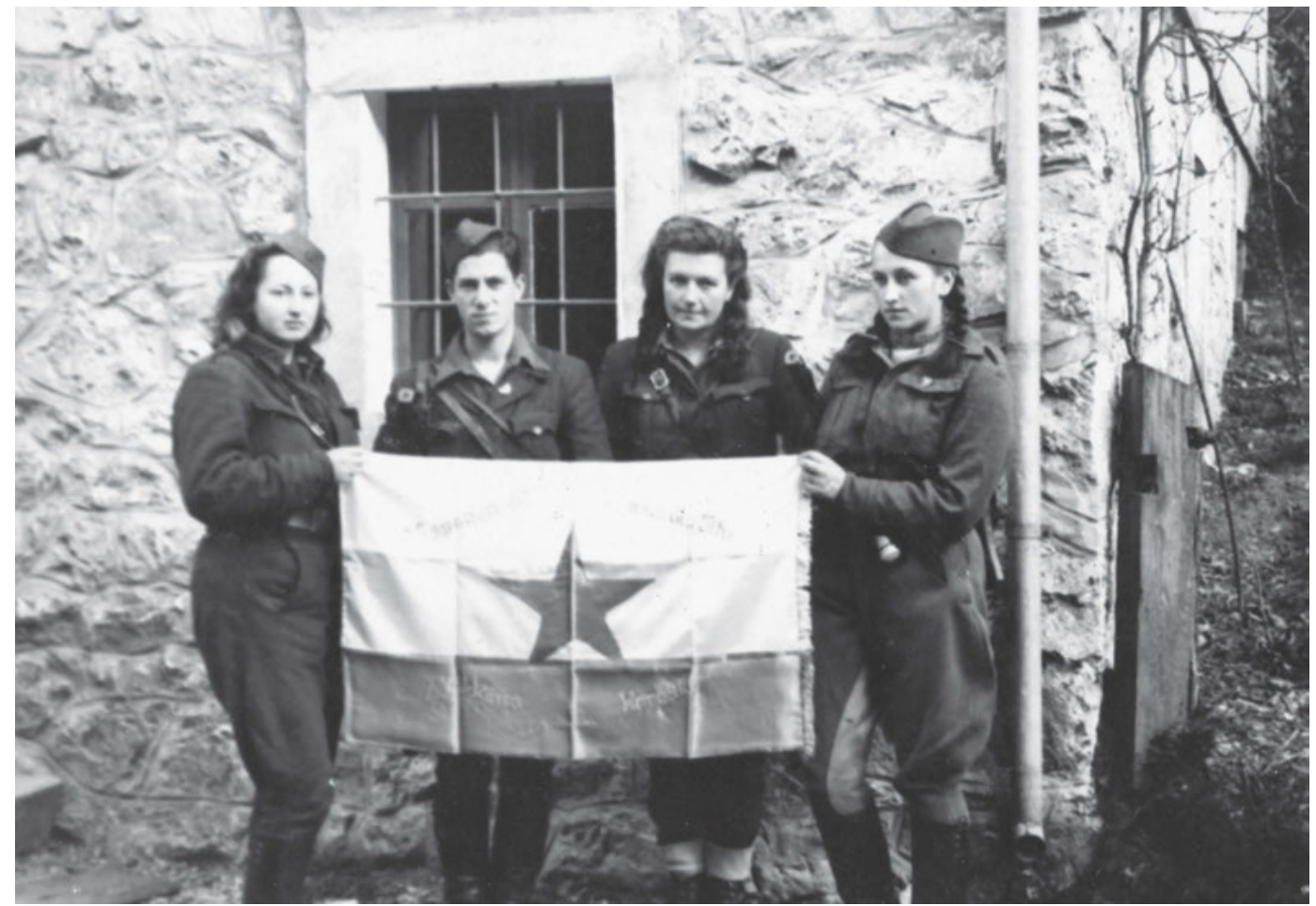

Anfertigung von Fahnen für die Koroška-Einheit, Solčava, 12. November 1944. Fotograf unbekannt. Museum für Neuere Geschichte der Stadt Celje | FZ25583.

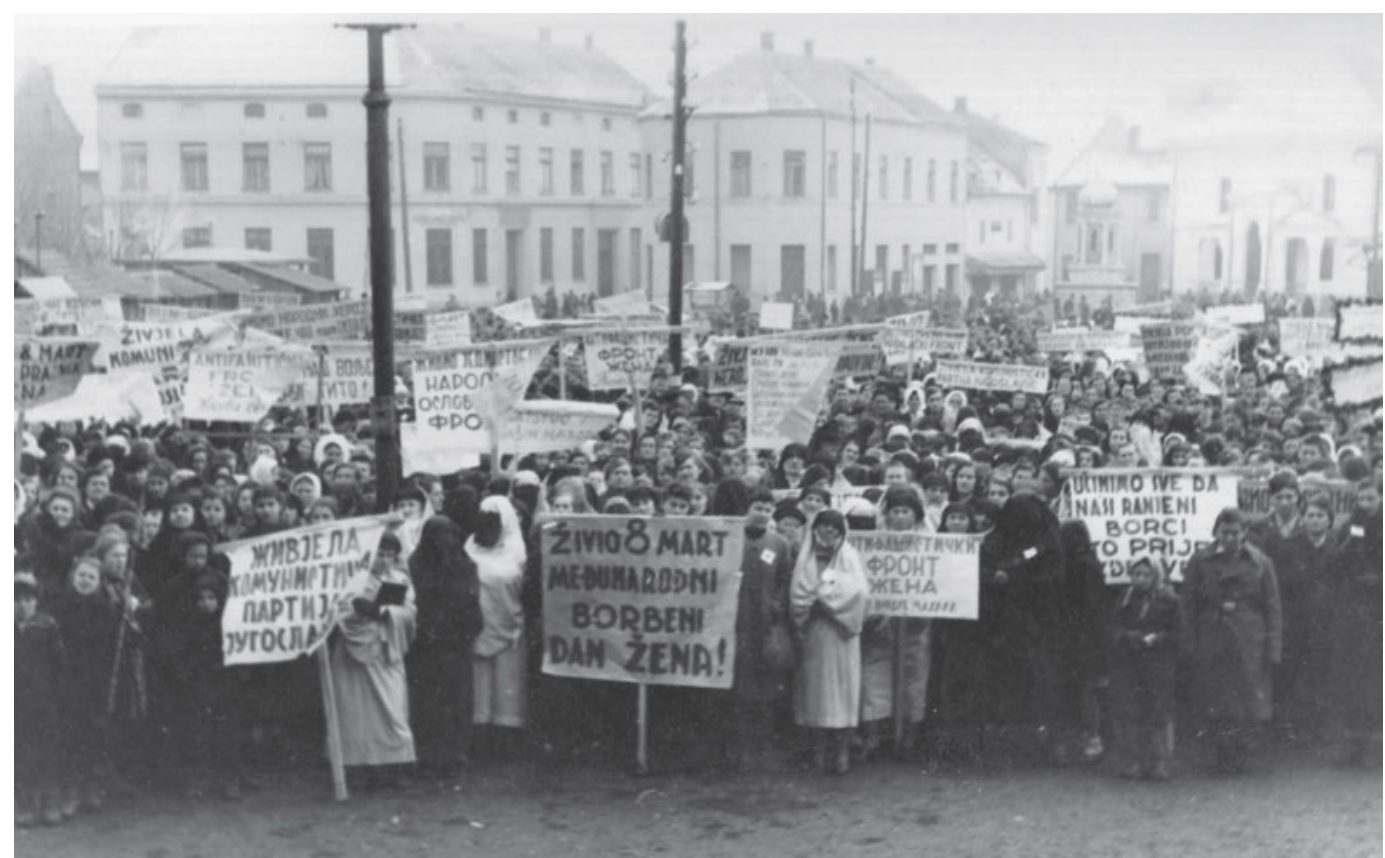

Kundgebung der Antifaschistischen Frauenfront in Tuzla, 8. März 1945. Foto: Drago Mažar. Banja Luka, Archiv der Republika Srpska. Ohne Inv.-Nr. 


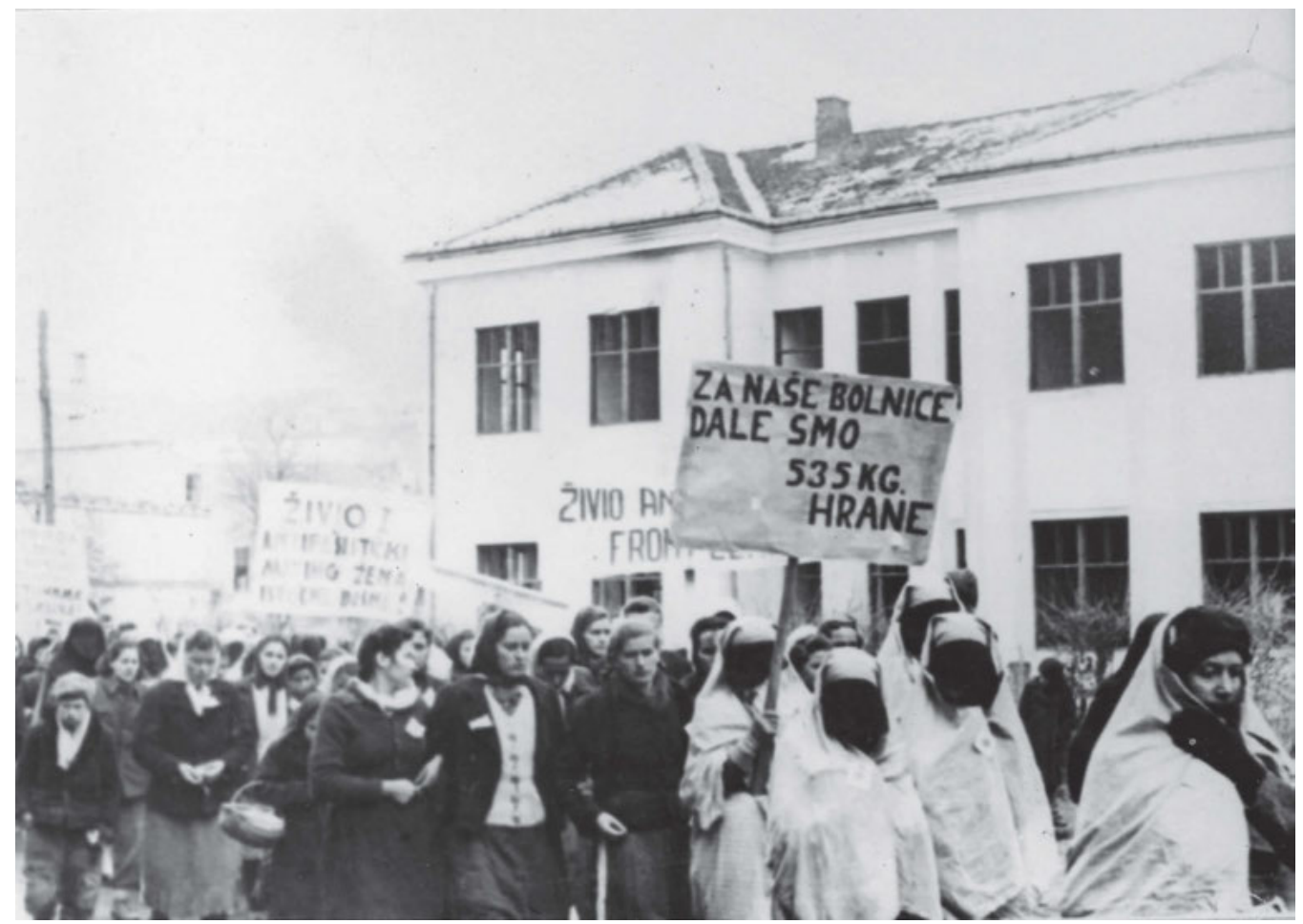

Kundgebung der Antifaschistischen Frauenfront in Tuzla, 8. März 1945. Fotograf unbekannt. Sarajevo, Historisches Museum von Bosnien und Herzegowina | FNOB 1683.

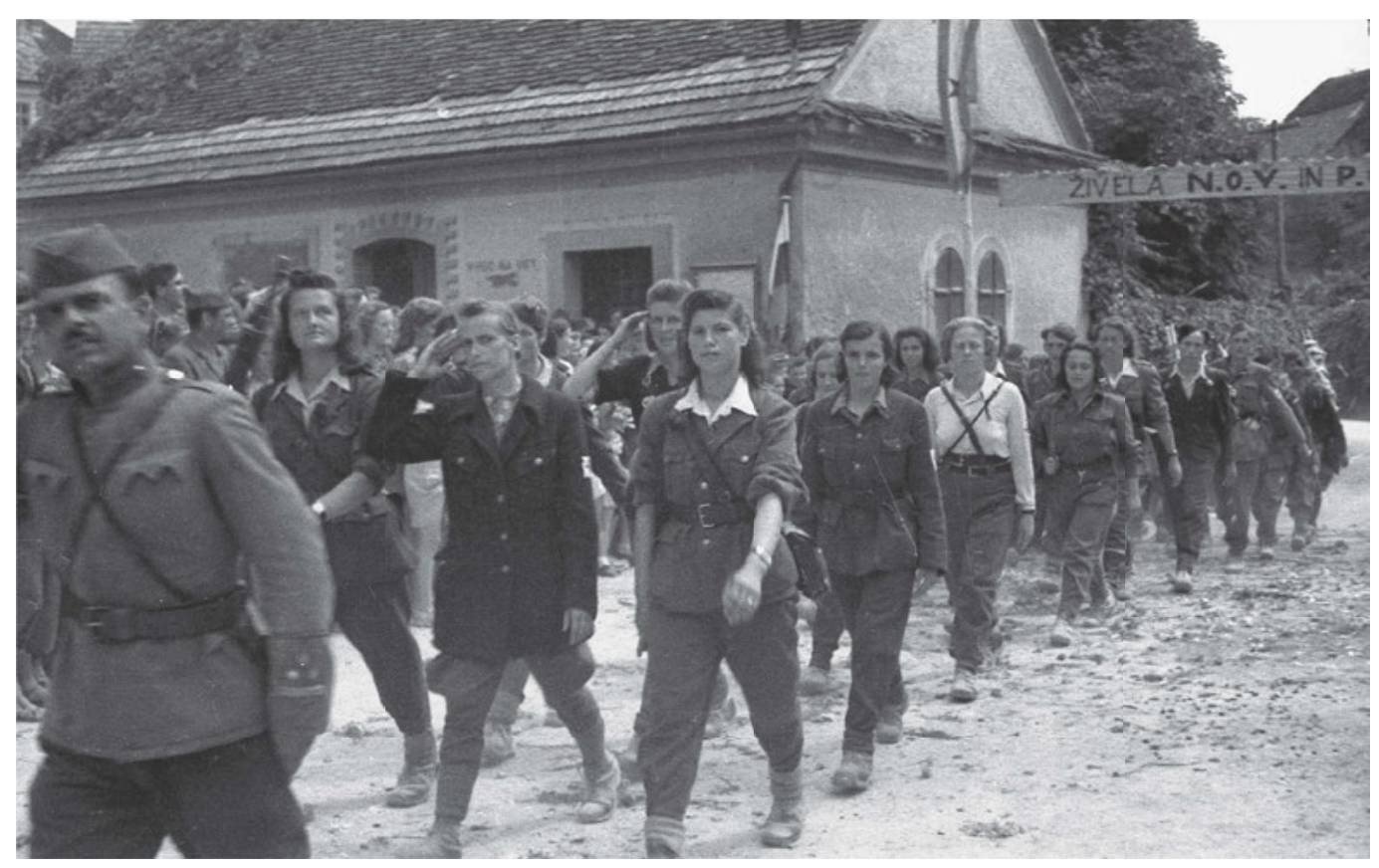

Defilee der slowenischen und kroatischen Einheiten an der Ehrentribüne in Metlika, 9. Juli 1944.

Foto: Mirko Trobec. Ljubljana, Museum für Neuere Geschichte Sloweniens | TN184/0. 


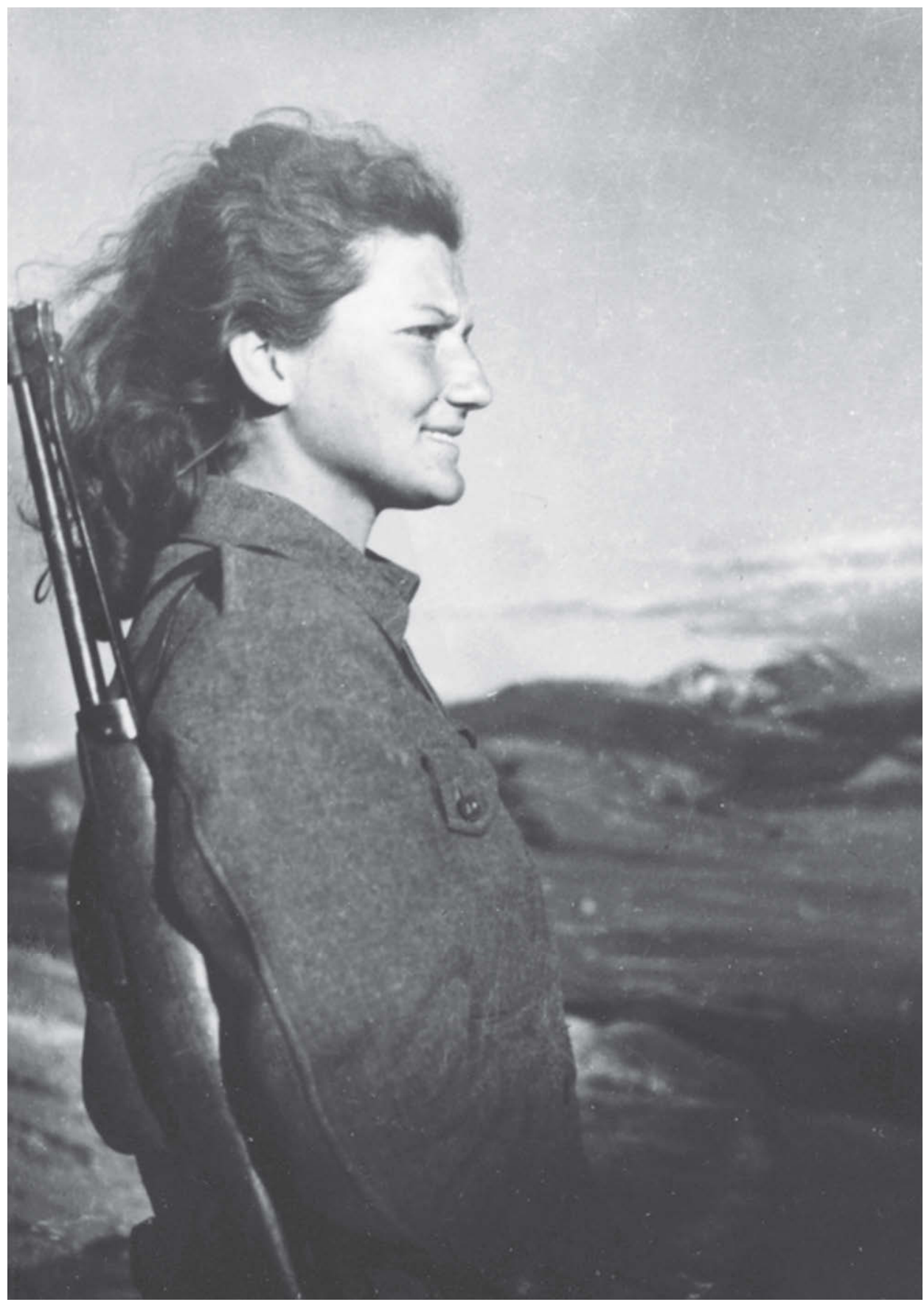

Die Partisanin Mira Pejić im Šator-Gebirge während der Siebten Offensive 1944. Foto: Žorž Skrigin. znaci.net. 


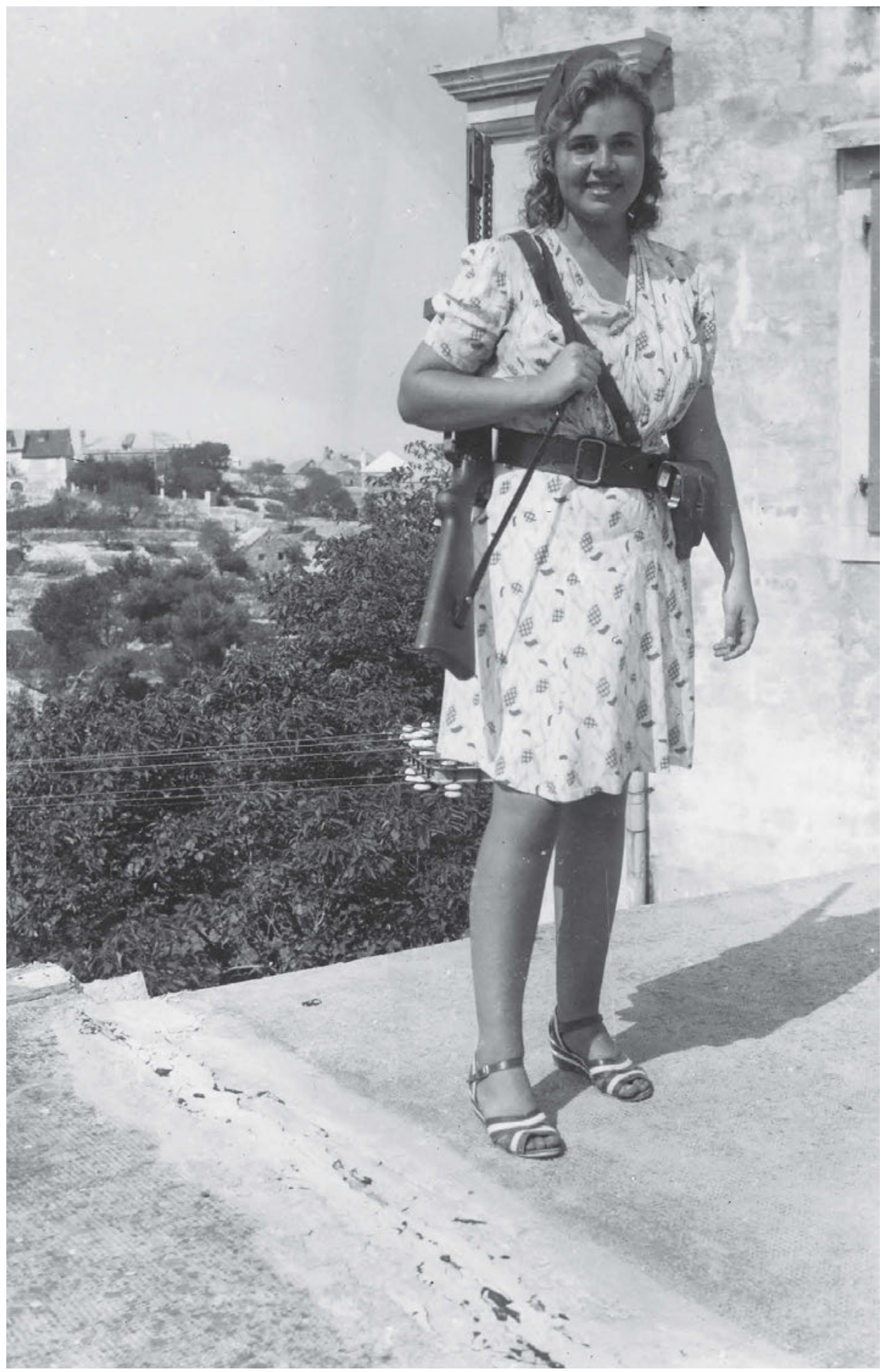

Partisanin in Supetar, 1943. Fotograf unbekannt. Abgekauft von Mikelija Ćoći. znaci.net. 


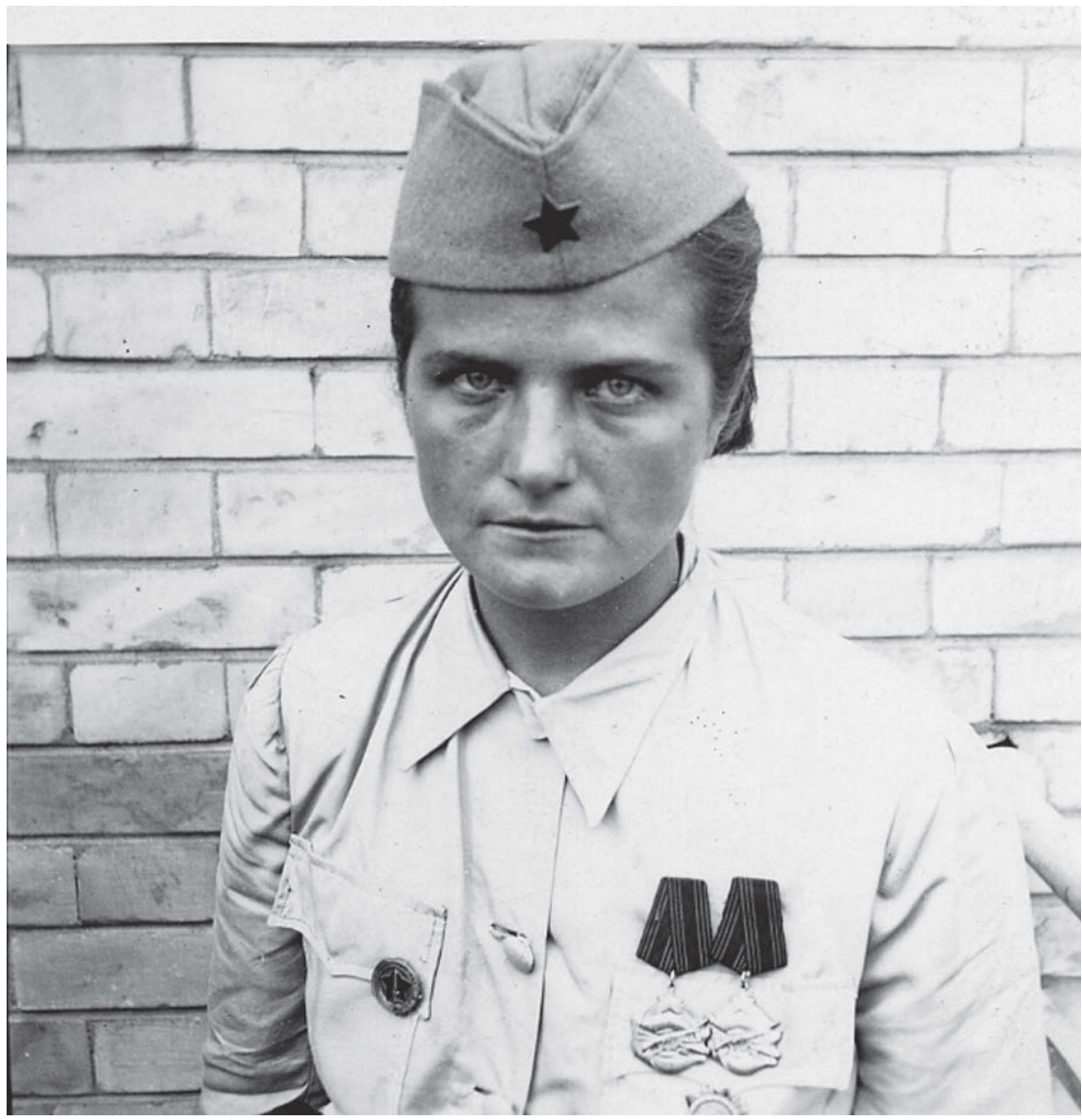

Dragica Madjarec, die als Maschinengewehrschützin einst barfuß durch den Schnee schritt. Kämpferin seit 1941. Foto: Vilko Hajduković. Museum der Stadt Zagreb. Ohne Inv.-Nr. 


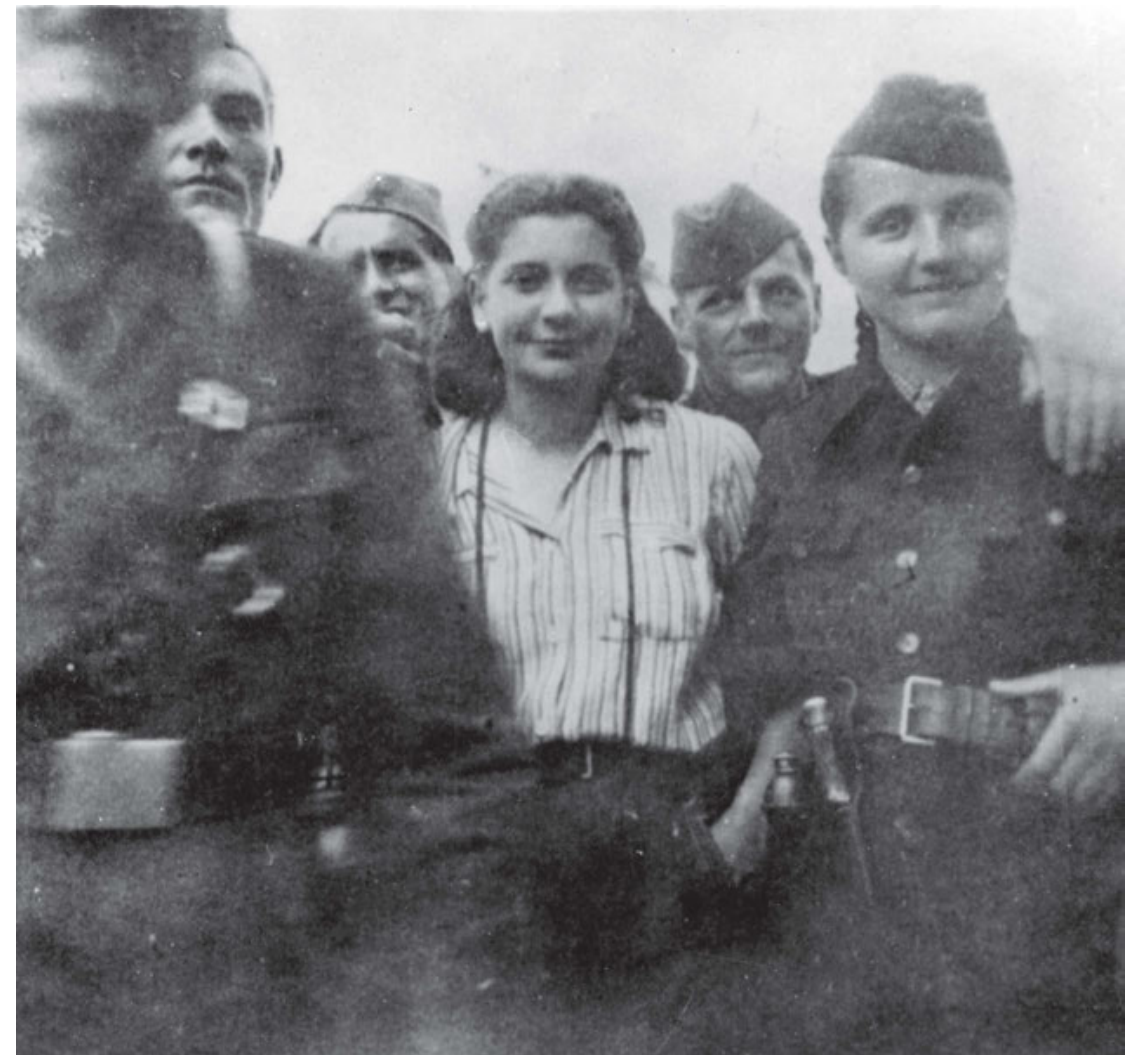

Kämpferinnen und Kämpfer der Ersten Krajina-Brigade bei Bugojno, 1943. Fotograf unbekannt. Sarajevo, Historisches Museum von Bosnien und Herzegowina | FNOB 18811.

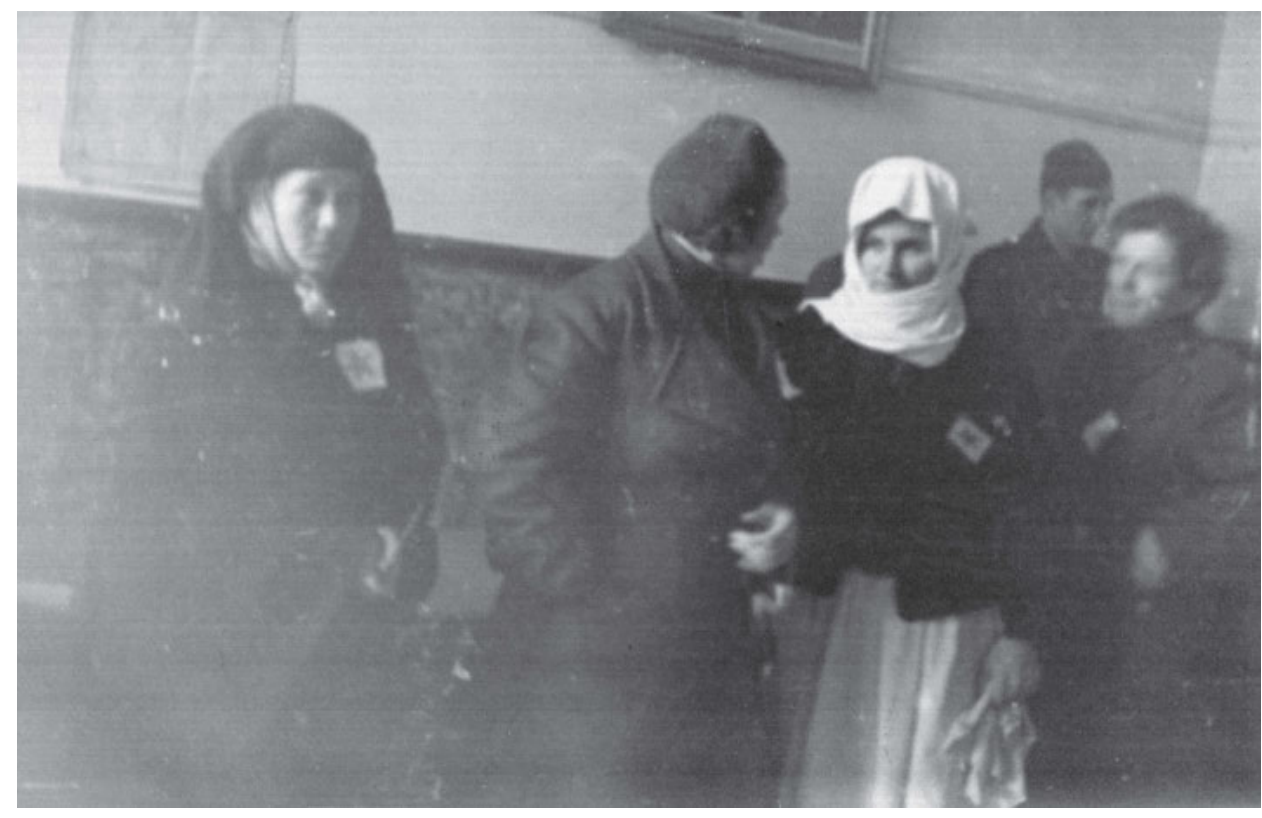

Keine Angaben. Foto: Drago Mažar. Banja Luka, Archiv der Republika Srpska. Ohne Inv.-Nr. 


\section{Im Kampf}

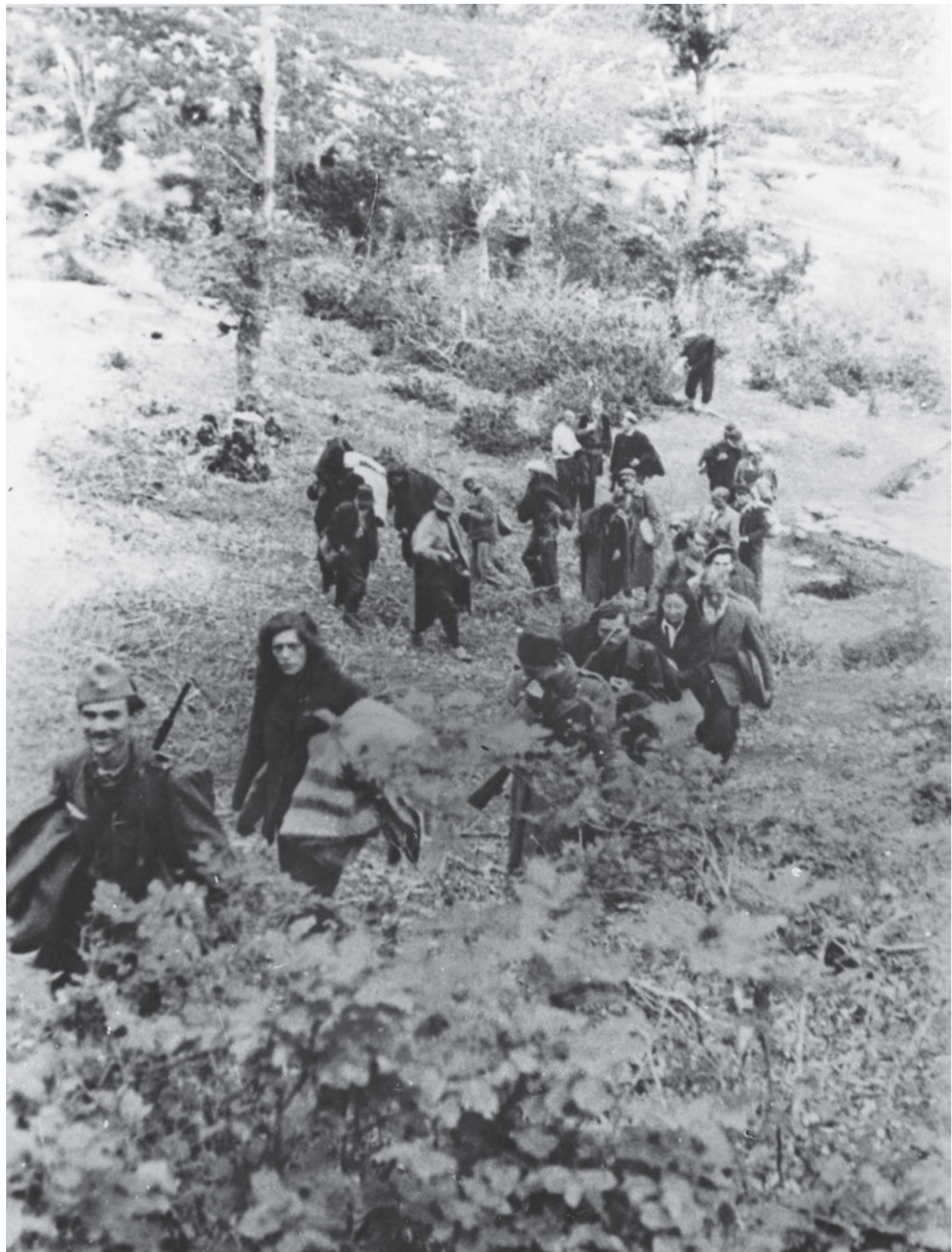

Rückkehr der Dinara-Partisaneneinheit von der Säuberungsaktion gegen die Tschetniks in Crni Lug, Livanjsko polje, Mai 1942. Fotograf unbekannt. Sarajevo, Historisches Museum von Bosnien und Herzegowina | FNOB 17797. 


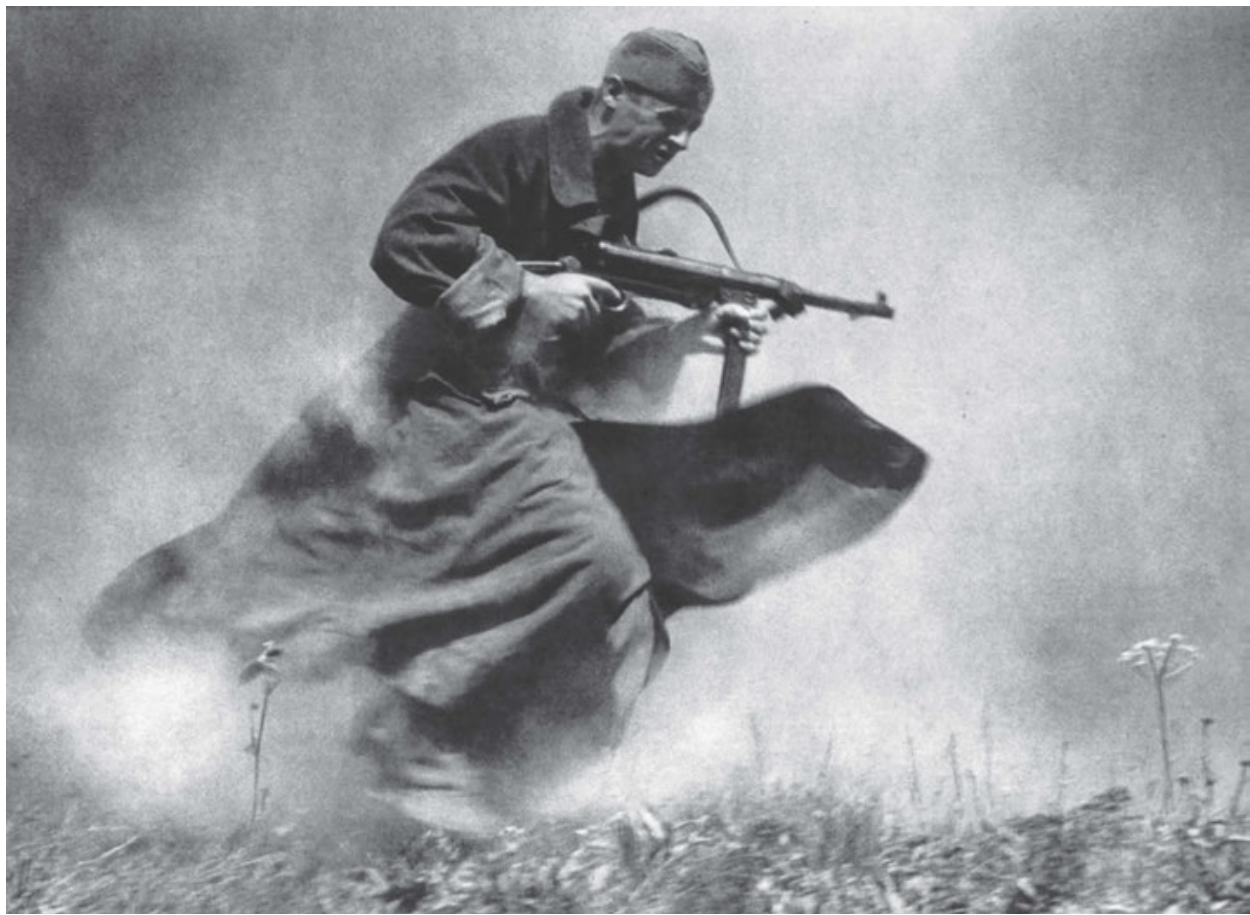

Na juriš (Sturmangriff), 1945. Foto: Marjan Pfeifer. Ljubljana, Moderne Galerie | MG_750_F.

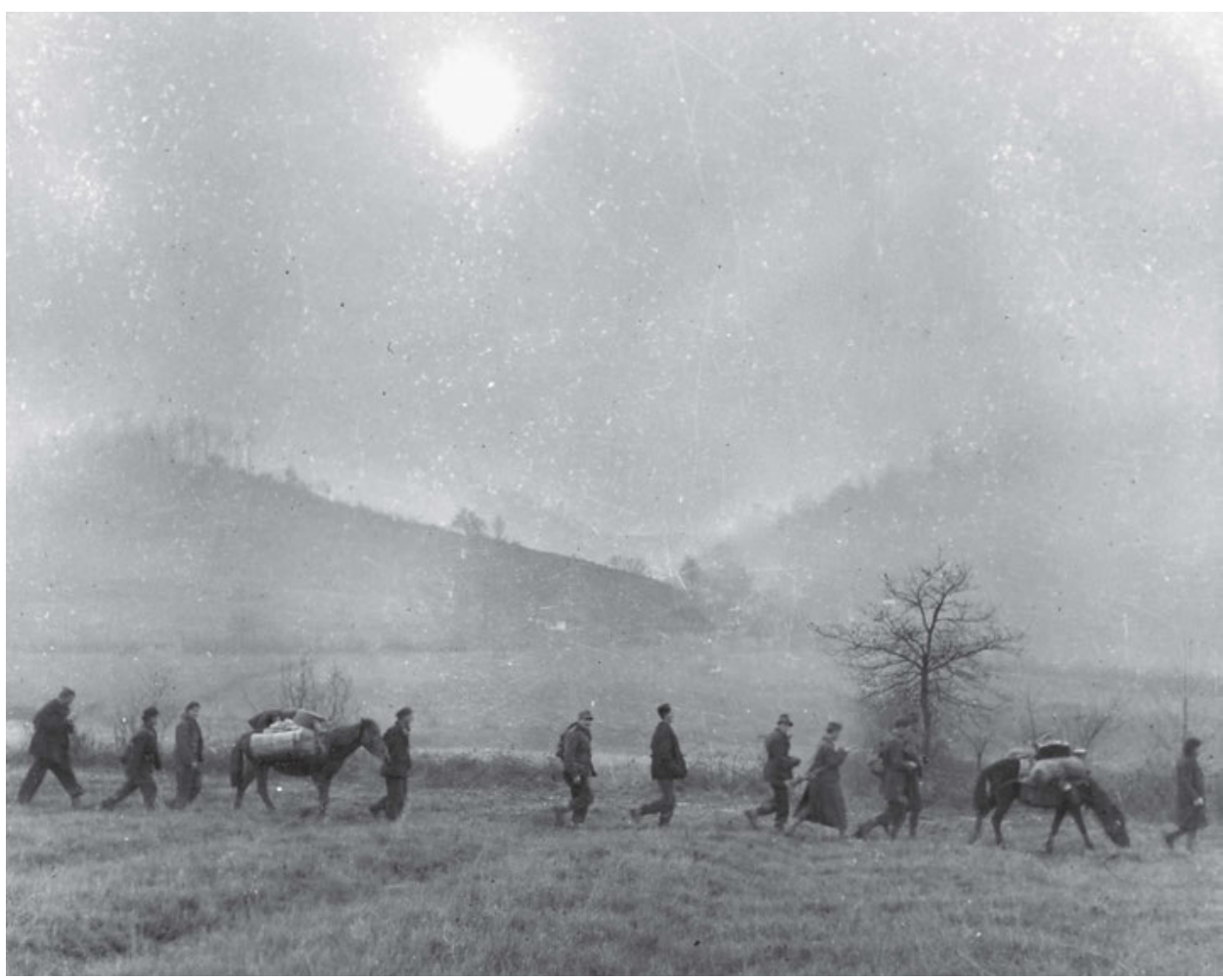

Truppenbewegung der Krajina-Brigaden im Kozara-Gebirge, 1944. Foto: Žorž Skrigin. znaci.net. 


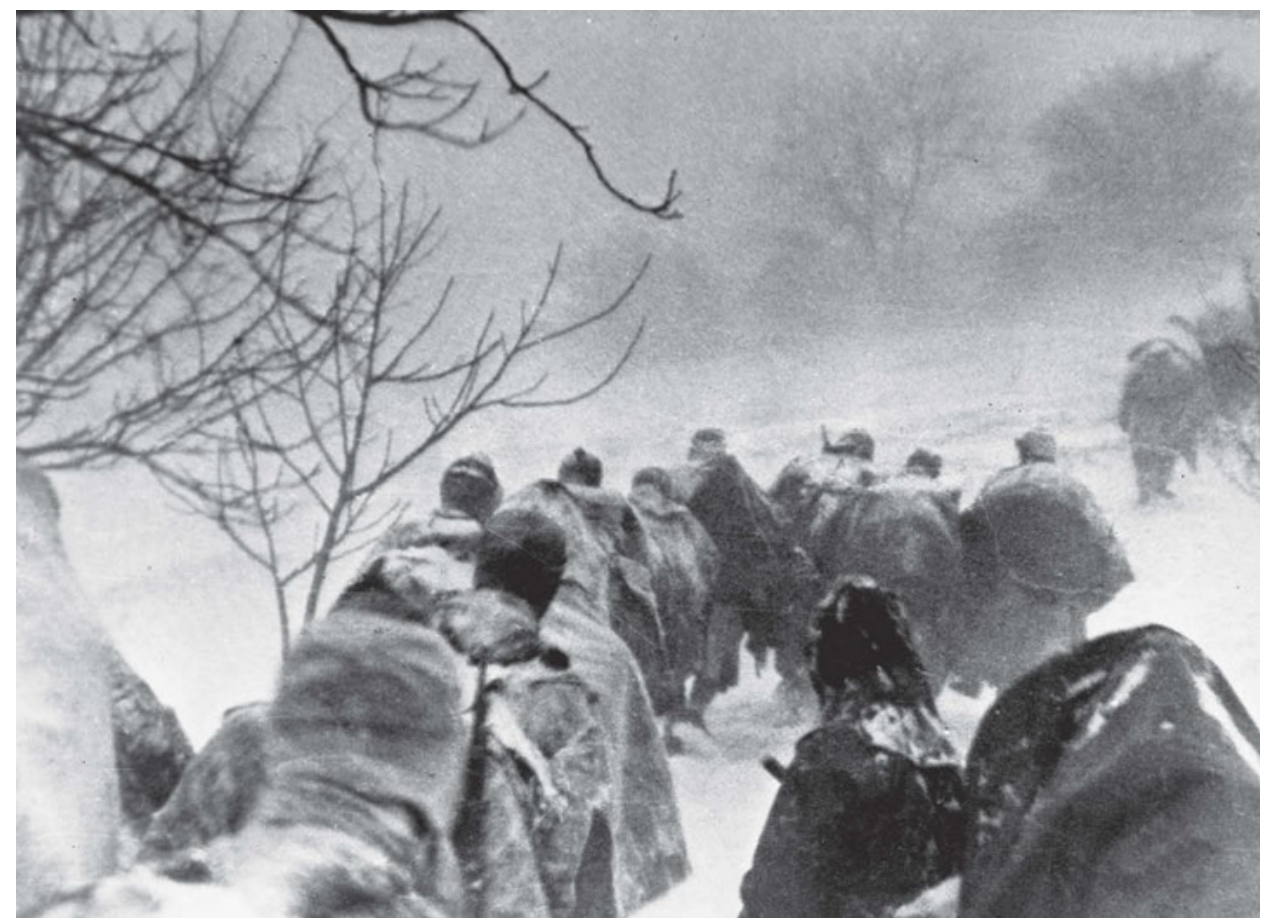

Marsch der 14. Division. Foto: Jože Petek. Ljubljana, Museum für Neuere Geschichte Sloweniens | 1325.

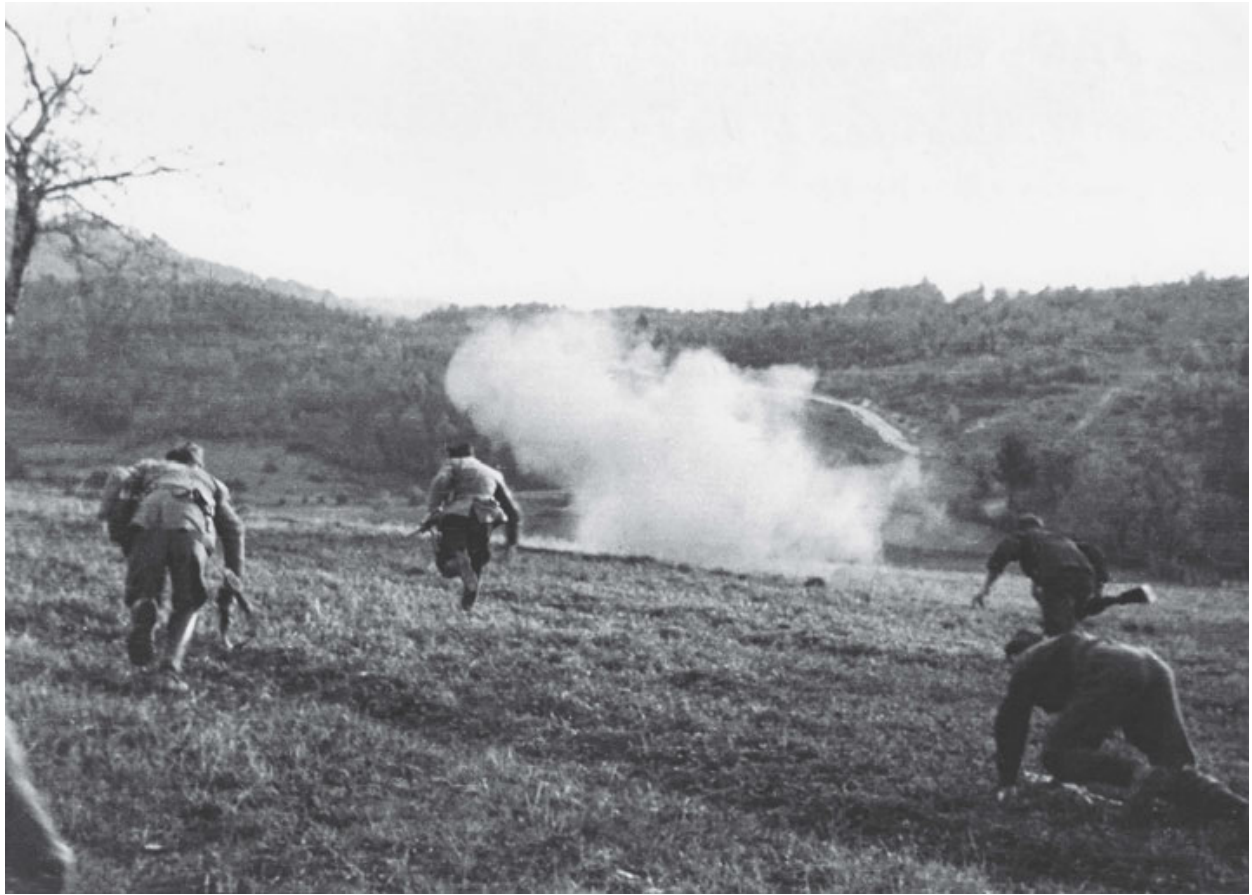

Kampfhandlungen der Zwölften Slowenischen Brigade bei Sv. Križ am 5. August 1944, durch die der Angriff der Landwehrdivision abgewehrt wurde. Fotograf unbekannt. Belgrad, Museum Jugoslawiens | III-1620. 


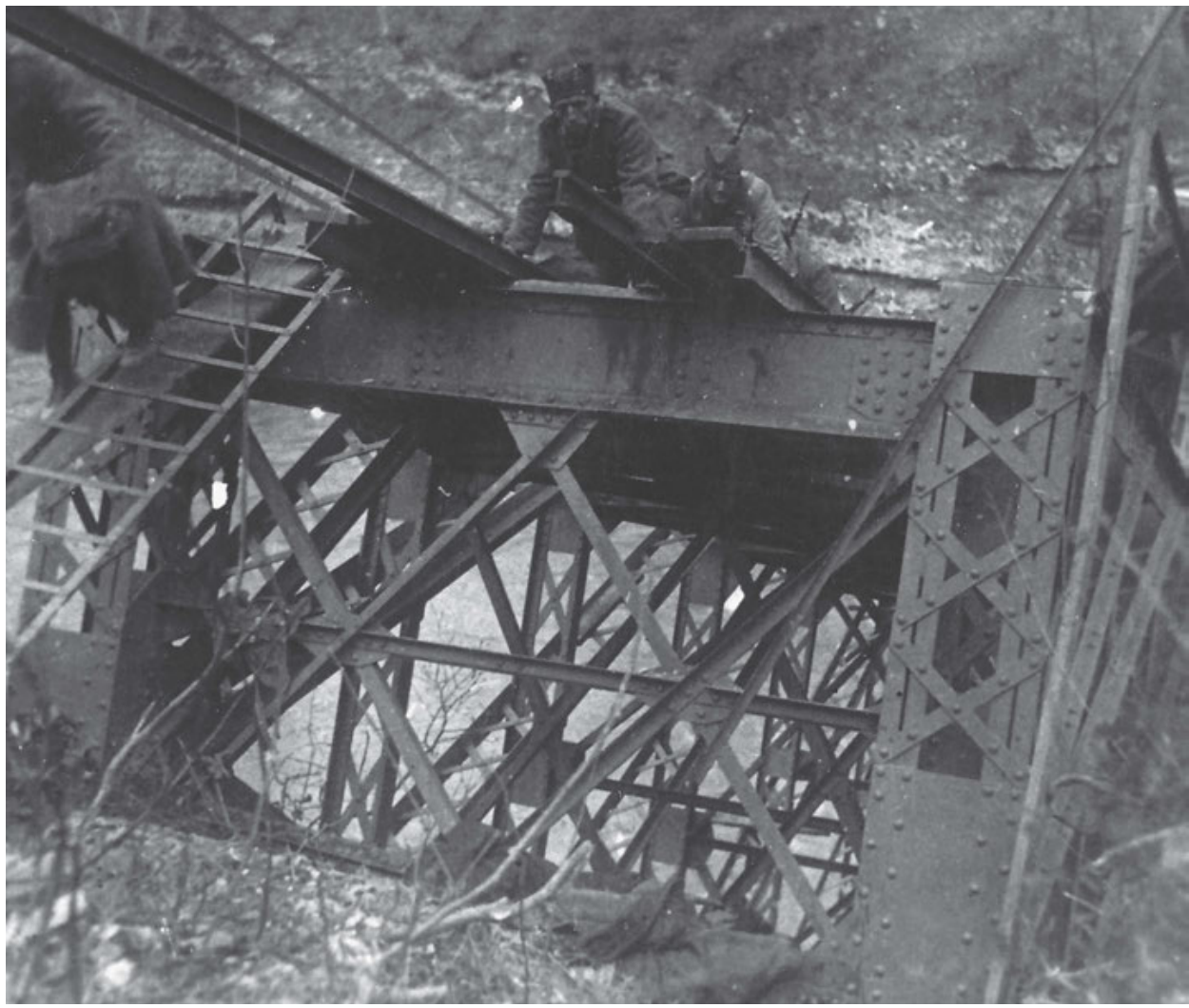

Mijalko Todorović, Politkommissar der Ersten Proletarischen Brigade, überquert die zerstörte

Neretva-Brücke bei Jablanica während der Vierten Offensive im März 1943. Fotograf unbekannt.

Belgrad, Militärmuseum | 4428.

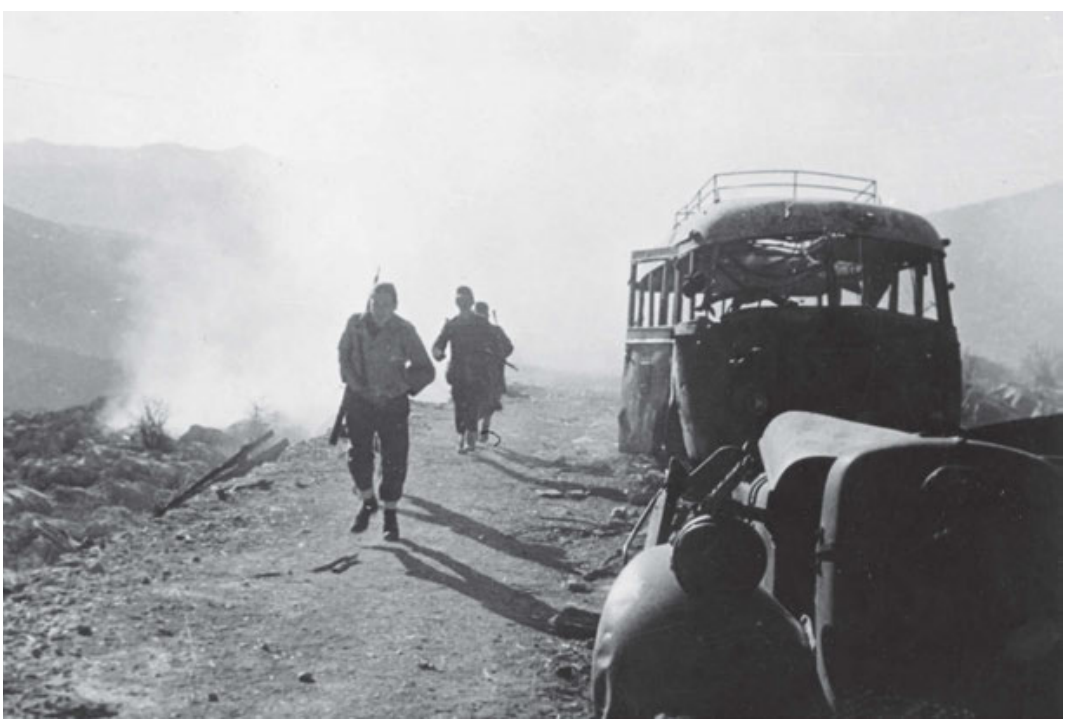

Bei ihrem Rückzug vor der Dritten Division brannten die deutschen Soldaten Lastkraftwagen mit Material und Lebensmitteln nieder. Aufgenommen zwischen Podgorica und Kolašin im Jahr 1944. Fotograf unbekannt. Belgrad, Militärmuseum | 12337. 


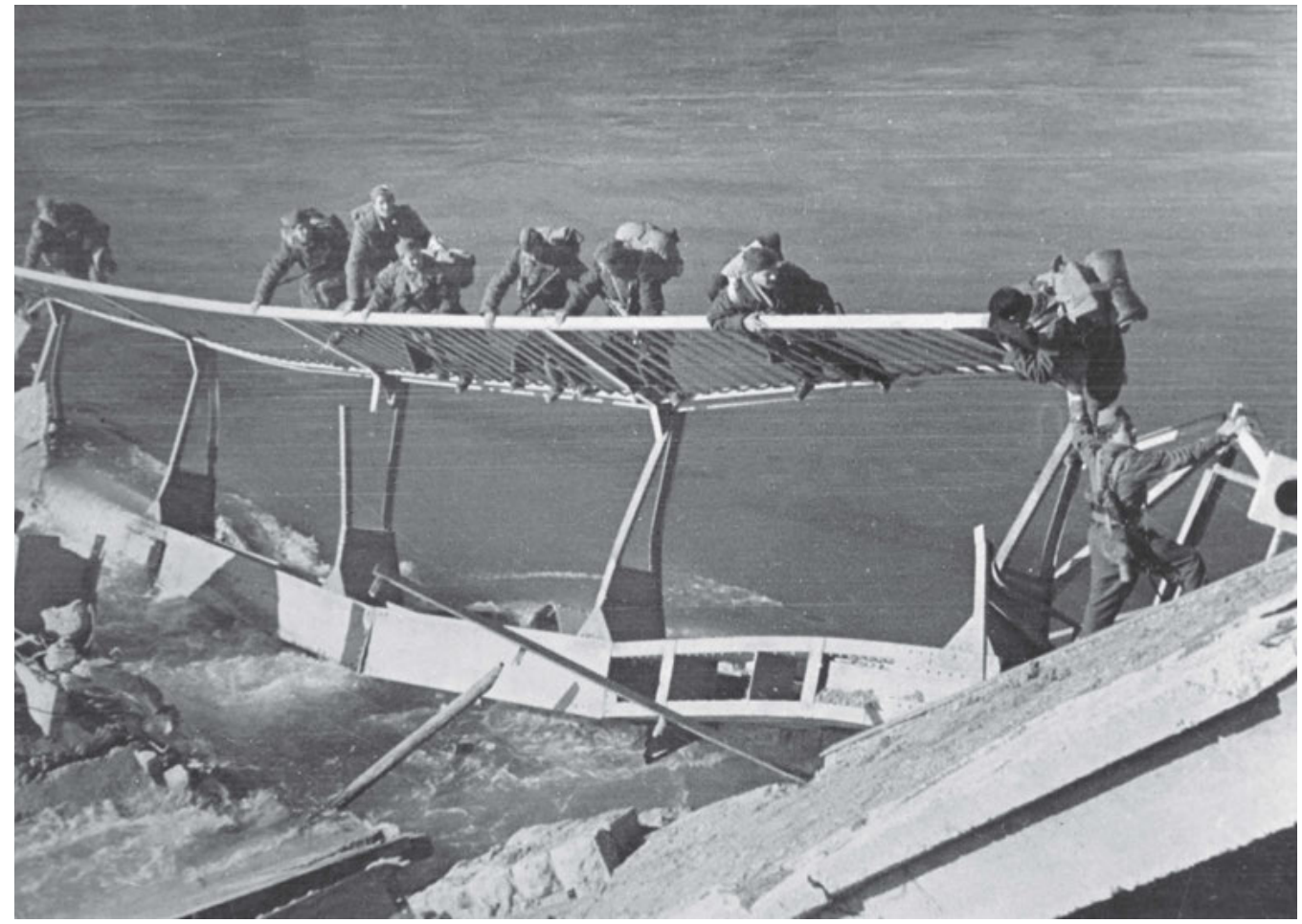

Die Zweite Division der Volksbefreiungsarmee überquert den Fluss Morača bei Podgorica, Montenegro 1944. Fotograf unbekannt. Belgrad, Militärmuseum | 12350.

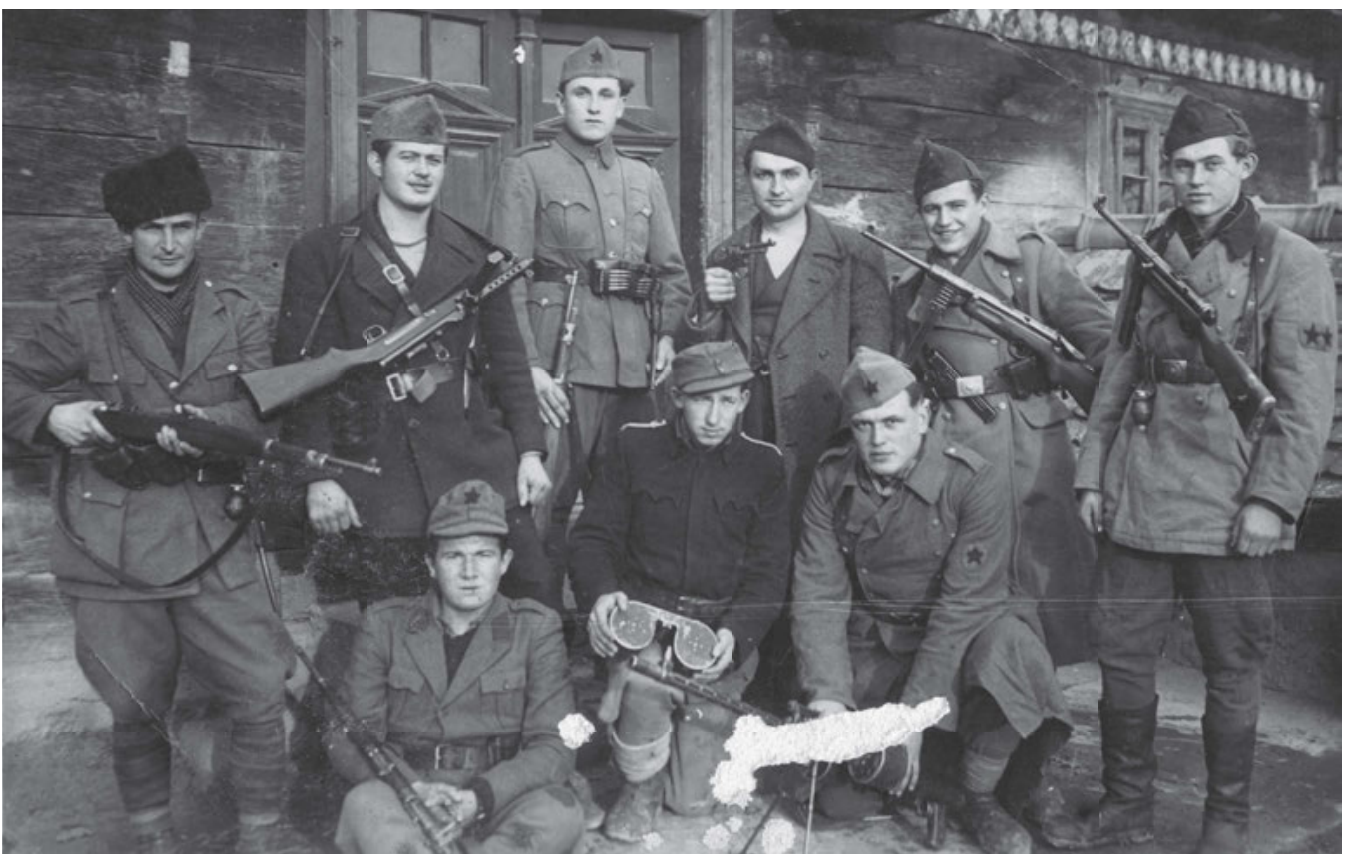

Die wahrscheinlich im Herbst 1942 in Westslawonien entstandene Fotografie ist wegen der unterschiedlichen Uniformen interessant: Der stehende Partisan trägt eine graugrüne Uniform der Landwehr, der sitzende Partisan eine deutsche Uniform und der Partisan in der Mitte eine Feuerwehruniform. Fotograf unbekannt. Privatarchiv von Robert Čopec. 


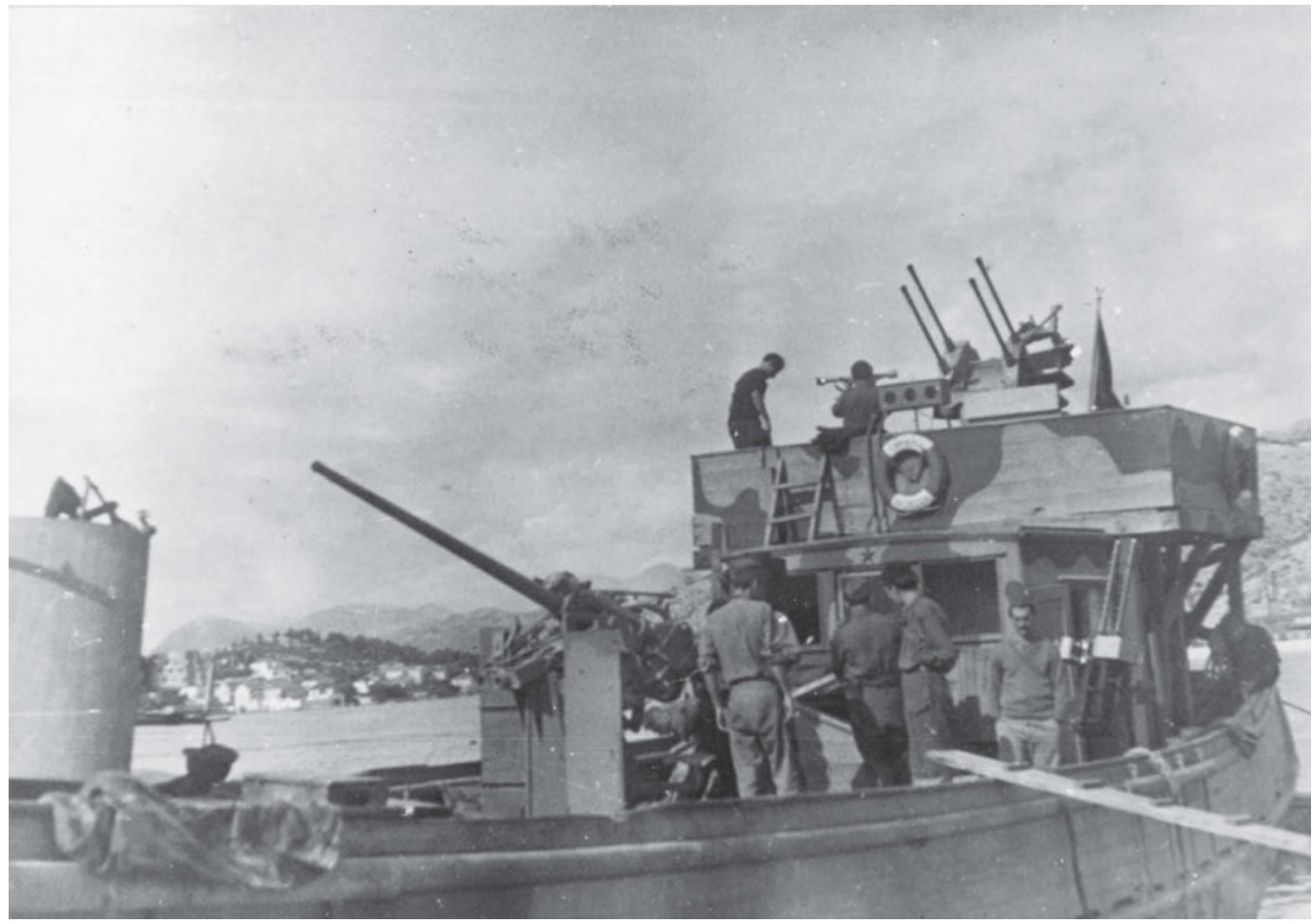

Schiff im Hafen von Dubrovnik, Oktober 1944. Fotograf unbekannt. Sarajevo, Historisches Museum von Bosnien und Herzegowina | FNOB 19473.

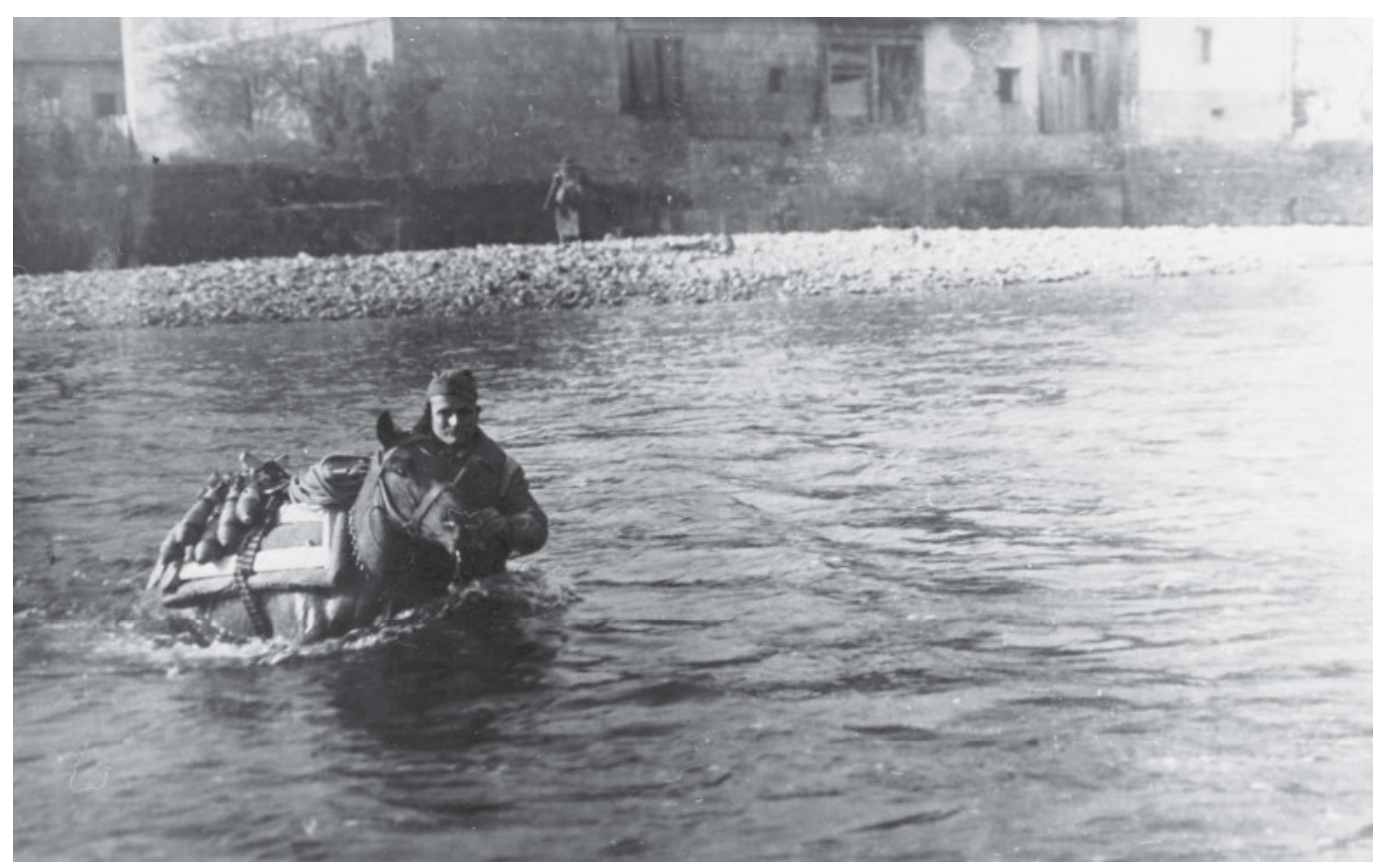

Partisan mit Pferd im Wasser während der Kämpfe um Istrien. Fotograf unbekannt. znaci.net. 


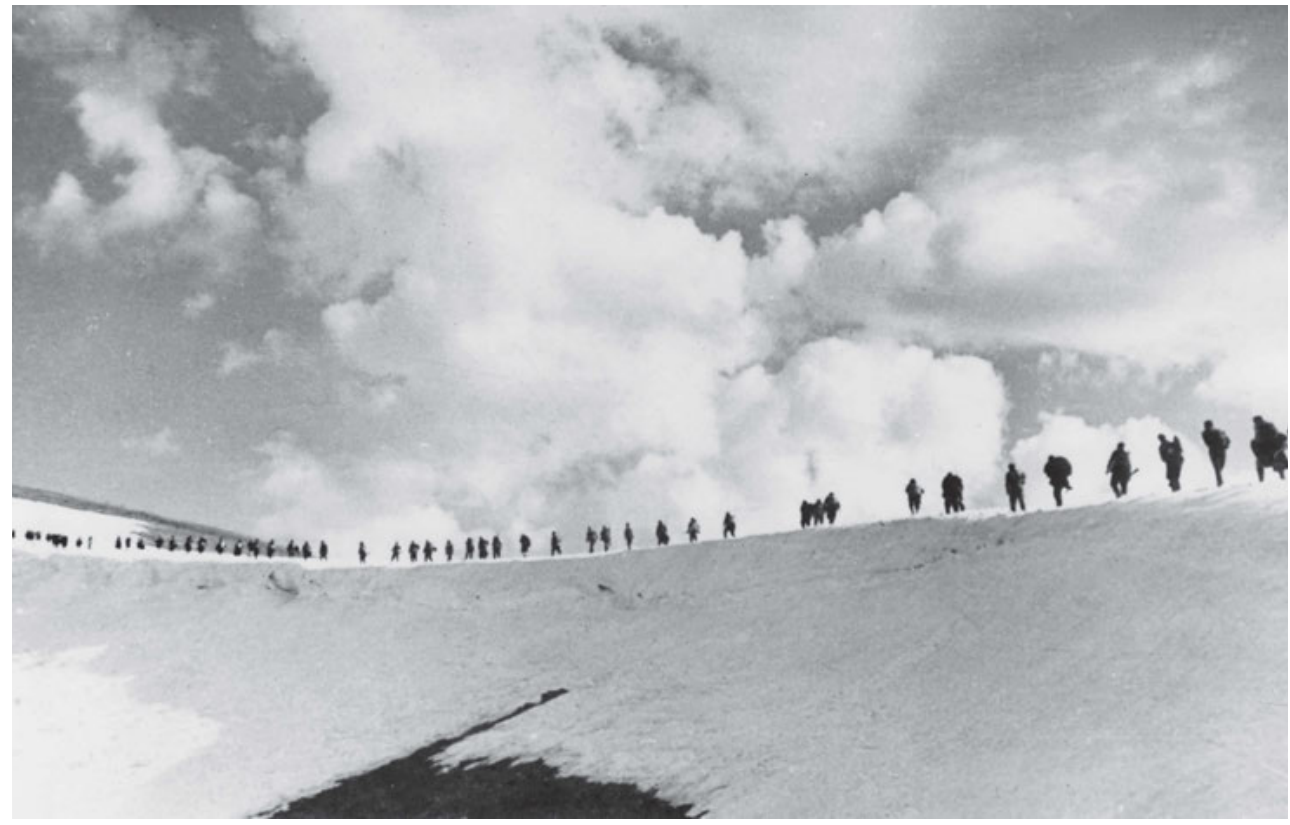

Kolonne von Kämpfern der Sechsten Lika-Division in Kupres, 1943. Fotograf unbekannt. Bestand des Historischen Archivs beim ZK BdKJ | 3898/znaci.net.

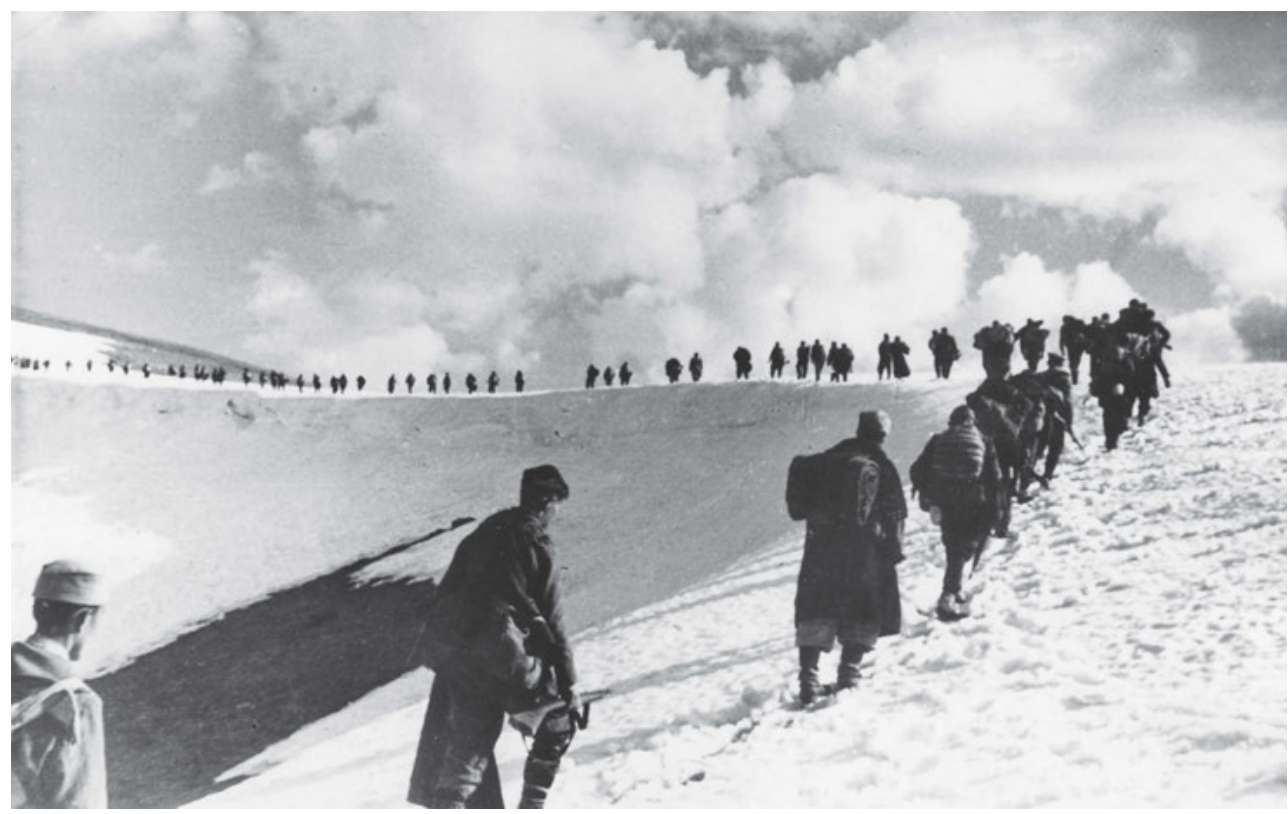

Kolonne von Kämpfern der Sechsten Lika-Division in Kupres, 1943. Fotograf unbekannt. Bestand des Historischen Archivs beim ZK BdKJ | 3899/znaci.net. 


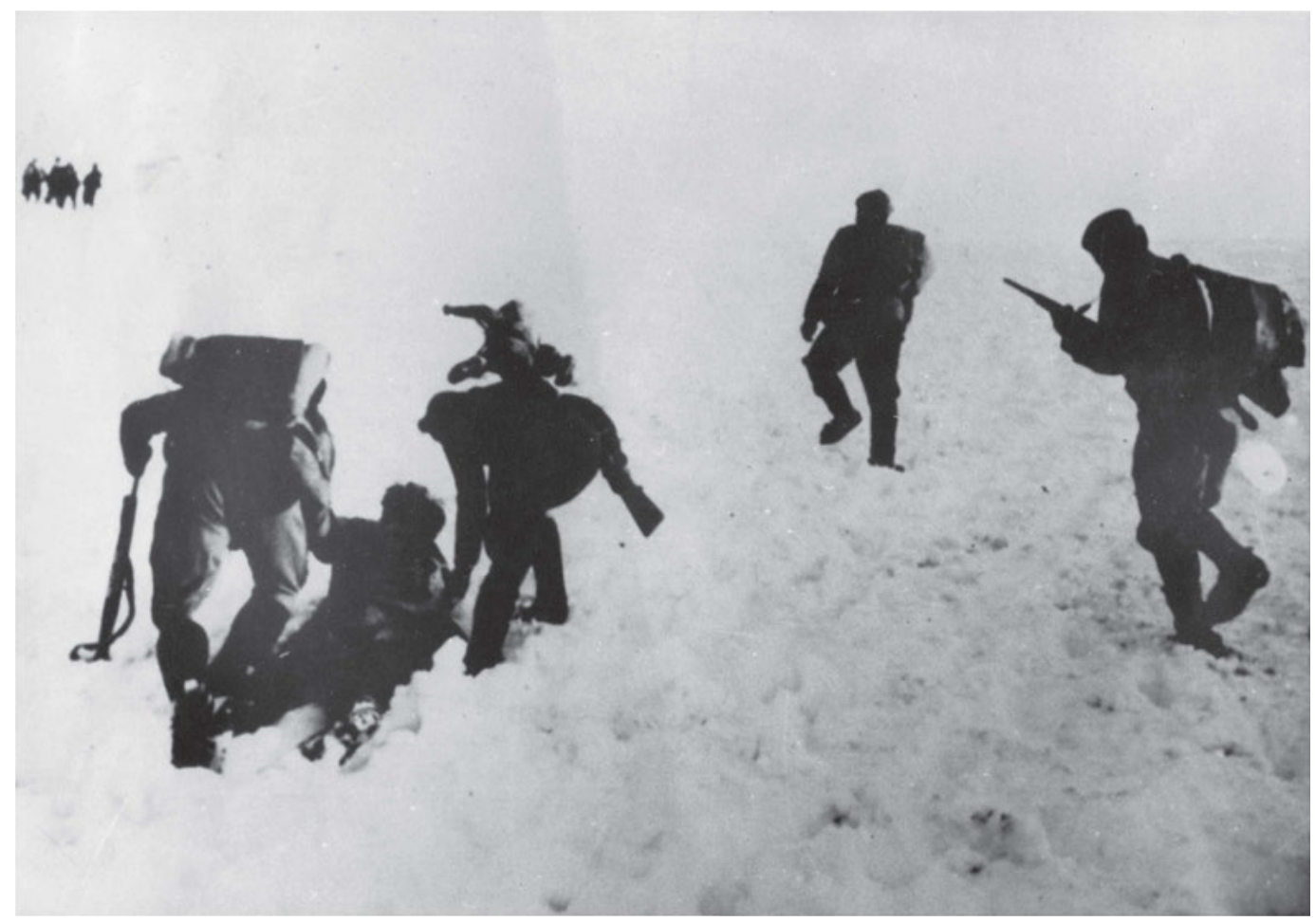

Offensive der mazedonischen Partisanen auf dem Territorium von Ost-, Zentral- und Westmazedonien im Februar 1944. Nach dem Februar-Feldzug befreiten die mazedonischen Partisanen einen Teil Mazedoniens und traten als bedeutende Kraft an der jugoslawischen Front hervor. Fotograf unbekannt. znaci.net.

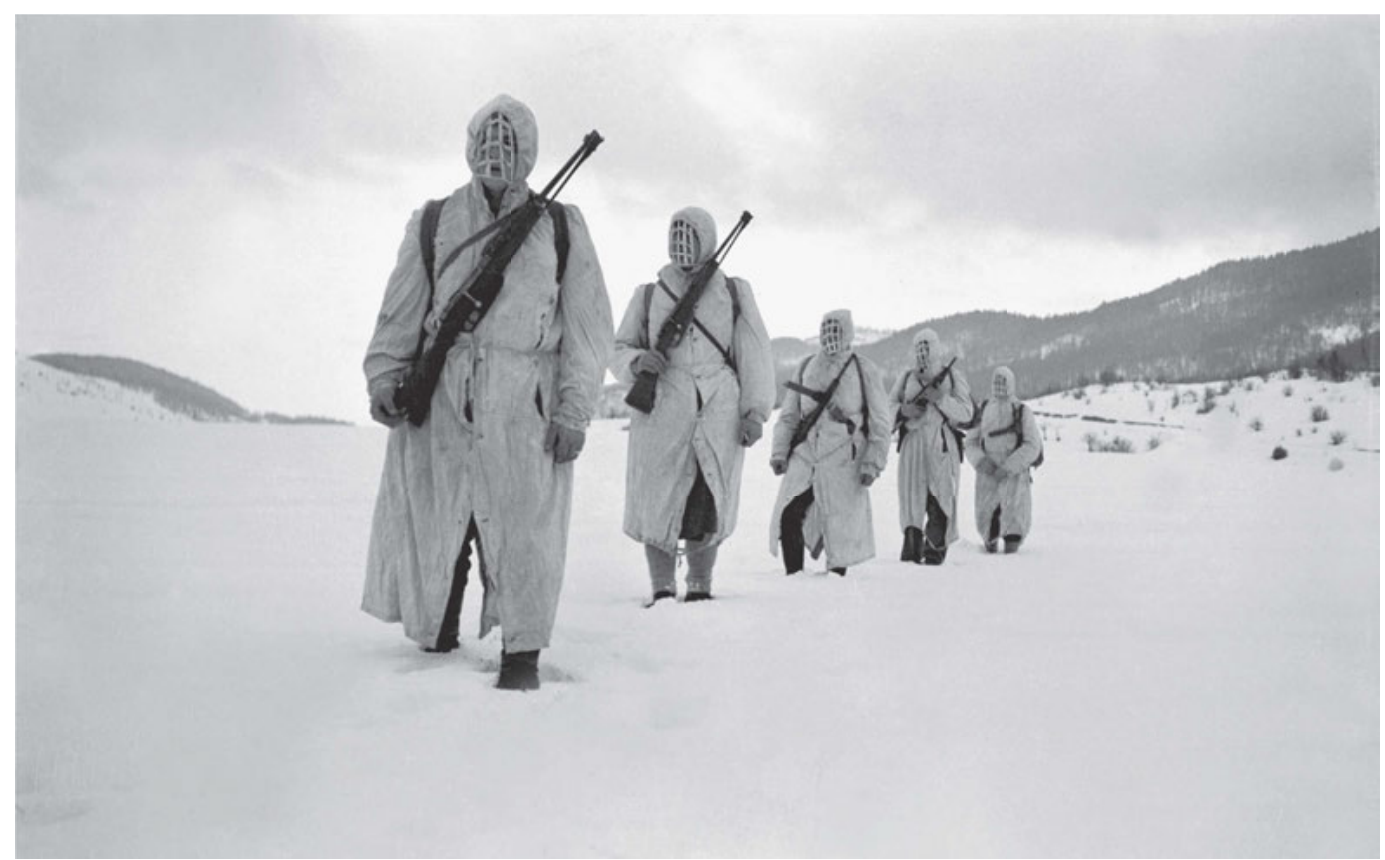

Die Patrouille der Kuriere der Innerkrain-Einheit auf dem Weg zur Befehlsausführung. Laška-Tal, Babno polje, 1945. Foto: Edi Šelhaus. Ljubljana, Museum für Neuere Geschichte Sloweniens | TN553/8. 


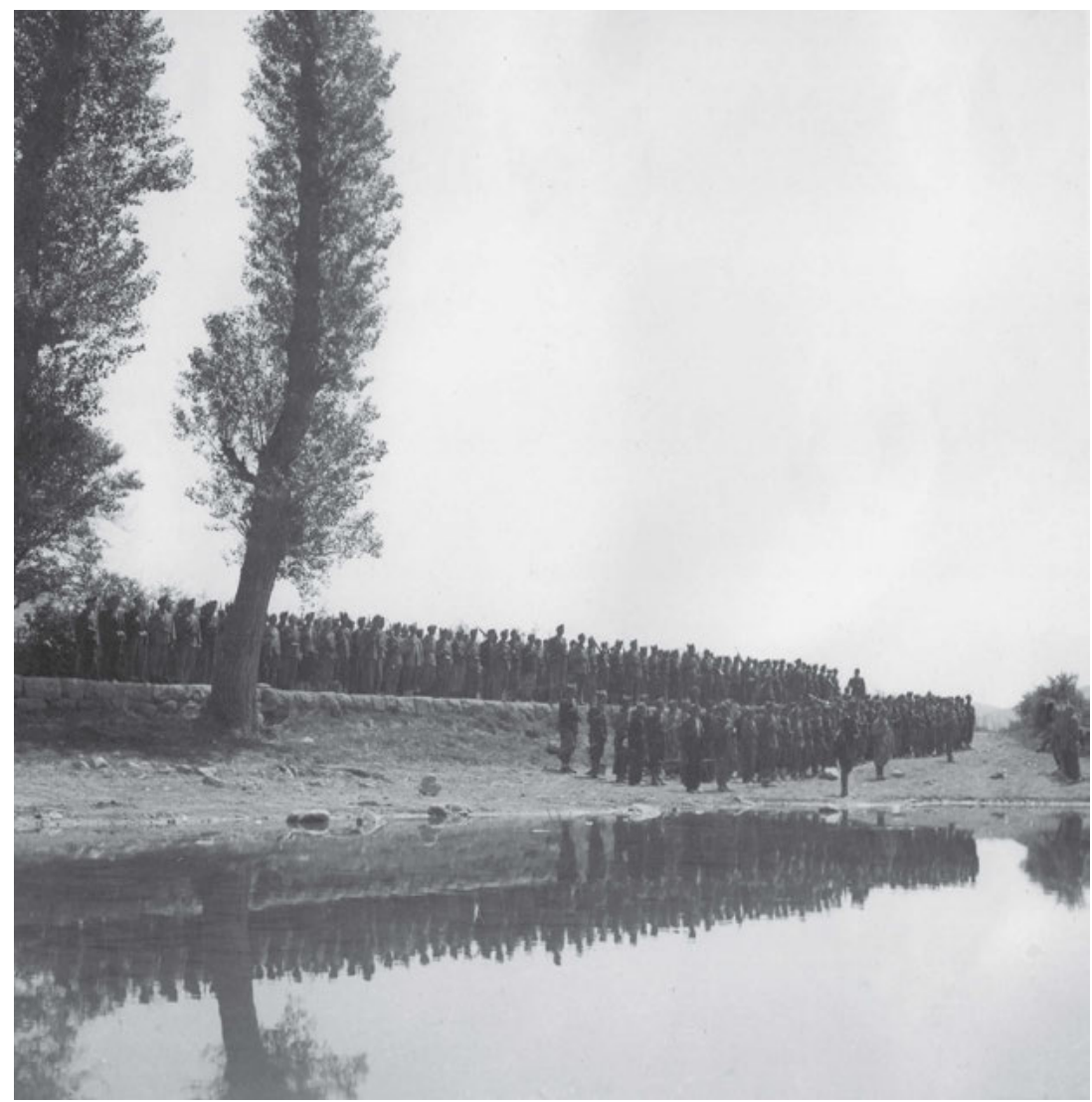

Antreten des Kroatischen Proletarier-Bataillons zum Appell bei Brlog anlässlich seiner Gründung im Jahr 1942. Foto: Žorž Skrigin. znaci.net.

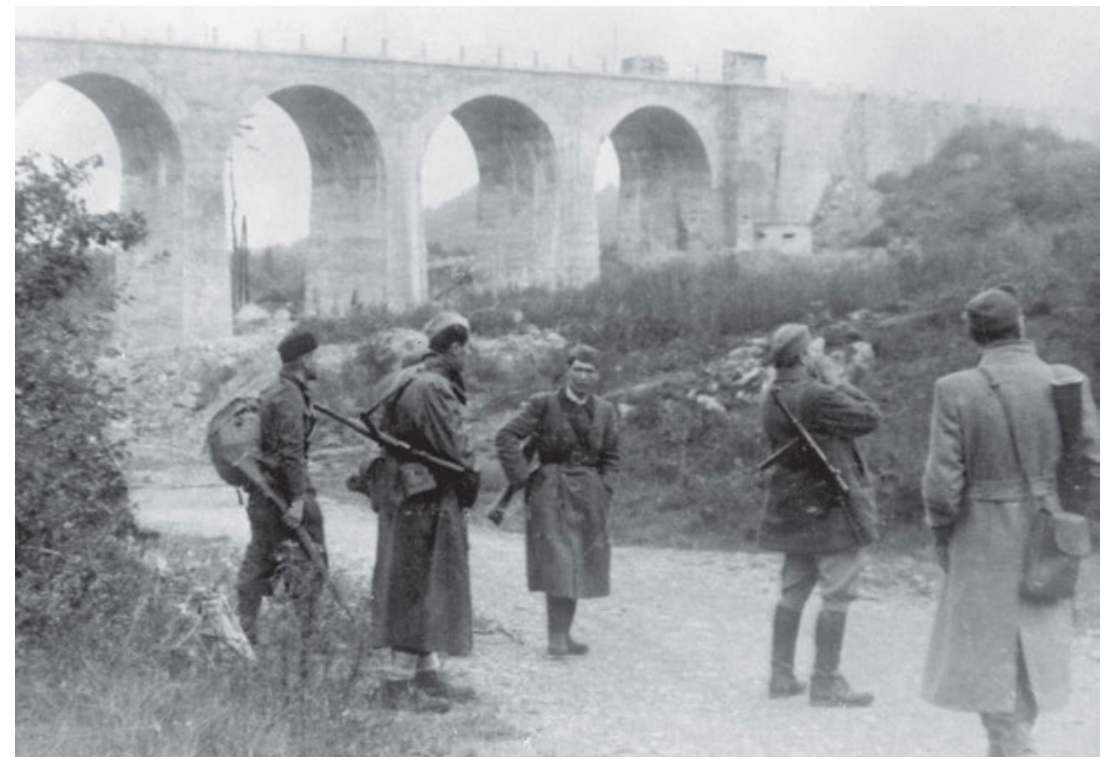

Mitglieder der Ersten Slowenischen Brigade Tone Tomšić an der Stampetta-Brücke vor der Aktion ihrer Sprengung. In der Nähe von Vrhnika, Slowenien, 14. November 1943. Foto: Jože Petek. Ljubljana, Museum für Neuere Geschichte Sloweniens | 2317. 


\section{Fotografien der Solidarität}

Dem Thema der Solidarität kommt auf den Fotografien der Partisanen ein besonderer Stellenwert zu. Zumeist in Serien von Fotografien der Partisanenkrankenhäuser oder der Hilfe und der Versorgung von Verwundeten betonte man den Humanismus der Revolution. Der medizinische Dienst war in organisatorischer Hinsicht eine wahre Meisterleistung: Es wurden Krankenhäuser, ein pharmazeutischer und zahnmedizinischer Dienst, Kurse für die Ausbildung von Sanitätern sowie tierärztliche Abteilungen eingerichtet. Von Anbeginn des bewaffneten Widerstands im Jahr 1941 an war der Sanitätsdienst in verschiedenen Einheiten der Partisanen organisiert, während die Installierung der ersten stationären Krankenhäuser auf dem befreiten Territorium erfolgte. Eines der ersten Krankenhäuser gründeten die Partisanen 1941 in Užice. Im selben Jahr nahm auch das Krankenhaus im Gebirge Petrova Gora seine Arbeit auf, bei dem es sich um das erste stationäre Krankenhaus in Kroatien handelte, das bis zum Kriegsende funktionierte. Das bekannteste Krankenhaus in Slowenien befand sich in Kočevski Rog. Im Jahr 1942 gelang eine Vernetzung der militärischen Partisanenkrankenhäuser und im September 1942 wurde die Satzung des Sanitätsdienstes der Volksbefreiungsarmee und der Widerstandbewegung Jugoslawiens verabschiedet, die die Gründung von mobilen Krankenhäusern innerhalb jeder Division vorsah. ${ }^{1}$ Eines der größten mobilen Krankenhäuser war das Zentrale Krankenhaus des Oberkommandos. Das erste Chirurgenteam kam im September 1942 zum Einsatz. Auf dem Territorium des ehemaligen Jugoslawiens waren zu jener Zeit 3.081 Ärzte, darunter 319 Frauen, tätig. Im Krieg fielen 231 als Ärzte wirkende Partisanen. Eine außerordentlich bedeutende und fotografisch wertvolle Serie über die Krankenhäuser der Partisanen schuf der slowenische Arzt Janez Milčinski. 


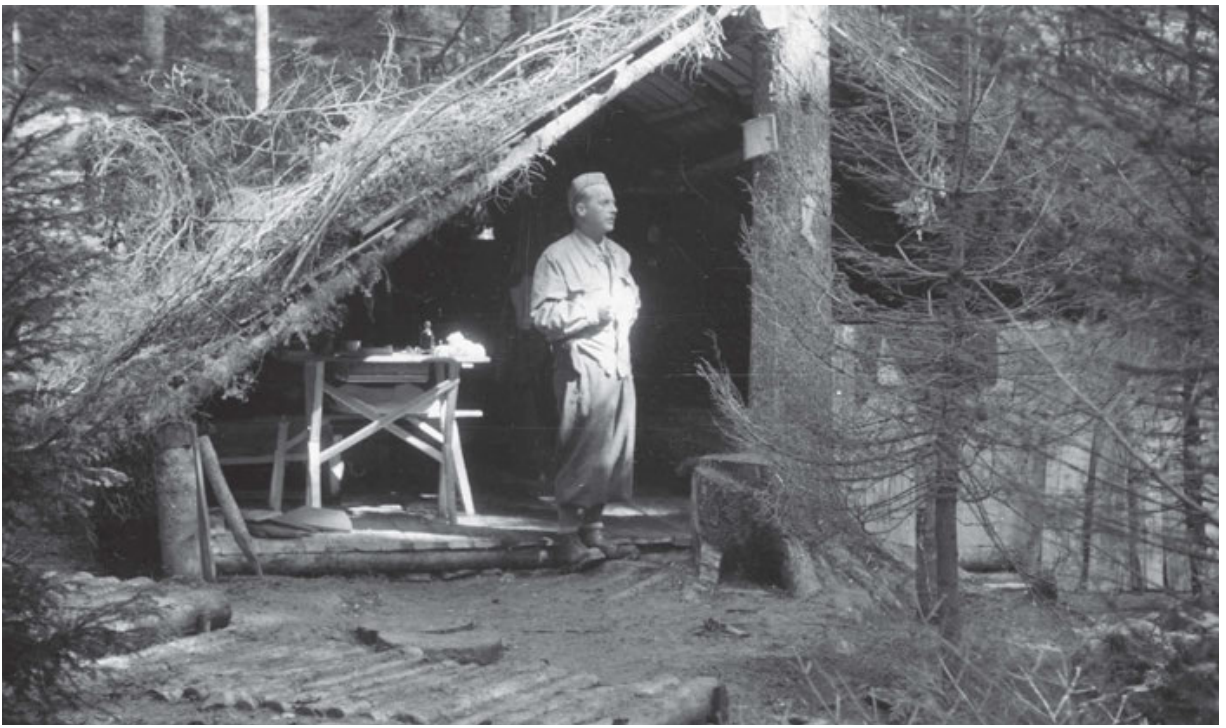

Der Arzt Dr. Bogdan Brecelj im Partisanenkrankenhaus Drveni kamen, Kočevski Rog, September 1943. Fotograf unbekannt. Ljubljana, Museum für Neuere Geschichte Sloweniens | TN33/27.

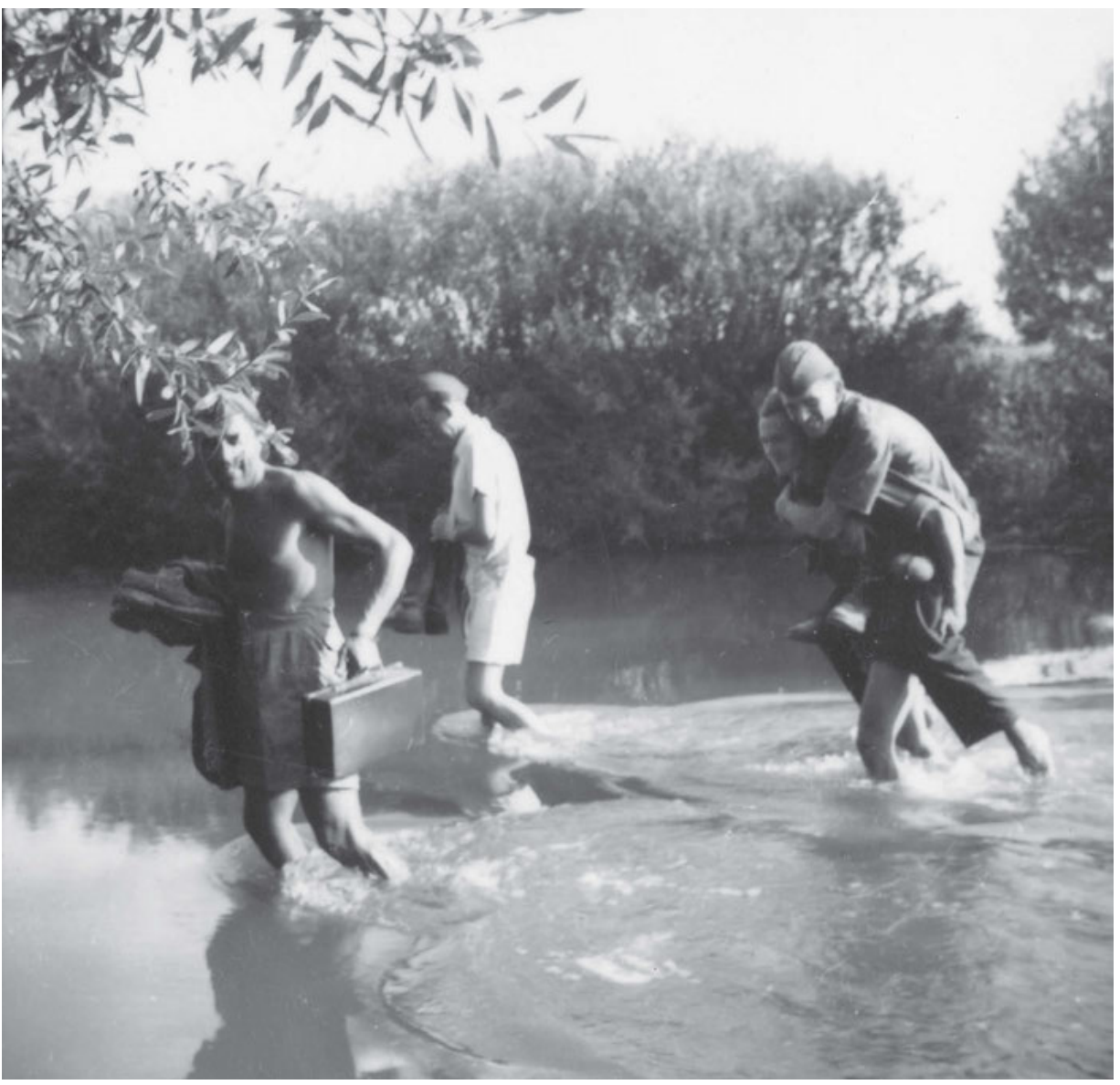

Flussüberquerung in den Tagen der abschließenden Operationen für die Befreiung des Landes, Mai 1945. Fotograf unbekannt. Zagreb, Kroatisches Historisches Museum I HPM-MRNH-A-11700_7. 


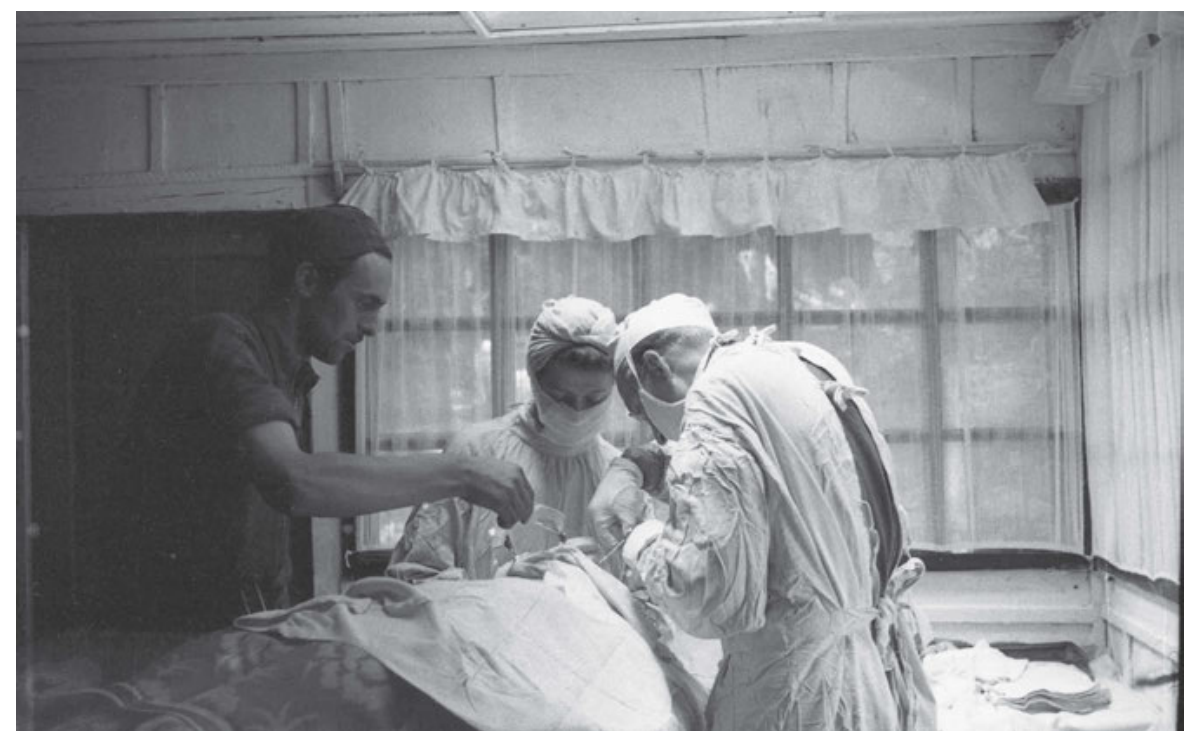

Sterile Operation im Krankenhaus Zgornji Hrastnik, 1944/45. Links Polde Košorok, in der Mitte Marija Jeras, rechts der Operateur Dr. Janez Milčinski. Fotograf unbekannt. Ljubljana, Museum für Neuere Geschichte Sloweniens | 1232/8.

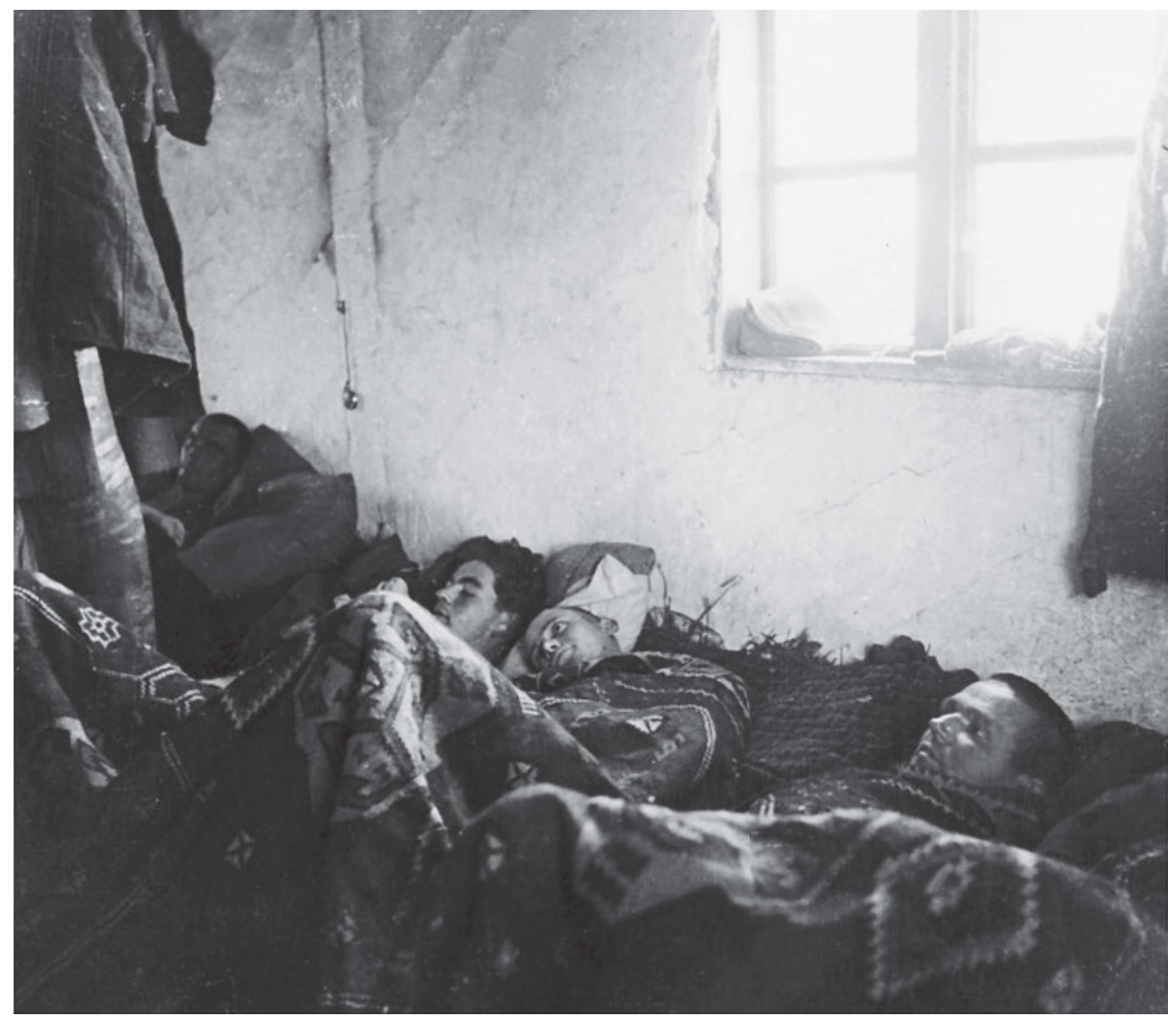

Verwundete der Volksbefreiungsarmee im Krankenhaus bei Bosanski Petrovac, 1942. Foto: Žorž Skrigin. Belgrad, Museum Jugoslawiens | III-3456. 


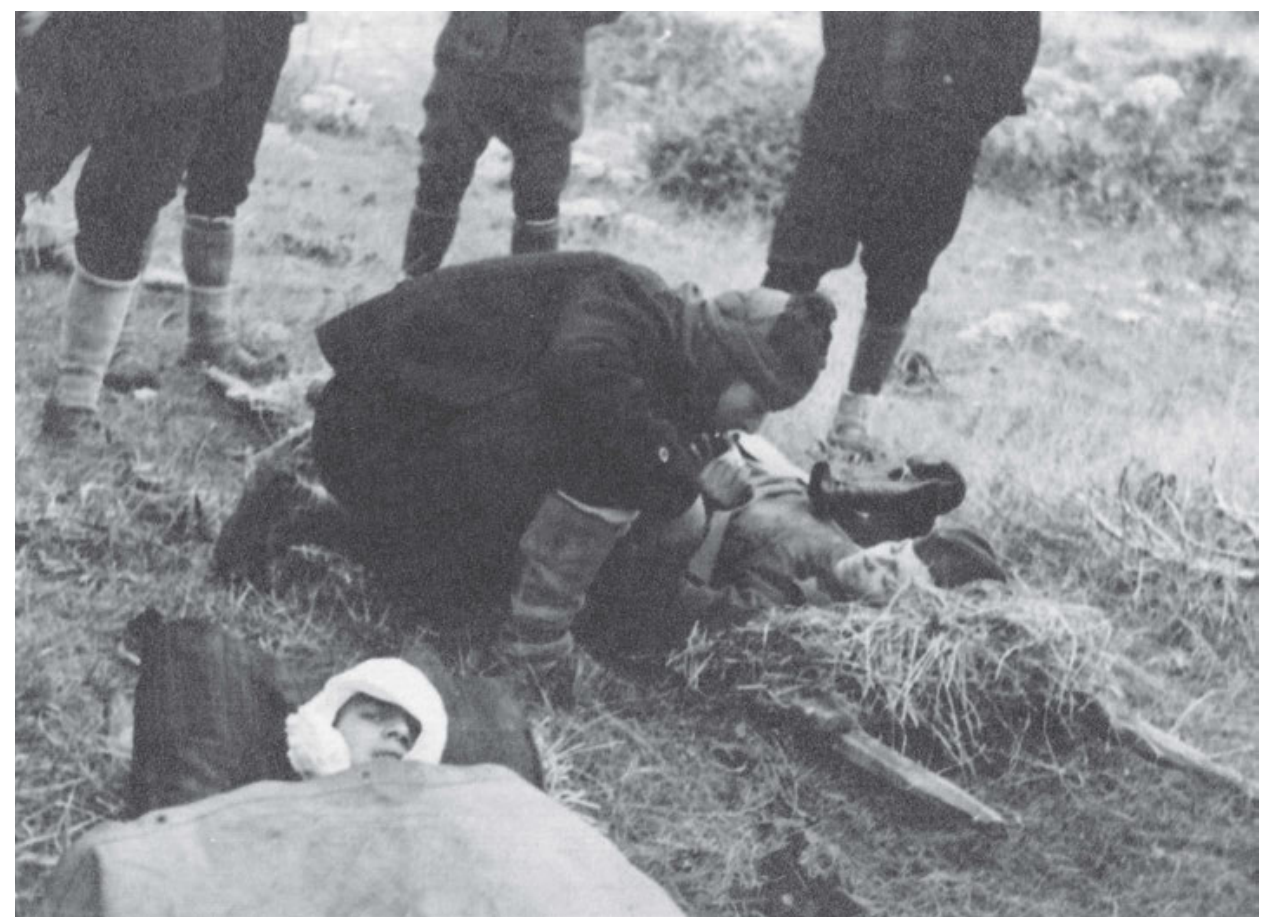

Keine Angaben. Foto: Drago Mažar. Banja Luka, Archiv der Republika Srpska. Ohne Inv.-Nr.

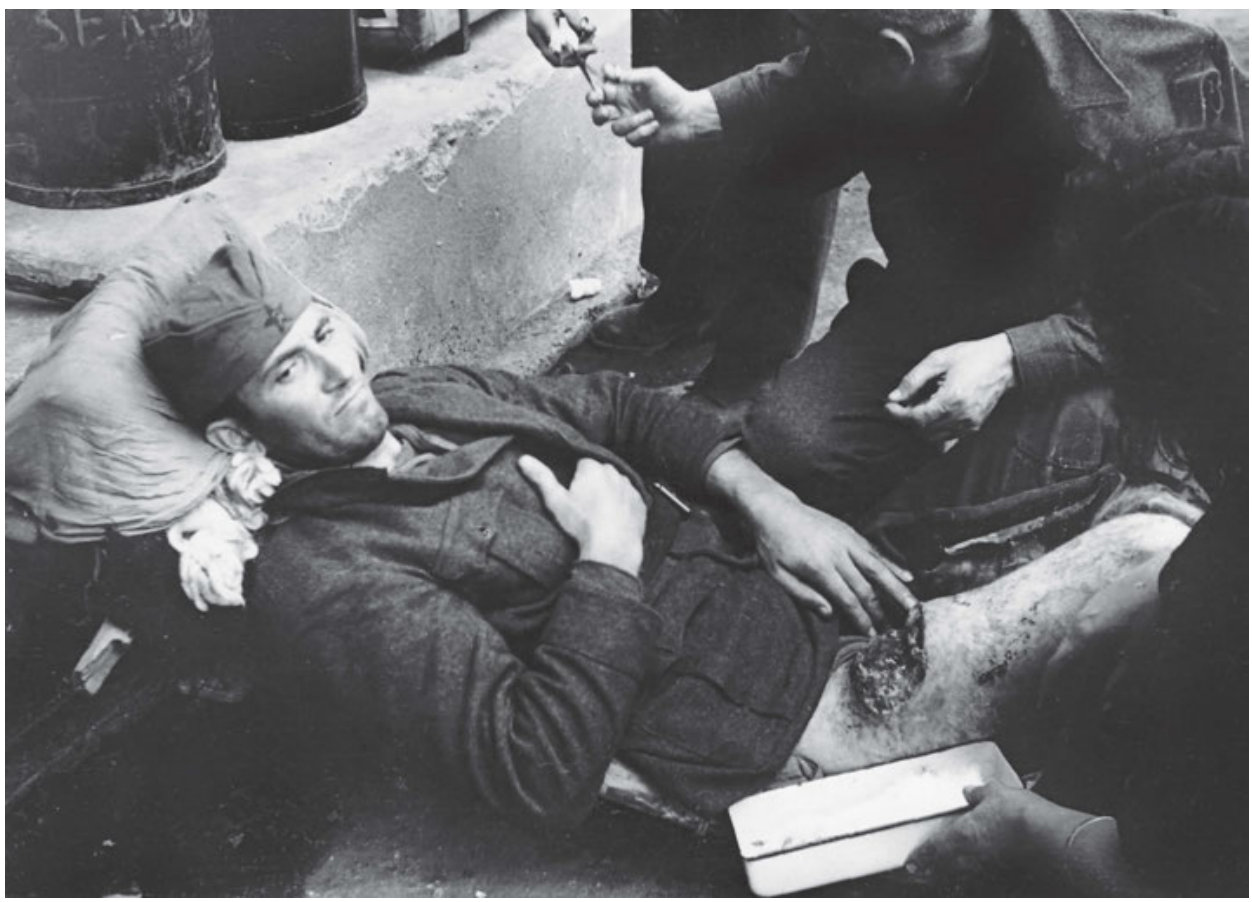

In den Kämpfen, die die Sechste Montenegrinische Brigade gegen Einheiten der Tschetniks führte, wurde auf diesen Partisanen eine italienische Bombe geworfen, die über seinem Knie explodierte und eine riesige Wunde verursachte. Tapfer assistiert er selbst bei der Wundversorgung. Kloster Morača, Mitte Februar 1944. Fotograf unbekannt. Belgrad, Museum Jugoslawiens | III-4516. 


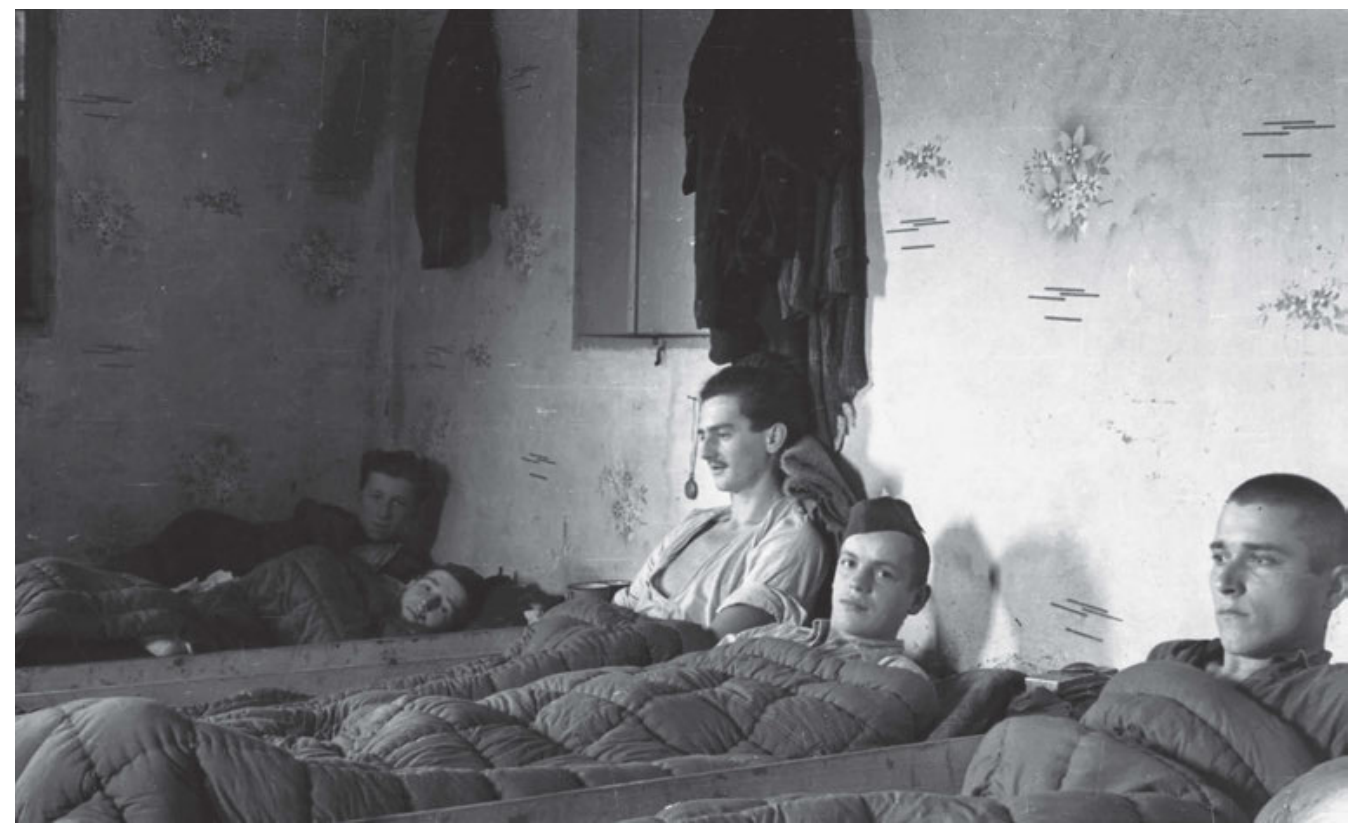

Žumberak SCVPB (Zentrales slowenisches Militärkrankenhaus) und Sanitätsschule des Siebten Korps (November 1944-Januar 1945). Foto: Dr. Janez Milčinski. Ljubljana, Museum für Neuere Geschichte Sloweniens | TN1223/34.

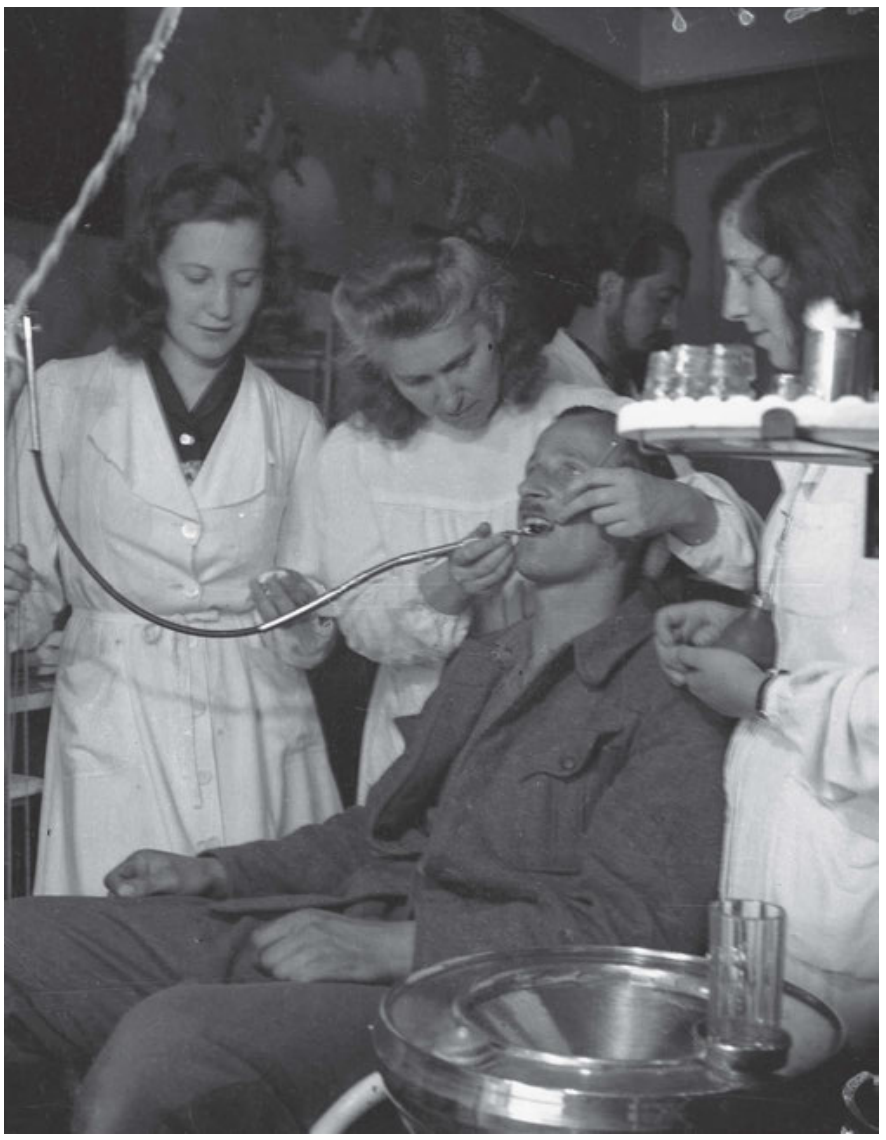

Zahnmedizinische Ambulanz der Partisanen. Črnomelj, 1944/1945. Unbekannter Autor. Ljubljana, Museum der neueren Geschichte Sloweniens | TN193/2. 


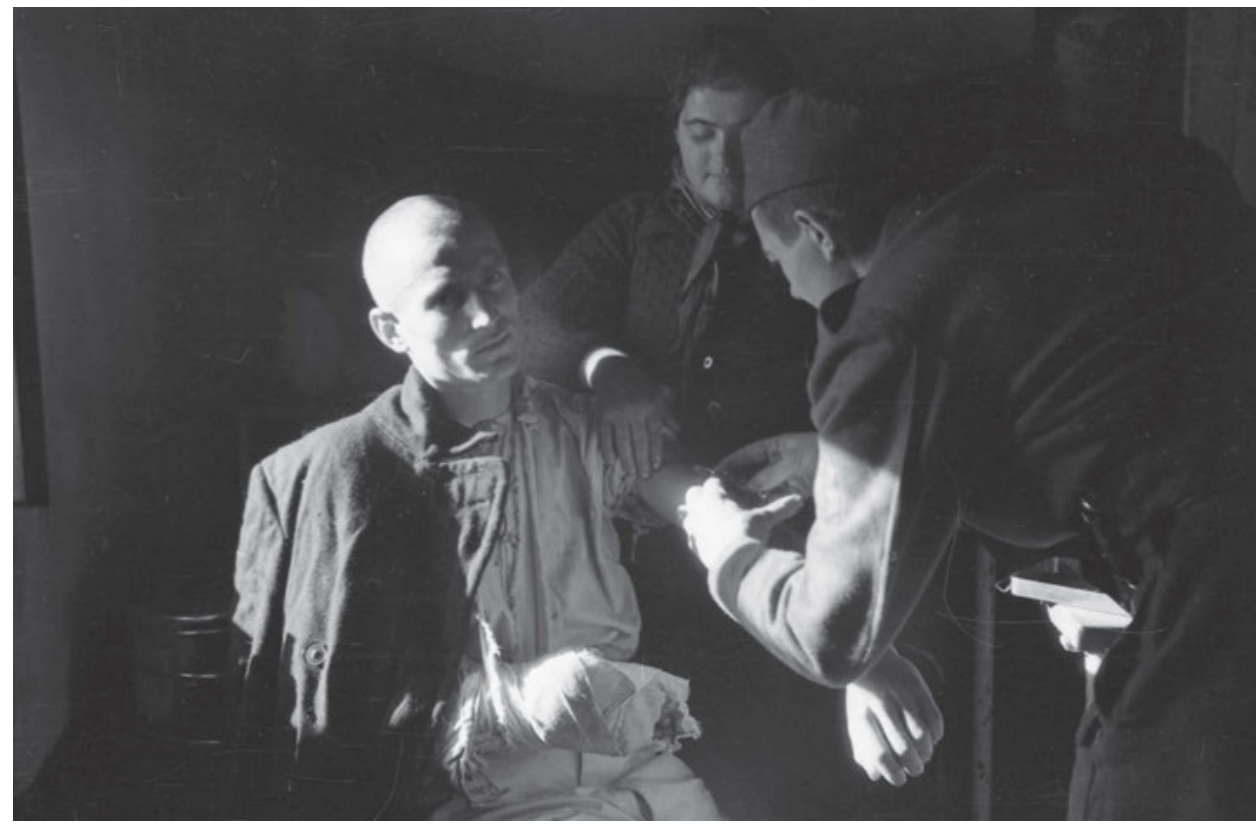

Verbandswechsel in der Ambulanz des Partisanenkrankenhauses in Lika, nahe Turjanski, Winter 1943. Fotograf unbekannt. Zagreb, Kroatisches Historisches Museum I HPM-MRNH-A-2601-f83_035.

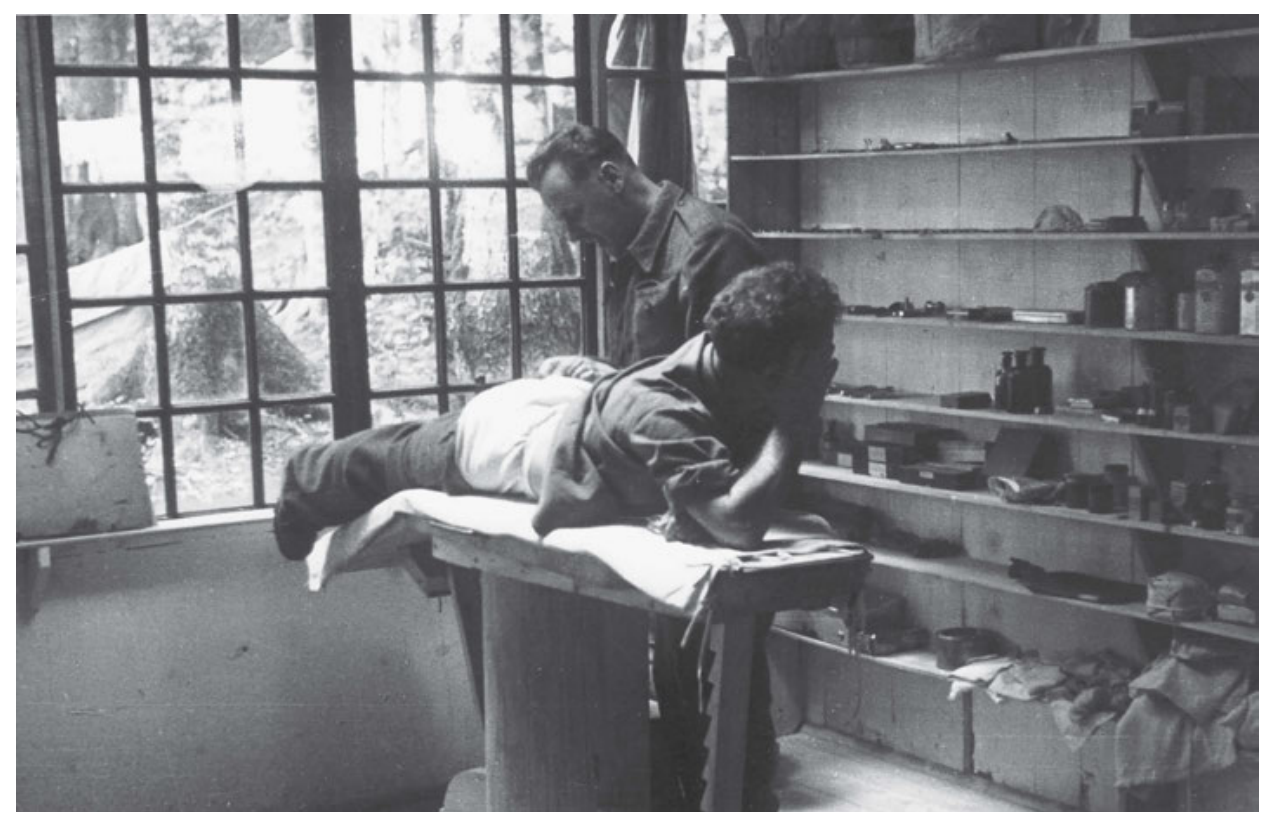

Ein Arzt nimmt einen leichteren chirurgischen Eingriff an einem Patienten in Slowenien vor. Fotograf unbekannt. Ljubljana, Museum der Volksbefreiung Sloweniens | znaci.net. 


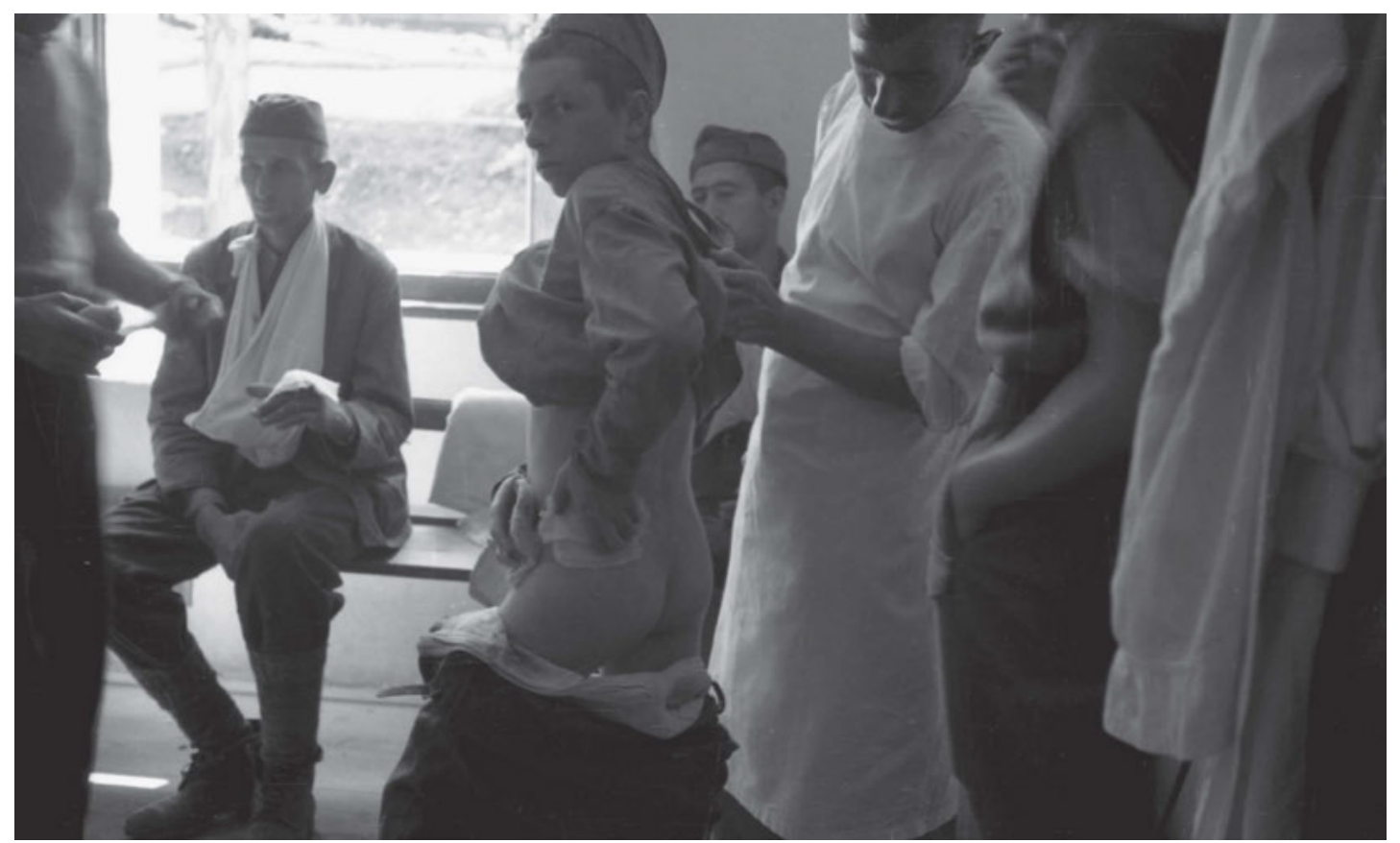

In der Ambulanz der 13. Division von Primorje-Gorski, Gorski Kotar, 1944. Fotograf unbekannt. Zagreb, Kroatisches Historisches Museum | HPM-MRNH-A-2603-f18_035.

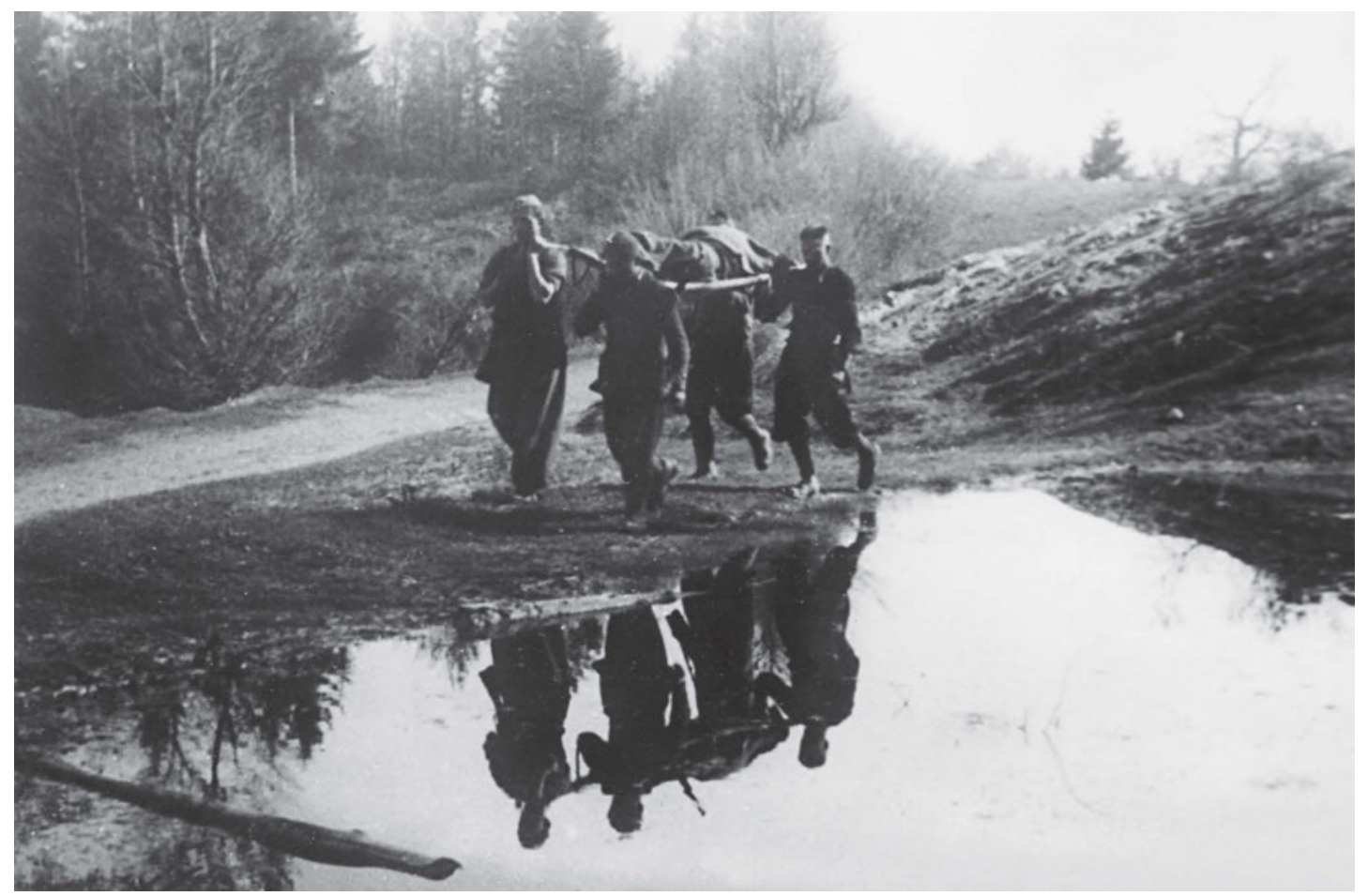

Transport eines Verwundeten ins Krankenhaus, Hrastnik, Slowenien, 1944.

Fotograf unbekannt. Belgrad, Museum Jugoslawiens | III-3370. 


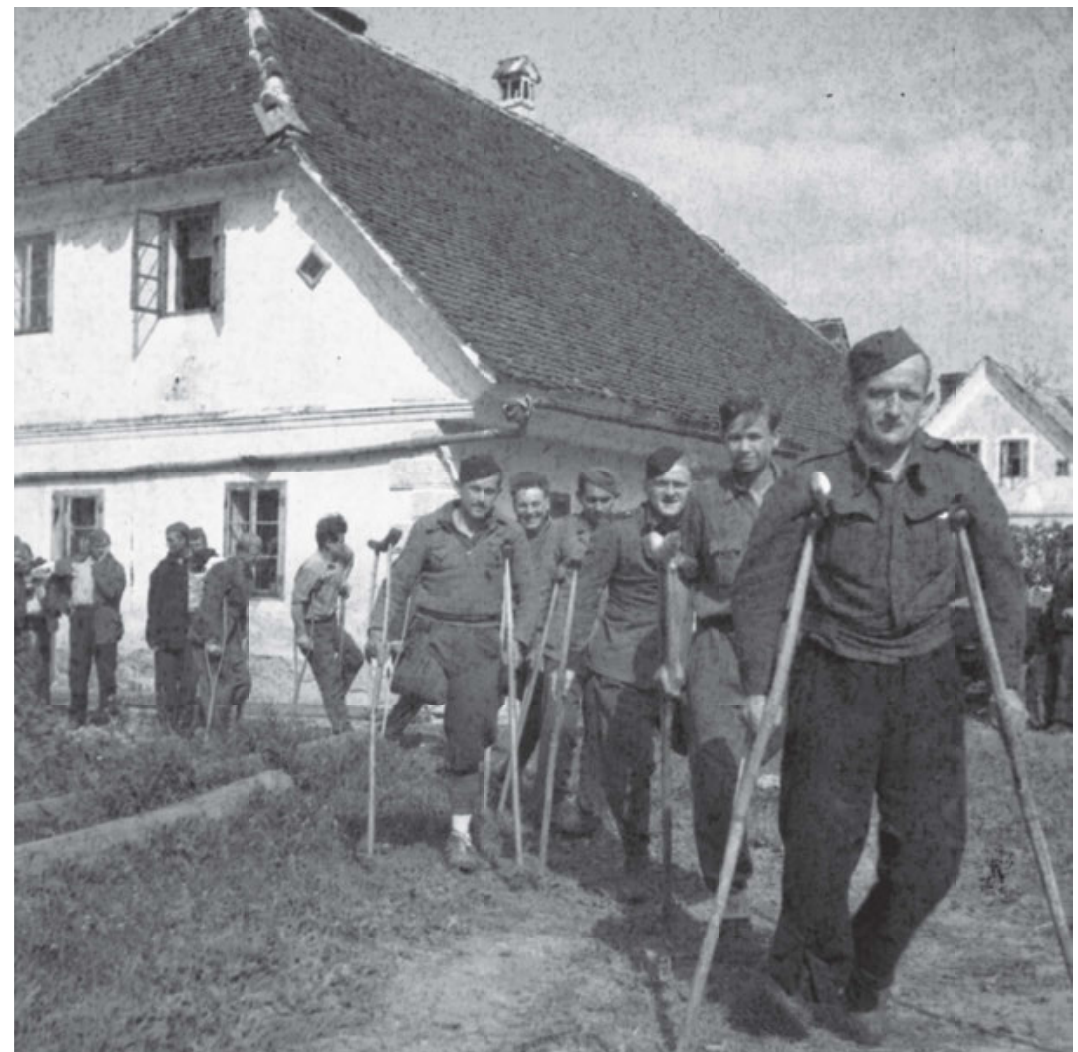

Gruppe Schwerverwundeter und Einheiten des Neunten Korps, Innerkrain, September 1944. Fotograf unbekannt. Ljubljana, Museum für Neuere Geschichte Sloweniens | TN314/4.

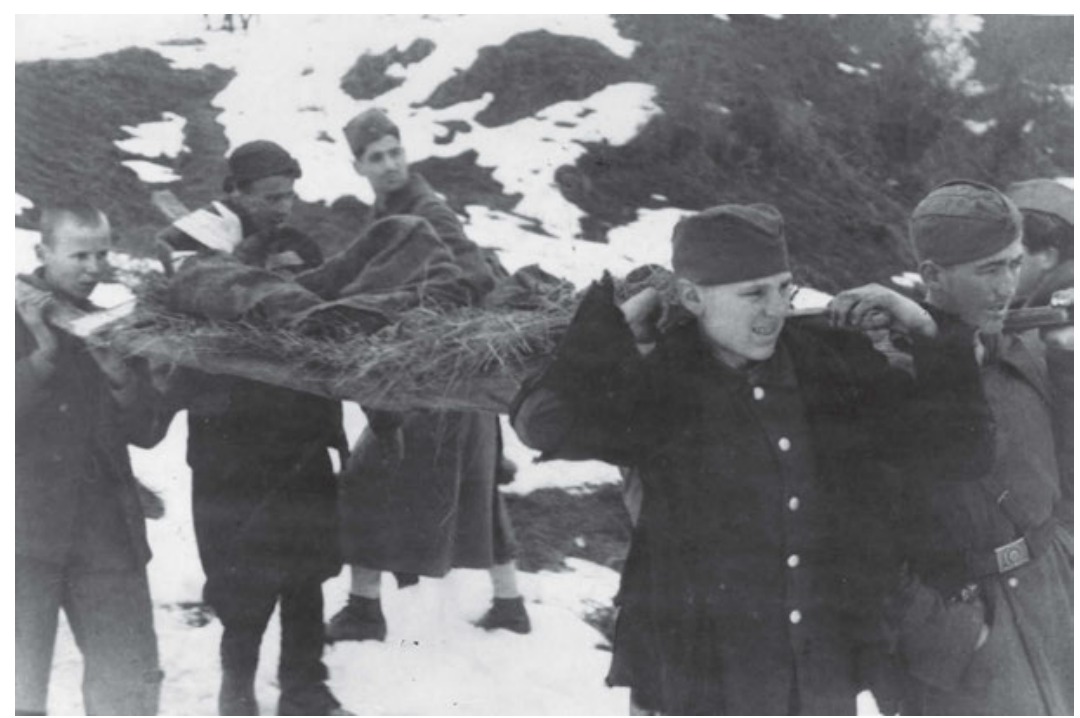

Nach den Kämpfen gegen die 22. Division der deutschen Wehrmacht. Die Verwundeten der 17. Division des Dritten Korps werden zur Behandlung nach Redžići transportiert, Ende Januar 1945. Fotograf unbekannt. Belgrad, Militärmuseum | 6767. 


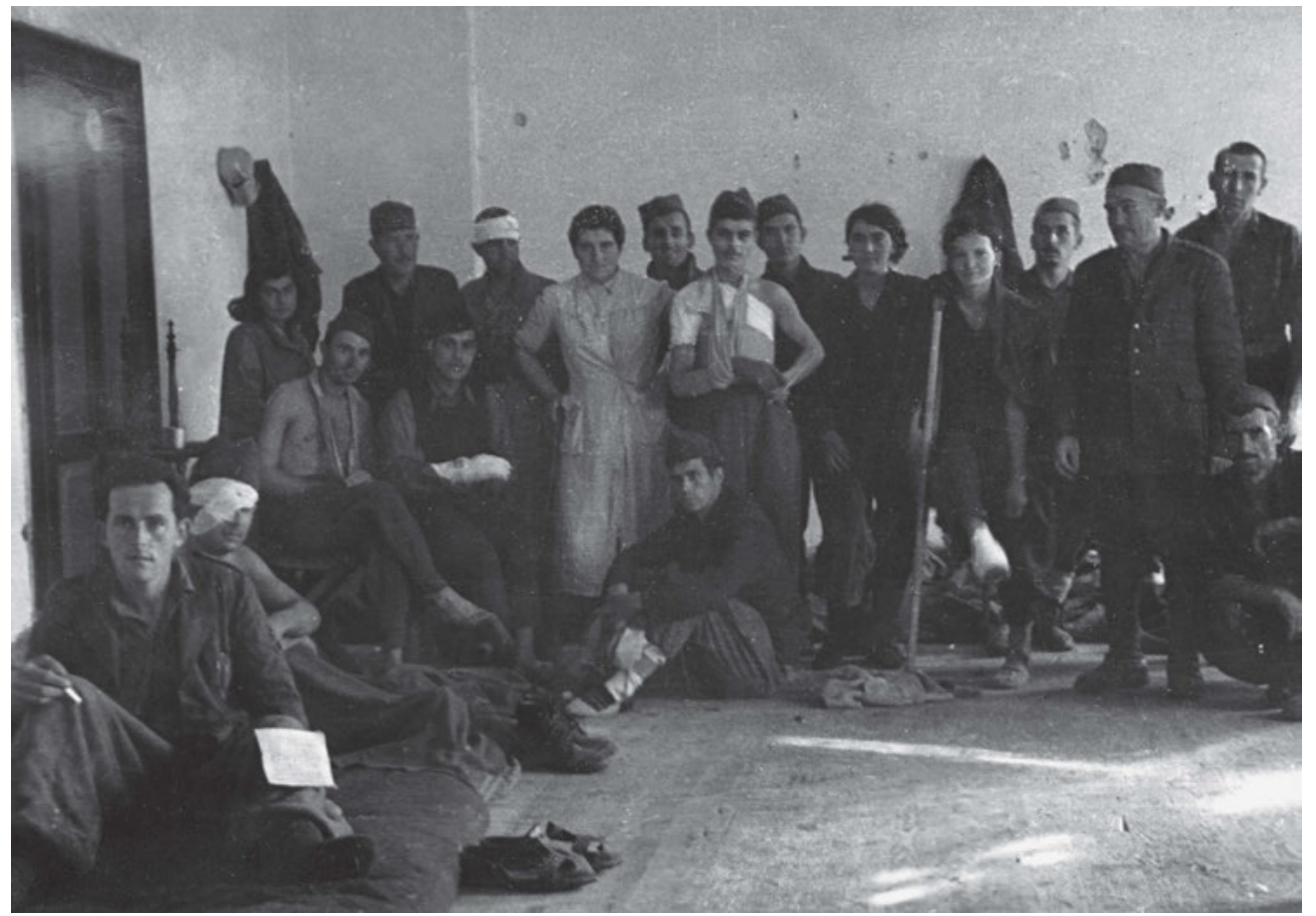

Belegschaft und Patienten einer Klinik in Livno, 1943. Belgrad, Museum Jugoslawiens | III-1793.

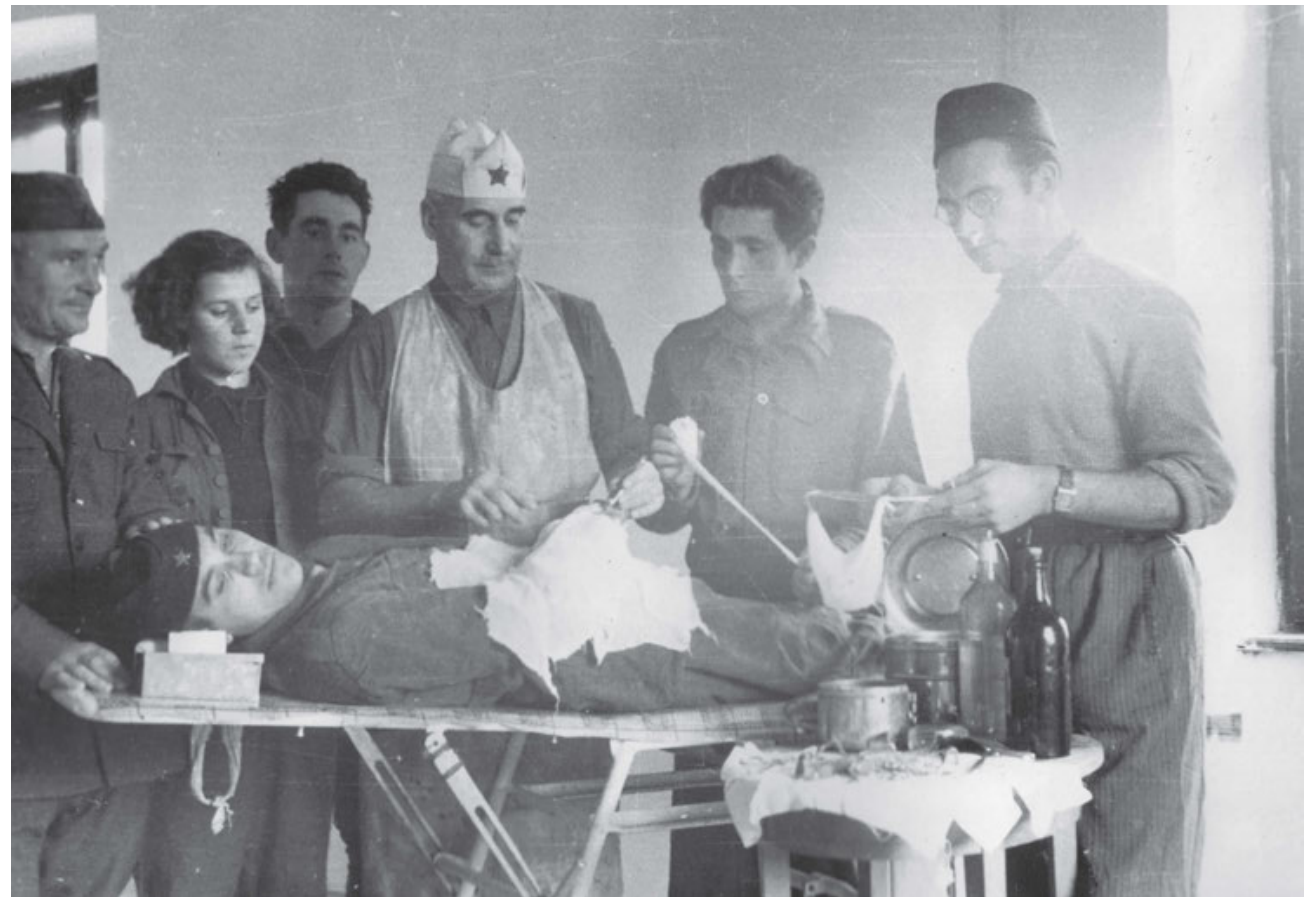

Dr. Mladina während einer Operation eines Verwundeten im Krankenhaus in Livno, 1943. Fotograf unbekannt | znaci.net. 


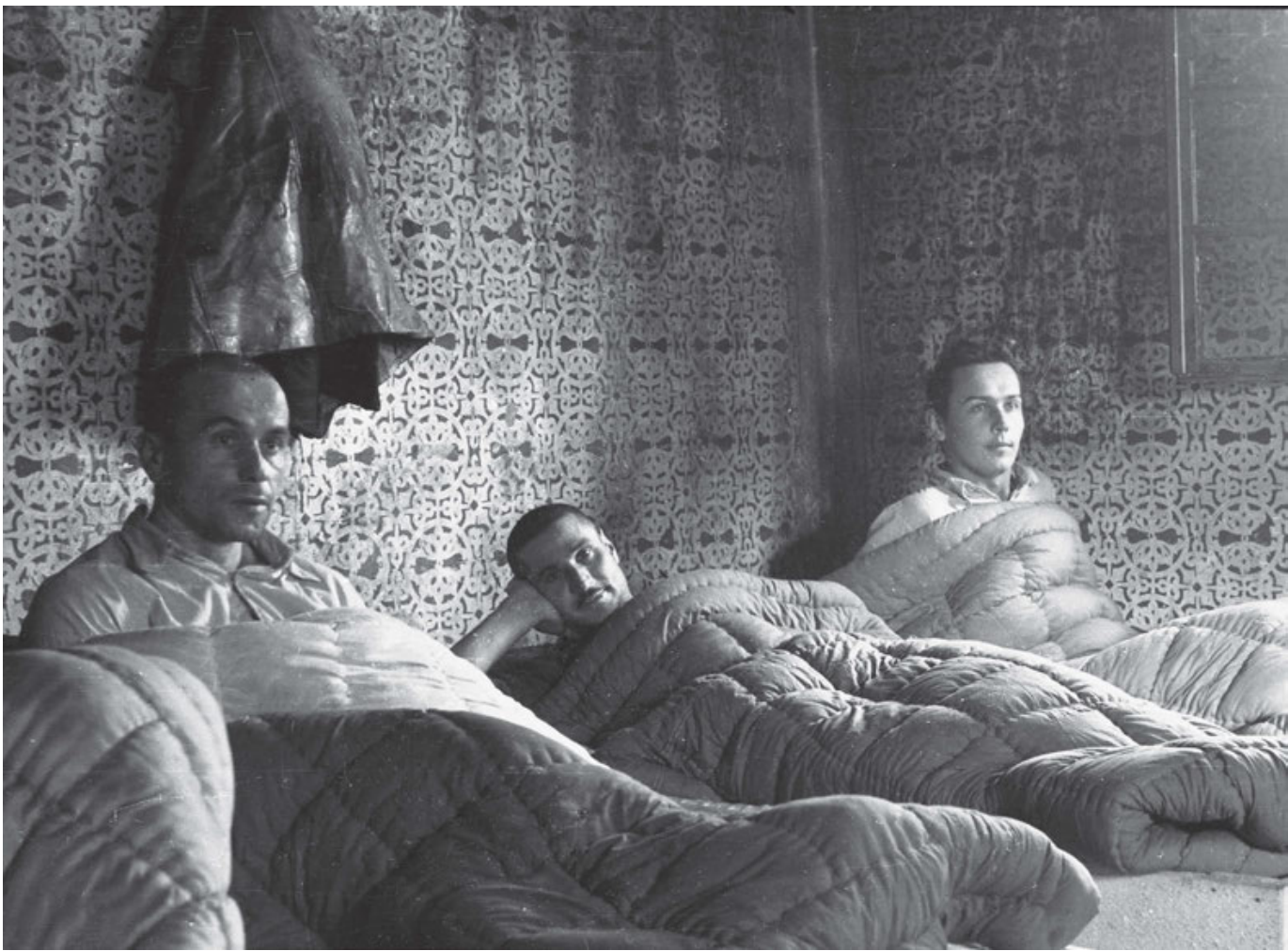

Szene aus einem Krankenhaus. Foto: Dr. Janez Milčinski. Ljubljana,

Museum für Neuere Geschichte Sloweniens | TN1224/31.

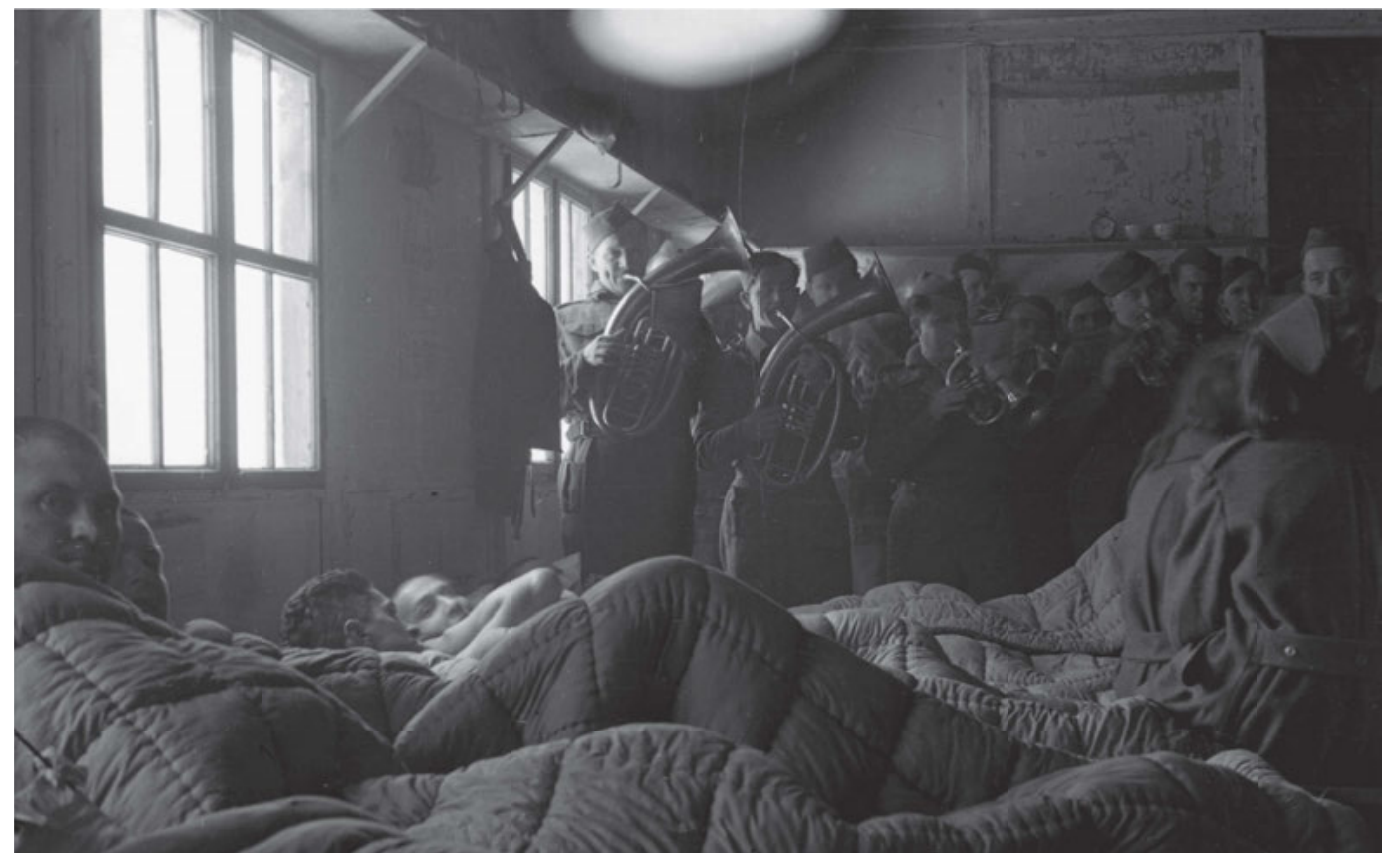

Szene aus einem Krankenhaus in Gorjanci. Foto: Dr. Janez Milčinski. Ljubljana, Museum für Neuere Geschichte Sloweniens | TN1223/981. 


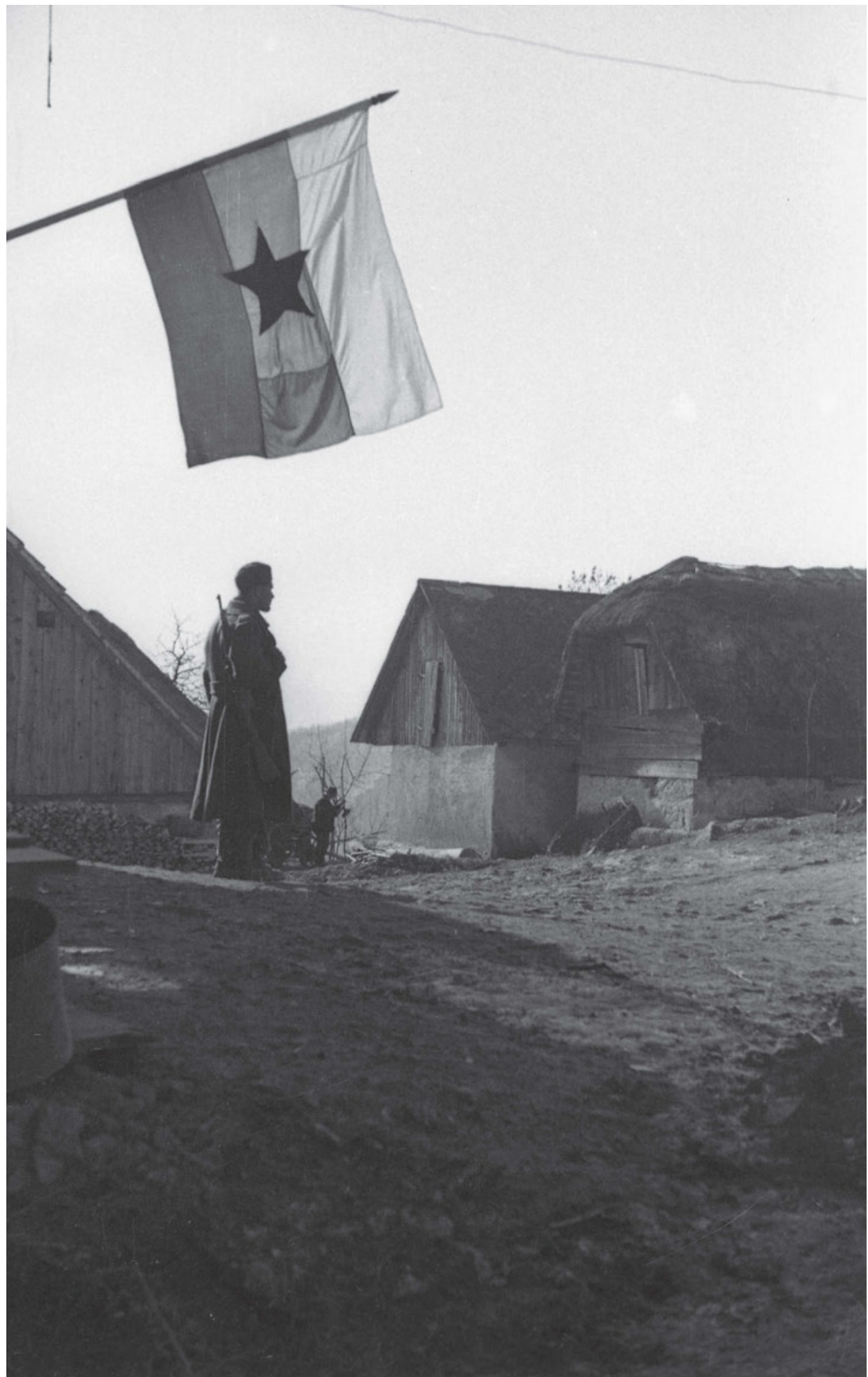

Vor dem Krankenhaus in Gorjanci. Foto: Dr. Janez Milčinski. Ljubljana, Museum für Neuere Geschichte Sloweniens | TN1224/21. 


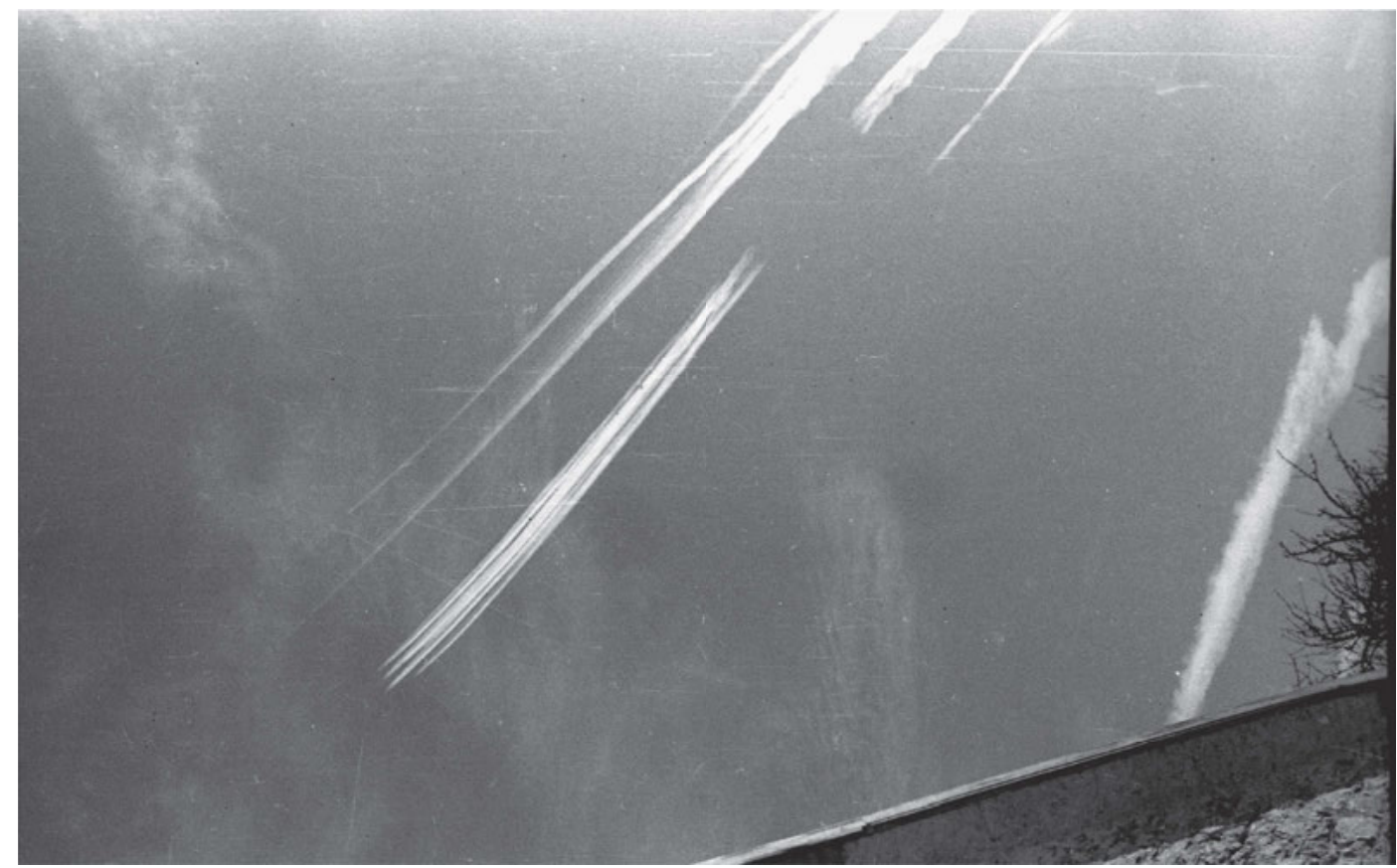

Vor dem Krankenhaus in Gorjanci. Foto: Dr. Janez Milčinski. Ljubljana, Museum für Neuere Geschichte Sloweniens | TN1224/31.

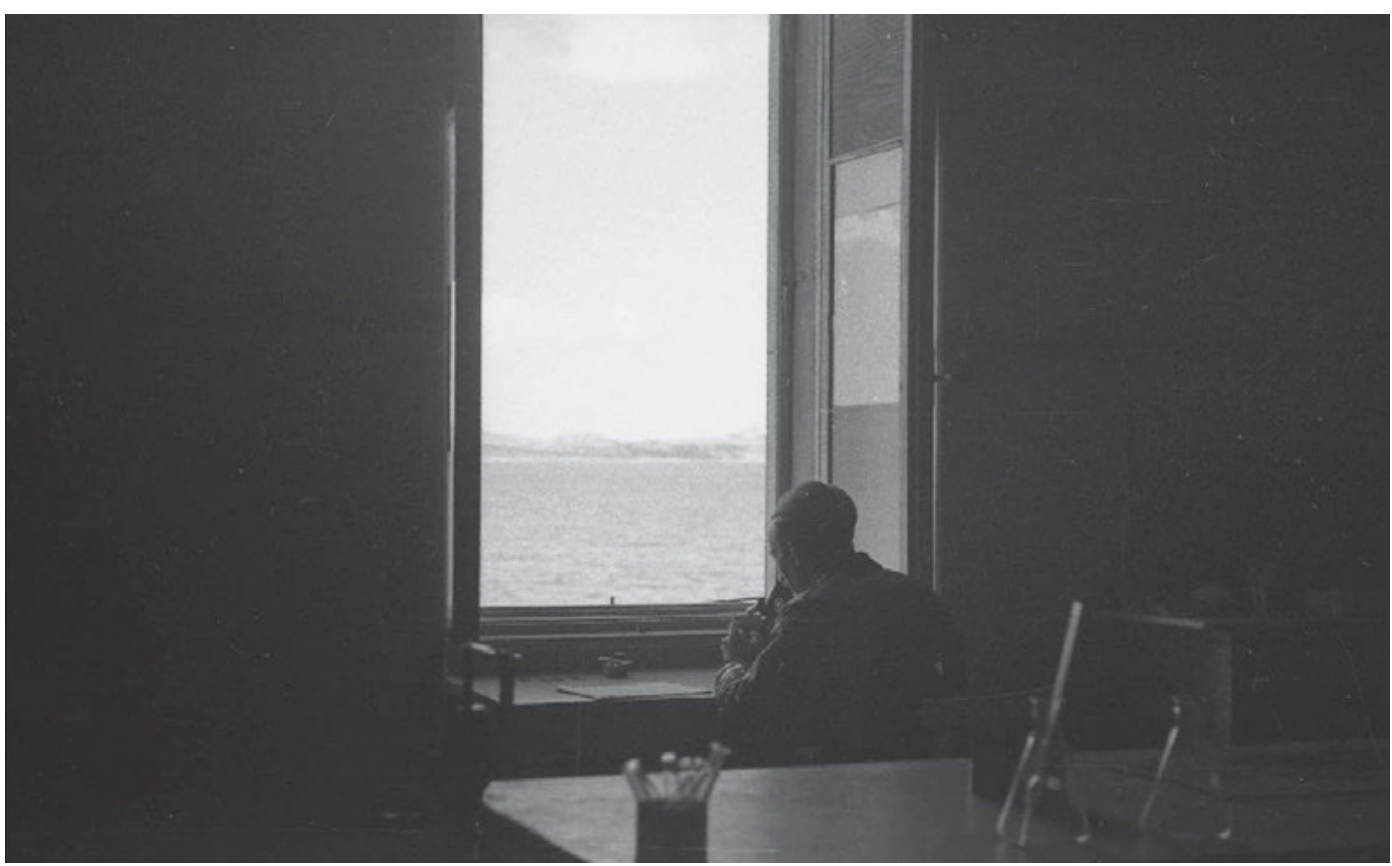

Blick aus dem Fenster des Krankenhauses in Zadar, April/März 1945. Foto: Dr. Janez Milčinski. Ljubljana, Museum für Neuere Geschichte Sloweniens | 1234/17. 


\section{Kriegserfolge}

Fotografien von Kriegserfolgen sind oftmals schlecht aufgenommen und aus ästhetischer Sicht unzureichend. Doch die Bilder der in Kriegsaktionen eroberten militärischen Ausrüstung - Waffen, Munition, Kleidung, Lebensmittel, telegrafische Apparate, Fahrzeuge und Fotomaterial - stellten die ersten Siegesaufnahmen dar, die sich überaus positiv auf die Moral der Kämpfer in den Partisaneneinheiten auswirkten, und bilden somit einen besonderen thematischen Komplex.

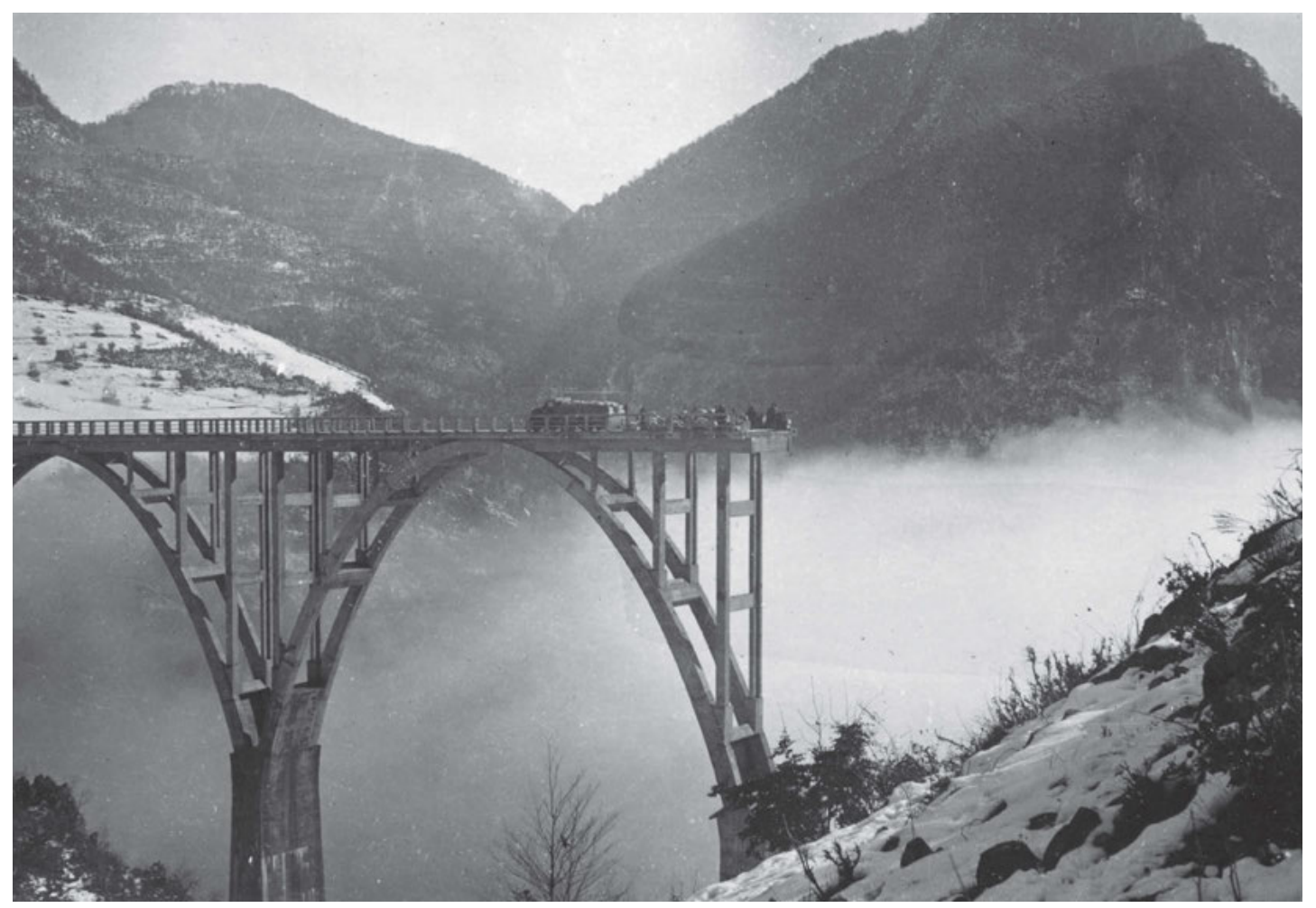

Gesprengte Brücke über dem Fluss Tara, Montenegro, 1943. Fotograf unbekannt. Zagreb, Kroatisches Historisches Museum I HPM-MRNH-F-1043. 


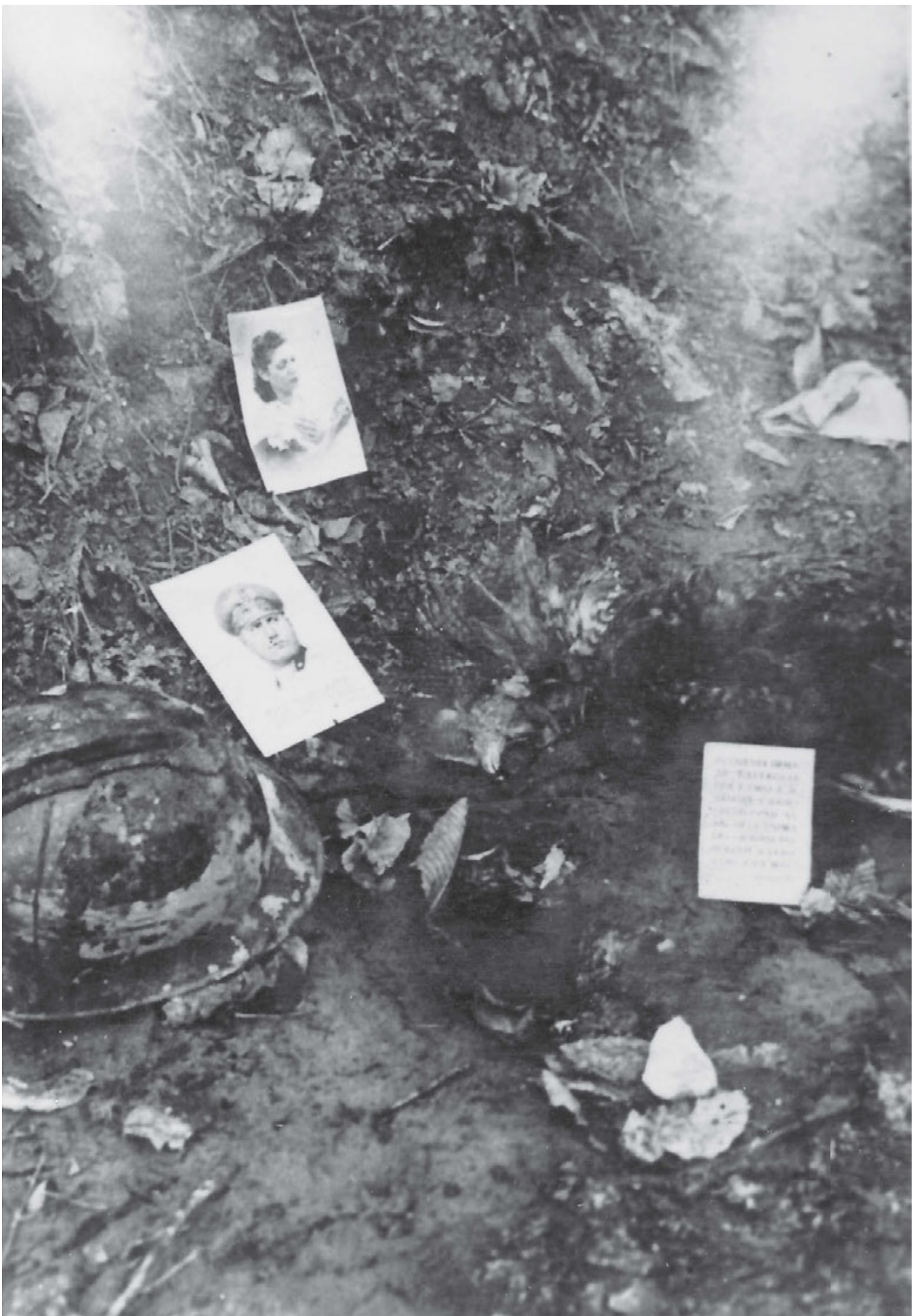

Persönliche Gegenstände eines italienischen Soldaten, der im Tal des Flusses Rama während der Vierten Offensive im Jahr 1943 fiel. Fotograf unbekannt. Belgrad, Militärmuseum | 4469. 


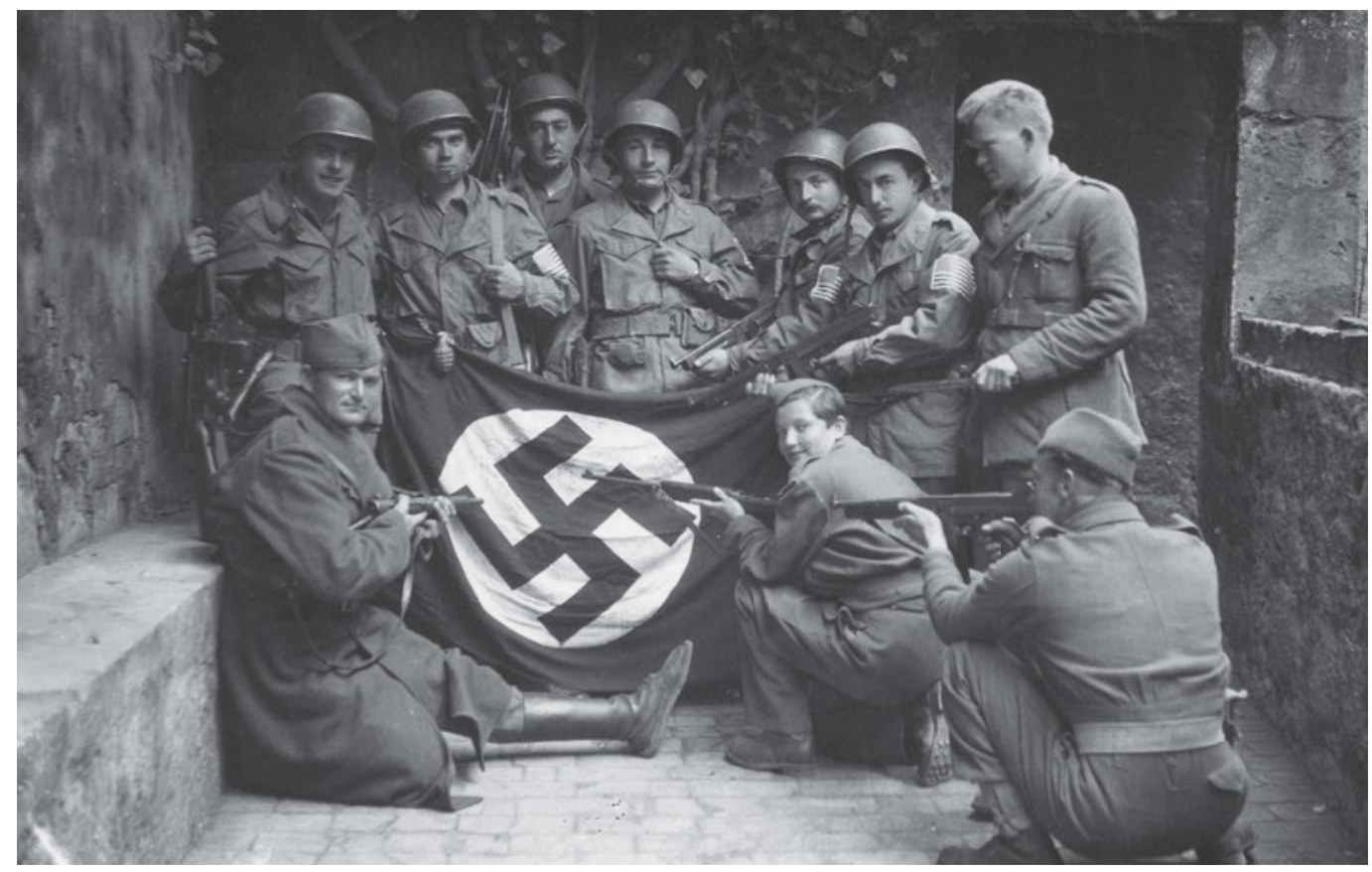

Gruppe amerikanischer Soldaten und Partisanen der Volksbefreiungsarmee und der Widerstandsbewegung Jugoslawiens versammelt um eine eroberte deutsche Fahne. Insel Vis, 1944.

Foto: Andrija Božanić. Zagreb, Kroatisches Historisches Museum | HPM/MRNNH-F-10355.

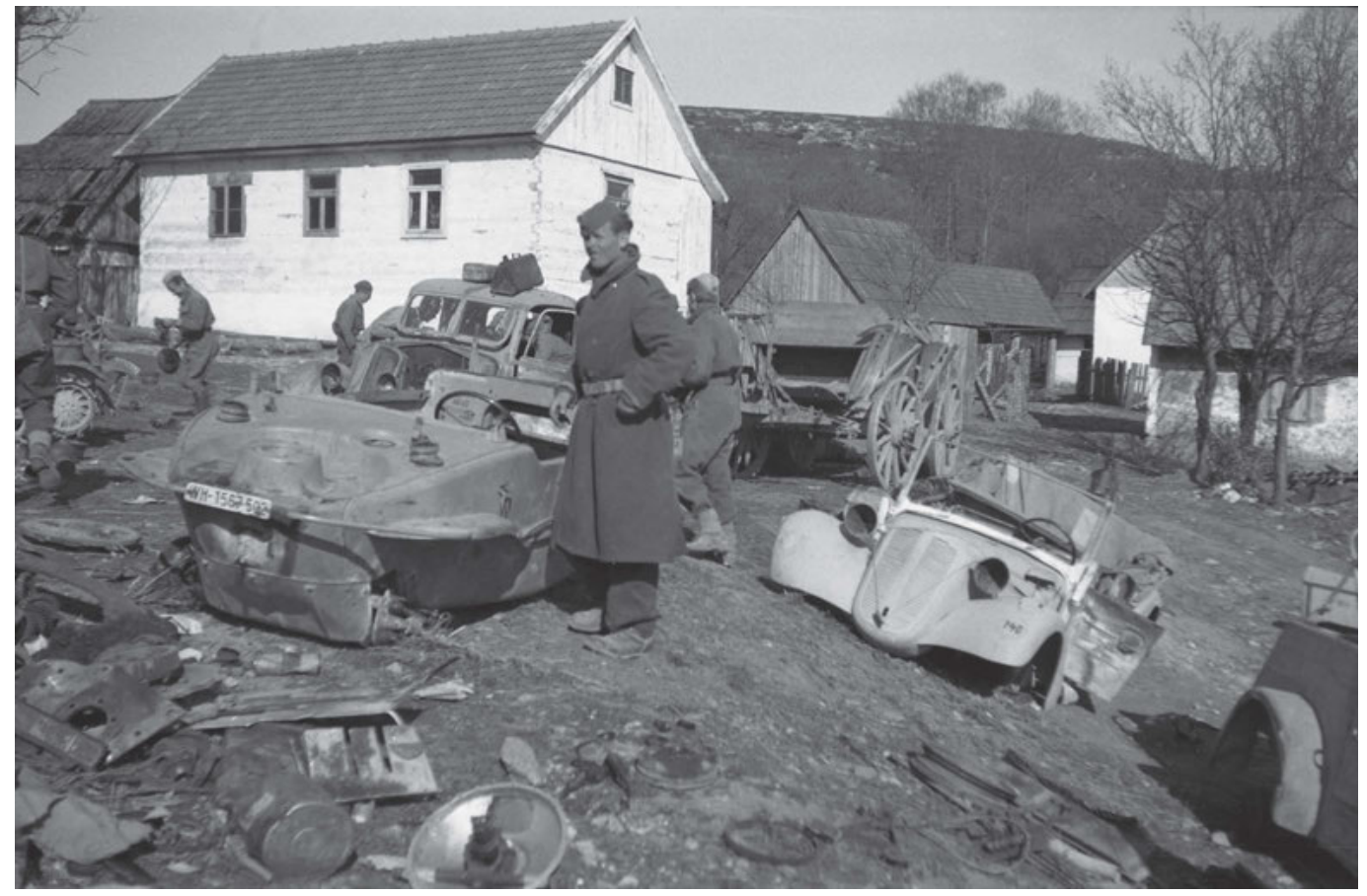

Überreste eines Wagens, den die Deutschen zerstörten, als sie sich zurückziehen mussten. Foto: Mlekuž. Ljubljana, Museum für Neuere Geschichte Sloweniens | TN786/5. 

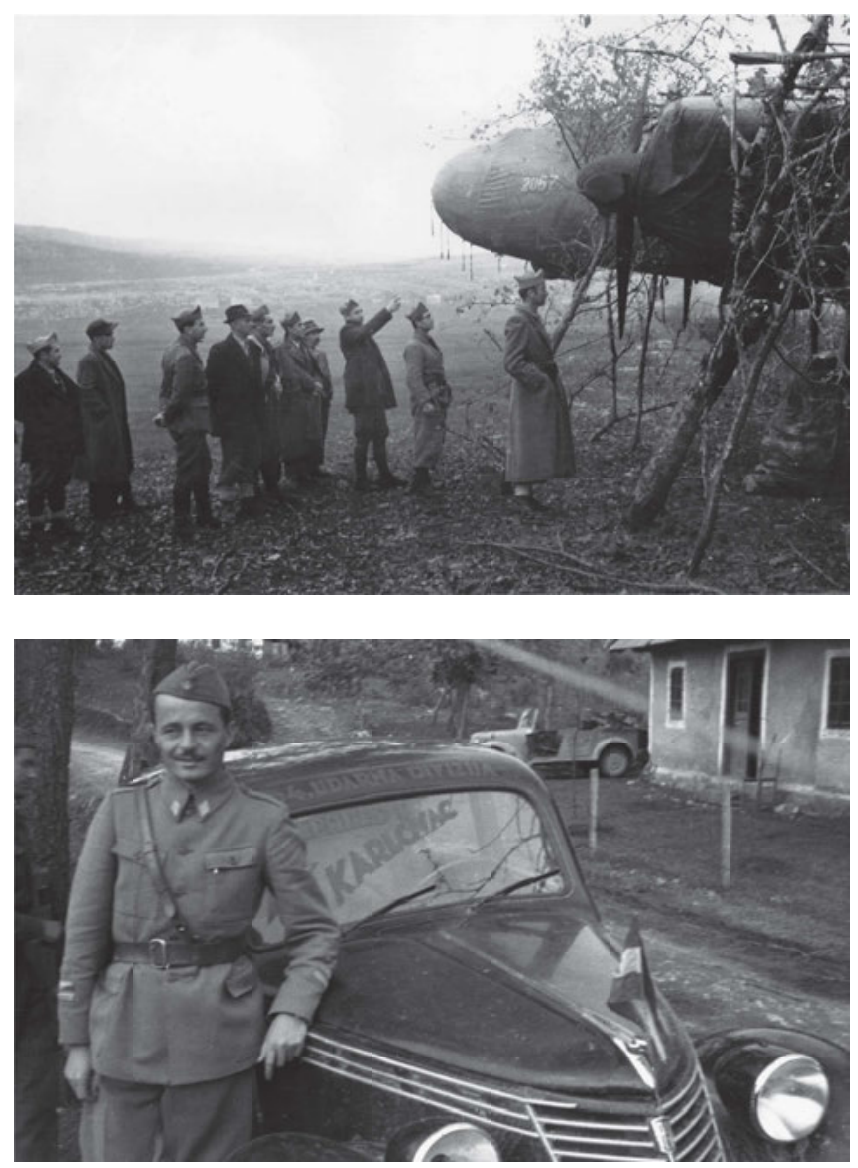

Abgeordnete der Zweiten Sitzung des Antifaschistischen Rats der Volksbefreiung Jugoslawiens bei der Begutachtung eines Flugzeugs. Fotograf unbekannt. Belgrad, Museum Jugoslawiens | III-252.

Automobil der 34. Stoßdivision, Otočac, Kroatien, 24. April 1945. Foto: Ivo Pelicon. Ljubljana, Museum für Neuere Geschichte Sloweniens | TN707/23.

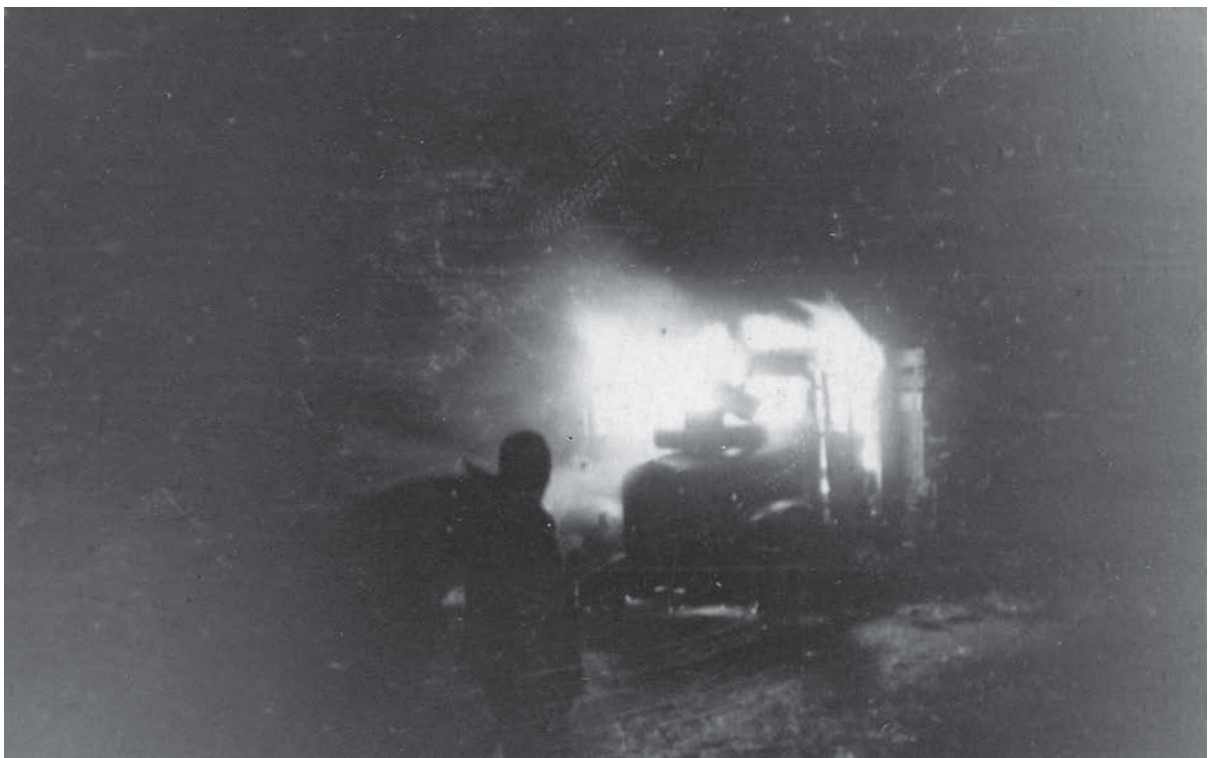

Die Partisanen des Zehnten Zagreber Korps vernichten feindliche LKWs, Šumećani, 1944. Fotograf unbekannt. Museum der Stadt Zagreb. Ohne Inv.-Nr. 


\section{Fotografien des besiegten Feindes}

Die Partisanenfotografie entstand wie erwähnt unter Umständen, in denen die deutschen Besatzer und ihre einheimischen Handlanger den Mitgliedern der Partisanenbewegung das Recht auf Existenz absprachen. ${ }^{1}$ Der einzige Ausweg aus der Situation, in der sich die unter physischer Okkupation stehende Gesellschaft befand, war der bewaffnete Widerstand, um die zivilisatorischen und emanzipatorischen Errungenschaften der Menschheit zu bewahren und für die Nachwelt zu erhalten. ${ }^{2}$ Die Menschen und Völker vereinten sich nicht aufgrund ihrer ethnischen Verbundenheit, ihrer Tradition oder der Perspektive einer Fortführung des jugoslawischen Staates, sondern vielmehr auf der Grundlage des gemeinsamen Kampfes gegen den Faschismus, der keine Identität, sondern vielmehr eine emanzipatorische Gemeinschaft hervorbrachte.

Die Partisanen wandten sich der Zukunft, dem Leben und dem Fortschritt zu, sie verstanden den Tod als Niederlage, nicht als Ideal. Nur selten fotografierten sie ihre gefallenen Kameraden, weil solche Aufnahmen aus Propagandagründen strengstens verboten waren. Auf der anderen Seite nutzten die Faschisten ihre Toten zu Propagandazwecken, was wie bereits dargelegt ein bedeutender praxeologischer Unterschied ist. Der Tod war fester Bestandteil der faschistischen Ideologie und Kultur, unter anderem zeigte sich der Totenkult in der Verwendung von Abzeichen wie Totenköpfen. Auch Trophäenfotografien, auf denen getötete feindliche Soldaten zu sehen sind, gab es bei den Partisanen nur selten. Eine der raren Fotografien der Erschießung deutscher Wehrmachtssoldaten durch die Partisanen bei den Kämpfen um Rijeka bei Drenova nahm Hugo Fischer Ribarić auf, doch ist bis heute ungeklärt, ob sein Motiv eine Form des Protestes war oder ob er auf Befehl fotografiert hatte.

Bei der fotografischen Dokumentation der Gewalt während des Krieges legten die Partisanen ihren Fokus in erster Linie auf Verbrechen an Zivilisten und die Folgen der Kriegszerstörungen. In den meisten Fällen verfolgten diese Fotografien einen positiven Zweck und dienten zur Sicherung der Unterstützung der Bevölkerung für den Aufbau einer neuen und gerechteren Gesellschaft. Ein Jahrzehnt später sollten die nordvietnamesischen Fotografen im Vietnamkrieg (1955-1975) unter ähnlichen Umständen wie die Partisanen wirken. Bei diesem gleichfalls asymmetrischen Krieg waren die Produktionsbedingungen ebenso wie die Themenwahl identisch: die Darstellung der heldenhaften Bemühungen der Kämp-

\footnotetext{
1 Stojaković, Krunoslav. Revolucionarno nasilje u narodnooslobodilačkom ratu. In: Radanović, Milan. Kazna i zločin: Snage kolaboracije u Srbiji. Belgrad: Rosa Luxemburg Stiftung 2014, S. 21.

2 Ebd., S. 24.
} 
fer und der Bevölkerung im Widerstand gegen die Besatzer sowie die große Herausforderung, auf welche Weise eine gute Korrelation zwischen der fotografischen Ästhetik und der durch Fotografie repräsentierten Ideologie zu verwirklichen ist. ${ }^{3}$
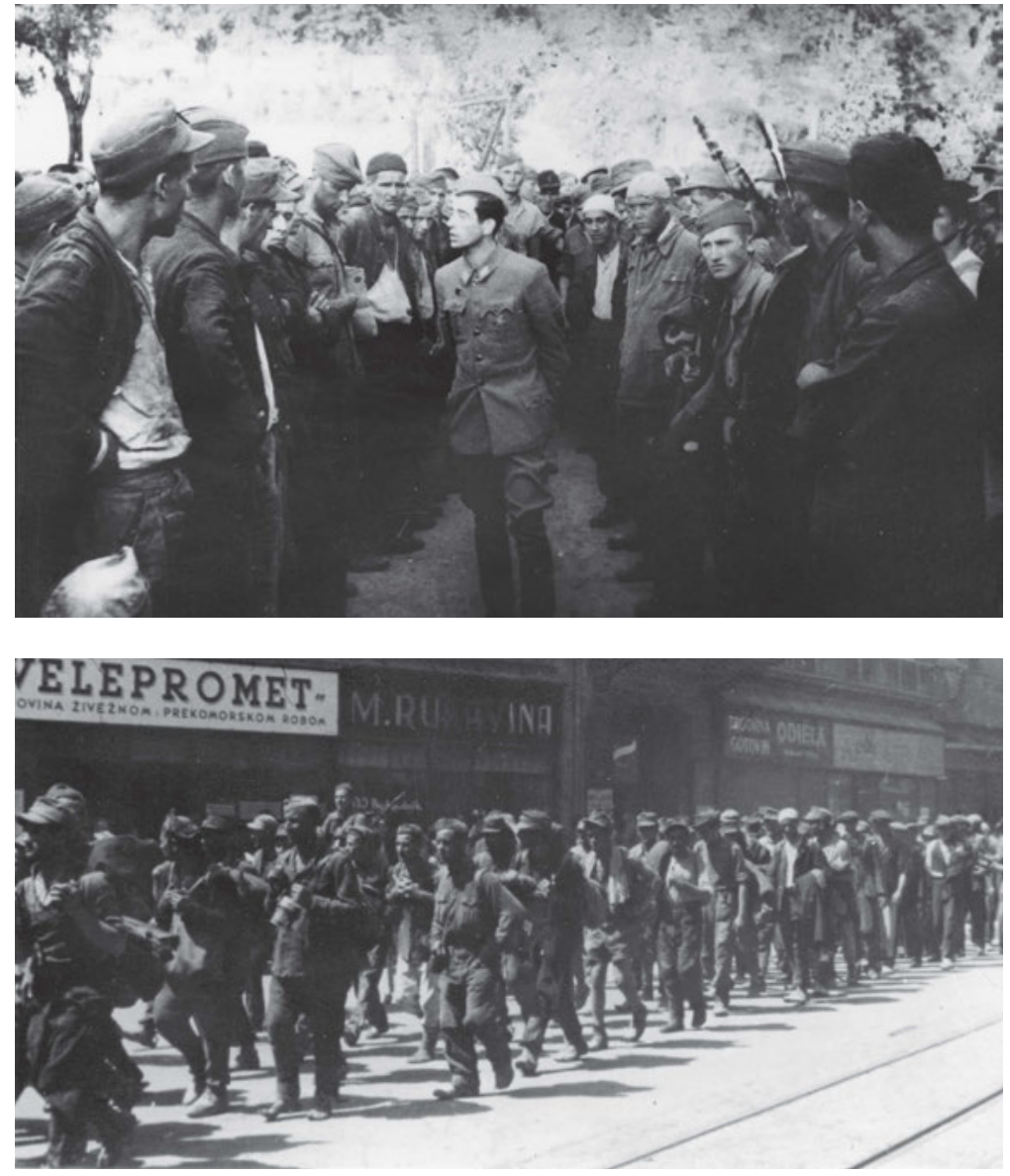

Nisim Albahari spricht bei der Entlassung der Landwehrsoldaten aus der Gefangenschaft, Anfang Mai 1945. Fotograf unbekannt. Sarajevo, Historisches Museum von Bosnien und Herzegowina | FNOB 3651.

In Gefangenschaft geratene deutsche Soldaten in Zagreb, Mai 1945. Foto: Jan Beran. Sarajevo, Historisches Museum von Bosnien und Herzegowina I FNOB 6614 .

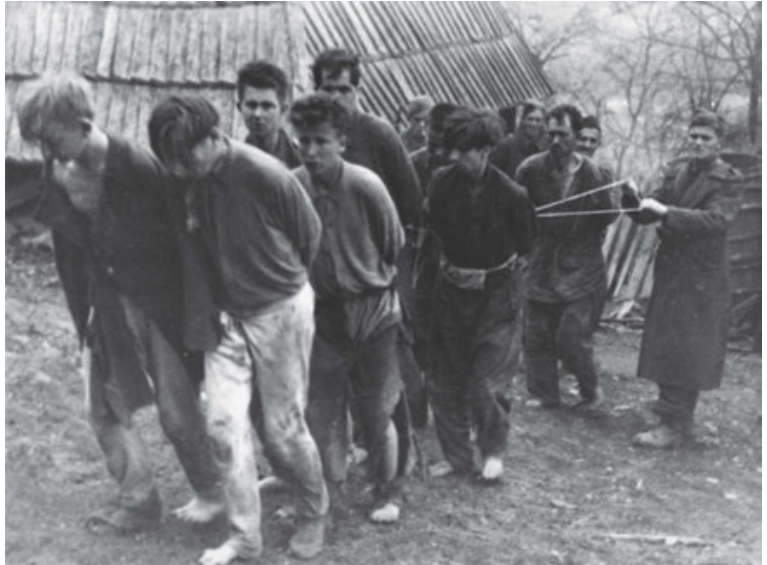

Gefangen genommene Mitglieder der SS. Fotograf unbekannt. Sarajevo, Historisches Museum von Bosnien und Herzegowina I FNOB 19422. 


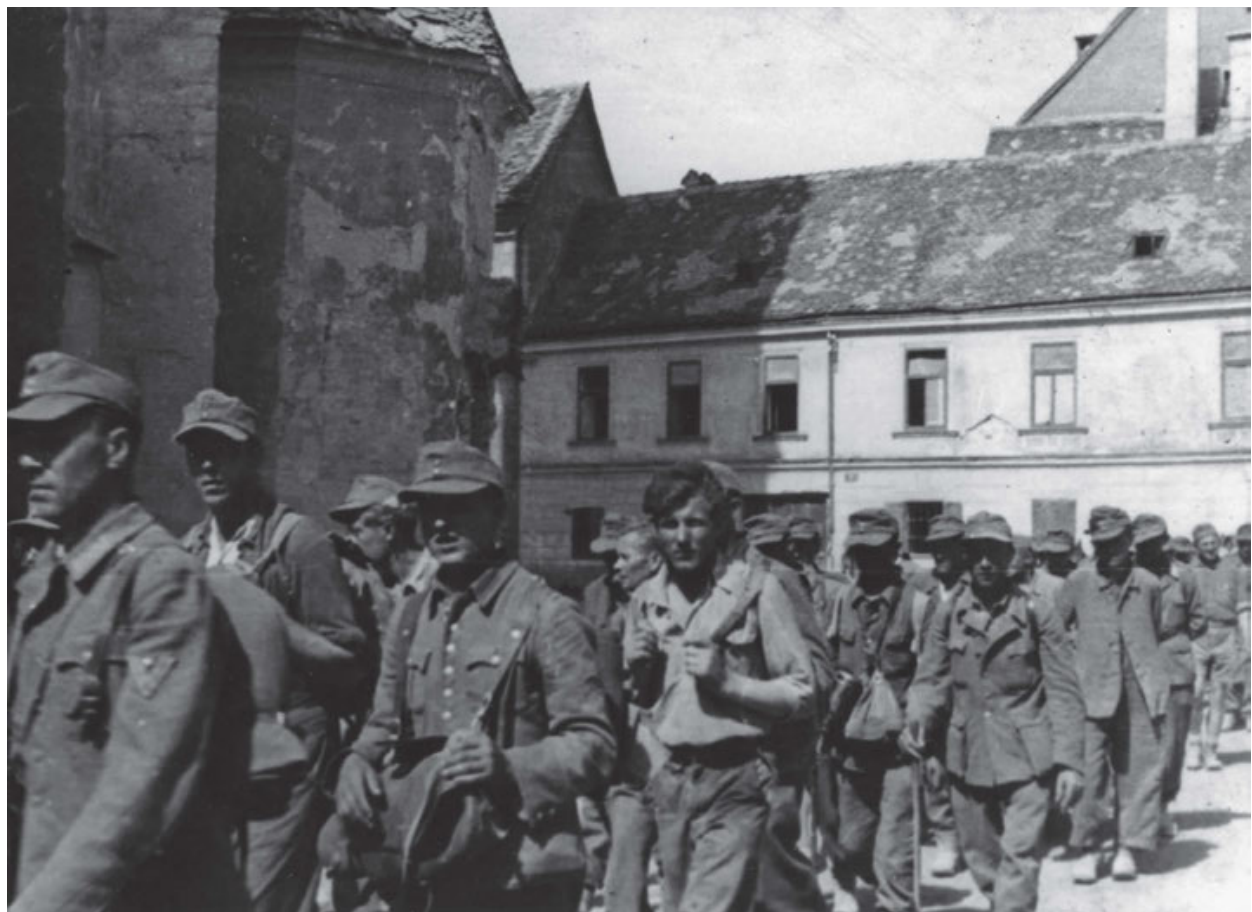

Deutsche Gefangene in Celje, Mai 1945. Sarajevo, Historisches Museum von Bosnien und Herzegowina | FNOB 6663.

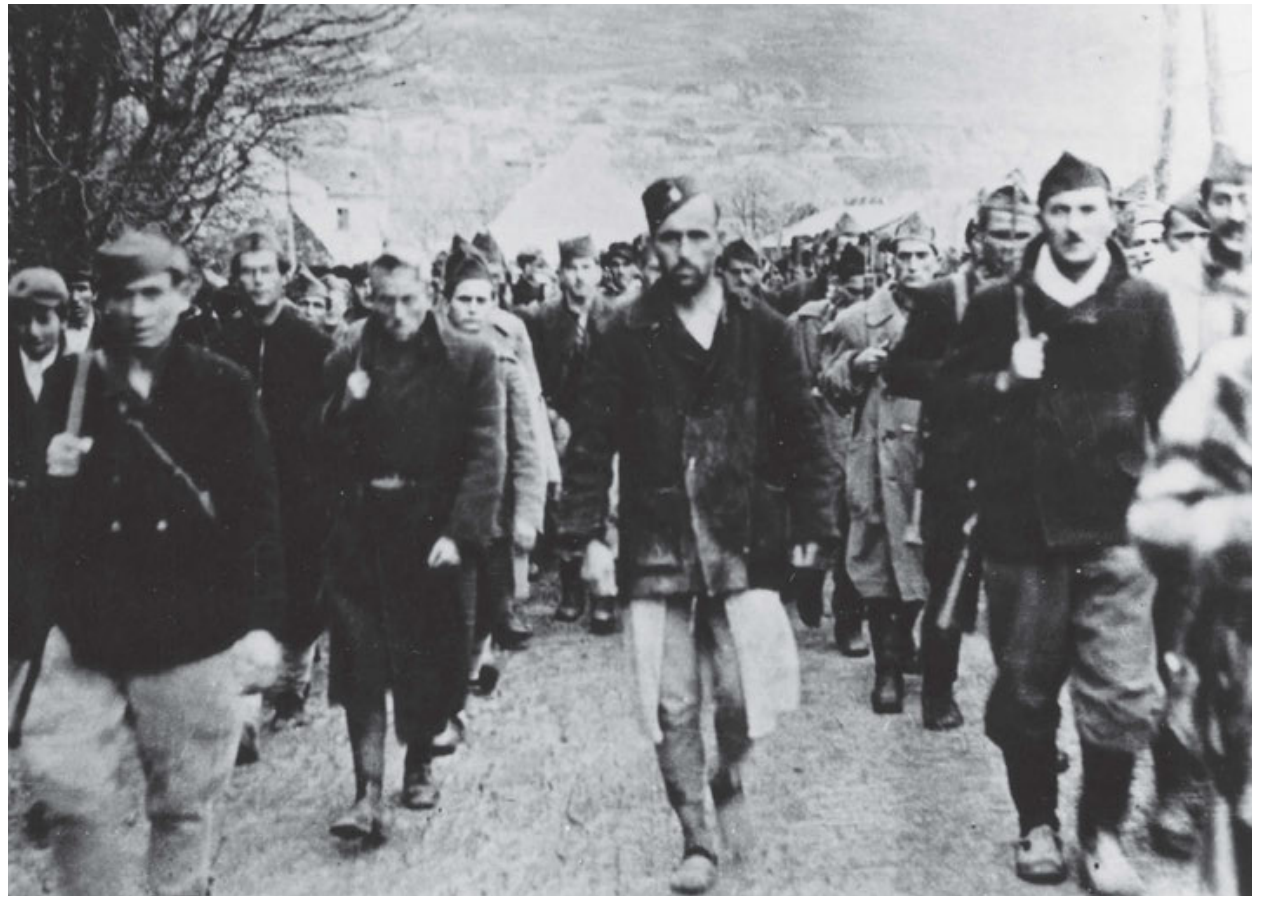

Der gefürchtete Oberleutnant der Ustascha, Mirko Perajica, wird nach seiner Verurteilung zum Tod zur Hinrichtung durch Erschießen begleitet. Livno, 1942. Sarajevo, Historisches Museum von Bosnien und Herzegowina | FNOB 11972. 


\section{Ausstellungen und Wandzeitungen}

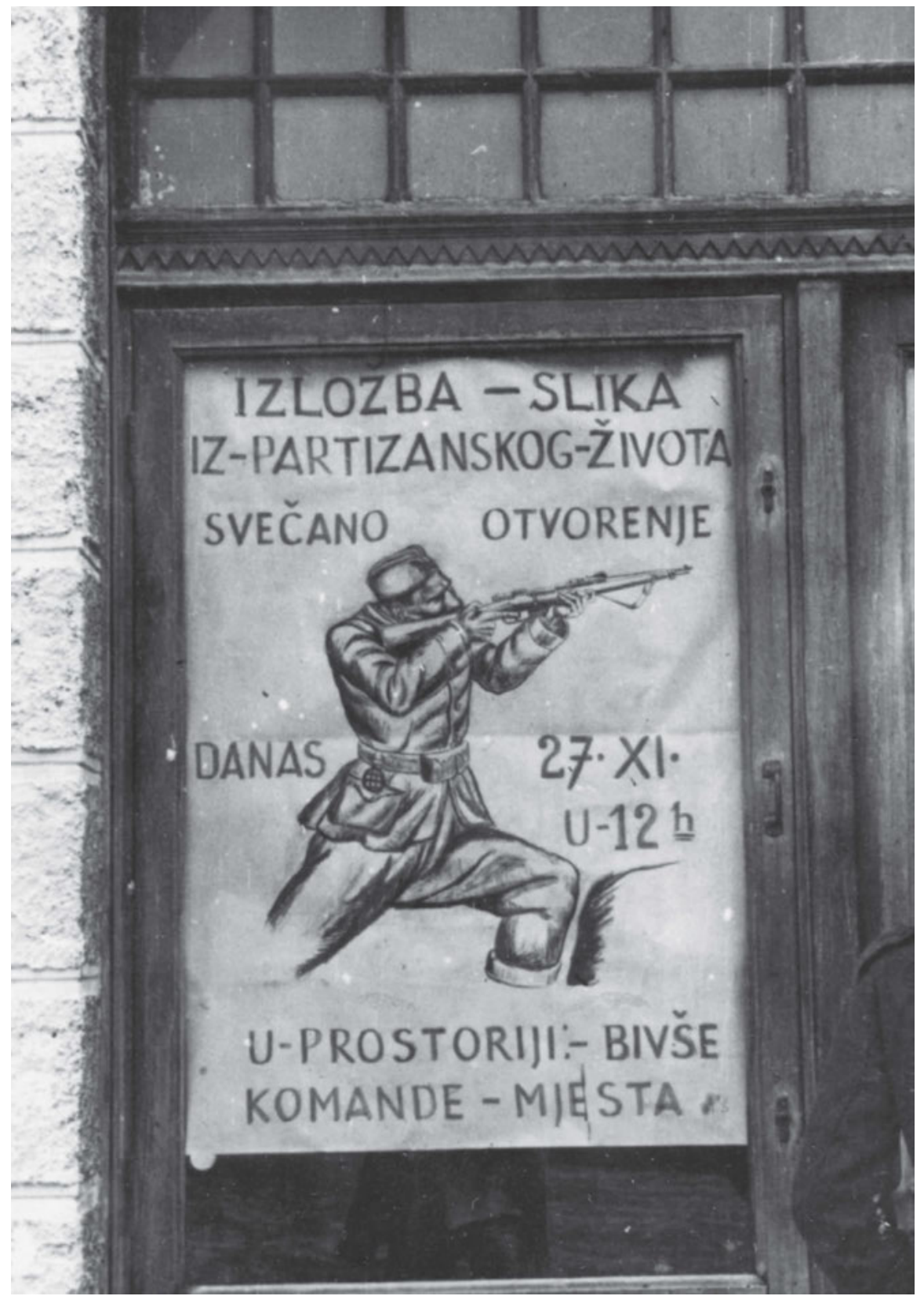

Ankündigung der Eröffnung einer Ausstellung mit Fotos aus dem Leben der Partisanen am 27. November 1943. Die Ausstellung fand im Rahmen der Zweiten Sitzung des Antifaschistischen Rats der Volksbefreiung Jugoslawiens vom 29. November 1943 in Jajce statt. Zagreb, Kroatisches Historisches Museum I HPM/MRNH-F-5377. 


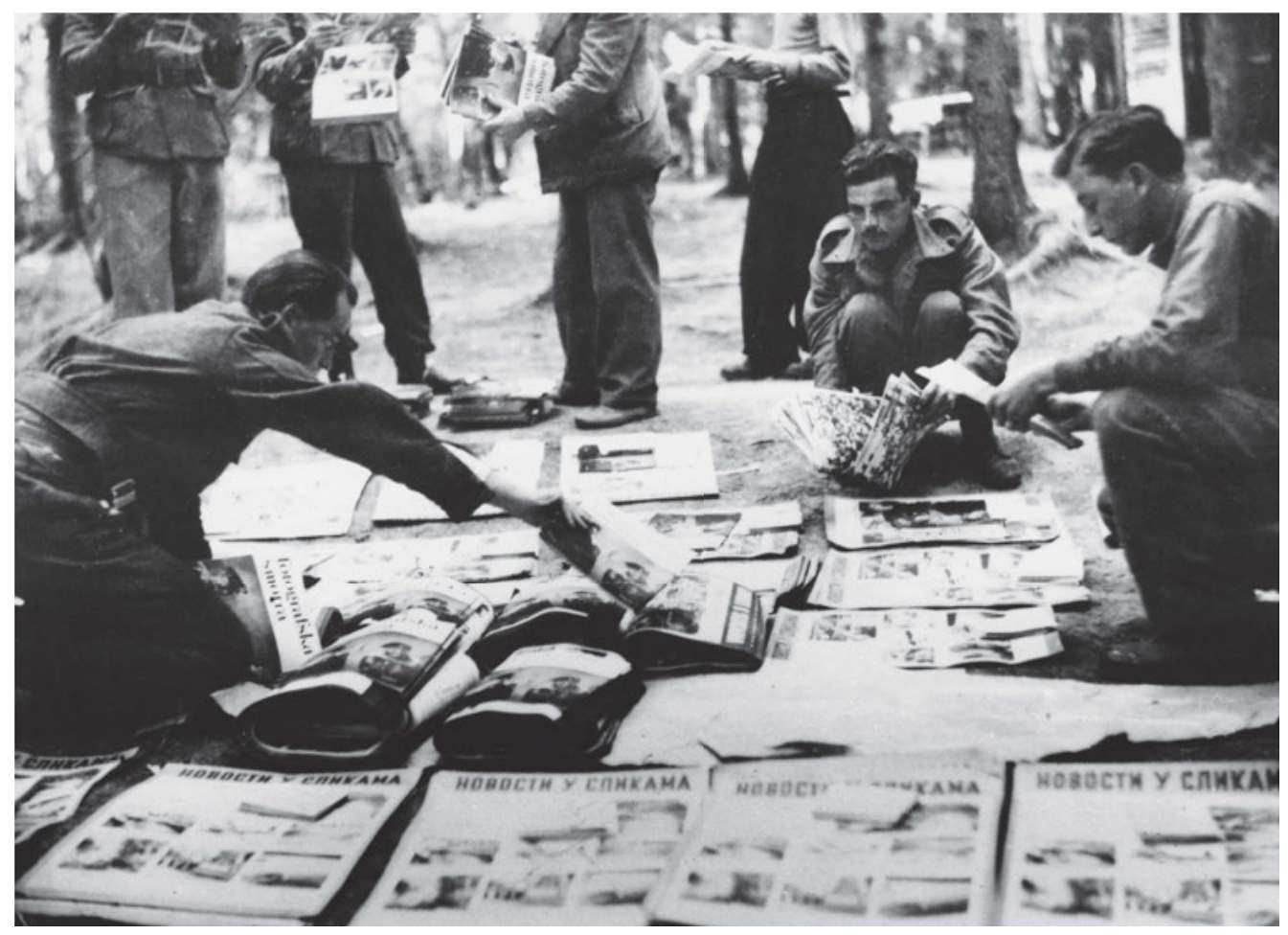

Sortieren von Propagandamaterial im Agitprop bei Zvečevo, Herbst 1944.

Fotograf unbekannt. Belgrad, Museum Jugoslawiens | III-1370.

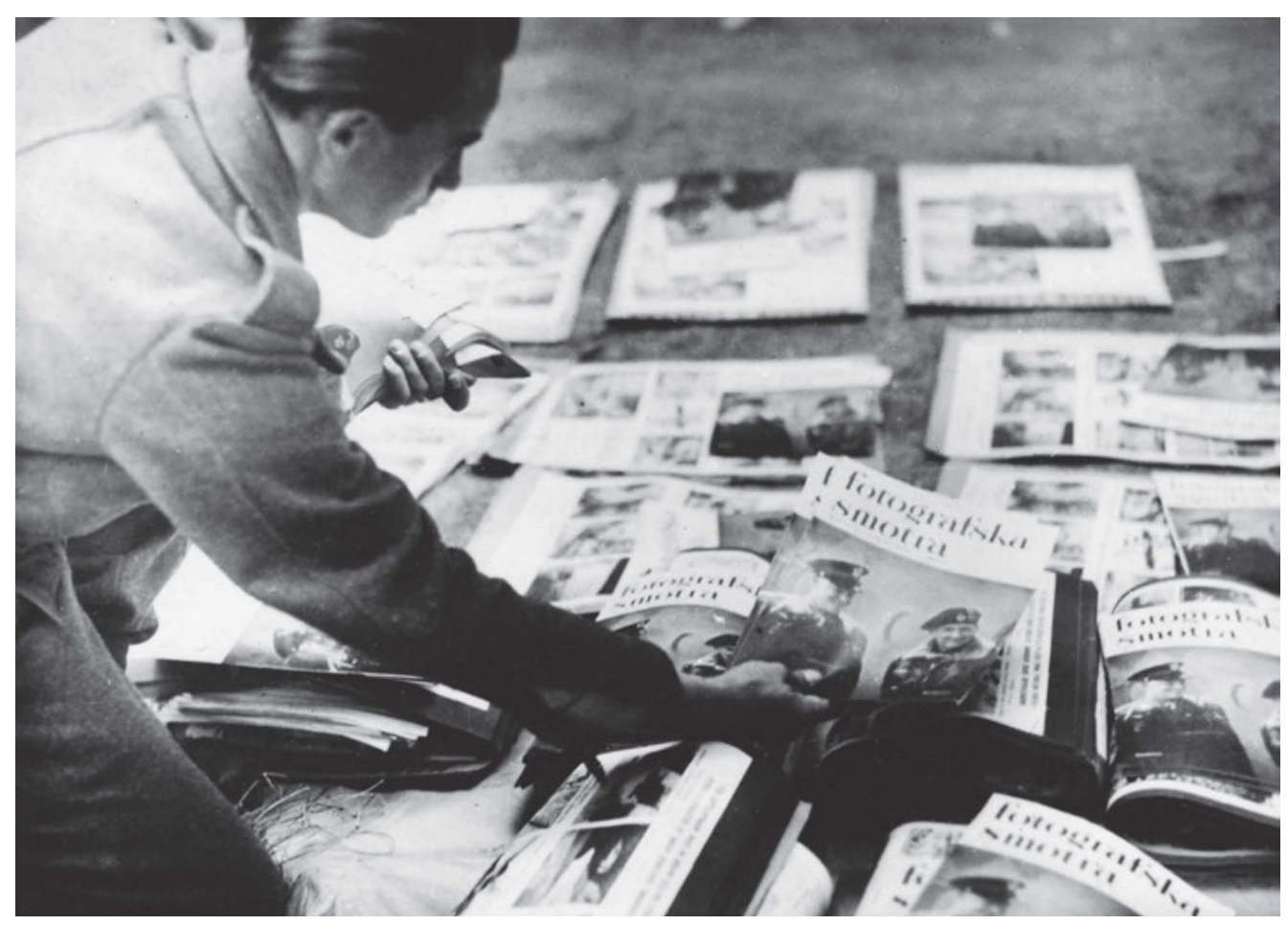

Sortieren von Propagandamaterial im Agitprop bei Zvečevo, Herbst 1944. Fotograf unbekannt. Belgrad, Museum Jugoslawiens | III-1373. 


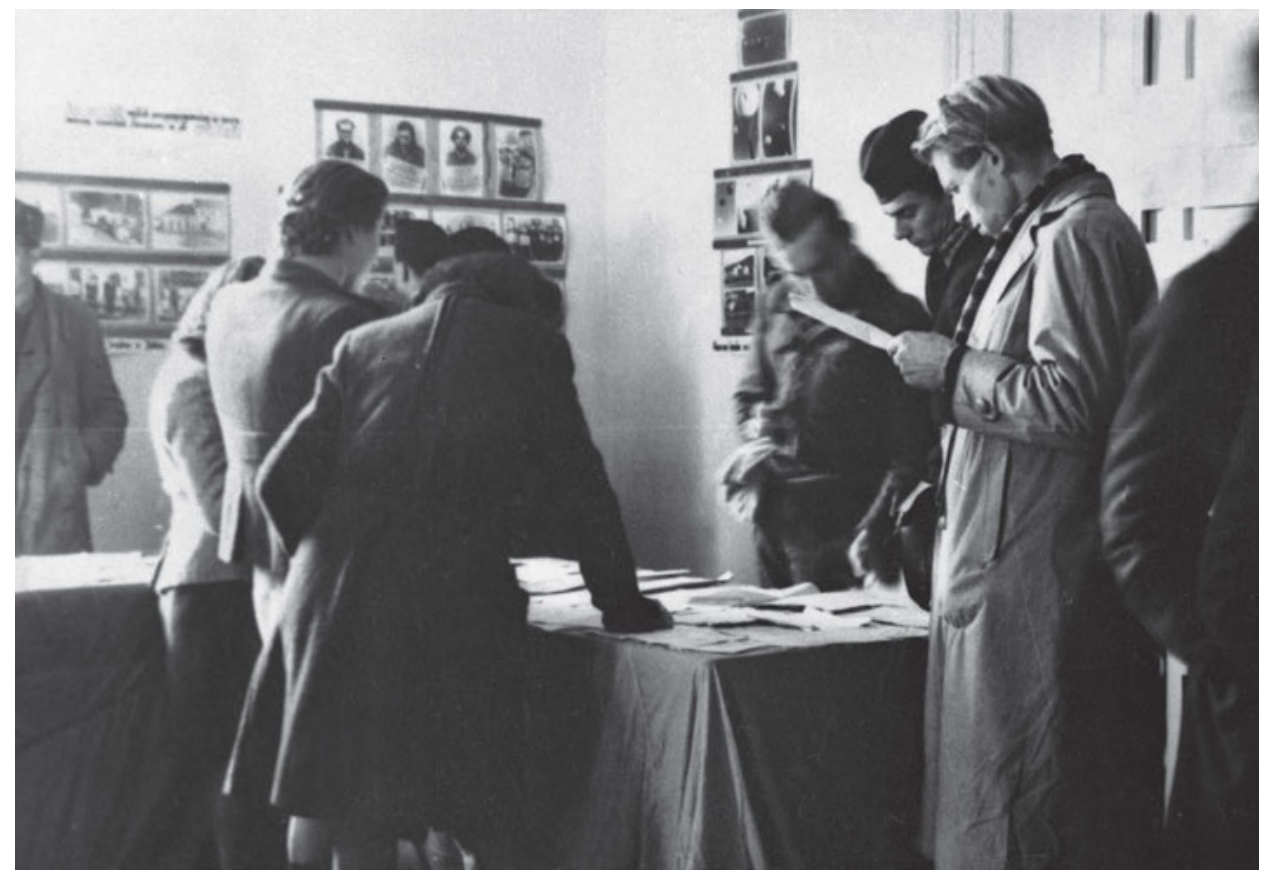

Presse- und Fotoausstellung von Jože Petek in Gornji Grad, 20. November 1944.

Foto: Marjan Mlekuž. Ljubljana, Museum für Neuere Geschichte Sloweniens | TN454/2.

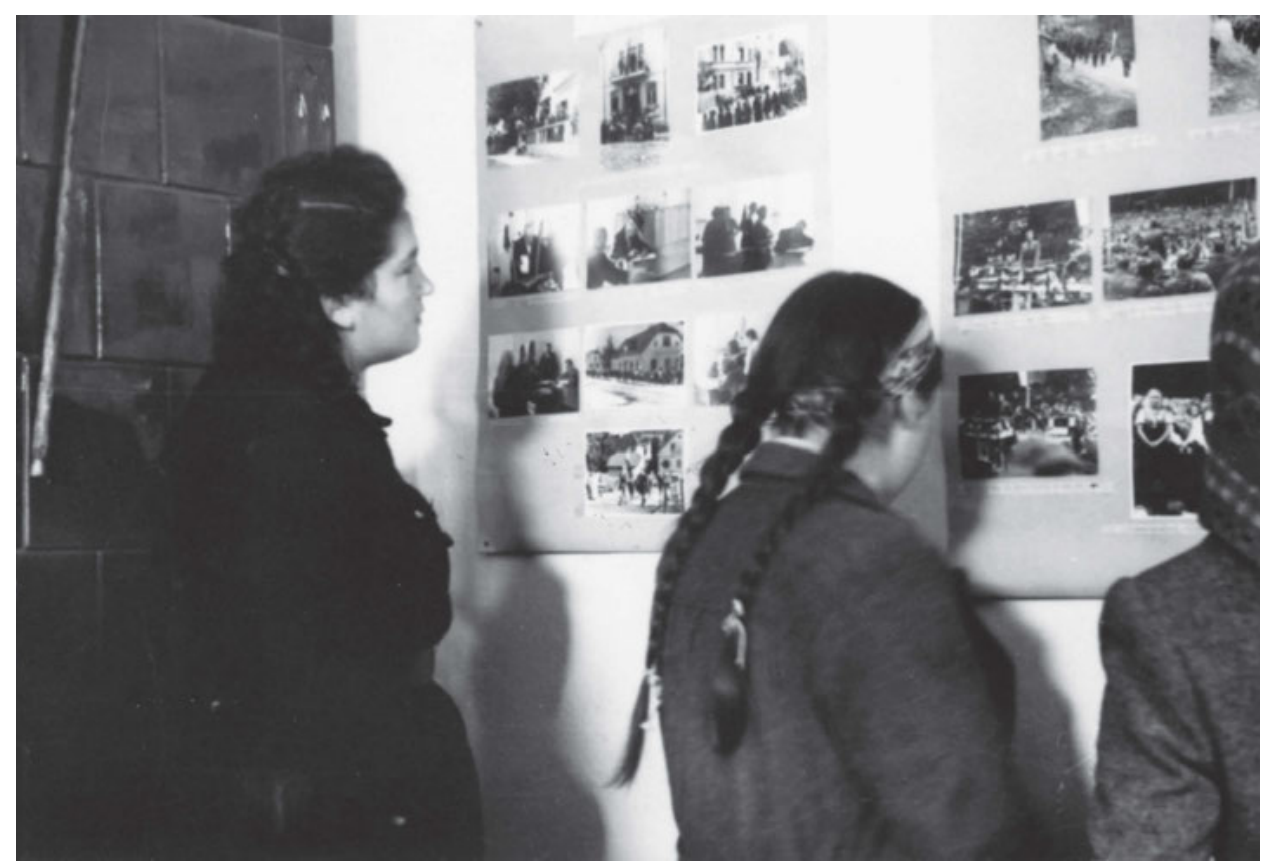

Presse- und Fotoausstellung von Jože Petek in Gornji Grad, 20. November 1944. Fotograf unbekannt. Museum für Neuere Geschichte der Stadt Celje | FZ21635. 


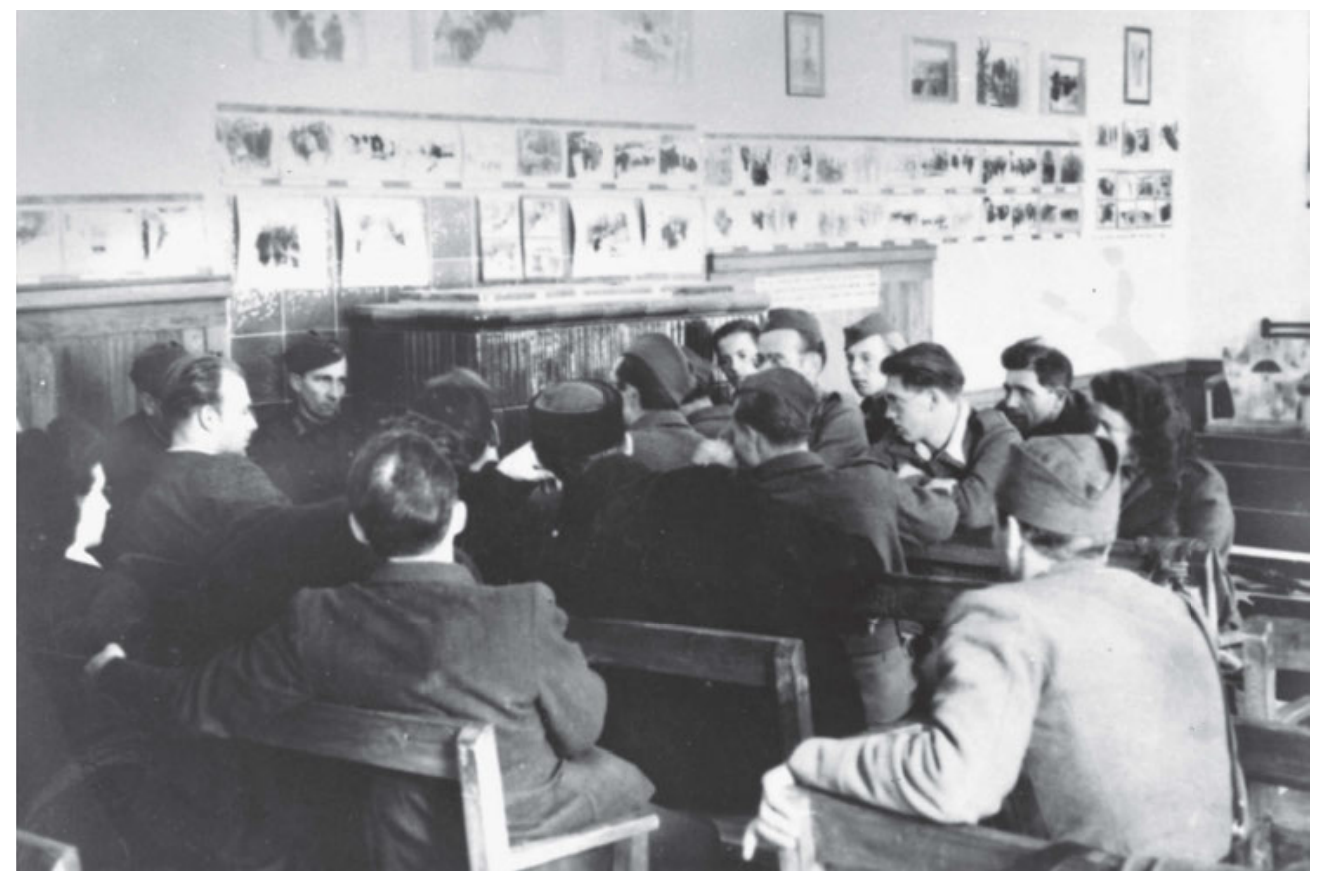

Presse- und Fotoausstellung von Jože Petek in Gornji Grad, 20. November 1944.

Foto: Marjan Mlekuž. Ljubljana, Museum für Neuere Geschichte Sloweniens | TN454/2.

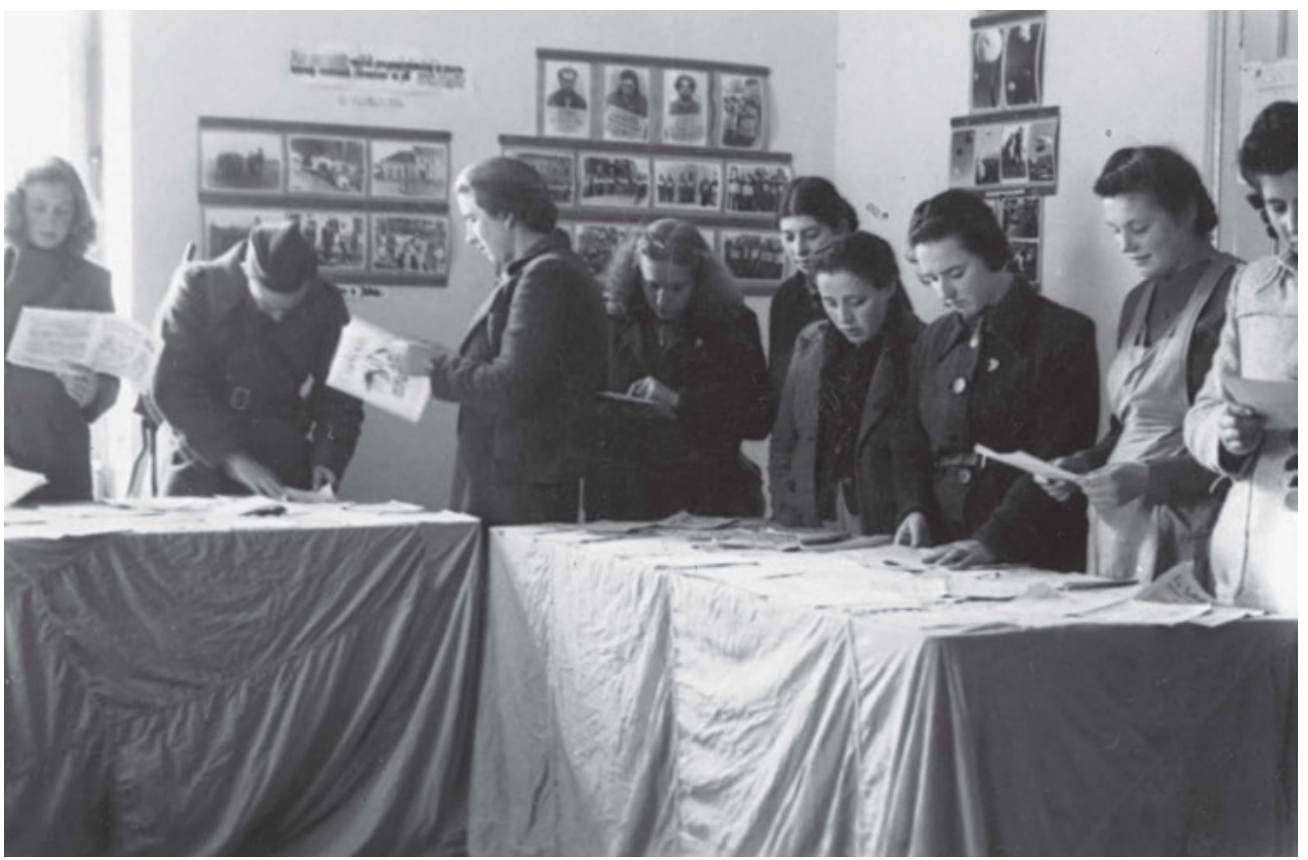

Presse- und Fotoausstellung von Jože Petek in Gornji Grad, 20. November 1944.

Fotograf unbekannt. Museum für Neuere Geschichte der Stadt Celje | FZ21771. 


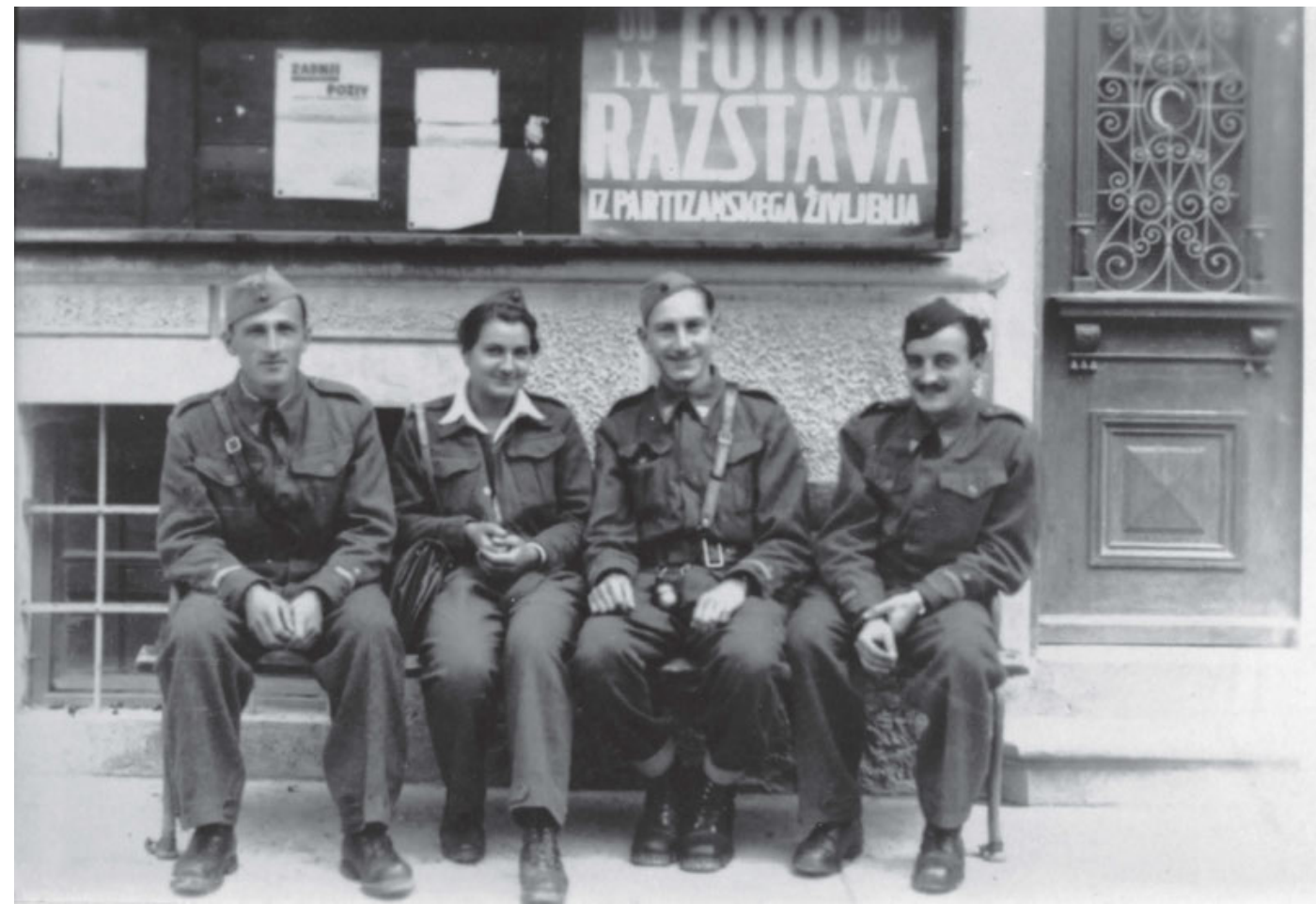

Von links nach rechts: Stane Zabovnik, Vera Hreščak-Bebler, Radovan Gobec und Jože Škrinjar. Gornji Grad vor der Bibliothek in Črnomelj, in der eine Fotoausstellung stattfindet, November 1944. Fotograf unbekannt.

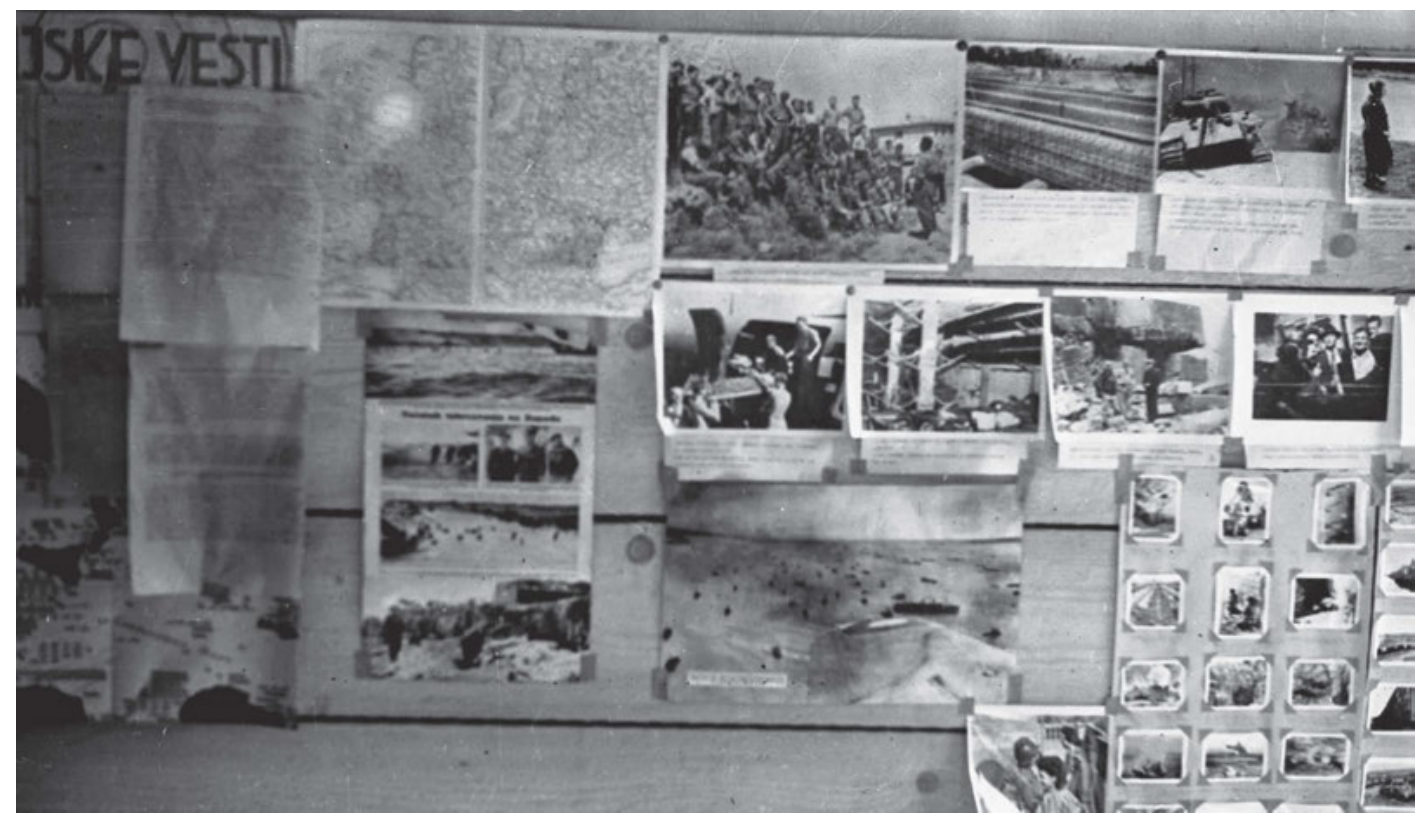

Fotografien an der Wand des Lesesaals in Črnomelj, 10. April 1945. Foto: Viršek Stane und France Cerar. Ljubljana, Museum für Neuere Geschichte Sloweniens | TN129/11. 


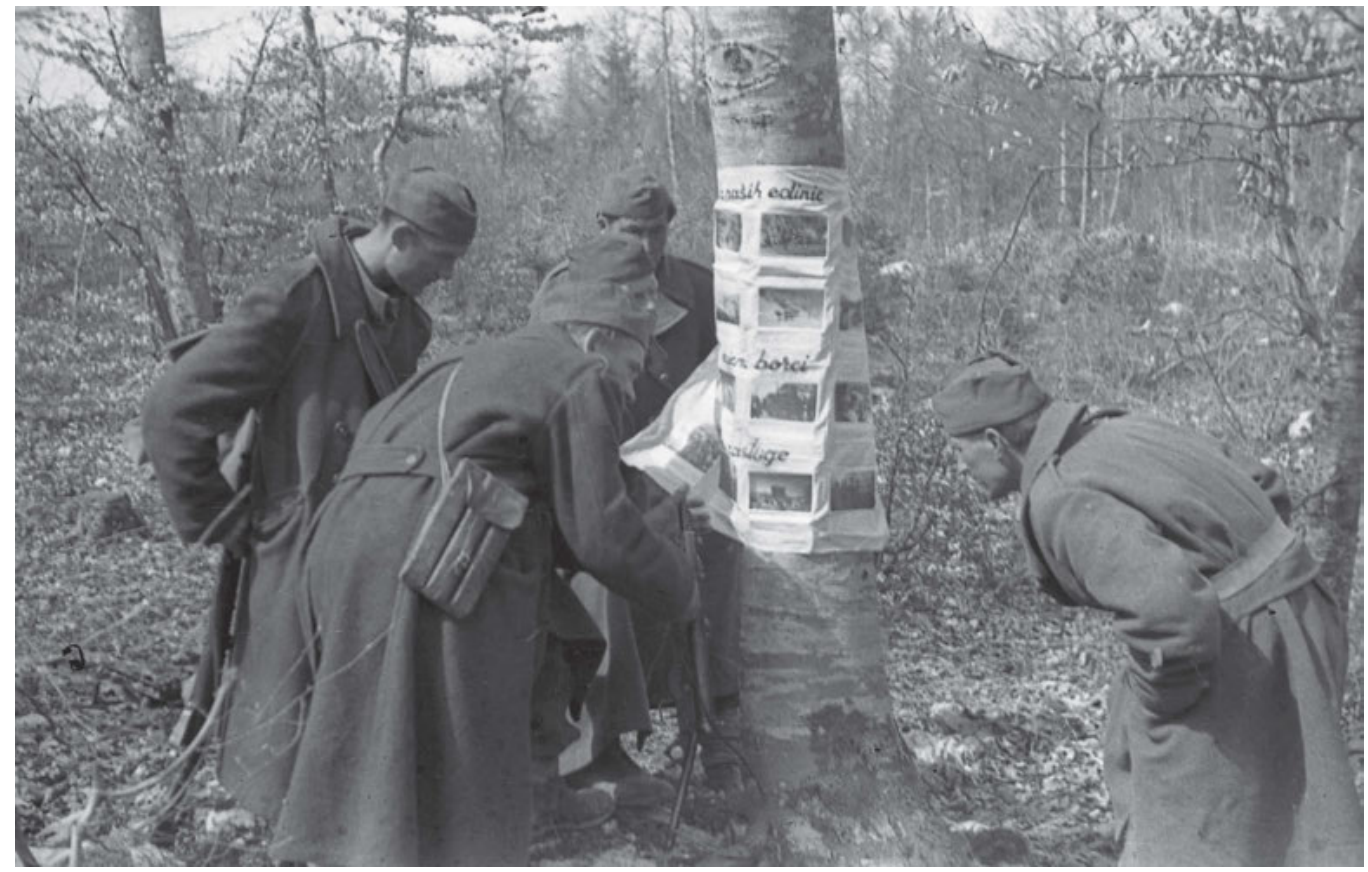

Kämpfer des Ersten Bataillons der Zehnten Brigade sehen sich Fotografien einer Wanderausstellung an einem Baumstamm an, Suha Krajina, 25. März 1945. Foto: Milan Štok. Ljubljana, Museum für Neuere Geschichte Sloweniens | TN904/24.

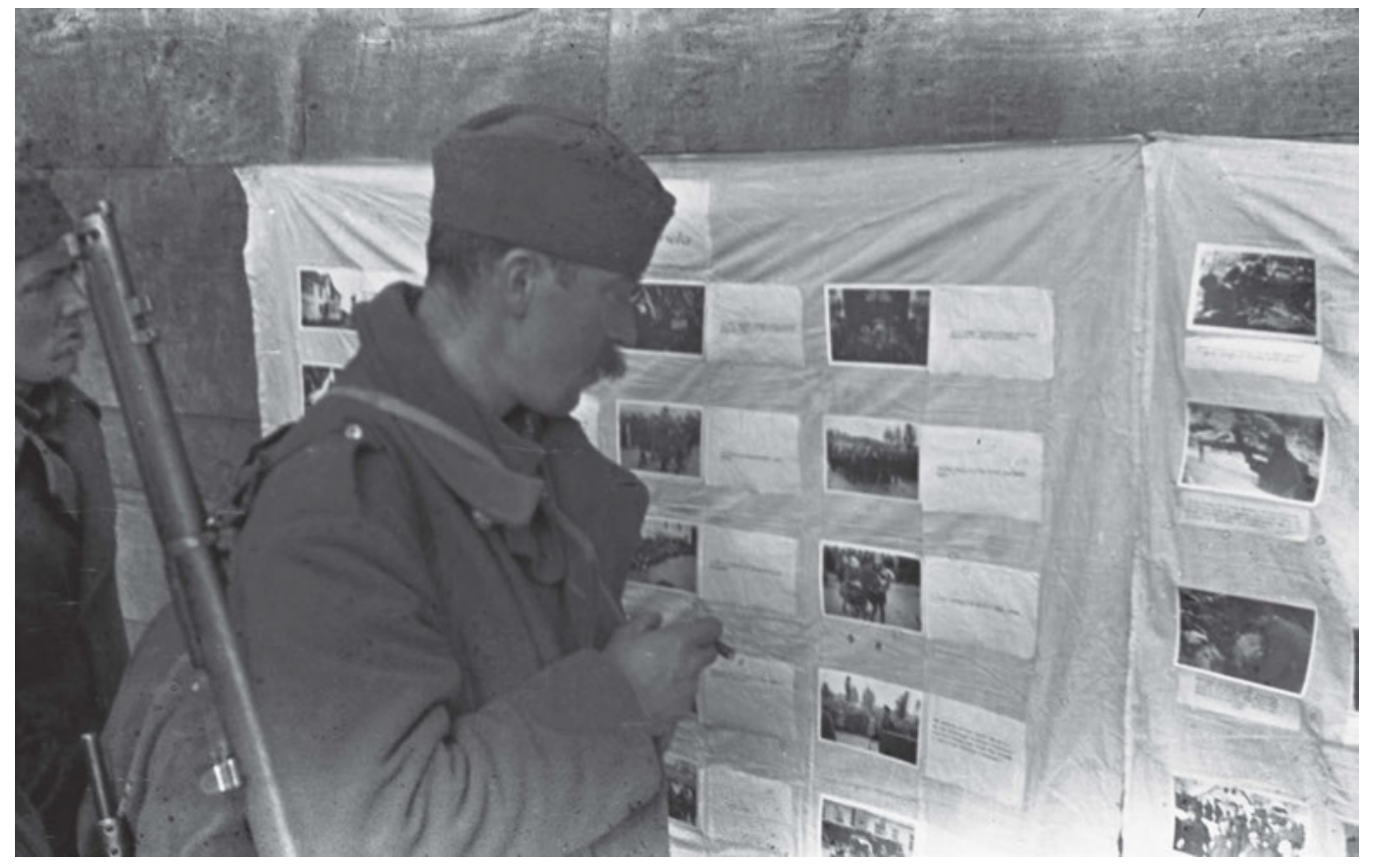

Partisanenkämpfer beim Betrachten der Fotoausstellung, Suha Krajina, 25. März 1945.

Foto: Milan Štok. Ljubljana, Museum für Neuere Geschichte Sloweniens | TN904/5. 


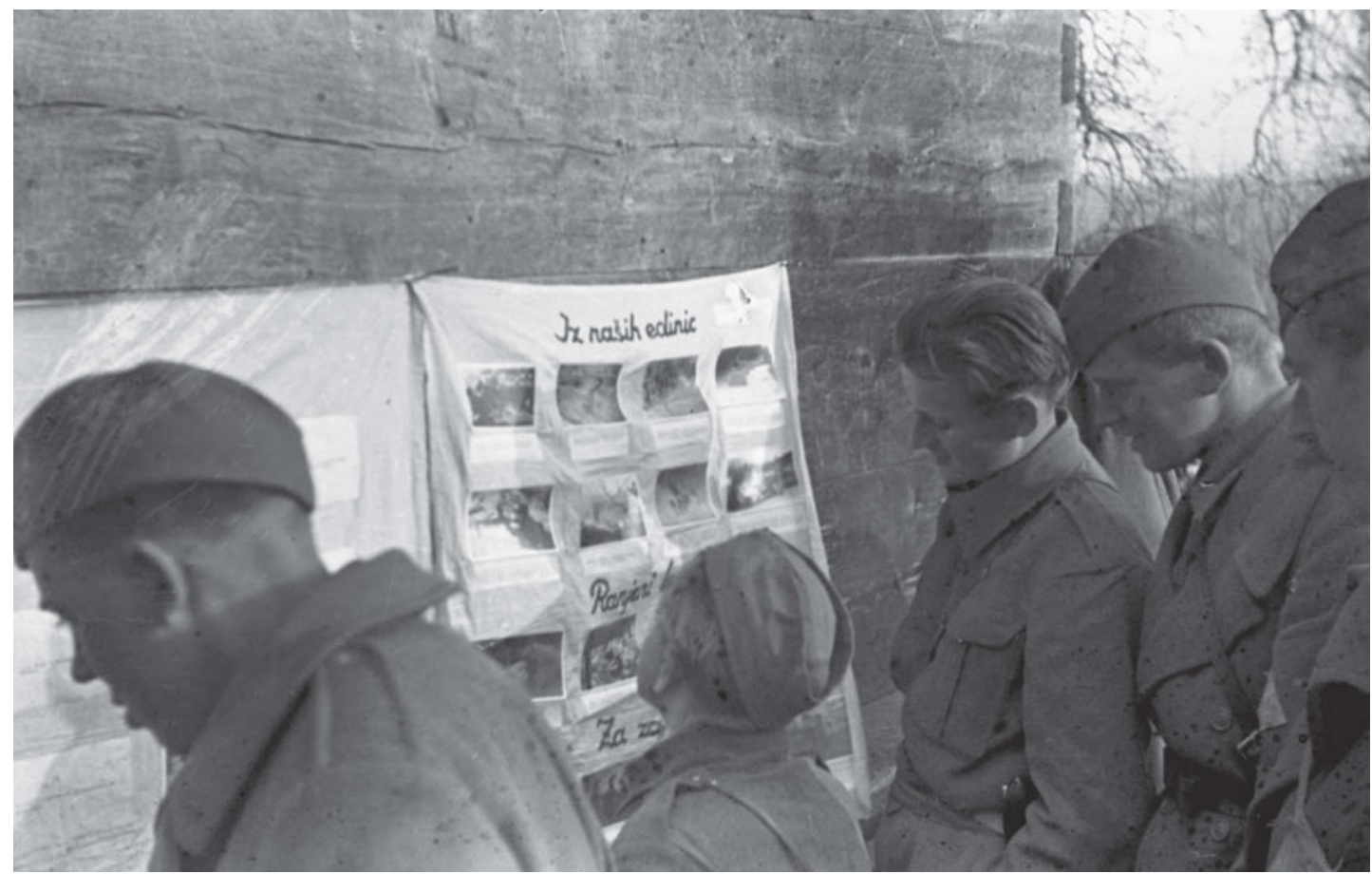

Kämpfer beim Betrachten der Fotografien, Suha Krajina, 25. März 1945.

Foto: Milan Štok. Ljubljana, Museum für Neuere Geschichte Sloweniens | TN904/6.

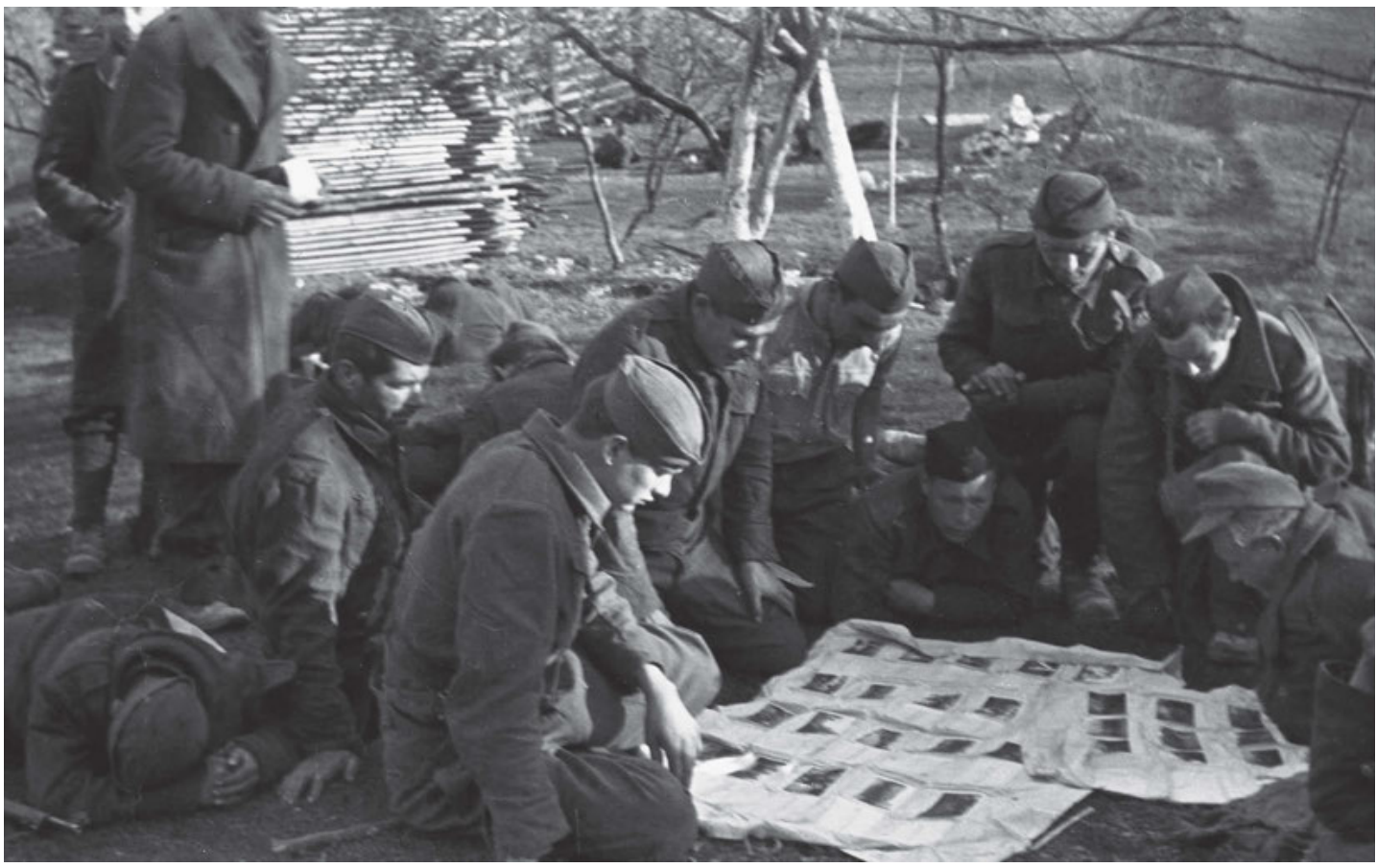

Soldaten des Zweiten Bataillons der 14. Brigade sehen sich die Fotoausstellung der Brigade Fontanot und des Begräbnisses von Franc Rozman-Stane während des politischen Unterrichts an, 24. März 1945. Foto: Milan Štok. Ljubljana, Museum für Neuere Geschichte Sloweniens | TN934/19. 


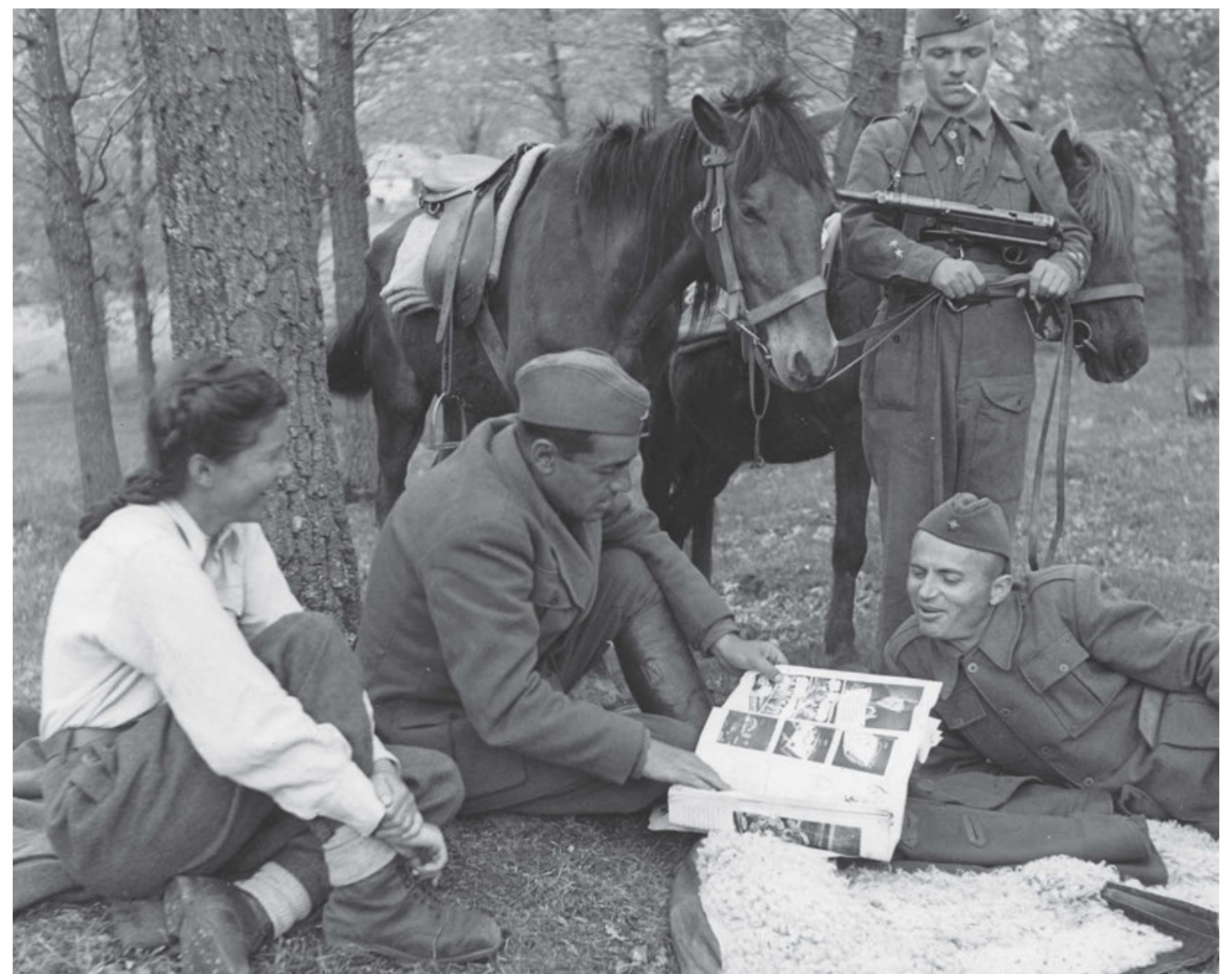

Eine unbekannte Partisanin, Vladislav Ribnikar, der Dichter Radovan Zogović und Radovan Bulatović (stehend) bei der Durchsicht von abgedruckten Fotografien. Fotograf unbekannt. Belgrad, Militärmuseum | 4637.

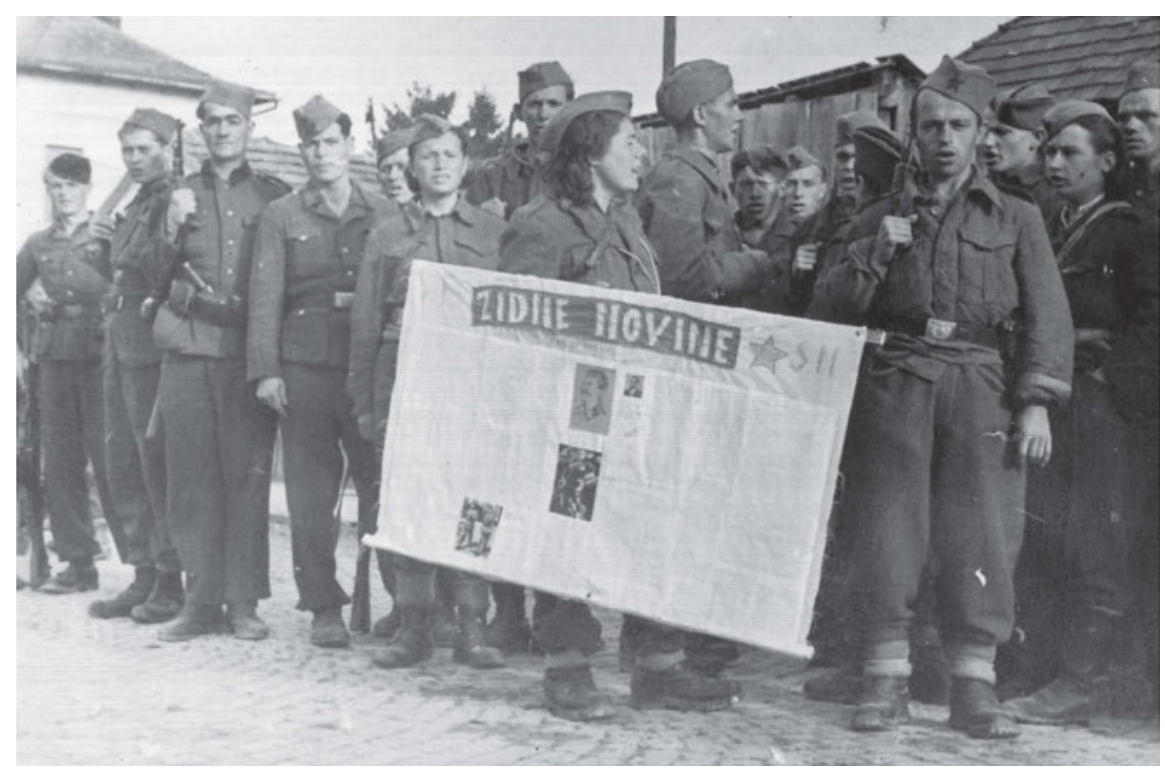

Partisanen mit einer Wandzeitung. Foto: Drago Mažar. Banja Luka, Archiv der Republika Srpska. Ohne Inv.-Nr. 


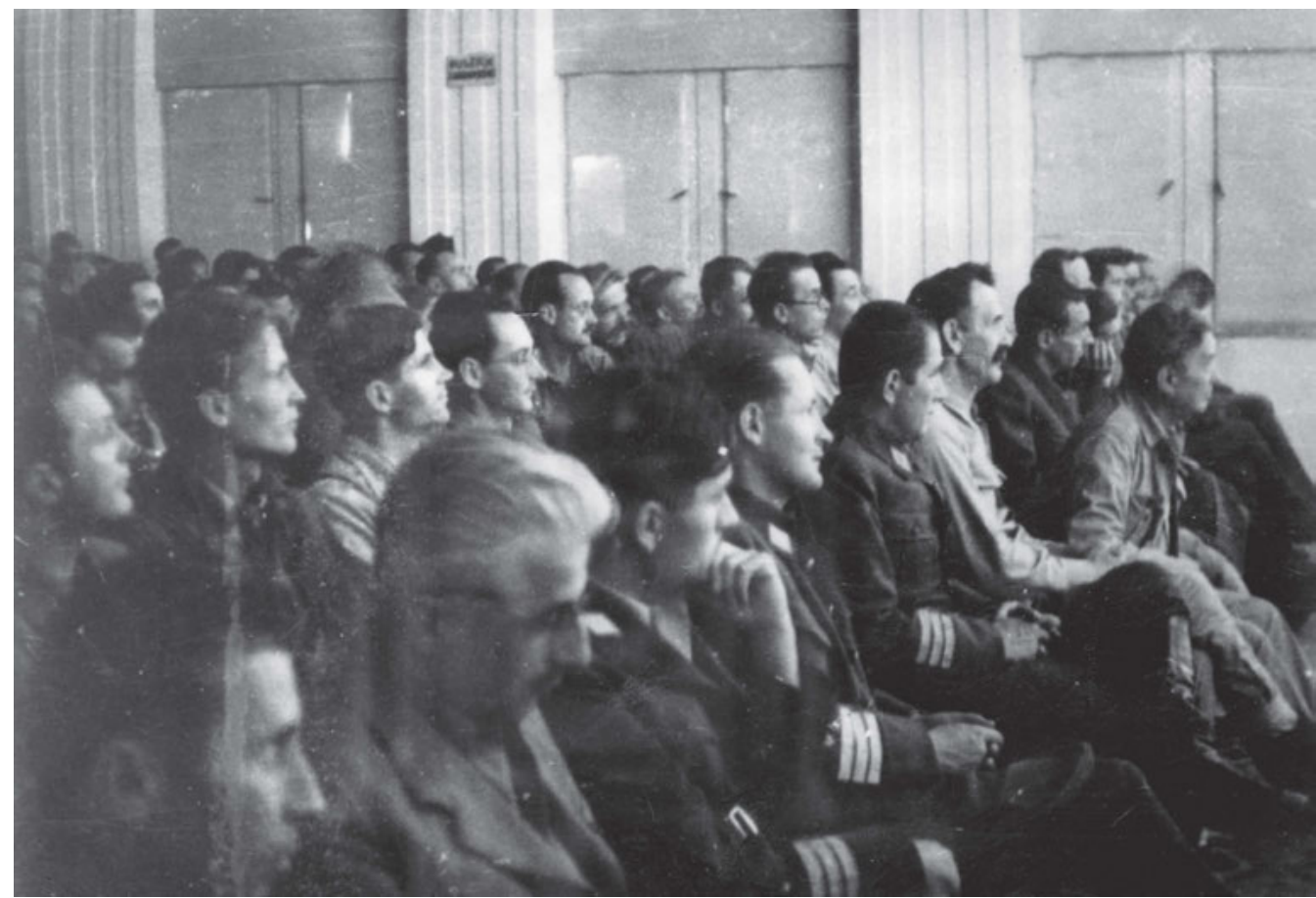

Ausstellung anlässlich der Feier der Gründung der Ersten Dalmatinischen Brigade auf der Insel Vis, September 1944. Zagreb, Kroatisches Historisches Museum I HPM-MRNH-R-5634.

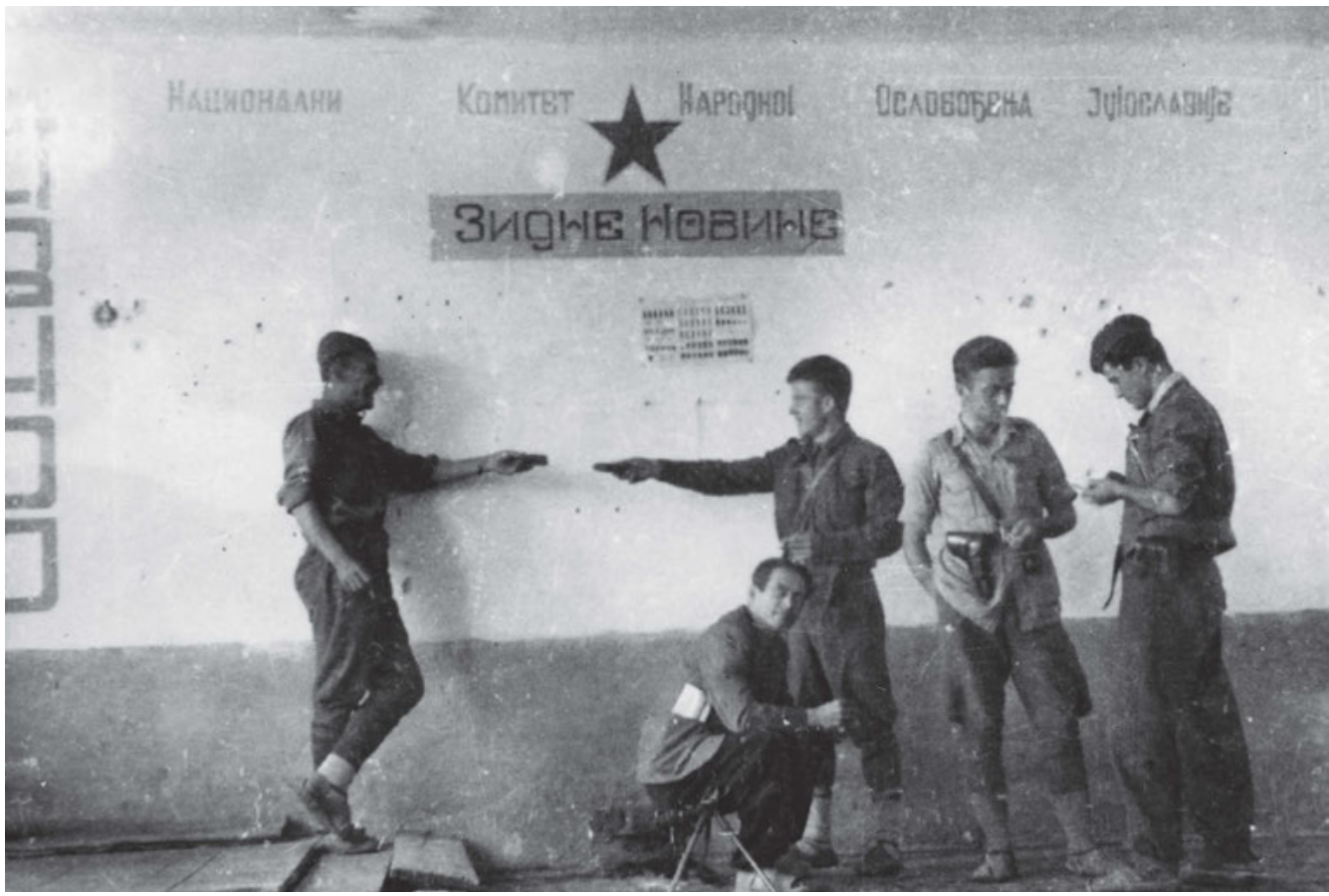

Eine unbekannte Partisanin, Vladislav Ribnikar, der Dichter Radovan Zogović und Radovan Bulatović (stehend) bei der Durchsicht von abgedruckten Fotografien. Fotograf unbekannt. Belgrad, Militärmuseum | 4637. 


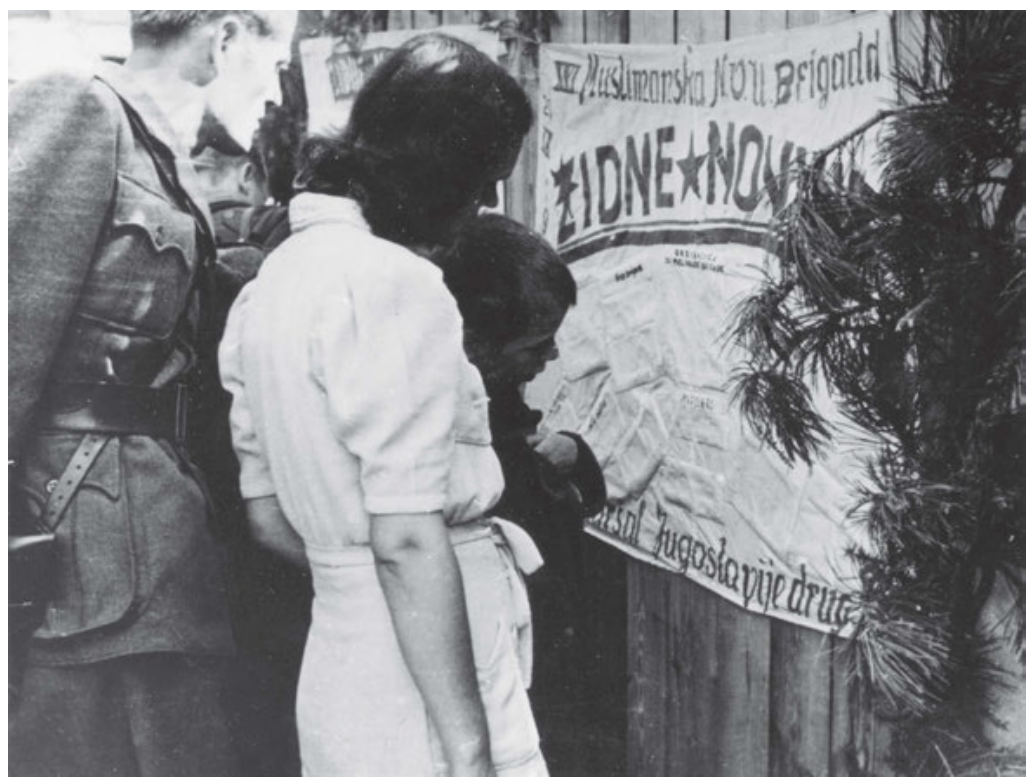

Ausgestellte Wandzeitung der Sechzehnten Muslimischen Brigade in Tuzla,

21. September 1944. Sarajevo, Historisches Museum von Bosnien und Herzegowina I FNOB 14248.
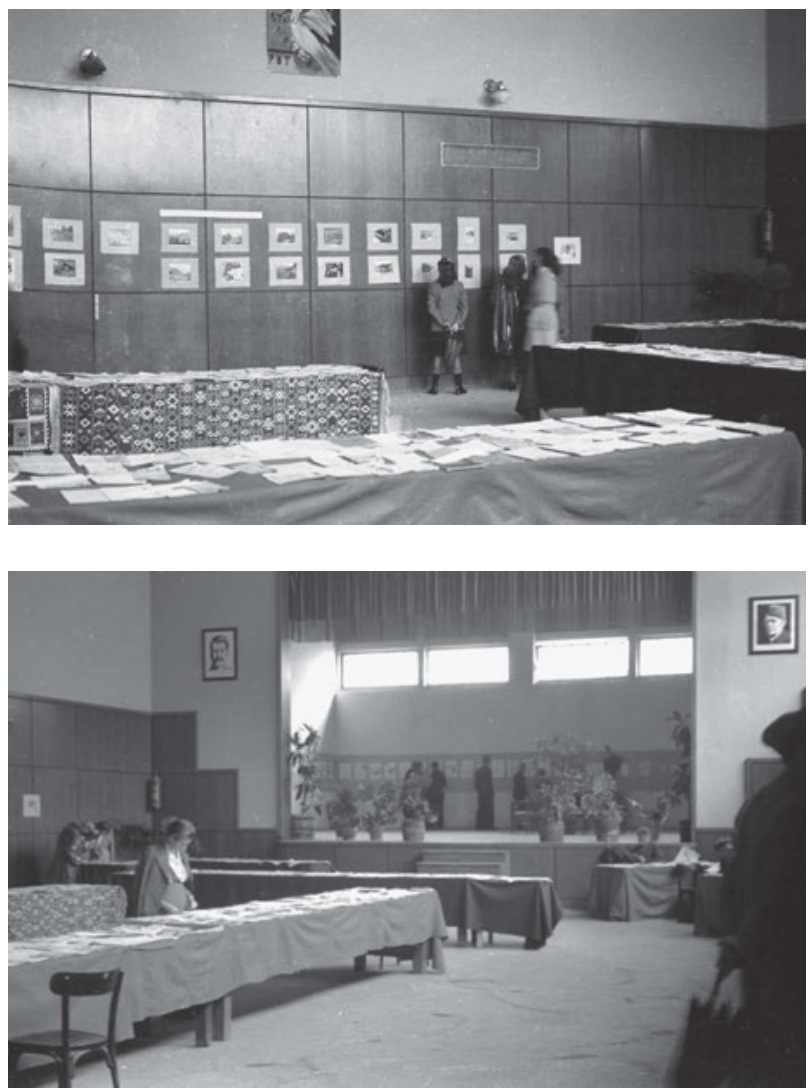

Blick in einen Saal, in dem eine Ausstellung mit Fotografien, Gemälden, Karikaturen und Zeitungen aus dem Volksbefreiungskampf gezeigt wird. Crikvenica, September-Oktober 1943. Zagreb, Kroatisches Historisches Museum | HPM/MRNH-A-2601-f69-001.

Blick in den Saal, in dem eine Ausstellung mit Fotografien, Gemälde, Karikaturen und Zeitungen aus dem Volksbefreiungskampf gezeigt wird. Crikvenica, September-Oktober 1943. Zagreb, Kroatisches Historisches Museum I HPM/MRNH-A-2601-f69-003. 


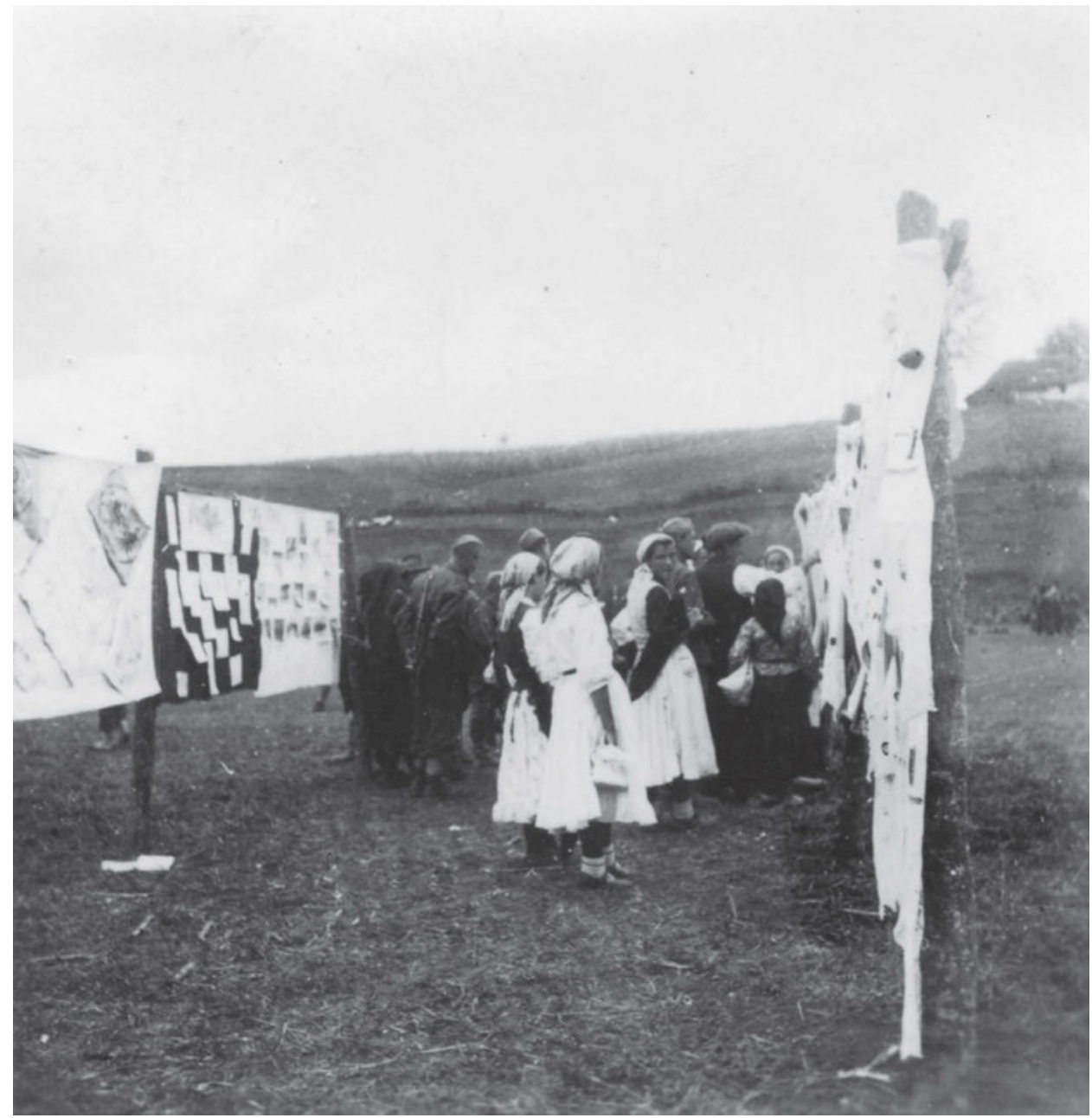

Ausstellung von Handarbeiten, Fotografien und Zeitungsausgaben im Rahmen der Feierlichkeiten anlässlich des dritten Jahrestags des Aufstands in Kordun, Sommer 1944. Fotograf unbekannt. Zagreb, Kroatisches Historisches Museum | HPM/MRNH-F-4744. 


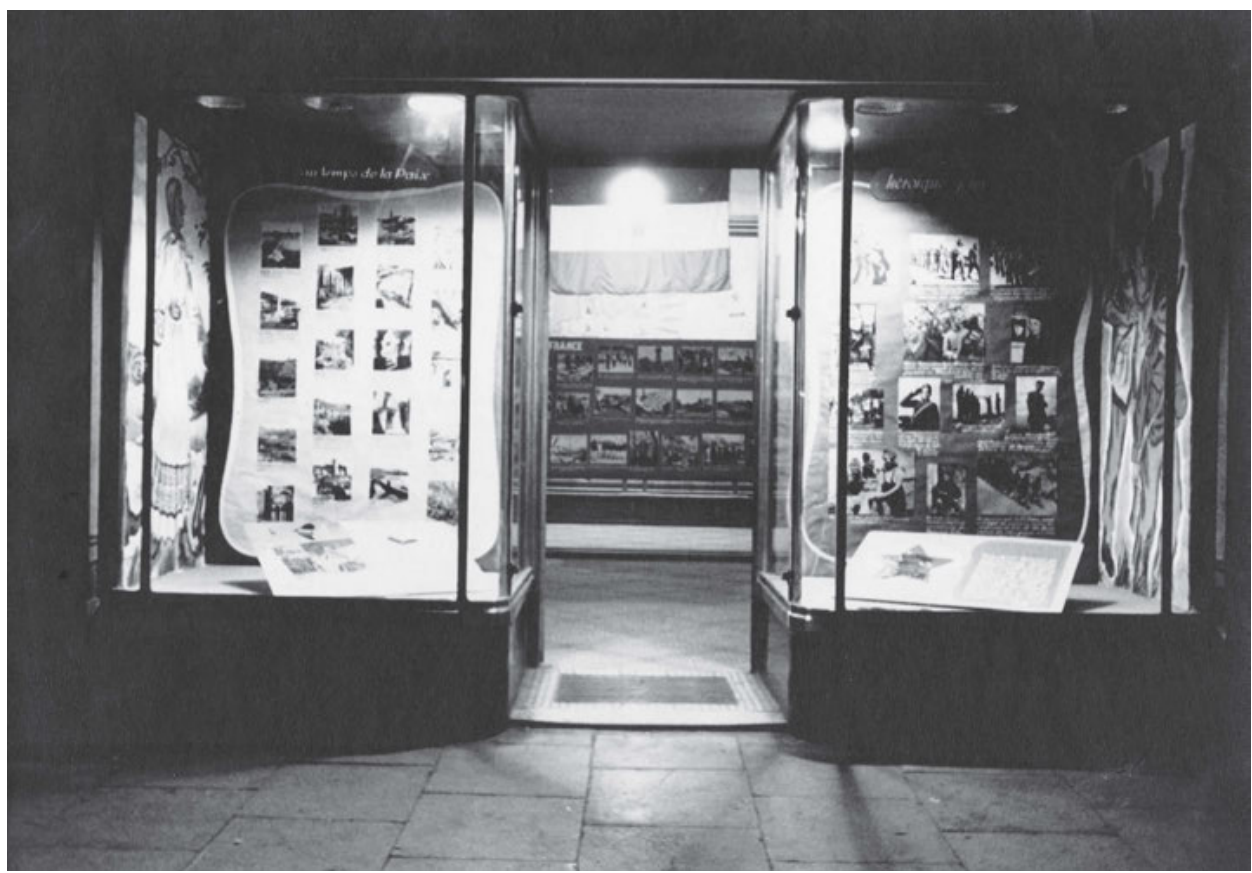

L'exposition sur la Yougoslavie nouvelle. Dank der Familie von Vanja Žanko sind Fotografien der höchst interessanten Ausstellung L'exposition sur la Yugoslavie nouvelle (Ausstellung über das neue Jugoslawien) erhalten geblieben, die 1944 in Algerien stattfand und in deren Rahmen der Kampf der Partisanen und die Kunst Jugoslawiens präsentiert wurden. Fotograf unbekannt. Privatarchiv von Dunja Žanko Darrot.

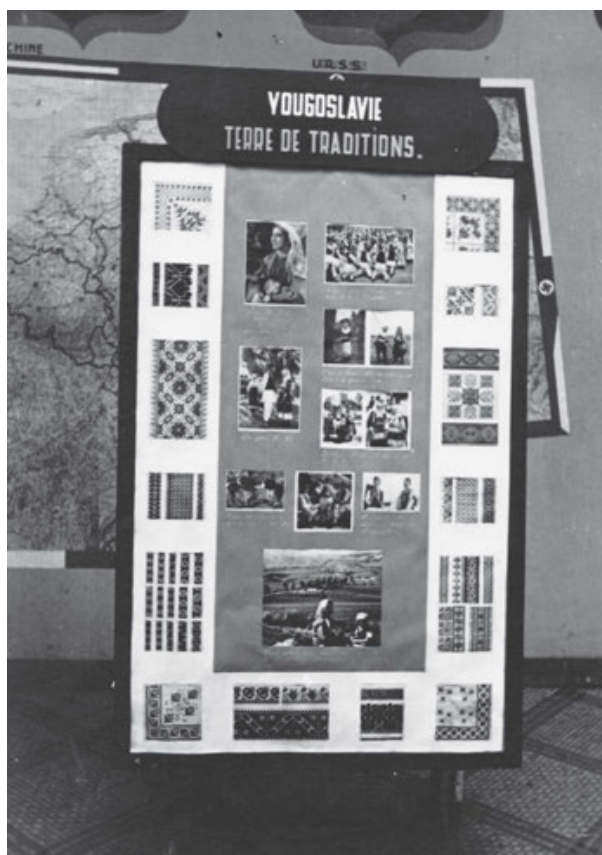

Detail der Ausstellung L'exposition sur la Yougoslavie nouvelle, 1944, Algerien. Fotograf unbekannt. Privatarchiv von Dunja Žanko Darrot.

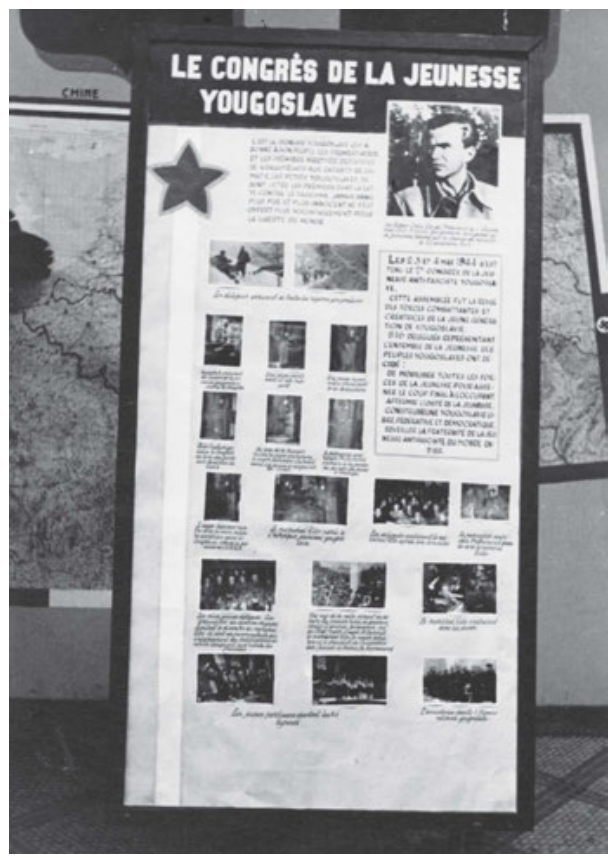

Detail der Ausstellung L'exposition sur la Yougoslavie nouvelle, 1944, Algerien. Fotograf unbekannt. Privatarchiv von Dunja Žanko Darrot. 


\section{Befreiung}

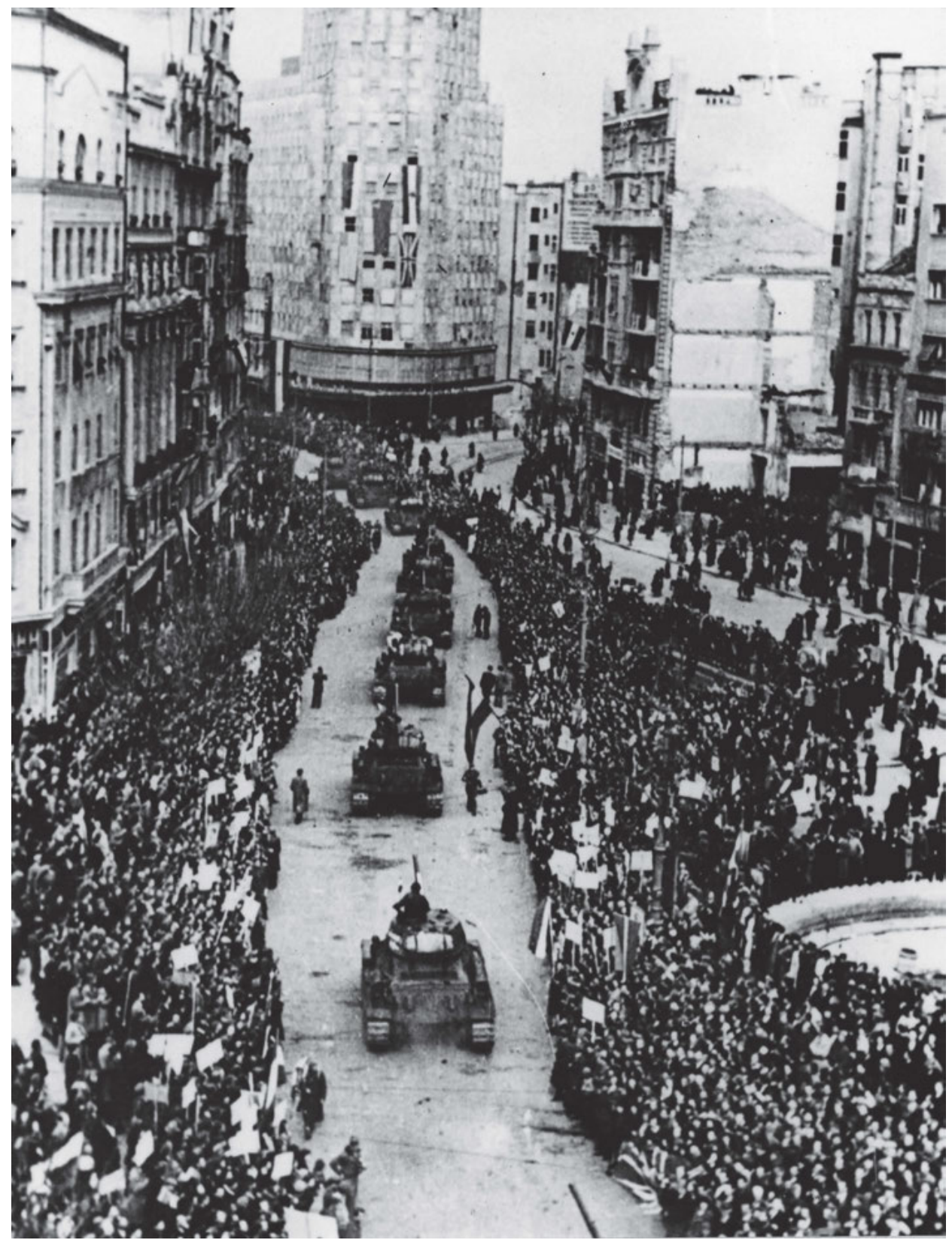

Befreiung Belgrads. Fotograf unbekannt. Sarajevo, Historisches Museum von Bosnien und Herzegowina | FNOB 19439. 


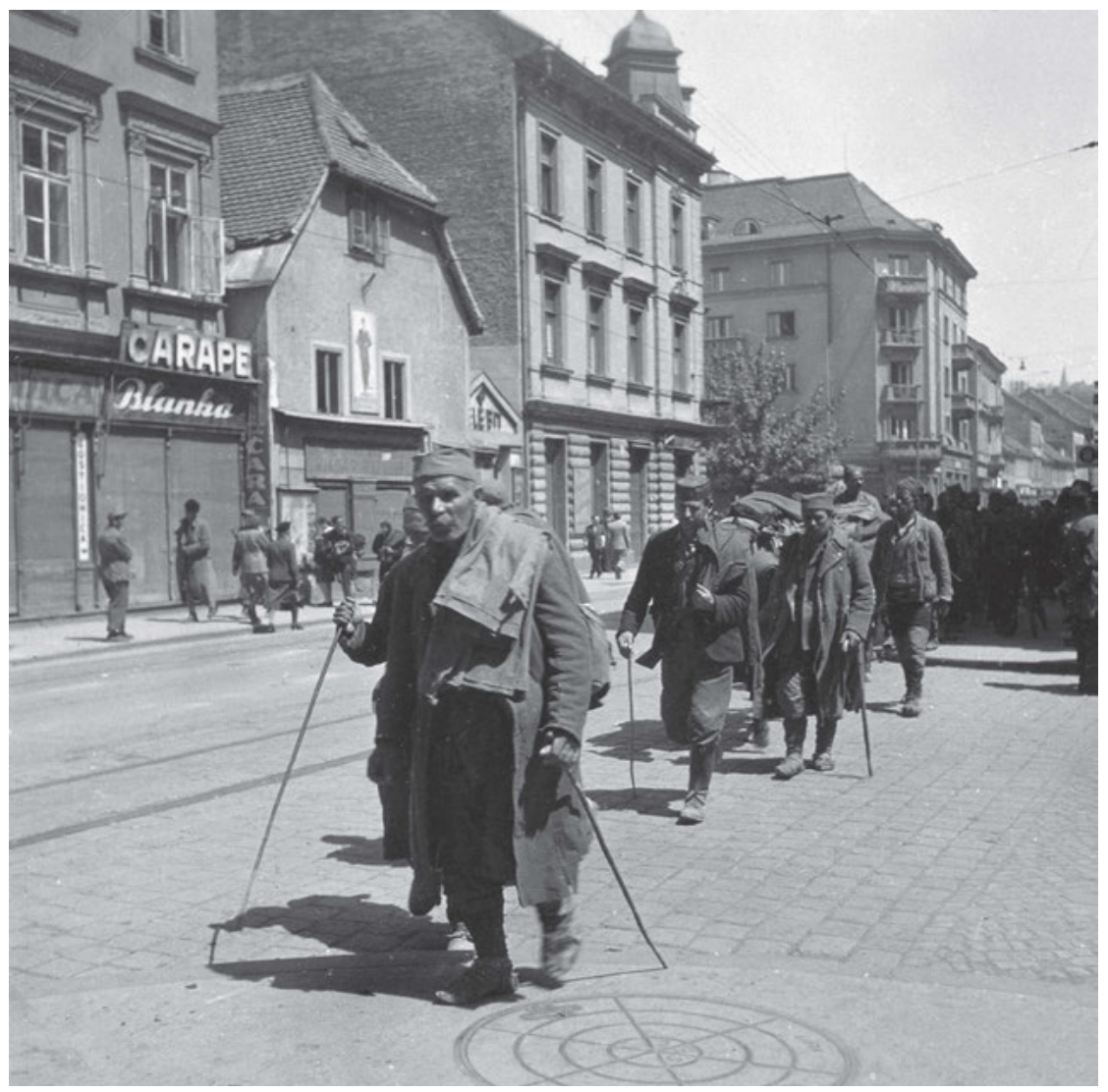

Rückzug der montenegrinischen Tschetniks in Richtung Westen. Zagreb, Mai 1944. Foto: Milan Pavić. Zagreb, Kroatisches Historisches Museum | HPM-MRNH-A-11697_94.

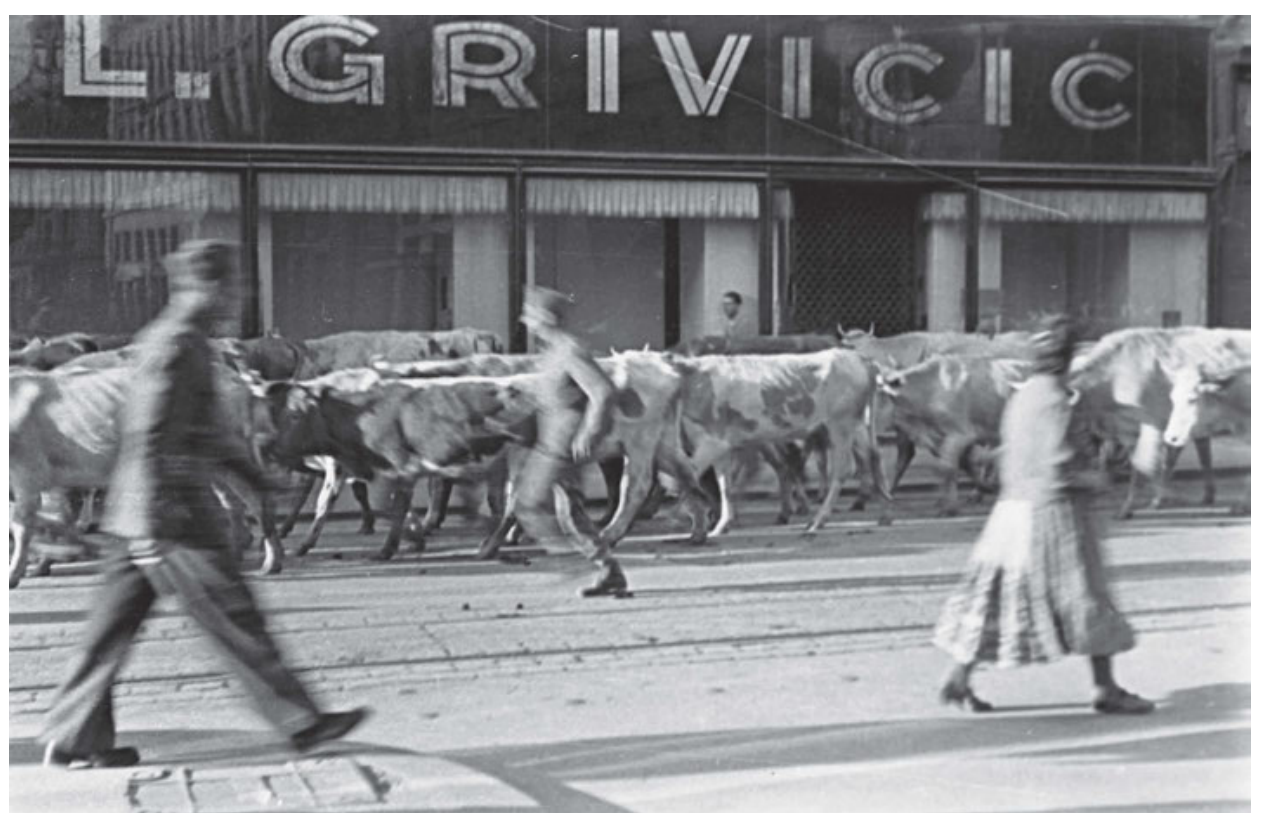

Zagreb in den Tagen der Befreiung, Mai 1945. Fotograf unbekannt. Zagreb, Kroatisches Historisches Museum I HPM-MRNH-N-2501. 

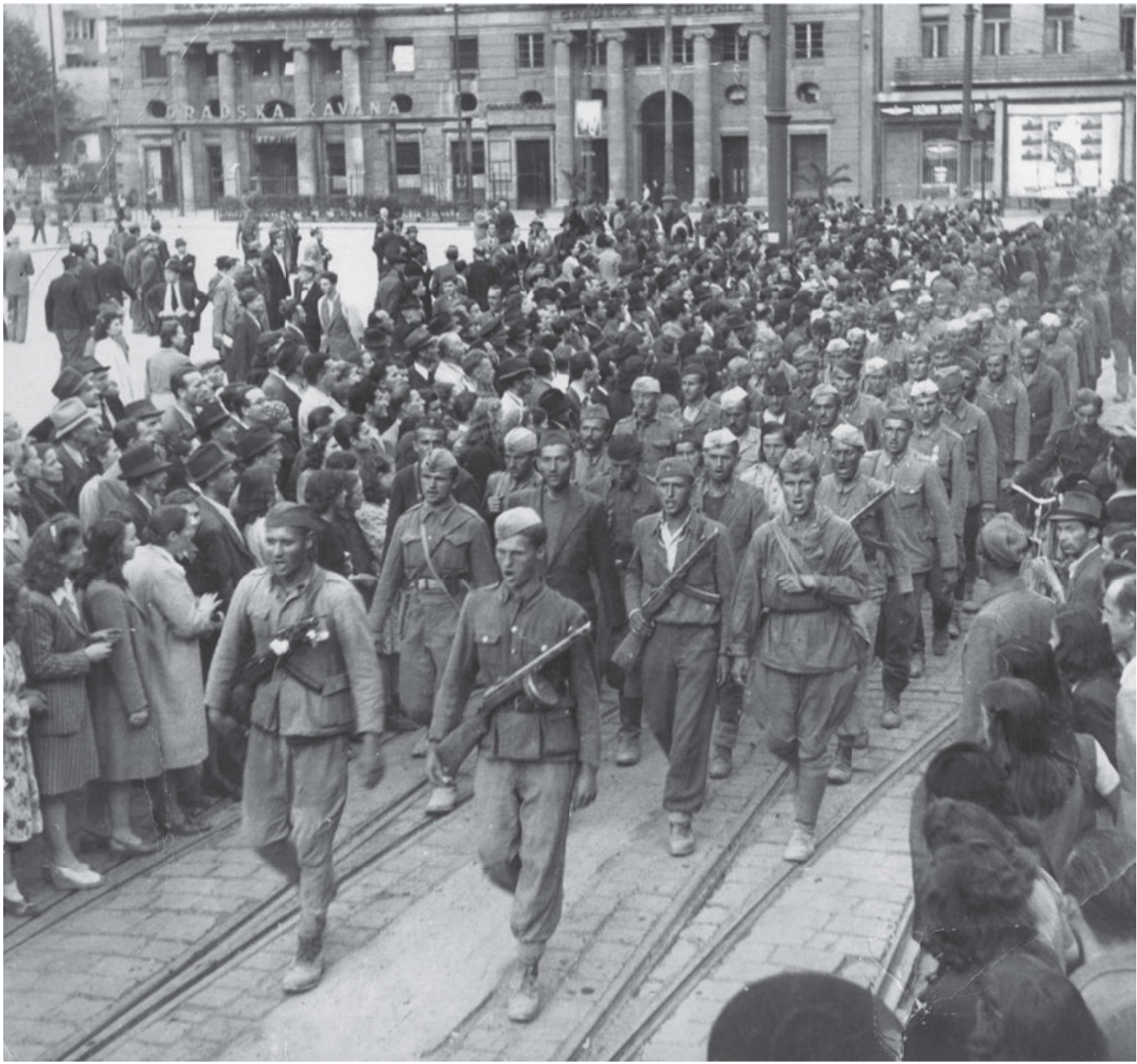

Einmarsch der Partisanen in Zagreb am 8. Mai 1945. Foto: Milan Pavić.

Zagreb, Kroatisches Historisches Museum | HPM-MRNH-F-11201.

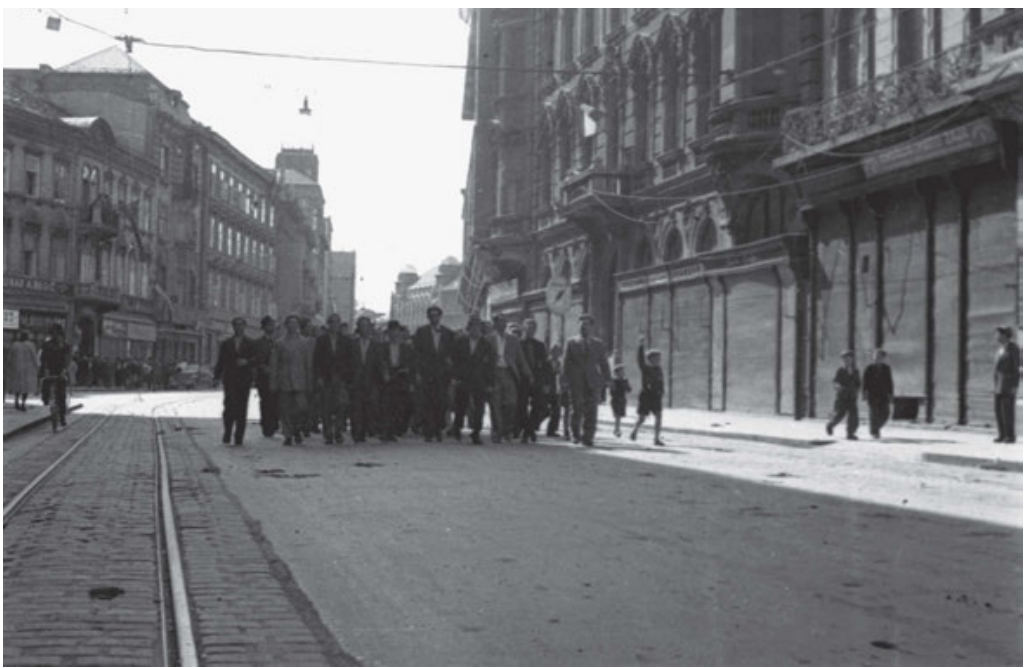




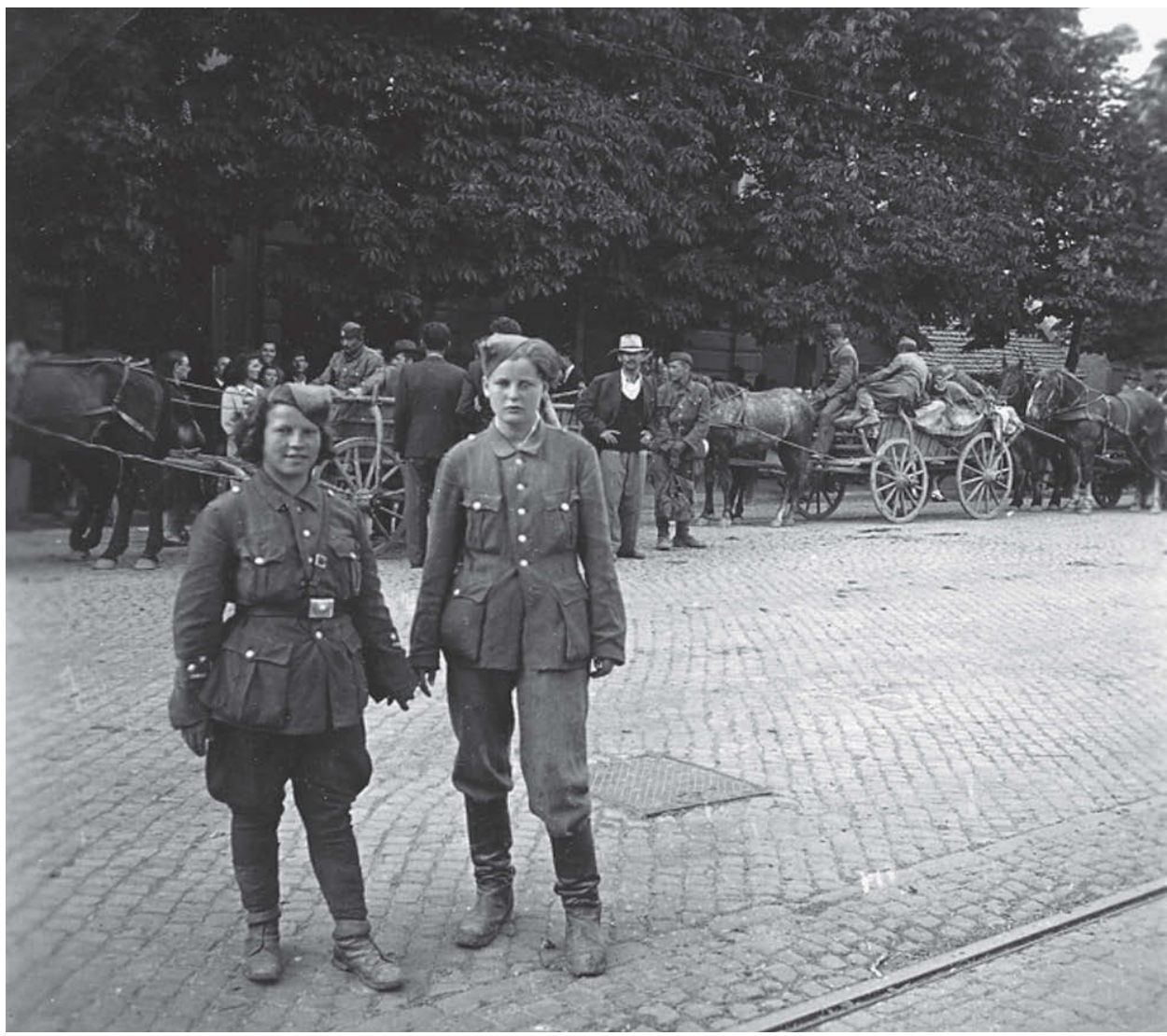

Einzug der jugoslawischen Armee über die Maksimir-Straße in Zagreb, Mai 1945. Foto: "Zaza«. Museum der Stadt Zagreb. Ohne Inv.-Nr.

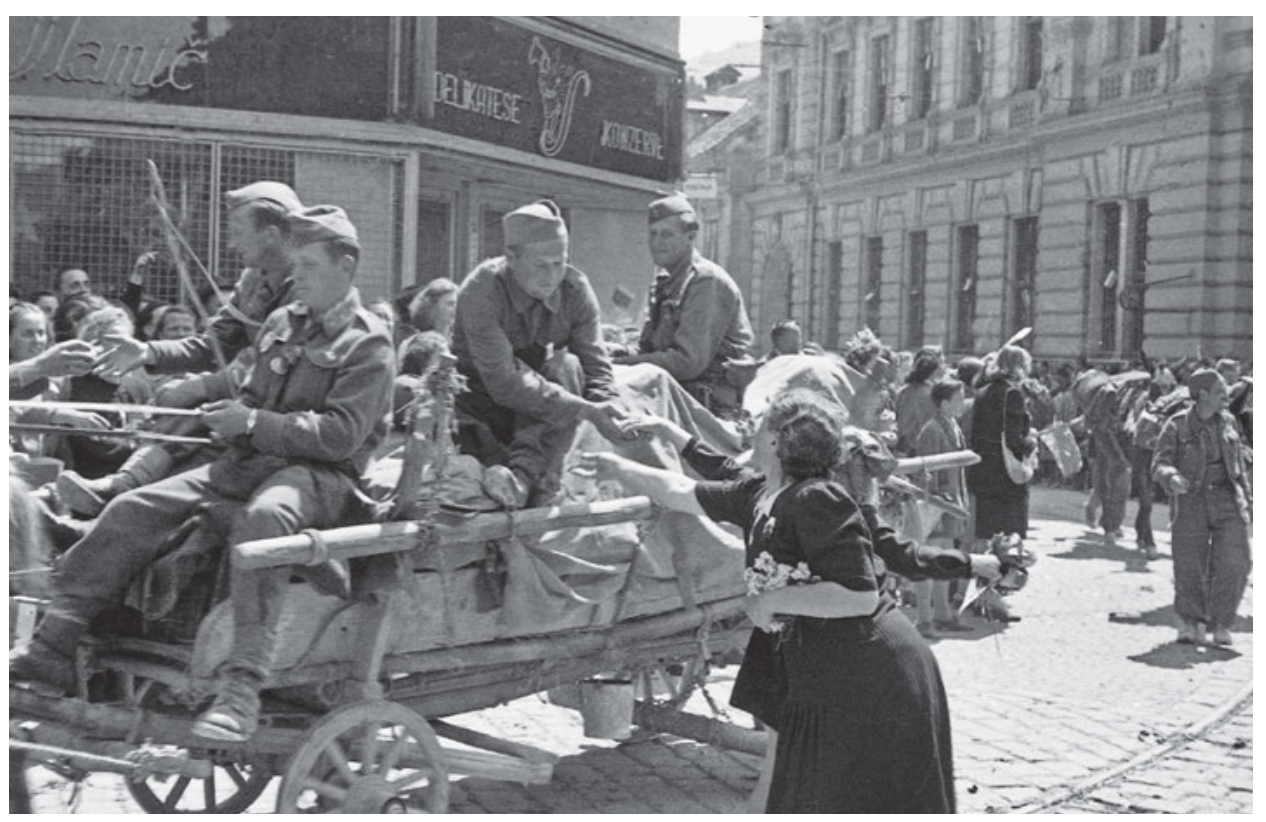

Eintreffen der Partisanen in Ljubljana am 9. März 1945. Foto: Ivan Tavčar. Ljubljana, Museum für Neuere Geschichte Sloweniens | FS2171/9. 


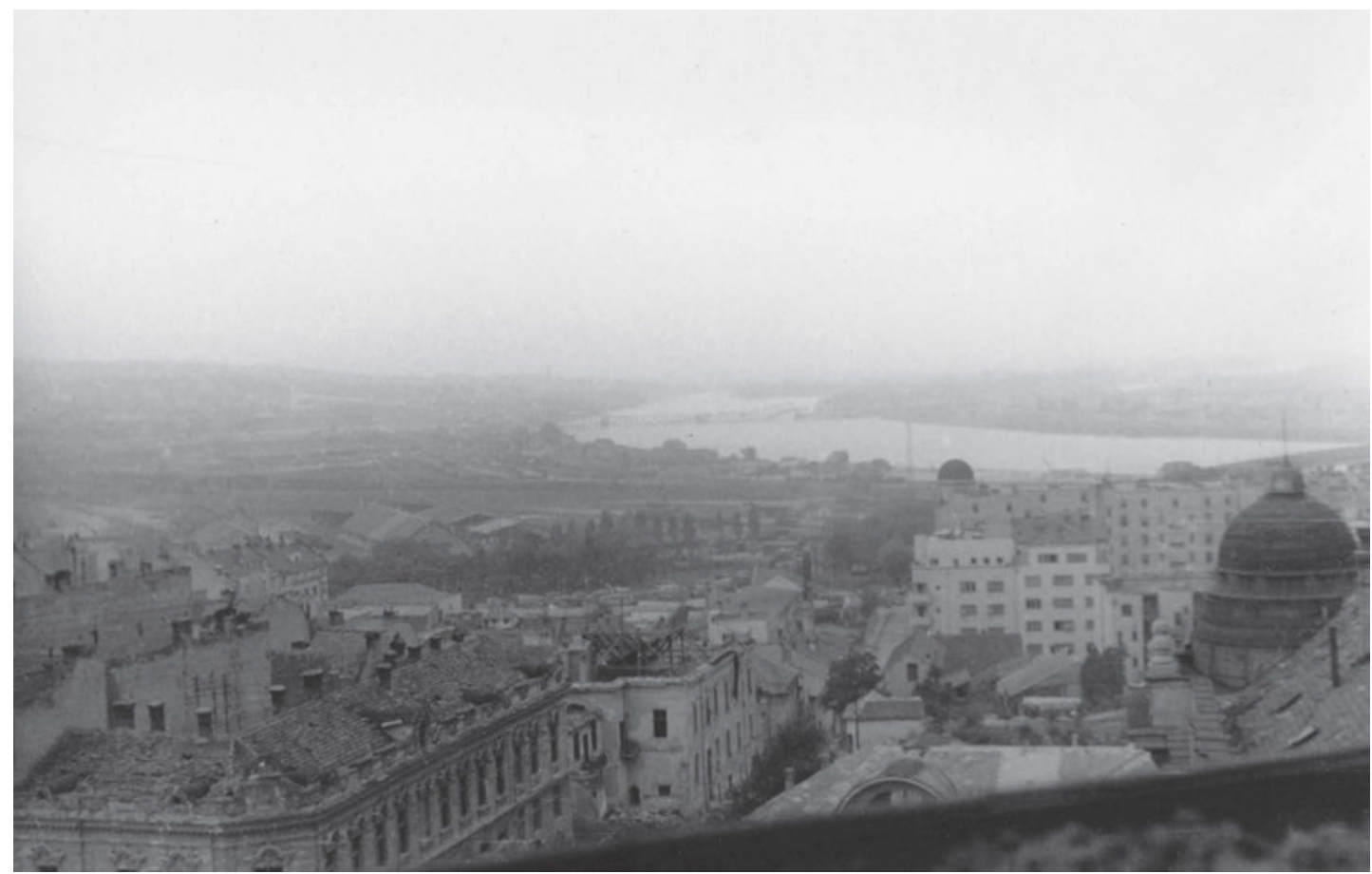

Blick auf das befreite Belgrad, 20. Oktober 1944. Fotograf unbekannt. Belgrad,

Militärmuseum | 2264.

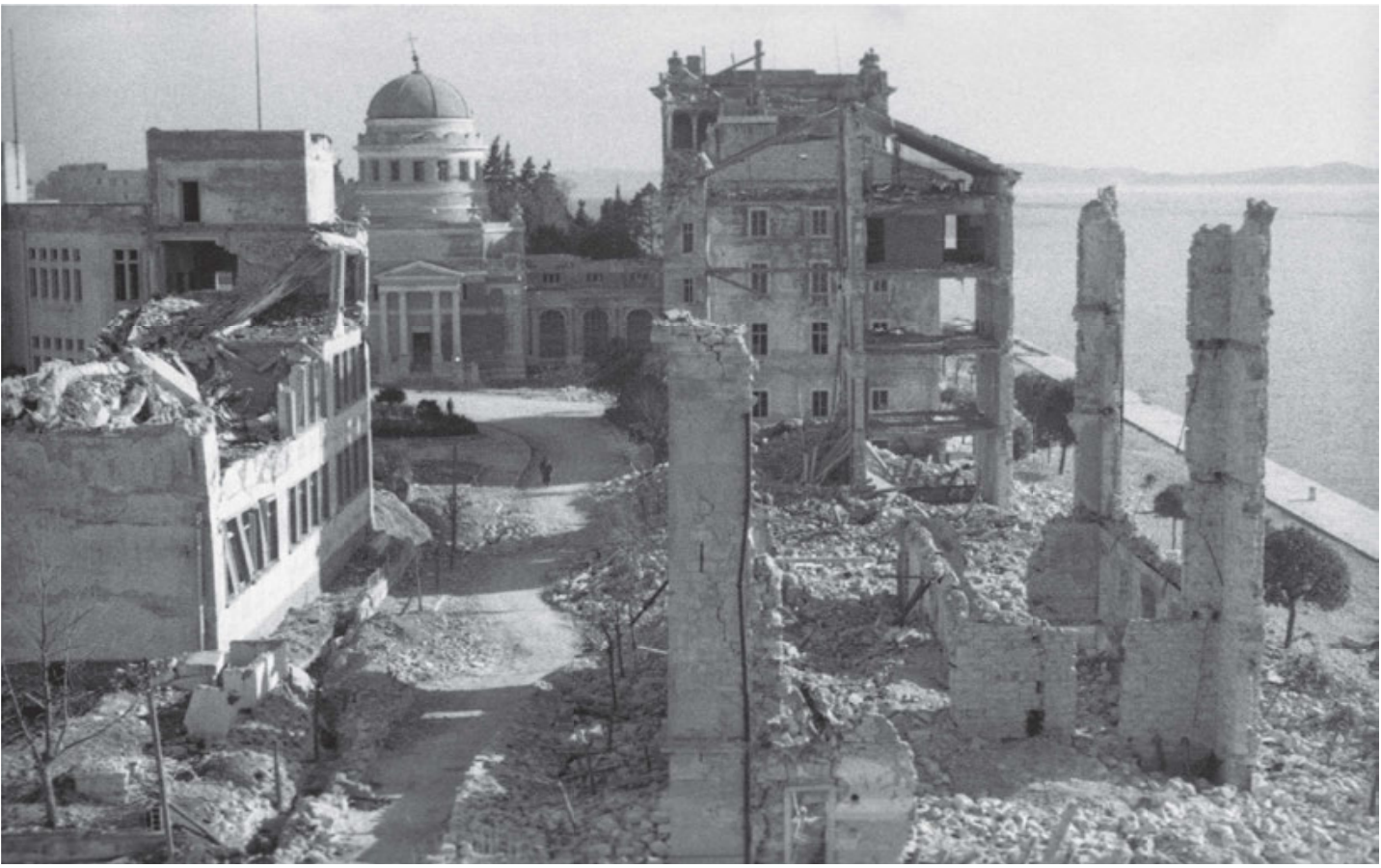

Blick aus einem Krankenhaus auf Ruinen nach der Bombardierung durch die Alliierten, Zadar, März 1945. Foto: Dr. Janez Milčinski. Ljubljana, Museum für Neuere Geschichte Sloweniens | 1238/7. 


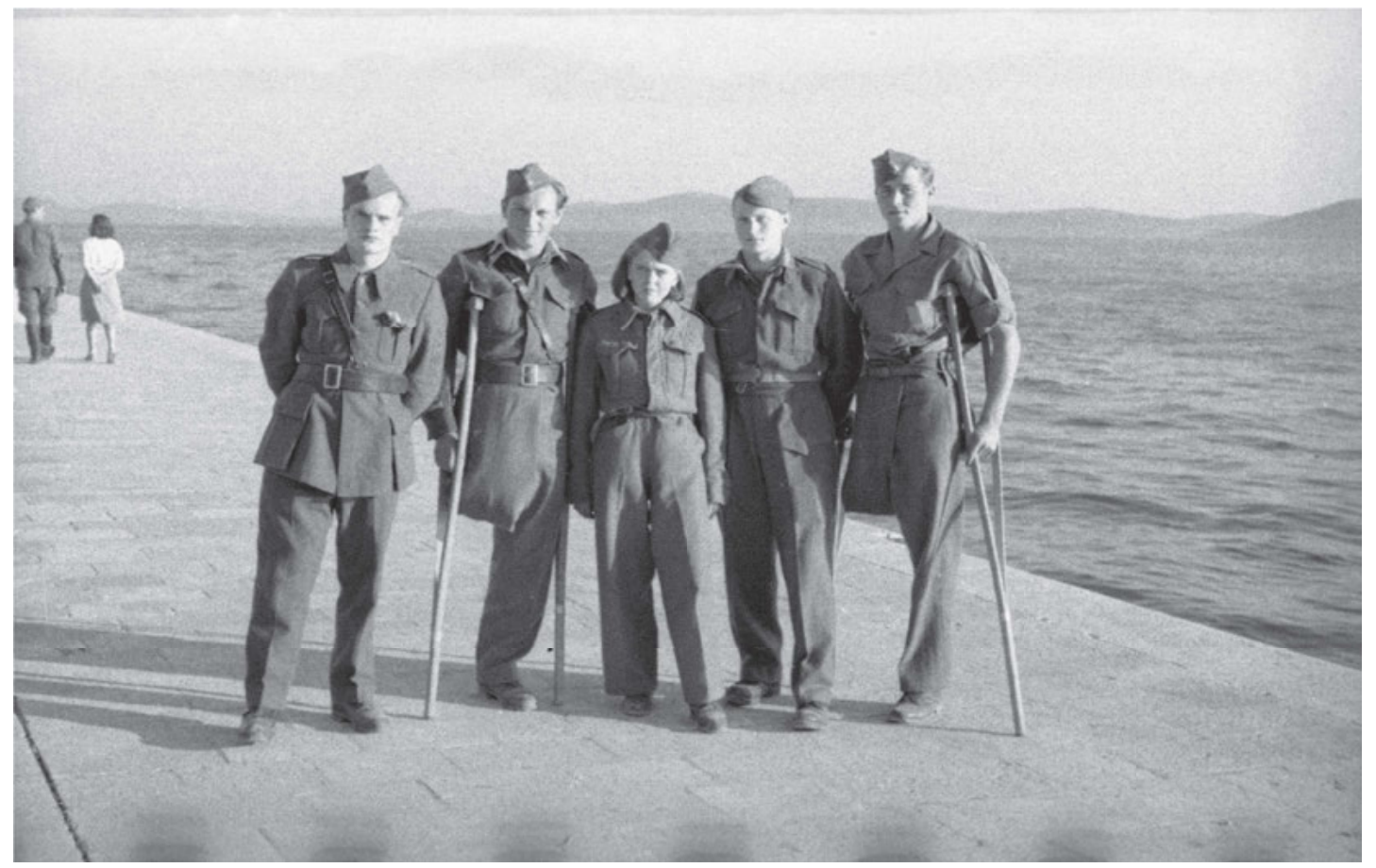

Keine Angaben. Foto: Dr. Janez Milčinski. Ljubljana, Museum für Neuere Geschichte Sloweniens | 1241/11.

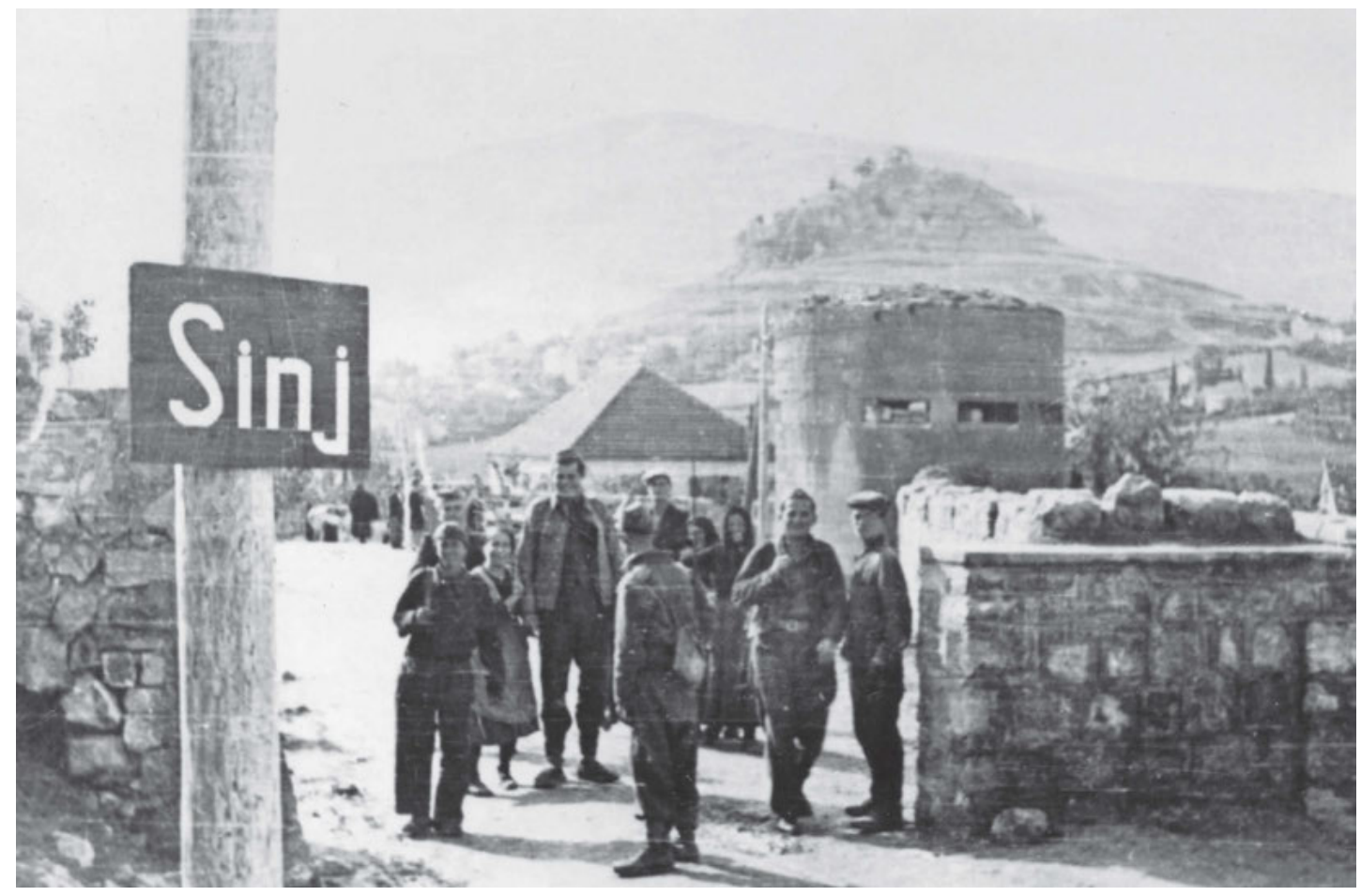

Kämpfer aus der Achten Dalmatinischen Brigade der 20. Dalmatinischen Division im befreiten Sinj, 25. Oktober 1944. Fotograf unbekannt. Belgrad, Militärmuseum | 8453. 


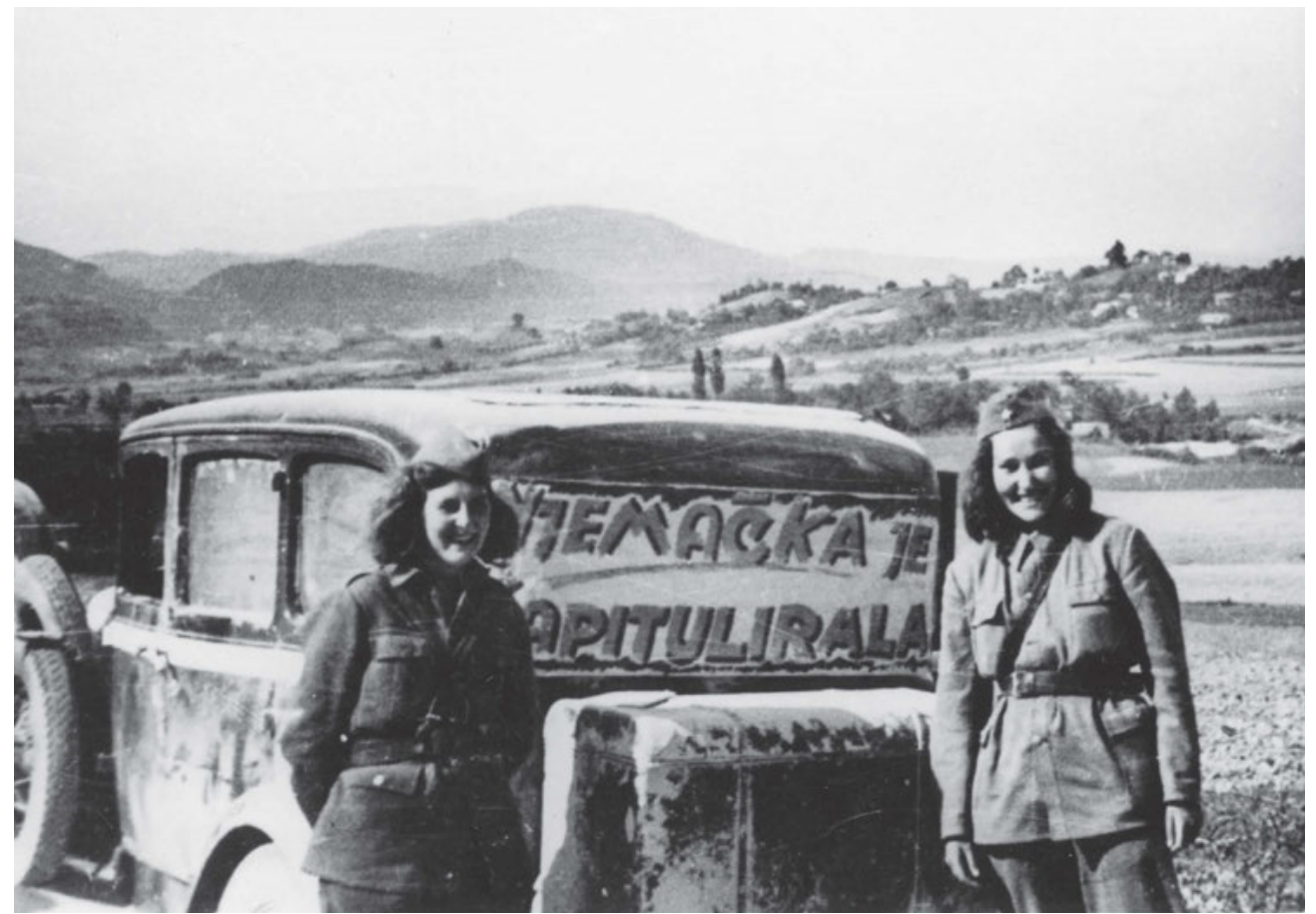

Kämpferinnen der Zehnten Krajina-Brigade nach der Kapitulation der deutschen Wehrmacht auf der Straße von Karlovac nach Zidani Most, Mai 1945. Fotograf unbekannt. Sarajevo, Historisches Museum von Bosnien und Herzegowina | FNOB 6144.

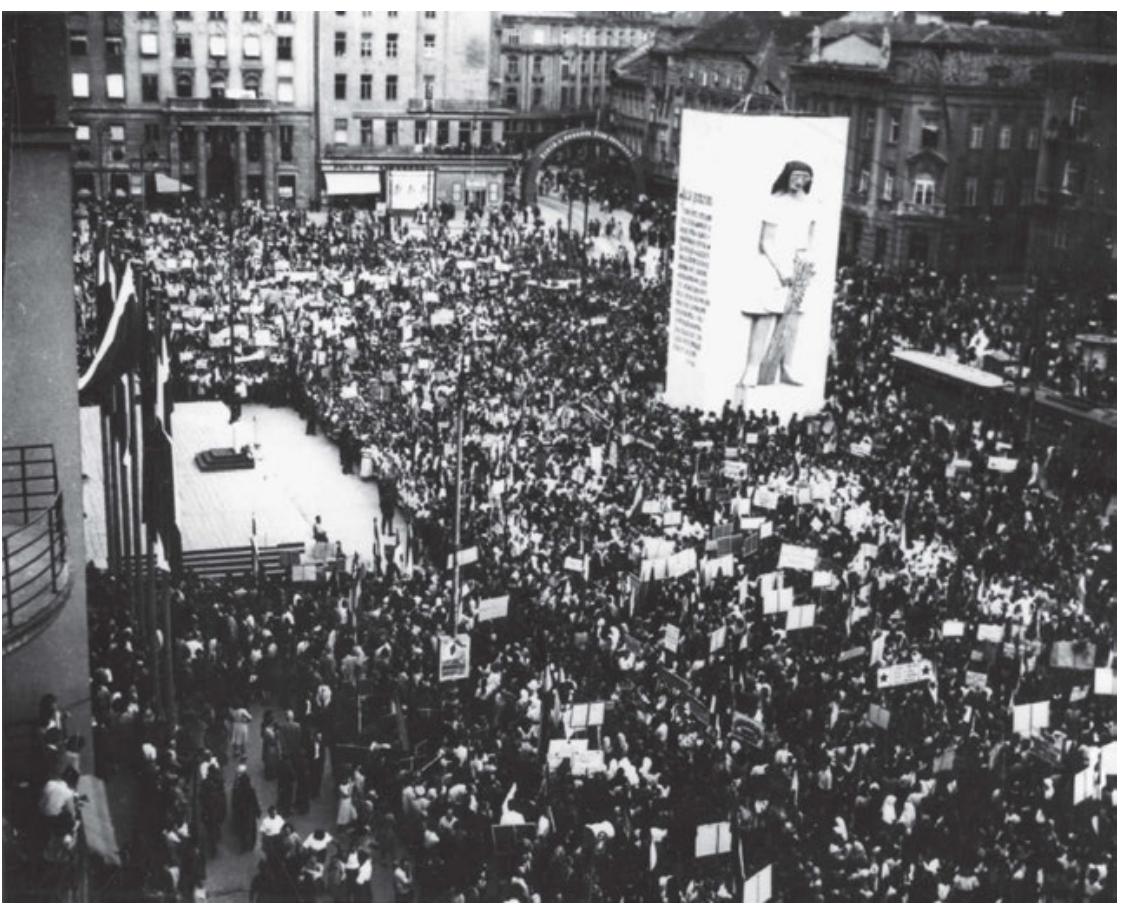

Kundgebung auf dem Platz der Republik anlässlich des Ersten Kongresses der Antifaschistischen Frauenfront, Zagreb, 1945. Fotograf unbekannt. Sarajevo, Historisches Museum von Bosnien und Herzegowina | FNOB 10700. 


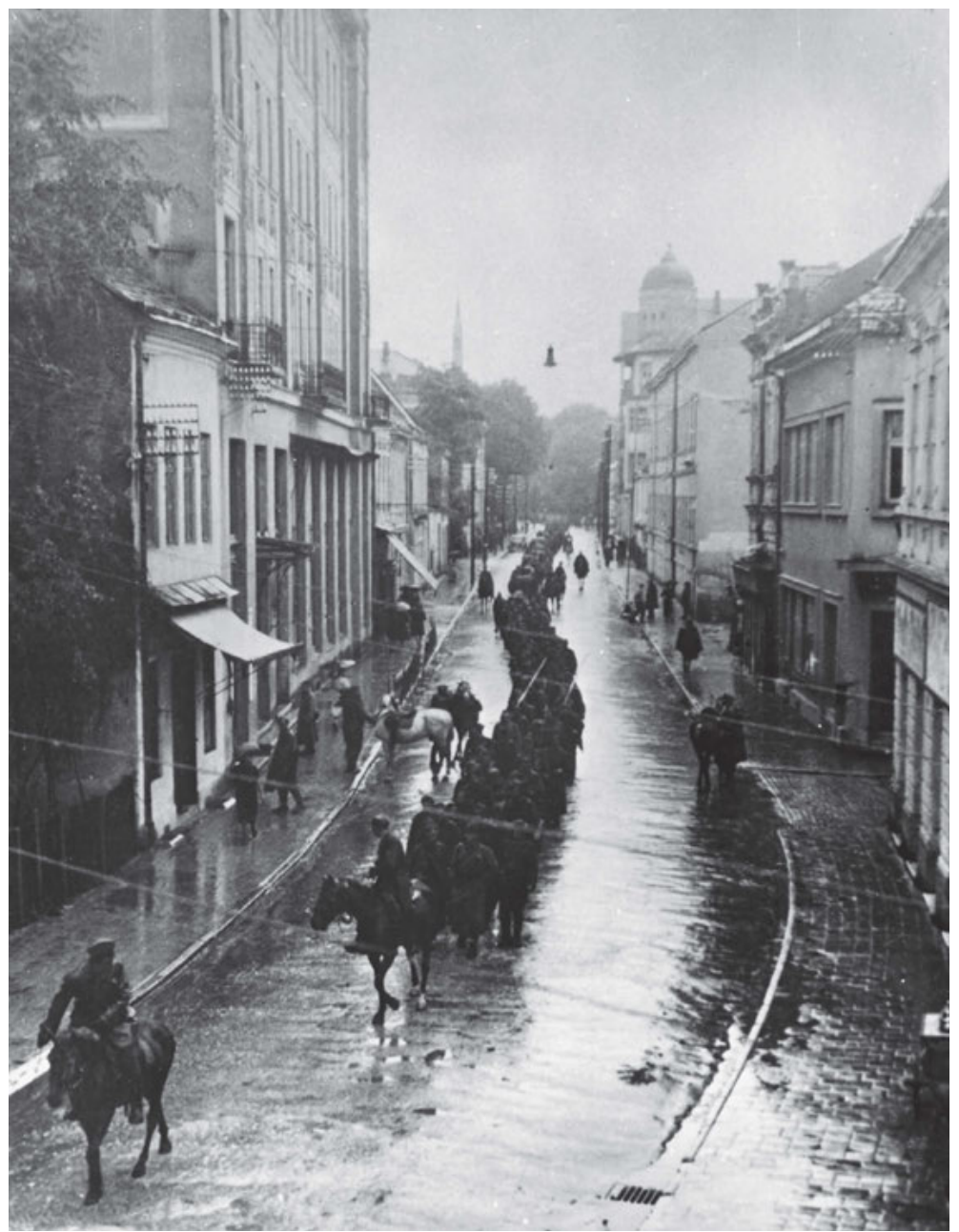

Einzug der Truppen der Volksbefreiungsarmee in Tuzla, 17. September 1944. Fotograf unbekannt. Sarajevo, Historisches Museum von Bosnien und Herzegowina | FNOB 19424.

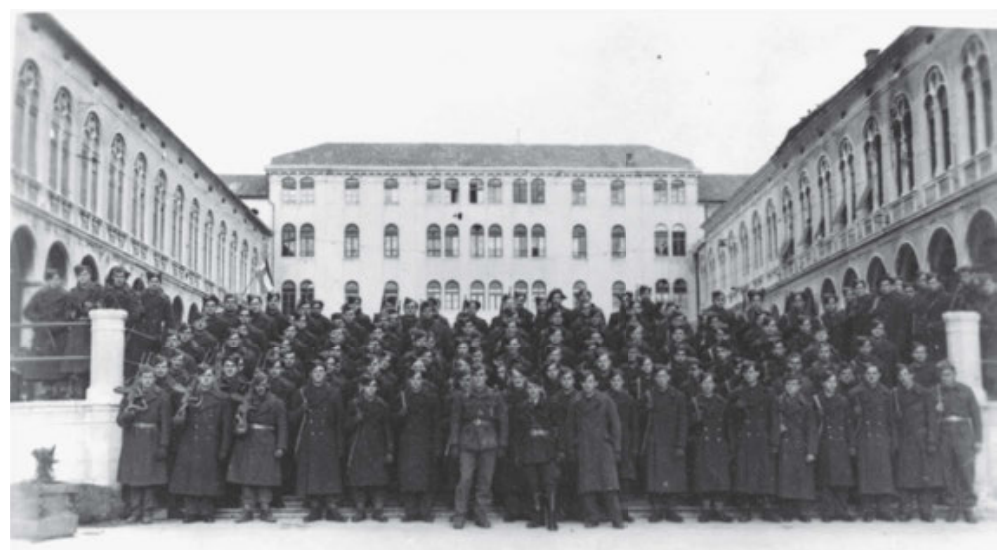

Erste Kompanie des Dritten Bataillons der Fünften Überseebrigade, Split, Januar 1945. Fotograf unbekannt. Museum für Neuere Geschichte der Stadt Celje | FZ2960. 


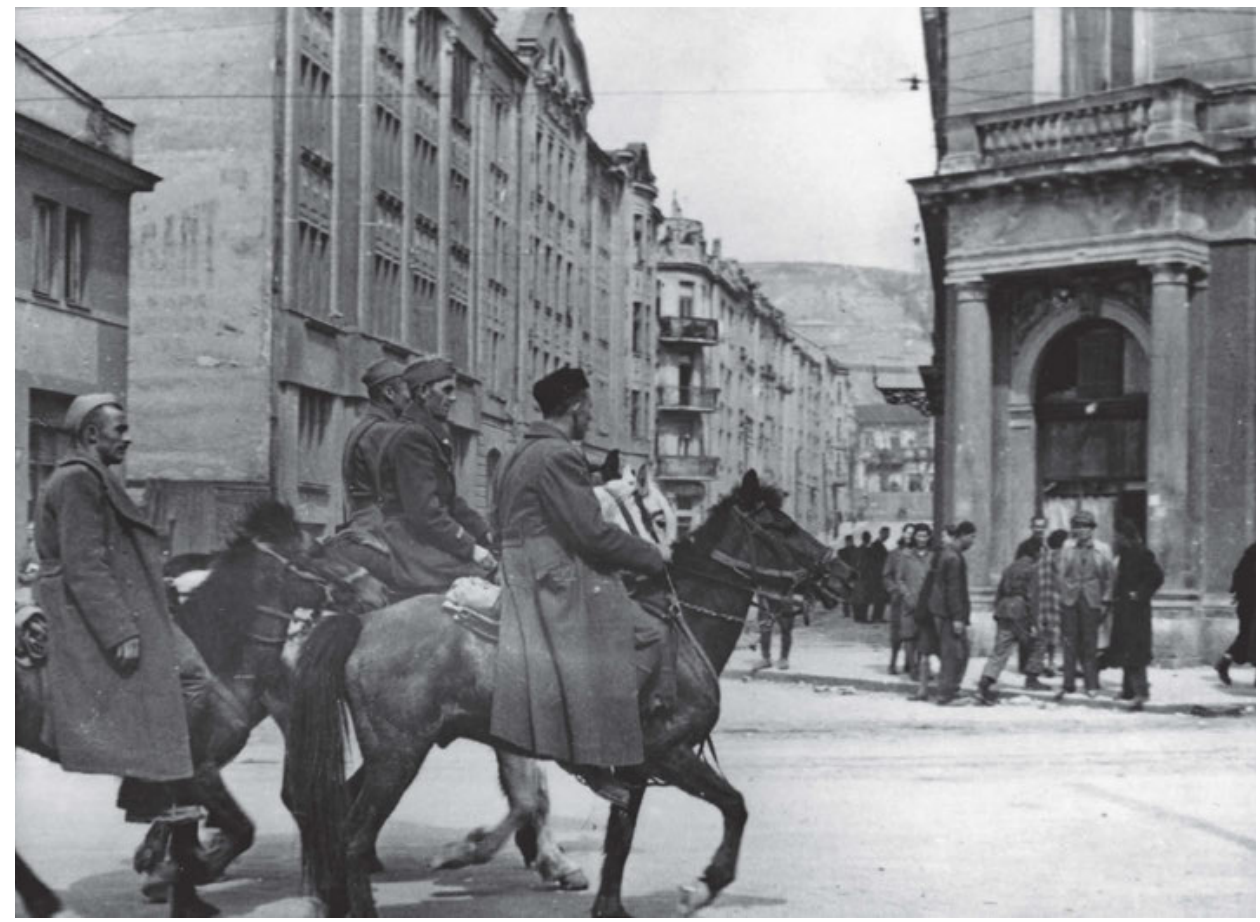

Kundgebung anlässlich der Befreiung Sarajevos, Marijin Dvor. Foto: Ivica Lisac. Sarajevo, Historisches Museum von Bosnien und Herzegowina | FNOB 10831.

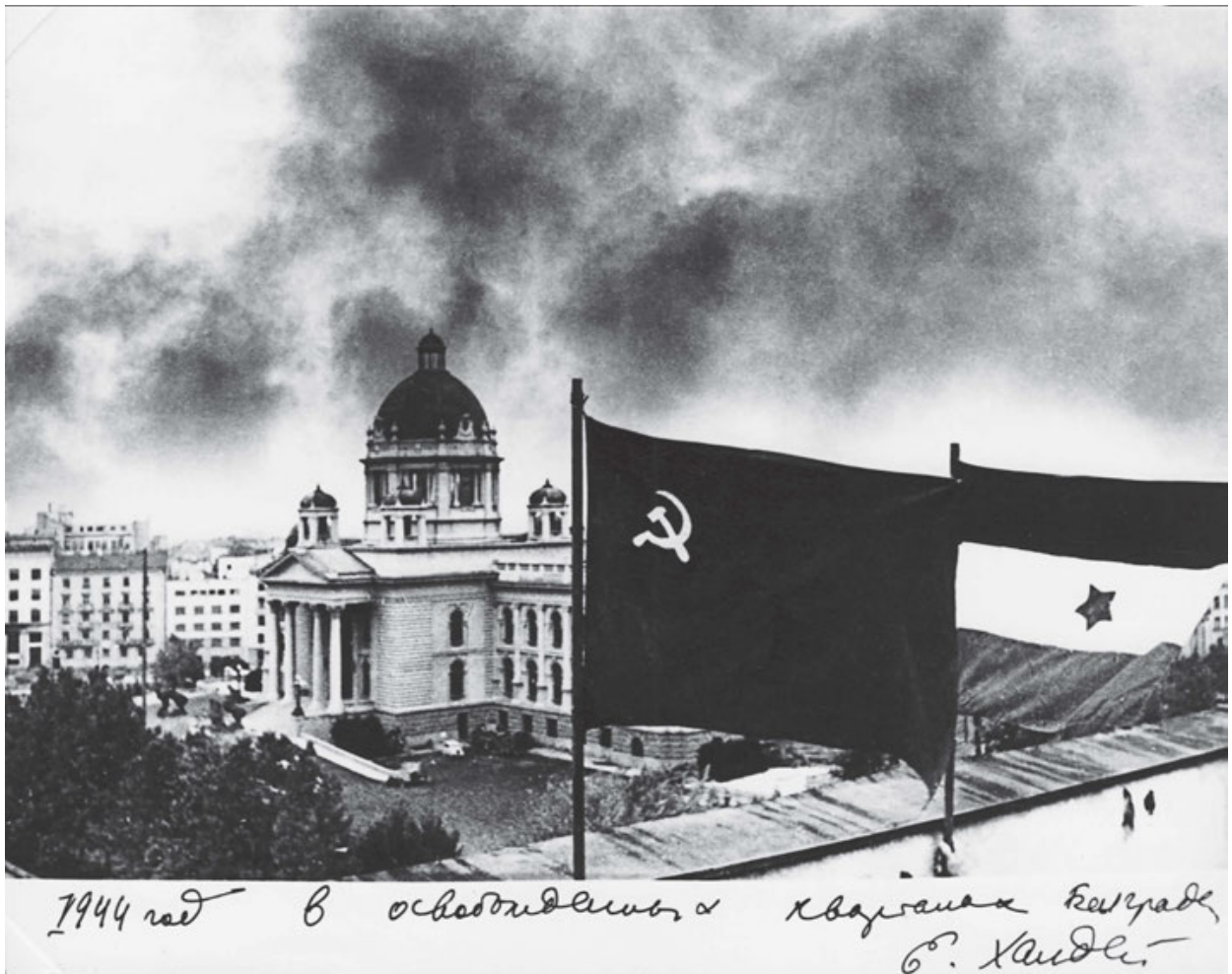

Das befreite Belgrad, 1944. Fotograf unbekannt. Belgrad, Museum Jugoslawiens | III-7466. 


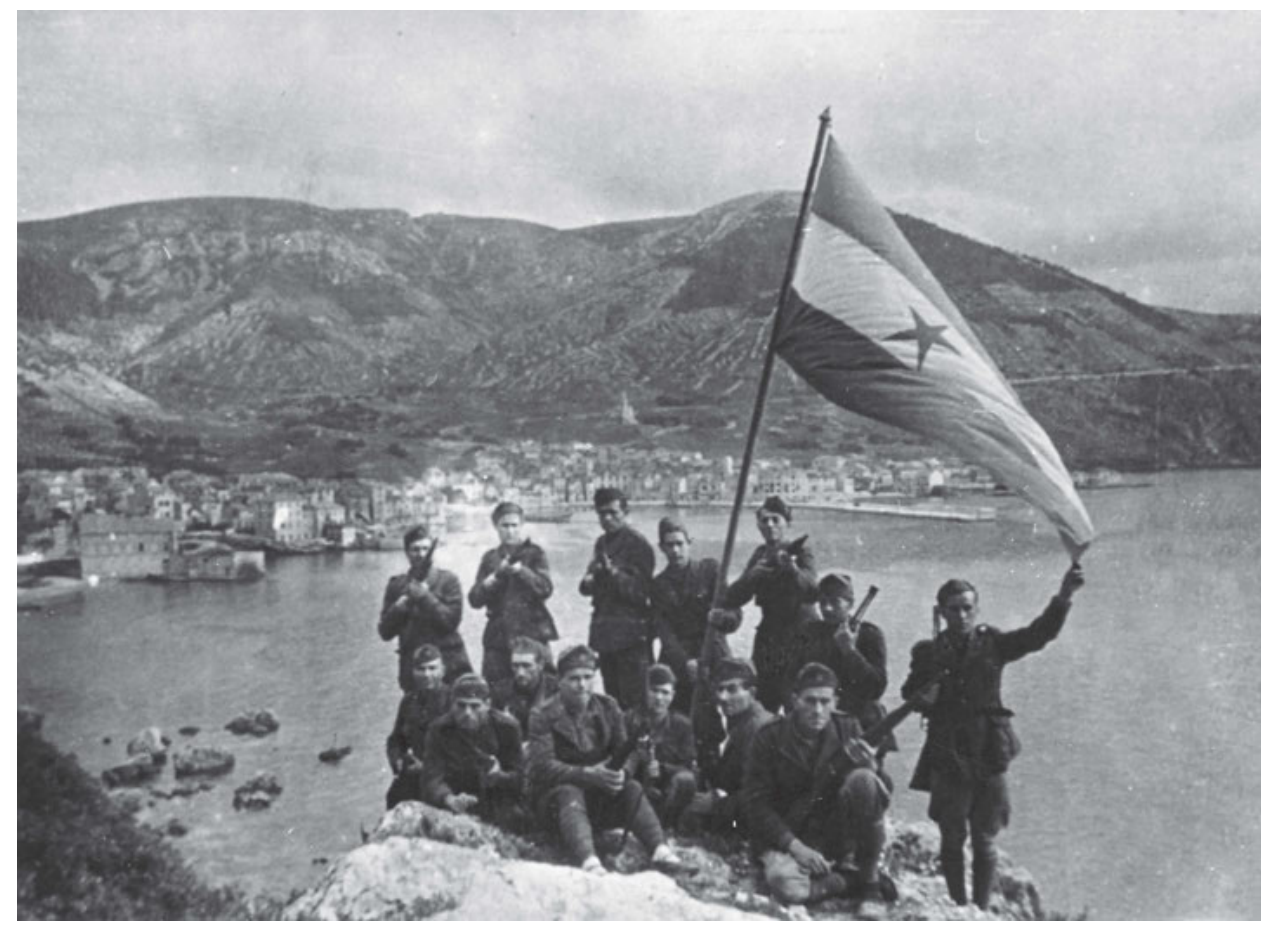

Kämpfer der Volksbefreiungsarmee nach der Kapitulation Italiens auf der befreiten Insel Korčula. Fotograf unbekannt. Bestand des Historischen Archivs beim ZK BdKJ | znaci.net.

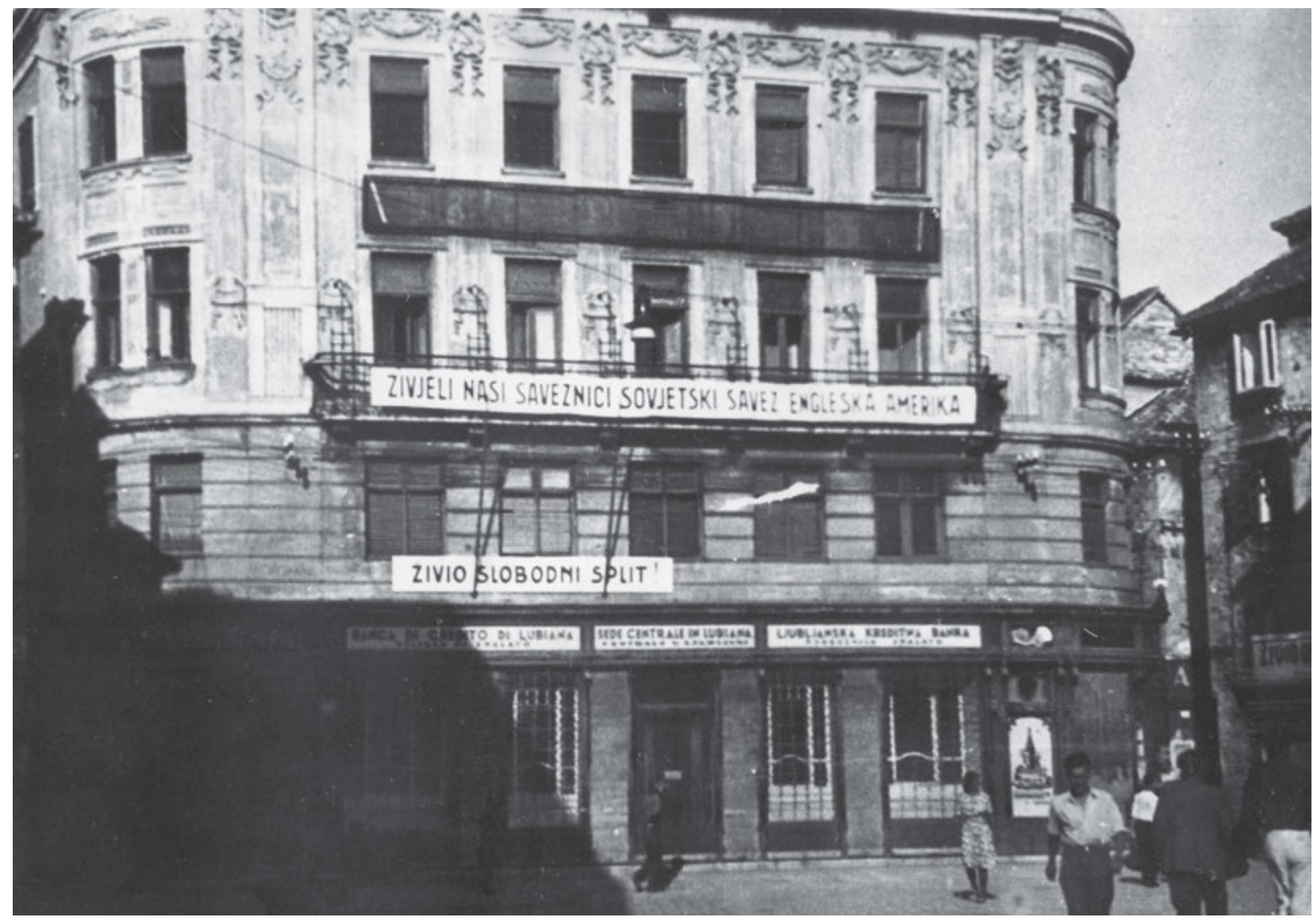

Parolen auf dem Volksplatz im befreiten Split. Fotograf unbekannt. znaci.net. 


\section{Zusammenarbeit mit den Alliierten}

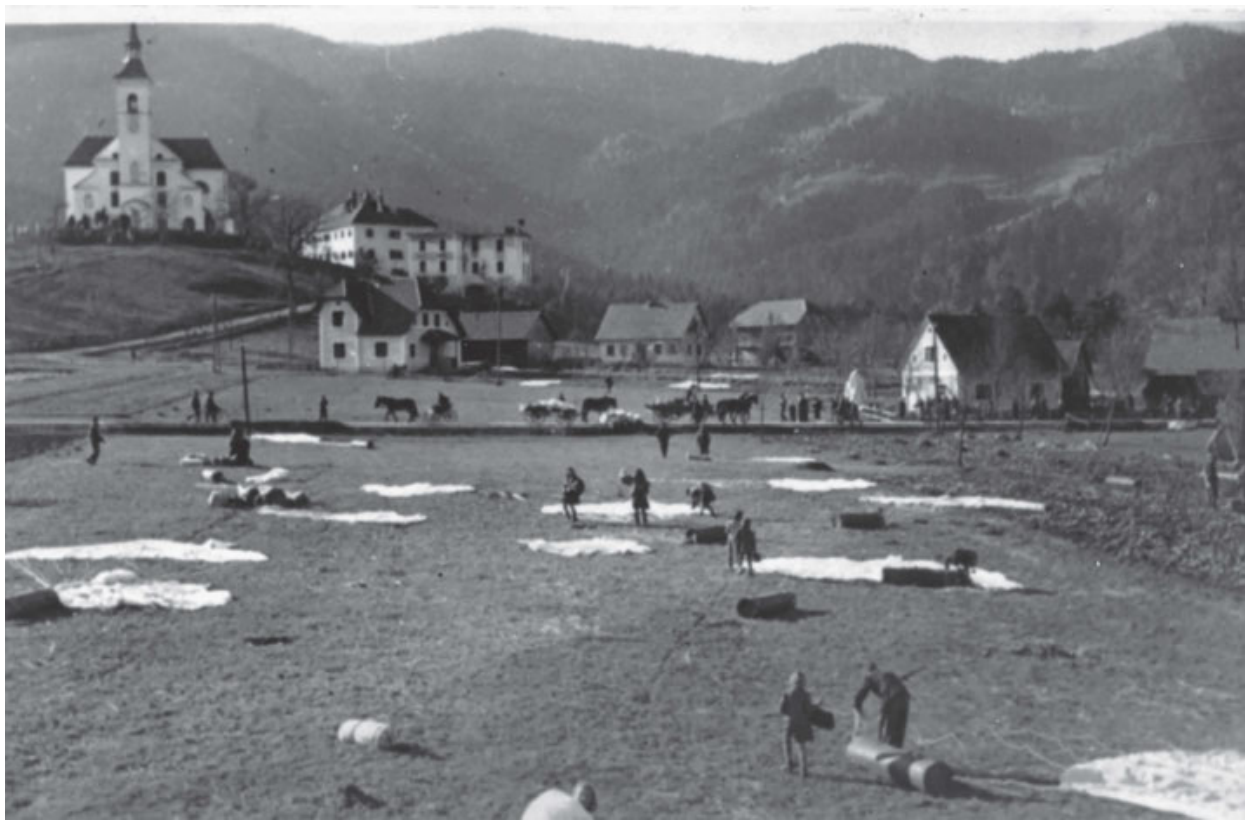

Abwurf von Hilfsgütern der Alliierten über dem befreiten Territorium, Radmirje. Fotograf unbekannt. Museum für Neuere Geschichte der Stadt Celje | FZ2 1580.

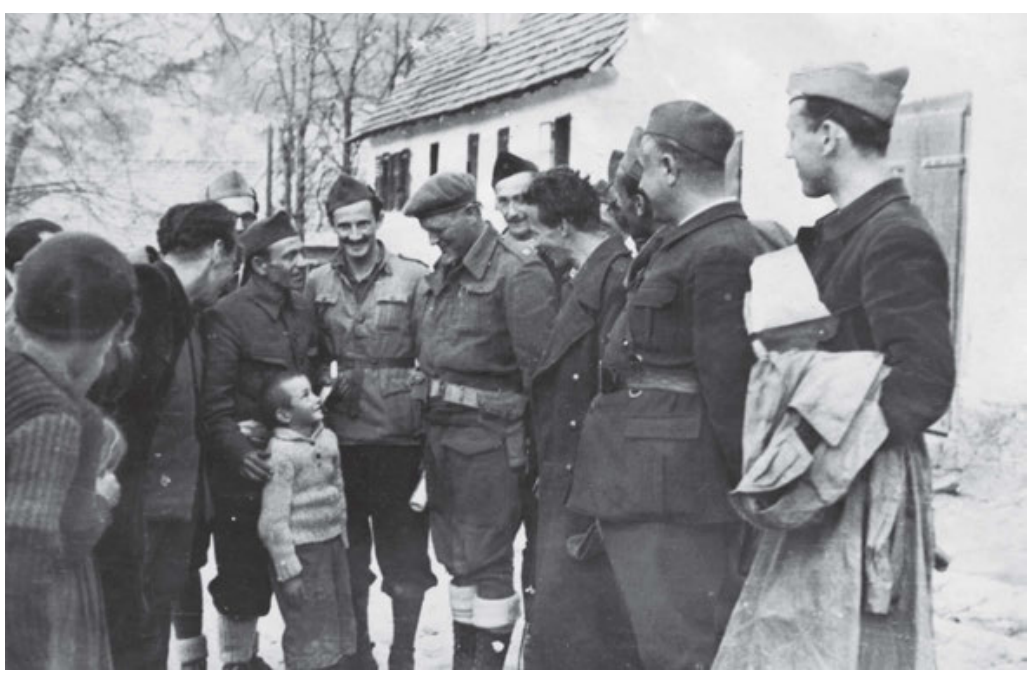

Randolph Churchill, Mitglied der britischen Militärmission, in Gesellschaft militärischer und politischer Führungskräfte der Partisanen. Von rechts nach links: Joža Horvat, Andrija Hebrang, Leo Mates, Randolph Churchill. Auf dem Foto sind zudem Dr. Mladen Iveković und Vicko Maslov zu sehen. Slunj, Frühling 1944. Foto: Fotodienst des Antifaschistischen Landesrats der Volksbefreiung Kroatiens. Zagreb, Kroatisches Historisches Museum I HPM-MRNH-A-2601_f23_32a_s. 


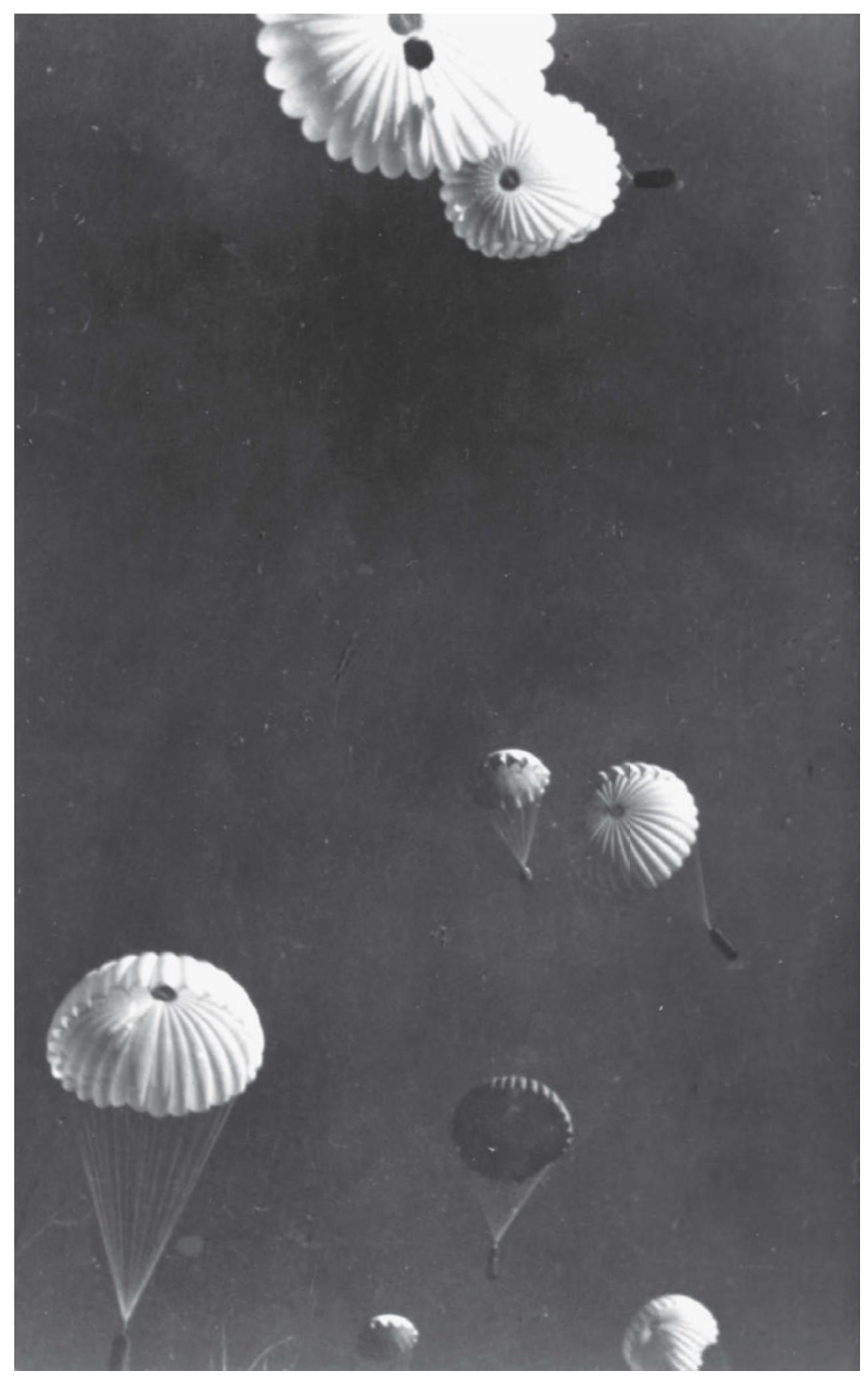

Abwurf von Hilfsgütern der Alliierten über dem befreiten Territorium. Fotograf unbekannt. Museum für Neuere Geschichte der Stadt Celje | FZ2 1585. 


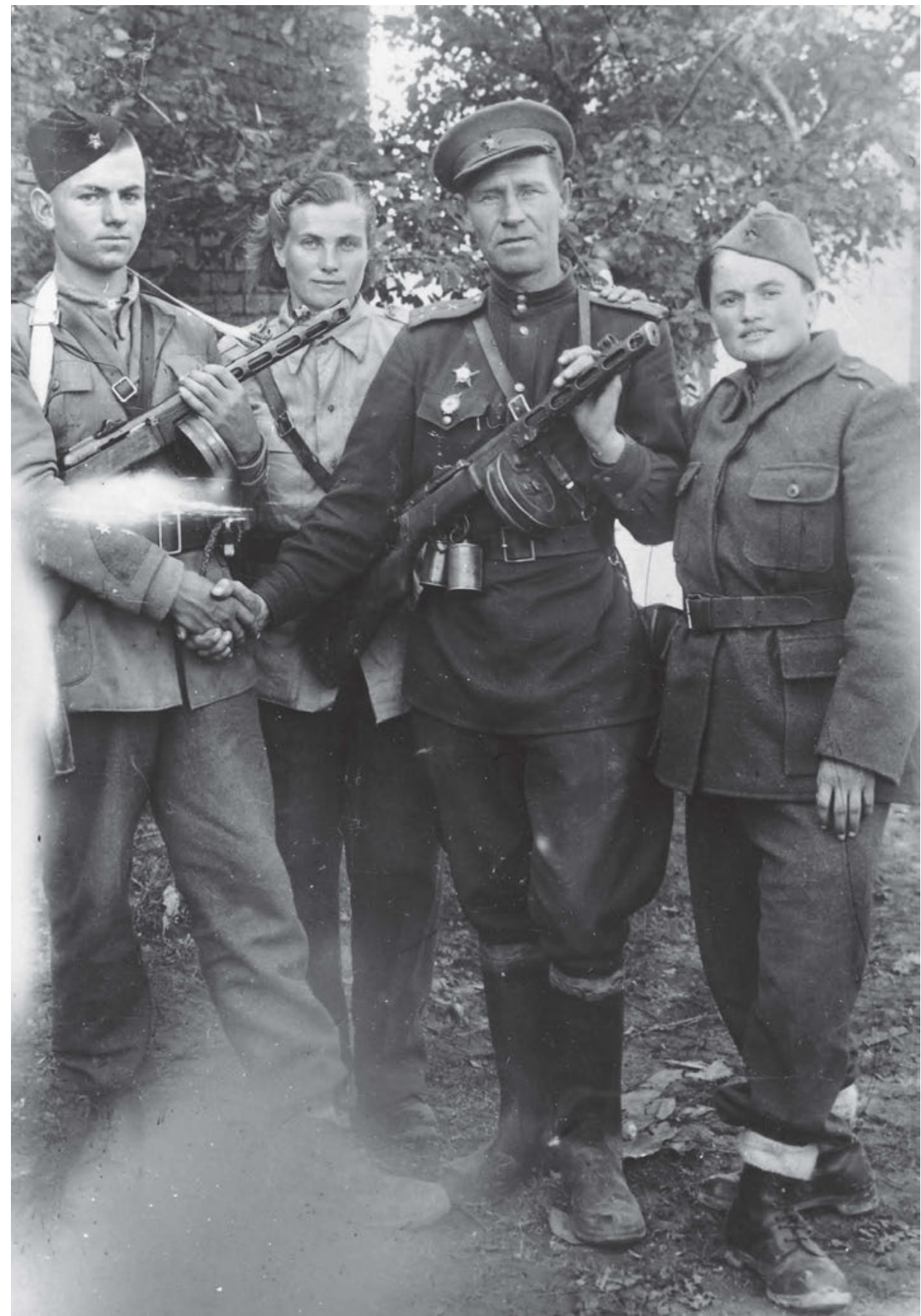

Begegnung der Soldaten der Achten Montenegrinischen Brigade mit Rotarmisten bei Kosmaj, 1944. Fotograf unbekannt. Vervielfältigt für das Museum der Revolution der Völker Jugoslawiens im März 1962. znaci.net. 


\section{Studiofotografien des Sieges}

Gegen Ende des Krieges, als der Sieg schon greifbar nahe war, bildete sich eine neue Art der Fotografie heraus, die zwar außerhalb der offiziellen Entwicklung der Partisanenfotografie angesiedelt, aber dennoch ein fester Bestandteil war. Es handelt sich um die Fotografie der Sieger, um das Bedürfnis, die persönliche Beteiligung an den historischen Ereignissen im Studio festzuhalten und den Moment des Sieges in Gesellschaft der Mitkämpfer zu verewigen. Ein Großteil dieser Fotografien entstand in den Studios lokaler Fotografen. Nach der Befreiung von Belgrad, Zagreb und aller anderen Städte waren die Fotogeschäfte zumeist voll von Soldaten, die sich fotografieren lassen wollten, wie beispielsweise in Koprivnica, wo die Soldaten Schlange standen, um ihr eigenes Foto zu bekommen. ${ }^{1}$ Besonders interessant ist bei diesen Fotografien, dass sie einfache Soldaten zeigen, die in der künstlichen Umgebung des Fotostudios mit der handwerklichen Ästhetik lokaler Fotografen aufgenommen sind.

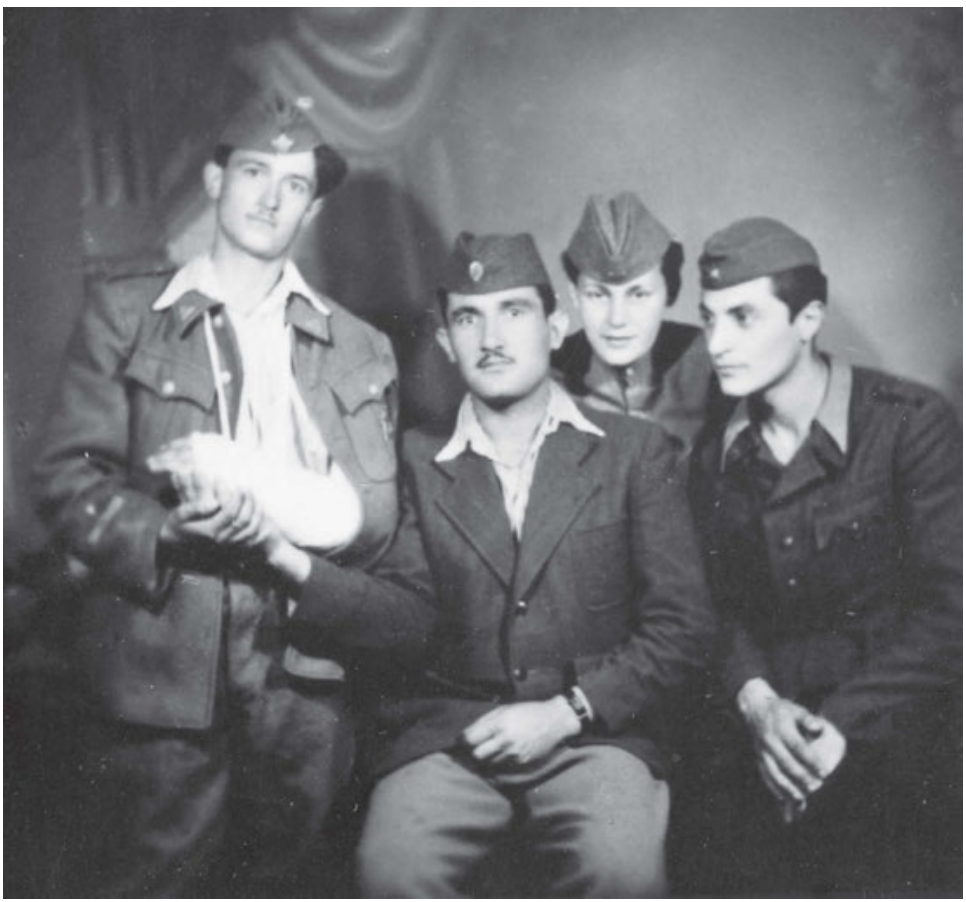

Verwundete Partisanen der Siebten Krajina-Brigade in der Nähe von Gornji Vakuf. Fotograf unbekannt. Sarajevo, Historisches Museum von Bosnien und Herzegowina | FNOB 1360.

1 Bosiočić, Bogdan S. 21. slavonska udarna brigada. Belgrad: Vojnoizdavački zavod 1981, S. 95. 


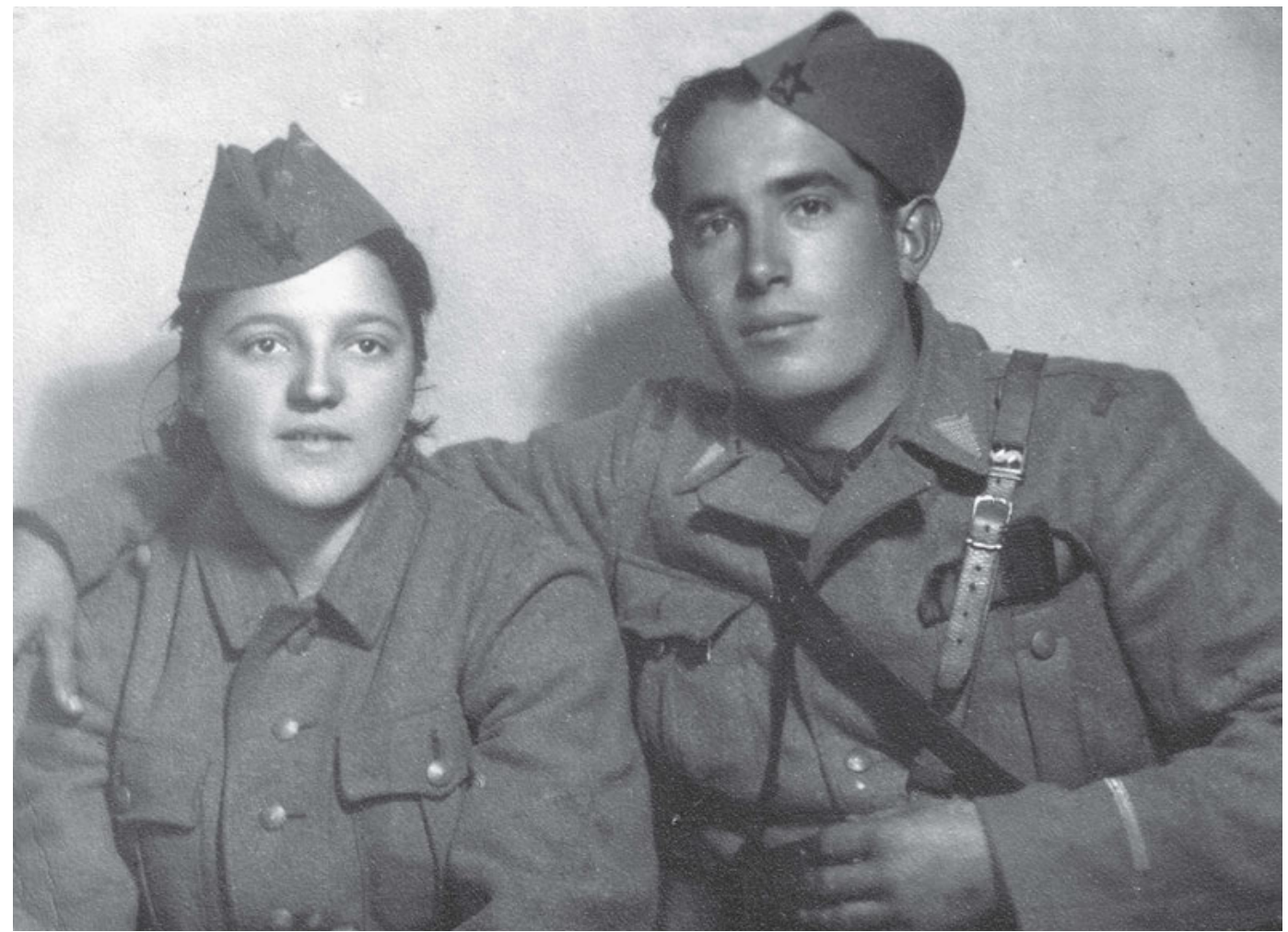

Nach der Befreiung Belgrads, 26. Oktober 1944. Fotografie abgetreten von Marko Strpić.

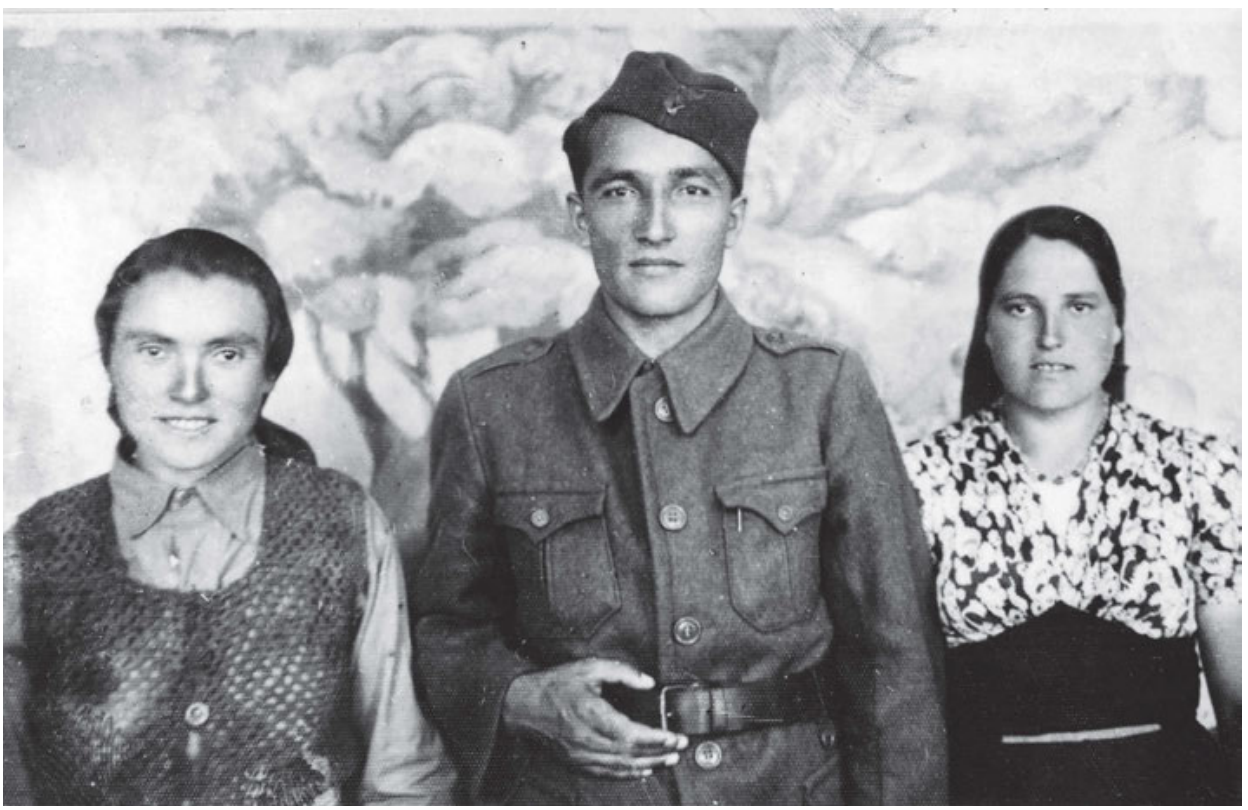

Links Kosa Pilipović, geboren 1919, Hausfrau. Während der Kozara-Offensive kam sie in Gefangenschaft und wurde in ein Konzentrationslager in Kroatien gebracht, wo sie zwei oder drei Monate blieb, um anschließend nach Donji Jelovac zurückzukehren. Dort wählte man sie zur Abgeordneten der Volksversammlung und in den Ausschuss der Antifaschistischen Frauenfront. Sie war ab dem 15. Februar 1943 Mitglied der KPJ und Kommandantin der Kompanie für Donji Jelovac innerhalb der Zoja-Brigade. Fotograf unbekannt. Sarajevo, Historisches Museum von Bosnien und Herzegowina | FNOB 1509. 


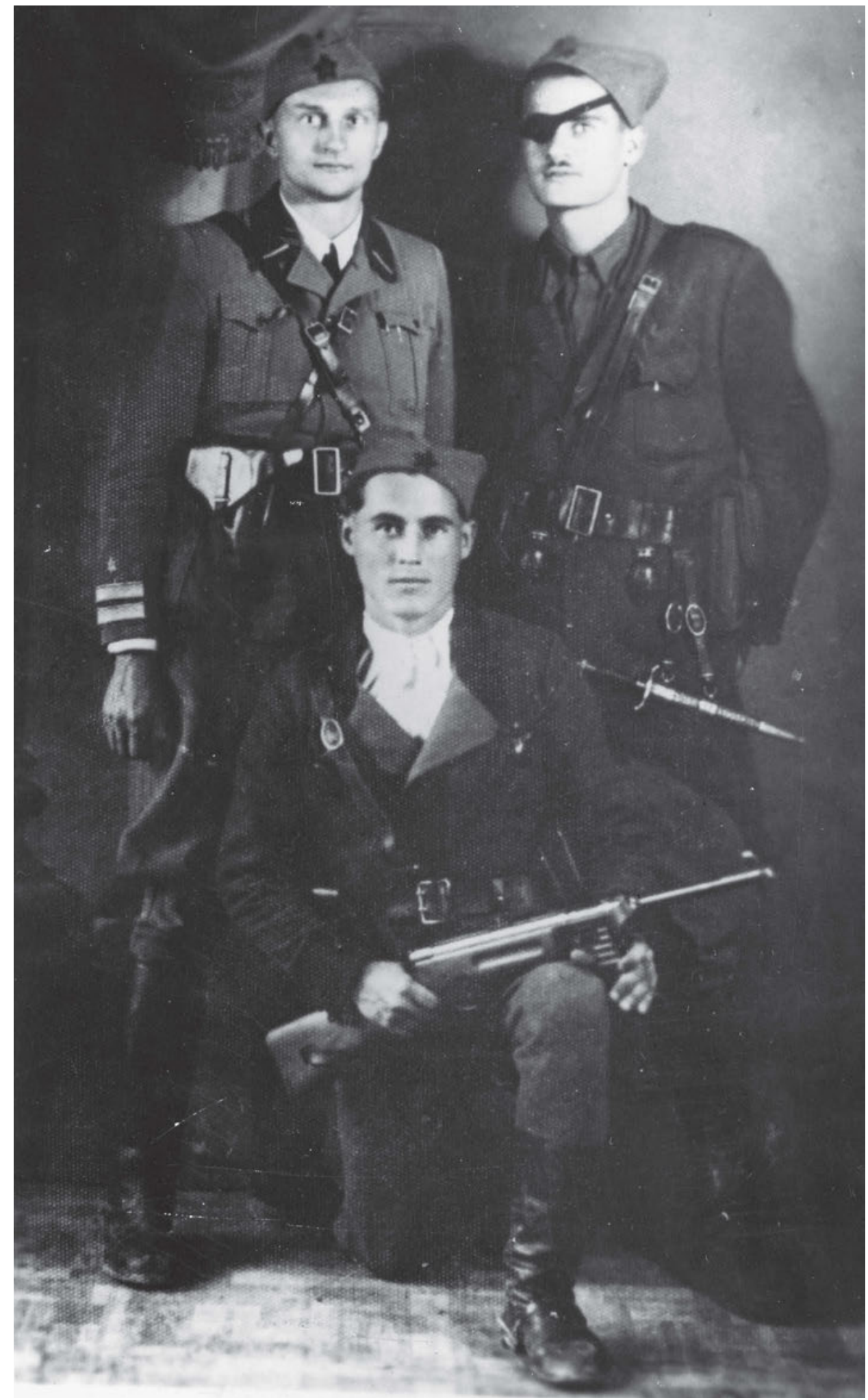

Todor Vujasinović-Tošo mit zwei Kameraden. Fotograf unbekannt. Sarajevo, Historisches Museum von Bosnien und Herzegowina | FNOB 4602. 


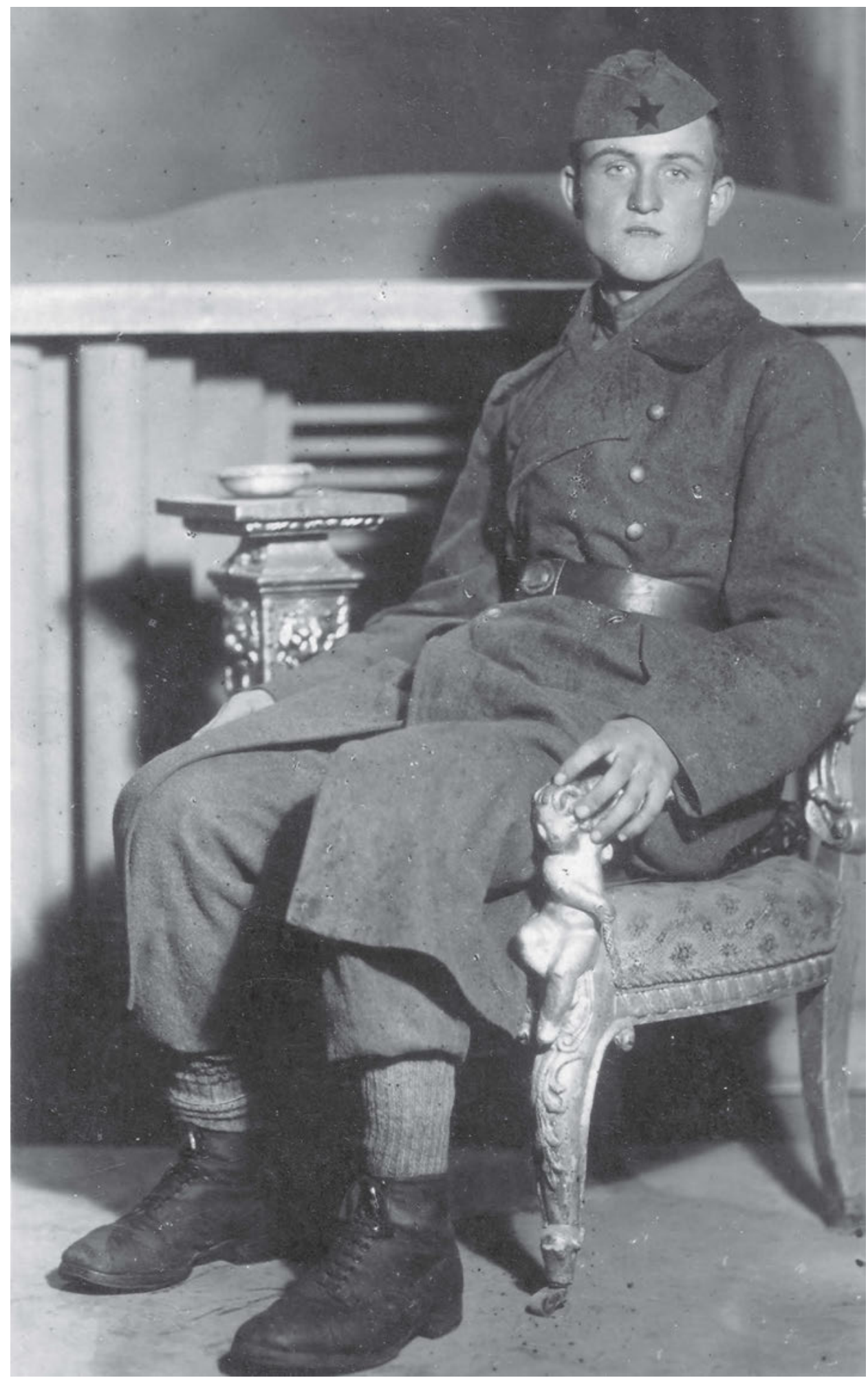

"Ante zum Andenken und als Erinnerung vom Kameraden Dragan Andjelić«, 19. Oktober 1944.

Fotograf unbekannt. Fotografie abgetreten von Marko Strpić. 


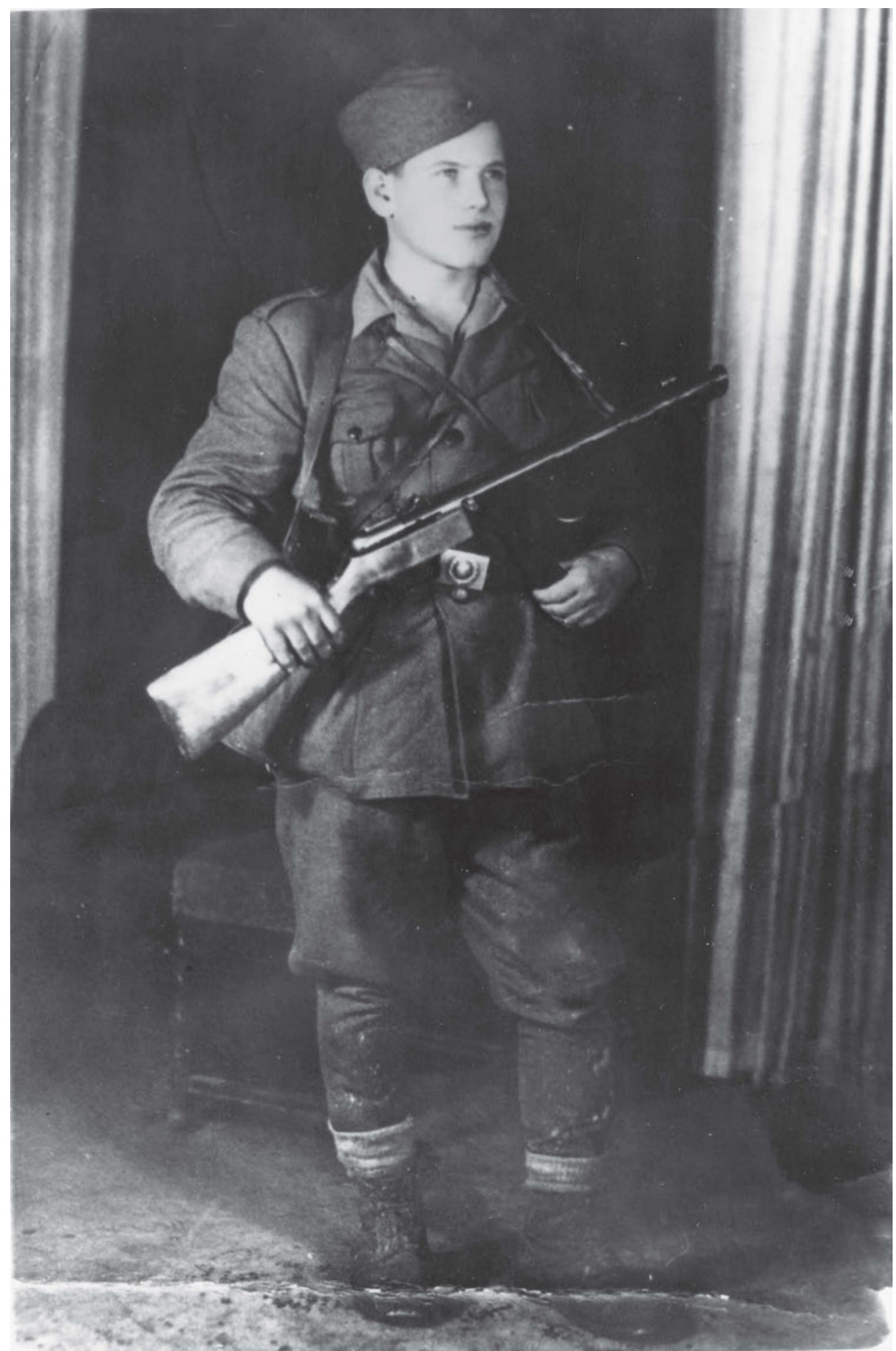

Kurier des Dritten Kragujevac-Bataillons der Ersten Proletarischen Brigade, 1944.

Fotograf unbekannt. Sarajevo, Historisches Museum von Bosnien und Herzegowina | FNOB 4707. 


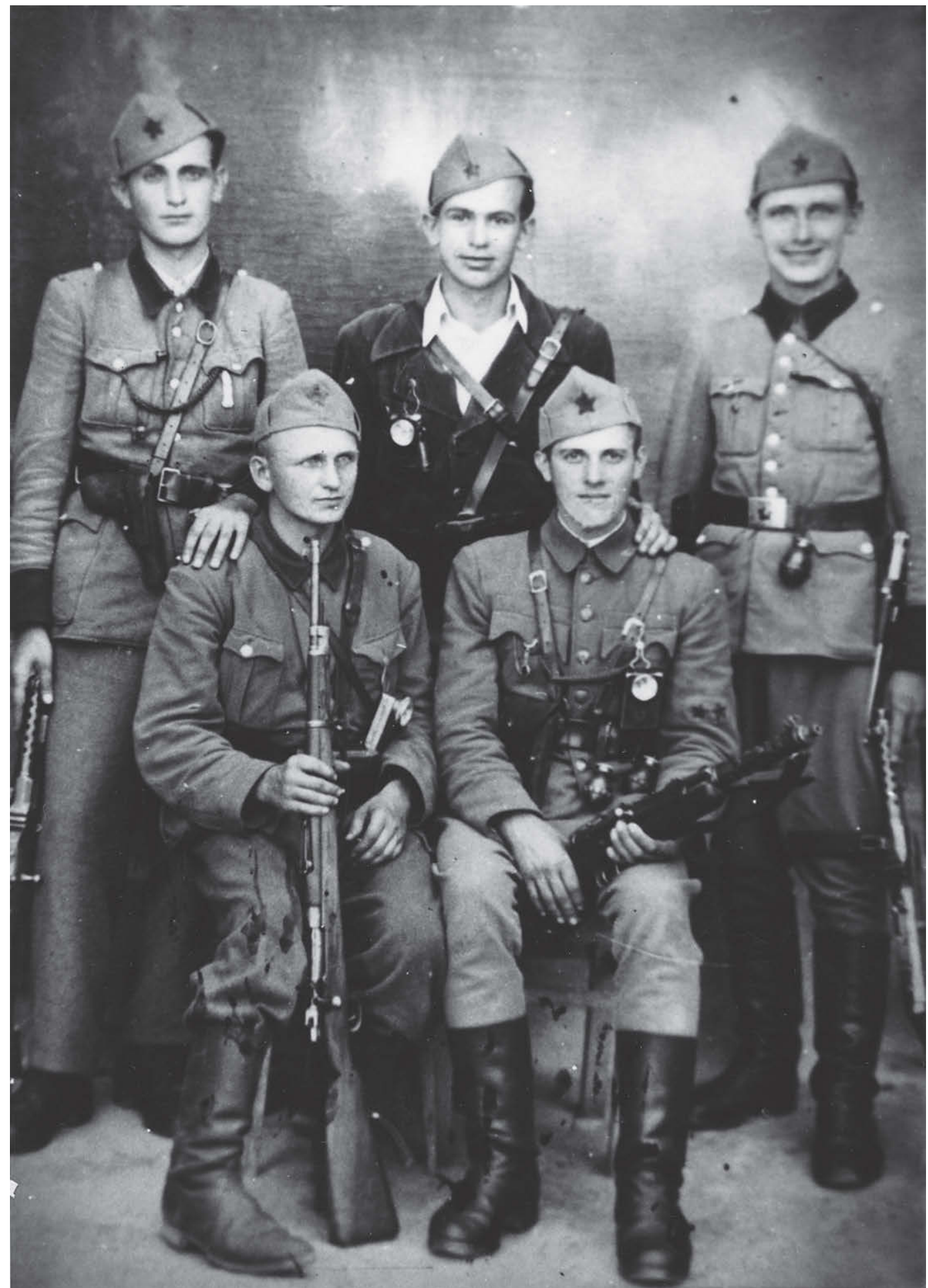

Mirko Vorkapić, Informationsoffizier der Osijek-Kompanie, mit seiner Gruppe des Sechsten Slawonien-Korps, Herbst 1943. Fotograf unbekannt. Museum der Stadt Zagreb. Ohne Inv.-Nr. 


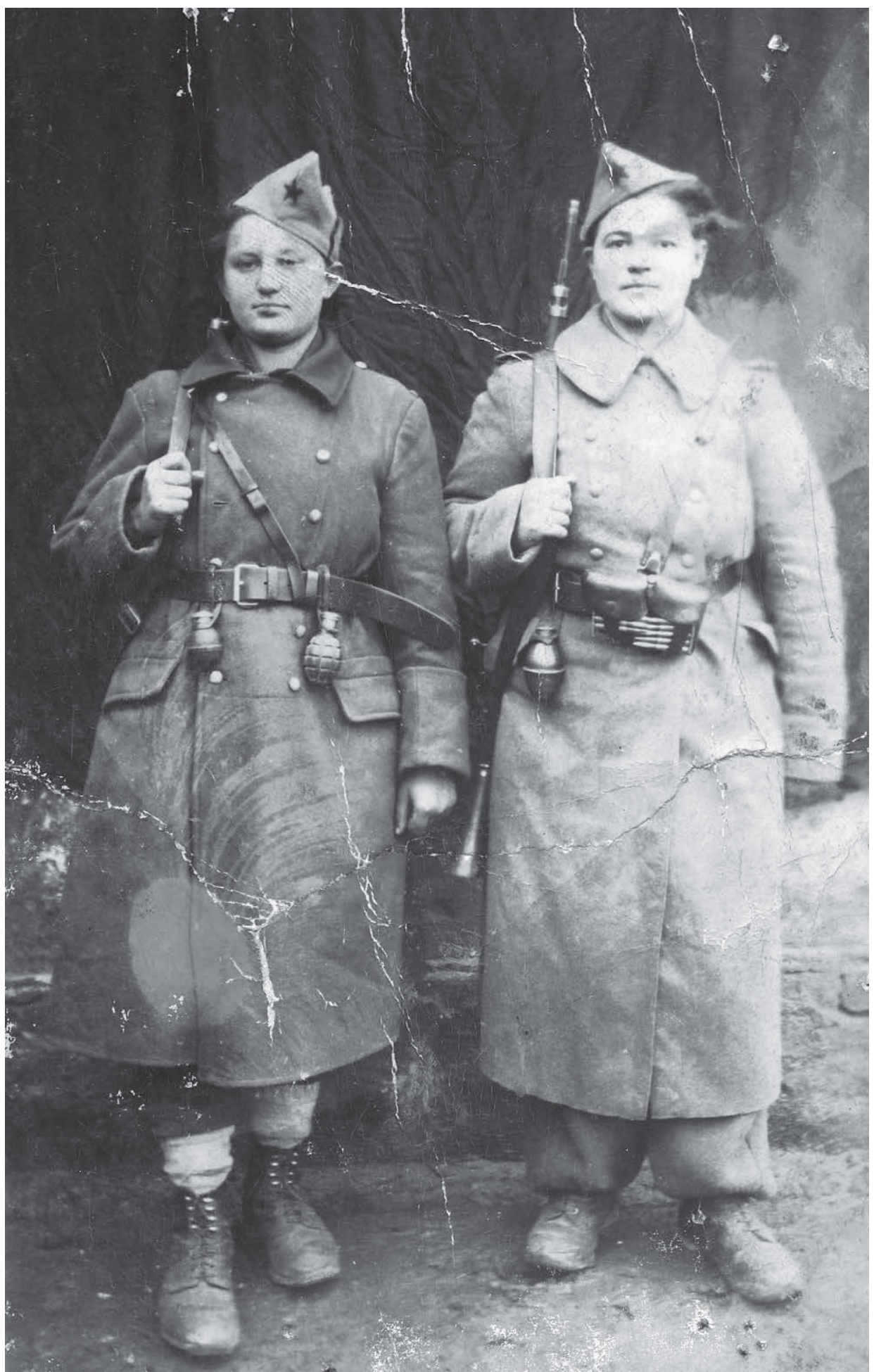

Krankenschwestern des Ersten Bataillons der Zweiten Moslava-Brigade des Zehntes Zagreber Korps. Rechts Katica Baloch, gefallen 1944 bei der Bombardierung von Dubrava, links Vlahović Milka aus Rogoža. Dezember 1944 (?). Fotograf unbekannt. Museum der Stadt Zagreb. Ohne Inv.-Nr. 


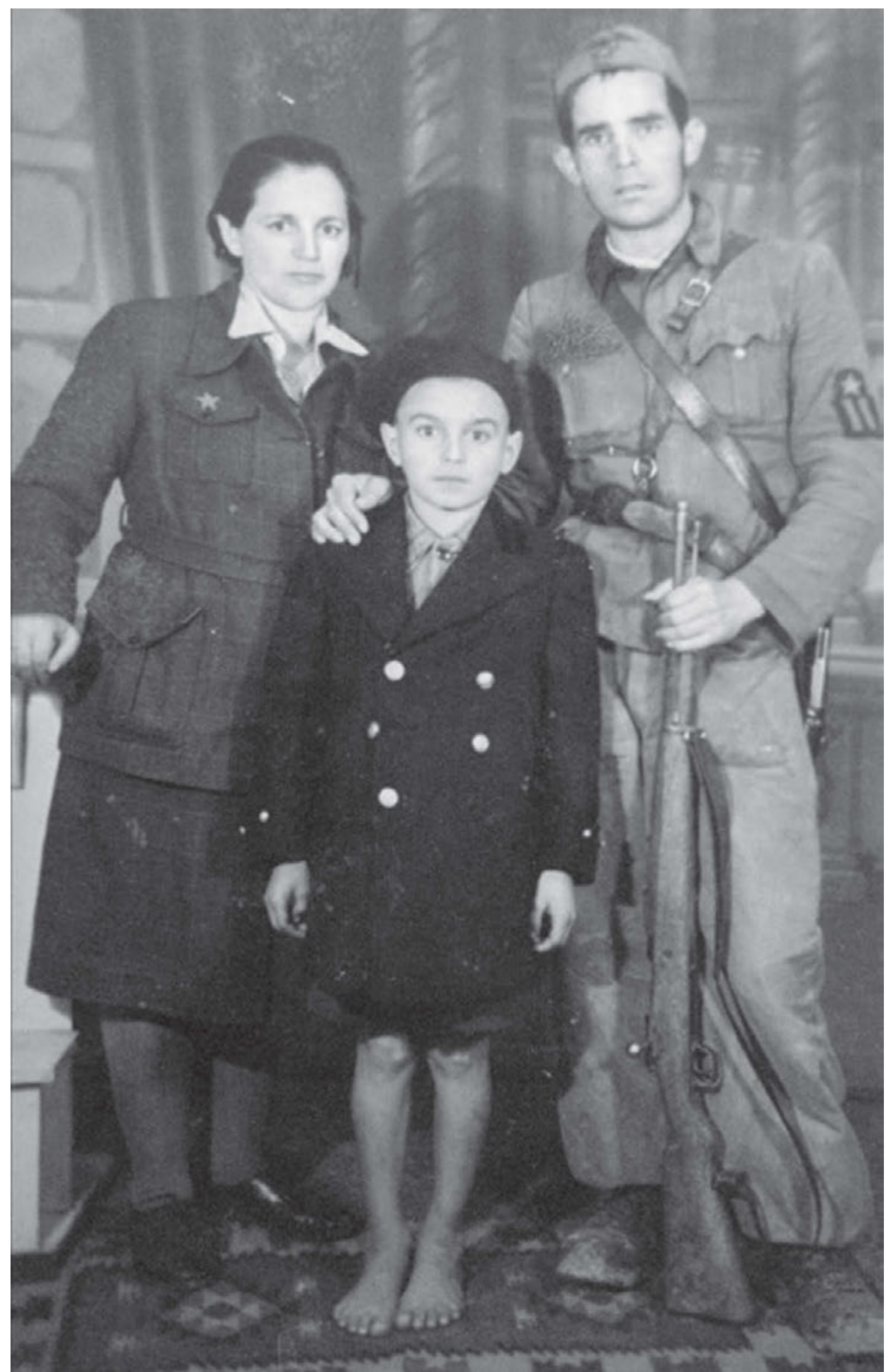

In der befreiten Stadt Tuzla, Oktober 1943. Fotograf unbekannt. znaci.net. 


\section{Private Fotografien}

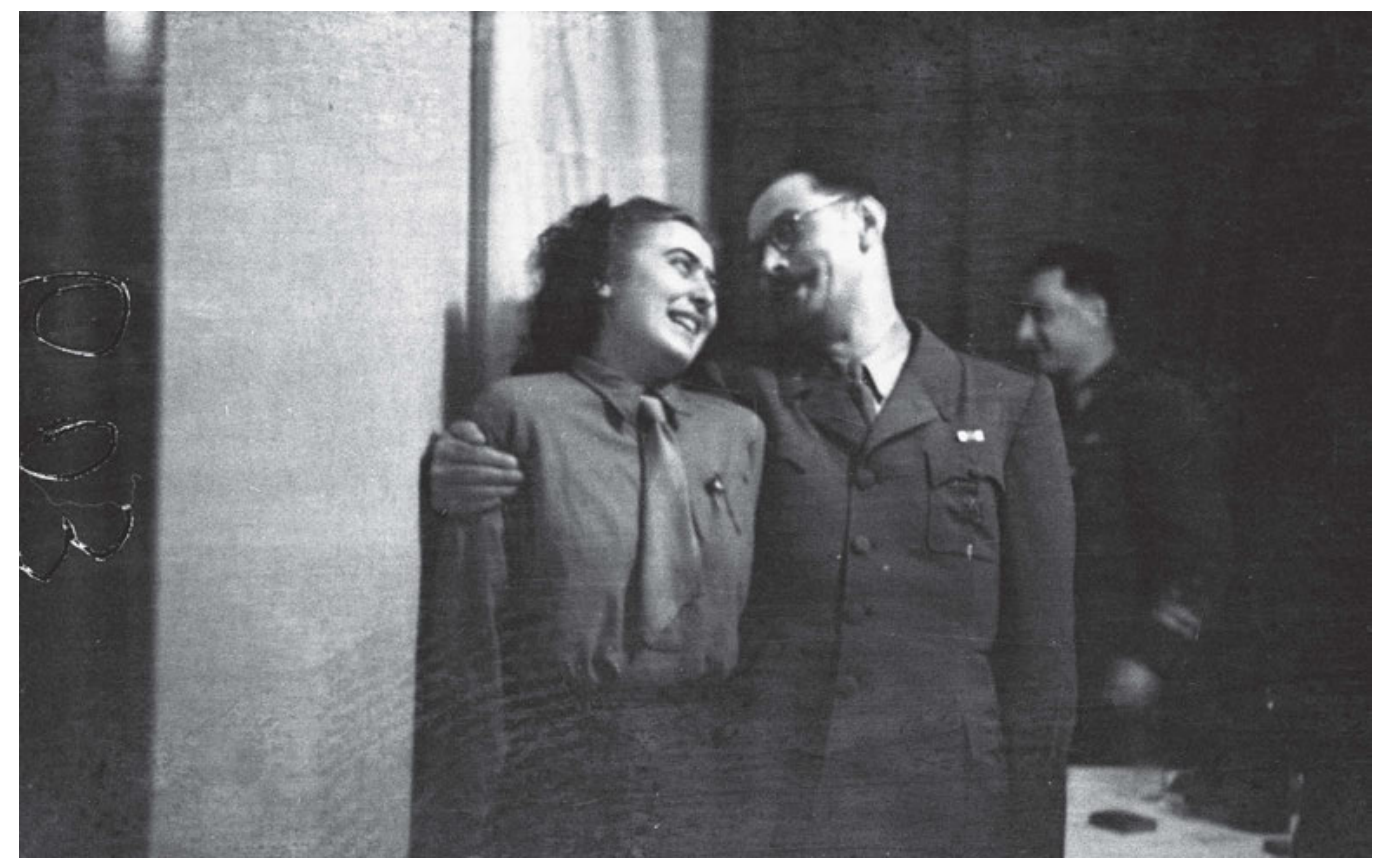

Alenka Gerlovič und Franc Leskovšek-Luka in ausgelassener Stimmung, Črnomelj, 3. April 1945. Foto: Stane Lendarič. Ljubljana, Museum für Neuere Geschichte Sloweniens | TN603/6.

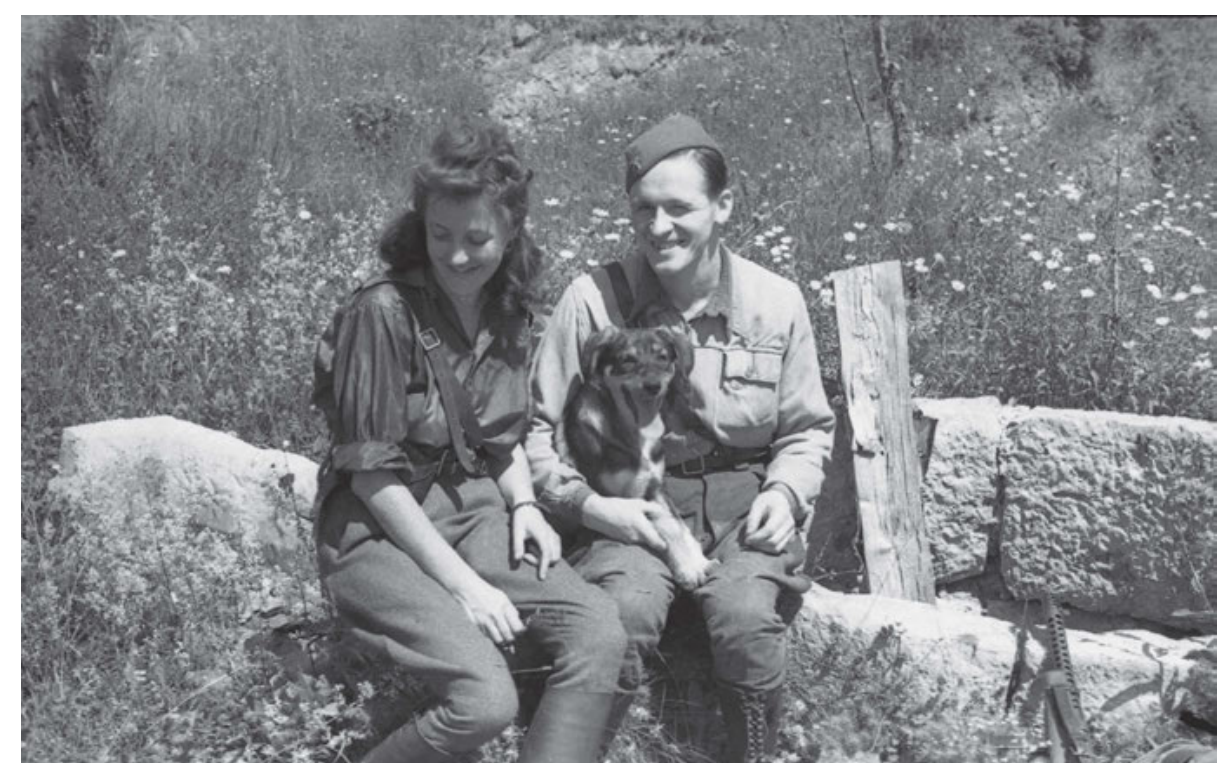

Dr. Marija Jeras und ein unbekannter Partisanenkämpfer. Foto: Dr. Janez Milčinski. Ljubljana, Museum für Neuere Geschichte Sloweniens | 1232/32. 


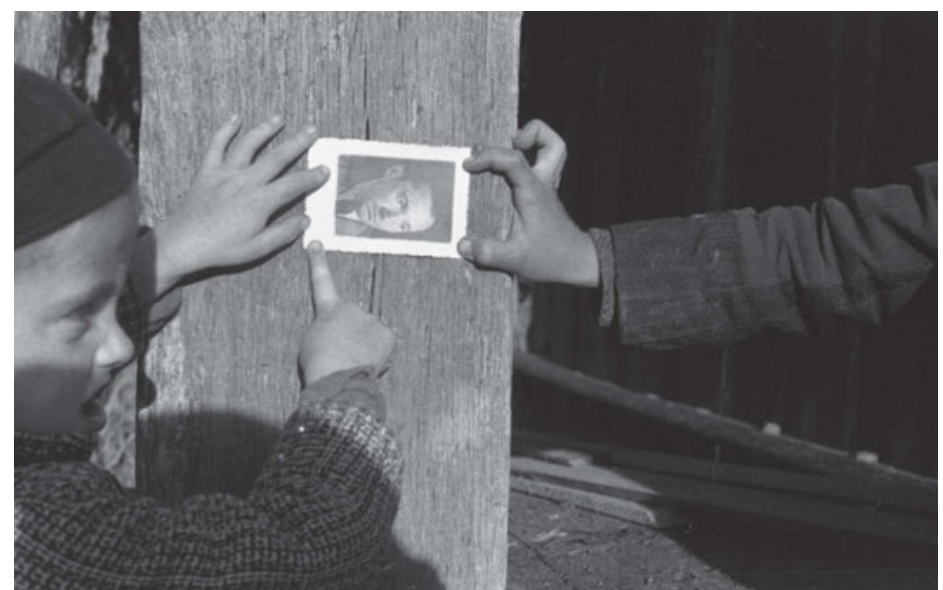

Private Erinnerungen eines Partisanen aus Ribnica, Oktober 1943.

Foto: Vinko Bavec. Ljubljana, Museum für Neuere Geschichte Sloweniens | TN52/17.

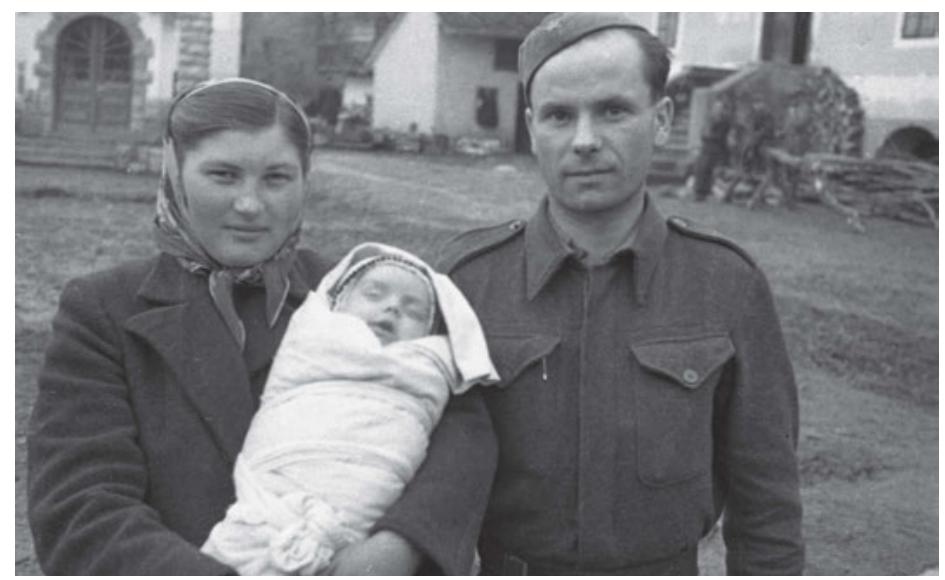

Vater und Mutter mit Neugeborenem. Fotograf unbekannt. Ljubljana, Museum für Neuere Geschichte Sloweniens | TN691a/35.

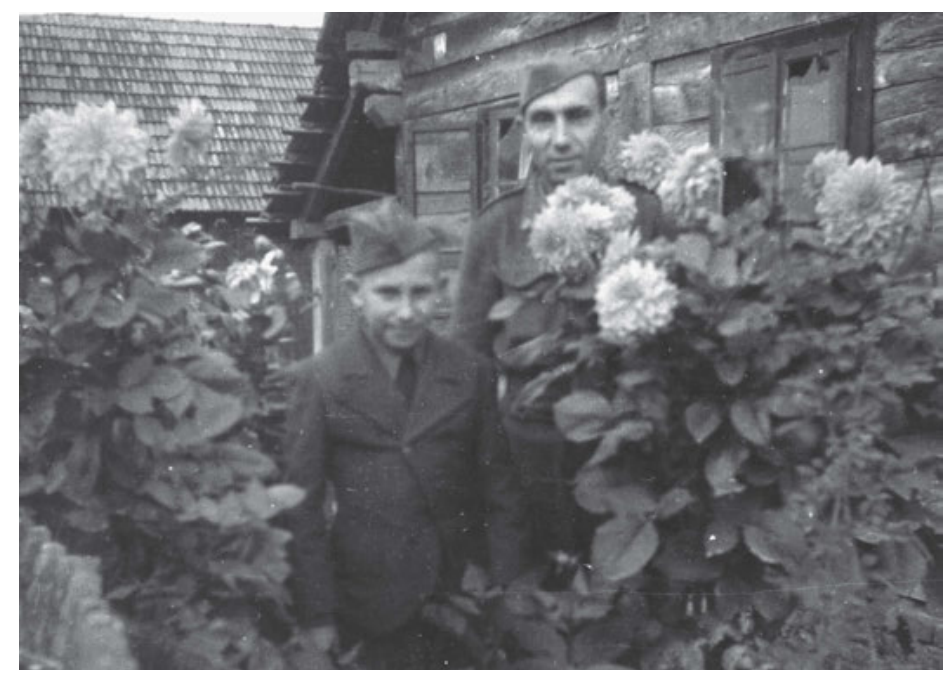

Keine Angaben. Fotograf unbekannt. Museum der Stadt Zagreb. Ohne Inv.-Nr. 


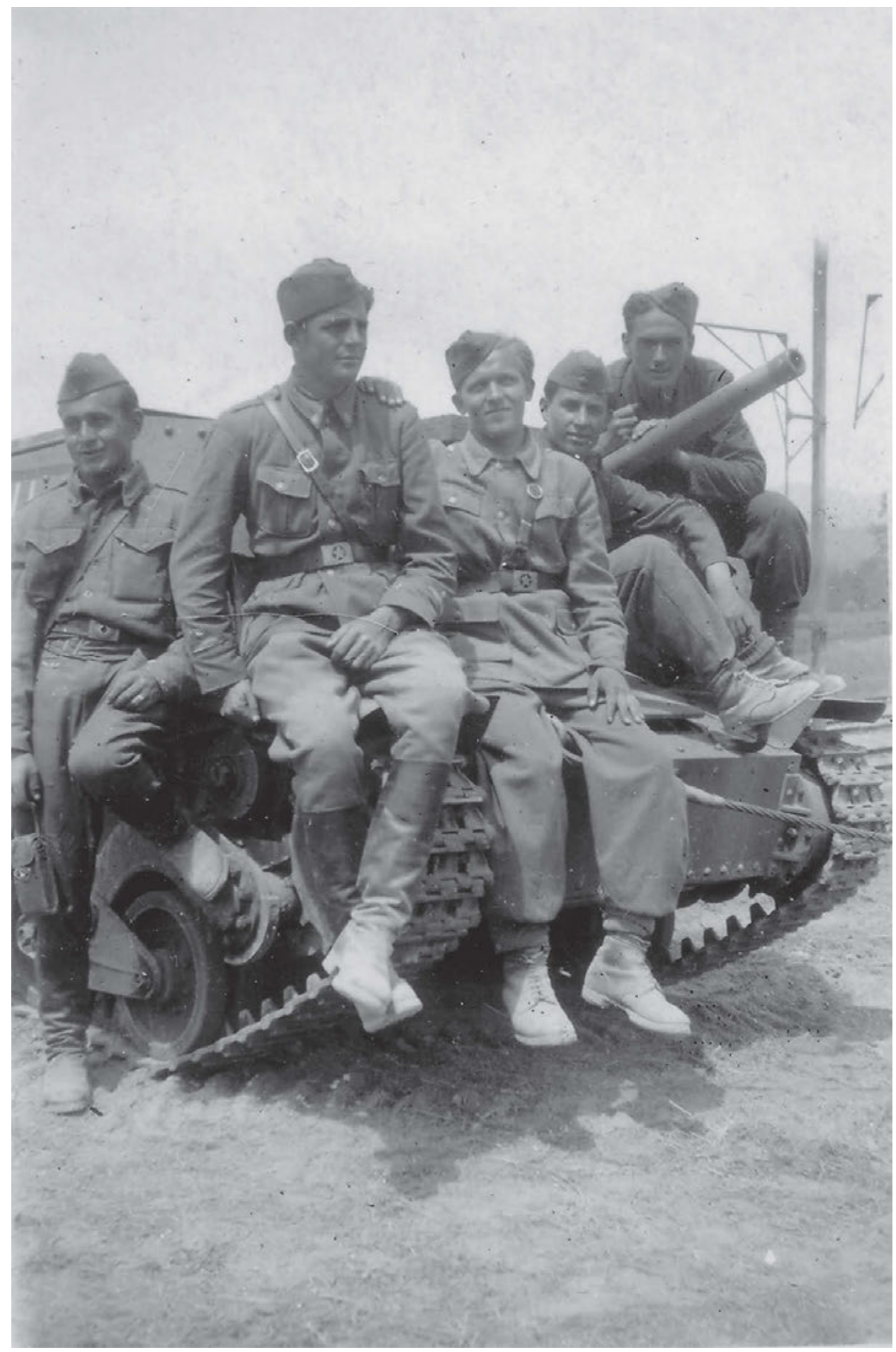

Ante Alerić (sitzend in der Mitte) mit Kameraden. Fotograf unbekannt. Foto abgetreten von Marko Strpić. 


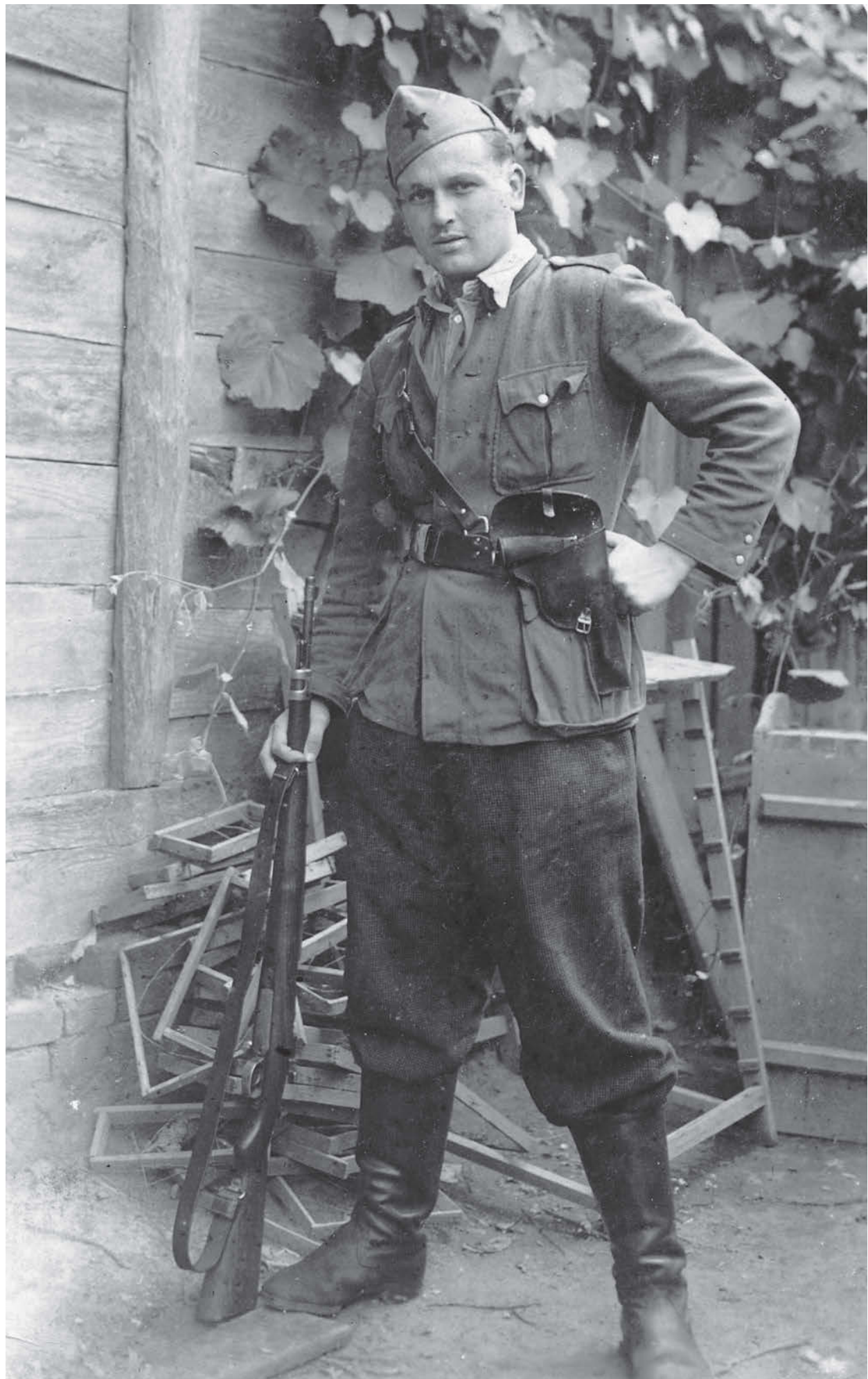

Zvonko Ivanković-Vonta, Seminarleiter des ersten Parteikurses für Moslavina und Mitglied des Zehnten Zagreber Korps. Fotograf unbekannt. Museum der Stadt Zagreb. Ohne Inv.-Nr. 
